


\section{Bound 1948}

\section{HARVARD UNIVERSITY}

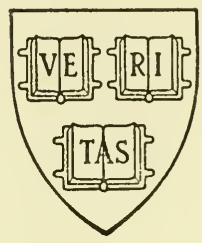

\section{LIBRAR Y}

OF THE

MUSEUM OF COMPARATIVE ZOÖLOGY 




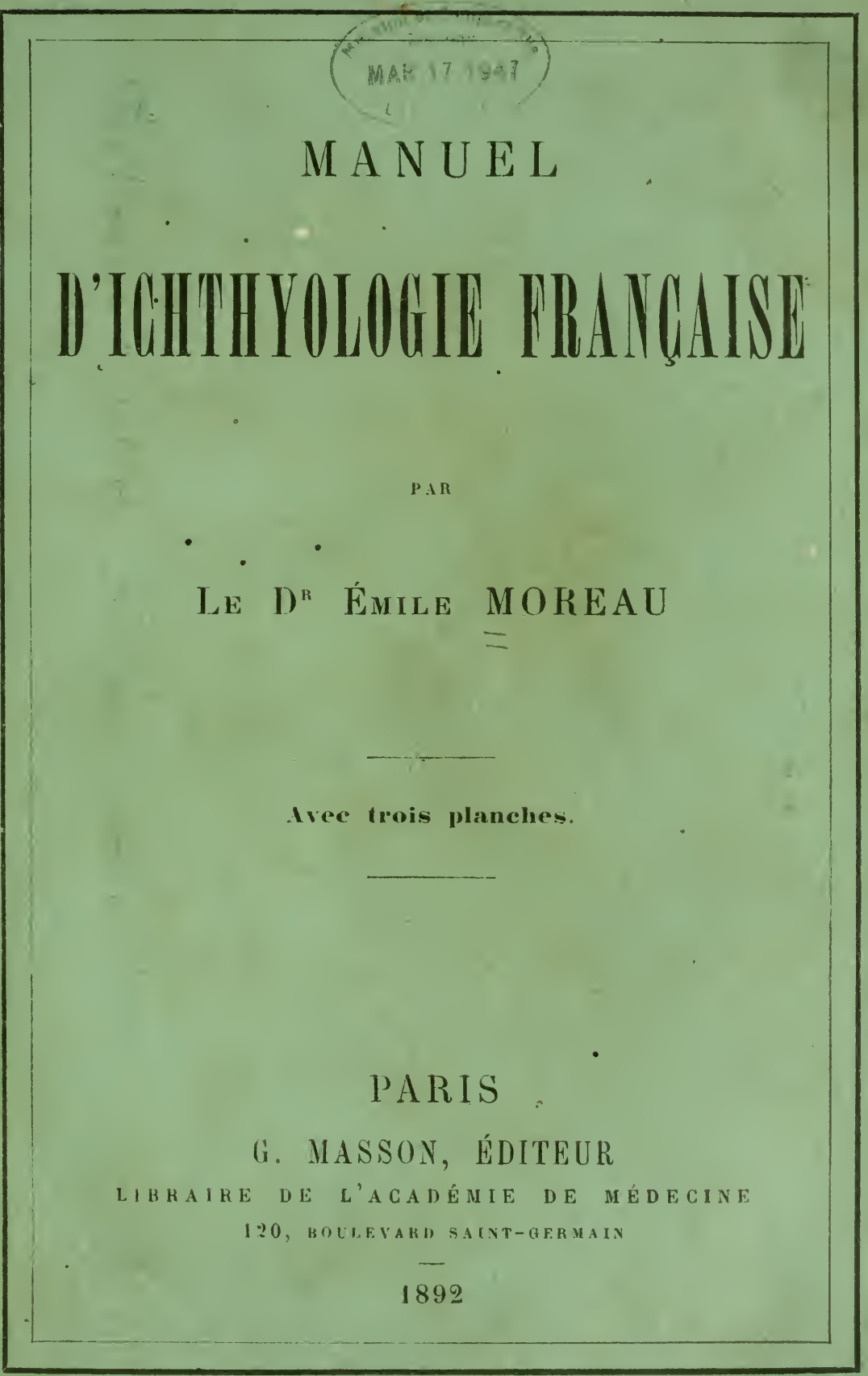



tommage de l'auteur

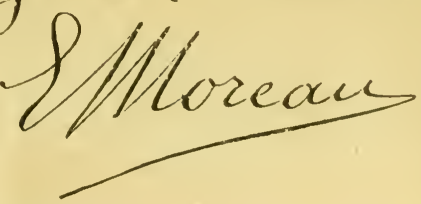

MANUEL

D'ICHTHYOLOGIE FRANGAISE 



\section{A N U E L}

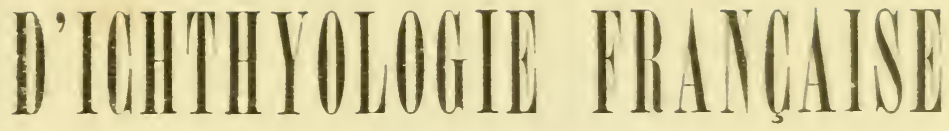

$P+R$

Le D ${ }^{\text {R }}$ émle MOREAU

Irec trois planches.

\section{PARIS}

G. MASSON, ÉdTEUR

LIBRAIRE DE L'ACADÉMIE DE MÉDECINE $1 \geq 0$, BOELEVARD SAINT-GBRMAIN 


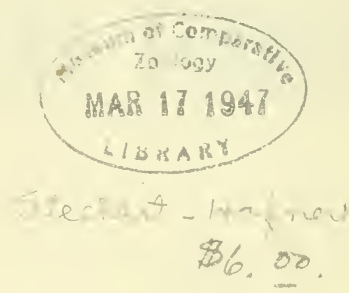

Droits de traduction el de reproduction réservés. 


\section{AVANT-PROPOS}

Depuis la publication de mon Ilistoire naturelle des Poissons de la France, bien des personnes, qui s'intéressent aux progrès de l'Ichthyologie, m’ont demandé de faire paraitre un travail beaucoup moins étendu que le premier, un simple volume, facile à emporter en voyage, destiné principalement aux jeunes gens qui vont passer leurs vacances à la mer, et qui, désireux de s'instruire, s'appliquent à connaittre les diverses espèces de Poissons qu'ils ont sous les yeux. - Ces personnes ont insisté sur les services que doit rendre un tel ouvrage, et à différentes reprises ont cru à propos d'essayer de me le démontrer. - Mieux que qui que ce soit, j'étais à même de comprenđre, je ne dirai pas seulement l'utilité, mais encore la nécessité d'une œuvre semblable. - Au début de mes recherches sur nos plages de l'Onest, j'avais pour tout guide l'Essai d'Ichthyologie des côtes océaniques et de l'intérieur de la France ou Diagnose des Poissons observés, par M. Desvaux, Angers, 18:̈1. La classification des Poissons est des plus simples; l'auteur admet seulement deux divisions : $1^{\circ}$ Chondroptérigiens ou à squelette cartilagineux; $2^{\circ}$ Acanthoptérigiens ou à squelette osseux. - Je ne me permets aucune réflexion; d'après l'énoncé d'un système de classification aussi extraordinaire, je laisse à penser 
de quel secours pouvait bien miètre un pareil trailé d'Ichthyologie.

Dans ces conditions la tàche que j'entreprenais était remplie de difficultés; il m'a fallu des efforts prolongés pour atteindre au but que je me proposais. - Aussitôt arrivé au bord de la mer, je m'empressais d'aller voir les pècheurs, je m'entretenais avec ces braves gens, je leur adressais des questions auxquelles ils répondaient avec la plus grande obligeance, c'est ainsi que japprenais les noms par lesquels ils désignent les Poissons de leur pays; je fréquentais le marché, voulant chaque jour ajouter à ma collection de la veille. C'était bien tant qu'il s’agissait d'espèces comestibles; mais il en est d'autres qui n’intéressent pas moins le Naturaliste et ne le lui sont pas souvent faciles à trouver; elles composent tout le menu frelin, Blennies, Gobies, Cottes, etc., si dédaigné sur nos còtes de l'Ouest, qui, n’ayant aucune valeur vénale, n’est jamais porté à la Poissonnerie. Je ne pouvais m'en procurer les divers spécimens qu'en me domnant la peine d'aller les chercher moi-même; il me fallait alors courir la plage; je partais, à marée basse, muni d'un petit filet arec lequel je fouillais les anfractuosités des rochers, les trous couverts de goëmon; je faisais ainsi des captures généralement assez abondantes.

Après un séjour plus ou moins prolongé sur les côtes, je revenais avec un butin souvent riche, toujours varié. A Paris il fallait m'occuper du classement des espèces que j’avais rapportées de mes excursions; pour m’aider dans ce travail, j'avais à ma disposition plusieurs ourragges, un

- surtout fort précieux, celui de Cuvier et Valenciennes. Lorsqu’il se trouvait des sujets dont la détermination était douteuse ou par trop difficile, j'allais les comparer avec les types du Muséum, ce qui m’était possible, grâce au bon vouloir, à l'extrême amabilité de MII. les Professeurs 
A. Duméril et L. Vaillant; je leur en garde une vive reconnaissance.

L'étude des Poissons de la Méditerranée m'a donné beaucoup moins de peine; les auvres de Risso m'ont rendu grand service relativement surtout à ce qui se rapporte à la détermination des spécimens de Nice; en 1867, j’ai passé un certain temps dans cette ville, j'ai pu recueillir ainsi un bon nombre des espèces qui fréquentent les parages des Alpes-Maritimes.

Longtemps j'ai hésité à entreprendre ce nouveau travail; je comptais en donner un autre, qui nous manque, sur l'anatomie comparée des Poissons de notre pays. Ayant dans mes cartons un assez grand nombre de figures originales, j'avais l'intention d'en faire achever la gravure, et de les publier avec un texte explicatif ; mais songeant à l'intérèt des étudiants, j’ai pensé qu'il valait mieux renoncer, pour le moment, à l'exécution de mon projet et me meltre à écrire un modeste traité d'Ichthyologie. - Ce Manuel n'est en aucune façon le résumé de mon Histoire naturelle des Poissons de la France; il est conçu d'après un tout autre plan; ainsi j'ai dû renoncer à présenter des notions d'anatomie un peu étendues; à mon grand regret, je n ai pu reproduire une synonymie à peu près complète, indispensable à qui veut être au courant de la science; j'ai même, à cause du format de ce volume, été obligé de modifier la disposition des tableaux analytiques; après les changements dont je viens de parler, je ne dois pas oublier de signaler l'addition fort importante que j'ai faite. - A la table des noms scientifiques, latins et français, j’ai cru nécessaire d'en joindre une autre, celle des noms vulgaires des espèces, et afin d'en rendre l'emploi plus facile, plus pratique, j’ai pris soin de faire suivre chaque nom vulgaire de l'indication de la localité dans laquelle il est usité, c'est le seul moyen d'empêcher toute confusion; car lo même nom est, 
suivant l'habitat du Poisson, appliqué à des espèces différentes, et même parfois à des espèces appartenant à des genres distincts : ainsi le nom de Vairon ou Véron est donné au Phoxinus lxvis, par les pêcheurs des bords de la Seine, et au Leuciscus pallens, par ceux du lac d'Annecy; le nom de Sardine sert à désigner sur nos côtes un Clupe bien connu, Alosa sardina, tandis qu'en Savoie, la Sardine du lac d'Annecy est un Vairon, Phoxinus læxvis, celle du lac du Bourget est une Ablette, Alburnus lucidus. - Cette table des noms vulgaires sera fort utile aux commençants; elle épargnera à ceux qui n'ont pas encore acquis l'habitude de s'en servir, la peine de faire des recherches plus ou moins longues dans les tableaux dichotomiques.

Enfin, je dirai qu'à la suite du texte, j'ai donné plusieurs planches destinées à montrer la disposition de la plupart des pièces squelettiques, qui entrent dans la composition de la tête chez différents types de Poissons osseux. - Au lieu de définir les caractères des principaux organes extérieurs des Poissons, qu'il faut connaître pour comprendre les descriptions, j'ai, ce qui est plus court et me semble surtout plus clair, préféré les indiquer sur une figure, qui évidemment ne représente aucune espèce particulière. - Je n'ai rien négligé pour rendre aussi facile que possible l'étude de l'Ichthyologie; j'espère que mes efforts ne seront pas stériles.

\section{E. Moreat.}

Paris, juillet 1892. 


\section{MANUEL}

\section{D’ECHTYOLOGIE FRANGAISE}

\section{CARAGTÈRES GÉNÉRAUX DES POISSONS}

Les Poissons forment la dernière classe de l'embranchement des Vertébrés; ce sont des animaux à sang froid, respirant par des branchies l'air dissous dans l'eau; à nageoires impaires soutenues par un squelette plus ou moins développé; à membres pairs, quand ils existent, transformés en nageoires et terminés par des pièces plus ou moins nombreuses.

D’après la disposition que présente l'appareil branchial des êtres qui la composent, eette classe doit être divisée en trois sous-classes, ainsi que nous allons l'indiquer brièvement.

$1^{\circ}$ Les branchies sont supportées par des arcs mobiles et articulés de l'appareil hyoïdien dans la sous-classe des Hyobranches.

20 Les branchies, non soutenues par des ares mobiles de l'appareil hyoüdien, sont logées dans des espèces de bourses ou de sacs dans la sous-classe des Marsipobranches.

$3^{\circ}$ Enfin les branchies, couvertes de cils vibratiles, sont posées sur de nombreuses lamelles squelettiques, séparées par des fentes, à travers le quelles passe dansla cavité abdominale l'eau qui a servi à l'entretien de la respiratien, dans la sousclasse des Pharyngobranches.

Noreau. - Ichthyologie. 


\section{SOCS-CLASSE DES HYOBRANCHES. - HYORRAYCHII.}

Corps de forme variable; ceinture scapulare plus ou moins com:plète, parfois trìs réduite, manquant peut-ètre chez quelqu's Apodes; peau assez rarement nue, le plus souvent couverte d'écailles, de pièces dures.

Tête variant lans sa forme; bouche transversale; machoires io plus souvent dentées; màchoire inférieure reliée au cràne au moyel: d'un suspenseur mobile, excepté chez les Chimères.

Narines placées de chaque còté de la lignne médiane.

Oreille composée d'un restibule el de trois canaux semi-circulaires.

Appareil branchial; branchies supportées par des arcs mobilus et articulés de l'appareil hyoïdien.

La sous-classe des Hyobranches comprend deux dirisions nettement distinctes.

Dans la première division se rangent les Poissons qui ont la première branchie portée sur la corne de l'os hỹöle et que pour celte raison nous appelons Branchiocères ou Cératobranches. Cetle division forme la section des Plagiostomes qui se partage en deux ordres: l'ordre des Sélaciens et l'ordre des Chimères.

Dans la seconde division, se placent les Poissons qui nont pas de branchies sur les cornes de l'os hyoüde, et que nous nommons A $6 r^{2}(\mathrm{~m}$ chiocires ou Acératolranches. Cette dirision se compose de deux sections : I. La section des Gamoz̈les ayant pour caractères principaux : un cœur à bulbe artériel musculeux, contractile. sarni de valvules disposées eu plusieurs rangées, un intestin pourvu d une valvule en spirale; elle comprend un seul ordre, celui des Sturioniens. II. Ia section des Poissons osseux ou Téléostéens, se distinguant des Ganoüdes par un cœur à bulbe artériel non musculeux, n’avant généralement que deux valvules, un intestin sans valvule spirale: elle compte quatre ordres : l'ordre des Lophobranches, l'ordre des Plectogmathes, l'ordre des Chorignulhes, enfin l'orilre des Apucles.

Pour donner une idée plus nette de celte distribution nouvelle des Poissons, nous allons la présenter sous forme d'un simple tableau, qui trouvera son explication dans le courant de ce travail.

\section{DIVISION I. EBranchiocères ou Cératobranches.}

\section{Section I. Plagiostomes.}

Ordre I. Sélaciens.

Ordre 11. Chimeres. 
DIVISION II. Abranchiocères ou Acératobranches.

\section{Section II. Ganoïdes.}

Ordre I. Sturioniens.

Section III. Poissons osseux ou Téléostéens.

Ordre I. Jophobranches.

Ordre II. Plectognatlies.

Ordre III. Chorignathes.

Ordre IV. Apodes.

Cette sous-classe renferme presque la totalité des Poissons de notre Faune, à l'exception de quatre ou cinq espèces qui représentent la sous-classe des Marsipobranches et celle des Pharyngobranches.

\section{Section des Plagiostones. - Plagiostomi.}

Squelette cartilagineux.

Corps de forme variable.

Tête; cràne constitué par des pièces cartilagineuses confondues entre elles, sans ligne de démarcation netlement indiquée; màchoires garnies de dents ou de plaques dures.

Nageoires ; nageoires paires ne manquant jamais ; ceinture scapulaire non altachée au cràne; pectorales très variables dans leur forme et leur développement; ventrales toujours abdominales, entourant l'anus ou plutòt le cloaque; nageoires impaires, moins constantes, manquant toutes parfois.

Système nerveux; pas de processus ni d'éminences dans le ventricule optique.

Organes des sens ; œil pourvu généralement de procès ciliaires ; nerfs optiques formant un véritable chiasma; narine à une seule ouverture; oreille communiquant arec l'extérieur au moyen d'un canal particulier: peau traversée par les tubes de Lorenzini.

A ppareil digestif; intestin ayant une valrule en spirale; anus sourrani dans le cloaque, ainsi que l’appareil génito-urinaire.

Appareil circulatoire; cour à bulbe artériel musculeux, contractile, muni de plusieurs rangées de valvules.

Appareil branchial; corne de l'hyoüde portant la première branchie; fentes des branchies au nombre de cinq de chaque còté, très rarement de six ou sept.

Conservation de l'espèce; fécondation interne; màles pourvus 
d'appendices copulateurs, attachés aux ventrales, qui les font distinguer facilement des femelles.

Cette section se compose de deux ordres.

Branchies s'ouvrant de chaque côté par cinq fentes au

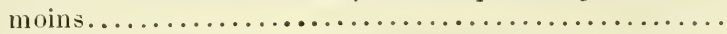

Branchies s'ouvrant de chaque còté par une seule fente...

1. Sfrlaciens.

2. Cuimères.

\section{Ordre des Sélaciens, Selacha.}

Corps allongé, soit arrondi, soit prismatique ou raccourci et déprimé; peau le plus souvent chagrinée, hérissée de scutelles épineuses, de boucles plus ou moins développées, parfois lisse et nue.

Tête de forme très variable; màchoire inférieure s'articulant avec la màchoire supérieure et le suspenseur commun, qui s'attache au cràne; dans certaines espèces, il existe autour de la bouche des cartilages, qui ont été désignés sous les noms de cartilages labiaux supérieurs et inférieurs.

L'ordre des Sélaciens se partage en deux sous-ordres suivant la position des ouvertures externes des branchies.

Fentes des branchies placées latéralement............. 1. Soundes.

- en dessous.............. 2. Raies.

\section{Sous-ordre des Squales, Squali.}

Gorps allongé, se continuant avec une queue bien déreloppée.

Tête libre; bouche généralement sous le museau.

Yeux sur les còtés de la tète le plus ordinairement, pourvus, dans certaines familles, d'une membrane nictitante.

Narines sous le museau, rarement vers le bord antérieur.

Évents manquant dans quelques familles.

Appareil branchial; ourertures des ouies latérales; lames de la première branchie portées sur la corne de l'hyoüde et sur le suspenseur commun.

Nageoires; pectorales libres; rentrales attachées à une ceinture pelvienne; dorsale double, excepté chez les Notidaniens; anale manquant dans une tribu entière (Squales anhypoptériens); caudale plus ou moins déreloppée.

Les Squales, excepté les Scylliidés et peut-ètre le Laimargue à conrtes nageoires, sont tous ovovipares; ils se partagent en deux tribus. 
Anale plus ou moins développéc.......... 1. Squales mypoptimens.

2. - ANHYPOPTERIENS.

\section{TRIBU DES SQUALES IIYPOPTÉRIENS. - SQUALI IIYPOPTERII.}

Celte tribu se compose de deux sous-tribus.

Dorsale double; cinq fentes branchiales..... 1. Soundens.

- unique; six on sept fentes branchiales. 2. Notidaniens.

\section{SOLS-TRIBU DES SQUALIENS. - SQUALII.}

Appareil branchial; cinq fentes branchiales.

Nageoires; deux dorsales, une anale.

Cette sous-tribu se divise en huit familles.

a. Yeux à membrane nictitante nulle......... b.

$$
\text { - } \quad \text { - développée...... e. }
$$

b. 1re dorsale au-dessus ou en arrière des ventrales. 1. Scrubnoés.

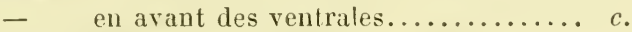

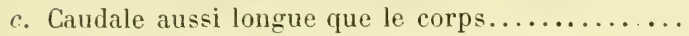

- moins longue que le corps........... d.

d. Troncon de la queue sans carène latérale......

e. Évents existants.......................... $f$.

2. ALOPÉCIDÉS.

d.

3. Odoxtaspidés.

4. LAMNIDÉs.

f.

5. MustÉLiDÉs.

6. Galéidés.

7. ZYGÉNidÉS.

8. Carcharidés.

\section{Famille des Scylliidés, Scylliidx.}

Corps allongé, plus ou moins cylindrique en avant, comprimé eu arrière, couvert de petites scutelles à trois pointes.

Tête; museau de longueur variable; dents aigruës à trois et mème cinq pointes chez les jeunes, disposées en séries assez nombreuses et assez rapprochées.

Yeux sans membrane niclitante.

Évents placés derrière les yeux.

Appareil branchial; fentes des ouies régulières, de moyenne grandeur; la dernière est au-dessus de la base de la pectorale.

Nageoires; première dorsale au-dessus ou en arrière des ventrales.

Les Scylliidés sont ovipares; ils sont généralement appelés Chiens de mer, Roussettes; ils n’alteignent pas à une grande laille. 
Cette famille se compose de deux genres.

Caudale à bord supérieur non dentelé; museau court..... 1. Roussetre. dentelé; museau allongé........ 2. Pristiure.

\section{GENRE ROUSSETTE. - SCYLLIUM, Cuv.}

Tête aplatie en dessus; museau court, demi-circulaire; bouche arquée, dents à trois ou cinq pointes chez les jeunes, la pointe médiane plus longue que les autres; parfois, chez les individus àgés, les dents n'ont plus de pointes latérales; plis labiaux supérieurs et inférieurs assez longs.

Narines à valvules développées.

Évents assez étroits, ouverts près de l'angle postérieur de l'œil.

Nageoires; première dorsale sur la seconde moitié de la longueur tolale, commençant plus en arrière que les ventrales.

Eufs allongés, quadrangulaires, portant à chaque extrémité deux longs filaments, qui les attachent, comme font les vrilles de certains végétaux.

Deux espèces.

Valvules nasales contiguës; ventrales triangulaires. 1. Grande Roussette. bien séparées; veutrales quadrangulaires................... 2. Petite Roussette.

\section{LA GRANDE ROUSSETTE OU ROUSSETTE A PETITES TACIES.} SCYLLIUM CANICULA, Cuv.

Poiss. France, t. I, p. 278, fig. 34, anim., fig. 33̈, museau.

N. vulg. : Pintou roussou, Nice; Cata roussa, Cette; Calonyé, Ande; Rousse, le Havre.

Long. : 0,30 à 0,80 .

Le corps est plus allongé que dans l'autre espèce. La tête est assez large, aplatie; la bouche est très arquée. Les valvules nasales sont contiguës; elles sont attachées en dedans, sur la ligne médiane, par un frein très court. La première dorsale commence un peu en arrière des ventrales; la caudale, chez les animaux de grande taille, est comprise au moins quatre fois et demie dans la longueur totale; les ventrales sont triangulaires, étroites ; chez les mâles, elles sont réunies, presque complètement, par leur bord interne.

La coloration est, sur le dos et les côtés, d'un gris rougeàtre. 
marcué de nombreuses petites taches de nuance foncée; la région ventrale est d'un gris sale.

Habitat. La Grande Rousselle est commune sur toutes nos còtes, surtout sur les còtes de la Manche.

Les aufs éclosent généralement vers la fin de l'année, après une incubation de neuf it dix mois.

2. LA PETITE ROUSSETTE OU hOUSSETTE A (iRANI)E TACHES. SCYLLIUM CATULUS, Cuv.

Poiss. France, t. I, p. 280, fig. 36, muscau. OEuf et fotus, loc. cit., P. 270, fis. 33 .

N. vulg. : Gatta d'Arga, Nice; Cata rouquiëyda, Cette; Vache, le llavre.

Long. : 0,60 à 1,90 .

Le corps est plus épais que dans la Roussette à petites laches. La tête est aussi plus large, plus haute et plus longue. Les valvules nasales ne sont pas confondues sur la ligne méliane; elles sont au contraire séparées par un espace assez Iarge. La première dorsale commence vers le milieu de la longueur totale, au-dessus de linsertion des rentrales; la caudale est plus déreloppée que dans l'autre espèce, sa longueur fait le quart de la longueur totale; les rentrales sont larges, quadrangulaires, coupées presque carrément à leur bord postérieur et chez le mâle, elles sont libres en arrière.

La coloration est d'un brun cendré, parfois d'un gris jaunâtre ou rougeàtre arec de grandes taches arrondies d'un violet noiràtre, à centre sourent moins foncé.

Habitat. Cetle espèce se trouve sur toutes nos còtes; mais elle est moins commune que l'autre, surtout dans la Manche.

D'après le professeur Doderlein, le sujet décrit et figuré par de Filippi, sous le nom de Scyllium acunticonotum, est un embryon de Scyllium catulus on stellare.

Les petits paraissent natre ver's le commencement du printemps. Jai reçu de Cette un auf, preché le 13 mars, contenant un futus tres

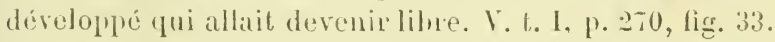


2. GENRE PRISTIURE - PRISTIURUS, CBP.

Tête aplatie en dessus; museau allongé; bouche arquée.

Narines larges, éloignées de la bouche; valvules nasales petites, distantes l'une de l'autre.

Nageoires; première dorsale sur la moitié antérieure du corps, au-dessus du tiers postérieur des ventrales; caudale longue à bord supérieur garni de petits écussons épineux.

OEufs ovales, arec une petite échancrure médiane à l'extrémité postérieure et deux petites cornes latérales à lextrémité antérieure.

\section{LE PRISTIURE A BOUCHE NOIRE. - PRISTIURUS MELA NOSTOMUS.}

Poiss. France, t. I, p. 284, fig. 37, anim.

N. vulg. : Bardoulin, Nice.

Long. : 0,50 à 0,90 .

La hauteur du tronc est contenue dix à onze fois dans la longueur totale. Le museau est long, déprimé; la bouche est très arquée, tapissée d'une muqueuse noiràtre, armée de petites dents à cinq pointes chez les jeunes, à trois ou cinq pointes chez les adultes; la pointe médiane est toujours la plus longue. Les évents sont petits, un peu en arrière de l'angle postérieur des paupières. La première dorsale commence sous la moitié antérieure de la longueur totale, au-dessus du tiers postérieur des ventrales; l'anale est très longue; sa longreur est au moins égale à la distance qui sépare le bout du museau de l'évent. La caudale est fort développée, sa longueur mesurant plus du quart de la longueur totale; son bord supérieur est hérissé d'une crête rude formée de trois ou quatre séries de petites épines à pointe dirigée en arrière.

La teinte générale est d'un gris rougeâtre sur le dos, d'un gris assez clair sur les llanes, avec de grandes taches plus ou moins foncées, disposées sur plusieurs rangées horizontales; la première série est la plus longue, elle s'étend de la tête jusque sur le bord supérieur de la caudale.

Habitat. Méditerranée, assez commun à Nice. Océan, golfe de Gascogne, excessivement rare, Arcachon. 
Risso indique bien la forme de l'œuf; il dit que le petit écarte les parois réunies de la fissure supérieure de l'œuf pour en sortir, mais ne parle pas de l'époque de l'éclosion.

\section{Famille des Alopécidés, Alopecidre.}

Corps à peu près fusiforme, couvert de petites scutelles à pointe mousse.

Tête courte; museau conique très court; dents assez petites, non dentelées sur les bords, à peu près semblables aux deux mảchoires; pas de dent médiane.

Yeux sans membrane nictitante.

Évents très étroits, parfois même difficiles à voir.

A ppareil branchial; fentes des oulies assez peu étendues.

Nageoires; caudale excessivement longue, faisant la moitié environ de la longueur totale; première dorsale en avant des ventrales; seconde dorsale et anale excessivement petites.

GENRE RENARD. - ALOPIAS, Rafin.

Caractères de la famille.

\section{IE RENARD. - ALOPIAS VULPES, CBP.}

Poiss. France, t. I, p. 287, fig. 38, dents.

N. vulg. : Renard; Singe de mer; Poisson épée; Faux; Touille à l'épée, còtes du Poitou; Péi espaza, Cette; Pei ratou, Nice.

Long. : 2,00 à $ّ, 00$.

Le corps est à peu près fusiforme, pas plus long, et même souvent moins long que la queue. La tète est courte; la bouche est arquée, peu dilatable; les dents varient un peu dans leur forme suivant l'àge des sujets, généralement elles sont aplaties, triangulaires, non dentelées sur les bords; elles sont assez. semblables aux deux màchoires. Les yeux sont assez grands; le diamètre mesure la moitié de l'espace préorbitaire. Les narines sont plus rapprochées de la bouche que du bout du museau. Les évents sont très petits; ils sourrent dans une petile rainure située on arrière de l'oeil. La première dorsale sélève à peu près sur le milieu de la longueur totale; la seconde, qui est très petite, est placée un peu en avant de 
l'anale; la caudale est excessivement longue, faisant au moins la moitié de la longueur totale.

Le dos et les flancs sont d'un gris ardoise; le rentre est blanchâtre.

Habitat. Se trouve sur toutes nos còtes, principalement sur les còtes de Ja Méditerranée. Les petits sont peu nombreux, de deux à quatre; les fuetus atteignent à une très grande taille; quatre folus d'une mème portée mesuraient 1,30 à 1,00 , le tiers à peu près de la longueur de leur mère, gui avait une taille de 4,60 environ; les petits, sur le point de naitre, ne présentaient plus ancune trace de cicatrice ombilicale. Les pècheurs de Cette ont fail celte intéressante capture dans la nuit du 30 au 31 mai 1881.

\section{Famille cies Odontaspidés, Odontaspidr.}

Corps fusiforme; troncon de la queue sans carène latérale; peau couverte de scutelles à trois petiles carènes.

Tête assez longue; nuseau pointu ; bouche en croissant, graude, ouverte en arrière jusque sous l'évent, armée de dents épaisses, semblables de forme, mais rariables de longueur aux deux màchoires, avec une pointe médiane allongée et un ou deux petits cònes de chaque còté ; pas de dent médiane.

Yeux sans membrane nictitante.

Évents très petils, au-dessus de l'angle de la bouche.

Appareil branchial; fentes des ouïes grandes, régulières.

Nageoires; première dorsale au-dessus de l'espace qui sépare les pectorales des ventrales; seconde dorsale et anale bien déreloppées; caudate très longue, faisant près du tiers de la longueur totale.

\section{GEYRE ODONTASPIDE. - ODONTASPIS, Agass.}

Michoire supérienre ayant ses deuxième et troisième dents très grandes, suivies d'une on plusieurs dents très petiles, faisant lacune, après, une longue dent, puis d'autres à la file diminuant par degré.

Ce genre comprend deux espèces.

Màchoire supérieure ayant, de charque còté, une lacune formée par une ou deux petiles dents................... Màchoire supéricure ayant, de chaque còté, une lacune forméc par quatre dents tres contes................ 2. FÉHOce. 


\section{L'ODONTASPIDE TAUREAU. - ODONTASPIS TAURUS, Mïll. Henl.}

Poiss. France, t. I, p. 291.

N. vulg. : Lamie, Verdoun.

Long. : 2,00 et plus.

Le corps est fusiforme; la longueur fait sept à huit fois la hauteur. I la màchoire supérieure, la première dent est assez petite : la deuxième dent presque toujours et la troisième sont les plus longues; la quatrième dent et parfois la cinquième sont beaucoup plus courtes que la première, elles font lacune; la sixième dent est longue, mais un peu moins que la troisième; les dents suirantes à partir de la septième diminuent graduellement. A la mandibule, la première dent latérale est très courte. Les dernières rangées, à chaque màchoire, sont composées de dents courtes, à bord très tranchant. La base des longues dents ne porte ordinairement quin petit cone de chaque côté.

La coloration est d un gris jaunàtre ou rougeàtre, avec ou sans taches noires.

Habitat. Méditerranée, Nice, excessivement rare.

2. L'ODONTASPIDE FÉROCE. - ODONTASPIS FEROX, Agass.

Poiss. France, t. I, p. 293, fig. 39, dents.

Long. : 2,00 à 4,00 .

La hauteur du trone est contenue huit fois environ dans la longueur totale. Les màchoires sont armées de dents très aignuës, à cinq pointes le plus généralement. A la màchoire supérieure, la première dent latérale est petite, gorèle; les deuxième et troisième dents sont grandes; les quatre dents suivantes sont très petites, forment lacune; la huitième dent est grande mais moins lonğue que la seconde et la troisième; les neuvième, dixième, onzième el douzième dents sont à peu près aussi longues que la huitième; les autres ront diminuant de longueur progressivement jusqu’à la dix-septième dent; 
les cinq ou six dernières sont très courtes. A la mandibule, la première dent latérale est petite, grêle; les deuxième, troisième et quatrième dents sont les plus grandes, les autres vont diminuant par degré jusqu'à la dernière. Les dernières dents, surtout à la mandibule, sont semblables aux autres, elles sont très pointues, tandis que dans l'Odontaspide taureau, elles sont pour ainsi dire coupantes. Le nombre des dents est variable; sur un spécimen renant d'Algérie, je compte mâchoire supérieure $23+23=46$; mandibule $18+18=36$; il y en a davantage dans la figure donnée par Agassiz. Au musée de Gênes, est un superbe spécimen $\mathrm{O}$ de cette espèce, ayant une formule dentaire semblable à celle que j’ai indiquée d’après le sujet venant d'Algérie, seulement la plupart des dents ne portent qu'un seul cône de chaque côté; cette disposition tient fort probablement à l'àge du sujet qui avait atteint à une taille de $3^{\mathrm{m}}, 7 \mathrm{~s}$.

La coloration est rougeâtre sur le dos, avec des taches noirâtres.

Habitat. Méditerranée, excessivement rare, Nice.

\section{Famille des Lamnides, Lamnida.}

Corps allongé, plus ou moins fusiforme; tronçon de la queue avec une carène de chaque còté, et une fossette en dessus et en dessous vers la base de la caudale.

Tête plus ou moins conique; bouche arquée.

Yeux sans membrane nictitante.

Events très petits, en arrière de l'ceil.

Appareil branchial; ouvertures des ouïes très larges; la dernière placée en avant de l'insertion de la pectorale.

Nageoires ; première dorsale très développée, au-dessus de l'espace qui sépare les pectorales des ventrales; seconde dorsale et anale très petites; caudale en croissant; pectorales plus ou moins falciformes.

Cette famille se compose de quatre genres.

a. Dents Iongues.......................... $b$.

b. Dents dentelées sur les borrls...................

4. Pèlerin.

- non dentelées......................

3. Carcharodonte. 
c. Dents a base sans cônes latéraux..............

munies de cônes latéraux.........

2. OXYrhiNe.

1. LAMIE.

1. GENRE LAMIE OU TOUILLE. - LAMNA, CUV.

Corps fusiforme, couvert de très petites scutelles lisses.

Téte; museau pointu, pyramidal; dents pointues, triangulaires, aplaties, non deatelées sur les bords, portant de chaque còté, sur la base, un còne pointu, simple ou double chez les adultes; il n'y a souvent, chez les jeunes, a la base de la dent qu'un talon plus ou moins prononcé.

\section{LE LAMIE LONG-NEZ. - LAMNA CORNUBICA, Guv.}

Poiss. France, t. I, p. 296.

N. vulg. : Nez, Pas-de-Calais, Boulogne; Taupe, Manche, Cherbourg; Touille-bœuf, Vendée ; Touille, Charents-Inférieure; Longnez, Gironde, parfois Requin, Arcachon ; Nas-Harg, Roussillon ; Mélantoun, Alpes-Maritimes, Nice.

Long. : 1,00 à 3,00 et plus.

Le corps est fusiforme; sa hauteur est comprise six à sept fois dans la longueur totale; la carène de la queue est longue; généralement elle commence un peu en avant de lorigine de la seconde dorsale. Le museau, relevé en avant, est en forme de pyramide quadrangulaire; la bouche est arquée; les dents sont aplaties, triangulaires, arec cone pointu, simple ou double de chaque côté de la base, avec un petit talon, le plus sourent, chez les jeunes; pas de dent médiane; à la màchoire supérieure, la troisième dent latérale est plus courte que la deuxième. Les évents sont excessirement petits. La première dorsale a le bord postérieur échancré; la seconde dorsale est fort petite, elle est opposée ì l'anale; la caudale est en croissant à lobe supérieur d'un tiers au moins plus grand que le lobe inférieur; les pectorales ont moins de longueur que le lobe supérieur de la caudale.

La coloration est ardoisée sur le dos; blanchâtre sous le ventre.

Habitat. Méditerranée, assez commun. Nice.Océan, assez com- 
mun dans le golfe de liascogne; commun entre la Gironde et la Loire. Manche, assez rare, Cherbourg, le Havre, Boulogne.

Pennant a trouré deux fœtus seulement dans la femelle qu'il a examinée; le nombre des foctus, suivant A. Duméril, irait à quinze dans chaque poche utérine.

\section{GENRE OXYRHNE. - OYYRHINA, Agass.}

Corps fusiforme, couvert de petites scutelles à peu près lisses.

Tête allongée; museau pointu; dents longues, pointues, sans dentelures sur les bords, ni cònes latéraux à la base.

\section{L'OXYRHINE DE SPALLANZANI. - OXYRHINA SPALLANZANII, CBp.}

Puiss. France, t. I, p. 298 , fig. 40, tète; fig. 41 , dents, et p. 226 , fị. 23, cràne.

N. vulg. : Lamie, Cette; Lamia, Aigues-Mortes.

Long. : 2,00 à 4,00 .

La hauteur du tronc est comprise de cinq à sept fois dans la longueur totale; la carène du trongon de la queue est bien développée. La tête est longue, aplatie en dessus; le museau est en forme de pyramide quadrangulaire, sa longueur fait la moitié, et plus, de la distance séparant son extrémité de l’angle postérieur de la bouche. La bouche est grande, variable dans ses proportions suivant l'ìge des sujets; elle est armée de fortes dents, écartées, ressemblant à des espèces de clous; sur le derant des mâchoires, elles peuvent mesurer, chez les grands spécimens, trois centimètres et plus de longueur; elles soni épaisses, un peu ondulées; leur face externe est aplatie, leur face interne est convexe, arrondie, les bords sont lisses; sur les individus que j’ai examinés, la màchoire supérieure est armée de trente-deux dents $(16+16)$; la troisième dent est plus courte que les autres; la mandibule en a vingt-deux $(11+11)$ avec un groupe de dents vers la symphyse. Les évents sont très éloignnés de l'œil. - La première dorsale commence à peu près an-dessus de l’angle postérieur de la pectorale; la seconde dorsale et l'anale sont fort petites, opposées; la caudale, en eroissant, a son lobe supérieur d'un quart plus long 
que l’inférieur: les peetorales sont fusitormes, leur longueur, qui est plus grande que celle du lobe suprérieur de la caudale, mesure le einquiome de la longuentr totale.

La colomation est d’un golis ardoisé sur le dos el les flanes, blanchitre sous le ventre.

Habitat. Méliterranée. Ce Squale est assez commun à Nice, i Cette. Océan, très rare, Arcachon, la liochelle.

\section{GENRE CARCHAROWONTE. - CARCHARODON.}

Corps allongé, fusiforme, courert de très petites scutelles.

Tête forte, grosse; museau assez court; bouche grande, arquée; dents longues, larges, aplaties, triangulaires, dentelées sur les bords, à peu près semblables aux deux màchoires.

\section{LE CARCHARODONTE LAHE. - CARCHARODON LAMIA, CBP.}

Poiss. France, t. I, p。302, fig. 42, dents.

N. vulg. : Lamea, Nice; Lamie, Celle.

Long. : 3,00 à $̋, 0$ o et plus.

Le corps est renflé en avant de la première dorsale; sa hauteur est comprise cinq à six fois dans la longueur totale; le troneon de la queue porte une carène latérale. - La tète est forte; le muscau est pyramidal, court, assez obtus; la bouche est très grande, armée de dents tranchantes, excessirement développées, ayant jusqu'ì trois ou quatre centimètres de longueur, triangulaires, dentelées sur les côtés, à base très large, à pointe droite u à peine déjetée en arrière, diminuant de grandeur d'une façon assez régulière d'arant en arrière; les dents de la mandibule sont semblables à celles de la màchoire supérieure. un peu moins larges seulement. Les érents, excessivement étroits, sont éloignés du bord postérieur de lorbite d'une longueur à peu pròs égale à la longueur de l'espace préorhilaire. - La première dorsale commence plus pres des pectorales que des rentrales; la seconde dorsale et lanale sont petites; l'anale est plus reculée; la caudale est en croissant à lobe supérieur une fois et demie plus grand que l'inl'éricur; les pectorales sont falciformes, leur longueur, qui est 
le double de leur largeur, mesure le cinquième de la longueur totale.

Le dos est d'un gris bleuâtre ou brunâtre; le ventre es! blanchâtre.

Habitat. Méditerranée, assez commun, Nice, Cette. Océan, excessirement rare; deux spécimens ont été pèchés sur les còtes de la Charente-Inférieure, l'un en 1872 pesant 1,700 kilogrammes et long de 13 pieds, l'autre en 1880. Il est très redouté des pècheurs à cause de son extrème voracité; c'est à cette espèce qu'il faut, sans doute, rapporter le Requin capturé en octobre 1889 aux environs de Toulon, et dans l'estomac duquel se trouvaient le bassin et les membres inférieurs d'un homme et le corps d'un marsouin; il avait $4 \mathrm{~m}$. de long.

\section{GENRE PELERIN. - SELACHE, Cuv.}

Corps allongé, fusiforme, couvert de petites scutelles épineuses.

Téte; museau peu développé, conique; dents nombreuses, petites, non dentelées, plus ou moins coniques et crochues.

Appareil branchial; fentes branchiales très étendues; bord libre des membranes intrabranchiales formant de grands replis.

\section{LE PĖLERIN. - SELACHE MAXIMUS, Guv.}

Poiss. France, t. I, p. כ00̈.

Long. : 8,00 à 12,00 .

Le corps est couvert de petites scutelles épineuses, réunies par groupes plus ou moins rapprochés; sa hauteur est comprise quatre fois et demie à six fois dans la longueur totale, la carène latérale commence au-dessus de l'origine de l'anale. La tète est petite; les mâchoires sont garnies de dents excessivement nombreuses, petites, non dentelées, coniques et crochues. Les évents sont très petits, très reculés, au-dessus de l'angle de la bouche. - La première dorsale est triangulaire, placée sur le milieu de la ligne allant du bout du museau à la base de la caudale; la seconde dorsale est petile et lanale encore plus; la caudale est en croissant, elle est développée; son lobe supérieur est d’un tiers plus long que l’inférieur; les pectorales sont triangulaires, et relativement de moyenne grandeur. 
Le dos est d'un brun ardoisé, ou noiràtre; le ventre es grisàtre.

Habitat. Còtes de l'Ouest, excessivement rare, Boulogne, Dieppe, Saint-Malo, Concarneau.

\section{Famille des Mustélidés, Mustelidix.}

Gorps allongé, couvert de très petites scutelles; troncon de la queue sans carène, ni fossette, creusé d'un sillon entre l'anale et la caudale.

Tête de moyenne longueur, aplatie en dessus; museau avancé, arrondi sur les bords; bouche arquée, avec des plis latéraux bien marqués; cartilages labiaux développés; à l'angle de la bouche, un petit lobe se détachant du cartilaøe labial supérieur; dents nombreuses, en petits pavés serrés, avec l'angle postérieur mousse ou légèrement pointu, disposées par rangées obliques.

Yeux pourvus d'une membrane nictitante.

Narines ayant sur le bord antérieur une valvule triangulaire à sommet arrondi.

Évents en arrière de l'œil.

Appareil branchial; fentes des ouïes assez petites, régulières, la dernière au-dessus de l'origine de la base de la pectorale.

Nageoires ; première dor'sale au-dessus de l'espace séparant les pectorales des ventrales; seconde dorsale semblable à la première, seulement un peu moins grande; anale moins développée que la seconde dorsale, placée un peu plus en arrière; caudale ne faisant pas le cinquième de la longueur totale, à lobe inférieur très court, peu saillant.

\section{GENRE ÉHSSOLE. - MUSTELUS.}

Caractères de la famille.

Le genre Enissole comprend deux espèces.

Dents n'ayant pas de saillie pointue sur le côté externe... 1. cownuxe. Dents avec une saillic pointue sur le côté externc....... 2. LISse.

\section{L'ÉMISSOLE COMMUNE. - MUSTELUS VULGARIS, Müll. et Henl.}

Poiss. France, t. I, p. 311, et p. 71, fig. 10, canal latéral; p. 73, fig. 11, tube de Lorenzini. 
N. vulg. : Moutelle, Chien de mer, còtes de Normandie; Doncette, Landes; Lentillat, Missola, Cette, Languedoc; Meissolo, Provence ; Mustela de Mar, Roussillon.

Long. : 1,00 à 2,00 .

Le corps est allongé, la longueur faisant dix fois à dix fois et demie la hauteur : il est comprimé en arrière. La pean est couverte de petits tubercules pointus. La tête paraît un peu moins longue que celle de l'Émissole lisse, et le museau un peu plus court. Les mâchoires sont garnies de petites dents plus ou moins lisses; les dents qui sont placées sur les côtés des mâchoires sont complètement lisses, elles sont un peu plıs longues ou plus larges que celles qui se trouvent près des symphyses; ces dernières sont ordinairement carrées arec l'angle postérieur plus ou moins aigu. Les yeux sont grands; le diamètre de l'ceil varie suivant l'àge : chez les jeunes, il fait plus de la moitié de l'espace préorbitaire; chez les adultes, il en mesure à peine la moitié. Les évents sont placés un peu au-dessous du prolongement du diamètre horizontal de l'œil. La première dorsale commence au-dessus du bord interne de la pectorale, un peu en arrière de l'aisselle; la caudale fail le sixième de la longueur totale : la pectorale n'a pas le bord postérieur échancré ; quand elle est appliquée contre le corps, son bord interne arrive à l'aplomb du quart et même du tiers antérieur de la base de la première dorsale.

La coloration est d'un gris brunâtre ou ardoisé sur le dos et les flancs, gris blanchâtre sous le ventre, parfois d'un gris légèrement jaunâtre.

Habitat. Celte espèce est commune sur toutes nos côtes.

Les femelles semblent avoir deux portées par an; une en mai ou juin, l'autre vers la fin de novembre ou le commencement de décembre. Les petits sont plus ou moins nombreux; il y en a souvent une vingtaine à chaque portée, et parfois beaucoup plus, de quarante à soixante d'après Risso; une fois cependant, au mois de novembre, je n'ai trouvé que six fœetus, trois dans chaque utérus. J'avais écrit, t. I, p. 343 : "les tortus n'ont pas de placenta, mais ils ont la bursu entiuna bien développée "; je ne sais pour quelle raison Fis Day s'exprime ainsi : Morean refers.... Although the foetus has no placenta, "the lursa entiuna is well developped". V. Dar, t. II, p. 296. 
- C'est précisément par suite de l’absence de placenta que la bursa entiana est bien développée.

\section{L'ÉMISSOLE LISSE. - IUSTELUS LEVIS, Riss.}

Poiss. France, t. I, p. 313, fig. 43, animal; fig. 44 , dents.

N. vulg. : Nissoila, Cetle; Palloun, Nice.

Long. : 1,00 ì $1, \because 0$.

Le corps est couvert d'une peau douce au toucher; sa hauteur lait le dixième à peu près de la longueur totale. Les dents placées rers la symphyse des màchoires sont triangulaires, avec la pointe principale tournée en arrière et faisant suite à une espèce de petite carène médiane; sur le côté externe, elles portent une saillie pointue ; chez les jeunes, elles ont, parfois encore, une pointe sur le côté interne. A la mâchoire supérieure, presque toutes les dents sont pointues, mais à la mandibule elles sont obtuses rers l'angle de la bouche, assez larges transversalement et étroites ou courtes d'avant en arrière. Le diamètre horizontal de l'aril ne mesure guère que le tiers de l'espace préorbitaire chez les adultes, un peu moins de la moitié dans les jeunes. Les évents sont placés sur la ligne qui prolonge en arrière le diamètre horizontal de l'ceil. La première dorsale est plus reculée que dans l'autre espèce; son origine est à peine au-dessus de l'angle postérieur et supérieur de la pectorale; la caudale mesure le septième environ de la longueur totale; la pectorale est un peu moins longue que chez l'Émissole commune.

La coloration est très variable; le dos est d'un gris olivâtre, parfois d'un gris cannelle; le ventre est blanchâtre; parfois, chez les jeunes, le bord supérieur de la seconde dorsale, ainsi que celui de la caudale, est teinté de noir.

Habitat. Méditerranée, cette espèce est assez commune, Nice, Cette; Océan, golfe de Gascogne, très rare, Arcachon ; Manche?

D'après Aristote, les chiens de mer. qu'on nomme les chiens-lisses, ont, comme les petits chiens, leurs ceufs entre les deux parties de lit matrice. Attachés sur les deux parois de la matrice qu'ils tapissent, les aufs descendent; les petits se forment en ayant leur cordon ombilical sur la matrice, de telle sorte que, quand les œufs sont absor- 
bés, il semble que l'embryon est tout à fait pareil à celui des quadrupèdes. Le cordon ombilical de la matrice, qui est fort long, est attaché à sa partie inférieure; et chaque cordon est comme suspendu à une cavité ou cotylédon; V. Aristote, Histoire des Animaux, traduct. Barthélemy Saint-Hilaire, liv. VI, c. x, § 12, t, II, p. 297. - Les fœtus sont moins nombreux que dans l'Emissole commune; ils sont pourvus d'un placenta et manquent de bursa entiana.

L'ÉMISSOLE POINTILLÉE. - MUSTELUS PUNCTULATUS, Riss.

Poiss. France, t. I, p. 316.

N. vulg. : Nissola, Nice; Missola lénteyda, Cette.

L'Emissole pointillée de Risso est une variété de l'espèce commune.

\section{Famille des Galeidés, Galeidx.}

Corps allongé, fusiforme, couvert de petites scutelles.

Tête aplatie en dessus et en avant; dents pointues et dentelées, semblables aux deux màchoires, comprimées, tranchantes.

Yeux à membrane nictitante.

Évents en arrière des yeux.

Nageoires; première torsale au-dessus de l'intervalle séparant les pectorales des ventrales; seconde dorsale opposée à l'anale.

Deux genres.

Dents, excepté la dent médiane, dentelées sur le côté ex-

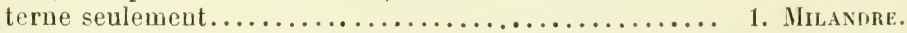
Dents dentelées sur les deux côtés................. 2. Thalassine.

1. GENRE MILANDRL: - GLLEUS, Cuv.

Tête; museau allongé, aplati en dessus; bouche arquée; cartilages labiaux assez développés; dents latérales, dentelées sur le bord externe, lisses sur le bord interne; à chaque màchoire, une dent médiane triangulaire dentelée de chaque còté.

Appareil branchial; fentes des ouïes de moyenne grandeur.

\section{LE MILANDRE. - GALEUS CANIS, Rond.}

Poiss. France, 1. I, p. 317 , fig. 40, animal; fig. 46 , dents ; 1. 38, 41, 45, fig. 6-7-8, cerveau; p. 116, 117, fig. 1 1 -1

N. vulg. : Palloun, Nice; Cagnot, Provence, Languedoc; Canicule, 
Marseille; Milandré, Granda Missola, Cette; Touille, Arcachon; Has, Roscoff; Haut, Cherbourg ; Chien de mer, Calvados, Seine-Inférieure.

Long. : 1,00 it 1,30 et plus.

Le corps est allongé, fusiforme, couvert d'une peau très peu rugneuse; le museau est allongé, aplati en dessus; la bouche est grande avec un pli labial it chaque michoire; les dents latérales sont aplaties, triangulaires, obliques ì pointe rejetée en dehors, elles portent du cóté externe trois à six dentelures; la dent médiane est droite, triangulaire avec une ou deux petites pointes de chaque còté de la base. Les évents sont assez grands, placés au-dessous du prolongement postérieur du diamètre de l'ceil. La première dorsale est assez basse; elle est un peu plus rapprochée des pectorales que des ventrales; la seconde dorsale est moitié moins grande que la premic̀re, elle est au-dessus et à peine en avant de l'anale; la caudale ne mesure pas le quart de la longueur totale.

Le dos est d'un gris ardoisé, le ventre d'un gris plus clair.

Habitat. Commun sur toutes nos còtes.

La femelle, suivant Risso, produit, deux fois par an, trente on quarante petits; i Cette, elle a une portée en juin, parfois en mai.

\section{GENRE THALASSINE. - THALASSINUS.}

Tête ; museau assez pointu; dents larges à la màchoire supérieure surtout, triangulaires, dentelées sur les deux còtés.

Intestin garni à l'intérieur d'une lame dont l'étendue est considérable et qui est roulée sur elle-mème autour d'un bourrelet, Valenc. - Cette disposition rapproche la Thalassine des Carcharidés.

LA TIILASSINE DE RONDELET. - THALASSINUS RONDELETII.

Poiss. France, t. I, p. 319, fig. 47, dents.

N. vulg. : Pei can, Nice; Cágnot, Celte.

Long. : 2,111 (6 pieds et demi, Valenc.).

Le corps est allongé, fusiforme; clı̀z le spécimen décrit par Valenciennes, la hauteur du trone est contenue huit fois et deux tiers dans la longueur totale. Liouverture de la bouche 
est parabolique; les dents de la mâchoire supérieure sont triangulaires, un peu courbes vers l'arrière, dentelées des deux cotés; les dents de la mandibule sont pointues, plus droites, plus étroites, plus finement dentelées; il y a, d'après Valenciennes, vinğt-six dents à chaque màchoire. Derrière l'œil, à une distance égale à son diamètre, est un évent ovale, n'ayant d'ouverture longitudinale que le tiers du diamètre de l'wil. La première dorsale est attachée aux deux cinquièmes de la longueur totale; la longueur de sa base égale sa hauteur; la seconde dorsale fait un peu plus de la moitié de la lonğueur de la première, elle est opposée à l'anale qui lui ressemble; la caudale mesure à peu près le quart de la longueur totale; la pectorale est falciforme, sa largeur fait ì peu près le tiers de sa longueur; la ventrale est petite triangulaire.

Le dos est bleu d'ardoise, le côté est d'un bleu cendré, le dessous est blanc. Une figure coloriée accompagne le manuscrit de Valenciennes; l'érent est très visible.

Habitat. Océan, excessivement rare; Mediterranée, très rare, Nice, Cette.

J'ai reçu de Cette une tète de Squale à laquelle se rapporte fort exactement la description faite par Valenciennes de son Alopecula thalassina. La disposition et le nombre des dents sont les mèmes; toutefois, j'ai constaté, dans le spécimen pèché à Cette, la présence, à la màchoire inférieure, d'une dent médiane dont il n'est pas fait mention dans le manuscrit de Valenciennes. - Duvernoy a décrit et fignuré la valvule spirale du Galeus thalassinus, qu'il disséqua avec Valenciennes, dans Annales sc. nat., t. III, p. 278, pl. X, Paris, 1833. Duvernoy a signalé aussi quelques détails sur la structure de l'intestin de ce Squale dans Cuv., Anat. comparée, t. IV, 2e part., p. $16 \ddot{\text { et }}$ p. 401 .

\section{Famille des Zygénidés, Zygrnidx.}

Corps allongé, plus ou moins arrondi, légèrement conique en arrière, couvert de scutelles peu développées. Tronęon de la queue avec une fossette en dessus et en dessous, vers la base de la caudale.

Tête très large, remarquable par les prolongrements latéraux qui portent les yenx; museau tout à fait tronqué; bouche très arquée; 
dents à peu près semblạbles aux deux màchoires, à pointe droite ou plus ou moins oblique en dehors, avec un talon à la base du còté externe, souvent les còtés sont finement dentelés; dent médiane droite et pointue.

Yeux à membrane nictitante, à l'extrémité des pédoncules latératux.

Narines, loin de la bouche, sous le bord antérieur des prolongements latéraux.

Évents nuls.

Appareil branchial; fentes des ouïes grandes, régulières.

Nageoires; première dorsale grande, au-dessus de l'espace séparant les pectorales des ventrales; seconde dorsale et anale petites, opposées; caudale très longue.

Intestin à valvule enroulée daus le sens de la longueur.

\section{GENIE MARTEAU. - ZYGRNA, Cuv.}

Caractères de la famille.

Tète trois fois aussi large que longue, peu arquée........ 1. connun. Tête deux fois ì peu près aussi large que longue, très arquée. 2. MaILlet.

La mesure est prise évidemment sur les prolongements latéraux.

\section{LE MARTEAU OU MARTEAU COMMUN. - ZYGENA MALLEUS, Valenc.}

Poiss. France, t. I, p. 324, fig. 48, tète; fis. 49, dents.

N. vulg. : Marteau, Marteu, Nice; Peï luna, Chandarma, Cette.

Long. : 2,00 à 3,00 et mème plus, Risso.

La hauteur du tronc est comprise neuf à dix fois dans la longueur totale. La tête est excessivement élargie transversalement, sa largeur mesure le quart et même parfois le tiers de la longueur totale; le bord antérieur est peu arqué, il est échancré en dessous vers l'ouverture des narines; une ligne droite, menée suivant l'axe des yeux, passe un peu en arrière de l'are de la màchoire supérieure. La bouche est demi-circulaire: les dents sont aplaties à leur face antérieure, un peu convexes à leur face postérieure ou interne; la pointe, assez allongée, est légèrement portée en dehors ou en arrière; les dents sont souvent finement denticulées sur les bords, sur le 
bord externe principalement; parfois au milieu de dents à bords denticulés, s'en montrent d'autres qui sont entièrement lisses. La première dorsale commence sur le tiers antérieur de la longueur totale; elle est plus haute que longue; la caudale est très déreloppée, elle mesure le quart au moins de la longueur totale; les pectorales sont triangulaires, à bord postérieur échancré; les ventrales sont petites.

Le dos est brunâtre, le rentre est d'un gris blanchàtre.

Habitat. Le Marteau se trouve sur toutes nos còtes, mais il est toujours plus ou moins rare. Méditerranée, assez rare, Nice, Cette; Océan, excessivement rare, golfe de Gascogne, Bayonne, còtes du Poitou; Manche, accidentellement, Pas de Calais, Boulogne (Bouchard-Chantereaux).

Suivant Risso, la femelle doit mettre bas vers la fin du printemps.

2. LE MARTEAU MALLET. - ZYGENA TUDES, Valenc.

Poiss. France, t. I, p. 327.

N. vulg. : Scrosena, Nice.

Long. : 1,50 et mème 3,00, Risso.

Le corps semble un peu plus allongé que dans l'autre espèce; sa hauteur est comprise onze à douze fois dans la longueur totale. La tête est beaucoup moins large que dans le marteau commun, la largeur ne faisant que deux fois la longueur et sonvent même un peu moins encore; elle est d'un tiers moins grande que la caudale; le bord antérieur est très arqué, onduleux, légèrement échancré sur son milieu et sinueux seulement au niveau des narines. Les dents paraissent un peu moins déreloppées que dans l'autre espèce; elỉes sont moins longues et elles ont la base proportionnellement plus large. La dorsale commence sur le second tiers de la longueur totale; la seconde dorsale est au-dessus de l'anale; la caudale mesure le quart de la longueur totale.

Le dos est d'un gris plus ou moirs foncé, le ventre d'un gris blanchâtre.

Habitat. Méditerranée, Nice, excessivement rare. 
8. Famille des C'archaridés, Carcharidx.

Corps allongé, fusiforme, couvert de petites scutelles à peu près mousses; troncon de la queue avec une fossette en dessus et en dessous avant la caudale.

Tête plus ou moins aplatie en dessus; bouche très arquée.

Yeux pourvus d'une membrane nictitante.

Ėvents nuls.

Nageoires; première dorsale entre les pectorales et les ventrales. Intestin à valvule médiane enroulée suivant sa longueur.

\section{GENRE REQUIN. - C.RCIIRIAS, Cuv.}

Tête légèrement léprimée en dessus; bouche très arquée, armée de dents plus ou moins aplaties et plus on moins triangulaires, sans còne latéral, à bords généralement dentelés chez les adultes; une dent médiane, au moins à la màchoire inférieure.

Narines rapprochées du bord du museau.

Ce genre comprend trois espèces.

a. Museau a yant une longueur beaucoup plus grande que la largeur de la bouche ou que la distince comprise entre ses angles postérieurs........

Museau ayant une longueur à peu près égale ì

la largeur de la bouche.................. $b$.

b. Longueur de la pectorale faisant le double de

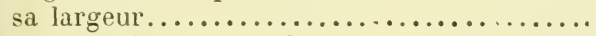

Longueur de la pectorale ne faisant pas le double

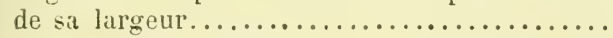

1. BLet.

2. A MUSEAU OBTUS.

3. de Milbert.

\section{LE REQUIN BLEU. - CARCHARIUS GLAUCUS.}

Poiss. France, t. I, p. 329 , fig. כ̋0, anim.; fig. כ̌l, dents, anim. jeune; fig. 32 , dents, an. adulte.

N. vulg. : Bleu, Peau bleue, côtes de l'Ouest; Blu, Cagnot, Cette ; Cagnot bleu, Languedoc; Pei can, Nice.

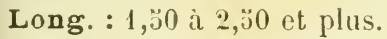

Le corps est fusiforme, effilé en arrière: sa hauteur est contenue huit à neuf fois dans la longueur totale. La tète est aplatie en dessus; sa longueur est de beauconp plus grande que la hauteur du tronc. Le museau est pointu très allongé; 
sa longueur, prise de la pointe à la màchoire supérieure, dépasse d'un tiers, et plus, la largeur de la bouche, ou la distance séparant l'un de l'autre les angles postérieurs de la bouche; les dents ont les bords finement dentelés, au moins chez les adultes; à la mâchoire supérieure, elles sont larges, aplaties, plus ou moins triangulaires, avec la pointe rejetée en dehors, il y a généralement une dent médiane; à la mandibule, les dents sont plus étroites quà la màchoire supérieure et la dent médiane, qui est dentelée, parait constante. L'espace préorbitaire est plus grand que l'espace interorbitaire. La première dorsale est reculée, elle est plus rapprochée des rentrales que des pectorales; la seconde dorsale est opposée à l'anale; la eaudale mesure le quart, et parfois plus encore, de la longueur totale; les pectorales sont falciformes, elles sont deux fois et demie à trois fois aussi longues que larges; leur longueur est comprise de cinq à six fois dans la longueur totale.

Le dos est bleu foncé ou ardoisé chez les grands, plus clair chez les jeunes; le ventre est blanchàtre.

Habitat. Le Bleu se trouve sur toutes nos còtes.

Une femelle, mesurant 3,10 , prise à Cetle, au mois de mai 1881, portait soixante-trois fœtus, ayant une taille de 0,30 à à 0,57 . - Les petits sont nés immédiatement après la capture de la mère, la plupart dans le bateau, quelques-uns, environ une huitaine, après le débarquement. Outre les petits, il y avait des œufs fort développés, préparés pour une autre gestation.

\section{LE REQUIN A MUSEAU OBTUS. - CARCHARIAS OBTUSIROSTRIS.}

Poiss. France, t. I, p. 332, fig. 53, tète; fig. 54, dents.

N. vulg. : Souras, Cette.

Long. : 2,00 à 4,00 .

Le corps est fusiforme; sa hauteur, chez les jeunes, est comprise neuf à dix fois dans la longueur totale. La tète est large, aplatie en dessus; le museau est court, large, déprimé, obtus, arqué ; chez les très jeunes animaux, sa longueur, ou la distance qui s'étend de son extrémité à la dent médiane de la 
mâchoire supérieure, est à peu près égale à la largeneur de la bouche, elle est moindre chez les adultes. La bouche est très arquee, plus large que longue; à la mâchoire supérieure, les dents sont aplaties, triangulaires, à bord externe légèrement concave ou échancré; la dent médiane est dentelée comme les autres; à la mandibule, les dents sont pointues, élroites, subulées, à base assez large ; la dent médiane, (qui ressemble à un petit crochet pointu, n’est pas dentelée. L'espace prénasal, mesuré de l’angle interne de la narine au bout du museau, est plus court que l'espace internasal, surtout chez les adultes. La première dorsale est avancée, elle commence au-dessus de la fin de la base des pectorales, ou un peu en arric̀re; la caudale mesure à peu près le quart de la longueur tolale; la pectorale est falciforme; elle est au moins deux fois plus longue que large.

En dessus, la coloration est d'un brun cendré, blanchàtre en dessous.

Habitat. Méditerranée, assez rare, Cette, Nice.

C'est à cette espèce que doit ètre rapporté le Squalus cœruleus de de Blainville, Fn. française, p. 90. - En novembre 1887, j'ai reçu de Nice un fœtus $\sigma^{x}$, mesurant 0,420 de longueur.

3. LE REQUIN DE MILBERT. - CARCHARIAS IILBERTI, Valenc.

Poiss. France, Suppl., p. 2, fig. 221-222, dents.

N. vulg. : Méchant Requin, Méchant Souras, Cette.

Long. : 0,60 à 3,00 .

Le corps est allongé ; sa hauteur est comprise de sept à dix fois dans la longueur totale. La tête est assez aplatie en dessus; le museau est déprimé, à bord antérieur convexe, sa longueur est à peu près égale à la largeur de la bouche. La bouche est très arquée, plus large que longue; ì la màchoire supérieure, les dents varient de forme suivant l'àge des sujets. chez les jeunes elles ont le bord externe ou postérieur assez peu échancré, chez les adultes l'échancrure est beaucoup plus profonde, avec les dentelures plus marquées; la dent médiane est dentelée: ì la mandibule, les dents ressemblent beancoup 
à celles du $C$. obtusirostris, elles sont étroites, subulées, droites, finement dentelées, insérées sur une base assez large; la dent médiane est petite, non dentelée. L’espace prénasal, mesuré de l'angle interne de la narine au hout du museau, est égal, ou très peu s'en faut, à l'espace internasal, au moins chez les 'spécimens que j’ai pu éludier. La première dorsale commence au-dessus de la fin de l'insertion des pectorales; la caudale mesure le quart environ de la longueur totale; la pectorale est triangulaire, sa longueur ne fait pas le double de sa largeur.

Le dos est d'un gris bleuâtre, d'un gris plombé; le ventre est hlanchâtre.

Habitat. Méditerranée, rare, Nice; très rare à Cette, un spécimen a été capturé en 1887, un autre en 1888.

Deux femelles prises à Nice, la première, le 26 juin 1879 , la seconde, le 26 octobre 1887 , portaient chacune treize fœetus. - Je tiens de l'obligeance du docteur Bellotti deux fotus $\sigma^{x}$ et $q$, mesurant le màle 0,410 , la femelle $0,40 \ddot{3}$, provenant du sujet capturé à Nice en 1887, ayant une taille de 2,80 .

\section{SOUS-TRIBU DES NOTIDANIENS. - NOTIDANI OU SQUALES A DORSALE UNIQUE.}

Appareil branchial; six ou sept fentes branchiales. Nageoires; dorsale unique, en arrière des rentrales.

\section{Famille des Notidanidés, Notidanidre.}

Corps allongé, plus ou moins fusiforme.

Tête aplatie en dessus; bouche arquée; dents fort dissemblables; dents étroites, longues sur le devant de la màchoire supérieure; dents larges, dentelśes sur le bord libre à la mandibule.

Yeux sans membrane nictitante.

Évents étroits.

Cette famille comprend deux genres.

Fentes branchiales au nombre de six............... 1. Hexaxche.

- sept. ................ Heptanche.

1. GENRE HEXANCHE. - HEXANCHUS, Rafin.

Appareil branchial; six fentes branchiales. 
LE GRISET OU HEXANCHE. -- IIEXANCHUS GRISEUS, Rafin.

Poiss. France, t. I, p. 336, fig, $\dddot{3} 3$, anim.; fig. ə̈6, dents, et p. 6, fig. 2, colonne vertébrale.

N. vulg. : Mounge gris, Nice; Bouca-douca, Celle; ? Arhano, Landes.

Long. : 2,00 à 4,00 .

Le corps est fusiforme; sa hauteur fait le huitième environ de la longueur totale; la peau est couverte d'un chagrin assez. fin. La tète est large, aplatie; le museau est court, arrondi; la bouche est arquée, beaucoup plus large que longue; le pli labial supérieur est très développé. A la màchoire supérieure, il n'y a pas le dent médiane; les deux premières dents latérales sont assez étroites, à une seule pointe; les suivantes ont la base plus large, avec une ou plusieurs pointes sur leur bord externe; les dernières forment des espèces de petits parés. La mandibule porte une dent médiane assez large, dentelée sur les bords de l'axe; les dents latérales sont larges. à bord libre taillé obliquement d'arant en arrière et dentelé comme une scie; la première dentelure ou dentelure interne est un peu plus longue que la suivante. Les évents sont à peu près à égale distance de l'orbite et de la première fente branchiale. - Les ouvertures des ouïes sont rapprochées, grandes. - La dorsale commence un peu en arrière de l'insertion des ventrales; la caudale est très développée, elle fait le tiers, et parfois plus, de la longueur totale.

Le dos est d'un brun ou d'un gris rougeàtre; teinte grisâtre sur les flanes avec une bande longitudinale blanchàtre.

Habitat. Méditerranée, assez commune à Nice; assez rare à Cette. Océan, très rare, Bayonne; Arcachon ; la Rochelle; île de Ré; Concarneau, d'après J. Van Beneden.

La femelle, suivant Risso, met bas des petits vivants plusieurs fois dans l'année.

2. GENRE HEPTANCHE. - MERTANCIUS, Müll. et Hen..

Appareil branchial; fentes des ouies au nombre de sept. 
LE PERION. - HEPTANCHUS CINEREUS, Müll. et Ilenl.

Poiss. France, t. I, p. 339, fig. כ̈7, dents.

N. vulg. : Nounge rous, Nice; Bouca-douça ì sept traous, Cette. Long. : 2,00 i 3,00 et plus.

Le corps est couvert de scutelles carénées très rudes. La tête est moins large que dans le Griset; le museau est rétréci en avant, pointu, allongé; la bouche est à peu près aussi longue que large. La màchoire supérieure n’a pas de dent médiane; ses dents latérales sont des espèces de crochets à pointe tournéc en dedans; la mandibule porte une dent médiane à pointe verticale beaucoup plus développée que les pointes des côtés; ses dents latérales ont le bord libre taillé comme un peigne oblique; à leur bord interne, il existe une, deux ou trois petites dentelures formant une espèce de talon à pointe sensiblement plus longue que les dentelures suivantes. Les yeux sont très grands.

La coloration est grisâtre sur le dos, blanchâtre sous le ventre.

Habitat. Méditerranée, assez rare, Nice, Cette. Océan, Bayonne, Ll. Darracq.

11. TRIBU DES SQUALES ANHYPOPTÉRIENS. - SQUALI ANHYPOPTERII OU SQUALES MANQUANT D'ANALE.

Corps de forme variable.

Yeux sans membrane nictitante.

Évents ne manquant jamais.

Nageoires; deux dorsales, pas d'anale.

Cette tribu se compose de trois familles.

a. Aiguillon à chaque dorsale..................... manquaut........................ $b$.

๖. Première dorsale en avant ou au-dessus des ventrales. en arrière des rentrales..........

1. Spinacidés.

3. ScYuxués.

3. SQuatinidés.

1. Famille des Spinacidés, Spinacidx.

Corps plus ou moins allongé.

Téte; bouche légèrement arquée, avec une entaille de chaque 
côté; dents tantòt tranchantes, tantòt pointues ì la màchoire supérieure, tranchantes ì la mandibule.

Nageoires; une épine à chaque dorsale; première dorsale plus rapprochée des pectorales que des ventriles; pas d'anale.

Cette famille se partage en cing grenres.

a. Seconde dorsale opposée à la base des ventrales.

- non opposée

b.

5. Centrine.

b. Màchoires ì dents ser

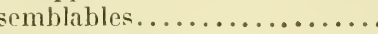
non semblables............. $c$.

c. Dents de la mâchoire supéricure à plusieurs pointes.

d. Plus ou moins triangulaires à uwe seule pointe.

Subulées, écartées les unes des autres..........

1. MiguilLot.

c.

2 SAGRE.

d.

3. Centrophore.

4. Centroscyme.

\section{GENRE AIgULLAT OU ACANTHIAS. - ACANTIIAS, Bp.}

Corps allongé, couvert de scutelles tridentées.

Tête aplatie en dessus; bouche peu arquée avec une entaille de chaque còté; dents semblables aux deux màchoires, à bord libre tranchant, à pointe rejetée en dehors; pas de dent médiane.

Appareil branchial; fentes des ouies de moyenne grandeur, régulières; la dernière avant l'insertion de la pectorale.

Nageoires; seconde dorsale en arrière des ventrales; aiguillon des dorsales plus ou moins développé, à base cachée daus la peau de la nageoire.

Ce genre compte deux espèces.

Ventrales commençant après le milieu de la longueur

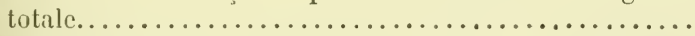

Ventrales commencant avant le milieu de la longueur

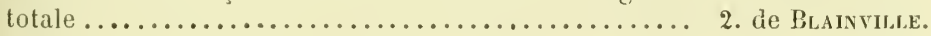

\section{L'AIGUILLAT ou ACANTHIAS CONHUN. - ACANTHIAS VULGARIS, Riss.}

Poiss. France, t. I, p. 342, fig. 58, anim. et p. ̈̈, fig. 1, cellules de la corde dorsale d'un jeune foetus: p. 8, fig. 4, corde dorsale d'un grand fortus.

N. vulg. : Igugliat, Nice; Aguïat, Cette ; Bilan, Bayonne; Chien hroquu, Épinette, Loire-Inférieure; Chien de mer; Chien de mer épineux。

Long. : $0, ; 0$ à 0,70 et plus.

La hauteur du tronc est comprise neuf à dix fois dans la 
longueur totale: sur le troncon de la queue, existent deux sillons longitudinaux; le sillon supérieur est peu marqué, l'inférieur, qui part des ventrales, l'est beaucoup plus, surtout vers la caudale. Le cloaque s'ouvre un peu après le milieu de la longueur totale. La tète est aplatie en dessus; le museau est allongé; les plis labiaux sont développés. Le diamètre de l'ceil mesure presque les deux tiers de l'espace préorbitaire, qui est égal à l'espace interorbitaire; l'angle postérieur des paupières se prolonge en un sillon qui remonte plus ou moins vers l'évent. L’espace internasal est généralement un peu plus court que l'espace prénasal. La première dorsale commence ordinairement ì l’aplomb de l'anğle postérieur et supérieur de la pectorale; sa longueur est moindre que l'espace séparant l'extrémité de la pectorale de la base de la ventrale; son aiguillon est assez court, il est à peu près d'un tiers moins haut que la membraue qui le suit. L'aiguillon de la seconde. dorsale est un peu moins haut que la nageoire. La longueur de la caudale est comprise à peu près quatre fois et demie dans la longueur totale.

Le dos et les flancs sont d'un gris brunâtre ou ardoisé; le ventre est blanchâtre; le corps est souvent marqué de taches blanchàtres lenticulaires.

Habitat. Commun sur toutes nos còtes.

Le mode de reproduction est des plus singuliers; les petits naissent au nombre de quatre, deux dans chaque poche utérine et encore un màle et une femelle, c'est du moins ce que j'ai remarqué, en décembre, chez les divers spécimens que j’ai examinés. - J'ai constaté les faits suivants : $1^{\circ}$ dans chaque utérus, deux jeunes fœtus, ovaires peu développés, pas d'œufs en état de maturité; $2^{\circ}$ de chaque còté, deux petits sur le point de naître et deux cufs engagés dans l'oviducte; $3^{\circ}$ enfin, et toujours de chaque còté, deux petits, et deux oufs dans la cavité péritonéale assez rapprochés du pavillon; il est probable qu'il y a des gestations successives pendant une certaine période. - Il serait intéressant de contròler les observations que je cite et de voir s'il en est toujours ainsi. - Les petits ont la teite dirigée vers le cloaque; ils acquirrent une grande dimension dans ley puches utérines, sur une femelle mesurant 0,68 de longueur, les petits avaient une taille de 0,210 à 0,230 . 


\section{LAIGLHLAT DE BLANVHLL. - ACANTHAS}

BLAINVILLE, Riss.

Poiss. France, t. I, p. $3 \%$.̈.

N. vulg. : Mangin, Nice; Iguïat, Cette.

Long. : 0,30 it 0,70 .

La hauteur du trone est comprise huit fois et demie à dix fois et demie dans la longueur totale; le tronçon de la queue est creusé d'un sillon en dessus et en dessous; le cloaque s'ourre vers la fin de la première moitié de la longueur tolale. La tète est large, aplatie en dessus. Le diamètre de l'oil mesure les deux tiers de l'espace préorbitaire, qui est. en général, sensiblement moins grand que l'espace interorbitaire; l'angle postérieur des paupières se continue en un sillon, qui se dirige vers l'évent. L'espace internasal est généralement un peu plus grand que l'espace prénasal. La première dorsale commence à peu près au-dessus du milieu du bord interne de la pectorale; sa longueur, prise du commencement de son insertion à son angle postérieur, est à peu près égale à la distance qui s'étend de l'angle supérieur et postérieur de la pectorale à l'origine de la ventrale; l'aiguillon de la seconde dorsale est aussi haut et parfois plus haut que la nageoire. La longueur de la caudale est contenue quatre fois et demie à cinq fois dans la longueur totale. Les ventrales commencent un peu en arrière de l'aplomb de l'extrémité de la première dorsale.

Le dos est gris ardoisé, le ventre est blanchàtre.

Habitat. Méditerranée, assez commun à Nice, plus rare à Celle. La femelle, d'après Risso, ne porte que dix à douze petits qu'elle met bas à direrses époques de l'année. Cet Aiguillat se tient dans les grandes profondeurs.

\section{GENIE SAGIL. - SPINAT, Bp.}

Corps allongé, couvert de scutelles semblables à des épines très fines.

Tête aplatie; museau larg̣e; bouche arec une entaille de chaque Ioreat. - Irhthyologie. 
còté; dents dissemblables, elles sont, à la màchoire supérieure, verticales, à plusieurs pointes, avec la pointe médiane plus longue, tranchantes à la mandibule.

Nageoires; seconde dorsale plus développée que la première, armées l'une et l'autre d'un aiguillon creusé d'un sillon de chaque òté.

\section{LE SAGRE. - SPINAX NIGER, H. Cloquet.}

Poiss. France, t. I, p. 348, fig. 39, anim.

N. vulg. : Morou, Bardoulin, Nice.

Long. : $0,2 \ddot{z}$ à 0, ว̈0, Riss.

Le dos est assez arrondi, les flancs sont légèrement comprimés et le ventre est large; la hautem du tronc est comprise de huit fois à neuf fois et demie dans la longueur totale. La peau est couverte de spinules simples, ressemblant à des poils, formant une espèce de relours. La tète est aplatie, large au niveau des évents, échancrée dans la région interorbitaire; le museau est aplati, large; les lèvres sont noirâtres; l'intérieur de la bouche est d'un violacé noiràtre; les dents de la mâchoire supérieure ont une pointe médiane plus longue que les pointes latérales ( 1 à 3 de chaque côté); celles de la mandibule ont le bord tranchant, oblique; avec une pointe tournée en dehors; l'ceil est grand, orale; les narines sont allongées, placées sous le bord antérieur du museau; les évents sont ovales, un peu plus larges que longs. Les ourertures branchiales sont assez petites, régulières. La première dorsale est moins développée que la seconde; elle est placée entre les pectorales et les rentrales; elle est assez courte, assez basse; son bord postérieur est presque droit; l'aiguillon est court, il est creusé d'un petit sillon de chaque côté; son bord antérieur est épais; la seconde dorsale est grande, son aiguillon est très allongé, aussi haut que la nageoire elle-même; il est profondément cammelé de chaque côté; la caudale est longue et large, sa longueur mesure à peu près le quart de la longueur totale; le troncon de la queue est marqué d'un sillon en dessus et en dessous: les pectorales sont un peu plus longues que larges.

Le dos et les flanes sont d'un ardoisé foncé, noiràtre, le 
ventre est complètement noir; une bande d'un gris blanchìtre s'étend le long des flanes. Le péritoine est très noir. La muqueuse de l'ourerture dı cloaque est noiràtre ainsi que celle des narines, des érents, des fentes branchiales.

Habitat. Méditerranée, Nice, pas très commun. Océan, Arcachon, excessivement rare.

L.e Sagre, dit Risso, ne parvient qu'au poids d'un kilogramme; sa femelle dépose dans toutes les saisons de quinze à vingt petits aussitòt qu'ils ont alteint la dimension d'un décimètre. (Risso, Hist. nat., p. 134.)

Squale d'enfer. - Squalus infernus, Blainv., Fn. frene., p. 59.

Poiss. France, t. I, p. 3ł6, Syn., de Acanthias uyatus, Müll. et Henl. Peut-ètre, écrivait de Blainville, à propos de son Squale d'enfer. est-ce cette espèce que M. Rafinesque a figurée dans ses caracl̇̀res, elc..., sous le nom de Squalus uyalus, quoiqu'il ne dise rien de la gueule noire et de la forme des dents. - C. Bonaparte n'a pas gardé la réserve que montrait de Blainville; il n'a pas hésité à considérer comme étant identiques le $S q$. infernus, Blainv., et le $S q$. uyalus, Rafin., deux espèces essentiellement distinctes; le plus fàcheux c'est que l'opinion de Bonaparte ait été adoptée, sans contròle, par Müller et IIenle, ainsi que pour tous les ichthyologistes qui ont traité le mème sujet jusqu'à ce jour; il est temps de faire cesser une erreur qui se perpétue depuis une cinquantaine d'années. - Rien de plus facile que de fournir la démonstration que le $S q$. infernus, Blainr., n'est pas l'A. uyatus, Müll. et Henl., mais bien un Spinar nigcr, et cela en se bornant à reprendre les caractères spécifiques indiqués par de Blainville dans la description de son Squale d'enfer : dents très différentes de celles de l'Aiguillat; les supérieures... formées d'une pointe droite, étroite, aiguë... assez longue et d'une petite pointe accessoire de chaque còté. Les inférieures à peu près conformées comme dans l'Acanthias... Narines encore plus terminales et plus marginales que dans l'Aiguillat (et par conséquent beaucoup plus rapprochées du pourtour du museau que dans le Squale de Rafinesque). Dorsales armées chacune d'un aiguillon cannelé de chaque còté. - C'est de Blainville qui le premier a signalé la cannelure des aiguillons. - En résumé, les caractères, tirés de la forme des dents supérieures, à plusieurs pointes, de la camnelure latérale des aiguillons des dorsales, appartiennent exchusivement au genre 
Spinax ou Sagre, et, comme ce genre est représenté par une seule espèce, le Sq. infernus, Blainv., est un Spinax niger. - Enfin, une remarque d'une certaine importance, c'est que les petits du Centrophore granuleux (dont l'Acanthius uyatus est le jeune), ont, à leur naissance, une taille plus grande que celle du Squale d'enfer étudié par de Blainville, long de 0,271 ; j’ai reçu de Nice un foetus de Centrophore granuleux mesurant 0,281 , qui était loin d'avoir acquis son déreloppement embryonnaire; le $\mathrm{D}^{\mathrm{r}} \mathrm{C}$. Sarato tient de l'obligeance de MM. Gal un fretus de Centrophore granuleux ayant 0,400 de longueur.

5. GENRE CENTHOPHORE. - CENTROPHORUS, Müll. et Henl.

Corps allongé, anguleux, couvert de scutelles sessiles ou pédonculées.

Tête large, aplatie; bouche large avec une entaille de chaque còlé; dents fort dissemblables, plus ou moins triangulaires à la màchoire supérieure, sécuriformes à la mandibule avec la pointe dirigée en arrière; une dent médiane à la màchoire supérieure.

Nageoires; aiguillons des dorsales creusés d'un sillon latéral.

Le genre Centrophore comprend deux espèces.

OEil plus près du bout du museau que de la $1^{\text {re }}$ branchie. 1. Graxuleux.

- loin

2. CALCÉlFORME.

\section{LE CENTROPHORE GRANULEUX. - CENTROPHORUS} GRANULOSUS, Müll. et Henl.

Poiss. France, t. I, p. 3ə2, fig. 60 , dents.

Long. : 0,50 à 1,20 et mème 1,50 .

Le corps est allongé, en forme de prisme triangulaire jusqu'à l'anus; le ventre est aplati en dessous; le troncon de la queue est en pyramide quadrangulaire avec un sillon en dessus et en dessous; la hauteur du tronc est comprise sept fois et demie à huit fois et demie dans la longueur totale; la peau est couverte de scutelles sessiles. La tète est presque triangulaire; le museau est court et mousse; les dents sont dissemblables aux mâchoires; à la mâchoire supérieure, elles subissent de notables changements suivant l'âge des sujets: chez les adultes, elles sont triangulaires, plus ou moins droi- 
tes et symétriques; chez les jeunes, elles sont triangulaires, non symétriques, à bord externe presque perpendiculaire dans les rangées antérieures s'inclinant de plus en plus vers les rangées postérieures, à bord interne plus ou moins oblique, ¿̀ pointe dirigée de plus en plus en dehors à partir des rangées internes ou antériemres; la dent médiane est droite : ì la mandibule, pas de dent médiane, les dents latérales sont sécuriformes, à pointe oblique dirigée en dehors ou en arrière, à bord tranchant finement denticulé. Les yeux sont très grands; leur diamètre est à peine moindre que l'espace préorbitaire. Les narines sont plus rapprochées du bout du museau que de la bouche. Les évents sont semi-lunaires. La première dorsale conmence sur le licrs antérieur de la longueur totale; son aiguillon est assez fort; relativement assez court, moins développé que celui de la seconde dorsale. La pectorale est assez grande; son angle interne et postérieur s'allonge en une pointe fort développée.

La coløration est variable, souvent d'un gris jaunâtre, avec des lignes noirâtres séparant les petits tubercules; la muqueuse de la bouche est souvent noirâtre chez les jeunes.

Habitat. Méditerranée, Nice.

D'après les renseignements qu'ont eu l'obligeance de me donner MI. Gal, les femelles ouvertes devant eux ne portaient jamais qu'un seul fœtus, arrivant parfois à la taille de 0,40 , ainsi que l'a constaté le $D^{r}$ C. Sarato. Y aurait-il chez le Centrophore granuleux une suite de gestations rapprochées comme le fait semble probable pour l'Aiguillat commun?

\section{Jeune. - Aiguillat uyat. - Acanthias uyatus.}

Poiss. France, t. I, p. 346.

Dans le jeune àge, la teinte de la bouche n'est pas toujours noiràtre, ainsi que l'indiquent la plupart des auteurs. L'importance qu'on attachait à ce système de coloration, regardé comme étant un caractère spécifique est peut-être la raison principale qui pendant de longues innées a entretenu l'erreir faisant distinguer comme deux espèces différentes le jeune et l'adulte, erreur qui persisterait sans doute encore, si M. C. Sarato n’avait prouvé directement l'identilé du Centrophore granuleux et de l'Acanthias uyat. - Chez un 
fœtus $\sigma^{x}$, long de 0,190 , la muqueuse de la bouche est rosée; chez un autre $q$ mesurant 0,282 , la muqueuse de la bouche est noiràtre ; l'œuf, malgré la taille de ce lernier foctus, est fort développé, il a 0,081 dans son grand diamètre et 0,160 de circonférence.

A propos du C. gramulosus, nous lisons dans un travail de M. Vinciqnerra les appréciations suivantes : Egli (Canestrini) considera il C. lusitanicus Bocage e Capello, come sinonimo del granulosus, mentre sli autori ed il Günther ne sostengono... la differenza sperifucu. Moreau, piir recentumente, ripete questi errori, egli serive che l'A. nyatus si pesea nel golfu di Genova, $e$ che il Centrophorus granulosus è eccessivamente ruro nel Mediterrameo (Vincignerra, Risultati ittiologici delle erociere del Violante, lienova, 1883, p. 19).

II. Vinciguerra reproche à Canestrini de considérer le $C$. lusitanicus, Bocage et Capello, comme identique an C. granulosus et cela. affirme-t-il, malgré l’opinion des auteurs et de Günther, qui en soutiennent la différence spécifique. - Pour éviter toute équivoque, il ne faut pas rechercher quelle est la manière de voir de Günther, mais s'en rapporter aux travaux des naturalistes portugais et surtout bien tenir compte de la date de leur publication. Très probablement, d'ailleur's, Canestrini n'avait pas encore entre les mains le $8^{\mathrm{e}}$ volume de Günther quand il a donné à l'impression la partie de son ichthyologie relative aux Plagiostomes.

C'est vraiment fàcheux à dire et difficile à croire, M. Vinciguerra critique, faute de l'avoir compris, le texte de Canestrini, qui cependant est des plus clairs. Dans la synonymie du C. gramulosus, Canestrini n'exprime pas une opinion personnelle, il se borne a citer les ichıhyologistes qui ont employé des dénominations différentes pour désigner ce Squale : Stualus gramulosus, BI. Schn.; Centrophorus lusitunicus, Boc. e Capel. (Canestr., Fn. Ital., p. 40). - Évidemment, si II. Vinciguerra avait été au courant de la science, il n’aurait pas rendu Camestrini responsable d'une erreur yu’il n'avait pas commise ; il ne lui aurait pas altribué l'identité spécifique qu'il lui reproche. Loin d'ètre en désaccord avec les auteurs portugais, Canestrini reproduit fidèlement leur manière de voir. - Voici, en effet, ce que nous trouvons dans les travaux des ichthyologistes de Lisbonne cités par Canest.rini : Centrophorus gremulosus (tab. I, fig. 3, adult., tab. III, fig. i, junior); C. granulosus, Müll. et Henl.; C. Irsitunicus (partim), Bocage et Capello. Iroceed. Z. S. L., 1864, p. 261, lig. 1. Les auteurs, après aroir en premier lieu considéré le $C$. lusitunicus comme une espèce distincte, écrivent : actuellement nous les rapportons tous (les spécimens de C. yramulosus et $C$. lusitunicus) à une seule espèce, le $C$. gramulosus, dont nolre $C$. lusitmicus doit ètre regardé comme 
une simple variété d'ìge et de saison, Barboza du Bocage el de Brito Capello, Peir. Plagiost., Lishoa, 1866, p. 2:3-26. - Dans son calalogue des Poissons de Porlugal, de Brito Capello reproduit la míme synonymie. V. Cat. Peix. Porluy., Bril. Capel., dans Jorn. sr., etc., Lisbonne, $1869, n^{\circ}$ VI, p. 13-1\%. - Evidemment M. Vinciguerra ne connaissait pas ces deux ourrages, la preuve s'en trouve dans la bibliographie des Ris. iltiol. croc. del Violante, p. 13, où est indiqué seulement : de Brito Capello, Culalogn dos Pcixes de Porluggal. Lisboa, 1880. - Il est rai que dans ce second catalogue, publić après la mort du regretté de Brito Capello, le C. lusilunicus reparait comme espece distincte (loc. cit., p. 48). - Franchement, Canestrini ne pouvait supposer que les ichthyologistes de Lisbonne reviendraient à leur première opinion, ni consulter un catalogue qui a paru longtemps après l'impression de ses Pesci dans la Fauna d'Italia; Canestrini n’avait pas à citer, dans son Ichthyologie, un Poisson, qui n’avait jamais été signalé dans les eaux baignant les còtes d'Ilalie ; l'assertion de M. Vinciguerra est donc absolument fausse. - Pour mon compte, j’ai recu en $18 \%$ de M. B. du Bocage et de son sarant collaboraleur leurs travaux Pcix. Plagiost. et Cat. Peix. Portuj. ; j’ai parlé à M. du Bocagge du genre Centrophorus; à celle époque, il nétait nullement question de rétablir, comme espèce distincte, le C. lusilanicus.

En ce qui me concerne, voici ce que dit M. Vinciguerra : egli scrice che il Centrophorus granulosus è ecressivamente raro nel Mediterraneo. Pour donner une idée de la manière dont M. Vinciguerra fait les citations et du peu de souci qu'il a de la vérité, je me borne à reproduire le texte relatif à l'habitat du C. gramulosus, voir mon t. I, p. 4 ö1 : "Habitat. Méditerranée, excessivement rare sur nos còtes. Le Muséum possède seulement deux Centrophores venant de Nice, l'un par Laurillard, l'autre par Cosle. " Ici, comme toujours, je n’ai parlé que des eaux de la Méditerranée baignant nos cótes, et jusqu’alors ce Squale n’avait pas été signalé ailleurs qu’à Nice.

A mon nom, Vinciguerra aurait pu joindre celui de Giglioli, qui dans sou Cal. Pesci italiani, P. 113, écrit : 329 , Acanthias uyatus. Livorno, Niza. Sperie rara et 530, Centrophorus granulosus. Genova, non commune; firghioli n'est pas réprimandé, il est évidemment dans les bonnes grices du critique de Gènes.

Suivant M. Vinciguerra (loc. cit., p. 20), il Centrophorus granulosus... è frequente a Nizza, etc.; p. 13, il avait écrit : Questo (C. granulosus), con tulla probabillu, non fu conosciulo dul Risso. Comment un Squale, commun à Nice, aurait échappé aux recherches de Risso, qui, pendant une quarantaine d'années, s'est appliqué avee tant de 
zèle et de soin à l'étude des Poissons de Nice! Est-ce supposable? J'autre part, dans son introduction (loc. cit., p. 6), M. Vinciguerra s'exprime ainsi : Presentono.... speciale importanza alcune forme medilerrance non molto communi e non abbastanza conosciute come il Centrophorus granulosus, il Serranus alexandrinus... D'après les divers passages du travail de M. Vinciguerra, le C. gramulosus est-il rare ou commun dans la Mléditerranée? Oui et non, suivant la page qu'on lit. - Quant is son fameux Serrumus alexundrinus, il n'a aucun rapport avec celui de Cuvier et Valenciennes.

M. Vincignerra aurait-il la prétention de faire croire qu'il ne serait pas tombé dans l'erreur commise par la plupart des ichthyologistes qui ont suivi C. Bonaparte, si le docteur Sarato n’avait, dès 1881, établi l’identité spécifique de l'Acanthias uyatus et du Centrophorus granulosus? Pourquoi, alors, au lieu de la corriger, a-t-il reproduil une autre erreur, au moins aussi extraordinaire que la précédente, en citant dans la synonymie du C. granulosus le Squalus infernus, Blainv., qui est une espèce différente, n’appartenant mème pas au genre Centrophorus? - C'est à notre savant confrère de Nice, et à personne autre, qu'est dù le mérite d’avoir fait la lumière sur un point obscur d'histoire naturelle; il est regrettable que M. C. Sarato ait donné pour titre à son étude : "Le Centrophore granuleux et le S'quale d'enf'cr " (V. Notes sur les Poissons del Nice, Nice, janvier 1888); le Stfualus infermus, Blainv., est, nous l'avons nettement démontré (p. 33̈-36, un Spinax niger.

Je pourrais indiquer la cause première de l'erreur que j'ai commise, je l'avoue franchement, après le regretté professeur A. Duméril, qui écrit à propos de l'A. uyatus, "Habitat. Méditerr. : còte d'Alger, 2 exempl. adressés au Muséum, par M. le docteur Bourjot ", A. Dumér., t. 1, p. 440. - Ces deux spécimens, en fort mauvais état, placés dans un bocal sous la mème désignation, ne sont nullement identiques, il n'y a qu'un seul A. uyatus, ainsi que plus tard je l'ai recomnu et fait constater par le prof. Vaillant, l'autre est un Aiguillat, dont évidemment les dents sont semblables aux deux mảchoires.

\section{LE CENTROPHORE CALCÉIFORNE. - CENTROPHORUS CALCEUS, Lowe.}

Poiss. France, Suppl., p. 132.

Long. : 0,60 a 1,06 , Vall.

Le tronc est allongé, prismatique; la peau est couverte de petites scutelles pédonculées. La tète est dépriméc; les dents 
de la màchoire supérieure sont aignuës; celles de la mandibule sont sécuriformes, à borl tranchant ne paraissant pas denticulé; le museau est excessivement allongé, mince, large, aplati en forme de spatule, ou plutot de sandale, de pantoufle, d'oì le nom spécilique donné à ce Squale par Lowe et par Barboza du Bocage el de Brito de Capello. L'wil est beaucoup plus éloigné du bout du museau que de la fente de la première branchie. L'aiguillon de la seconde dorsale est plus développé que celui de la première; la pectorale est coupée à peu près carrément arec les angles arrondis, et par conséquent bien différente de celle du Centrophore granuleux, dont l'angle supérieur et postérieur est plus ou moins allongé suivant l'âge des sujets; la ventrale semble se porter un peu plus en arrière que dans l'autre espèce.

Suivant les auteurs, la coloration, sur le frais, est d'un gris cendré ou d'un gris bleuâtre: elle m’a paru d'un gris légèrement rosé d'après l'aquarelle laissée par $\|^{\text {me }}$ de Nadaillac.

Habitat. Golfe de Gascogne, Biarritz, un seul spécimen dont $\mathbf{M}^{\mathrm{mo}}$ la comtẹsse de Nadaillac a donné une figure très remarquable.

4. GENRE ClNTROSGYMNE. - CENTROSCYMNUS, Bocage et Capello.

Corps allongé, prismatique triangulaire, couvert de scutelles pédonculés.

Téte aplatie; museau court; dents fort dissemblables aux màchoires, étroites, presque subulées, assez écartées à la màchoire supérieure, sécuriformes à la mandibule, avec le bord libre oblique, à pointe rejetée en dehors ou en arrière.

Nageoires ; aiguillons des dorsales très courts, enfoncés dans la peau et plus ou moins cachés.

\section{LE CENTROSGYMNE CÉLOLÉPIS. - CENTROSCYMNUS}

COELOLEPIS, Boc. et Capel.

Poiss. France, Suppl. p. 8.

Long. : 0,80 ì 1,20 .

Le corps est une espèce de prisme triangulaire; la peau est couverte de scutelles pédonculées formant un chagrin assez 
doux. Le museau est court, large ; à la commissure des lèrres existe un sillon bien marqué; à la mâchoire supérieure, les dents sont disposées sur trois ou quatre rangées, elles sont aiguës, étroites, presque subulées, ressemblant beaucoup à celles du Scymnus lichia; à la mandibule, elles sont larges, à bord libre, tranchant, légèrement oblique de dedans en dehors, avec la pointe rejetée en dehors ou en arrière; le diamètre de J'wil parait d'un tiers moindre que l'espace préorbitaire; les narines sont à peu près vers le tiers antérieur de la distance qui sépare le bout du museau de la mâchoire supérieure; les érents sont fort grands; les fentes branchiales sont assez petites. La première dorsale commence un peu en arrière de l'extrémité de la pectorale, son épine est courte; la seconde dorsale est très reculée, elle commence au-dessus du milieu de la base des ventrales; son aiguillon parait encore plus court que celui de la première dorsale; le tronçon de la queue est fort court; la caudale est échancrée, d'après Bocage et Capello, sur un spécimen en peau, elle semble plutot triangulaire; la pectorale est trapézoüde, grande; la ventrale est déreloppée.

La coloration est d'un chàtain assez foncé.

Habitat. Néditerranée, accidentellement, Nice, une femelle prise en aoit 1883.

D’après le prof. Vaillant, les femelles, en état de gestation, pèchées à Sétubal, lors de l'expédition du Truvailleur, en aoùt 1881, portaient de treize à quinze futus; la femelle, capturée à Nice, avait cinq petits, d'après MII. Gal.

\section{b. GeNRE CENTRiNe. - CENTRINA, Cuv.}

Gorps ramassé, prismatique, triangulaire, couvert de scutelles excessivement rudes.

Tête petite, aplatie en dessus; museau court; bonche très petite arec une entaille de chaque còté; màchoire supérieure à dents coniques sur plusieurs rangées; mandibule ayant une dent médiane et des dents latérales droites à bord libre triangulaire.

Nageoires; seconde dorsale opposée aux ventrales; aiguillons des dorsales enveloppés dans la peau, faisant à peine saillie. 


\section{LA CENTRINE IIUMANTIN. - CENTRINA VULPECULA.}

Poiss. France, t. I, p. 3\%̈, fig. 61, anim.

N. vulg. : Puore marin, Nice; Porc, Provence, Languedoc; Peï porc, Porquél, Triocha, Cette; Colfre, Arcachon; Cochon de mer, Poitou.

Long. : 0, 70 à 1,00; Risso indique 2,00 de longueur.

Le corps est trapu, en forme de prisme triangulaire; le dos est étroit, le ventre est large, aplati, avec un fort repli cutané allant de la pectorale à la ventrale. Le museau est court oblus : la michoire supérieure porte une plaquette de dents en crochets coniques à pointe très fine, disposées sur trois à cinq rangées et formant une espèce de carle; à la mandibule, les dents sont aplaties, pentagonales, à bord libre triangulaire et dentelé; l'ril est très grand, son diamètre est un peu moins long que l'espace préorbitaire; les narines sont très rapprochées du bord du museau; les érenis sont très larges, presque triangulaires; les fentes branchiales sont très petites. La première dorsale, fort développée, commence au-dessus des pectorales; elle est traversée par une épine inclinée d'arrière en avant et sortant sur le bord antérieur de la nageoire; la seconde dorsale est opposée aux ventrales; la caudale est large, triangulaire; les pectorales sont bien développées.

La coloration est noirâtre sur le dos, brunatre en dessous: parfois elle est d'un rougeàtre teinté de noir.

Habitat. Méditerranée, assez rare, Nice, Cette. Océan, rare, Arcachon; excessivement rare, la Rochelle.

Chez une f'emelle d'une assez grande taille, j'ai compté seize œufs très volumineux $(0,06$ de diamètre), qui n'étaient pas encore arrivés dans les oviductes.

\section{Framille des Scymnidés, Scymnida.}

Corps plus on moins allongé, parfois comprimé.

Tête; houche armée de dents plus ou moins aiguës ou tranchantes. 
Nageoires; dorsales sans aiguillons; première dorsale en avant ou au-dessus des ventrales.

Cette famille se compose de trois genres.

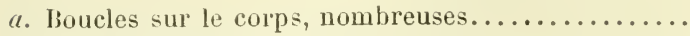

Pas de boucles sur le corps............... b.

b. Dents de la mâchoire infériemre à pointe oblique,

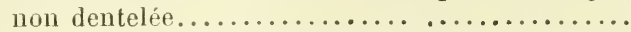

Dents de la màchoire inférieure à pointe droite et

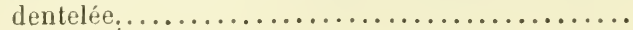

3. ECHINORHINE.

2. Lamargue.

1. Scrmae.

1. GENRE SCYMNE. - SCYMNUS, CuY.

Corps allongé, couvert d'une peau rude.

Tête aplatie en dessus; museau conrt, épais; bouche à peu près transversale, avec une entaille de chaque còté; màchoire supérieure garnie de dents étroites, longues et pointues; mandibule avec dents pentagonales, à base assez large; à pointe triangulaire dentelée latéralement, une dent médiane.

Nageoires; première dorsale un peu plus rapprochée des pectorales que des ventrales.

\section{LA LICHE oU SGMMNE COMMUNE. - SCYMNUS LICHIA.}

Poiss. France, t. I, p. 3วั8, fig. 62, dents.

N. vulg. : Gatta causieriera, Nice ; Gatte, Biarritz; Liche, BassesPyrénées.

Long. : 1,00 ì 1,50 , quelquefois plus.

Le corps est allongé, arrondi, couvert de tubercules excessivement rudes. La tète est aplatie. La bouche est presque transversale; les cartilages labiaux sont bien développés; les dents de la màchoire supérieure sont allongées, étroites, à pointe très effilée à peine rejetée en dehors; à la mandibule est une dent médiane ressemblant aux dents latérales, qui ont la forme d'une plaque quadrangulaire dont la partie supérieure ou libre est surmontée d'une pointe triangulaire, à bords latéraux dentelés. Les yeux sont très grands, ovales; les narines sont près du bord du museau; les évents sont larges, en arrière et au-dessus des yeux. La seconde dorsale est plus grande que la première, elle commence au-dessus de la fin de l'insertion des ventrales; la caudale est bien développée. 
La teinte générale est d'un brun violacé, arec des taches noirâtres mal limitées.

Habitat. Méliterranée, ce Squale est assez commun à Nice; rare à Cette. Océan, commun à Saint-Jean-de-luz; excessivement rare au-dessus de la Gironde, la Rochelle.

Suivant Duhamel, les femelles portent quatre ou six petits ; d'après Risso, la femelle met bas dix a seize petits.

\section{GENRE LAIMARGUE. - LAIMARGUS, Müll, et Henl.}

Corps allongé, couvert de petits tubercules.

Tête à profil assez arrondi; bouche avec une entaille de chaque còté; dents de la màchoire supérieure étroites, triangulaires, à pointe un peu rejetée en dehors; celles de la mandibule sont en forme de plaquettes allongées à bords latéraux parallèles, à bord libre tranchant, terminé en pointe très oblique tournée en dehors.

Nageoires; première dorsale en avant des ventrales.

Partie inférieure du museau très relevée de la bouche à son extrémité.................. Partie inférieure du museau à peu près horizontale...............................

1. A COURTEs Nageoires.

2. A LONG MUSEAU.

\section{LE LAIMARGLS A COLRTES NAGEOIRES. - LAIMARGUS BREVIPINNA.}

Poiss. France, t. I, p. 361, fig. 63, dents.

Long. : 3,00 à '́,00.

D'après Valenciennes, le corps de ce Laimargue est assez semblable à celui de la Centrine humantin. La tète est compriméc; le museau est très relevé de la bouche à sa pointe ; les dents de la màchoire supérieure sont assez fortes, étroites, triangulaires, arec la pointe rejetée en dehors; celles de la mandibule sont en forme de plaquettes, à bords latéraux parallèles, à bord libre tranchant avec une pointe très oblique rejetée en dehors. Les yeux sont petits; les narines scont près du bout du museau, assez loin de la bouche; les évents sont assez loin en arrière de l'œil; les fentes branchiales sont petites, elles finissent avant l'insertion de la pectorale. Toutes les nagenores sont peu déreloppées; la première dorsale est 
for't petite, très basse, à peu près au-dessus du milieu de l'intervalle qui s'étend des pectorales aux ventrales; la seconde dorsale est aussi très petite; la caudale est peu développée; la pectorale est fort courte; sa longueur est moindre que la distance qui sépare son insertion de l'angle de la bouche.

La teinte générale est grisâtre.

Habitat. Manclie, accidentellement, le Havre, en 1832; second spécimen échoné à Mers, le $2 \tau$ juin 188̈̈. V. Supplèm., p. 138.

Suivant lütken, rapporte Fis Day, le mode de propagation est, dans cette espèce, différent de celui qui se remarque chez les autres Squales. Ce Laimargue ne donne pas naissance à des petits vivants, il ne pond jamais non plus d'œufs à enveloppe résistante, comme les Roussettes, mais il produit un grand nombre d'œufs mous globuleux. Quant à la fécondation est-elle interne on externe? La question n'est pas encore résolue; en tout cas, les œufs sont déposés saus enveloppe solide, cette disposition est en rapport avec l'absence apparente de la dilatation utérine et de la glande nidamenteuse dans les oviductes de ce grand Squale du nord. (V. Day, Fish. Great Brit., t. II, p. 321.) - D'un autre còté, Günther prétend qu'il est établi que ce Squale est vivipare et qu'il domne naissance à environ quatre petits a chaque portée. (V. Günth., Stud. Fish., Édimb., 1880, p. 333.) D'après Valenciennes, le màle a les appendices sexuels petits, très courts, ne dépassant pas l'angle de la ventrale.

\section{LE LAIMARGUE I.ONG MUSEAU. - LAIMARGUS ROSTRATUS.}

Poiss. France, t. I, p. 363.

N. vulg. : Houre plat, Nice.

Long. : 0,30 à 0,80 , quelquefois un peu plus.

Le corps est prismatique, triangulaire, couvert de petiles scutelles lisses; sa hauteur est comprise sept à huit fois dans la longueur totale. La lête est grande; le museau est large et allongé, à peu près horizontal en dessous, à peine oblique d'arrière en avant; la bouche est large, peu arquée; à la mâchoire supérieure, les dents sont subulćes, très aiguës, à pointe tournée an arrière; ì la mandibule, elles sont larges, sécuriformes, à bord libre ou supérieur tranchant, terminé par une pointe dirigée en dehors. L'œil est plus ou moins petil; son diamètre est compris, chez les sujets de grande 
taille, deux fois et un liers à trois fois et quart dans l'espace préorbitaire et trois à quatre fois dans l'espace interorbitaire. La narine est un peuplus rapprochée du bout du museau que du milieu de la mâchoire supérieure. L’évent est à une certaine distance en arrière de l'ceil, et au-dessus du prolongement de son diamètre horizontal. La première dorsale parait occuper une position assez variable, elle commente ordinairement, au moins chez les sujets de taille moyenne, plus près du bout du museau que de l'origine de la caudale; la seconde dorsale est un peu en arrière des ventrales; il existe dans les proportions des nageoires des différences assez notables, suivant les sujets.

La coloration est d'un gris bleuâtre.

Habitat. Méditerranée, assez rare, Nice.

En mars 18\%4, MM. Gal de Nice ont préparé une femelle qui portait douze petits; ils mont procuré, en 188z̈, deux sujets, un màle mesurant 0,323 de longueur et une femelle un peu moins grande, 0,477 , et en 1889 deux fuetus, un màle ayant 0,150 de long et une femelle de 0,148. - Dans le genre Laimargue, les appendices copulateurs sont très peu développés, chez le màle de 0,3223 de taille, ils n'atteignent pas à l'extrémité de la ventrale.

\section{GLNRE ÉCHINORIINE. - ECHINORHINUS, Blainv.}

Corps allongé, plus ou moins fusiforme, couvert de boucles à base large, striée.

Tête aplatie; un sillon à l'angle des màchoires; dents semblables aux deux màchoires, à bord libre oblique et tranchant, à bords latéraux avec une ou deux dentelures.

Nageoires; première dorsale reculée, ati-dessus des ventrales.

LE BOUCLÉ. - ECHINORHINUS SPINOSUS, Blainv.

Poiss. France, t. I, p. 363 , fig. 6' , boucles; fig. $6 \ddot{3}$, dents.

N. vulg. : Mounge clavelat, Nice; Broucu, Landes et BassesPyrénées; Bilan, Bayonne; Chenille, Gironde, Charente-Inférieure, Vendíe.

Le corps est légèrement fusiforme, un peu comprimé en arrière. La peau est garnie de place en place de petites épines, 
ou de boutons épineux parfois confluents, espèces de disques à contour radié, portant une épine centrale à pointe dirigée en arrière. La tête est épaisse; le museau large, assez arrondi; la bouche est arquée; les màchoires sont armées de dents semblables à bord libre tranchant, à bords latéraux armés d'une ou de deux pointes, quelquefois ces pointes manquent sur les dernières dents. Le diamètre de l'œil, qui est grand, mesure le tiers de l'espace préorbitaire; les narines sont placées vers le bord du museau; les évents sont petits. La ligne latérạle est bien marquée, munie de papilles développées. Les dorsales sont petites; la première est opposée aux rentrales; la seconde est à peu près sur le milieu du troncon de la queue; la caudale est bien développée; les pectorales sont assez larges, les rentrales sont relativement assez grandes, trapézoïdes.

La teinte générale est d'un brun violacé, moucheté de taches irrégulières plus foncées, parfois d'un brun olivàtre.

Habitat. Méditerranée, assez rare, Nice, Cette. Océan, commun an fond du golfe de Gascogne, à Saint-Jean-de-Luz; Arcachon, assez rare; très rare au-dessus de la Gironde, Charente-Inférieure. Manche, Finistère, Roscoff.

\section{Famille des Squatinidés, Squatinida.}

Corps aplati, déprimé, beaucoup plus large que haut; queue développée.

Tête déprimée, semi-circulaire sur son bord libre, logée dans une échancrure formée par les pectorales; museau court; bouche au bout du museau; cartilages labiaux très développés ; dents semblables aux deux màchoires, pointues, disposées en rangées symétriques, pas de dent médiane.

Yeux très petits, placés en dessus, sans membrane nictitante.

Nageoires; dorsales en arrière des ventrales, tout à fait sur la queue, rapprochées l'une de l'autre; caudale à deux lobes assez larges; pectorales larges, avancées, à bord antérieur concave; ventrales larges, rapproclıées des pectorales.

GENIE SQUATINE. - SQUATINA IEL RHINA

Caractères de la famille. 
LANGE. - SQUATINA A VGELUS.

Poiss. France, t. I, p. 370, fig. 66, squelette des màchoires, et p. 50, fig. 9, nerfs cràniens.

N. vulg. : Angre de mer, Angelot; Mordacle, Vendée; Bourget, Bourgeois, Charente-Inférieure; Martrame, Arcachon; Angel, Roussillon; Anchou, Cette; Pei ange, Nice.

Long. : 1,00 à 1,50, queliquefois 2,00 .

Le corps est déprimé; les dimensions transversales sont augmentées en raison du mode d'insertion des pectorales; la queue est grosse, assez arrondie en dessus, aplatie dans sa région inférieure; la peau, rude en dessus, est plus ou moins lisse en dessous; il y a généralement des aiguillons sur la ligne médiane du dos. La tête est portée sur une espèce de cou; elle est discoïde, un peu plus large que longue; la bouche est terminale, large, garnie de dents triangulaires à base élargie, disposées par rangées symétriques, généralement plus nombreuses à la màchoire supérieure qu'à la mandibule. Les yeux sont très petits. Les narines s'ourrent en avant sur le bord libre du museau; elles ont des valvules découpées en franges plus ou moins nombreuses. Les évents sont semi-lunaires; leur angle interne est en dehors du prolongement du diamètre longitudinal de l'œil. Les fentes des ouïes sont de grandeur moyenne; elles sont cachées en partie par le bord interne des pectorales. Les dorsales sont en arrière de l'extrémité des rentrales, sur le tronçon de la queue, elles sont à peu près de même dimension; la caudale est presque triangulaire; les pectorales sont de forme quadrilatérale, à bord antérieur fort échancré; les ventrales sont trapézoïdes.

La teinte générale est en dessus d’un vert brunàtre, avec de petites taches plus ou moins foncées, parfois blanchàtres; en dessous la coloration est blanchàtre. La teinte est rougeàtre, chez la squatine ocellée, qui est une simple variété de l'espèce commune.

Habitat. L'Ange se trouve sur toutes nos còtes, semble plus commun sur nos còtes de l'Ouest que dans la Méditerranée.

Morear - Ishthvologie. 
La mère porte de treize à vingt petits; elle semble produire deux fois par an.

\section{Sous-ordre des Raies, Raiinæ.}

Corps de forme variable, le plus sourent en disque aplati.

Tête de forme variable; bouche en dessous.

Yeux sans membrane nictitante.

Évents ne manquant jamais, plus on moins larges.

Appareil branchial; cinq fentes branchiales ourertes en dessous.

Nageoires; dorsales variables dans leur nombre, leur position, manquant parfois; anale nulle; caudale variable dans sa forme, manquant dans certains genres; pectorales bien développées.

Le sous-ordre des Raies se divise en trois tribus.

$a$. Dorsale double......................... $b$.

- unique ou nulle...................

๖. Queue distincte du tronc, qui est toujours dis-

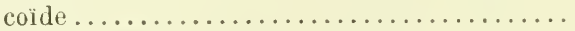

Quene grosse, continuant le tronc.......... 1. Squatixokates.

3. Céphaloptériexs.

2. Batides.

\section{TRIBU DES SQUATINORAIES. - SQUATINORALE.}

Queue grosse, charnue, continuant le tronc avec lequel elle est confondue à sa base.

Nageoires; deux dorsales; caudale plus on moins déreloppée. Deux familles :

Museau prolongé en lame garnie de dents latérales.... 1. Pristidés.

-. non prolongé en lame dentelée............. R. Rhiмobatidés.

\section{Fanille des Pristidés, Pristidæ.}

Corps assez semblable à celui des Squales; allongé, déprimé en avant, plus ou moins arrondi en arrière; queue grosse, continuant le tronc sans ligne de démarcation distincte; peau courerte de petites scutelles.

Tête; museau déprimé, prolongé en une lame aplatie, portant de chaque còté une série de pièces dentiformes, pointues, espacées, plus ou moins nombreuses; bouche transversale, sarnie de petiles dents plates; pas de cartilages labiaux.

Yeux latéraux. 
Narines en dessous.

Évents larges en arrière des yeux.

Appareil branchial; fentes des ouies assez petites, en dessous.

Nageoires; première dorsale au-dessus ou peu s'en faut de la base des ventrales; pectorales libres, séparées des cartilages de la tète, éloigruées des ventrales.

Cette famille forme un genre comprenant deux espèces, distincles l'une de l'autre par le nombre des dents que porte la scie.

\section{GENRE SCIE. - PRISTIS, Latham.}

Dents au nombre de vingt paires au plus........... 1. DEs ANCIExs. vingt-quatre paires au moins..... 2. pectróé.

\section{LA SCIE DES ANCIENS. - PRISTIS ANTIQUORUM, Latl.}

Poiss. France, t. I, p. 376.

Long. : 2,00 à $\{, 00$.

Le prolongement rostral, qui forme la scie, est relativement large, sa largeur faisant le cinquième de sa longueur; il est assez épais; il est armé de chaque côté de seize à ringt dents, qui se correspondent à peu près d’une façon régulière; il y a parfois une dent de plus d'un côté que de l'autre. Le bord antérieur des dents est mince; le bord postérieur, plus épais, est généralement creusé d'un sillon.

Habitat. Méditerranée? Pyrénées-Orientales, d'après le D² L. Companyo.

\section{I.A SCIE PECTINEE. - PRISTIS PECTIVATUS, Lath.}

Poiss. France, t. I, p. 377.

Long. : 2,00 d 4,00 .

I.e bec est assez étroit, sa largeur étant comprise sept à huil fois dans sa longueur; il est plus long, plus grêle que dans l'autre espèce; il est armé de dents en nombre variable de vingt-quatre à trente paires, parfois même il $y$ en a trentequatre paires; les dents sont plus grêles, plus courtes et beaucoup moins cannelées sur leur bord postérieur que dans l'autre espèce. 
Le corps est gris brunâtre en dessus, gris jaunâtre en dessous.

Habitat. Méditerranée, excessivement rare, Nice.

\section{Famille des Rhinobatidés, Rhinobatidx.}

Gorps en forme de disque uni à la tète; queue développée, confondue avec le tronc, ayant de chaque còté une carène ou plutòt un pli cutané.

Tête; museau triangulaire; bouche transversale; petites dents en pavés.

Nageoires; dorsales en arrière des ventrales; ventrales rapprochées des pectorales.

GENRE RHINOBATE. - RHINOBATUS, Bl. Schneid.

Évents placés immédiatement derrière les yeux.

LE RHINOBATE DE COLONNA. - RHINOBATUS COLUMNE, Müll. et Henl.

Puiss. France, t. III, p. 621 .

Long. : 0,30 à 1,00 .

Du bout du museau aux ventrales, le Rhinobate a l'aspect d'une Raie à disque rétréci, puis il finit comme un Squale. Le disque est un peu plus long que large. Un repli cutané s'étend de linsertion de la rentrale à la base de la caudale. La peau est couverte d'un chagrin très fin. Sur le milieu du dos règne une série d'aiguillons pelits et mousses, se continuant plus ou moins loin sur le tronçon de la queue. Le museau est allongé. obtus; la bouche est droite, garnie de dents en petit; pavés. L'uil et l'évent semblent placés dans une mème cavité; ils ne sont séparés que par un repli membraneux; sur le bord postérieur des spiracules se montrent deux petits appendices. Les narines sont largement ouvertes, beaucoup plus rapprochées de la bouche que du museau. La première dorsale est sur le tronçon de la queue, plus près de la ventrale que de la caudale, elle est trapézoïde, plus haute que longue : la seconde 
dorsale est de même forme; la caudale a le bord postérieur coupé obliquement: les ventrales sont plus longues que larges.

En dessus, la teinte est gris jaunatre ou blanc verdâtre, en dessous d'un blanc sale.

Habitat. Méditerranée, accidentellement, Marseille (Marion). Ainsi que je l'écrivais, t. I, p, 37', il n’est pas impossible que le Rhinobate de Colonna se rencontre un jour sur nos còtes.

\section{TRIBU DES BATIDES. - BATIDES.}

Corps formant avec les pectorales une espèce de disque; queue distincte du tronc.

Nageoires; dorsales sur la queue; pectorales développées, s’étendant jusqu'aux rentrales.

Cette tribu est formée de deux familles.

Queue grosse, nue; caudala bien développée......... 1. Tonpedidées.

- grêle, épineuse; caudale nulle ou très réduite... 2. Ramı́s.

\section{Famille des Torpédidés, Torpedidx.}

Corps discoíde; quene conrte et grosse avec un repli de chaque còté; peau nue, lisse.

Tête; museau non proéminent; bouche peu fendue, garnie de petites dents aiguës.

Narines à valvules antérieures confluentes.

Appareil électrique très développé.

\section{GEXRE TORPILLE. - TORPEDO, C. Dumér.}

Nageoires; deux dorsales, la première qui est la plus développée est à peine en arrière des ventrales; caudale développée, triangulaire, à peu près symétrique.

Ce genre comprend trois espèces.

a. Events circulaires ou ovales.................. b.

- rẻniformes, grands, sans tentacules..........

b. Taches ocellées sur le disque généralement distinctes; évents a tentacules nuls, ou fort réduits.........

Pas de taches ocellées sur le disfue; évents i tenta-

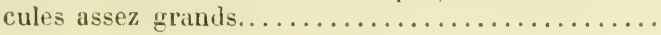

3. DE NOBILI.

2. A TACHES.

1. MARBRÉE. 
1. LA TORPILLE MARBRÉE. - TORPEDO MARMORATA, Riss.

Poiss. France, t. I, p. 381 et p. 236, figure 2', fœtus.

N. vulg. : Tremble, Tremblard, Tremblant et quelquefois Trembleux, Vendée, Charente-Inférieure; Arounce-bras, Biarritz; Tourpya, Calina, Endourmidoüyda, Cette; Tremoulina, Nice.

Long. : $0,3 \ddot{3}$ à 0,30 et mème 1,00 .

Celte Torpille est de forme assez variable; le disque est généralement à peu près circulaire arec le bord antérieur rectiligne ou légèrement concave; parfois il est ovale, avec les bords latéraux peu convexes. La bouche est médiocrement fendue. Le diamètre de l'cil fait le tiers et parfois le quar' seulement de l'espace préorbitaire, il est égal au grand diamètre de l'évent qui est ovale; sur le bord du spiracule se voient sept ou huit tentacules formant des espèces de dentelures. La première dorsale est au-dessus ou un peu en arrière de l'insertion des ventrales; elle est un peu plus développée que la seconde: la caudale est à peu près aussi large que longue.

La teinte est très variable; tantôt la peau est en dessus d'un jaune rougeâtre sans taches et d'un blanc légèrement roussâtre en dessous; tantôt elle est en dessus d'un gris assez clair arec des marbrures sinueuses brunâtres, des taches brunes plus ou moins nombreuses, quelquefois encore avec des taches blanches, la face ventrale est d'un blanc rougeâtre.

Habitat. Manche, excessivement rare, Boulogne. le Havre; moins rare dans l'Océan, dans la Loire-Inférieure; commune en Vendée, atux Sables-d'Olonne, dans la Charente-Inférieure; assez comnune dans le golfe de Gascogne; commune dans la Méditerranée.

\section{LA TORPILLE A TACHES. - TORPEDO OCULATA, Bel.}

Poiss. France, 1. II, p. 38', fig. anim.

N. vulg. : Tremoulina, Nice; Tourpya, Calina, Endourmidoüyda, Cette.

Long. : 0,33 ì 0,60 .

Excepté sur le bord antérieur qui est droit ou légèrement schancré, le disque est à peu près arrondi, et son diamètre 
transverse est un peu plus long que l'espace qui sépare le bout du museau de la fin des pectorales. Le diamètre de l'oil est un peu plus grand que celui de l’évent. L’érent est circulaire; son bord n'a pas de tentacules chez les sujets de grande taille; chez les jeunes, il porte souvent sept ou huit tentacules excessivement réduits.

En dessus la teinte est jaunâtre ou brun rougeâtre avec de larges taches, d'un blanc grisatre en dessous. Il y a beaucoup de variétés dans le nombre et la disposition des taches; les taches sont généralement au nombre de cinq, parfois il y en a six, sept, parfois il n'en existe qu'une seule et mème pas du tout, ce qui est fort rare évidemment. Les taches sont presque toujours ocellées, le centre est d'un bleu plus ou moins foncé arec un cercle plus clair; parfois elles sont d'une coloration uniforme. Outre ces grandes taches, il y en a souvent d'autres petites, blanchàtres.

Habitat. Océan, excessivement rare, Bayonne; Méditerranée, rare à Cette, assez rare à Nice.

\section{LA TORPILLE DE NOBILI. - TORPEDO NOBILLANA, Bp.}

Poiss. France, t. I, p. 386.

Long. : $0, \ddot{3} 0$ à 1,00 au plus.

Le disque est échancré sur le còté, vis-à-vis des yeux, et parait ainsi formé de deux portions de disques inégaux. Les évents sont réniformes, plus grands que les yeux, n'ayant pas de tentacules ni de franges à leur bord. La première dorsale est deux fois plus développée que la seconde.

Le système de coloration semble assez variable, il est ordinairement d'un l'ouge noiràtre en dessus, d'un blanc rosé en dessous; très sourent l'reil est entouré d'une bande d'un blanc sale.

Habitat. Méditerranée, accidentellement Nice. Océan? Manche? Les Torpilles ont à chaque portée de trente à soixante petits. Les furtus ont des branchies externes fort développées; en aoủt 1873, à laquarium d'Arcachon, j’ai eu a ma disposition un certain nombre de Torpilles marbrées, en état de gestation; sur un fotus (V. Poiss. 
France, t. I, p. 236, fig. 24) mesurant 0,042, j’ai constaté que des filaments branchiaux avaient une longueur d'au moins 0,028 , plus de moitié de la longueur totale de l'animal. L'appareil électrique et l'appareil folliculaire nerveux des Torpilles fournissent des sujets d'étude fort intéressants qu'il ne faut pas négliger.

\section{Famille des Raiidés, Raiiar.}

Corps rhomboïdal, aplati, très large; queue grèle ayant de chaque còté un repli cutané, portant presque toujours une ou plusieurs rangées d'aiguillons; peau rarement nue, couverte le plus souvent d'aspérités, de tubercules épineıx.

Tête; museau formant en général un angle plus ou moins saillant; bouche en dessous, sans cartilages labiaux, armée de dents nombreuses, mousses ou pointues suivant les espèces, et mème suivant l'àge et le sexe.

Yeux munis d'une palmette frangée, servant a diminuer plus on moins le champ de la pupille.

Narines en dehors, à valvules réunies.

Évents larges, très rapprochés des yeux.

Nageoires; pectorales très grandes, s'avançant de chaque cúté de la tète, mais n'atteignant pas l'extrémité du museau, se prolongeant en arrière jusqu'aux ventrales; ventrales divisées en deux lobes; deux dorsales reculées vers l’extrémité de la queue; caudale nulle ou peu développée.

Les Raies sont ovipares; les œufs sont des quadrilatères allongés, avec les angles terminés en cornes plus ou moins développées; les coques desséchées qui se trouvent souvent sur les plages sont appelées coussinets, châtaignes de mer, et parfois Rats de mer.

GHAR RAIE. - RAIA, Cuv.

Tête; museau aỵant son extrémité complètement libre, non enveloppée par le prolongement des pectorales.

Dans l'anatomie de Bartholin (Lugd. Butuv., 1586, p. 297), est une planche dont les fig. 2 et 3, d'après Swammerdam, représentent l'intestin valvulaire d'une Raie; dans la fig. 2, les tours de spire sont marqués sur la tunique intestinale; dans la fig. 3, la tunique intestinale externe est enlevée, et la valvule est mise à découvert.

Le genre liaie compte un assez grand nombre d'espèces. 


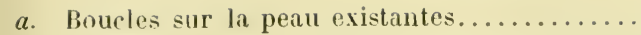
nulles.

b. Boucles à base en forme le houton......... i base en forme de còne radié......

c. Milieu de la queue nu............... $d$. portant des aiguillons...

d. Queue ayant, de chaque côté, plusieurs rangées d'aiguillons.................... Queue ayaut, de chaque còté, une scule

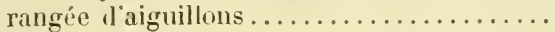

e. Museau allongé, la ligne menée du bout du museau à l'angle externe de la pectorale passe en dehors du disque............

Muscau assez court, la ligne menée du hout du museau à l'angle de la pectorale coupe le bord antérieur du disque...........

f. Orifices des tubes de Lorenzini à la face ventrale bordés de noir.

Orifices des tubes de Lorenzini à la face ventrale non bordes de noir..............

g. Largeur du museau, prise vers le bord antérieur des orbites, a peine plus grande que

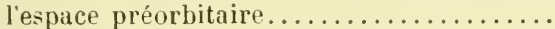

Largeur du museau, prise vers le bord anterieur des orbites, d'un quart au moins plus grande que l'espace préorbitaire.....

h. Dents très serrées, à base plus large que longue.

Dents espacées, assez étroites, i base plus lon-

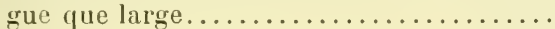

i. OEil très petit, beaucoup moins grand que

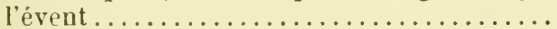

OEil aussi grand ou plus grand que l'évent. .

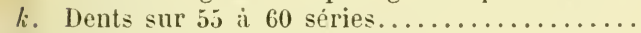

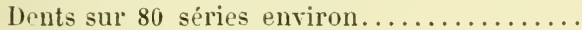

l. Nuseau coupé carrément...............

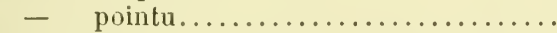

$m$. Tache ocellée sur la pectorale bien marquéc.

Tache ocellée sur la pectorale nulle........

$n$. Tache ocellée de la pectorale a centre rou-

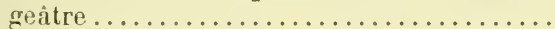

Tache ocellée de la pectorale á centre jaunànàtre, ou brunàtre.

o. Tache ocellée de la pectorale isolée........

Tache ocelléc de la pectorale accompagnéc d'une autre tache ....................

p. Bandes ondulées sur le disque bien dessinces.

Bandes ondulées sur le disque nulles.......

q. Aiguillons formant une ligne sur le sourcil.. diguillons ne formant pas de ligne sur le sourcil

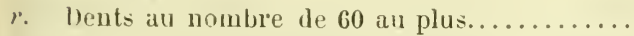

Dents au nombre de 70 au moins........... b.

c.

1. BOUCLÉE.

2. RADIÉE.

e.

3. Circulaire.

4. CHAGRINÉE.

8. BLANCHE.

5. OXYRHYNQUE.

h.

6. MACRORIYNQUE.

7. BATIS. k. I.

9. A PETITS YeUx.

10. A QUEUE COURTE.

11. RAPE.

$m$.

$n$.

$p$.

$o$.

14'. MIROIR.

12. MIRIILLET.

13. A QCATRE TACHES.

17. MOSAIQUE.

$q$.

16. CHARDOX.

1i. PoNCtule.

15. estellée. 
Les Raies peuvent ètre rangées dans quatre groupes distincts.

A. Raies ayant des boucles sur la peau $(1-2)$.

B. Raies ayant le milieu de la queue nu ou sans aiguillons (3-4).

C. Raies à bec allongé (:̈-8).

D. Raies à bec assez court (9-17).

Les dents sont:

$1^{\circ}$ Pointues dans les deux sexes chez les Raies.... radiée; circulaire; clagrinée; oxyrhynque; macrorhynque; bàtis; blanche ; queue courte; estellée; mosaïque adulte.

$2^{0}$ Mousses dans les deux sexes chez les haies.... ràpe; chardon ơ et suivant CBp., chez ర్.

$3^{\circ}$ Pointues chez les màles adultes, toujours mousses chez les femelles dans les Raies.... bouclée; à petits yeux; miraillet; à quatre taches; ponctuée.

A. Raies ayant des boucles sur la peau (1-2).

\section{LA RAIE BOLCLEE. - RAIA CLAVATA, Rond.}

Poiss. France, t. I, p. 391 ; p. 392, fig. 69, anim., et p. 11, fig. $\ddot{3}$, colonne vertébrale, p. 242, etc., fig. 25, 26, 27, 31, organes de la génération.

N. vulg. : la Bouclée, Clouée, còtes de l’Ouest; Clavelada, Nice, Marseille; Clabélada, Cette.

Long. : 0,80 à 1,00 et plus.

Le disque est ondulé sur son bord antérieur; sa largeur fait presque les deux tiers de la longueur totale; en dessus il est couvert d'aspérités, au milieu desquelles se trouvent généralement des boucles plus ou moins nombreuses, plus ou moins développées; en dessous les aspérités sont moins prononcées, les boucles plus rares. Le milieu du dos porte une rangée d'aiguillons, qui se continue sur la queue, dont elle forme la rangée médiane; à partir de l'insertion des rentrales, la queue a de chaque côté une série d'épines qui ne se prolonge pas, ordinairement, aussi loin en arrière que la rangée médiane. Les dorsales sont très petites, à peu près de mème dimension; la seconde dorsale est ordinairement séparée de la petite caudale. Le museau est couvert d’aspérités; il porte souvent des boucles; il est mousse, on arrondi. Les dents sont différentes chez les femelles et les màles adultes. Chez les femelles, les 
dents, semblables à des tètes de clous carrées, sont disposées par rangées obliques, au nombre de 20 à 27 à la mâchoire supérieure, de 2 ' à 29 à la mandidule. Les jeunes màles ont les dents plates conme les femelles. Chez les màles adultes, les dents sont placées en séries verticales, variant de 36 à 40̈ sur la mandibule; les dents des rangées externes sont très rapprochées, taillées en losange, à bord libre tranchant; celles des rangées internes sont très pointues, ce sont des crochets à pointe acérée, tournée en arrière. Les yeux sont assez grands; il y a ordinairement une ou deux épines vers l'angle antérieur de l'orbite, une autre vers l'angle postérieur. L'espace internasal est à peu près égal à l'espace prénasal. Le diamètre de l'évent est un peu moins grand que celui de l'œil; il y a généralement une épine vers l'angle interne du spiracule.

La coloration est rariable; elle est en dessus, le plus souvent, gris verdàtre ou gris jaunâtre, avec des taches brunes et des taches blanches plus ou moins arrondies; quelquefois sur les pectorales existe une tache ocellée, blanche, bordée de noir.

Habitat. Cette Raie est commune sur toutes nos còtes.

\section{LA RAIE RADIÉE. - RAIA RADIATA, Donov.}

Poiss. France, t. I, p. 394.

Long. totale; 0,00 à 0,60 .

Le disque a le bord antérieur ondulé; il mesure un quart de plus en largeur qu'en longueur; il est très rude en dessus, plus ou moins couvert d'aspérités et de boucles ressemblant ì des cônes radiés; ce sont des tubercules à base étoilée, à stries profondes, à pointe aiģuë, recourbée en arrière. Il y a une quinzaine de ces tubercules entre la tête et la première dorsale; il y en a plusieurs sur la ceinture scapulaire. Outre la rangée médiane de tubercules, la queue en porte de chaque côté une autre série de moins développés. Le museau est court. lisse en dessous, très rude en dessus. La bouche est garnie de dents assez fines, assez longues, pointues dans les deux sexes, rangrées par séries verticales, au nombre d'une quarantaine à 
chaque màchoire. Les yeux sont assez grands; il y a généralement $n n$ fort aiguillon radié à l'angle antérieur de l'orbite, un autre à l'angle postérieur. L'espace prénasal est d'un cinquième environ plus grand que l'espace internasal. Le diainètre de l'évent ne lait guère que les trois cinquièmes de celui de l'oril.

La coloration est d'un blond cendré assez pâle chez les sujets frais, brunàtre chez les animaux conservés; le ventre est blanchâtre.

Habitat. Excessivement rare sur nos còtes; Manche, Calvados; Océan, Arcachon.

B. Raies ayant le milieu de la queue nu, sans aiguillons $(3-4)$.

3. LA RAIE CIRGULAIRE. - RALA CIRCULARIS, Couch.

Poiss. France, t. I, p. 397, fig. 70, anim.

Long. : 0,60 à 1,20 .

La largeur du disque mesure les trois cinquièmes de la longueur totale: elle est égale à la distance qui sépare le bout du museau de la fin des ventrales. Généralement la peau n’est pas très rugueuse. Sur la partie antérieure et médiane du dos est un groupe d'aiguillons, placés ordinairement sur cinq rangées formant une espèce de triangle isocèle dont le sommet est derrière la tète et la base sur la ceinture scapulaire; après, il n'y a plus daiguillons sur le milieu du dos; un peu en avant de la ceinture pelvienne, commence, de chaque coté du rachis, une série d'aiguillons se continuant sur la queue d'une façon assez régulière. La queue est grosse et large; le milieu, qui est nu, est concave, creusé en une gouttière bordée de chaque côté par la série d’aiguillons commençant sur le disque; en outre, il y a encore latéralement une ou deux rangées d’aiguillons plus petits: la rangée externe s’arrête à la première dorsale; il uy a plus d'aiguillons à la base de la seconde dorsale. Le museau est un petit lobe en pointe arrondie. La bouche est muniede petites dents pointues dans les deux sexes, disposées par rangées verticales, au nombre d'environ 70 à la mâchoire supérieure, de 66 à 68 à la mandibule. Les 
yeux sont grands. Le bord antérieur ainsi que le bord interne de l'orbite et le bord interne de l'évent portent une rangée semi-circulaire d'aiguillons plus ou moins serrés. L'espace internasal est d'un tiers plus court que l'espace prénasal. Le diamètre de l'évent est d'un tiers moins grand que celui de l'oxil.

En dessus est une teinte chamois, et le disque est marqué de taches arrondies, disposées d'une façon symétrique, au nombre de six à huit de chaque côté; en dessous, le disque est blanchàtre au milieu, d'un blane rosé sur les bords. La coloration est différente dans les variétés de cette espèce; chez la Raie fausse-roile, le disque est d'une teinte uniforme, sans taches particulières: chez la Raie nievus, la base de la pectorale est marquée d'une grande tache à fond noirâtre, avec des lignes assez larges de teinte jaune blanchàtre.

Habitat. Assez rare sur nos còtes; Manche, Saint-Valery-surSomme, Tréport, le Havre; Océan, Arcachon; Méditerranée, Celte, Toulon.

\section{La Raie Chagrivél. - RAIA Chagrivea, Pennant.}

Poiss. France, t. I, p. 401.

N. vulg. : Florade, Nice.

Long. : 0,80 à 1,20 .

La Raie chagrinée se distingue facilement des autres espèces par la forme de son disque et l'absence d'aiguillons sur le milicu de la queue. Le bord antérieur de l’aile est échancré, de sorte qu'une ligne menée de l’angle externe des pectorales au bout du museau ne touche en aucun point le contour du disque. En dessus, comme en dessous, la peau est couverte de petites épines fort pointues. La queue est nue dans sa partie médiane; elle ne porte de chaque còté qu’une seule rangée d’aiguillons, continuant la série qui commence, sur le disque. en arrière de la ceinture scapulaire. Les dents sont pointues dans les deux sexes, disposées par séries verticales, au nombre d'une soixantaine environ sur chacune desmàchoires. Liorbite est bordée en avant el en dedans par une série de neuf à douze aiguillons. Les évents sont à peu près aussi grands que les yeux. 
En dessus, la coloration est d'un brun jaunatre, et blanchâtre en dessous.

Habitat. Méditerranée, rare, Nice; Océan, très rare, Arcachon. C. Raies à bec allongé; la ligne menée du museau à l'angle externe de la pectorale ne touche pas le bord antérieur du disque (ə̆-8).

ว̈. LA RAIE OXYRHYNQLE ou RAIE AU BEC POINTU. - RAlA OXYRHYYCHUS, Rond.

Poiss. France, t. I, p. 403.

N. vulg. : Alène, Flossade, Languedoc; Capoutchin, Cette ; Fuma, Nice.

Long. : 0,80 à 1,10 .

Le disque est seulement un peu plus large que long; le bord antérieur est très échancré, beaucoup plus long que le bord postérieur; l'angle externe de la pectorale est légèrement pointu, il est d'un tiers plus éloigné du bout du museau que de l'angle postérieur de la nageoire. La queue est courte; sa longueur étant comprise deux fois et quart à deux fois et demie dans la longueur totale. La tête est longue; elle mesure cnviron la moitié de la longueur du disque. Le museau est très pointu; sa largeur, prise au niveau du bord antérieur des orbites, est à peu près égale à sa longueur chez les jeunes, un peu plus grande chez les adultes. Les dents sont pointues dans les deux sexes, au nombre de quarante-deux à cinquante à rhacune des màchoires. L'espace préorbitaire est compris à peu près deux fois et demie dans la longueur du disque; il est environ six à sept fois plus grand que l'espace interorbitaire. L'espace internasal fait le tiers, ou à peine un peu plus du tiers de l'espace prénasal. Le diamètre de l'érent est moindre que celui de l'ceil.

En dessus la coloration est d'un brun noirâtre ou légèrement violacé, ou bien encore d'un jaune chamois avec quelques taches blanchâtres, parfois il y a des taches noiràtres; le dessous du corps est jaunâtre, les orifices des tubes de Lorenzini sont noiratres.

Habitat. Cette Raie est assez commune dans la Méditerranée, Nice, Gette.-.- Océan? Manche, rare. 
6. LA R.LIE MACRORHYNQUE oU RAIE AU LONG BEC. - RALA MACRORHYNCHCS, Rafin.

Poiss. Frunce, t. I, p. 408̈, fig. 71, anint., fig. 72, dents.

N. vulg. : Alène, Lentillat, Fumat, Languedoc; Augustine, Cette; Pisova, Nice; Raie grise, Tire, marché de Paris.

Long. : 1,30 ì 2,00 .

Le disque est d'un quart environ plus large que long ; le bord antérieur est très échancré, plus grand que le bord postérieur qui est arrondi. La queue n'est pas très développée; sa longueur ne mesure généralement pas la moitié de la longueur totale; il y a une ou trois rangées d'aiguillons; la rangée médiane, qui est constante, commence ordinairement après la fin le l'insertion des ventrales. La tête est longue; sa lonğueur fait un peu plus du tiers de la largeur du disque. Le museau est allongé, pointu; sa largeur au niveau du bord antérieur des orbites est diun quart environ plus grande que sa longueur ou que l'espace préorbitaire. La bouche est fort peu arquée; elle est placée un peu avant le milieu de la ligne allant du bout du museau à l'anus. Les dents sont disposées, suivant l'àge, d'une façon différente; chez les jeunes, mâles ou femelles, elles sont rangées par séries obliques; chez les grands, elles sont placées par séries verticales; chez les jeunes màles, elles sont grosses, épaisses, avec une très petite pointe dirigée en arrière; chez les femelles très jeunes, les dents ont l'angle postérieur à peine plus prononcé que les angles latéraux. Le nombre des dents, chez les adultes, varie de $4 \mathbf{i}$ à

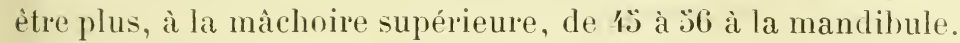
Les yeux sont assez petits; généralement leur diamètre l’emporte sur celui de l'évent.

La teinte est variable; le dos est parfois d'une coloration uniforme grris cendré ou brunâtre, parfois il est moucheté de taches lenticulaires d un blanc grisatre; la face inférieure est d'un blanc grisàtre, ou d'un jaune cendré, avec les points noirìtres, marquant les tubes de Lorenzini.

Habitat. Cielte espèce est pèchée sur loutes nos cỏtes. 
Poiss. France, t. I, p. 409, fig. 73 , dents.

N. vulg. : Raie cendrée; Raie commune; Coliart, Guillaume; quelquefois Tire, còtes de l'Ouest; Augustine, Cette.

Long. : 1,30 à 2,00 .

La Batis ressemble beaucoup à la Raie macrorhynque. Le disque est rhomboüdal, plus large que long; le bord antérieur est sinueux, doublement échancré, d'un tiers plus long que le bord postérieur qui est convexe. La queue est beaucoup plus courte que le disque; elle porte le plus ordinairement trois rangées d’aiguillons; la série médiane, qui est constante, commence généralement vers le niveau de la fin de l'insertion des ventrales. La tète est allongée; elle mesure à peu près le quart de la longueur totale. Le museau est développé. La bouche est à peu près horizontale, largement fendue. Les dents sont pointues dans les deux sexes; elles sont placées en séries verticales bien séparées les unes des autres, au nombre de 48 à 0 à la mâchoire supérieure, de 44 à $\breve{2} 2$ à la mandibule; mais le nombre des rangées peut aller parfois à $\dddot{3}$ ou 56 . La base de la couronne est toujours plus longue que large. Le diamètre de l'ceil est en général plus grand que celui duspiracule; il y a souvent, chez le jeune, une épine au bord antérieur de l'orbite.

Le système de coloration est assez variable; en dessus, il est gris ou gris jaunàtre assez pâle, parfois brunâtre avec des bandes grises; le dessous du corps est d'un gris ou d'un blanc sale tacheté de points noirs.

Habitat. La Batis se trouve sur toutes nos còtes; elle est commune dans la Manche et dans l'Océan, jusqu'à l'embouchure de la Gironde.

\section{LA RAIE BLAXCHE. - RAIA ALBA, Lacép.}

Poiss. France, t. I, P. 412 .

N. vulg. : Raie blanche; Blanquetla, Cette.

Long. : 1, 50 à 2,00 
Dans cetic espèce le disque est très apais; il estrhomboüdal, plus large que long, a bort antrieur ondulé ou doublement échancré, plus développé que le hord postérieur. La queue est large, grosse, déprimée, courte, garnie de trois rangées d’aiguillons. L'anus est ouvert bien en arrière du milieu de la longueur totale. La lète est allongée. Le museau est très long; il est étroit, assez épais jusqu'au niveau du tiers antérieur de l'espace préorbitaire, puis il s'élargit subitement; toute la partie rétrécie du museau est, en dessous, garnie d'aiguillons assez forts, arrondis, à pointe tournée en arrière, ressemblant ¿̀ une carde; ces aiguillons sont plus développés que ceux de la partie supérieure du bec. La bouche est large, peu arquée, almée de lents pointues dans les deux sexes, et disposées par séries verticales bien séparées, au nombre de 42 à 落 environ à la màchoire supérieure, de $4^{\prime}$ à la mandibule le plus sourent. Les yeux sont grands; il y a souvent une épine à l'angle antérieur de l'orbite, et une ou deux sur le bord interne. Les spiracules sont larges; mais leur diamètre est moindre que celui de l'œil.

En dessus, le disque est de couleur cendrée, ou d'un gris uniforme, parfois arec des taches arrondies d un gris blanchatre; en dessous, il est d'un blanc laiteux, sans mouchelures noiràtres; les tubes de Lorenzini n'ont pas de bordure noire. Les pectórales ne sont plus ordinairement bordées de noir chez les animaux adultes.

Habitat. Elle est pèchée sur toutes nos plages.

$$
\text { Jeune. - La Raie bordée. - Raia marginata. }
$$

Poiss. France, t. I, p. 116.

N. vulg. : Rat, Normandie; Fumat, Nirayet, Cette; Miragliet, Nice.

Long. : 0,30 à $0, \dot{1} 0$ et parfois plus.

Le disque est complètement lisse; il est d'un quart environ plus large que long; le bord antérieur est à peine ondulé. Le milieu du dos est nu, le plus ordinairement.

En dessus, le disque est d'une teinte chamois; les pectorales Voreau. - Ichthỵologie. 
sont bordées de noir, ainsi que les ventrales; olles sont les unes et les autres généralement marpuées de taches circulaires. En dessous, le disque est d'un blanc rosé dans le milieu; il montre à la périphérie, surtout vers l'angle externe, une large bande noirâtre. La queue en dessous est à peu près complètement noire à partir de la fin des ventrales; en dessus, elle est noire dans sa partie médiane et d'un gris jaunàtre sur les côtés; les dorsales sont d'un brun foncé.

A propos de la Raie blanche, t. I, p. 413 , j’arais écrit : Au musée de Gênes, j’ai examiné le squelette très bien préparé de deux sujets ${ }^{*}$ et $\rho$ de très grande taille, inscrits sous le nom de $R$. bramunte, Sassi, et je puis assurer que cette $R$. bramante est la Raie blanche de nos còtes et nullement une espèce nouvelle. - M. Vinciguerra nadopte pas mon opinion et dit: mi pare probabile la supposizione di Günther che la identificherebbe colla R. marorcana, Bl. - Je répondrai qu'aucun spécimen de $R$. muroccana n'a jusqu'à présent jamais été trouvé dans la Méditerranée, qu’il n’y a pas de raison pour que le jeune le la $R$. alba, qui n'est pas rare dans le golfe de Gènes, n'y devienne pas adulte comme ailleurs. M. Vinciguerra n'a pas la compétence nécessaire pour juger la question; il avoue luimème n'avoir pu arriver à déterminer la seule Raie qui ait été pèchée dans la croisière del Violante; comme cette Raie le gènait, à cause de ses grandes dimensions, il n'a trouvé rien de mieux que de s'en débarrasser en ne conservant que les màchoires : di essı,per le grandi dimensioni, non si conservarono altro che le mascelie. L'ichthyologiste del Violante ne s'est pas donné la peine d'en faire le croquis, d'en relever les proportions, d'en indiquer le sexe et le système de coloration; c'est en vérité une singulière façou d'étudier les spécimens recueillis dans un vorage d'exploration scientifique.

Suivant M. Günther, et il est difficile de soupconner la raison de sa manière de voir, la $R$. unduluta et la $R$. alba, Lacép., sont identiques; car de Lacépède avait pris soin d'écrire, à propos de la R. albı: la hauteur du corps de la Raie blanche doit ètre remarquée, ce qui est fort exact.

I). Raies ayant le bec assez court; la ligne, menée du bout du museau i l'angle externe de la pectorale, coupe plus ou moins lebord antérieur du disque (9-17). 
9. I.A R.AE A l'ETITS IELX. - R.ALA MLROCELLAT.1, Montan.

Poiss. Frunce, t. I, 1. 417.

N. vulg. - liat, liaie mèlée ou bàtarde, marché de Paris.

Long. : 0,60 à 0,90 .

Chez les grands individus, la largeur du disque mesure les trois quarts de la longueur totale, un peu moins chez les jeunes animaux. La distance de l'angle externe de la pectorale à son angle postérieur est d'un tiers plus courte que la dislance qui s'étend de l'angle externe de la pectorale à la pointe du museau. Le bord antérieur du disque est légèrement ondulé. La queuc est courte; sa longueur, après l'insertion des ventrales, est comprise deux fois et quart dans la longueur totale; il y a généralement trois rangées d’aiguillons assez faibles. Le museau est assez court, légèrement arrondi, couvert de petites aspérités. Les dents sont rangées par séries verticales; elles sont mousses chez les jeunes mâles et chez les femelles; telles sont pointues chez les mâles adultes; le nombre des dents est assez

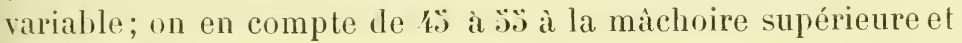
de : ô à 61 à la mandibule. Liceil est petit; son diamètre ne mesure pas le cinquième de l'espace préorbitaire; il est moindre que le diamètre de l'évent; la différence est plus marquée chez les spécimens de grande taille que chez les jeunes.

Le systime de coloration varie suivant l'àge; dans les jeunes, le dessus du corps est d'un jaune brunàtre avec des raies blanches sur les bords du disque, il y a souvent, de chaque côté, près de la région vertébrale, sept ou huit taches blanches assez mal dessinées; dans les grands individus, la teinte est uniforme, d'un gris jaunâtre; les ventrales sont parfois bordées de blanc.

Habitat. Océan, golfe de Gascogne principalement; cette Raie est assez commune à Arcachon, Lorient; assez rare dans la Manche.

10. LA RAIE A QUEUE COURTE. - R.IA BRACHYURA, Lafont.

Poiss. France, l. I, P. 420 .

N. vulg. : Raie blanche, Raie lisse, Arcachon.

Long. : 0,80 à 1,10 . 
D'après Lafonl, le disque forme un parallélogramme à peu près régulier, à bords antérieurs ondulés, à angles latéraux mousses. La queue est garnie de trois rangées d’aiguillons; sa longueur est beaucoup moindre que celle du corps. Le museau est arrondi.Les mâchoires portent quatre-vingt-cinq rangées de dents. Le diamètre de l'œil est plus petit que celui de l'évent.

La couleur générale est chamois en dessus arec de nombreuses taches étoilées noirâtres et cinq ou six taches jaunâtres ou blanchâtres, de chaque côté : la teinte est blanchâtre en dessous.

Habitat. Océan, Arcachon " de janvier à septembre, elle est assez commune ", Lafont.

M. Günther, dans Voy. Challenger, Zoology, t. I, Shore Fishes, p. 20, pl. VI, donne la deseription d'une Raia brachyura qui n'a aucun rapport avec la Raie à laquelle Lafont avait attribué le mème nom spécifique, V. Act. Soc. Lin. Bordeanx, t. XXVIII, pl. 23, Bordeaux, 1871.

\section{LA RAIE RAPE. - RAIA R.DUUL, Delaroche.}

Poiss. France, t. I, p. 421.

N. vulg. : Niraiet, Nice?

Long. : 0,28 à 0,3 ö.

Le disque présente la figure d'un rhombe dont l'angle antérieur est enlevé, et dont les angles externes sont arrondis légèrement; sa largeur est à sa longurueur dans la proportion de cinq à quatre; le bord antérieur est presque droit; l'angle externe est à peu près aussi loin du museau que de l'anus. En dessus le disque est très âpre. Il y a sur le dos une série d'aiguillons qui se continue sur le milieu de la queue. Outre cette rangée d'aiguillons, la queue en porte une autre de chaque côté; elle est moins longue que le disque. Le museau est très court, ‘̀ peine saillant, l'extrémité antérieure du disque paraît seulement un peu ondulée. La bouche est étroite, légèrement arquée. Les dents sont mousses. Le diamètre de l'œil mesure les deux cinquièmes de l'espace interorbitaire, un peu plus du quart de l'espace préorbitaire; il est un peu plus grand que celui de l'évent. 
En dessus la teinte est d'un gris jaunitre avec des bandes brunes plus ou moins irrégulières et des points blanes et bruns, ou d'un gris brunâtre avec une grande quantité de laches jaunitres. Une grande tache ocellée se remarque de chaque côté du rachis, vers le milieu de la pectorale; cette tache circulaire a le centre brunàtre entouré de blanc ou de jaunàtre arec une bordure plus ou moins foncée. Il y a parfois, en avant et en dedans de l'ocelle, une tache plus petite, arrondie, d'une teinte blanchàtre uniforme.

Habitat. Méditerranée; Nice, excessivement rare.

12. LA RAIE MIRAILLET. - RAIA MIRALETUS, Rond.

Poiss. France, t. I, p. 423.

N. vulg. : Miragliet, Nice.

Long. : 0,50 .

Le museau est d'un cinquième environ plus large que long; il est à peu près lisse; son bord antérieur est peu ondulé. La queue porte trois à cinq rangées d'aiguillons. Le museau est pointu, légèrement avancé ; la bouche est garnie de dents aiguës, chez les miles, et plates, mousses, chez les femelles. Les yeux sont assez grands; l'angle antérieur et l'angle postérieur de l'orbite présentent ordinairement deux ou trois aiguillons.

En dessus, le disque est d'un brun cannelle, arec de petites taches d'une teinte brunàtre et une tache ocelléc sur la base des pectorales; cette tache est ronde ou ovale, purpurine dans son milieu, entourée d'une bordure jaunàtre. Le dessous du corps est blanchàtre.

Habitat. Méditerranée; assez commune à Nice, Cette. Océan, Arcachon, rare.

13. LA RAIE A QUATRE TACHES. - RAIA QUADRIMLCLATA, Riss.

Poiss. France, t. I, p. 424.

N. vulg. : Miragliet, Nice; Pelouzéla, Cette.

Long. : 0,40 à 0,60 . 
Généralement la largeur du disque fait les trois cinquièmes de la longueur totale. La queue porte trois à cinq rangées d'aiguillons, parfois une seule chez les jeunes individus. Le museau est pointu. assez court; il est couvert d'aspérités en dessus et en dessous. Les dents sont plates chez les femelles, pointues chez les mâles adultes. L'espace préorbitaire est deux fois et demie plus grand que l'espace interorbitaire.

Le disque est en dessus jaune clair arec de petites taches noirâtres; il est en dessous d'un blanc grisàtre. Sur chaque pectorale, un peu en arrière de la ceinture scapulaire, est une grande tache à centre rougeâtre entouré de noir arec une bordure d'un blanc jaunâtre; à l’extrémité postérieure de la nageoire, il y a parfois une tache non ocellée, noiràtre, plus ou moins marquée; cette tache manque généralement chez les femelles.

Habitat. Méditerranée, assez rare, Nice; peu commune à Cette. Océan, très rare, Arcachon.

\section{1'. LA RAIE PONGTLEE. - RAlA PUNCTATA, Riss.}

Poiss. France, t. I, p. 426.

N. vulg. : Miraiet, Yice; Raie douce, marché de Paris et quelquefois Demoiselle.

Long. : $0, \dot{1} 0$ à $(1, \tilde{i} 0$.

La Raie ponctuée et la Raie miroir ne forment qu'une seule espèce.

La largeur du disque est d'un quart plus grande que sa longueur; le bord antérieur est sinueux; langle externe arrondi. La queue est de longueur rariable ; elle porte une rangée médiane d'aiguillonsassez forts, conlinuant la rangée du dos; elle a crénéralement. chez les jeunes au moins, une séric latérale d’aiguillons moins développés que ceux de la rangée impaire. Le muscau se termine par une proéminence plus ou moins arrondic; il est tries âpre, surtout chez les jeunes. La bouche est assez petite, arquéc. Les dents sont mousses, chez les fe- melles, aplaties, en forme de petits parés. au nombre de 40 à ¿̈0 sur chaque màchoire et disposées par rangées obliques; 
chez les mâles adultes, elles sont pointues, rangées par séries verticales en nombre variable de $3 \ddot{3}$ à 58 . Le diamètre de l'ocil fail le quart environ de l'espace préorbitaire, il est plus grand que le diamèlre de l'érent chez les animaux adultes.

Dans la majorité des cas, le disque est en dessus d'un gris jaunâtre arec de petites taches brunes et d'autres plus grandes d'un blanc jaunâtre, souvent ocellées, entourées d'une bordure noirâtre. Le dessous du corps est blanchâtre ou plutôt d'un blanc rosé.

Var. : La Raie miroir. - Raia speculum, Blainv.

Chez certains sujets, il y a, de chaque côté de la ceinture scapulaire, une tache arrondie, à fond jaunâtre avec une bordure d'un brun foncé, en arrière, il peut se trouver une autre tache semblable, seulement plus petite; parfois la tache des pectorales est entourée de cinq ou six taches peu développées, rangées avec une espèce de symétrie; souvent les taches disparaissent ou deviennent moins nettes quand les animaux grandissent.

Habitat. Cette Raie est commune sur toutes nos còtes.

13. IA RAIE ESTELLEE OU ETOILEE. - RAIA ISTERIAS, Rond.

Poiss. France, t. I, p. 429 et p. 236-257, fig. 28-29, glande de l'appareil copulateur.

N. vulg. : Raie douce.

Long. 0,70 à 1,00 .

Le disque est d'un cinquième environ plus large que long ; son bord antéricur est légèrement anguleux; son angle externe est un peu arrondi, généralement il est à la même distance que l'anus du bout du museau. La queue porte sur le milieu une rangée d’aiguillons faisant suite à la rangée du dos el parfois une autre série de chaque crité. La tète est large; le museau est légèrement échancré sur le bord, près de sa pointe qui est arrondie et courte. La bouche est grande. Les dents sont toujours pointues daus les deux sexes, rangées 
par séries verticales très nombreuses variant de 78 chez les jeunes, à 92 chez grands spécimens. Le diamètre de l'ceil fait à peu près le quart de l'espace préorbitaire; il est un peu plus grand que celui de l'évent.

Le système de coloration est très variable; en dessus le fond est gris ou brun jaunàtre, avec des taches noirâtres, arrondies, nombreuses; souvent au milieu de ces taches noirâtres s'en montrent d'autres plus larges, mais moins nombreuses, d'un gris jaunâtre; quelquefois il n'y a que des taches noirâtres arec une seule tache claire, arrondie et large sur la base de la pectorale; en dessous la teinte est d'un blanc légèrement rosé.

Habitat. Néditerranée, assez commune; très commune dans l'Océan el dans la Manche.

16. LA RAIE CHARDON. - RAIA FULLONICA, Rond.

Poiss. Frunce, t. I, p. ‘32, fis. 74, animal, A, aiguillon.

Long. : 0,60 à 0,70 .

Le disque représente un rhombe assez régulier, à bord antérieur un peu onduleux; il est hérissé, en dessus, d'épines ou plutôt d'aiguillons à pointe recourbée en arrière. Sur la région médiane du dos, il existe une ou plusieurs séries d’aiguillons qui se continuent sur la queue. La longueur de la queue paraît très variable. Les aiguillons de la queue, dit Rondelet, sont courbes, disposés par trois rangs; souvent encore il y a d'autres épines plus petites, placées en séries moins régulières. Le museau est large, à pointe peu saillante. La bouche est légèrement arquée; les dents, au moins chez les femelles, sont mousses, oblongues, à surface convexe, disposées en séries obliques au nombre de $2 ّ$ à 26 sur chaque mâchoire. Le diamètre de l'wil fait le quart de l'espace préorbitaire, parfois un peu moins; il est d'un tiers plus grand que le diamètre de l'évent.

En dessus, le corps est d'un vert jaunâtre, marqué le plus souvent d'une grande quantité de petites taches arrondies noirâtres; en dessous, il est blanchâtre. 
Habitat. Múdilerranée, assez l'are, Nice, Cette. Océan, excessivement rare, la liochelle.

Linné a malheureusement indiqué sous le mème nom de fullonica deux especes de Raies bien différentes l'une de l'autre el très falciles a distinguer au premier comp d'ocil, d'apres le nombre et la disposition des séries d’aiguillons qui hérissent la queue. La R. fullonica de Rondelet est ainsi caractérisée: cauda aculei... triplici ordine dispositi. La R. aspera nostras, White horse, de Willoughby, a les aiguillons de la queue en nombre pair, cauda duplici ordine aculeormm horrel. L’épithète de fullonic doil ètre réservée à l'espèce décrite et figurée par Rondelet; lui en substituer une nouvelle serait aussi embarrassant que peu logique. Quant à l'autre espèce, il faul, à l'exemple de la plupart des auteurs, lui appliquer la dénomination de chugrinea, Pennant, ou du moins lui rendre le nom sous lequel Willoughby l'a fait connaître.

\section{LA RAIE ONDULEE OU MOSAIQUE. - RAIA UNDULAT.I vel MOS.IIC.1.}

Poiss. Finunce, t. I, P. 43 '.

N. vulg. : Razza, Nice; Blanquelta, Marbrada, Cette; Brunette, Cherbourg; Rat, marché de Paris.

Long. : 0,00 à 1,20 .

Dans cette espèce, le disque a les angles externes arrondis et les bords antérieurs à peine ondulés; il est d'un dixième environ plus largze que long ; il est complètement lisse chez les jeunes; il a, chez les adultes, quelques aspérités sur le dos el sur les hords antérieurs. La queue porte sur le milieu une rangée d'aiguillons assez forts; elle a parfois, chez les adultes, une courte série latérale d'aigzuillons. Les ventrales ont une certaine longueur, surtout le lobe externe. Le museau n'a que de tris faibles spinules; sa pointe est courte. Les mâchoires sont plus ou moins arquées. Chez les jeunes animaux, les dents sont mousses, de lorme ovalaire ou plutôt hexagnonale; elles sont disposées en séries obliques sur le milieu des mâchoires. en rangées verticales sur les côtés; il y en a de 36 d̀ 10 séries à chaque màchoire. Chez les grands individus, mâles et femelles, les dents sont toutes par ranģées verlicales; elles ressemblent aux dents des mâles adultes de la Raie bouclée; les 
dents du milieu sont aiguës, ayant la forme de crochets à pointe tournée en arrière; les dents des rangées externes sont plus larges, à bord oblique un peu tranchant et terminé en pointe à son angle externe; la pointe est en général moins prononcée chez les femelles. Le diamètre de l'œil est assez variable; il est un peu plus grand que celui de l'évent.

Le système de coloration est variable. En dessus dans le type mosaïque, le disque est d'une teinte jaunàtre, tirant sur le rouge, parfois châtain avec des bandes ondulées brunâtres, bordées de taches laiteuses assez petites; d'autres taches semblables sont disséminées sur le disque; ordinairement une grande tache blanchàtre, mal circonscrite, se montre sur la pectorale, en arrière de la ceinture scapulaire; dans le type ondulé, la teinte générale est d'un jaune rougeâtre avec des bandes ondulées brunàtres, mais sans taches laiteuses. Parfois chez les grands individus, les bandes ondulées sont plus ou moins effacées, et sa coloration est d'un ton chamois tirant sur le brun. En dessous le disque est blanchâtre chez les adultes; quelquefois d'un blanc jaunâtre chez les jeunes, très rarement noirâtre.

Habitat. Méditerranée, assez commune, Nice, Cette; Océan, commune; Manche, assez commune.

\section{TRIBU DES CÉPHALOPTÉRIENS. - CEPIIALOPTERI.}

Corps; partie antérieure du corps formant avec les pectorales un disque plus ou moins développé; queue mince, armée d'un ou de deux aiguillons, de dards à dentelures latérales.

Tête portant sur les còtés des nageoires faisant suite aux pectorales, parfois en paraissant distinctes el formant des espèces de cornes.

Nageoires; dorsale unique ou nulle; pas de caudale (dans nos especes); ventrales non divisées en deux lobes.

Les Céphaloptériens sont ovovivipares.

Cette tribu se compose de trois familles

a. Tête a prolongements latéraux en forme de

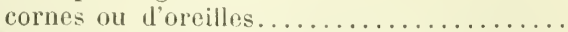

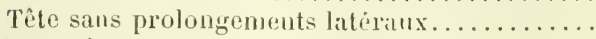

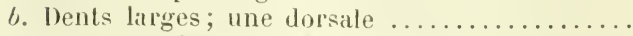

- étroites; pas de dorsale.............

1. Céphingoptéridés. l).

2. MYLIORATIDÉs.

3. Triginides. 
1. Famille des Céphaloptéridés, Cephalopteridie.

Tête; pectorales s'irancant sur les còtés de la tète et formant ì droite et a gauche un grand prolongement, une espèce de corne.

GENRE CÉPHALOPTİRE. - CEPHALOPTERA, C. Dumér.

Corps déprimé, couvert d'une pean à peu près complètement lisse; queue grèle, effilée, an moins aussi longue que le ulisque, armée d'un aiguillon dentelé sur les còtés.

Tête large, portant de chaque còté une corne enroulée à concavité externe; bouche en dessous, à fente horizontale; màchoires garnies de petites dents tuberculeuses.

Yeux latéraux.

Narines à valuules confluentes, bordant la fente de la bouche. Ėvents latéraux.

Nageoires; une dorsale au-dessus des ventrales; pectorales très développées, à bord postérieur plus ou moins concave.

Ce genre compte seulement une ou deux espèces.

Prolongements céphaliques de teinte uniforme........ 1. Gronsa.

noirs à leur extrémité...... 2. MAssÉxA.

1. LE CEPHALOPTERE GIORNA. - CEPHALOPTER.I GIORNA, Lacép.

P'viss. France, t. I, p. 439.

N. vulg. : Vachetta, Nice.

Long. : disque 0, 30 , enverg. 1, 40 , Riss.

Le disque est un peu bombé; la queuc est longue, mince, effilée, lisse dans son quart antérieur, tuberculée dans le reste de son étendue, armée d’une longue épine dentelíe sur les côtés. Les pectorales sont très étendues, à hord antérieur légèrement convexe, ì bord postérieur concave, arec langle exlerne très pointu; la dorsale est " petite, triangulaire, d'un bleu foncé, lisérée de blanchâtre au sommet " (Riss.). Ventrales peu développées. La bouche est largement fendue; les mâchoires sont garnies de dents excessivement petites, disposées en séries très nombreuses. 
La coloration est " d'un bleu indigo à reflets glauques et violets en dessus, d'un blane mat en dessous " (Riss.).

Habitat. Méditerranée, très rare, Nice. - Océan?

2. IE CÉPHALOPTĖRE DE MASSÉNA. - CEPHALOPTERA MASSENA, Riss.

Poiss. France, t. I, P. $4 \mathbf{4 0 .}$

N. vulg. : Vacea, Nice.

Long. : disque long, 1,80, enverg. 3,49, Riss.

Le corps est presque elliptique, relevé en carène au milieu du dos (Riss.). La queue est garnie dans toute sa longueur de trois rangées de tubercules.

La coloration est brun noirâtre en dessus, argentée sur les côtés et d'un blanc mat en dessous avec une infinité de petits points noirs (Riss.).

Habitat. Méditerranée, excessivement rare, Nice.

2. Famille des Myliobatidés, Myliobatidx.

Gorps; disque très large; quene longrue, effilée, armée d'un ou de deux aignillons dentelés.

Tête boubée; museau plus ou moins avancé; bouche transversale; plaques dentaires occupant une longue surface d'avant en arrière; dents plates, beaucoup plus larges que longues sur la ligne médiane, formant une espèce de mosaïque.

Yeux latéraux.

Narines; valvules nasales confluentes, à bord postérieur frangé ou dentelé.

Évents placés en arrière des yeux, sur les còtés de la tète.

Nageoires; dorsale petite, en avant de laiguillon; pectorales ayant leur angle externe très allongé.

GeNRE MYLIOBATE oU MOURINE. - MYLIOBATIS, G. Dumér.

Tête; museau terminé par la réunion des rayons antérieurs des pectorales; dents médianes formant des hexagones irréguliers; dents 
latérales disposées en plusieurs séries, beaucoup moins développées que les dents médianes, semblables it de petits pavés.

Ce genre comprend deux especes.

Museau large et court................... I. AGLe.

- pointu, allongé $\ldots \ldots \ldots \ldots \ldots \ldots \ldots \ldots \ldots \ldots \ldots \ldots \ldots \ldots \ldots \ldots$. Vichette.

1. LE MYLOBATE MIGLE. - MLLOBATIS AQUILA, C. Dumér.

Poiss. France, t. I, p. 442, fig. 73, anim., fig. 76, dents.

N. vulg. : Mourine, Aigle de mer; Terre ou Tare, Sables-d'Olonne; Nadame, la Rochelle; Terrefranche, île de Ré; Épervier, Arcachon; Mourina, Choncha, Cette; Lancette, Marseille; Ferraza, Nice.

Long. : 0,80 ì 1,50 et plus.

Le disque est variable dans ses proportions. Le dos est bombé au niveau de la ceinture scapulaire. Les ailes ont leur bord antérieur légèrement convexe et le bord postérieur échancré, elles sont falciformes. La queue est très longue, très grêle, presque filiforme après l'aiguillon; elle est excessirement flexible. La peau est lisse et nue. La tête est bombée, large, aplatie en dessus, elle est élevée. Le museau est large, déprimé, à bord antérieur convexe, mince. La bouche est horizontale; les màchoires sont fortes; les dents sont généralement disposées sur sept rangées; la série médiane est composée de dents en forme d'hexagones très développés en travers, de quatre à six fois plus larges que longs, occupant une surface au moins égale à celle que couvrent les autres séries. Les yeux sont grands. Les valrules des narines sont confluentes, à bord postérieur frangé. Les spiracules sont larges. La dorsale est unique, placée en arrière de la fin des ventrales, un peu en arant de l'aiguillon; les ventrales sont courtes, coupées à peu près carrément. Le dard est une espèce de lame étroite, pointue, ayant sur les côtés des dentelures à pointe tournée en avant.

La coloration est variable; le plus souvent le dessus du corps est bronze cuirré, parfois jaunâtre; le dessous est gris blanchâtre, brunâtre ou d'un brun jaunâtre. Parfois, chez les jeunes, il y a des taches blanchâtres.

Habitat. Toutes nos còtes; Manche, assez rare; Ocŕan, assez 
commun sur la cóte de Bretagne, commun de la Loire à la Bidassoa; Múdilerranée, assez commun, Celle, Nice.

2. LA MOURINE VACHETTE. - MYLIOBATIS BOVINA, Geof.-St-Hil.

Poiss. France, 1. I, p. 446.

Long. : 0,80 ì 1,30 .

Le disque a les bords postérieurs plus échancrés que dans le Myliobate aigle. La peau est lisse chez les jeunes, parfois rugueuse chez les grands individus, vers la nuque et sur le dos en arrière. Le museau est plus avancé que dans l'autre espèce; les dents médianes ont huit ì dix tois plus de largeur que de longueur. - La dorsale n'est pas complètement opposée aux ventrales, mais elle est insérée en arrière de la base le ces nageoires.

La teinte est d'un brun verdâtre, quelquefois d'un brun assez foncé.

Habitat. Méditerranée?

\section{Famille des Trygonidés, Trygonidie.}

Corps; disque plus ou moins large, ayant l'extrémité antérieure ou rostrale formée par la jonction des pectorales; queue sans carène latérale, armée le plus souvent d'un, parfois de plusieurs aiguillons à bords latéraux dentelés.

Events larges, en arrière des yeux.

Nageoires; pas de dorsale ni de caudale (dans nos espè̀ces); Cette famille se divise en deux genres.

Quene longue, faisant plus des trois quarts de la longueur du disque...........................

Queue conrte, faisant moins de la moitié de la longueur du disque.........................

1. Pastenague.

2. Ptéroplatée.

\section{GENME PASTENAGUE: OU TIRGON. - PASTINACA VLL TRYGON.}

Corps; disque ì peu près rhomboïdal, assez semblable à celui des Raies; queue longue, faisant plus de trois quarts de la longueur du disque, grèle, armée d'un ou de plusieurs aiguillons, pourvue en 
dessus et en dessous diun repli cutamé qui cesse après un assez court lrajet, ou rui, du moins, ne val pats jusqu'it l'extrémité de la quene.

Tête non dégagée; houche i peine arquée, presque transversale; michoires garnies le dents assez petites, rangées par séries régulières.

Yeux en lessus.

Narines à valvules confluentes, maintenues par un frein médian, à bord postérieur dentelé ou plutòt frangé.

Le genre Pastenague se compose de quatre espèces.

a. Quene armée de boucles.

4. BOUGLÉE.

- lisse................................

h. Extrémité antériemre du disque tronquée, sinucuse... 3. violettr. anguleuse .......... $c$.

c. Longueur de la queue faisant plus d'une fois et demie la longueur da disque........................

Longueur de la queue faisant moins d'une fois et demie la Iongueur du disque.......................

2. BRUCCON.

1. CoMHUNE.

\section{LA PASTENague COMMUNE. - TRYGOA VULGaris, Riss.}

Poiss. Frunce, 1. I, p. 449, fig. 77, michoires, et p. 36\%, fig. 32, utérus. N. vulg. : Terre, Lorient; Terre, Tonare, Touare, Poitou; Tère, Areaclion; Pasténagra, Celte; Pastenaigra. Nice.

Long. : 1,00 à 1,40 et plus.

Le disque est de forme rhomboïdale, d'un cinquième environ plus large que long; les côtés antérieurs, à peu près droits, sont un peu plus longos que les côtés postérieurs; l'angle antérieur est obtus et les angles latéraux ou externes sont mousses. La queue porte eu dessus et en dessous un petit repli cutané, elle est de longueur variable, tantôt plus courte que le disque, tantit plus longue, surtout chez les jeunes animaux; elle est armée d’un aiguillon à peu près semblable à celui du Mỵliobate. La peau est lisse el nue; parfois il y a de petits lubercules pointus sur la ceinture scapulaire et sur le milieu du dos. La tête est engagée dans le disque; le museau est très court; les michoires sont garnies de petites dents squamiformes chez les femelles, légèrement pointues chez les mìles. Les yeux sont de moyenne grandeur; le tapis est d'une teinte cuivée tirant sur le rouge. 
En dessus le disque est d'un gris bleuatre généralement uniforme, parfois d'un gris rougeâtre, assez rarement il est marqué de laches bleuâtres et grisâtres mal dessinćes; en dessous il est d'un blanc grisâtre ou rosé, avec le contour plus ou moins sombre chez les jeunes.

Habitat. Toutes nos còtes; Manche, assez rare; Océan, assez rare jusqu’à la Loire, plus commune au Sud; Méditerranée, assez rare.

\section{LA PASTENAGUE BRUCGON. - TRTGON BRUCCO, Bp.}

Poiss. France, Supplém. p. 10.

Long. : 0,60 à 1,30 .

Son disque a la forme d'un rhombe assez régulier, d'un sixième environ plus large que long; les bords sont légèrement convexes; le profil antérieur, sauf la faible proéminence du museau, dessine une courbe allongée. La queue porte un repli cutané en dessus et en dessous; elle a une longueur à peu près double de celle du disque proprement dit. La peau est lisse et nue. Le museau est court, mousse; la bouche est transversale peu fendue; les dents sont disposées en séries obliques, elles paraissent un peu plus elliptiques que chez la Pastenague commune. Le diamètre de l'œil est moindre que celui de l'évent. Les rentrales semblent continuer le pourtour du disque; le côté externe est d'un tiers environ plus grand que le côté interne.

En dessous le disque est brun verdàtre ou brun cuivré, en dessous il est d’un blanc un peu grisâtre.

Habitat. Méditerranée, Nice, très rare.

3. LA PASTENAgue VIOLETTE. - TRYGON VIOL.ACEA, Bp.

Poiss. France, t. I, p. 449.

Long. : 0,60 à 0,80 .

Le disque est d'un tiers environ moins long que large; son extrémité antérieure est coupée carrément, elle est légèrement sinucuse. La queue porte en dessus el en dessous un repli eu- 
tané; elle est très longue, laisant presque les deux tiers de la longueur tolale, parfois même beaucoup plus. La peau est lisse; il y a seutement, sur le milieu du dos, une sćrie de quelques aiguillons s’étendant jusqu’à la base de la queue. Le nuseau est très court, logé dans l'espèce de retrail que forme le bord antérieur du disque; la bouche est garnie de dents obluses.

En dessus comme en dessous, le disque est d'une teinte violelte plus ou moins foncée.

Habitat. Méditerranée, Nice, excessivement rare.

4. LA P.STENAGUE BOLCLEE. - PASTINACA ASPERA, Bel.

Poiss. F'ance, Supplém. p. 12.

N. vulg. : Ferrassa, Niec.

Long. 0,90 à 1,30 et mème 2,00 .

En dessus le disque porte des épines ou plutôt des espèces de boucles à pointe plus ou moins acérée, disposécs sans ordre, à l'exception peut-être de celles qui se trouvent vers la ceinture scapulaire. La queue est excessivement longue, sa longueur mesurant une fois et demie environ celle du corps; elle est garnie d'un repli en dessus et en dessous; elle est armée en dessus d'un ou de deux aiguillons, ‘ de nombreuses boucles plus ou moins développées. Le museau est légèrement proéminent, un peu pointu; les dents, sur un spécimen d’assez grande taille, forment vingt-sept rangées à la màchoire supérieure et trente-neuf à la mandibule.

La teinte est brunatre en dessus, blanchàtre en dessous.

Habitat. Yice, excessivement rare.

2. GENRE PTÉROPLATÉ. - PTEROPLATEA, Müll, et Henl.

Corps; disque à peu près deux fois aussi large que long; queue très courte, armée d'un ou de plusieurs aiguillons, nue ou à replis 'cutanés fort peu développés.

Tête non dégagée du disque; bouche presque droite; màchoires garnies de petites dents pointues.

Iloneal. - Ichthyologie. 
Yeux en dessus.

Narines ì valvules confluentes.

Une seule espèce.

\section{LA PTÉROPlatée AlTAVELle. - PTEROPLATEA ALTAVELA, Mïll. et Henl.}

Poiss. France, Supplém. p. 14.

N. vulg. : Choucha bastarda, Cette.

Long. : 0,30 à 1,40 .

Le disque présente la figure d'un rhombe très irrégulier ou plutôt d'un triangle à base légèrement courbe, il a deux fois environ plus de largeur que de longueur. La queue est garnie en dessus et en dessous d'un pli cutané; elle est armée d'un ou de deux aiguillons dentelés; elle est fort courte; sa longueur ne fait pas la moitić de la longueur du disque. La peau est lisse et nue. Le museau est très court, obtus. Les màchoires sont munies de rangées très régulières de petites dents triangulaires à pointe excessivement fine. Le diamètre de l'cil est petit; il est d'un tier's, et plus quelquefois, moindre que celui de l'évent. Un tentacule est placé à l'angle postérieur du spiracule.

En dessus le disque est d'un gris jaunàtre assez clair ou d'un gris clair marbré de gris plus foncé; en dessous il est d'un blanc nuancé de brun, parfois d'un blanc mat teinté de rouge clair.

Habitat. Méditerranée, excessivement rare, Nice, Cette.

\section{Ordre des Chimères, Ghimæræ.}

Corps allongé, couvert d'une peau lisse, presque toujours complètement nue; corde dorsale persistante, sans aucune trace de seg. mentation.

Tête libre; museau saillant; bouche petite, ouverte en dessous; lèvre supérieure fendue; màchoires garnies de plaques dentaires; màchoire supérieure soudée aı cràne; mandibule articulée directe. ment à une proéminence crànienne.

Yeux latéraux, pourvus de procès ciliaires. 
Narines rapprochées l'une de l'autre, au-dessus de la bouche.

Oreilles communiquant avec l'extérieur; libyrinthe cartilagineux n'entourant pas complètement l'oreille interne.

Appareil branchial; les branchies sont au nombre de cinq de chaque còté; elles forment à leur partie interne ou profonde yuatre poches distinctes, mais incomplèles, elles sont libres à leur partie externe. Les fentes branchiales sont au nombre de qualre, elles donnent dans une cavité commune qui est recouverte uniquement par la peau et débouche au dehors par une seule ouverture. La première branchie est portée sur la corne de l'hyoüde.

Conservation de l'espèce; la fécondation est interue. Les màles, outre les appendices copulateurs attachés aux ventrales, en portent d'antres qui sont placés en avant de ces nageoires dans une petite poche, d'où ils peuvent sortir au gré de l'animal; ils ont encore, sur la tète, une espèce d'organe particulier, plus ou moins épineux, qui est dans une dépression, en avant des yeux. Les femelles pondent des œufs couverts d'une enveloppe cornée plus ou moins épaisse.

\section{Famille des Chiméridés, Chimæridx.}

Tête à système canaliculé très développé; cràne sans trace de divisions.

\section{Êvent nul.}

Nageoires; pectorales libres; ceinture scapulaire non attachée au cràne; rentrales abdominales, entourant l'ouverture de l'anus; ceinture pelvienne formée, à la région inférieure, de deux pièces distinctes, articulées l'une à l'autre, et non confondues en une barre transversale comme chez les Sélaciens; deux dorsales, la première placée au-dessus des pectorales, munie d'un aiguillon développé; seconde dorsale plus ou moins longue; anale de forme variable.

Vessie natatoire nulle.

\section{GENRE CHIMERE. - CHIMARI.}

Corps nu, comprimé, terminé en prolongement sétiforme.

Téte; museau proéminent, mou, sans cartilages; bouche petite; plaques dentaires développées, plus ou moins striées, deux paires à la màchoire supérieure, une paire à la mandibule.

Appareil branchial; première et cinquième branchie n'ayant qu'une rangée de lamelles respiratoires. 
Ligne latérale bien marquée, soutenue par une série de pièces solides.

Intestin; canal digestif allant presque directement dı pharynx à l'anus, pourvu d'une valvule en spirale, mais n'ayant pas de dilatation stomacale bien marquée, manquant d'appendice digitiforme, non maiıtenu par un mésentère. Anus s'ourrant directement au dehors.

Gavité abdominale ne communiquant pas avec l'extérieur; chacun des orifices placés près de l’anus est l'entrée d'une espèce de cul-de-sac.

\section{LA CHIMÉRE MONSTRUEUSE. - CHIMERA MONSTROSA.}

Poiss. France, t. I, p. 4303 ; fig. 78, partie antérieure de la colonne vertébrale, fig. 79 , anim., fig. 80 , système canaliculé de la tète.

N. vulg. : Rat de mer; Roi des barengs; Cat, Nice, Celte.

Long. : 0,60 à 1,00 .

Le corps est allongé, sa hauteur étant comprise neuf à dix fois dans la longueur totale; il se termine par une queue grèle, très longue, excessirement effilée. Le museau est mou, il s'avance au-dessus de la bouche qui est transversale, élroite. La mâchoire supérieure porte de chaque côté deux plaques dentaires; la mandibule n'a qu'une plaque dentaire sur chacune de ses moitiés. Liveil est très grand; son diamètre fait le tiers environ de la longueur de la tête. Les fosses nasales sont rapprochées l’une de l'autre; il n'existe entre elles qu'une cloison assez mince. Les branchies d'un même côté donnent dans une cavité, qui communique avec l'extérieur par une seule ouverture placée à la partie latérale inférieure de la gorge; la muqueuse branchiale est d'un lilas assez foncé, de même teinte que la muqueuse de la bouche. Le système canaliculé est très déreloppé sur la tête et sur le corps. La première dorsale est avancée; elle commence un peu en arrière de la tête, au-dessus de la pectorale, elle est armée d'une épine forte, dentelée en arrière; la seconde dorsale est rapprochée de l'autre, elle s'étend en arrière jusqu'au lobe supérieur de la caudale à laquelle elle est unie par la base. L'anale est courte; elle prend naissance assez loin des ventrales. La 
caudale semble ètre le prolongement de la seconde dorsale et de lanale; ses lobes restent complètement séparés; les derniers rayons du lobe inférieur paraissent une bordure du filament lerminal. La ceinture scapulaire n'est altachée ni au crìne ni à la colonne vertébrale; les pectorales ont une base très large, épaisse ; elles sont longues, beaucoup plus développées que les ventrales.

La teinte générale est d'un gris argenté nuancé de brun; les nageoires impaires sont d'un gris jaunâtre; elles sont bordées de noir.

Habitat. Méditerranée, assez rare, Nice; très rare, Cette; très rare, Pyrénées-Orientales. Océan?

\section{Section des Ganoides. - Ganoidei.}

Corps présentant de nombreuses différences dans l'ensemble de ses formes. Squelette de structure variable. Peau rarement nue, garnie le plus souvent de pièces dures recouvertes d'une couche d'émail.

Yeux; les nerfs optiques forment un chiasma.

Oreilles ne communiquant pas avec l'extérieur.

Appareil respiratoire; la corne de l'hyoïde ne porte pas de lames respiratoires; les branchies sont libres, logées de chaque còté dans une chambre qui n'a en dehors qu'une senle ouverture, et dont la paroi externe est formée par des pièces operculaires.

Vessie natatoire pourvue d'un conduit pnemmatophore.

Appareil circulatoire; bulbe artériel musculeux et muni de valvules disposées sur plusieurs rangées.

Appareil digestif; intestin arec une ralvule en spirale.

Conservation de l'espèce; organes de reproduction ne communiquant pas directement au dehors, en rapport avec l'appareil urinaire.

\section{Ordre des Sturioniens, Sturiones.}

Cet ordre forme une seule famille.

Famille des Acipenséridés, Acipenseridx.

Corps allongé, en forme de pyramide, porlant sur clıacun de ses angles une série d'écussons, couvert en outre de scutelles dures et 
rudes. Queue hétérocerque. Squelette interne en grande partie cartilagineux; rachis non composé de vertèbres dislinctes. Corde dorsale persistante, sans aucune trace de segmentation.

Tête allongée, couverte de pièces osseuses plus ou moins striées, disposées d'une façon régulière; cràne cartilagineux, exceptè dans sa partie basilaire. Nuseau plus ou moins allongé, pourvu, à sa face inférieure, de quatre barbillons en série transversale; bouche en dessous, loin du bout du museau, protractile, complètement privée de dents; appareil maxillaire attaché au cràne par un suspenseur conmun.

Yeux latéraux, dépourvus de procès ciliaires.

Narines placées en arant de l'œil, ayant chacune deux orifices distincts.

Appareil respiratoire; pas de rayons branchiostèges; opercule ne s'articulant pas avec le suspenseur commun.

Nageoires; nageoires paires ne manquant jamais ; ceinture scapulaire attachée au cràne ou plutòt à la plaque mastoïdienne; pectorales avec un rayon externe développé; ventrales abdominales.

Vessie natatoire très díveloppée, communiquant avec l'œsophage ou plutôt l'estomac.

Appareil circulatoire; péricarde communiquant avec la cavité abdominale au moyen d'un canal uniq̣ue placé sur l'œsophage; cœur et bulbe artériel couverts d'une substance mamelonnée, blanchàtre.

Appareil digestif; œsophage hérissé de papilles; estomac guère plus large que l'œsophage, à muqueuse lisse; appendices pyloriques réunis en masse par du tissu conjonctif.

Gonservation de l'espèce; testicules el ovaires séparés des conduits vecteurs. Les œufs sont petits el très abondants, ils montent parfois au nombre de plusieurs millions.

\section{GENRE ESTURGEON. - ACHEENER, Arted.}

Corps ayant la forme d'une pyramide à cinc faces et dont les angles sont couverts de boucliers osseux; troncon de la queue non complètement enveloppé par les écussons. Anus très reculé, s'ouvrant au niveau du bord interne des ventrales.

Tête couverte de plaques osseuses; museau plus ou moins allongé; bouche transversale, très protractile; quatre barbillons placés sur une rangée transversale, en dessous, entre la bouche et le bout du museau.

Évent plus ou moins arrondi, ouvert sous le bord externe de la pièce temporale. 
Appareil branchial; quatre branchies hyoüdiennes, une branchie operculaire; une branchie de l'évent; pas de rayous branchiostègres.

Nageoires; dorsale unique, reculée, opposée à l'anale; caudale hétérocerque, à bord supérieur relevé; ventrales placées très en arrière.

Pores abdominaux cxternes mettant la cavité abdominale en communication avec l'extériemr.

Le genre Esturgeon est formé de deux espèces.

Dorsale ayant plus de trente-six rayons........ 1. ondinaine.

moins de trente-six rayons....... 2. of Valenciennes.

\section{L'ESTURGEON ORDINAIRE OU COMMUN. - ACIPENSER STURIO, Linn.}

Poiss. France, t. I, 471, fig. 81, anim., fig. 82, plaques de la région supérieure de la tète.

N. vulg. : Gréac, còtes du Poitou et de la Gascogne; Estorjeon, Roussillon; Esturioun, Languedoc, Estidioum, Cette; Esturjhoùn, Estijoùn, Provence; Sturioun, Nice.

Long. : $1, \dddot{30}$ à 2,00 et plus.

Le corps est allongé, sa hauteur est comprise huit à dix fois dans la longueur totale; il a la forme d'une pyramide à cinq pans; la crête dorsale est prononcée; le ventre est aplati en dessous. Les écussons de la série dorsale sont les plus développés: ils sont au nombre de neuf à treize de la plaque nuchale à la plaque de la nageoire dorsale; les écussons latéraux sont en nombre variable de vingt-huit à trente-six; il y a dix à treize écussons ventraux. La tête est longue; sa longueur est comprise quatre fois et demie à cinq fois dans la longueur totale; elle est couverte de plaques osseuses disposées d'une façon régulière; le museau est effilé, pointu; les lèves sont garnies de papilles; entre le museau et la bouche se trouvent quatre barbillons disposés en ligne transversale. Les yeux sont petits. Les narines sont placées en avant de l'ceil sur le còté du museau. La fente des branchies est très longue. La ligne latérale traverse la série des écussons placés sur les flancs... Les nageoires impaires sont précédées de scu- 
telles, d'écussons ou de fulcres; la dorsale est basse, reculée, elle comple une quarantaine de rayons; l'anale qui est opposée à la dorsale est composée de vingt-quatre rayons; le troncon de la queue est très court, il présente la forme d’une pyramide à six faces; la caudale mesure le cinquième environ de la longueur totale; son lobe supérieur est relevé el se termine en pointe allongée; son bord supérieur est couvert de fulcres. Les pectorales ont le premier rayon très développé; les ventrales sont assez petites, reculées.

$$
\text { D. } 38 \text { a } 43 ; \text { A. } 24 \text {; P. } 34 \text {; V. } 25 .
$$

La coloration est d'un gris cendré ou jaunâtre, quelquefois rougeâtre avec des taches grisâtres ou brunes; les flancs ont souvent des roflets argentés.

Habitat. L'Esturgeon est anadrome; au moment du frai, il quitte les mers pour remonter dans les eaux douces; il se trouve sur toutes nos còtes; parfois il est pèché dans nos grands fleuves et mème dans quelques-uns de leurs affluents, l'Yonne, le Doubs, la Saòne.

\section{L'ESTURGEON DE VALENGIENNES. - ACIPENSER VALENCIENNII, A. Iumér.}

Poiss. Frunce, t. III, p. 623 .

Long. : 1,50 à 3,00 .

L'Esturgeon de Valenciennes présente la plus grande ressemblance avec l'Esturgeon commun; les proportions du corps sont les mêmes; les écussons plus développés sont moins nombreux que chez l'Esturgeon commun; ì la série supérieure, ils sont au nombre de neuf entre la plaque nuchale et la plaque dorsale; sur les côtés, il y en a de vingt-quatre à vingtsept; à la rangée abdominale, il s'en trouve de huit à onze avant chacune des rentrales. La tête semble un peu moins developpée que dans l'Esturgeon commun; sa longueur est comprise environ cing fois et demie dans la longueur totale; relativement le museau est assez court; il est arrondi à son extrémité. La dorsale est plus haute que longue, elle compte trente-quatre rayons seulement; lanale et la pectorale ont des 
rayons moins nombreux que dans l'Esturgeon commun; la rentrale est d'un liers environ moins longue que la pectorale.

$$
\text { D. } 3 \text { '; 1. } 21 ; \text { P. } 31 ; \text { V. } 2501226 .
$$

Chez les animaux montés depuis longlemps, la teinte est bruncitre.

Habitat. Dans la collection du Muséum de Paris se trouvent deux spécimens, l'un, mesurant 3,00, a été pèché aux Sables-d'Olonne; l'autre, ayant 1,50 de long, a été acheté par Valenciennes, au marché de Paris, comme provenant de l'embouchure de la Seine (A. Dumér.).

III. - Section des Poissons osseux ou Ichtiyostés. Ichthyostei.

Les Poissons osseux ont un squelette plus ou moins solidifié par le dépòt de sels calcaires, montrant mème assez souvent de véritables ostéoplastes. La colonne rachidienne est formée de vertèbres distinctes; la corde dorsale est persistante, moniliforme. Le cràne est composé de pièces réunies par des sutures. La ceinture scapulaire manque rarement ; elle est généralement attachée au cràne. Les nageoires sont en nombre variable, parfois très réduit. Les branchies sont libres, logées dans une chambre dont la paroi externe est constituée par un appareil operculaire, et par une membrane soutenue par des rayons plus ou moins nombreux. Le bulbe artériel n'est pas contractile, le plus ordinairement il est garni de deux valvules.

Corps présentant les formes les plus variées; queue paraissant plus ou moins symétrique; peau rarement nue, généralement courerte de pièces plus ou moins dures.

Tête ayant un squelette constitué par des pièces nombreuses.

Yeux, le plus souvent latéraux; généralement pourrus d'un procès falciforme et d'une glande choroïdienne ; nerfs optiques ne formant pas un véritable chiasma.

Narines ayant ordinairement deux orifices.

Oreille logée dans la cavité crinienne; il y a le plus sourent trois otolithes.

Appareil respiratoire; battant operculaire composé de plusieurs pièces distinctes, au nombre de quatre le plus souvent : opercule, sous-opercule, préopercule, interopercule; membrane branchiostége soutenue par des rayons articulés sur la corne de l'hyoüde; ares de l'appareil hyoüdien portant sur leur bord externe, généralement 
quatre paires de branchies. Outre les branchies hyoïdiennes, il y a, chez un certain nombre de Poissons, des organes particuliers appelés fausses brunchies ou pseudobranchies.

Vessie natatoire, se trouvant chez beaucoup d'espèces, tantòt pourvue, tantòt manquant de conduit pneumatophore.

Appareil circulatoire ; bulbe artériel élastique mais non contractile, muni généralement de deux valrules.

Appareil digestif ; tube digestif ayant le plus souvent une dilatation slomacale, n'ayant pas de valvule en spirale, s'ouvrant directement au dehor's; souvent fourni d'appendices pyloriques.

Conservation de l'espèce; fécondation presque toujours externe; le plus souvent le testicule ou l'ovaire est pourvu d'un canal vecteur portant au dehors le produit de la sécrétion, qui sort par les conduits péritonéaux, quand le canal vecteur manque; les Poissons osseux sont ovipares à quelques exc.eptions près ; certaines espèces sont ovoviripares.

Les Poissons osseux sont très nombreux ; ils se divisent en quatre ordres :

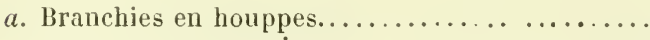

en peignes.................. 1 .

1. LOPHOBRANCHES.

b. Cœur placé en avant de la ceinture scapulaire, qui est presque toujours attaché au cràne....

Ciour placé en arrière de la ceinture scapulaire qui n'est pas attaché au cràne............

c. Maxillaire supérieur fixé à l'intermaxillaire qui forme seul la màchoire..................

Maxillaire supérieur non fixé à l'intermaxillaire, ou formant avec lui la mâchoire............

1. LopHobrancises. $c$.

4. APODES.

2. Plectognathes.

3. Chorignathes.

\section{Ordre des Lophobranches, Lophobranchii, Cur.}

Gorps peu déreloppé, couvert de petits écussons, qui, réunis par séries verticales, forment des amneaux plus ou moins nombreux.

Tête longue; museau tubuleux, ì son extrémité s'ourre une petite bouclie non dentée.

A ppareil branchial; les lamelles respiratoires sont portées sur des tiges très courtes, et enroulées en forme de massues ou de houppes, d'où le nom de Lophobranches donné par Cuvier aux Poissons de cet ordre. La chambre branchiale est grande; à l'extérieur ellè n’a qu'un orifice très étroit pour la sortie de l'eau.

Gœur; bulbe artériel à deux valrules.

L'ordre des Lophobranches comprend une senle famille. 
Famille des Siyngmalhidés, siyngmalhidir.

Corps de forme variable, entouré de pièces dures unies entre elles et formant une espèce de cuirasse ariiculée.

Téte faisant tantòt un coude avec le tronc, tantôt continuant l'axe du corps; bouche à l'extrémitè d'un lube plus ou moins long, à fente presque verticale, non dentée; máchoire supérieure formée par les intermaxillaires et les maxillaires.

Yeux latéraux, arrondis.

Narines placées au devant des yeux, pourvues de deux petits orifices.

Nageoires; dorsale unique; anale peu développée ou manquant; caudale n'existant d'une façon complète que chezles Syngnathiniens; ceinture scapulaire non attachée au crane, mais à la colonne vertébrale et aux anneaux antérieurs; pectorales assez développées chez les Hippocampiniens, les Syngnathiniens, manquant chez les Nérophiniens; rentrales nulles.

Vessie natatoire de forme variable, sans conduit pneumatophore nettement distinct, pourvue de corps rouges.

Conservation de l'espèce; les màles portent les œufs soit dans une poche incubatrice, soit fixés sous leur ventre.

Les Syngnathidés n'ont, qu'un système musculaire excessivement peu développé; ils ne sont, par conséquent, d'aucune utilité au point de vue de l'alimentation.

Cette famille se partage en trois sous-familles.

a. Pectorales bien développées.............. b.

nulles ........................ 3. Nérophingens.

b. Caudale distincte....................... 2. Syngnathiniens.

nulle....................... 1. Hippoganpiniens.

\section{Sous-Famille des Hippocampiniens, Hippocampini, Bp.}

Corps heptagonal en avant, comprimé ; ventre à carène médiane convexe. Queue préhensile, en pyramide quadrangulaire. Angle libre des écussons plus ou moins saillant.

Tête ressemblant à une tète de cheval, inclinée en bas el en avant; museau arrondi.

Nageoires; dorsale unique; anale très petite; pectorales assez développées; pas de caudale. 
GENIR: HPPOCAMPE. - IIPROCAMPUS, CUV.

Corps; tronc heptagonal, raccourci, muni d'une cuirasse formée de douze anneaux, compris les deux anneaux de la ceinture scapulaire.

Tête longue, comprimée, relevée dans la région occipitale qui porte trois tulercules; une épine sur chaque sourcil; une protubérance ippelée épine nasule sur le milieu de l'espace préorbitaire; ces direrses éminences sont garnies souvent d'appendices cutanés.

Yeux assez grands, auxquels, suivant Lyonnet, les animaux peuvent imprimer des mouvements indépendants et regarder en mème temps des oljets placés dans uno direction opposée.

Nageoires; dorsale insérée sur des anneaux plus hauts que les autres, au nombre de trois dans nos espèces, deux appartenant au trone, le troisième à la région caudale; le premier anneau est formé de sept écussons, le second de huit, le troisième de six. Anale pen développée. Pectorales assez grandes.

Vessie natatoire ovale.

Poche incubatrice ayant une petite ouverture ovale placée après l'anale.

N. vulg. : Cheval marin; Chihaon de ma, Biarritz; Cavall mari, Roussillon; Tchival de nar, Tehival marin, Celle; Cavau, Nice.

Le genre Hippocampe eomprend deux espèces.

La longueur du còté externe du triaugle orbito-nasal est à peine égale i la distance qui sépare la protubérance nasale du bout du mnsean........................ plus grande que la distance qui sépare la protubérance nasale du bout du museau.....................

1. MOUCHETÉ.

2. BกÉvinOSTRE

1. IIIPOCAMPE MOUCHETE. - MPPOC.MPUS GUTTULATUS, Cills.

Poiss. Frunce, 1. 11, p. 36.

Long. : 0,10 it 0,1 ', quelquefois 0,16 .

Chez l'llippocampe moucheté, les épines des boucliers sont plus développées el plus pointues que dans l’autre espèce; elles sont généralement garnies d’appendices culanés, surtout celles du trone et des pièces latérales supérieures. La tète est longue ; sa longueur, prise du bout du museau au hord posté- 
rieur de la rommone nuchale, fait plus du cinquiène de la longueur du corps; le museau est régulier, non déprimé a la racine de la protubérance nasale. L’épine nasale est plus saillante que dans l'llippocampe hrévirostre; elle a sa pointe dirigée en avant. La couronne de la pièce nuchale antérieure est large, bordée généralement de ciny luberenles pourvus presque toujours de filaments cutanés plus ou moins allongrés. Les épines sourcilières sont grandes, gammies ordinatrement d'appendices culanés; elles sont séparées des épines mastoïdiennes par une distance moins grande que la longueur du museau.

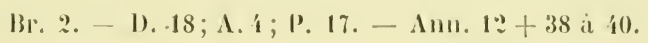

la systeme de coloration est assez variable; il est parfois d’un brun assez foncé, matis le plus souvent grisitue, grris brunâtre, rougeâtre, aver des points ou des lignes d'un blane soil argenté, soit jaunâtre. Là dorsale est grisâtre ou hrunâtre, parfois avec une bande noirâtre et une bordure jaunàtre; l'anale est d'un brun foncé; les pectorales sont hrunâtres.

Habitat. Océan, rare alu Nord de la Loire; moins rare entre la Loire et la Cironde; Arcachon, commun. Méditerrannée, assez commun.

2. L'IIPPOCAMPE BREVIROSTRE UE A MUSEAU COURT. IIPPOC.IMPUS BREVIROSTRIS, Cuv.

Poiss. Frunce, 1. II, p. 38.

Long. : 0,10 a 0,14 , quelquefois 0,16 .

Les épines des boucliers sonl généralement beaucoup plus longues que dans l'autre espèce; les appendices cutanés sont peu développés en général el manquent même assez souvent. - Chez la plupart des animaux, la longueur de la tête ne mesure pas lout à faille cinquiène de la distance qui sépare la couronne nuchale de l'extrémité de la queue. Le bord supérieur du museau est irrégulier, il est creusé ou déprimé à la base de la prolubérance nasale; la longueur du museau est moindre que celle du cóté externe du triangle orbito-nasal; 
protubérance nasale comprimée ì pointe peu développée. La pièce nuchale antérieure a sa couronne de forme variable, souvent sans appendices cutanés. Les épines sourcilières sont grandes, pointues; elles sont séparées des épines mastoïdiennes par un espace égal à peu près à la longueur du museau.

$$
\text { Br. 2. - D. } 17 \text { à } 20 ; \text { A. } 4 \text {; P. } 15 .- \text { An11. } 12+36 \text {. }
$$

La teinte est d'un brun cendré pâle ou d'un brun foncé varié de bleuâtre avec des taches blanchâtres; les individus à teinte pâle sont marqués de bandes ou de raies d'un brun plus ou moins foncé. La dorsale est d'un teint grisâtre chez les jeunes, brune chez les grands individus ; elle est plus foncée en haut avec une bordure d'un blanc jaunâtre qui n'a rien de régulier.

Habitat. Cet Hippocampe se trouve sur toutes nos còtes; Manche, excessivement rare, Boulogne, Dieppe, Granville, Roscoff. Golfe de Gascogne, commun à Arcachon ; moins commun à Biarritz. Méditerranée, assez commun à Cette.

\section{Sous-famille des Syngnathiniens, Syngnathini.}

Corps heptagonal au tronc, hexagonal entre l'anus et la fin de la dorsale, puis finissant en pyramide quadrangulaire. Queue non préhensile, munie d'une nageoire terminale. Ligne latérale du tronc, ou mieux ligne du flanc, tantòt interrompue après l'anneau anal, tantòt continuée par l'angle ou le bord supérieur des anneaux de la queue.

Tête continuant l'axe du corps; museau plus ou moins allongé.

Nageoires ; dorsale, anale, caudale et pectorales.

Vessie natatoire allongée, à peu près cylindrique, pourvue, d'après Francis Day, d'un conduit pneumatophore chez le S. acus.

Poche incubatrice très longue, occupant la plus grande partie de la région sous-caudale, fendue sur toute sa ligne médiane.

Cette famille se divise en deux genres.

Museau à peu près arrondi; anneau scapulaire complet, fermé en dessous par la première pièce impaire. Museau comprimé; anneau scapulaire non fermé en dessous, sans piẻce impaire..................

1. Symgiatie.

2. Siphonostome. 


\section{GENRE SYNGNATIE. - SYNGNATIUUS.}

Corps allongé, plus ou moins anguleux. Le bord supérieur du tronc sarrète vers la fin de la dorsale; en dehors de la nageoire, il forme souvent avec la ligne latérale une espèce de $\mathrm{V}$ allongé ouvert en avant. Anneau scapulaire complet, fermé en dessous par une pièce impaire.

Tête plus ou moins allongée; museau à peu près arrondi, moins élevé que la tète.

Nageoires; dorsale longue, commencant sur le dernier ou l'avant-dernier anneau du tronc, placée sur des anneaux ayant le même niveau que les autres; anale à trois ou quatre rayons; caudale le plus souvent arrondie en éventail; pectorales bien développées.

N. vulg. : Ser dé mar, Cette.

Le genre Syngnathe se compose de sept espèces.

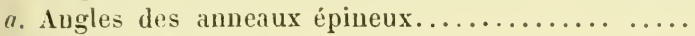
Angles des anneaux non épineux.............

b. Museau faisant moins de la moitié de la longueur

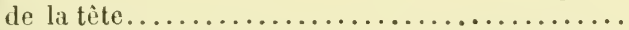

Museau faisant plus de la moitié de la longueur de la tète.................................

c. Dorsale commencant sur le $14^{\mathrm{e}}$ anneau du tronc.. Dorsale commençant après le $15^{\circ}$ anneau du tronc.

d. Sourcil peu prononcé, non continué par une arête en arrière de l'orbite.....................

Sourcil continué en arrière par une arète plus ou

moins prononcée.................... $e$.

e. Dorsale aussi longue, an moins, que l'espace qui sépare le bout du museau du bord supérieur de

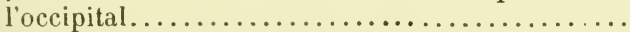

Dorsale moins longue que l'espace qui sépare le mu-

seau du bord supérieur de l'occipital......... $f$.

f. IIauteur du museau comprise 5 à 6 fois dans sa

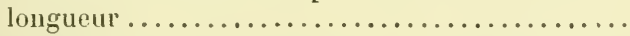

Hauteur du museau comprise 8 fois dans sa lon-

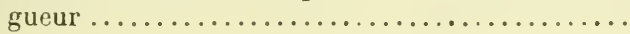

7. PHLÉGON.

b.

6. ABASTER.

c.

d.

5. DE DUUÉRIL.

4. ĖTHON.

1. Aiguille.

2. hovgeatre.

3. TÉNUIROSTRE.

1. LE SYNGNATHE AIGUILLE. - SYNGNATHUS ACUS, Linn.

Poiss. France, t. II, p. 42, fig. 8\%, I, anneau du tronc, II, anneau de la queue.

N. vulg. : Trompette, Vendée; Serpent de mer; Cunate, Bayonne.

Long. : 0,20 à 0,40 et plus. 
Les anneaux sont au nombre de soixante à soixante-deux; il y en a dix-neuf ou vingt pour le trone. - La longueur de li tête est comprise sept fois el demie environ dans la longueur tolale, elle est un peu plus grande que celle de la base de la dorsale chez les adultes, elle est au contraire plus courte chez les jeunes; la nuque est relevée en carène ayant plus de hauteur que le profil du dos; le museau est allongé, il fail, chez les adultes, plus de la moitié de la longueur de la lête, il est d'un tiers environ plus long que l'espace postorbitaire, il est étroit, à peu près arrondi, avec une crète longue, denticulée. La ligne latérale ou plutôt la ligne des flancs est généralement interrompue, elle ne se raccorde pas à la ligne du dos. - La dorsale est portée sur neuf ou dix anneaux; elle commence sur le dernier ou l'avant-dernier anneau du trone; elle compte une quarantaine de rayons; exceplé chez les jeunes, la longueur de sa base est moindre que la longueur de la tête entière.

D. 38 a 41 ; A. 4 ; C. 10 ; P. 12. - Ann. 19 ou $20+40$ à 42.

La teinte est d'un gris jaunâtre avec des bandes transversales plus foncées, d'un gris noirâtre, quelquefois rougeâtre, parfois le dos et les côtés sont traversés par de larges bandes alternativement brunes et d'un gris jaunâtre.

La poche des aufs, très longue, est placée sous vingt-quatre à vingt-cinq anneaux; sa longueur est plus grande que celle du trone.

Habitat. Mauche, assez commun. Océan, assez conmun sur la còte, très commun à Noirmoutiers. Méditerrannée, Cette, assez rare; Nice.

2. LE SYNGNATHE ROUGEATRE. - SYNGNATHUS RUBESCENS, Riss.

Poiss. France, t. II, p. 4t'

Long. : 0,18 i 0,30 .

Le nombre des anneaux est de cinquante-huit à soixante, dont quarante pour la queue, qui mesure à peu près le double de la longueur du tronc. - La tête est beaucoup plus longue 
que la base de la dorsale; sa longueur est comprise six fois et demie environ dans la longueur tolale; le museau est lisse, plus étroit, plus arrondi, plus allongé que dans l'Aiguille, sa longueur fait plus de la moitié de la longueur de la lête, et le double, ou peu s'en faut, de l'espace postorbitaire. - La dorsale est portée sur sept ou huit anneaux; elle commence sur le dernier ou l'avant-dernier anneau du trone; la longueur de sa base est égale, ou peu s'en manque, à la distance qui sépare le bout du museau du bord postérieur de l'orbite.

D. 36 à 38 ; A. 4 ; C. 10 ; P. $13 .-$ Ann. 18 à $20+40$.

La teinte générale est rougeâtre, tirant sur le brun, avec des points blance sur les côtés; parfois il y a des bandes transversales d'un brun plus ou moins foncé, à peu près semblables aux bandes qui se montrent chez l'Aiguille.

La longueur de la poche des cufs est égale ì celle du tronc.

Habitat. Méditerranée, assez commun à Cette, à Nice.

\section{LE SYNGNATHE TÉNUIROSTRE. - SYNGNATHUS \\ TENUIROSTRIS, Rathke.}

Poiss. France, t. II, p. 4 כ̈.

Long. : $0,2 \ddot{\text { à }} 0,3 \ddot{\text {. }}$

Le nombre des anneaux varie de cinquante-huit it solxantedeux; il y en a dix-huit ou dix-neuf au tronc, en comptant l'anneau pectoral. - La longueur de la tête est comprise six fois et quatre cinquièmes à huit fois dans la longueur totale; le museau est très allongé: chez les individus de grande taille, il fait le double el plus de l'espace postorbitaire; il est très mince, sa hauleur est contenue environ huit fois dans sa longueur. Le diamètre de l'œil est compris quatre ì six fois dans la longueur de l'espace préorbitaire; les sourcils sont bien dessinés. - La dorsale est portée sur le dernier anneau du trone et sur les sept ou huit premiers anneaux de la queue; elle est moins longue que la distance qui s'étend du bout du museau au bord supérieur de l'nccipital; elle est, chez les su- 
jets de grande taille, à peine plus longue que le museau, et parfois moins longue.

D. 34 à 38 ; A. 3 ou 4; C. 10 ; P. 13 ou 14. - Ann. 18 ou $19+41$ à 43.

La teinte est brunâtre dans les jeunes, d'un gris jaunâtre ou rougeâtre chez les grands individus, qui portent souvent des bandes transversales d'un brun plus ou moins foncé. L'anale a ses rayons blanchâtres, parfois teintés de noir à leur extrémité; la caudale est brunâtre, bordée de blanc.

Habitat. Méditerranée, rare, Cette.

4. LE SYNGNATHE ÉTHON. - SYNGNATHUS ETHON, Riss.

Poiss. France, t. II, p. 47.

N. vul. : Cavau, Nice.

Long. : 0,12 à $0,1 \%$.

Les anneaux, ayant les angles peu saillants, donnent au corps une forme assez arrondie; ils sont au nombre de cinquantetrois; il y en a dix-sept ou dix-huit au tronc. La quene fait deux fois el plus la longueur du tronc. La ligne latérale parait continue. - La tête est à peu près aussi longue que la dorsale; sa longueur est comprise sept à huit fois dans la longueur totale. La nuque n’est pas relerée; la région occipitale n’est pas bombée et la crête est presque nulle. Le museau mesure à peu près la moitié de la longueur de la tête; il est légèrement comprimé; il a sur le côté, à partir du tubercule nasal, une crête qui est assez prononcée en arrière. L'œil est de moyenne grandeur; le sourcil, peu saillant, est très court, ne débordant pas en arrière le contour de l'orbite. - Généralement la dorsale est portée sur dix anneaux; elle commence sur le dernier nu l'avant-dernier anneau du tronc; elle est à peu près aussi longue que la têle; parfois un peu moins, parfois un peu plus; le nombre de ses rayons est ordinairement de vingt-neuf chez les femelles, de trente chez les mâles.

D. 29 a 31 ; A. 2 ou 3 ; C. 10 ; P. 12 ou 13. - Ann. 17 ou $18+34$ ou 35.

Le dos et les côtés sont d'un verdâtre plus ou moins foncé; le ventre est grisâtre. 
Lit poche incubatrice est placée sous vingt ì vingt-deux anneaux; sa longueur l'emporte sur celle du tronc.

Habitat. Ninche, très rare, baie de Somme. Océan, très rare. Véditerranée, rare, Cette; élang de Berre (je liens de l'obligeance du Prof. Marion plusieurs spécimens de cette espèce, qu’il regarde comme étant identique an S. buceulentus de Rathke, V. Marion, Etude des coun saumatres de Berre, daus C. R. Acall.sc., Paris, 9 mai 1887, p. 1306-1308); Nice. - Le S. ethon, Riss., ne peut ètre rapporté au S. pelagicus, Osbeck, qui a la poche incubatrice d'une Iongueur moindre que celle dı tronc.

\section{:. LE SYNGNATHE DE DUMÉRIL. - SYNGNITHUS DUMERILII, Nob.}

Poiss. France, t. II, p. 49, lig. 86, anim.

Long. : 0,10 a 0,12 .

Le dos est aplati; la queue est légèrement concave en dessous, sa longueur mesure au moins deux fois el demie celle du tronc. Les anneaux sont au nombre de cinquante à cinquantetrois; le trone en a toujours quinze, compris l'anneau scapulaire; la ligne latérale est ordinairement continuc. - La longueur de la tête est contenue sept fois et demie à huit fois dans la longueur totale; les pièces nuchales sont basses, elles ne font pas saillie au-dessus du profil supérieur qui est droit; le museau est plus long que la moitié de la tête; il est assez haut, lógèrement comprimé; il porte en dessus une crète mince; son bord inférieur est anguleux, très étroit. Les yeux sont grands; le sourcil est marqué.

Li dorsale est plus longue que la tête; elle s’étend sur dix ou onze anneaux, dont les deux premiers appartiennent au tronc; clle compte généralement trente-six rayons chez les miles, trente-quatre chez les femelles.

D. 34 it 36 ; A. 3 ; C. $10 ;$ 1. 11 ou 12 - Ann. $15+35$ it 38 .

La coloration est d'un gris brunâtre sur le dos et les côtés, d'un gris blanchâtre sous le ventre; la dorsale est pâle, ainsi que lanale et les pectorales; la caudale est noirûtre.

Habitat. Manche, très rare, le Havre. 
6. LE SYNGNATHE ABASTER. - SYNGNATIUS AB.STER, Riss.

Poiss. France, t. II, p. 50 .

Long. : 0,12 à $0,1 \%$.

Le tronc est assez élevé; sa cuirasse est composée de seize anneaux; la queue en a trente-six à trente-huit; sa longueur fait deux fois et quart à deux fois et demie la longueur du tronc. Les anneaux ont les angles prononcés. La ligne latérale est fort saillante, non interrompue le plus sourent. - La tête est courte; sa longueur, qui est un peu moindre que celle de la dorsale, ne fait que le neuvième de la longueur totale et souvent moins; le museau est comprimé, il ne mesure pas la moitié de la longueur de la tête, il porte, sur le bord supérieur, une crête mince, assez haute, allant de l'espace interorbitaire jusqu'à la mâchoire supérieure et présentant une légère échancrure à sa partie antérieure; une petite crête latérale prolonge la crête du sourcil et va border la crête du museau jusqu’à sa terminaison; la région occipitale est légèrement relevée, elle porte sur le milieu une petite crête, qui est suivie de la crête plus saillante des pièces nuchales. Les yeux sont assez grands ; les sourcils sont relevés, saillants, ils se continuent en arrière par une arête horizontale qui finit sur le côté de la pièce nuchale antérieure. - La dorsale, à peine plus longue que la tête, est portée sur huit ou neuf anneaux, dont le premier appartient au trone; elle paraît avoir un nombre de rayons assez variable; d'après Canestrini, la caudale aurait de six à dix rayons.

\section{32 à 36 ; A. 3 ; C. 10 ; P. 12 ou 13 - Ann. $16+36$ à 38 .}

La teinte est d'un brun rougeâtre, avec des taches ou des bandes verticales tantôt jaunâtres, tantôt blanchâtres, plus marquées sur les femelles que sur les mâles.

Habitat. Méditerranée, rare, Nice. Océan, très rare, Bayonne, la Rochelle. 
LE SYNGNATHE PILLGON. - SYNGNATIUS PIILEGON, Riss.

Poiss. Frunce, t. II, p. ̈̈2.

Long. : 0,14 a 0,20 .

Le corps est fort grêle; le nombre des anneaux varie de soixante-six à soixante-dix-sept; il y en a dix-sept ou dix-huit au tronc. Les angles des anneaux sont excessivement rudes, ils portent plusieurs dentelures assez fines, suivies d'une petite épine. La queue est très longue; elle mesure deux fois et demie à trois fois la longueur du tronc. La tête est à peu près aussi longue que la dorsale; sa longueur est comprise de sept à huit fois dans la longueur totale; la région occipitale est à peine relevée; le museau est étroit, droit, peu comprimé, très allongé, il fait plus de la moitié, parfois les deux tiers de la longueur de la tète. Les yeux sont de moyenne grandeur, les sourcils prononcés, saillants. L'opercule porte sur la moitié antérieure une crète prononcée. - La dorsale s'élend sur douze ou treize anneaux; elle commence sur le dernier ou le plus souvent sur l'avant-dernier anneau du tronc; elle a, suivant Canestrini, de trente-huit à quarante-cinq rayons; je n'ai jamais trouvé une différence aussi grande dans le nombre des rayons; Canestrini compte seulement quatorze rayons aux pectorales.

40 à 42 ; A. 2 ou 3 ; C. 10 ; P. 16 í $18 .-$ Ann. 17 ou $18+48$ à 59.

Le système de coloration est bleuâtre sur le dos, argenté sur les côtés el le venire, d'après Risso ; chez les animaux conservés, le fond parait brunâtre arec des bandes verticales d'un gris tirant un peu sur le jaune.

Habitat. Méditerranée, assez rare, Nice, rare, Marseille, d'où je l'ai recu par les soins du Professeur Marion.

\section{GENRE SIPHONOSTOME. - SIPHONOSTOMA.}

Corps anguleux; dos aplati ou mème légèrement convexe; anneau scapulaire non fermé en dessous par une pièce impaire. 
Tête longue; museau très allongé, très comprimé, très haut, continuant à peu près le profil de la tète.

Nageoires; dorsale longue, commencant sur le dernier anneau du tronc, et s'étendant sur les sept à neuf premiers anneaux de la queue; caudale arrondie ou légèrement pointue.

Ce genre se compose de trois espèces.

$a$. Dorsale plus longue que le museau.............. courte que le museau............. b.

I. TYPHLE.

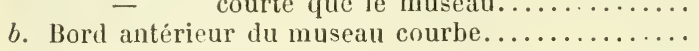

2. ARGENTÉ.

anguleux ...........

3. DE RONDELET.

1. LE SIPHONOSTOME TYPILE. - SYPHONOSTOMA TYPHLE.

Poiss. France, t. II, p. 5ّ̋, fig. 87, tète.

N. vulg. : Anguille vésarde, Charente-Inférieure; Ser dé mar, Celte, ainsi que les deux autres espèces.

Long. : 0,20 à 0,30 .

Les anneaux sont au nombre de cinquante-quatre à cinquante-huit; il y en a dix-huit, quelquefois vingt pour le tronc. - Le crâne est aplati en dessus ou plutôt légèrement concave; la longueur de la tête est comprise cinq fois et trois quarts à six fois el demie dans la longueur totale; le museau est très comprimé, à peine moins haut que le tronc, il porte en dessus une crête qui mesure, en avant, près du tiers de la hauteur du rostre; sa longueur, qui est quadruple de sa hauteur, ne fait pas les deux tiers de la longueur de la tête; la mâchoire inférieure dessine en avant une courbe, ou bien un arc de cercle, dont une ligne passant verticalement par la bouche ferait la corde. Les yeux sont assez grands; les sourcils sont minces, fort saillants, ils se prolongent de chaque côté sur le commencement du museau. La dorsale est placée sur huit à dix anneaux; elle commence sur le dernier anneau du tronc; sa base a une longueur d'un quart ou d'un cinquième plus grande que la longueur du museau; la caudale est généralement anguleuse.

Br. 3. -D. 34 à 40 ; A. 3 ; C. 10 ; P. 14 ou 15 - Ann. 18 it $20+36$ à 38 .

La coloration est d'un gris verdâtre assez foncé, teinté de 
jaune sur les côtés; d’un gris blanchâtre sous le tronc; parfois la teinte générale est brunàtre.

Habitat. Manche, assez rare, Roscoff. Océan, très commun à Noirmoutiers ; commun, île de lié ; moins commun, Sables-d'Olonne, la Rochelle; assez commun, Arcachon : rare, Saint-Jean-de-Luz. Méditerranée, rare à Cette; Nice?

\section{LE SIPHONOSTONE ARGENTÉ. - SIPHONOSTOMA ARGENTATUM.}

Poiss. France, t. II, p. $: 3$, fig. 88 , tète.

Long. : 0,20 à 0,30 .

Le nombre des anneaux varie de quarante-neuf à cinquantetrois; il y en a dix-huit ou dix-neuf pour le tronc. - La longueur de la tète est contenue cinq à six fois dans la longueur totale; le museau est beaucoup moins haut que dans le Typhle, sa hauteur, prise vers le milieu, au point où elle est le plus réduite, mesure à peine le septième de sa longueur, elle égale à peu près le diamètre de l'ceil ; le bord supérieur n’est pas droit, il est au contraire légèrement concave; la longueur du museau fait presque les deux tiers dé la longueur de la tête, le double, et plus, de l'espace postorbitaire; la mâchoire inféricure a le bord antérieur convexe, plus haut que le museau dans sa partie médiane. Les sourcils ne paraissent pas saillants. - La dorsale est placée sur le dernier anneau du tronc et les huit ou neuf premiers rayons de la queue; la longueur de sa base est moindre que la longueur du museau ; la caudale est généralement arrondie en éventail.

D. 33 a 38 ; A. 3 ; C. 10 ; P. 14 ou 15. - Ann. 18 ou $19+33$ ou 34.

La teinte est d'un brun rerdàtre ou jaunâtre sur le dos et les côtés, d'un gris argenté dans la région abdominale.

Habitat. Méditerranée, assez commun à Cette; étang de Berre, par Prof. Marion. 
3. LE SIPHONOSTOME DE RONDELET, - SIPHONOSTOMA RONDELETII.

Poiss. France, t. II, p. 39.

Long. : 0,20 à 0,33 .

Le corps est relativement développé ; le dos est aplati; les anneaux sont au nombre de cinquante-trois à cinquante-huit; la cuirasse du tronc en compte dix-neuf ou ringt. - La tête est plate en dessus; sa longueur est comprise cing fois et demie à six fois dans la longueur totale; le museau est très allongé, sa longueur l'emporte sur celle de la base de la dorsale; à son extrémité il a une hauteur égale à celle de la tête; il est très comprimé, son bord supérieur figure une espèce de crête tranchante; le menton est anguleux, fort saillant; la mandibule n'a pas le contour arrondi, elle forme un angle très prononcé en avant. Il n'y a pas de crête sourcilière. - La dorsale est portée sur huit ì dix anneaux, elle commence sur le dernier anneau du trone, et parfois mème sur la partie postérieure de l'anneau, directement au-dessus de l'anus.

D. 33 à 35 ; A. 4 ; C. 10 ; P. 15 à 17 . Ann. 19 ou $20+34$ à 38 .

Le système de coloration est gris brunâtre, quelquefois olivâtre, parfois encore d'un gris légèrement nuancé de jaunâtre; la tête el surtout le museau sont traversés par des lignes étroites d'un brun très foncé, ces lignes manquent chez certains sujets; la caudale est noirâtre.

\section{Var. - Le Siphonostome pyroïs. - Siphonostoma pyrois.}

Le Siphonostome pyroïs n'est qu'une variété du Siphonostome de Rondelet; il est d'un gris verdâtre plus ou moins foncé sur le dos et sur les côtés, arec des taches blanchâtres; il est d'un blanc argenté, teinté de jaune doré sous le ventre. Le museau est traversé de lignes noiràtres; l'opercule est marqué de traits noirâtres et de points blancs; les nageoires sont grisâtres.

C'est le S. pelagicus, Risso (1cht., p. 63) et nullement le 
S. pelagicus, Osbeck, ainsi que l'indique M. Giglioli, Cat., Pesc. ital., p. 109, n 487.

Habitat. Méditerranée, Nice, assez commun ; Cette, rare. Océan, Arcachon?

\section{Sous-famille des Nérophiniens, Nerophini.}

Gorps à peu près lisse, moins anguleux que chez les Syngnathiniens; tronc allongé, se continuant, sans ligne de démarcation bien sensible, avec une queue grèle, effilée, préhensile.

Nageoires; une seule nageoire développée, la dorsale, qui est opposée ì l'anus; pas d'anale, pas de pectorales; caudale nulle ou rudimentaire.

Poche incubatrice nulle; œufs altachés sous le ventre, en avant de l'anus, chez les màles, qui ont la région abdominale plus aplatie que les femelles.

Les Nérophiniens portent à Cette le nom de Ser dé mar.

La sous-famille des Nérophiniens se compose de deux genres.

Nageoire eaudale rudimentaire, ou dorsale portée sur 11 à

18 anneaux dont les trois ou quatre derniers appartiennent

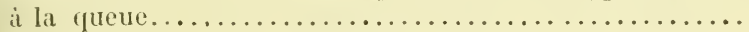

Nageoire caudale nulle; dorsale portée sur 7 a 11 anneaux

dont les deux ou trois premiers appartiennent au tronc. 2. Néropms.

1. GENRE ENTELURE. - ENTELURUS, A. Dumér.

Nageoires; caudale rudimentaire à rayons plus ou moins enveloppés par la peau (elle est fragile; elle parait manquer parfois chez les màles, au moins dans l'Entelure de mer, suivant A. Duméril); dorsale longue, placée sur onze à treize anneaux, dont les trois ou quatre derniers appartiennent à la queue.

Ce genre comprend deux espèces d'après la plupart des ichthyologistes, une seule suivant quelques autres.

Rayons de la caudale au nombre de six........... 1. DE MER.

cinq........... 2. SERPENTIFORME.

\section{L'ENTELLRE DE MER. - ENTELURUS EOUOREUS.}

Poiss. France, t. II, p. 62.

Long. : 0,30 ì 0,30 , quelquefois 0,60 . 
Le tronc est octogone; les angles latéraux sont peu prononcés; le ventre est aplati chez les mâles, il présente chez les femelles une carène assez saillante. La queue fait suite au tronc sans ligne de démarcation bien sensible. - La tête n'est pas relevée en arrière; sa longueurest contenue douze fois et demie à treize fois dans la longueur totale. Le museau ne mesure pas tout à fait la moitié de la longueur de la têle. - La dorsale compte une quarantaine de rayons; les cinq ou six derniers rayons sont placés sur les trois premiers anneaux de la queue. La caudale a six rayons enveloppés dans la peau mais distincts.

D. 38 à 40 ; C. $6 .-$ Ann. 28 à $30+68$ à 70 .

Chez les adultes, la coloration est gris olivâtre sur le dos et des flancs, gris jaunâtre sous le ventre, avec des bandes verticales argentées à bordure noire; après l'anus, les bandes sont moins brillantes; en arrière de la dorsale, elles deviennent peu distinctes, et même finissent par disparaître. Chez les jeunes, les bandes verticales sont moins marquées, le système de coloration est plus uniforme. Une ligne rougeâtre s'étend du museau à l'orbite et de l'orbite au bord supérieur de l'opercule.

Habitat. Manche, assez rare, le Tréport, le Havre, Cherbourg, Granville; assez commun à Roscoff. Océan, assez rare à la Rochelle ; assez commun à Arcachon.

\section{LENTELURE SERPENTIFORME. - ENTELURUS ANGUINEUS.}

Poiss. France, t. II, p. 63.

Long. : 0,20 à 0,30 .

Bien que présentant une grande ressemblance avec le précédent, l'Entelure serpentiforme s'en distingue par certains caractères. Le corps est très effilé, excessivement grêle. - La lête est plus allongée que dans l'Entelure de mer; sa longueur est contenue onze fois et demie à douze fois dans la longueur totale; le museau mesure au moins la moitié de la longueur de la tête. - La dorsale est portée sur huit anneaux du corps 
ef trois ou quatre anneaux de la queue; elle commence sur la fin du premier tiers de la longueur totale. La caudale a cing rayons seulement.

$$
\text { D. } 38 \text {; C. } 5 .- \text { An11. } 28 \text { ou } 29+6 \text { t á? }
$$

La coloration est à peu près uniforme, tantôt d'un vert jaunatre ou olive, devenant plus clair sur le bord des anneaux, tantòt d'un brun foncé, passant au grisâtre sur les côtés. Une ligne rougeâtre va du museau à l'opercule, elle est interrompue au niveau de l'ceil.

Habitat. Manche, assez commun à Roscotf. Océan, assez commun. Méditerranée, assez rare, Nice.

\section{GENRE NÉROPHIS. - NEROPHIS, Raffin.}

Nageoires ; caudale absolument uulle, sans aucun vestige de rayons; dorsale de longueur variable, placée sur sept à onze anneaux dont les deux ou trois premiers appartiennent au tronc.

Le genre Nérophis se compose de trois espèces.

a. Museau faisant le tiers seulement de la longueur de la tête, excavé en dessus...................

Iluseau faisant plus du tiers de la longueur de la

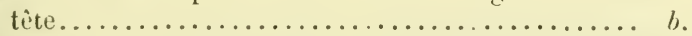

o. Musean à peu près arrondi, à bord supérieur sans

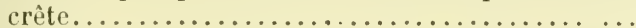

Iluseau comprimé, haut, aver, une crête sur le bord supérieur............................

I. LOMBRICUIDE.

3. ANNELÉ.

2. OPIILION.

\section{LE NÉROPHIS LOMBRICOIDE OU LOMBRICIFORME. NEROPHIS LUMBRICIFORMIS, Bp.}

Poiss. France, t. II, p. 6ö, fig. 90 anim.

Long. : 0,10 à 012 , quelquefois 0,15 .

Chez les femelles, le tronc est à peu près arrondi; il est aplati sous le ventre, chez les màles; la queue est eftilée, légèrement comprimée à son extrémilé, elle fait les deux tiers de la longueur totale. Les anncaux sont au nombre de soixantehuit à soixante-douze; il y en a dix-huit ou dix-neuf au trone. L'anus est placé sous le tiers antérieur de la dorsale. - La 
têtr est de mème hauteur que le trone; sa longueur est comprise treize à quatorze fois dans la longueur totale; le museau est très court, ramassé, excavé dans le milieu de son bord supérieur, il est moins élevé que la tête dont il mesure à peu près le tiers de la longueur. - La dorsale est portée sur deux anneaux du tronc et cinq de la queue; elle est un peu plus longue que la lète.

$$
\text { D. } 25 \text { ou } 26 \text {. - Anu. } 18 \text { ou } 19+50 \text { à } 53 \text {. }
$$

Ce Nérophis est d'un gris verdâtre foncé, coupé de lignes obliques formant une espèce de rayure plus ou moins bien dessinée.

Habitat. Còtes de l'Ouest; Manche, très rare. Océan, très rare au nord de la Loire; Vendée, très commun aux Sables-d'olonne; Charente-Inférieure, assez rare, la liochelle ; Gironde, rare, Arcachon.

\section{LE NÉROPHIS ANNELE. - NEROPHIS A NNULATUS.}

Poiss. France, t. II, p. 66.

N. vulg. : Cavau, Bisson, Nice.

Long. : 0,20 à 0,30 .

Le corps est légèrement fusiforme; il est à peu près arrondi, excepté sous le ventre et sur le dos, en arrière de la dorsale, ces régions sont faiblement aplaties. La tète est un peu moins haute que le trone; sa longueur est comprise seize à dix-sept fois dans la longueur tolale; le museau est moins haut que la tête, il est à peu près arrondi, il n'a pas de crête sur le bord supéricur; sa longueur est comprise deux fois et demie environ dans la longueur de la tète. - La dorsale a de vingt-cinq à trente rayons.

$$
\text { D. } 25 \text { à } 30 .-A n n . ~ 21 \text { ou } 22+70 \text { ou } 71 \text {. }
$$

Le système de coloration est très variable; le corps est d'un brun verdâtre, quelquefois gris rougeâtre, avec des taches oblongues jaunàtres à bordure noire; cestaches, en se rapprochant, forment des espèces de bandes ou d'anneaux plus complets vers la fin de la queue. Une courte bande jaunâtre, bordée 
de noir, s'étend de l'oxil à l'orifice branchial; une autre hande de mème couleur descend, en arrière de l'wil, sous la grorge; une troisième bande de teinte semblable entoure l'extrémité postérieure des pièces opereulates.

Habitat. Méditerranée, Nice, asez rare.

\section{LE NÉROPHIS OPHIDION. - NEROPHIS OPHIDION.}

Poiss. France, t. II, p. 68.

Long. : 0,20 à $0,2 .:$.

Chez l'Ophidion, le nombre des anneaux est de quatre-ringtquinze à cent; il y en a de trente ì trente-trois pour le tronc. Le corps est allongé et très grêle; l’anus est sous le tiers antérieur de la dorsale. - La tète est de même hauteur que le trone; sa longueur est contenue quinze à dix-huit fois dans la longueur totale; le museau est droit, à peine moins haut que la tìte, légèrement comprimé; il a le bord supérieur et le bord inférieur minces, anguleux; sa longueur ne fait pas tout à fait la moitié de la longueur de la tête. - La dorsale s'étend sur dix ou onze rayons, dont sept ou huit appartiennent à la queue.

$$
\text { D. } 35 \text { à } 38 .- \text { Ann. } 30 \text { à } 33+62 \text { à } 67 \text {. }
$$

La coloration est d'un vert bleuâtre, à reflets métalliques, sur le dos et les flanes, d'un vert jaunâtre sous le ventre; les parties latérales inférieures sont marquées de points arrondis d’un blanc jaunâtre ou azuré ; la tête est bleuàtre.

Habitat. Manche, très rare. Océan, rare entre la Loire et la Gironde; assez commun, Arcachon. Méditerranée, Nice, assez rare.

\section{Ordre des Plectognathes, Plectognathi, Cur.}

Corps de forme variable; peau quelquefois nue, mais le plus ordinairement couverte de pièces dures, épaisses, souvent rudes, épineuses. Système osseux assez peu développé, peu consistant; colonne rachidienne réduite à un petit nombre de vertèbres; còtes petites ou manquant. 
Tête peu distincte lu corps; bouche étroile; maxillaire supérieur uni solidement à l'iutermaxillaire; dents tantòt séparées les unes des autres et peu nombreuses, tintòt soudées entre elles et figurant une espèce de bec.

Appareil branchial ; fente des ouies étroite; branchies pectiniformes; pièces operculaires et rayons branchiostèges engagés dans la peau.

Nageoires; ventrales manquant on bien anormales, incomplètes; autres nageoires plus ou moins développées; ceinture scapulaire attachée au cràne.

Vessie natatoire, existant dans la plupart des Plectognathes, dépourvue de conduit pneumatophore

Appareil digestif; canal intestinal sans appendices pyloriques. Cet ordre comprend deux sous-ordres.

Dents soudées; màchoires en bec de Perroquet....... 1. Granodontes. -.. séparées et distinctes.................... 2. ScLÉrodermes.

\section{Sous-ordre des Gymnodontes, Gymnodontes, Cuv.}

Tête; màchoires garnies d'une substance d'ivoire, divisée intérieurement en lames, dont l'ensemble représente comme un bec de Perroquet, Cuv.; ce bec est très solide, ì bords tranchints.

Nageoires: dorsale unique; anale, candale, pectorales plus ou moins développées; pas de ventrales.

Ce sous-ordre se compose de deux familles :

Màchoires ayant une division mėdiane.......... 1. TÉtraodontuÉs.

- sans division médiane............... 2. Orrhagoriscidés.

\section{Famille des Tétraodontidés, Tetraodontidx.}

Corps assez allongé, mais pouvant se boursoufler par le refoulement de l'air dans une espèce de poche qui communique arec l'œsophage : queue distincte; peau le plus souvent hérissée d'épines sur une étendue plus on moins considérable, se redressant par l'effet de la dilitation du corps.

Tête; màchoires ayant l'une et l'autre une division médiane et paraissant aroir deux dents chacune.

Appareil branchial; trois paires de branchies; cinq rayons branchiostèges.

Vessie natatoire grande à deux lobes. 
GENRE PROMÉCHCEMALL. - PROMECOCEPHALUS, Bibron.

Caractères du genre d'après Bibron:

Narines en forme de cupule recouverte d'une peau molle, un peu distendue et percée de deux orifices artondis.

Des épines sur la tète, le dos et le rentre, ou bien seulement sur cette dernière région.

Epiptère et hypoptère courtes, pointues; uroptère à rayons externes plus longrs que les autres.

LE PROMÉCOCEPHALE LAGOCÉPHALE. - PROMECOCEPHALUS LAGOCEPHALUS, Bibron.

Poiss. France, 1. 11, p. 72.

Long. : 0,20 is 0,60 .

Le profil supérieur est presque droit; le profil inférieur est convexe de la tête à l'anale; la peau du ventre est plissée, garnie de quinze à vingt rangées longitudinales d'aiguillons à base étoilée. - La tète est forte, à profil antérieur légèrement arrondi; les màchoires sont avancées, recouvertes d'une substance éburnée, séparée en deux parlies sur chacune d'elles et figurant ainsi quatre dents; les yeux sont grands; les narines sont plus rapprochées de l'orbite que du bout du museau. La dorsale est au-dessus et un peu en avant de l'anale; elle est triangulaire avec le bord postérieur légèrement échancré ; l'anale est semblable à la dorsale; la caudale est échancrée; la pectorale a sa longueur comprise cinq fois et demie à six fois dans la longueur totale, et, d'après Bibron, elle a les rayons supérieurs une fois au moins plus longs que les inférieurs.

$$
\text { D. } 11 \text { i } 14 \text {; A. } 10 \text { i } 12 \text {; C. } 6 \text { ou } 7 \text {; P. } 14 .
$$

La teinte est ardoisée ou bleuâtre sur le dos, blanchâtre ou gris perle sur les flanes et le ventre; les jeunes portent généralement sur le ventre des taches arrondies d'un brun plus ou moins foncé et ordinairement, d'après Bibron, de largesbandes foncées en travers du dos.

Habitat. Océan, excessivement rare, Arcachon, Noirmoutiers. 


\section{Famille des Orthagoriscides, Orlhagoriscidie.}

Corps tronyué en arrière, laut, comprimé; peau couverte de tubercules ou de scutelles, parfois hérissée d'épines chez les jeunes, dure, épaisse, non extensible.

Tête; bouche petite; màchoires sans séparation médiane.

Appareil branchial ; quatre paires de branchies; une branchie accessoire.

Nageoires; dorsale et anale hautes, reculées vers la caudale à laquelle elles sont plus ou moins unies; pas de ventrales.

Vessie natatoire nulle.

\section{GENRE ORTIAGORISQUE. - ORTIIAGORISCUS.}

Caractères de la famille :

Longueur du corps faisant une fois et demie la hauteur..... 1. MOLE. deux fois au moins la hauteur... 2. овLoxa.

1. LORTHAGORISQUE MOLE. - ORTHA GORISCUS MOLA, Schneid.

Poiss. France, t. II, p. 74.

N. vulg. : Lune, Poisson lune, Lune de mer, còtes de l'Ouest; Lune d'argent, Bayonne; Bot (outre), Roussillon; Mola, Cette; Muola, Nice.

Long. : 0,30 à $1, \ddot{30}$ et plus.

Ce singulier animal présente des formes variables suivant l'àge; dans les adultes, le corps est ovale, la hauteur est contenue une fois et demie dans la longueur; chez les jeunes, la longueur est à peine plus grande que la hauteur ; chez les très jeunes, les deux diamètres sont égaux et le corps présente l'aspect d'un disque régulier; le dermosquelette est très dur, rude. - La tête est peu distincte du trone; la bouche est petile; les mâchoires sont d'une seule pièce, sans trace de séparalion médiane; les yeux sont petits, arrondis, rapprochés du profil supérieur de la tête. L'ouverture des ouïes est très petite, au devant de la base de la pectorale. La dorsale et l'anale sont pointues, très haules, presque triangulaires; la caudale est courte, arrondie, occupant toute la hauteur du tronc 
entre la dorsale et l'anale; les pectorales sont peu développées, elles sont arrondies.

$$
\text { Br. 5. - D. } 16 \text { i } 18 ; \text { 1. } 15 \text { a } 17 \text {; C. } 12 \text { a } 16 \text {; P. } 12 .
$$

Le dos est grrisitre; les côtés sont d'un éclat argenté très vil. Les nageoires sont hruntitres.

Habitat. La Mole se trouve sur toutes nos còtes; mais elle est toujours assez rare.

2. LORTHAGORISQUE OBLONG. - ORTHIGORLSCUS OBLONGUS, schneid.

Puiss. France, t. II, p. 7\%.

Long. : $0, i 0$ à 0,70 .

Le eorps a une longueur double au moins de sa hauteur; il est couvert d'une peau épaisse qui présente l'aspect d'une mo. saïque formée de petils segments polyédriques plus ou moins lisses. La tète est plus longue que dans la Mole; le museau est aussi plus étroit; les yeux sont arrondis; les narines sont à peu près au milieu de la distance qui sépare l'oeil du museau; la l'ente des ouïes est ovale, très roisine de la base de la pectorale. - Les nageoires impaires sont moins déreloppées que dans l'iutre espèce; la caudale est moins haute que l'exirémite du trone; les pectorales sont assez longues, triangulaires.

Le dos estbrunatre à rellets argentés; les côtés et le ventre sont d'un gris argenté.

Habitat. Toutes nos còles, mais excessivement rare; Manche; Océan, la Rochelle; Méditerranée, Nice.

\section{Sous-ordre des Sclérodermes, Sclerodermi.}

Corps de forme variable, couvert de scutelles rudes ou de plaques osseuses.

Tête développée; museau plus ou moins arancé; bouche petite, dents séparées.

Vessie natatoire grande.

Cet ordre se compose de deux familles:

Iloreau. - Ichthyologie. 


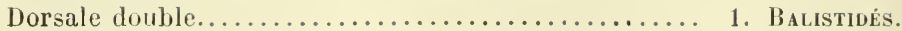

unique......................... Ostracionidés.

\section{Famille des Balistidés, Balistide.}

Corps ovale comprimé, couvert de pièces rudes; dix-sept ou dixhuit vertèbres.

Tête léveloppée; museau avancé; bouche petite.

Nageoires; deux dorsales, la première épineuse.

GENRE BALISTE. - BALISTES, Linn.

Tête; dents plus ou moins aplaties, sur deux rangées à la màchoire supérieure, sur une seule rangée à la mandibule.

Appareil branchial; fente des ouïes très étroite, au-dessus de l'articulation de la pectorale; quatre paires de branchies; os pharyngiens dentés.

Nageoires; première dorsale courte, à trois épines articulées sur une grande pièce osseuse; seconde dorsale longue, opposée à l'anale; caudale de forme variée; pectorales peu développées; pas de ventrales complètes; os pelvien portant à son extrénité uṇe pièce épineuse suivie d'un repli de la peau soutenu par de petits aigruillons.

\section{LE BALISTE GAPRISQUE. - BALISTES CAPRISCUS.}

Poiss. France, t. II, p. 79, fig. 91 inim.

N. vulg. : Fanfré, Nice; Porquet, Triocha, Cette; Purcell, Pyrénées-Orientales.

Long. : 0,15 à 0,33 , quelquefois 0,40 .

Le corps est ovale, très comprimé, couvert d'une peau rude ou plutôt d'une espèce de cuirasse formée de pièces losangiques, étroites, dures, souvent garnies de tubercules épineux; les vertèbres sont au nombre de dix-huit, $7+11$. - La tête est haute; elle est, comme le corps, garnie de scutelles losangiques; la màchoire supérieure est munie de deux rangées de dents appliquées l'une contre l'autre; les dents de la rangée externe sont au nombre de huit; les deux dents antérieures sont généralement un peu plus longues que les aulres; elles sont très rapprochées et semblent former une espèce de bec 
pointu correspondant ì celui de la mandibule qui a huit dents sur une seule rangée; les dents sont assez larges, plus ou moins coupantes; les yeux sont petits; les narines sont rapprochées de l'ceil; l'ouverture des ouïes est réduite à une petite fente placée en avant et au-dessus de l'insertion de la pectorale; les os pharyngiens portent des dents pointues. - La première dorsale a trois rayons épineux articulés sur une pièce allongée; la seconde dorsale est longue, opposée à l'anale; la caudale présente de grandes différences dans sa forme suivant le développement des animaux, elle est arrondie chez les jeunes sujets, d̀ peu près carrée chez les sujets de moyenne taille, en croissant chez les spécimens de grande taille; les pectorales sont peu développées; l'os pelvien porte à son extrémité postérieure une pièce mobile, courte, terminée par des pointes ou des dentelures, cette pièce est unie par un prolongement cutané à une série d'épines soutenant une membrane qui se continue jusqu à l'anus.

Br. 6 ou 7. - D. 3 - 27 ou 28 ; A. 23 à 27 ; C. 10 à 12; P. 14.

La coloration est d'un gris brunâtre teinté de jaune et de bleu, parfois d'un brun violacé; quelques sujets portent sur le corps et les nageoires verticales des taches bleues, jaunes, noiràtres.

Habitat. Méditerranée, rare, Nice, Marseille, Cette; PyrénéesOrientales. Océan?

\section{Famille des Ostracionidés, Ostracionida.}

Corps enfermé dans une espèce de carapace qui ne laisse de libre que le tronçon de la queue. Cette cuirasse, formée de pièces osseuses polygonales, tuberculeuses, soudées les unes aux autres, est tout à fait inflexible; elle est percée de plusieurs ouvertures qui laissent aux organes la faculté de se mettre en rapport avec le monde extérieur. La queue, les nageoires, la membrane des ouïes, la bouche et les yeux ont seuls conservé leur mobilité. Les vertèbres du tronc sont soudées et immobiles, mais restent distinctes.

Nageoires; dorsale unique, sans rayons épinenx; pas de ventrales.

Vessie natatoire sans conduit pneumatophore. 
GENRE COFFRE. - USTRACION, Lim.

Corps de forme variable, polyédrique, a face abdominale aplatie. Tête a profil déclive; bouche pelite, lèvres mobiles plus ou moins épaisses; maxillaire supérieur très réduit, soudé a l'intermaxillaire, dents coupantes ou pointues, sur une seule rangée ì chaque màchoire.

Yeux recouverts par la peau; sourcil plus ou moins saillant.

Narines a double orifice; en avant des yeux, dans une petite fossette.

Appareil branchial, ouverture des ouies étroite, verticale.

Nageoires; une dorsale reculée au-dessus de l'anale; une caudale, des pectorales.

Le genre Coffre comprend deux espèces :

Carapace à cinq arêtes; pas d'épine sur l'arête abdominale. 1. A BEc. Carapace à trois arêtes; une épine sur l'arête abdominale. 2. Trigone.

1. LE COFFRE A BEC. - OSTRACION NASUS, bloch

Poiss. France, t. 1I, p. 83 .

Long. : 0,20 à 0,30 .

Les faces litérales et la face inférieure sont planes; la région supérieure est relevée par une crète médiane courbe allant de la tète à la dorsale en sorte que la carapace présente cinq arêtes distincles; l'arête abdominale n'est pas armée d'épine. La hase de la dorsale est entourée par la carapace, qui forme en arrière un bouclier sur le tronçon de la queue. La tête est forte; la cuirasse fait au-dessus de la bouche une saillie plus ou moins prononcée, comme un nez, un bee conique. La dorsale est au-dessus et un peu en avant de l'anale.

$$
\text { D. } 9 \text { ou } 10: \text { A. } 9 \text {; C. } 10 ; \text { P. } 10 .
$$

Sur la carapace et le troncon de la queuese voient des taches noirâtres, arrondies, assez larges.

Habitat. Méditerranće, excessivement rare, Nice, Risso. 
2. LE COFFrE TRIGONE. - OSTRACION TRIGONUS, Linn.

Poiss. Frunce, t. II, p. S'.

N. vulg. : Coffre, Nice, Riss.

Long. : 0,20 à $0, \dot{4} 0$.

La carapace est triangulaire; la crête du dos est mince; les crêtes abdominales, très prononcées, portent l'une et l'autre, un peu avant la base de l'anale, une épine très développée à pointe dirigée en arrière. La tête est assez forte; l'ouverture rostrale de la carapace est un peu plus haute que large. La dorsale n'est pas complètement entourée par la carapace, qui se termine en formant, à la base de la nageoire, une échancrure à peu près fermée en arrière parl lécusson isolé du troncon de la queue. La caudale est tantôt arrondie, tantrit échancrée, de forme variable probablement suivant l'àge des sujets.

$$
\text { D. } 10 ; \text { A. } 10 \text {; C. } 10 \text {. }
$$

La coloration est d'un grris foncé ou d'un grris jaunâtre, avec des taches blanches dispersées sans régularité.

Habitat. Méditerranée, accidentellement, Nice, Risso.

\section{Ordre des Chorignathes, Chorignathi.}

Corps de forme variable; peau assez rarement nue ou tuberculeuse, généralement couverte d'écailles à bord postérieur lisse ou dentelé, écailles cycloüdes ou clénoüles.

Tête ; intermaxillaire et maxillaire supérieur distincts, non soudés l'un à l'autre, excepté dans la sous-famille des Béloniniens ; màchoires le plus souvent dentées.

Appareil branchial ; pièces operculaires ordinairement au nombre de quatre: opercule, sous-opercule, préopercule et interopercule; membranc et rayons branchiostèges plus ou moins développés; os pharyngiens le plus souvent dentés.

Vessie natatoire existant chez un assez grand nombre d'espèces, tantòt pourvue, tantòt privée de conduit pneumatophore.

Appareil digestif; canal intestinal ayant généralement une dilatation plus ou moins grande, l'estomac; souvent muni d'appendices pyloriques. 
Conservation de l'espèce; fécondation presque toujours externe; ovoviviparité très rare.

L'ordre des Chorignates se divise en deux sous-ordres; dans le premier, les rayons, soutenant la partie antérieure du lophioderme ou du repli de la peau qui forme les nageoires du dos et de l'anus, sont simples et épineux, ils sont mous et arliculés dans le second.

Dorsale et anale à rayons antérieurs simples et épinenx ............................. 1. Acantiloptér YGiens. Dorsale et anale à rayons mous et articulés...... 2. MaLAcoptértgiens.

\section{Sous-ordre des Acanthoptérygiens, Acanthopterygii.}

Nageoires; les rayons de la première dorsale et de la première anale, quand il y en a plusieurs, ou les premiers rayons de la dorsale et de l'anale, sont simples, plus ou moins épineux; les ventrales manquent rarement, elles ont presque toujours un premier rayon épineux, elles sont variables dans leur position; les os du bassin sont ordinairement en rapport avec ceux de la ceinture scapulaire.

Vessie natatoire manquant assez souvent; quand elle existe elle est dépourvue de canal pneumatophore, excepté chez le Saurel, Caranx trachurus.

Les Acanthoptérygiens se divisent en trois tribus, suivant la position des ventrales.

Ventrales placées en avant des pectorales........... 1. Juguinires. au-dessous des pectorales.......... 2. Thoracigues. en arrière des pectorales.......... 3. Aвbominaux.

Quelques Acanthoptérygiens sont privés de rentrales, ce sont de faux Apodes; ces nageoires manquent à toutes les époques de la vie ou seulement chez les adultes. En tout cas, il est facile de voir à quelle famille appartient chacun de ces faux Apodes; la candale n'existe pas chez le Trichiure (Trichiuridés), elle est arrondie chez l'Anarrhique (Blenniidés), elle est fourchue chez le Stromatée, en croissant chez l'Espadon (Scombridés).

\section{TRIBU DES ACANTIOPTÉRYGIENS JUGULAIRES. ACANTHOPTERYGIJUGULARES.}

Cette tribu se compose de cinq familles :

a. Pectorales non pédiculées.................. b.

Pectorales pédiculées..................... $d$. 
b. Préopercule de forme ordinaire............

Préopercule avec un prolongement postérieur,

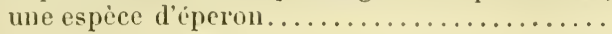

c. Ventrales a six rayons; deux dorsales..........

3. Cinchovymins.

d. fre dorsale i rayons antérieurs isolés sur la tête. unis par une membrane...

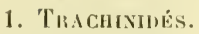

2. BLENNHUÉs.

4. LopHIIDÉs.

5. Batвachí:s.

1. Famille des Trachinidés, Trachinidie.

Corps allongé, couvert d'écailles lisses, peu développées, formant des espèces de handes obliques, parallèles.

Tête; museau court; màchoire supérieure moins avancée que la mandibule; dents sur les michoires, le vomer, les palatins.

Appareil branchial; ouïes largement fendues; six rayous branchiostèges; pseudobranchies.

Ligne latèrale hien marquée.

Nageoires; deux dorsales, la première épineuse el courle, la seconde plus ou moins longue, opposée à l'anale; caudale coupée carrément ou légèrement échancrée; ventrales jugulaires, à six rayons, un épineux et cinq mous.

Vessie natatoire nulle.

Appendices pyloriques en nombre variable.

La famille des Trachinidés se compose de deux genres:

Tête cuboïde, cuirassée en partie............... U. Unaxoscope.

- comprimée, non cuirassée............... 2. ҮHE.

1. GENRE LRANOSCOPE. - URANOSCOPUS, Linn.

Corps plus ou moins cunéiforme, couvert d'écailles lisses tris petites.

Tête grosse et large, aplatie en dessus, en partie cuirassée; museau très court; bouche à fente verticale; dents sur les màchoires, le vomer, les palatins.

Yeux placés à la région supérieure de la tète, dirigés en haut.

Appareil branchial; fente des ouïes très grande.

Nageoires; deux dorsales, la première à rayons peu nombreux; pectorales grandes.

Appendices pyloriques; au nombre de onze le plus souvent dans notre espèce. 
LIRANOSCOPE RAT. - TRINOSCOPUS SCIBER, Linn.

Poiss. France, t. I, p. 90, fig. 92, anim.

N. vulg. : Muou, Nice, Rascasse blanche, Responsadoux, Rat, Pro- vence et Languedoc; Bioou, Cette; Rat, Roussillon; Rose, Oreille, Basses-Pyrénées.

Long. : 0,15 à 0,23 , rarement plus.

Le tronc est épais; le dos est large, le ventre arrondi; la hauteur est comprise environ cinq fois et un liers dans la longueur totale; à partir de l'anus le corps est comprimé, et devient à peu près cunéiforme; la peau est couverte de petites écailles disposées en bandes légèrement obliques d'avant en arrière et de haut en bas. - La tête est cuboïde, aplatie en dessus et couverte de plaques osseuses chagrinées; le museau est court, aplati; la bouche est protractile; les lèvres sont garnies de petits tentacules; les mâchoires sont nues; l'intermaxillaire porte une bande de dents en eardes fines; la mandibule est munie d'une rangée de dents crochues; la membrane intramandibulaire s'eftile en un tentacule plus ou moins allongé. Le diamètre de l'ceil est compris sept fois à sept fois et demie dans la longueur de la tête, il fait les trois cinquièmes de l'espace interorbitaire; les sous-orbitaires soudés les uns aux autres forment une grande plaque à surface chagrinée; le sous-orbitaire n'est pas articulé avec le préopercule. La fente des ouïes est excessivement grande; les os pharyngiens sont garnis de dents en cardes assez fortes. La ligne latérale est bien marquée. - La première dorsale est courte, hasse, à quatre rayons très grêles; elle est unie, par une membrane, à la seconde qui est très longue, opposée à l'anale; la caudale est bien développée, coupée carrément.

$$
\text { Br. 6. -1). } 4-14 ; \Lambda 1 / 12 \text {; C. } 10 \text {; P. 17; V. } 1 / 5 \text {. - Vert. } 23 \text { ì } 26 .
$$

La coloration est d'un gris brunâtre sur le dos avec des taches plus claires, d'un gris pâle sur les côtés, blanchâtre en dessous. La première dorsale est noire, la seconde grisûtre; lanale est blanchâtre; la caudale est grris noirâtre; les pecto- 
rales sont grises avec une teinte violette ì leur extrémité; les ventrales sont rosées.

Habitat. Néditerranée, assez commun à Nice; très commun à Celle; assez commun à Port-Vendres. Océan, exclusivement rare, Bayonne.

\section{GENREVIVE. - TR RCIINUS, Arted.}

Corps allongé, comprimé, courert de petites écailles minces; anus très a viancé.

Tête comprimée; museau court; bouche à fente très oblique; dents en velours sur les michoires, le vomer, les palatins, les ptérygö̈diens; langue non dentée.

Yeux placés latéralement, vers le profil supérieur de la tète.

Appareil branchial; fente des ouïes étendue; opercule armé d'une épine longue, dirigée ell arrière.

Nageoires; première dorsale à six ou sept aiguillons très acérés; seconde dorsale et anale très longues, à plus de vingt rayons.

Vessie natatoire nulle.

Appendices pyloriques au nombre de six généralement.

Le genre Vive se compose de quatre espèces.

a. Épine sur le bord antérieur du sourcil manquant............................

Épine plus ou moins développèe........... b.

b. $1^{\text {re }}$ dorsale à sept rayons ................. 4. ARAigné.

- $\quad$ six rayons.................

c. Taches ocellées sur le corps biell marquées... 3. A tR̂te RaYonnée.
-
nulles ...........
2. COMHCNE.

A Cette le nom vulgaire des Vives est Idagna.

1. LA PETITE VIVE. - TRACHINUS VIPERA, Cuv.

Poiss. France, t. II, p. 96.

N. vulg. : Toquet, Abbeville; Boideroc, Dieppe; Bouderenx, Carentan; Petite Vive, còtes de louest; Lapouriche, Lapouricha des Basques, Basses-Pyrénées.

Long. : 0,10 à 0,12 , quelquefois 0,14 .

La hateur du tronc est comprise quatre fois ì quatre fois el deux tiers dans la longueur totale; le dos est légèrement 
convexe; le profil du ventre est plus arqué que dans la Vive commune; les écailles forment des bandes obliques moins marquées que dans les autres espèces. - La tête est moins raboteuse que dans les autres espèces; sa longueur fait le quart de la longueur totale; la màchoire supérieure a une échancrure en arant dans laquelle est recue la proéminence de la mandibule. Le diamètre de l'oeil mesure le cinquième de la longueur de la tête; il est un peu plus grand que l'espace préorbitaire; il n’y a pas d'épine sur le bord antérieur du sourcil, ni ì l'angle antérieur et inférieur du sous-orbitaire; les joues sont nues. L'opercule et le sous-opercule ont de très petites écailles; l'épine de l'opercule, dirigée horizontalement en arrière, est très pointue et relativement développée; le bord inférieur du préopercule est armé de deux épines. - La ligne latérale est rapprochée du dos. - La première dorsale a six épines, parfois sept chez les màles; elle porte sur les trois premiers espaces intraradiaires une lache d'un noir très foncé; la seconde dorsale finit avant lanale, elle est d'un gris pâle; l'anale est blanchàtre ou d'un blanc jaunàtre; la caudale est jaune pàle en avant, elle est noire sur le tiers postérieur; les pectorales mesurent le cinquieme de la longueur totale, elles sont d'un jaune pâle; les ventrales sont blanchàtres.

$$
\text { Br. 6. - D. } 6 \text { ou } 7-24 ; \Lambda .1 / 24 \text {. }
$$

La coloration est d'un gris jaunàtre sur le dos avec un léger pointillé brun sur les bandes d'écailles; sur les côtés, la teinte est d'un gris argenté passant au jaune pàle vers le ventre; la gorge el le dessous du ventre sont d'un blane d'argent; les joues sont argentées avec un léger pointillé brun ; le dessus de la tête est marqué de petites taches formées par un pointillé noirâtre.

Habitat. Toutes nos còtes, commune dans la Manche, l’Océan, la Méditerranée.

Suivant M. Giglioli, cette espèce est ovovivipare. V. Cat. Pese. itul., p. 84: le fait est fort donteux. - Suivant Parnell, elle dépose son frai vers le milieu du printemps; Yarrell émet la mème opinion et. ajoute que la Cirande Vive fraie en été. 
2. LA VIVE COMMUNE. - TRACHINTS DRACO, Linn.

Poiss. France, t. II, p. 98.

N. vulg. : grande Vive, Vive, Avive, Normandie; Liètre, Aunis; Chaquedit, Biarritz; Idagna, Cette; Aragna, Nice.

Long. : 0,20 à 0,30 et plus.

Le corps est comprimé et allongé; sa hauteur est comprise six fois à six fois et demie dans la longueur totale; le profil supérieur est presque droit, le profil inférieur est légèrement convexe. - La longueur de la lête est conterue quatre fois et demie à quatre fois et trois quarts dans la longueur totale; les mâchoires sont garnies de dents en velours ainsi que le vomer, ete. Le diamètre de l'wil est contenı cinq fois et quart à cinq fois et demie dans la longueur de la tête; il est d'un tiers environ plus grand que l'espace préorbitaire; l'angle antérieur et inférieur du sous-orbitaire s’allonge en une épine qui gagne le niveau de la mâchoire supérieure; sur le bord antérieur et supérieur de l'orbite se montre une épine triangulaire, qui est séparée, par un espace étroit, d'une autre épine plus courte tirigée en arrière. Liopercule se termine en arrière par une longue épine, qui se porte jusqu'au-dessus de la base de la pectorale; l'angle postérieur et inférieur du préopercule forme une espèce d'épine. - La ligne latérale est bien marquée. Écailles, 1. long. 78 à 80, 1. transv. :0. - La première dorsale commence au-dessus de l'épine du seapulaire, ses trois premier; aiguillons sont très développés; la seconde dorsale finit un peu en avant de l'anale; l'anale a deux épines enveloppées dans la peau.

$$
\text { Br. } 6 .- \text { D. } 6-30 ; \text { A. } 2 / 30 \text {; C. } 15 \text {; P. } 15 ; \text { V. } 1 / 5 \text {. }
$$

la première dorsale est marquée d'une grande tache noire qui s'étend sur les premiers espaces intraradiaires et sur les deux tiers du troisième espace, elle est blanchâtre dans le reste de son étendue; la seconde dorsale et l'anale sont d'un gris très pâle, avec une large bande longitudinale de teinte jaunàtre; la caudale est grisître avec des taches jaunàtres, 
elle a une bordure postérieure d'un gris noirâtre: les nagुeoires paires sont d'un blanc rosé. La partie supérieure du corps est d'un gris roussâtre ou jaunàtre ì reflets bleus, avec des bandes ou des taches brunâtres dirigées obliquement de haut en bas et d'arant en arrière; parfois les bandes sont plus ou moins confondues; la partie inférieure du corps est rayée de jaune. La tète est d'un gris foncé ou roussâtre avec des lignes bleuâtres qui se voient également sur les opercules et les pièces scapulaires.

Habitat. Commune sur toules nos côtes.

3. LA VIVE a TÊTE RAYONNÉE. - TRACHINUS RADITUS, Cuv.

Poiss. France, 1. II, p. 101, fig. 93, anim.

Long. : 0,30 à 0,40 .

La hauteur du tronc, qui l'emporte d'un tiers sur l'épaisseur, est contenue quatre fois et trois quarts à cinq fois dans la longueur totale. - La tête est massive; sa longueur, qui est d'un tiers plus grande que sa hauteur, est comprise trois fois et demie dans la longueur totale; la nuque est couverte de pièces osseuses marquées de stries profondes, disposées suivant trois directions différentes; la bouche s'ouvre au delà du diamètre vertical de l'ceil, elle est munie de dents en velours. L'iris est d'un rouge cuivré; le diamètre de l'ópil est contenu cinq fois et un tiers dans la longueur de la tête, il est à peine moindre que l'espace préorbitaire, il est deux fois et quart plus grand que l'espace interorbitaire; le bord supérieur et postérieur du sourcil est denticulé ; à la réunion du bord antérieur au bord supérieur de l'orbite, il y a deux épines bien développées. La muqueuse tapissant la paroi externe de la chambre branchiale est d'un gris hleuâtre. - L'anale n'a généralement qu’un seul aiguillon; la caudale est échancrée ; le surscapulaire est couvert de stries qui forment de petites dentelures sur le bord supérieur.

$$
\text { Br. 6. -D. 6-25 ou } 26 ; \text { A. 1/26; C. } 2 / 14 / 2 ; \text { P. } 16 ; \text { V. 1/5. }
$$

La première dorsale est noiràtre dans la plus grande partie 
de son étendue; elle est en arrière d'un blanc grrisitlre; la seconde est d'un gris jaunâtre pàle avec des laches brunes plus foncées sur les rayons qui ont la pointe noirâtre; l'anale est jaunitre; la caudale est grisittre, son bord postérieur est noiratre; les naggeoires paires sont jaunâtres. Le dos et les parties latérales supérieures sont jaunâtres el marqués de taches noires qui par leur rapprochement forment des anneaux plus ou moins réguliers; les anneaux les plus constants sont placés sur la ligne latérale au nombre de sept à neul'; entre eux, il y a d'itutres 'laches noires; le long du dos il y a douze à quinze anneaux plus ou moins confus; au-dessous de la ligne latérale, il y a souvent cinq ou six anneaux; les flanes sont jaunâtres; le ventre est d'un jaune très pâle. La tète est en dessus d'un brun rougeàtre, sur les parties latérales el inféricures d'un violet très foncé; le museau est d'un brun rougeâtre.

Habitat. Méditerranée, rare, Nice, Cette.

\section{LA VIVE ARAIGNEE. - TRACHINUS ARANEUS, Guv.}

Poiss. Frunce, t. II, p. 103̈, fig. 9', anim.

Long. : 0,30 à 0,40 .

La hauteur du corps, d'un tiers plus grande que l'épaisseur, est comprise quatre fois et deux liers ì cinq fois et demie dans la lonğueur lolale. - La tête est forte; sa longueur est contenue quatre fois et demie ì quatre fois et trois quarts dans la longueur totale; le museau est gros; la bouche est garnie de dents en velours, elle est fendue jusqu'à l'aplomb du diamètre vertical de l'oil. Lïris est jaunâtre: le diamètre de l'œil fait environ le sixième de la longueur de la tête, il est à peine plus grand que l'espace préorbitaire qui est égal à l'espace interorbitaire; l'épine du sourcil n’est pas très développée. - La première dorsale est plus longue que haute; ello est en grande partic noirâtre, d'un gris blanchâtre en arrière: la seconde dorsale est grisâtre avec des points bruns; l'anale a deux épines, elle est grise, marquée d'une bande longitudinale plus foncée; la caudale, assez échancrée, est grisàtre 
avec des taches brunes dans ses deux premiers tiers, noirâttre dans le reste de son étendue; les pectorales et les ventrales sont grisâtres.

$$
\text { Br. 6.-D. } 7 \text {-28; A. } 2 / 28 \text { ou } 29 \text {; C. } 2 / 15 / 2 ; \text { P. } 15 \text { ì } 17 \text {; V. } 1 / 5 \text {. }
$$

La coloration est d'un gris roussâtre vers le dos avec de très nombreuses taches noirâtres, d'un gris jaunâtre sous le ventre. La tête, le dos et les flanes sont marqués de points ou de petites taches arrondies noirâtres. Au-dessous de la ligne latérale règne une série de grandes taches noirâtres au nombre de six ou sept, quelquefois il y en a davantage.

Habitat. Méditerranée, assez rare, Nice, Cette.

Steindachner regarde le T. araneus et le T. radiatus comme étant de mème espèce; les différences qui se remarquent entre ces.Vives ne permettent guère d'adopter l'opinion de l'auteur que nous venons de citer, V. Steindach., Icthth. Ber. Span. Portug. Rcise, Wien, 1867, t. LVI, p. 96.

Les blessures faites par les aiguillons des Vives déterminent parfois des accidents fort graves. - Il m'est impossible de rappeler les différentes recherches faites sur l'appareil à venin des Vives. Je parlerai seulement de deux thèses pour le doctorat en médecine présentées à la Faculté de Paris. - La première ayant pour titre : "Contribution à l'étude de l'appareil à venin chez les poissons du genre vive, a été soutenue par M. Gressin en 1884. - L'auteur cite l'opinion de quelques naturalistes à propos de la cause du danger qui résulte des blessures faites par les aiguillons des Vives, les uns niant, les autres affirmant la présence d'un appareil à venin chez ces Poissons. - De mème que Cuvier et Soniui, Guichenot, écrit M. Gressin, p. 13, ne veut pas admettre l'existence de venin, et il explique la gravité des piqùres de la mème facon que les auteurs précédents... En 1849, Canestrini vient cependant jeter une note discordante... Pendant longtemps on a refusé à cette classe (poissons) l'existence d'appareils à venin ; mais on a récemment démontré que les épines canaliculées qui se trouvent sur le dos et sur les opercules des poissons du genre " trachine " sont des organes venimeux... Canestrini néglige de nous dire sur quelles expériences il a conclu, et qui a réccmment démontré l'existence d'une glande. Aussi voyous-nous Moreau confirmer sans hésiter les affirmations de Sonini et de Cuvier ". - Avant de les critiquer, M. Gressin aurait dù prendre la précaution de se faire expliquer les textes dont il n'a pas compris le sens. Au lieu de sa traduc- 
tion, je vais domner la phrase originale de Canestrini : Si é negata per lungo tempo la presenza di organi veleniferi in questa classe (Pisces), ma recentemente fu dimostrato che le spine seanalate dorsali ed operculari nel genere Trachinus, sono organi veneliferi (Byerley, 1849). V. Canestr., Compendio Zool. ed Anut. comp., Milano, 1869, t. I, p. 307. - Il me semble que le texte est assez clair et que le nom de celui qui a récemment démontré, etc., n’est pas oublié. - Evidemment II. Gressin a pris le nom de Byerley pour celui du libraire chez lequel aurait été publiée, en 1849, la note un peu discorlante qu'il attribue à Canestrini. - Quant à l'opinion que j'ai exprimée, elle n'est pas celle que me prète M. (iressin, on peut s'en convaincre en prenant la peine de lire ce que j’ai écrit t. II, p. 107 de mon travail. Je ne reconnais pas non plus le tableau résumant les caractères différentiels des Vives (loc. cit., p. 2ə̈) que M. Gressin dit m’avoir emprunté. - Je regrrette que M. Gressin m'ait obligé de réfuter les assertions yu'il a produites et de faire connaître la cause des erreurs qu'il a commises.

Dans la seconde thèse, soutenue en 1889, l'auteur, M. Bottard, s'occupe non seulement de l'appareil à venin des Vives, mais encore de celui d'un certain nombre de Poissons, ainsi que l’indique le titre de son travail: Les Poissons venimeux, Contribution à l'Hygiène navale. - I. Bottard établit une division des appareils à venin d'après cinc types distincts: 1 , appareil à venin de la Synancée; 2 , appareil à venin du genre Vive; 3 , appareil à venin du Thalassophyrne; 4, appareil à venin de la Murène; 0 , appareil ả venin du genre Scorpène. - Les grlandes à venin paraissent formées de grosses cellules à contenu granuleux. Voici, d’après l'auteur, l'opinion du Dr Rémy sur la structure de la glande operculaire: M. le professeur agrégé Rémy, qui a bieu voulu contròler nos recherches propres, pense que la grlande ì venin de la Vive est une glande analogue, par sa structure, aux glindes sébacées. $L$. cit., p. 116. - Je ne puis faire une analyse complète de ce long travail, qui est le résultat de recherches fort intéressantes et mérite d'ètre consulté.

\section{Famille des Blenniidés, Blenniidie.}

Gorps allongé, plus ou moins comprimé, assez rarement fusiforme; pean enduite de mucus, nue ou couverte d'écailles généralement peu développées.

Tête ordinairement comprimée; nichoires dentées.

Appareil branchial; fente des ouïes généralement très grande; 
les deux membranes branchiostèges s'unissent fréquemment sous l'isthme du gosier et ne paraissent entourer qu'une poche; rayons branchiostèges au nombre de six, rarement de cinq ou de sept. Fausses branchies.

Nageoires; dorsale unique le plus souvent, parfois divisée en deux ou trois parties, très longue, occupant à peu près toute la longueur du dos, à rayons nombreux, parfois tous épineux, le plus souvent les rayons antérieurs sont simples, plus ou moins épineux, excepté dans le Zoarcès, suivis de rayons articulés plus ou moins nombreux; anale longue; ventrales peu développées, manquant chez l'Anarrhique, elles sont jugulaires, parfois cependant elles semblent presque thoraciques.

Vessie natatoire nulle. - Appendices pyloriques manquant.

Reproduction; l'ovoviviparité a été constatée dans quelques espèces. Cette famille comprend six genres.

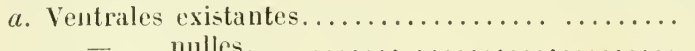
$b$.
6. Avalimigue.

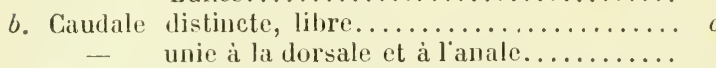
c. Ventrale
i plusieurs rayons..................
$d$.
5. Zoarcès.
à un seul rayon appirent. trés réduit,

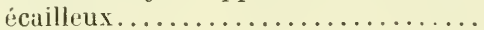

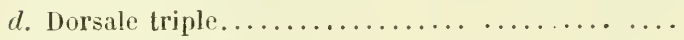

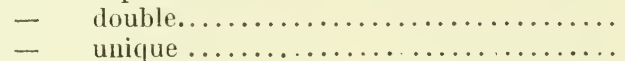
4. Gonnelle.
3. Thiptingan.
2. Clinus.
1. Blennie.

1. GENRE BLENNIE- BLENYIUS, Arted.

Gorps allongé; peau nue, visqueuse.

Tête comprimée dans sa partie supérieure; museau court; bouche petite; dents sur une seule rangée qui se termine souvent aux deux màchoires, ou à la mandibule seulement, par une canine à crochet lourné en arrière, plus ou moins isolée, parfois il y a deux canines.

Yeux latéraux.

Appareil branchial; oües très ouvertes; six rayons branchiostèges.

Nageoires; dorsale très longue, très avancée, ayant onze à quatorze rayons épineux ou simples, et un nombre plus ou moins grand de rayons articules dont le dernier est généralement pourvu d'une membrane, qui s'insère sur le tronçon de la queue et parfois se prolonge sur la caudale. Anale longue. Caudale plus ou moins arrondie. Ventrales peu développées, à deux ou trois rayons, parfois qualre. 
Les Blennies ont à Cette plusieurs noms vulgaires: Bigoula, Masca, Lébré. Le genre Blennie se compose d'espèces assez nombreuses.

a. Tentacule du sourcil faisant au moins le tiers du diamètre de l'wil..... b.

Tentacule du sourcil nul......... $l$.

b. Filaments sur la tête au nombre de

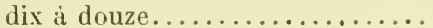

Filaments sur la tête nuls....... c.

c. Dorsale à peu près égale........ d.

- très inégale ........... $i$.

d. Ocelle sur la joue bien marqué... - sur la joue nul...........

e. Tentacule du sourcil très court, pas plus long que le diam. de l'œil.. $f$.

Teutacule du sourcil beaucoup plus long que le diam. de l'œil.......

f. Anale commencant après la fin de la pectorale.................

Anale commencant sous le tiers postérieur de la pectorale......

g. Mâchoire supérieure sans canine bien distincte...............

Màchoire supérieure avec une canine forte, bien distincte.......

h. Dorsale séparée du bord postérieur de l'orbite par une distance égale à l'espace préorbitaire.........

Dorsale séparée du bord postér. de l'orbite par une distance plus grande que l'espace préorbitaire.

i. Dorsale à partie antérieure élevée.

Dorsale à partie antérieure plus basse que la régiou molle......

i. Dorsale à partie antérieure marquée d'un ocelle..................

Dorsale sans ocelle............

$k$. Rayons antérieurs de la dorsale dépassant les suivants...........

Rayons antérieurs de la dorsale ne dépassant pas les suivants......

l. Filaments sétacés sur le milieu de la tête plus ou moins nombreux. Filaments sétacés sur le milien de la tête uuls.................

$m$. Appendice à la narine manquant,

Appendice de la narine palmé.....

n. Bord postérieur de l'orbite plus près de la dorsale que du bout lu

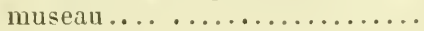

Bord postérieur de l'orbite an mi-

Mureat. - Ichthyologie.

11. CIIEVELU. d.

1. PAOx. $e$ $h$. g.

4. DE Roux.

2. Palmicorne.

3. Cagnette.

5. GATtorlgine.

6. Tentaculaire.

10. AUX DORSALES INÉGALES.

7. Papillon.

8. TÈte ROLGE.

9. SPHINX.

12. De Montage. $m$.

13. BAsilic. $n$.

14. TIIGLOIDE. 
lica de la ligne qui s’étend du museau à la dorsale..............

15. PHOLIS.

\section{LE BLENTE PAON. - BLENVIUS PAVO, Riss.}

Poiss. France, t. II, p. 111, fig. 9̈, anim.

N. vulg. : Bigoula, Cette; Bavecca, Nice.

Long. : 0,09 à 0,11 .

Le corps est comprimé, surtout après l’anus; sa hauteur est comprise quatre fois et demie à cinq fois et demie dans la longueur totale. - La tête est aussi haute que longue, elle mesure à peu près le cinquième de la longueur totale; chezles mâles adultes, elle est surmontée d'une crète charnue, érectile; chez les jeunes mâles et les femelles cette crète est nulle ou à peine sensible; le museau est court; les dents sont au nombre de vingt-deux à trente à la màchoire supérieure, de seize à vingt-deux à la mandibule; la dernière dent est une canine qui est très crochue et beaucoup plus forte à la mandibule qu'à la mâchoire supérieure. Le diamètre de l'œil fait le cinquième de la longueur de la tête; il est d'un tiers moins grand que l'espace préorbitaire; le sourcil porte un tentacule très petit. - La dorsale est régulière; elle commence audessus de l'opercule et se continue jusque vers la caudale à laquelle elle est unie par la membrane qui attache son dernier rayon sur le tronçon de la queue; l'anale est moins haute que la dorsale; ces deux nageoires sont d'une teinte verdâtre avec une bordure d'un brun violacé, chez quelques mâles, l'anale est bordée de bleu; la caudale est arrondie, elle est d'un vert plus ou moins foncé avec le contour rougeàtre chez. les mâles; les pectorales sont grandes, oblongues, d'un vert jaunâtre; les ventrales sont d'une teinte jaunâtre.

$$
\text { D. } 12 / 21 \text { ou } 22 ; \text { A. } 24 \text { ou } 25 ; \text { C. } 13 ; \text { P. } 14 ; \mathrm{V} .1 / 3 .- \text { Dents } \frac{2+20 \text { à } 28}{2+14 \text { aे } 20}
$$

Le plus généralement, la teinte de la région supérieure du corps est d'un jaune verdâtre avec six ou sept larges bandes verticales d'un bleu foncé descendant de la base de la dorsale jusque sur le milieu des flanes, souvent des lignes d'un bleu 
lilas bordent les bandes verticales. La partie inférieure est d'un jaune verdâtre. Sur la tempe est un grand ocelle ovale, noirâtre, cerclé de blanc lilas chez les femelles, de bleu chez les mâles; du sommet de la tête partent deux bandes assez. larges d'un vert noirâtre, la bande postérieure se termine vers la membrane branchiostège, l'antérieur'e descend vers l'œil, oủ elle est interrompue, reprend sous l'orbite et va rejoindre sous la gorge la bande du côté opposé. Chez les màles adultes, la crête est d'un jaune plus ou moins brillant.

Habitat. Méditerranée, assez commun à Nice, Toulon, Marseille; très commun à Cette, étang de Than; assez commun à Port-Vendres. Océan, assez rare, Arcachon, Moulleau.

\section{LE BLENNIE PALMICORNE. - BLENNIUS PALMICORNIS.}

Poiss. France, t. 11, p. 114.

N. vulg. : Bavecca, Nice; Loca, Cette; Cabot, Basses-Pyrénées.

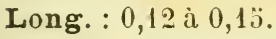

En avant le corps est assez large, assez épais, il est comprimé à partir de l'anus; sa hauteur est comprise quatre fois et quart à cinq fois et demie dans la longueur totale. - La tête est à peu près aussi haute que longue; sa longueur mesure le cinquième environ de la longueur totale; son profil supérieur décrit une courbe allongée. La bouche est petite; les mâchoires sont armées de trente-quatre à trente-huit dents; à la màchoire supérieure la canine manque, ou elle est peu distincte des autres dents; à la mandibule, elle est crochue, fort apparente. Le diamètre de l'œil fait le cinquième environ de la longueur de la tète, la moitié de l'espace préorbitaire; le tentacule du sourcil est une palmette à quatre, cinq ou six divisions, il n'a guère que la moitié de la longueur du diamètre de l'œil. - La ligne latérale, bien marquée, forme une grande courbure au-dessus de la pectorale. - La dorsale est très avancée, elle commence au-dessus de l'insertion des ventrales; elle est régulière; une membrane l'unit à la caudale; elle est d'une teinte gris jaunitre et souvent marquée d'une tache noire dans son premier espace intraradiaire; l'anale a, 
près de son bord libre, une bande brunàtre parfois peu distincte; la pointe de ses rayons est blanchâtre; sur le premier rayon est une excroissance charnue, souvent déprimée; toutes les nageoires sont tachetées de brun; les pectorales et la caudale sont parsemées de points rougeâtres; parfois les pectorales sont jaunitres avec des taches d'un rouge ocracé.

$$
\text { D. } 12 \text { ou } 13 / 19 \text { à } 21 \text {; A. } 22 \text { à } 24 \text {; C. } 13 \text {; P. 14; V. } 2 .
$$

La coloration est très variable: elle est olivâtre ou brunàtre avec des macules noirâtres.

Habitat. Méditerranée, assez commun à Nice; assez rare, PortVendres. Océan, assez commun à fiuétary; rare à Arcachon. Manche excessivement rare, le Harre.

\section{LE BLENNIE CAGNETTE. - BLENNITS CAGNOTA, Linn.}

Poiss. France, t. II, p. 116.

N. vulg. : Chasseur, lac du Bourget; Lièvre, Agde; Bavecea, Nice. Long. : 0,10 ì 0,12 et mème 0,13 .

Le corps est d'une souplesse remarquable; sa hauteur est contenue de einq fois à six fois et demie dans la longueur totale. - La tête est longue, sa longueur mesurant à peu près le quart de la longueur totale; chez les males adultes, elle porte une crête allongée, tranchante, se terminant un peu en avant de la dorsale; le museau est arrondi ; les mâchoires ont chacune en arrière et de chaque côté une grande canine crochue; le nombre des incisives est variable, il y en a de seize à vingt-quatre et parfois vingt-huit à la màchoire supérieure et quatorze à dix-huit, rarement vingt-deux, à la mandibule. Le diamètre de l'cil est compris quatre fois à quatre fois et deux tiers dans la longueur de la tête; il est d'un tiers plus petit que l'espace préorbitaire; le tentacule du sourcil est placé en arrière du diamètre vertical de l'ceil, il est beaucoup moins long que le diamètre de l'ceil. L'orifice antérieur de la narine est garni d'un appendice tentaculaire plus ou moins grand. - La ligne latérale est bien marquée; elle décrit en avant une courbe allongée. - La dorsale commence au-dessus 
de l’angle de l'opercule, elle est légèrement échanerée; elle se termine par une membrane qui lantôt finit sur le tronçon de la queue, tantît gagne la base de la caudale, elle est d'une teinte jaunâtre avec de petites taches brunes, d'autres taches plus larges sont disposées en séries vers la base de la nageoire; la pointe des rayons est d'un blanc rosé. L'anale est souvent précédée de deux fraises; elle commence après la fin des pectorales, elle se termine par une membrane qui ne va pas aussi loin sur le tronçon de la queue que la membrane de la dorsale; elle est jaunâtre arec une bordure d'un brun asse\% foncé; la pointe des rayons est blanchâtre. La caudale est coupée à peu près carrément avec les angles arrondis; elle est d'un jaune souvent teinté de rose chez les milles; elle est jaunâtre, dans les jeunes, avec des taches brunes sur les rayons. La pectorale est jaunàtre; elle mesure environ le cinquième de la longueur totale; la ventrale en fait le sixième, elle est jaunâtre ou d'un vert tirant sur le jaune.

$$
\text { D. } 12 / 17 \text { a } 20 ; \text { A. } 18 \text { a } 20 \text {; C. } 12 \text { à } 14 \text {; P. } 14 \text {; V. } 4 .
$$

La coloration est très variable, le plus souvent d'un jaune verdàtre, plus ou moins pointillé de brun; le ventre est jaunàtre; la gorge est d'un jaune assez clair. Il y a ordinairement sur les joues deux bandes foncées dirigées d'arrière en avant et de bas en haut.

Habitat. Eaux douces, Garonne, canal du Midi, Lez, Var, lac du Bourget et ses affluents.

\section{千. LE BLENNIE DE ROUX. - BLENyIUS ROUXI, Cocco.}

Poiss. France, 1. II, p. 120.

Long. : 0,0 ä à 0,06 .

La hauteur du trone, qui est très comprimé, est contenue cinq fois et demie dans la longueur totale. - La tète a le profil autérieur légèrement courbe; sa longueur fait le cinquième de la longueur totale; le museau est court; les dents sont grèles, excepté les canines qui sont crochues et beaucoup plus fortes à la mandibule qu'à la màchoire supérieure. Le 
diamètre de l'ceil mesure le quart de la longueur le la tète; le tentacule du soureil est légèrement palmé, il est moins grand que le diamètre de l'wil; le tentacule de la narine est plus long et plus grêle. - La ligne latérale disparaît après la pectorale. - La dorsale est égale; elle commence avant la fin de l'opercule; elle est libre en arrière; l'anale commence sous le tiers postérieur des pectorales, ou peut-être un peu avant; la caudale est arrondie; les pectorales sont triangulaires; les ventrales sont longues, elles vont jusqu'à l'anus.

$$
\text { D. } 13 / 21 ; \text { A. } 26 ; \text { V. } 2 \text {. }
$$

Sur le frais, d’après Bonaparte, le corps est transparent, pointillé de noir sur le dos; le rentre est argenté; une bande châtain foncé va de l'œil à la queue.

Habitat. Méditerranée, rare, Cette.

\section{̈. LE BLENNIE GiATTORUGINE. - BLENNILS G.ATTORLGINE.}

Poiss. France, t. II, p. 121.

N. vulg. : Cabot à Cherbourg; Cabos, Biarritz, Guétary.

Long. : 0,13 à 0,20 .

L’épaisseur du tronc fait la moitié de la hauteur qui est comprise quatre fois à quatre fois et demie dans la longueur totale. - La tête est comprimée, sa longueur est contenue quatre fois el demie dans la longueur totale; son profil supérieur est arrondi, la courbe est interrompue, en arrière des tentacules surorbitaires, par une échancrure transrersale; la bouche est grande; les mâchoires ont chacune une rangée de trente-six à quarante dents; il n'y a pas de réritables canines, seulement la mandibule porte en arrière parfois une ou deux dents séparées des autres et légèrement crochues. Le diamètre de l'oeil, d'un tiers moindre que l'espace préorbitaire, fait le quart de la longueur de la tète; le tentacule du sourcil est en arrière du diamètre vertical de l'œil, il est plus long; il se partage dès la base en ramifications, qui généralement se divisent elles-mèmes en filets plus ou moins nombreux; à l'orifice antérieur de la narine est un petit tentacule un peu frangé. 
- La dorsale est trìs avancée; la distance qui sépare son premier rayon du bord postérieur de l'orbite est moins grande que la distance comprise entre ce même bord et l'extrémité du museau; elle est généralement échancrée, plus haute en arrière; elle se termine par une membrane qui l'unit à la base de la caudale; elle est de teinte variable d'un gris foncé ou d'un brun jaunâtre; elle porte souvent sur les troisième et quatrième rayons et sur l'espace intraradiaire, une tache noirâtre, quelquefois d'un bleu foncé; l'anale commence après l'extrémité des pectorales et finit avant la dorsale; elle est d'un gris jaunâtre, parfois bordée d'un liséré noirâtre avec la pointe des rayons blanche; la caudale est tantôt grisâtre avec des taches noires, tantót d'une teinte uniforme ainsi que les nageoires paires; parfois cependant le tiers postérieur de la pectorale est d'un roux plus ou moins clair.

$$
\text { D. } 12 \text { à } 14 / 17 \text { à } 20 ; \text { A. } 21 \text { ou } 22 ; \text { V. } 1 / 2 \text {. }
$$

Le dos est d'un gris brun tirant sur le roux semé de petites taches foncées avec des bandes verticales qui se prolongent sur la dorsale; quelquefois une bande brunâtre, plus ou moins continue, va de la pectorale à la caudale; le ventre est gris roussàtre; la tète porte en dessus des taches ou des bandes brunes; il y a sous le menton et sous la gorge deux bandes d'un brun foncé; la teinte générale est parfois uniforme d'un brun tirant sur le roux.

Habitat. Toutes nos còtes, Méditerranée, assez commun, Nice, Marseille, Cette. Océan, assez rare, la Rochelle. Manche, rare, Granville, Cherbourg.

Le Blennie rouge. - Blennius ruber.

Poiss. Fiance, t. II, p. 124 .

Long. ; 0,16 .

Ce Blennie, écrit Valenciennes, est parfaitement semblable au Gattorugine pour les formes, mais il semble en différer, parce que son tentacule sourcilier paraît plus court, et que 
dans certaines circonstances du moins il prend une teinte générale d'un rouge vif.

$$
\text { D. } 13 / 20 ; \text { A. } 22 ; \text { P. } 14 \text {; V. } 2 .
$$

Les rayons des nageoires sont comme le corps d'un rouge de feu ou de sang, et il y a dans leurs intervalles des lignes obliques blanches; et Valenciennes termine ainsi: ne serait-ce pas un Blennie gattorugine dans quelque état passager, peut-être dans la saison de l'amour?

Habitat. Océan, Ouessant. Manche, Granville.- Au Pouliguen, j’ai remarqué un Blennie gattorugine à tentacule du sourcil rougeàtre, qui m’a paru être un jeune mâle.

\section{LE BLENNIE TENTACULAIRE. - BLENNIUS TENTACULARIS, Brunn.}

Poiss. France, t. II, p. 125.

N. vulg. : Bavecca, Baroua, Nice.

Long. : 0,10 à 0,12 et mème 0,13 d'après Risso.

La hauteur du tronc fait le cinquième environ de la longueur totale, elle est égale à la longueur de la tête ou un peu moindre; le museau est arrondi; le nombre des dents à chaque mâchoire varie de vingt-six à trente, la dent postérieure est une canine crochue beaucoup plus développée que les autres dents; la canine de la mâchoire supérieure est aussi forte et parfois même plus forte que celle de la mandibule; la mầchoire inférieure a souvent deux ou quatre dents de moins que l'autre mâchoire. Le diamètre de l'œil est compris de quatre à cinq fois dans la longueur de la tète, il est plus court que l'espace préorbitaire; le sourcil porte un peu en avant du diamètre vertical de l'œil, un lentacule allongé, plus grand que l'espace préorbitaire, deutelé mais généralement beaucoup moins divisé que chez le Blennie gattorugine. Le tentacule de l'orifice antérieur de la narine est plus développé que celui du Blennie gattorugine, il est ordinairement plus grand que le diamètre de l'œil. Il n'y a presque jamais de ligne latérale bien marquée. - La dorsale est régulière ; elle est atta- 
chée sur le fronegon de la queur par une petite membrane, qui le plus souvent finit avant la base de la caudale, mais qui parfois la dépasse el se prolonge sur les rayons supérieur's de la nageoire; elle est grisàtre, tachetée de jaunàtre, elle est marquée, dans le premier espace intraradiaire, d'une tache qui s'étend jusqu'au quatrième aiguillon chez quelques sujets; le bord postérieur de l'orbite est à la mème distance du bout du museau que du commencement de la dorsale. L'anale commence après la fin des pectorales; elle est grisâtre rayée de blanc el de bluu, parfois elle est d'un brun assez clair uniforme avec la pointe des rayons blanchâtre. La caudale est assez longue, de teinte brunatre. Les pectorales, nous l'avons dit, finissent avant le commencement de l'anale; les ventrales sont grèles, effilées; les nageoires paires sont brunàtres.

$$
\text { Br. } 6 .- \text { D. } 12 \text { à } 14 / 19 \text { a } 21 \text {; A. } 23 \text { a } 25 \text {; C. } 11 \text {; P. } 14 \text {; V. } 2 .
$$

Le plus souvent la teinte générale est d’un gris roussàtre, tiqueté de noir, avec sept ou huit grandes bandes verticalcs, parfois ces bandes manquent et le dos et les còtés ne portent que de petites macules noirâtres; la tète est d'un brun tirant sur le roux avec des taches brunes; la gorge est d'un brun rougeàtre assez clair.

Habitat. Méditerranée, assez commun à Nice, Marseille; assez rare à Cette.

\section{Le Blennie yruphique. - Blennius graphicus, Riss.}

Poiss. France, t. II, p. 128.

Long. : 0,0 \%.

Le Graphique n'est probablement qu'une variété du Bl. lentaculaire. D’après Risso, le corps est comprimé, la tète est presque arrondie, la bouche, étroite, est garnie de petites dents; les latérales droites, épaisses ; l'oeil rond, muni en dessus d'un long tentacule subulé, ayant chacun deux appendices à leur base; la ligne latérale, droite, ne s’étend que jusqu'aus nageoires pectorales, disparait ensuite. - Sur la figure donnée par Risso, la dorsale est lihre en arrière, et la ventrale 
a trois rayons dont le médian est le plus allongé. D’après Risso, il n'y a que cinq rayons branchiostèges, chez le Blennie graphique, il y en a six dans le Blennie tentaculaire.

$$
\text { Br. J. - D. } 35 \text {; A. } 26 \text {; C. } 10 \text {; P. } 15 \text {; V. } 2 \text {. Riss. }
$$

Le système de coloration est d'un jaune rouggeâtre, finement pointillé de brun; les opercules sont bariolés de petites ondulations d'un bleu céleste; les nageoires sont variées de vert, de jaune et de verdâtre, Riss.

Habitat. Méditerranée, Nice.

7. LE BLENNIE PAPILLON. - BLENNIUS OCELLARIS, Linn.

Poiss. France, t. 11, p. 128.

N. vulg. : Bavecca, Nice; Baveuse, Marseille; Lébra, Diablé, Bigoula, Cette.

Long. : 0,15 à 0,18 .

La hauteur du tronc est contenue quatre fois et demie à cinq fois et quart dans la longueur totale. - La tète est forte; sa longueur est comprise quatre fois à quatre fois et demie dans la longueur totale; le museau est court; les mâchoires sont garnies de dents assez longues, serrées, grêles, au nombre de trente à trente-six, rarement plus, à la fin de la rangée est une canine longue, forte, crochue, ordinairement plus développée à la mandibule, qui parfois porte une double canine. Le diamètre de l'œil est contenu trois fois et demie à quatre fois dans la longueur de la tête, il est un peu moins grand que l'espace préorbitaire, le tentacule sourcilier est inséré un peu en avant du diamètre vertical de l'oril, il est de longueur variable; ¿ l'orifice antérieur de la narine se montre généralement un petit tentacule. - La ligne latérale est nulle ou peu visible. - La dorsale est très haute en avant; elle présente une échancrure profonde à la réunion des rayons épineux et des rayons mous; elle esı d'un gris pâle teinté de brun assez clair, avec des taches d'un brun plus foncé; sur le sixième et le septième rayon épineux se dessine une tache ovale, noirâtre ou noir bleuâtre, à pourtour blanchâtre, cette espèce 
docelle occupe la partie supérieure des rayons, mais n'atteint pas le bord de la nageoire. L'anale est d'un jaune pâle vers son insertion, brunatre dans le reste de son étendue généralement avec la pointe des rayons blanchâtre. La caudale est d'un gris noiratre ainsi que les pectorales; les rentrales sont brunâtres.

\section{11 o11 $12 / 1$ it 16 ; A. 18 ; C. 11 i 13 ; P. 12 ; V. $1 / 2$.}

La coloration est très variable; elle est d'un gris cendré ou rerditre, roussatre, jaunitre, arec quatre, cinq, parfois six bandes brunàtres qui de la région dorsale descendent vers les cótés; ces bandes sont en général mal dessinées chez les grands individus, et le corps est marqué de taches noires; le ventre est d'un gris jaunâtre. La tête est d'un brun jaunâtre arec des points et de très petites bandes d'une teinte plus foncée; elle est marquée en arrière des yeux d'une espèce de $\checkmark$ d'un blanc jaunâtre dirigé d'avant en arrière.

Habitat. Méditerranée, commun à Nice, Toulon, Cette. Océan, très rare. Manche, très rare, le Havre.

\section{S. LE BLENNIE TÉTE ROUGE. - BLENYIUS ERYTHROCEPHALUS, Riss.}

Poiss. Fiance, I. II, 131.

N. vulg. : Bavecca, Nice.

Long. : vं,08 à 0,10 .

La hauteur du tronc est contenue trois fois et trois quarts ì quatre fois et demie dans la longueur totale. - La tète est d'un quart environ plus haute que longue; sa longueur est comprise cinq fois à cinq fois et quart dans la longueur totale; elle porte, chez les màles, une crète un peu moins élevée que celle du Blennie paon; à la suite des dents ordinaires, qui sont au nombre de vingt-six environ à la màchoire supérieure, d'une vingtaine à la mandibule, existe une canine développée. Le diamètre de l'wil fait le quart de la longueur de la tête; le tentacule sourcilier est petit, ne semble pas divisé. - La dorsale commence au-desșus du milieu de l'opercule; ses deux. 
trois, parfois quatre premiers rayons sont plus élevés que les -uivants diont ils sont séparés par une échancrure.

\section{12 ou 13,$21 ;$ A. 22 ou 23 .}

La teinte générale est d'un gris verdâtre avec des bandes verticales mal dessinées, d'un brun plus ou moins foncé. Une lache muge minium sétend sur la tête et les premiers rayons de la dorsale. Les nageoires sont d'un vert jaunàtre avec un pointille brun.

Habitat. Méditerranée, très rare, Nice.

9. IL BLENNIE SPHIXY. - BLENNIUS SPHINX, Valenc.

Poiss. France, t. II, p. 133.

Long. : $0,0.36$ à 0,07 .

lia hauteur du tronc est généralement un peu plus grande que la longueur de la tête qui est comprise cinq fois et demie it rinq fois et trois quarts dans la longueur totale; le museau est très court; il y a une, parfois deux canines développées à (hayue mathoire, plus une quarantaine de dents ordinaires a la màchoire supérieure, une trentaine à la mandibule. Le diamitre de l'uil fait le quart à peu près de la longueur de la líte, il est moins grand que l'espace préorbitaire; le tentacule du soureil est de lonģueur très variable, il est sétacé, non divisé; lo tentacule nasal est fort réduit, parfois difficile à wir. - Lal dorsale est trìs échancrée dans son milieu; la partie épineuse ust sensiblement plus élevée que la partie molle; la moitié supérieure de la région épineuse est par(onrur par cinq handes longitudinales lilas et argent; la moitié inferieure de la partie épineuse et la région molle sont d'une teinte verdatre avec des taches brunes dans la région épinouse el des points argentés, disposés en séries sur la partie molle. Lamale "st jaunitre, hordée de noir; la caudale est d'un gris verdilre; les ventrales sont jaunatres ainsi que les pectorales. 
Le corps est d'un vert jaunatre avec cinq ou six bandes rerticales d'un rert olive à bordure blanche; des bandes noiràtres marquent le museau, les joues, la gorge; un ocelle ovale, bleu de ciel, encadré de rouge, se montre sur la tempe; il y a généralement une bande verticale noirâtre en avant de la pertorale; parfois la teinte générale est d'un jaune grisàtre avoc quelques bandes brunes verticales.

Habitat. Méditerranée, très rare à Nice; assez commun à PortVendres.

\section{LE BLENNIE AUX DORSALES INÉGALES. - BLENYIUS INAQUALIS, Valenc.}

Poiss, France, t. II, p. 135, fig. 96, anim.

Long. ; 0,0 ä à 0,06 .

La hauteur du tronc est comprise de quatre à cinq fois dans la longueur totale. - La longueur de la tête est contenue quatre fois à quatre fois et deux tiers dans la longueur tolale; le museau est court, la bouche petite; il y a sur les màchoires une rangée de douze à quatorze dents terminée par une canine crochue assez forte, plus développée à la mandibule qu’ì la mảchoire supérieure. Le diamètre de l'oeil fait le quart ou le cinquième de la longueur de la tète; il est d'un tiers plus petit que l'espace préorbitaire; le tentacule sourcilier est en général moins grand que le diamètre de l'aril, il so divise parlois en plusieurs filaments; le tentacule nasal est encore plus court que l'autre, il est bifurqué. - La dorsale est très inégale, très échancrée; elle est dans sa réggion épineusis beaucoup plus basse que dans sa région molle, elle est allachée par une membrane sur le troncon de la queue; l'anals commence assez loin des pectorales; les ventrales sont asse\% courtes; les nageoires verticales et les pectorales sont jaundtres arec des points orangés sur leurs rayons; les ventrales sont jaunatres.

D. 11 ou $12 / 16$ ou 17 ; A. 17 it 19 ; C. 10 ; V. 2.

La teinte est d'un jaune grisâtre sur la tète et la partie anté- 
rieure du trone; jaunâtre vers le dos avec cinq à huit courtes bandes verticales noirâtres; les côtés sont jaunâtres, tiquetés de brun; la gorge et le rentre sont lilas. Des raies brunes marquent les joues et les pièces operculaires.

Habitat. Méditerranée, très rare à Cette, rare à Port-Vendres.

\section{LE BLENNIE CHEVELU. - BLENNIUS CRINITTS, Cuv.}

Poiss. France, t. II, p. 137.

Long. : 0,03 à 0,10 .

Chez les jeunes animaux, la hauteur du corps est contenue cinq fois à cing fois et demie dans la longueur totale, quatre fois à quatre fois et demie chez les grands. - La longueur de la tête mesure le cinquième de la longueur totale; le museau est court; les mâchoires ont une trentaine de dents très lisses; pas de canine à la mâchoire supérieure, une fort petite à la mandibule. Le diamètre de l'œil fait le cinquième de la longueur de la tête, la moitić de l'espace préorbitaire; le sourcil porte trois ou quatre petits tentacules déliés; sur le milieu de la tète, de l'espace interorbitaire à la dorsale, se trouvent dix ¿ douze filaments sétacés; le tentacule nasal parait manquer. - La dorsale commence avant la fin de l'opercule, elle porte une tache noire dans son premier espace intraradiaire; l'anale est bordée de noir, elle a des excroissances en champignons sur les deux premiers rayons; les pectorales ne vont pas jusqu'à l'anale.

D. $12 /$ It $^{\text {ou }} 15 ;$ A. $2 / 16$ à $18 ;$ C. $15 ;$ P. 16 ; V. $1 / 2$.

La teinte est variable, tantôt d'un brun assez uniforme, tantôt d'un gris brunâtre avec de larges taches noires formant des bandes verticales sur le dos et le haut des côtés.

Habitat. Océan, excessivement rare, la Rochelle.

12. LE BLENNE DE MONTAGU. - bLENNIUS MONTAGUI, Flem.

Pois?. France, t. II, p. 138.

Long. : 0,0 ä à 0,08 . 
La hauteur du trone est comprise cinf fois et demie à six fois dans la longueur totale. - La tête est aussi haute que longue, sa longueur fait le cinquième de sa longueur totale; le museau est court; la mâchoire supérieure est légèrement avancée, elle est garnie d'une rangée de quarante à cinquante dents; il y en a une dizaine de moins à la mandibule, qui seule est armée d'une canine assez forte; sur le milieu de la tête est attaché un lambeau charnu, plus haut que large, de forme triangulaire, garni de nombreuses petites franges, principalement sur le bord supérieur; à la suite se montrent sur la nuque cinq ou six filaments sétacés. Le diamètre de l'œil mesure le quart de la longueur de la tête; il n’y a pas de tentacule sur le sourcil. Le tentacule nasal est petit. - La dorsale commence avant la fin de lopercule; elle est échancrée; elle est attachée par une membrane au troncons de la queue; elle est d'un gris pàle, avec de petites taches brunes sur les rayons. L'anale commence après l'extrémité des pectorales; elle est d'un gris pâle avec une bordure d'un gris rougeàtre; la pointe des rayons est blanchàtre. La caudale est arrondie, assez courte, d'un gris jaunâtre pâle, avec trois ou quatre rangées de points gris rougeâtre formant des bandes verticales. Les pectorales sont bien déreloppées, de teinte grisàtre; les ventrales sont moitié moins longues que les pectorales, d'un blanc jaunâtre.

D. 12 ou $13 / 16$ a $18 ;$ I. 1 ou $18 ;$ C. $12 ;$ P. $12 ; \mathrm{V} .2$.

La teinte générale est un gris brunàtre avec des taches plus foncées; ordinairement une série de taches blanches se montre sur les côtés, allant des pectorales à la caudale; la gorge est d'un gris roussâtre; le ventre d'un gris bleuâtre.

Habitat. Méditerranée, très rare, Nice. Océan? Manclie, excessirement rare, Roscoff, Perros.

13. LE BLENNIE BASILIC. - BLENNIL'S BASILISCUS, Valenc.

Poiss. France, t. II, p. 1 'to.

Long. : 0,13 à $0,1 \mathrm{~s}$. 
La hauteur du tronc fait le cinquième de la longueur totale. - La longueur de la tête est contenue quatre fois et trois quarts à cinq fois et demie dans la longueur totale; le museau est court; la mâchoire supérieure est munie d'une trentaine de dents, l'inférieure en a quelques-unes de moins; la dernière dent est une canine assez faible à la màchoire supérieure, beaucoup plus forte à la mandibule; la crête est mince, assez haute, moins saillante que dans le Blennie paon; il n'y a pas de tentacule nasal, ni de sourcilier, à moins de donner ce nom à un tubercule très court, peu distinct; le diamètre de l'oil est compris cinq fois et demie dans la longueur de la tête, il mesure environ les deux tiers de l'espace préorbitaire. - Après la fente branchiale commence la dorsale, qui est bien déreloppée, à peu près égale.

\section{D. $12 / 23$ à 25 ; A. 26 à 28 ; C. 15 ; V. 2 .}

Le ton général est des plus brillants, d'un vert ou d'un gris olivâtre arec des bandes rerticales d'un noir violacé, qui viennent de la dorsale et se continuent sur le corps; ces bandes sont bordées d'une ligne blanche sur la dorsale, le dos et la partie supérieure des côtés, puis elles semblent bifurquées; une ligne blanche sépare, en deux moitiés verticales, leur partie inférieure. Une bande noirâtre s’étend sur la base de la dorsale. En arrière de l'ceil et de la crête, une bande noire descend de la région supérieure sur les pièces operculaires; d'autres bandes noires se voient sur la tète.

Habitat. Méditerranée, très rare, Toulon. Océan, Arcachon?

1'. LE BLENNIE TRIGLOIDE. -- BLENNILS TRIGLOIDES, Valenc.

Poiss. France, t. II, p. 142.

Long. : 0,0 ว̋ à 0,090 .

La hauteur du tronc est contenue quatre fois et demie à cinq fois et demie dans la longueur totale. - La tète est cuboïde, fort semblable à celle d'un Trigle; sa longueur fait à peu près le quart de la longueur totale; le museau est court; les màchoires sont garnies de vingt à vingt-quatre dents, la dernière 
est une canine plus cléveloppée à la mandibule qu’à la mâchoire supérieure. Le diamètre do l'weil mesure le quart de la longueur de la tête, les deux tier's de l'espace préorbitaire; il n'y a pas de tentacule au sourcil; à l'orifice antérieur de la narine se voit un petit tentacule frangé. - La ligne latérale est bien dessinée; elle est arquée en avant. - La dorsale est basse en avant, très échancrée dans sa partie moyeune, elle est séparée de la caudale; le bord postérieur de l'orbite est plus rapproché de la dorsale que du bout du museau; la caudale est arrondie; la pectorale est aussi longue que la têle.

D. $12 / 16 ;$ A. $18 ;$ C. $14 ;$ P. $12 ;$ V. 2.

La teinte est d'un gris brunatre avec des taches ou des bandes transversales noirâtres en arrière de l'œil, sur le dos et les côtés; parfois une bande blanchâtres'allonge sur les flancs; la caudale est traversée de bandes noirâtres.

Habitat. Méditerranée, très rare, Nice, Cette; le spécimen qui me vient de Cette a 0,090 de longueur.

\section{LE BLENNIE PHOLIS. - BLENNIUS PHOLIS, Linn.}

Poiss. France, t. II, p. 143.

N. vulg. : Baveuse, Picardie, Normandie; Lentèque, Mordocet, Bretagne; Syrène et Serène, Noirmoutiers; Sirène, Poitou; Cabol, Basses-Pyrénées.

Long. : 0,10 à 0,12 et mème 0,13 .

La hauteur du corps est comprise cinq à six fois dans la longueur totale. - La tête est de proportions variables; sa longueur est contenue quatre fois à quatre fois et quart dans la longueur totale; le museau est arrondi; les lèvres sont grosses; les mâchoires sont à peu près égales; il y a une vingtaine de dents à la màchoire supérieure, chez les sujets de grande taille, quelques-unes de moins à la mandibule; la dernière dent est une canine assez forte. Le diamètre de l'œil fait. suivant la taille des sujets, le quart ou le cinquième de la longueur de la tète; il n’y a pas de tentacule sur le sourcil; le tentacule nasal est très court, palmé. - La lignne latérale est

Horeac. - Ichthyolugic. 
assez marquée; elle est courbe en avant. - La dorsale est inégale; elle est échancrée à la fin de sa région épineuse; sa région molle est régulière; le dernier rayon est attaché sur le tronçon de la queue par une membrane qui finit avant la caudale; l'anale commence au-dessous de l'échancrure de la dorsale; les pectorales sont bien développées, elles sont larges et longues, faisant près du quart de la longueur totale; les ventrales sont d'un cinquième plus courtes.

$$
\text { D. } 12 / 18 \text { ou } 19 \text {; A. } 18 \text { ou } 19 \text {; C. } 11 \text {; P. } 13 \text {; V. ? ou } 3 .
$$

Le système de coloration est des plus variables, parfois rougeàtre, parfois verdâtre semé de points noirs, ou bien encore gris jaunâtre; souvent, chez de petits individus, la teinte est d'un gris rougeàtre arec des taches noires et une suite de taches blanches, formant parfois une bande presque continue sous la ligne latérale. La dorsale est d'un gris plus ou moins pâle, parfois jaunâtre ou teinté de brun; il y a généralement une tache brunâtre dans le premier espace intraradiaire; l'anale est tantôt d'un jaune assez clair, tantôt grisâtre ; la pointe des rayons est blanche; la caudale est d'un gris jaunatre avec des taches brunes; les pectorales sont de même teinte à peu près que la caudale; les ventrales sont tantôt blanchâtres. tantôt d'un gris clair.

Habitat. Còtes de l'Ouest; Océan, assez commun. Manche, comnun, Bretagne, Normandie, un peu moins comnun en Picardie.

\section{GENRE CLINUS. - CLINUS, Guv.}

Corps allongé, comprimé, couvert de petites écailles cycloïdes.

Tête; màchoires garnies de dents sur plusieurs rangées; vomer denté; un tentacule sur le sourcil.

Appareil branchial; fente des ouïes très grande; six rayons branchiostèges.

Nageoires; deux dorsales; la première courte, la seconde longue.

LE CLINUS ARGENTE. - CLINUS IRGENTATLS, Riss.

Poiss. France, t: II, p. 147, fig. 9\%; anim.

Long. 0,06 à 0,10 . 
Le corps est très comprimé, allongé, sa hauteur est comprise six fois dans la lonğueur tolale. - La tête est longue, sa longueur est contenue einq fois à cinq fois el demie dans la longueur totale; le museau est court; les mâchoires sont munies de deux rangées de dents en avant, d'une seule en arrière; il y a sur le vomer un groupe de petiles dents. Le diamètre de l'œil fait le quart ou le cinquième de la longucur de la tête, il est égal à l'espace préorbitaire; le sourcil porte un tentacule fort petit. - La première dorsale est courte, à trois rayons seulement; elle est unie par une membrane à la la seconde dorsale qui est très longue, comptant une trentaine de rayons épineux et trois ou quatre rayons mous; l'anale est longue; elle est, comme la seconde dorsale, fixée par une membrane sur le tronçon de la queue; la caudale est carrée.

$$
\text { D. } 3-29 \text { à } 31 / 3 \text { ou } 4 ; \text { A. } 2 / 20 \text { à } 23 \text {; C. } 10 ; \text { P. } 9 \text { ou } 10 ; \text { V, } 1 / 2 \text {. }
$$

Le système de coloration est très variable; tantôt d'un jaune gris très clair arec des taches plus ou moins foncées; il y a souvent une série de cinq taches blanches sur les llancs; tantôt la teinte est d'un hrun foncé ou rougeâtre avec les nageoires plus ou moins noirâtres; la caudale a les rayons médians pâles et les externes noirâtres; il y a le long des flanes des taches d'un gris argenté; parfois la coloration est rougecitre.

Habitat. Méditerranée, assez rare à Nice; rare, Toulon, PortVendres.

\section{GENRE TRIPTÉRYGIOX. - TRIPTERYGION, Riss.}

Corps allongé, couvert d'assez grandes écailles ciliées.

Tête longue; màchoires et vomer dentés.

Nageoires; trois dorsales; anale unique.

LE TRIPTÉRYGION I BEC. - TRIPTERTGION N.ASUS, Riss.

Poiss. Frence, L. II, P. 130.

N. vulg. : Barecea d'Alga, Nice.

Long, : $0,0: 3$ is 0,06 . 
Le corps est légèrement fusiforme; sa hauteur est comprise cinq fois et demie à six fois dans la longueur totale. - La longueur de la tête mesure le quart ou le cinquième de la longueur totale; le museau est saillant, étroit, relevé en avant; la bouche est horizontale; les màchoires sont garnies de plusieurs rangées de dents; celles de la rangée externe sont plus fortes que les autres; le vomer porte des dents très fines. Les yeux sont grands, leur diamètre faisant le quart environ de la longueur de la tête; le sourcil porte un tentacule fort peu développé;il existe également un petit tentacule nasal. - La ligne latérale est droite; ligne long. écail. 34 à 40 ; ligne transr. $\frac{3 \text { ou } 4}{7 \text { i } 9}+1=11$ à 14 . - Il y a trois dorsales, la première est très avancée, basse et courte; la seconde dorsale est quatre fois plus longue que la première et double au moins de la troisième, son premier rayon est ordinairement le plus développé, il mesure, dans les màles, parfois le quart de la longueur totale, il est libre dans une partie de sa longueur; la troisième dorsale est formée de rayons mous, elle finit à une certaine distance de la caudale; l'anale est longue, elle commence avant la fin des pectorales et se termine sous le dernier rayon de la troisième dorsale; la caudale est large, arrondie; les pectorales sont bien développées.

Br. 6. -D. $3-14$ à $17-9$ à $12 ;$ A. 24 ou $25 ;$ C. $1 / 11$ ou $12 / 1 ;$ P. 14 à $16 ;$ V. 2.

Chez les mâles adultes, la tête est noirâtre; chez les femelles et les jeunes mâles, elle est grise avec des taches noires. Le corps est blanc grisâtre ou gris rougeâtre arec une huitaine de bandes verticales brunes. La première dorsale est grise souvent tachetée de noirâtre; les ventrales sont grises et le plus ordinairement noirâtres à partir de la bifurcation de leurs rayuns ; les autres nageoires sout orangées; les deux dernières dorsales et la caudale ont des bandes vertes ou bleues. Parfois la tête est rougeâtre avec le museau noir, la gorge jaunâtre, le corps rougeâtre marqué de taches noires.

Habitat. Méditerranée, assez rare, Nice, Toulon, Marseille; Cette? 
4. GENRE GONNEILE. - GUNNE I.LUS, Cuv.

Corps allongé, comprimé, couvert de petites écailles lisses.

Tête courte; bouche peu fendue; màchoires dentíes.

Appareil branchial; pièces operculaires cachées dans la peau, cinc rayons branchiostèges.

Nageoires; dorsale unique, très longue el très basse, à rayons tous épineux; anale longue, à premiers rayous épineux; ventrales rudimentaires.

\section{LE GONNELLE VULGAIRE. - GUNNELLUS VULGARIS.}

Poiss. France, t. II, p. 153.

N. vulg. : Papillon de mer, Poitou.

Long. : $0,13 ̈$ à 0,20 .

Le corps est ensiforme; sa hauteur est comprise huit à neuf fois dans la longueur totale. - La tête est très petite, sa longueur est ì peu près égale à la hauteur du tronc; le museau est court; la bouche oblique, petite; les mâchoires ont une rangée de petites dents coniques; le chevron du vomer porte quelques dents excessivement peu développées. Le diamètre de l'ceil est compris quatre à cinq fois dans la longueur de la tète, il est un peu plus grand que l'espace préorbitaire. Les membranes branchiostèges sont unies sous la gorge. - La dorsale s’étend sur toute la longueur du corps, elle est basse, elle finit près de la base de la caudale; l'anale est longue, elle est unie à la caudale par une membrane; la caudale est arrondie, courte; les pectorales sont un peu plus longues que la caudale; les ventrales paraissent réduites à un rayon court, épineux, mais elles ont en outre deux petits rayons mous enveloppés dans la peau.

$$
\text { Br. ๖. - D. } 7 \text { i } 1 \text { a } 81 ; \Lambda .2 / 39 \text { à } 13 \text {; C. } 15 \text {; P. } 11 \text {; V. } 1 / 2 \text {. }
$$

La coloration est grisâtre, quelquefois d'un brun roussâtre; une dizaine de taches arrondies, noirâtres, cerclées de blanc, se montrent sur le dos et la base de la dorsale; le dessous du corps est d'un gris assez clair. La tête est teintée de jaune et 
marquée d'une bande plus ou moins foncée, qui, du bord antérieur de l'orbite, descend rers l'angle de la bouche.

Habitat. Nanche, assez rare, Picardie, Normandie; assez commun, Finistère, Roscoff. Océan, assez rare, còtes de Bretagne; rare, Poitou, Aunis, la Rochelle.

\section{GENRE ZOARCES. - ZOARCES, CUV.}

Corps allongé, efflé en arrière : écailles très petites non imbriquées. Tête longue; dents sur les màchoires; romer el palatins lisses. Appareil branchial; six rayons branchiostèges; fausses branchies. Nageoires; nageoires impaires réunies; caudale non distincte; dorsale très longue, basse, à rayons mous dans la plus grande partie de son étendue, ayant en arrière une série de rayons beaucoup plus bas et formant ainsi une espèce d'échancrure après laquelle se trouvent des rayons mous; anale très longue, sans rayons épineux; ventrales peu développées.

\section{LE ZOARCES VIVIPARE. - ZOARCES VIVIPARUS, Valenc.}

Poiss. France, t. II, p. 136, fig. 98, anim.

N. vulg. : Loquette, Abbeville; Lolte, Dunkerque.

Long. : 0,15 à $0,2 \%$, quelquefois plus.

Chez le Zoarcès, le corps est allongé, comprimé en arrière, sa hauteur est comprise huit à neuf fois dans la longueur tolale; la peau est molle. - La tête a le profil supérieur légèrement arrondi; sa longueur fait le sixième environ de la longueur totale; la mâchoire supérieure est plus avancée que la mandibule; l'une et l'autre portent des dents coniques, mousses, placées sur deux rangées en arant, sur une seule latéralement; le palais et la lang'ue sont lisses. Le diamètre de l'œil est contenu de quatre à six fois dans la longueur de la tête; il est moins grand que l'espace préorbitaire. Les pièces operculaires sont enveloppées dans la peau. - La ligne latérale est droite, peu marquée. - Les nageoires impaires sont réunies; la dorsale commence au-dessus de la fin de l'opercule; sa partie antérieure très longue est composée d'environ quatre-vingts rayons mous, elle est séparée de la portion ter- 
minale par une série de layons durs, pointus, deux ou trois fois plus courts que les précédents, formant une dépression très sensible, après viennent des rayons mous un peu plus élevés. L’anale a tous ses rayons mous. Les pectorales sont arrondies, un peu plus longues que la tète. Les rentrales sont courtes, à rayons enveloppés dans la peau.

\section{78 i $80 / 10 / 22$ it $25 ;$ A. 84 à 89 ; P. 18 ; V. 3 .}

Sur le dos et les flanes, la coloration est diun gris roussatre; une douzaine de bandes brunatres descendent de la dorsale rers la région supérieure du corps; parfois ces bandes sont plus ou moins effacées; sur les côtés se voient quelques taches brunitres: la partie inférieure est d'un grls brunâtre. La dorsale est d'un gris roussâtre arec des bandes brunàtres rerticales; l'anale est teintée d'un jaune rougeàtre; les pectorales sont grrisàtres arec une bordure jaune rougeâtre.

Habitat. Mer du Nord, assez commun à Dunkerque. Manche, excessivement rare, le Crotoy.

\section{GENRE ANARRHIQUE. - ANARRIICHAS, Arted.}

Corps développé, allongé; écailles très petites, non imbriquées. Tête forte; dents sur les màchoires, le vomer, les palatins.

Appareil branchial; sept rayons branchiostèges; fausses branchies.

Nageoires; dorsale très Iongue; à rayons simples; anale longue; caudale libre, arrondie; pas de rentrales.

\section{LANARRIIQUE LOUP. - INARRHICHAS LUPUS, Linn.}

Poiss. France, t. 2, p. 139.

Long. : 0,80 à 1,300 .

Le corps est beaucoup plus développé que dans les autres Blenniidés; il est allongé, comprimé, sa hauteur est comprise cinq fois à cinq fois et demie dans la longueur totale; la peau est épaisse avec de petites écailles sous-épidermiques, isolées. - La tète est forte, à profil supérieur arrondi; sa longueur fait le cinquième environ de la longueur totale; le museau est 
arrondi ; la bouche est bien fendue; il y a des dents coniques sur l'intermaxillaire et le devant de la mâchoire inférieure; il existe des dents plus ou moins tuberculeuses sur les côtés de la mandibule ainsi que sur le romer et sur les palatins où elles sont disposées sur deux rangées. Les dents sont portées sur des espèces de pédoncules. Les dents pharyngiennes sont coniques. Le diamètre de l'ceil fait le septième environ de la longueur de la tête, un peu moins de la moitié de l'espace préorbitaire. La fente branchiale est grande ; les pièces operculaires sont peu distinctes. - La dorsale commence un peu avant la base de la pectorale et se continue jusqu'à la racine de la caudale, à laquelle elle est unie par une petite membrane; elle est formée de rayons simples ou flexibles. L'anale finit un peu avant la dorsale, elle est composée d'un rayon simple, de trente-cinq à trente-six rayons articulés et de neuf à dix rayons branchus. Les pectorales sont arrondies, larges et longues: les ventrales manquent.

$$
\text { Br. 7. - D. } 75 \text {; A. } 46 \text {; C. } 1 \text { ou } 2 / 15 / 2 \text { ou } 1 \text {; P. } 10 .
$$

Le système de coloration est d'un gris jaunâtre ou verdâtre chez les jeunes; la teinte est plus foncée chez les grands individus, le corps porte huit à dix bandes brunatres, assez larges, qui descendent verticalement du dos sur les côtés. La dorsale est d'un gris brunâtre avec des lignes noirâtres; l'anale, la caudale et les pectorales sont d'un gris plus ou moins foncé.

Habitat. Rare sur nos còtes; Manche, Boulogne, le Havre. Océan, Charente-Inférieure, Gironde, Basses-Pyrénées.

\section{Famille des Callionymidés, Callionymidx, Bp.}

Corps allongé, déprimé, cunéiforme; peau lisse et nue.

Tête plus large que le tronc, triangulaire, aplatie; bouche petite; màchoire supérieure très protractile, plus longue et plus large que la mandibule, garnies l'une et l'autre de petites dents en velours ou en cardes très fines; palais lisse.

Yeux très rapprochés l'un de l'autre, plus ou moins tournés en haut. 
Appareil branchial; ouverture des ouïes étroite, placée vers la nuque; pièces operculaires enveloppées dans la peau; le préopercule est prolongé en arrière par une espèce d'apophyse, d'éperon portant, sur le bord supérieur, deux ou trois épines terminales divergentes à pointe dirigée en haut, et souvent encore, sur le còté externe de son bord inférieur, une autre épine, tournée en avant et en dehors.

Ligne latérale droite, rapprochée du los; le canal latéral est sous une série de pièces cintrées.

Nageoires; deux dorsales; la première arancée à trois ou quatre rayons simples; seconde dorsale et anale à rayons peu nombreux, une dizaine au plus, articulés et simples, excepté le dernier qui est généralement divisé en deux; caudale plus ou moins allongée; ventrales jugulaires, aussi ou plus développées que les pectorales, écartées l'une de l'autre, composées de cinq rayons mous et d'une petite épine.

Les Callionymes portent le nom de Lazer, Lézard, à Cette.

GENRE CALLIONYME. - CALLIONYMUS, Linn.

Caractères de la famille.

Le genre Callionyme se compose de cinq espèces.

a. Éperon operculaire à deux épines terwinales.........

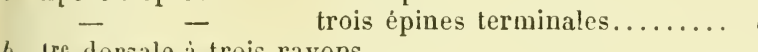

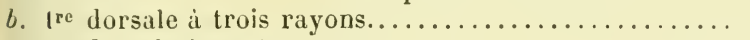

- dorsale à quatre rayons.................... $c$

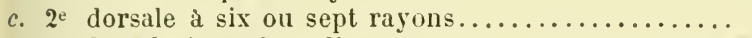

- dorsale à neuf ou dix rayons.................

d. Taches argentées sur le corps plus ou moins nom-

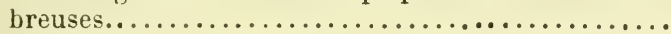

Taches argentées sur le corps nulles..............

5. PHAETON. b.

4. BEI.ÈNE.

3. LACERT. ,

2. TACHETÉ.

1. LYRE.

\section{LE CALLIONYME LYRE. - CALLIONYJUS LYRA, Linn.}

Poiss. France, t. II, p. 16 '.

Mále adulle.

N. vulg. : Chiqueur et Chiqueux, Dieppe; Lavandière, Fécamp ; Six-Deniers, le Havre; Savary, Caen; Cornard, Bretagne; Savary, Doucet, Poitou.

Long. : 0,2 ö à 0,30 .

La hauteur du tronc, qui ne fait guère que la moitié de la 
largeur, est comprise douze à quatorze fois dans la longueur totale. - La tête est oblongue, aplatie, beaucoup plus développée chez les mâles adultes que chez les femelles ou les jeunes mảles, sa longueur étant contenue, chez les premiers, trois fois et demie dans la longueur totale, et quatre fois chez les jeunes mâles. Le museau est arancé; la mâchoire supérieure est très protraciile; les deux màchoires sont garnies de dents en cardes fines. Chez les mâles adultes, le diamètre de l'œil mesure à peine le cinquième de la longueur de la tète, il en fait le quart chez les jeunes. Le préopercule se termine par une espèce d'éperon armé de quatre pointes; l'éperon est de grandeur variable, mais toujours moins long que le diamètre de l'oril. - La première dorsale commence au-dessus de la base des pectorales; elle a quatre rayons; le premier rayon est de longueur très différente suivant l’àge ou le développement des animaux; chez les màles adultes, il fait la moitié et plus de la longueur totale; dans les màles de grande taille mais non encore adultes, il mesure le tiers de la longueur totale, il a beaucoup plus de hauteur que la seconde dorsale; dans les tout jeunes mâles, il en a moins; la seconde dorsale est rapprochée de la première ; l'anale est à peu près aussi longue, mais moins haute que la seconde dorsale; la caudale est longue, coupée carrément; les pectorales sont larges; les ventrales sont très développées, écartées l'une de l’autre; enfin le dernier rayon de la seconde dorsale et le dernier de l'anale arrivent, quand ils sont couchés, à la base de la caudale.

$$
\text { D. } 4-9 ; \text { A. } 9 \text {; C. } 10 ; \text { P. } 19 \text { ou } 20 \text { V. } 1 / 5 .
$$

Le dessus du corps est d’un jaune orangé, avec des laches lilas, à bordure violacée; chez quelques animaux, la teinte générale est lilas ou violet clair avec des taches jaunâtres et brunâtres; le dessous du corps est blanc ou d'un goris très clair. La tête et les pièces operculaires sont marquées de taches lilas plus étroites que celles du corps. La première dorsale est de teinte orangée avec de larges taches lilas à bordure sombre ou violette; la seconde dorsale est orangée ou d'un gris jaunâtre assez pàle arec des bandes ou des taches lilas; l'anale est d'un blanc grisâtre vers la base, noirâtre dans le reste de son éten- 
dur ; la caudale est noirtre; les pectorales sont l'un gris très pile; les rentrales sont noiritres avec des taches arpondies d'un lilas plus ou moins violacé.

Femelle. - Le Callionyme dragonneau, Callinnymus dracunculus, Lacép.

N. vulg. : Doucet, Sèche, Cherbourğ; Dragon, Dragonnet, Poitou. Long. : 0,20 ì $0,2 \ddot{3}$.

La longueur de la tète fait le quart seulement de la longurueur Lotale. Le diamètre de l'óil mesure le cinquième de la longueur de la tìte el la moitié au moins de l'espace préorbitaire. - Le premier rayon de la première dorsale ne fait guère que le dixième de la longueur tolale; il est moins élevé que le premier rayon de la seconde dorsale; le dernier rayon de la seconde dorsale et le dernier de l'anale n'atteignent pas, quand ils sont couchés, à la racine de la caudale. La coloration est moins brillante que chez le mâle; elle esi jaunâtre avec des taches d'un lilas grisatre ou brunatre: les deux derniers rayons de la première dorsale sont noirùtres, parfois mème le second, le premier seul est orangé.

Jeune. - Le Callionyme élégant, Callionymus elegans, Lesueur.

Long. : $0,0 \%$ à $0,0 \%$.

Ce Poisson, d’après Lesueur, n'a guère plus de 7 centimètres de longueur; son corps est varié de dessins ocellés d'une couleur blanchâtre sur un fond brun.

Habitat. Manche, assez commun en Picardie, plus commun en Normandie; très commun au Ilarre, à Trouville, dans les mois de juin, juillet, aoùt; commun, Cherbourg; assez commun en Brelagne. - Océan, assez rare. - Méditerranée, Irès rare. J'ai eu de Celle des spécimens pèchés aux bateaux-bœufs. - I propos du Cullionymus lypa, II. Vineiguerra dit qu'il conserve encore quelque doute sur l'existence de cette espèce dans la Méditerranée; il ajoute que sur les marchés des villes francaises, anche poste sul Mediterraneo, sono frequentemente spediti pesci provenienti dall Oceano, ne sureble del tutto improbabile che tal origine avessero gli esemplari ricor- 
dati (comme ayant été capturés dans la Méditerranée). Vincig., Ap. ittiol., dans Ann. Mus. civ. Stor. nat. Genova, Gen. 1883̈, Ser. 2, t. II, p. $433-434$. - Cette insinuation malveillante, que je n'ai pas à relever, entraine une conséquence, non prévue sans doute par l’auteur, elle démontre nettement le manque de connaissance de M. Vinciguerra en litlérature ichthyologique; est-ce que, faisant l'histoire de cette espèce, Guichenot n’avait pas écrit? "Le présent poisson habite l'Océan et la Méditerranée, où il a été rapporté d'Alger. " (Guichen., Poissons et Reptiles, dans Expl. Sc. Algérie, p. 78.79).

\section{LE CALLIONYME TACHETÉ. - CALLIONYMUS MACULATUS, Rufin.}

Poiss. France, p. 169.

N. vulg. : Moulette, Lambert, Nice, Narseille; Pinaou, Cette.

Long. : $\sigma^{x}, 0,08$ à 0,$11 ;, 0,0,06$ à 0,08 .

Chez les mâles, la hauteur du tronc est contenue onze à treize fois dans la longueur totale, neuf à dix fois chez les femelles. - La longueur de la tête est comprise quatre fois et quart à cinq fois dans la longueur totale; le museau est obtus, la bouche assez grande. Le diamètre de l'œil, qui est égal à l'espace préorbitaire, fait le quart et parfois le tiers de la longueur de la tête; le prolongement du préopercule est muni de trois ou quatre pointes, l'épine inférieure, à pointe dirigée en avant, manque parfois. - La première dorsale a quatre rayons ; chez le mâle, le premier rayon est très mince et très allongé,il mesure les deux cinquièmes de.la longueur totale; le double des deux rayons suivants; la seconde dorsale est très développée, c'est une espèce de large voile soutenu par de grands rayons minces et flexibles; l'anale finit après la seconde dorsale, ses derniers rayons sont allongés, ils atteignent presque la caudale; chez les femelles, la première dorsale est triangulaire, moins haute que la seconde; les derniers rayons de l'anale ne vont pas jusqu'à la caudale; dans les deux sexes, la caudale est arrondie; les pectorales sont larges, mais courtes, d'un tiers moins longues que les ventrales.

D. $4-9$ ou $10 ;$ A. 8 ou 9 ; C. $13 ;$ P. $16 ;$ V. $1 / 5$.

En dessus le corps est d'un jaune verdâtre fort pâle, parfois 
grisàtre: sur les côtés, il y a quelques taches brunes et deux rangées de taches nacrées ou plutôt d'un blanc laiteux, parfois les taches nacrées sont dispersées sans ordre; le dessous du corps est d'un blanc rosé très pàle. La tète est d'un jaune clair, avec une teinte d'un blanc laiteux sur les côtés; l'espace préorbitaire et la nuque sont d'un rouge lilas. Quand elles sont déployées, les dorsales sont magnifiques, surtout la seconde, chez les màles, le fond est d'un gris pâle relevé par des taches noires et des taches d'un blanc laiteux à milieu plus foncé formant des espèces d'ocelles; chez les femelles, les dorsales sont pàles, marquées de taches noires. L'anale est grisâtre, bordée de noir ; la caudale est d'un jaune très pâle ainsi que les ventrales, qui sont bordées de gris foncé; les pectorales sont pâles.

Habitat. Méditerranée, assez rare à Nice, moins rare à Marseille, à Cette.

Ce Callionyme n'est pas le Dracunculus de Rondelet, ainsi que l'écrit Fis Day, t. I, p. 177 .

\section{LE CALLIONYME LAGERT. - CALLIONYMUS DRACUNCULUS,} Rond.

Poiss. France, t. II, p. 172, fig. 99, anim.

N. vulg. : Lambert, Nice.

Long. : $\sigma^{x}, 0,09$ à 0,11 , très rarement $0.14 ;, 0,0,07$ à 0,10 .

Chez les mâles, la hauteur du tronc est comprise dix à treize fois dans la longueur totale et neuf à dix fois chez les femelles. - La longueur de la tète fait le cinquième de la longueur totale; le museau est avancé, presque pointu. Le diamètre de l'iril mesure le cinquième de la longueur de la tète, la moitié ou les deux tiers de l'espace préorbitaire. L'ourerture des ouïes est très petite; l'éperon du préopercule est grêle et porte trois épines terminales; quant à l'épine inférieure à pointe dirigée en avant, elle parait toujours manquer. A l'exception de la première dorsale, les nageoires impaires sont beaucoup plus développées chez les mâles adultes que chez les temelles. Chez les mâles la première dorsale est basse, la seconde est très haute, 
trapézoïde, ses rayons antéricurs sont excessivement développés, mesurant, ou peu s'en faut, la moitié de la longueur totale; l'anale a le demier rayon très allongé; la caudale est pointue, lancéolée, à rayons médians plus développés que les autres. Chez les femelles, la seconde dorsale est un peu plus haute que la première; la caudale est arrondie.

$$
\text { D. } 4-6 \text { ou } 7 ; \text { A. } 9 \text { ou } 10 ; \text { C. } 10 ; \text { P. } 16 ; \text { V. } 1 / 5 .
$$

La teinte générale est grisâtre avec des points el des bandes d'un ton nacré; les parties latérales de la tête portent deux ou trois rangées de points argentés cerclés de noir; le dos est marqué de points noirs et de points argentés; les côtés sont traversés par seize à dix-huit bandes verticales nacrées et bordées de noir. Chez les màles, la seconde dor'sale est parcourue par des bandes obliques nacrées ou d'un bleu légèrement jaunàtre à bordure violette; la caudale est ornée de bandes semblables à celles de la seconde dorsale, sur un fond grisàtre clair; chez les femelles, la seconde dorsale est d'un gris clair, avec plusieurs bandes argentées; la caudale est marquée de quelques taches d'un brun plus ou moins foncé.

Habitat. Méditerranée, assez rare, Nice, Cette.

\section{LE GALLIONTME BELENE. - CALLIONYMUS BELENUS.}

Poiss. France, t. II, p. 1\%̈.

N. vulg. : Lambert, Nice.

Long. : 00,6 à 00.8 .

Chez les mâles, la hauteur du tronc fait le dixième de la longueur totale, le neurième chez les femelles. - La tête est développée, fort large en arrière, mesurant le quart de la longueur totale. Le diamètre de l'oil fait le quart de la longueur de la tête, il est égal à l’espace préorbitaire, à peu près de mème longueur que l'éperon du préopercule qui a trois pointes terminales. La première dorsale n’a que trois rayons, elle est très basse; la seconde dorsale est sensiblement plus élevée; son dernier rayon, chez les mâles adultes, est le plus développé, quand il est abaissé il s'étend jusque sur la caudale; il est 
moins long que les précédents, chez les femelles: chez les mâles adultes, l'anale a son dernier rayon plus allongé que chez les femelles; la caudale est à peu près carrée; les pectorales sont relativement bien développées, elles font le cinquième de la longueur tolale.

$$
\text { D. } 3-\text { i a } 9 \text {; A. } 9 \text {; C. } 10 \text {; P. } 17 \text {; V. } 1 / 5 \text {. }
$$

Chez les males, la coloration est d'un gris verdâtre ou jaunàtre avec des taches d'un rouge jaunàtre, le ventre est blanc; chez les femelles, la teinte est d'un gris plus foncé, jaunâtre arec des points noirs, la première dorsale est peut-ètre plus foncée que chez les màles; l'anale est d'une teinte à peu près uniforme; elle a, chez les mâles, une bordure d'un bleu plus ou moins foncé.

Habitat. Méditerranée, assez commun à Nice; rare à Cette.

ï. CALLIONYHE PHAETON. - CALLIONYMUS PHAETON, Günth.

Poiss, France, Suppl. p. 133.

Long: : 0,030 à 0,180 .

Dans ce Callionyme, l'éperon du préopercule est muni seulement de deux épines terminales et non de trois, comme chez les autres espèces; cette particularité fait nettement distinguer le C. phaëton de ses congénères. - Quant au mâle, il diffère de la femelle par le déreloppement des rayons médians de la caudale et du dernier rayon de la seconde dorsale.

$$
\text { D. } 4-8 \text { ou } 9 \text {; A. } 8 \text {; C. } 10 \text {; P. } 16 \text { à } 90 .
$$

Habitat. Méditerranée, accidentellement, Marseille; au commen-

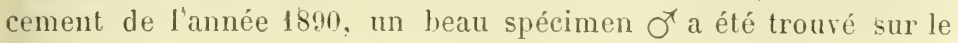
marché de Marseille; il a été acquis par le musée de Nice; jen ai donné les proportions, que M. le Dr C. Sarato avait eu la gracieuseté de me comnuniquer, ainsi que je l'ai rappelé, p. 122 du supplément it l'Histoire naturelle des Poissons de la France. Ce Callionyme n'a aucun rapport avec le C. Morissonii, bien que C. Bonaparte et Steindachner aient indiqué leur identité spécifique. 


\section{Famille des Lophiidés, Lophiidx.}

Corps déprimé, large en avant. Peau complètement nue; sur les còtés, appendices cutanés plus ou moins frangés. Squelette formé d'un tissu spongieux, de faible consistance; vertèbres au nombre de ringt-cinq à trente et une.

Téte énorme, aplatie, épineuse, portant deux ou trois tentacules libres, allongés, mobiles, qui sont des rayons détachés de la première dorsale. Bouche très fendue; mandibule avancée; màchoires armées de dents pointues, plus ou moins mobiles; palais denté.

Yeux placés en dessus; pas de sous-orbitaires.

Narines; organe olfactif porté sur un pédoncule.

Appareil branchial; ouverture des ouïes au-dessous de l'insertion de la pectorale; lames respiratoires sur trois arcs branchiaux seulement; pharyngiens dentés. Six rayons branchiostèges; pas de pseudobranchies.

Nageoires; deux dorsales; rayons antérieurs de la première dorsale isolés et placés très en avant, le premier, se trouvant vers le bout du museau, est terminé par une membrane plus ou moins développée. Pectorales pédiculées, portées sur deux us du carpe excessivement développés. Ventrales jugulaires, très rapprochées lune de l'autre.

Vessie natatoire nulle.

Appareil digestif; estomac très grand; deux appendices pyloriques.

GeNRF: PAUDRoIE. - LOPHIUS, Arted.

Caractères de la famille

Deux espèces.

Épine coracoïdienne faisant la moitié de la distance qui la sépare de la pointe supérieure du coracoïdien........ 1. Consuxe. Épine coracoldienne égale à la distance qui la sépare de la pointe supérieure du coracoïdien................. 2. BCDEgass.

1. IA BALDROIE COMMUNE. - LOPHIUS PISCATORIUS, Linn.

Puiss. France, t. II, p. 180.

N.vulg. : Boudraie, Nice; Booudroï, Cette; Crapaud, Arcachon ; Baudreuille, île de Ré; Narache, Loire-Inférieure, Vendée; CabotVorage, Vendée; Madeleine, Diable, Ange, Cherbouror ; Baudreuil et 
Vaudreuil, Seine-Inférieure; Diable de mer, Crapand de mer, Grenouille pècheuse, Pescheteau.

Long. : 0,70 à 1,50 et mème 2,00.

Les parties latérales du corps sont munies d'appendices cutanés plus nombreux et plus ciliés que dans la Budegassa; le nombre des vertèbres est de trente et une. - La tête est excessivement large, déprimée, concave depuis l'occipital jusqu'à la base du second tentacule; elle porte en dessus quelques épines et le plus souvent trois tentacules libres; sur les côtés de la tête el sur la mâchoire inférieure se trouvent de nombreux appendices cutanés; la bouche est énorme; la màchoire supérieure est beaucoup plus courte que la mandibule; elles sont, l'une et l'autre, armées de dents coniques, crochues, plus ou moins mobiles, disposées généralement sur deux rangées en avant; les palatins ont une rangée de sept ou huit dents, quelquefois dix; le chevron du romer en porte quelques-unes sur chacun de ses angles latéraux. Les yeux sont placés sur le dessus de la tête. L'ouverture de l'ouĩe est très reculée, audessous de la pectorale; la partie postérieure du préopercule se divise en une vingtaine de rayons allongés formant éventail. - La première dorsale se sépare en deux parties, la partie céphalique composée de trois rayons isolés, qui ont été nommés filets pêcheurs; la seconde partie de la dorsale est formée de trois rayons assez grêles, insérés à la région antérieure du tronc; la seconde dorsale est opposée à l'anale; la caudale est carrée. Le scapulare s'articule directement avec le crầne; le coracoïdien est très développé, il porte, au-dessus du pédoncule de la pectorale, une apophyse munie de trois pointes; faisant la moitié environ de la longueur de l'espace qui la sépare de la pointe supérieure du coracoïdien; le pédoncule de la pectorale est constitué par deux os du carpe très allongés.

D. $1+1+1+3-10$ a $12 ;$ A. 10 ou 11 ; C. 8 ; P. 23 ou $24 ;$ V. $1 / 5$.

Le système de coloration est d'un brun olivàtre en dessus, grris blanchâtre ou blanc sale en dessous:

Habitat. La Baudroie se trouve sur toutes nos còtes; elle est plus ou moins commune. 
Dans une note, fort intéressante, sur les ovaires de la Baudroie commune, M. Mocquard, Aide-naturaliste au Muséum, rappelle la fécondité extraordinaire de ce Poisson. Chez un spécimen mesurant 1, 千ä de longueur, il a calculé la quantité des œufs les plus développés, devant faire partie de la première ponte; il en a trouvé un nombre d'environ 1,800,000. - Cette évaluation, dit l'auteur, reste plutòt en decà qu'au delà de la réalité. Sur les ovaires de la Baudroie, par I. F. Mocquard, extrait du Bull. Soc. philomath. Paris, se série, t. $1, n^{0} 1$, p. 16 .

\section{LA BAUDROIE BUDEGASSA. - LOPHIUS BUDEGASSA, Spinola.}

Puiss. France, t. II, p. 18:2, fig. 100, anim.

N. vulg. : Gianelli, Nice.

Long. : 0,40 à 0,70 .

La Budegassa ne devient jamais aussi grande que la Baudroie commune; les lambeaux cutanés de ses flancs sont aussi moins nombreux, moins divisés; la colonne rachidienne n'a généralement que vingt-cinq ou vingt-six vertèbres. - La tête semble plus longue et moins large que dans l'autre espèce. - Le rayon antérieur de la prenière dorsale, ou le grand tentacule est plus grêle et plus court que dans la Baudroie commune, sa membrane est effilée; le plus souvent la seconde dorsale n’a que neuf rayons. L'épine coracoïdienne est beaucoup plus développée que dans l'autre espèce; sa longueur est égale à la distance qui existe entre sa base et la pointe supérieure du coracoïdien, elle fait le cinquième de la longueur de la tête, chez de jeunes animaux.

$$
\text { D. } 1+1+1+3-9 \text { ou } 10 ; \text { A. } 9 \text {; C. } 8 \text {; P. } 20 ; \text { V. } 1 / 5 \text {. }
$$

En dessus, la teinte est d'un roussàtre presque marron avec de petites taches étoilées, le plus souvent blanchâtres; en dessous la coloration est blanchitre.

Habitat. Méditerranér, commune a Nice; très commune à Marseille, à Cette. 


\section{Famille des Batrachides, Batrachidie.}

Corps large en arant et déprimé, plus ou moins arrondi en arrière.

Tête nue, large, déprimée; bouche très fendue; dents à peu près igales, coniques, sur les màchoires, le vomer, les palatius. Appendices cutanés plus ou moins nombreux.

Yeux latéraux; pas de sous-orbitaires.

Appareil branchial; fente des branchies presque verticale, assez peu étendue, en avant des pectorales; pas de fausses branchies; opercule épineux.

Nageoires; deux dorsales; la première courte, formée de trois épines basses, réunies par une peau assez épaisse; seconde dorsale longue, ainsi que l'anale; caudale arrondie; ventrale divisée en deux parties.

GENRE BATRACHOHDE. - BATRACHUS, BI. Schn.

Caractères de la famille.

\section{LE BATRACHOIDE DIDACTYLE. - BATRACHUS DIDACTYLUS.}

Poiss. France, Suppl. p. 1 .

Long. : 0,30 à 0,33 .

De la ceinture scapulaire ì l'anus, le corps est presque de forme prismatique, puis devient plus ou moins arrondi; il est couvert de petites écailles minces et lisses ; sa hauteur est comprise six fois à six fois et quart dans la longueur totale. - La lète est garnic de tentacules assez nombreux; sa longueur, à peu près égale à sa largeur, est contenue environ trois fois et demie dans la longueur totale; le museau est court; les mâchoires, le chevron du vomer et les ptérygopalatins sont garnis de dents en velours ou en cardes fines; près de la mandibule, il y a des barbillons ou des tentacules plus ou moins nombreux. Les yeux sont placés latéralement vers le profil supérieur de la tète; le diamètre de l'œil mesure environ le sixième de la longutur de la tète, la moitié de l'espace préorbitaire, le tiers de l'espace interorbitaire. La fente branchiale est presque verti- 
cale ; les pièces operculaires sont couvertes par la peau ; l'opercule est armé de deux épines. - La première dorsale est avancée; elle est basse, formée de trois aiguillons courts ; la seconde dorsale est longue; l'anale finit dans le mème plan vertical que la seconde dorsale; la caudale est arrondie; la pectorale, insérée sur une large base, se déploie en grand éventail ; la ventrale est partagée en deux parties, l'extérieure, d'un quart environ, plus longue que l'autre.

Br. 6 . - D. $3-21$ ou 22 ; A. 15 ou 16 ; C. 16 à 18 ; P. 22 ou 23 ; V. $1 / 2$ à ?

La coloration est d'un brun assez foncé sur le dos, d'un brun roussâtre sur les côtés avec de petites taches noirâtres, d'un blane gris sous le ventre. Les dorsales, la caudale et les pectorales sont d'un brun jaunâtre avec des laches noiràtres; l'aṇale est d'un blanc jaunâtre assez clair avec des taches foncées ; les ventrales sont grisâtres avec des taches brunes.

Habitat. Méditerranée; accidentellement; Nice.

\section{II. - TRIBU DES AGANTHOPTÉRYGIENS THORAGIQUES. ACANTHOPTERYGII THORACICI.}

Cette tribu se compose de treize familles.

a. Ventrales réunies, formant ventouse; deux dorsales.............................

Ventrales séparées, ne formant pas ventouse..

b. Barbillons, déux articulés sous le mentou; deux

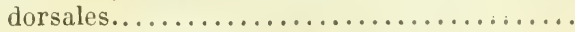

Barbillons articulés sous le menton nuls..... c.

c. Sous-orbitaire articulé avec le préopercule....

- non articulé avec le préopercule. $d$.

1. GobiInes.

d. Pharyngiens inférieurs soudés; dorsale unique. $m$.

2. Mullidés.

3. Triglidés.

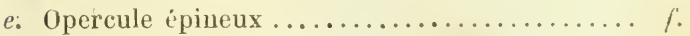

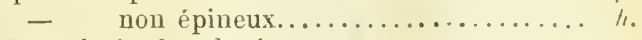

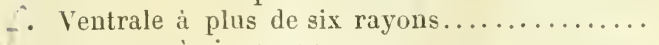

4. Bér Ycidés.

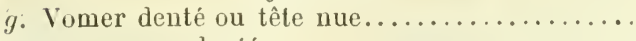

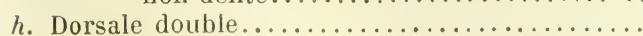

5. Percidés.

6. SCLÉnub́s.

i: Scombridés.

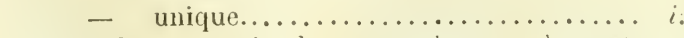

i. Dorsale composée de rayous à peu près seniblables................... 
Dorsale composée d'aiguillons et de rayous

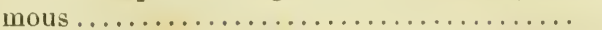

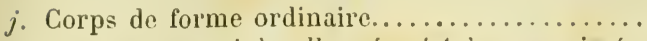

7. Sсомвнidés.

l. Ventrale nulle ou réduite a une écaille........

8. Thichiuridís.

- plus ou moins longue ou ì plusieurs

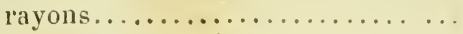

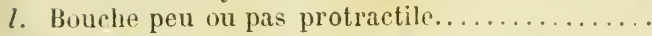

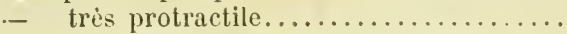
m. Écailles eycloïdes; caudale non fourchur...... Ecailles pectinées, caudale fourchue..........

9. T.eniombís.

10. SpariuÉs.

11. MÉnIDÉs.

12. LABRIDÉS.

13. Ponacenthidés.

\section{Famille des Gobiadés, Gobiidx.}

Corps allongé, couvert d'écailles, parfois caduques.

Tête; màchoires dentées; langue et palais lisses.

A ppareil branchial; pièces operculaires lisses; quatre ou cinq ravons branchiostèges; fausses branchies.

Nageoires; deux dorsales; ventrales soudées à leur base et formant ventouse, ayant un rayon épineux et cinq mous.

Cette famille se compose de deux genres.

Dents des màchoires sur plusieurs rangées............ 1. Gobre.

une seule rangée.............. 2. Арнуе.

1. GENRE GOBIE. - GOBIUS, Arted.

Corps allongé, arrondi, couvert d'écailles ordinairement cténoìdes; écailles de la gorge généralement non ciliées. Vertèbres au nombre de vingt-six à vingt-huit 10 à 12 †.

Tête plus ou moins allongée; màchoires à dents en velours ou en cardes, souvent plus fortes sur la ranøée externe.

Yeux rapprochés du profil supérieur de la tète, espace interorbitaire étroit.

Appareil branchial; fente des ouïes presque verticale; nem. brane branchiostège attachée à l'isthme.

Ligne latérale peu marquée ou nulle.

Nageoires; première dorsale à rayons simples, au nombre de cinq à sept; seconde dorsale avec un rayon simple et des rayons mous en nombre variable de neuf à seize.

Vessie natatoire tantòt présente, tantòt nulle chez des sujets de mème espèce. - Appendices pyloriques manquant.

Suivant certains auteurs, chez les Gobies, quand la vessie natatoire exisle, elle est fort petile, ce qui n'est pras toujours exact, ainsi 
chez le G. guttatus, elle a des dimensions très variables. - Ce qui est plus extraordinaire encore, c'est de trouver des sujets de même espèce et de même taille, tantôt pourvus, tantòt privés de cet organe. - Willoughby a constaté la présence de la vessie natatoire chez le Gobius niger Rondeletii: Vesica xrea temuis (Willughb., p. 206). D'après Hasselquist, il existe, chez le Gobius (paganellus, Linn.), un Duchus pneumaticus... infra initium vesicæ xrex incipiens (Hasselq., Iter Palæstinum, Pisces, p. 326). - Le D $\mathrm{D}^{\mathrm{r}}$ C. Sarato a découvert la vessie natatoire chez le G. ater, Bellotti, c'est le G. niger de Rondelet, chez le G. longiradiatus, G. ophiocephalus (G. lota), G. geniporus, G. cruentatus, G. auratus, G. fallax, G. quadrimaculatus, G. colonianus (C. Sarato, Notes ichthyologiques, dans Gazette de Nice, 2:-26 janvier 1890). - Dans une certaine quantité de spécimens de G.paganellus, C. V., j'ai pris deux sujets de grande taille et deux de taille moyenne, j'ai constaté la présence de la vessie natatoire chez un individu de grande taille et chez un de moyenne taille; il n'y en avait pas trace cliez les deux autres. - De nouvelles recherches sont nécessaires pour donner la raison de ce fait intéressant.

Le genre Gobie comprend un grand nombre d'espèces.

a. $1^{\text {re }}$ dorsale à six rayons, ou moins de 42 écailles en ligne longitudinale................. $b$.

$1^{\text {re }}$ dorsale à sept rayons.................. $s$.

$b$. Diamètre vertical de l'œil pas plus grand que l'espace interorbitaire ................. $c$.

Diamètre vertical de l'œil plus grand que l'esp ace interorbitaire .......................

c. Ventrales i membrane antérieure réduite; sans lobe latėral..........................

Ventrales à membrane antérieure large, développée .............................

$d$. Base de la première dorsale pas plus longue que l'espace postorbitaire...................

Base de la première dorsale plus longue que l'espace postorbitaire....................

$e$. Taches rouges sur les lèvres et le corps........ Pas de taches rouges sur les lèvres ni le corps.

$f$. Bandes blanches verticales sur le corps bien dessinées.......................... g.

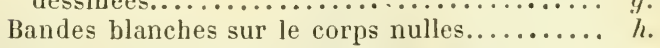

g. Bandes blanches au nombre de quatre....... - $\quad$ - plus de quatre..............

h. Rayons supérieurs de la pectorale non crinoïdes, ou it peine 2 , rarement $4 \ldots \ldots \ldots \ldots \ldots \ldots$. Rayons supérieurs de la pectorale crinoïdes,

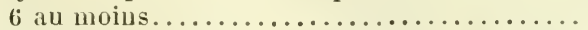

i. $2^{\mathrm{e}}$ dorsale à 10 ou 11 rayons, ou moins de 50 écailles dans la ligne longitudinale........ $j$.

1. LOTE.

d.

2. CÉPHALOTE.

3. A GOUTTELETTES.

4. FNSANGLANTÉ. $f$. 5. A 4 BANDES. (j. Ż̀BRE. 
2 e dorsale à 11 rayons au moins, ou plus de 50 écailles dans la ligne longitudinale......... $m$.

j. Largeur de la tite faisant au moins les trois

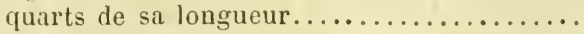

Largeur de la tète faisant moins des trois quarts

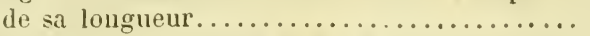

k. Ventrales plus longues que les pectorales......

Ventrales à peu près de mème longueur que les

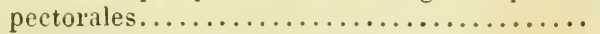

1. Taches noires sur les flancs peu marquées...

Taches noires sur les flancs, quatre bien mar-

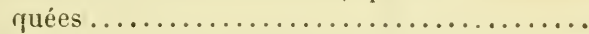

$m$. Ventrales i membrane antérieure développée..

Ventrales à membrane antérieure très réduite

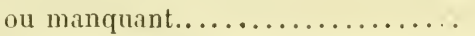

n. Écailles de la ligne longitudinale an moins 50..

- de la ligne longitudinale, 40 environ...

- de la ligne longitudinale moins de $30 .$.

o. Ligne longitudinale à plus de 48 écailles.......

à moins de 48 écailles.....

$p$. Taches noires sous la gorge en plusieurs séries.

Taches noires sous la gorge nulles...........

$q$. Écailles de la ligne longitudinale au nombre de

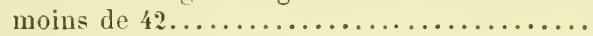

Écailles de la ligne longitudinale au nombre de

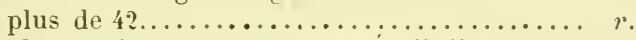

$r .2^{e}$ dorsale à 13 ou 14 rayons. Écail. ligne long.

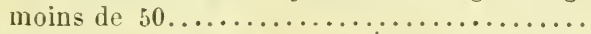

$?^{\circ}$ dorsale i 15 ou 16 rayons. Écail. ligne long.

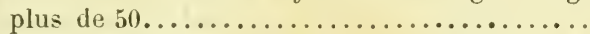

s. Tache i la base de la caudale noirâtre.......

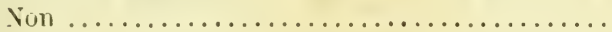

i. A LALGE TÉTE.

k.

10. RÉTICULÉ.

$l$.

S. COLONIEN.

9. A 4 TACHES. $n$.

$o$.

1!. BUHOTтE.

12. JOZO.

13. LESUEUR.

14. A JOUE PORECSE.

15. TROMPEUR.

16. DORÉ.

17. NOIR.

A Cette, les spécimens de grande taille portent le nom vulgaire de Gobi, les jeunes ou les petits, celui de Mougnou.

\section{GOBIE LOTE. - GOBIUS LOTA, Valenc.}

Poiss. France, t. II, p. 200, fig. 101, anim.

Long. : 0,1 t' à 0,18 .

La hauteur du tronc est comprise cinq lois et demie à six fois dans la longueur totale. - La tète est forte; sa longueur est contenue quatre fois à quatre fois et demie dans la longueur totale; les màchoires sont garnies de dents sur plusieurs rangées; les dents de la rangée externe sont relativement assez fortes, crochues, paraissant un peu moins développées à la mìchoire supérieure qu’à la mandibule. Le diamètre horizon- 
tal de l'wil est compris cinq fois et demie environ dans la longueur de la tête; le diamètre vertical est un peu moins grand que l'espace interorbitaire. La fente branchiale est grande relativement, elle est plus longue que la distance qui sépare, l'un de l'autre, les lobes anguleux de la membrane branchiostège, c'est le contraire dans le Gobie céphalote. -- Pas de ligne latérale marquée; les écailles sont au nombre de soixante ì soixante-cinq dans la ligne longitudinale, de dix-sept à dixhuit dans la ligne transversale: Ec., l. long. 60 à 6.3, l. transr., 17 à 18. - Généralement la première dorsale est un peu moins haute que le tronc; ses rayons se terminent en filaments libres dans une certaine étendue; les pectorales sont assez. larges, rarement ses rayons supérieurs sont crinoïdes; les ventrales sont assez courtes, elles ne vont pas jusqu'à l'anus ; leur membrane antérieure est peu développée, elle est dépourvue de ces lobes latéraux si remarquables chez le Gobie céphalote.

Br. 5. -D. 6-1/1' ou 1.5; A. $1 / 13$ à 15 .

A la région supérieure, la coloration est grisàtre ou d'un jaune rougeâtre avec des macules noires, qui descendent sur les côtés; le dessous du corps et la gorge sont d'un jaune plus ou moins uniforme. La tête a la partie supérieure d'un brun jaunâtre et les parties latérales jaunâtres, traversées par des lignes ou des traits noirâtres s'entrecoupant. A la base de la caudale, il y a ordinairement une tache assez large d'un noir foncé. La première dorsale, d'une teinte assez pâle, est parcourue par trois bandes longitudinales noirâtres; la seconde dorsale est, ainsi que la caudale, d'un gris brunâtre avec des taches noires ou parfois jaunâtres sur les rayons; l'anale est d'un gris jaunàtre avec les rayons d'un brun très foncé ; la pectorale est d'un gris foncé jaunâtre, sa base est jaunâtre, marquée dans sa partie supérieure d'une assez grande tache noire figurant parfois une bande verticale plus ou moins prolongée.

Habitat. Méditerranée, commun à Cette, à Martigues. 
Le Gobie à filament. - Gobius filamentosus, Riss.

Poiss, France, t. II, p. 237.

Long. : 0,14 .

D’après Risso, la membrane de la seconde dorsale, beaucoup plus ilevée que celle de la première, est terminée sur chaque rayon par un long filament bleuatre. - Les màchoires sont garnies de fines dents inégales, crochues.

$$
\text { D. } 6-17 \text {; A. 16:C. } 14 ; \text { P. } 1 \text {; ; Y. } 10 .
$$

Le corps est d'un jaune verdâtre avec des traits plus foncés. - Les dorsales sont d'un jaune clair transparent, avec des raies longitudinales obscures; la ventrale est bleuàtre, les pectorales sont ornées à leur base d’une lunule noiràtre cerclée de blanc.

Habitat. Méditerranée, Nice. J.-B. Vérany mentionne cette espèce dans sa Zoologic des Alpes-Maritimes, mais il ne cite pas le Gobie lote; ce qui s'explique très facilement, puisque, d’après II. Sarato, le Gobie lote est figuré dans l'album inédil de Risso, sous le nom de Gobius filamentosus.

\section{LE GOBIE CÉPHALOTE. - GOBIUS CAPITO.}

Poiss. France, t. II, p. 203, fig. 102, anim.

Long. : 0,18 à 0,23 et mème 0,27 .

Le corps est gros, épais en avant; sa hauteur est comprise cinq fois et demie à six fois et quart dans la longueur totale. - La lête, un peu aplatie en dessus, est un peu moins haute que large: sa longueur est contenue quatre fois à quatre fois et quart dans la longueur totale: les màchoires, à peu près de même longueur, sont garnies de dents assez petites: égales, ou parfois plus fortes à la mâchoire supérieure. Le diamètre horizontal de l'œil est variable suivant la taille des animaux, il est compris de cinq fois à six fois et demie dans la longueur de la tête; l'espace interorbitaire est aussi grand et parfois plus grand que le diamètre vertical. - Ec., l. long. 60 à 62 ; 1 . transr. 18 à 20. - Les dorsales sont à peu près de mème hauteur, moins hautes que le trone; la base de la première est tout au plus égale a l'espace postorbitaire: l'anale finit plus 
tôt que la seconde dorsale; les pectorales sont assez larges, à rayons supérieurs crinoïdes; les ventrales sont larges, courtes, d'un quart moins longues que les peclorales; leur membrane antérieure, bien développée, porte de chaque côté un lobe ovale.

Br. 5. - D. $6-1 / 13$ ou $14 ;$ A. $1 / 10$ a 12.

Le dos et les côtés sont d'une teinte jaunâtre ou jaune verdatre avec des taches irrégulières d'un brun plus ou moins foncó; le ventre est jaunitre arec quelques macules brunes. La partie supérieure de la lête, l'espace interorbitaire, le museau et les lèrres sont d'un brun foncé ; les joues sont jaunâtres, ou d’un brun teinté de jaune, ainsi que les pièces operculaires. Les dorsales sont brunes avec quelques taches plus claires; l'anale et les pectorales sont brunes, tachetées de jaune; la caudale est brune, marquée de taches d'un jaune grisâtre formant des bandes: les ventrales sont brunes; parfois les dorsales, les pectorales et la caudale sont brunâtres, narquetées de noir.

Habitat. Méditerranée, assez commun, Nice, Toulon, Martigues, Cette, Port-Vendres.

3. LE GOBIE A liOLTTELETTES. - GOBIUS GUTTATUS, Valenc.

Poiss. France, t. II, p. 20..

Long. : 0,1 à à 0,20 .

La hateur du tronc est comprise quatre fois el quart à cinq fois et quart dans la longueur totale. - La tête est aussi haute yue large; sa longueur est contenue quatre fois et quart à quatre fois et demie dans la longueur totale; les mâchoires sont égales, garnies de dents en cardes, plus fortes à la rangée antérieure. Le diamètre de l'bil mesure le cinquième de la longueur de la tète, il est à peu près égal à l'espace interorbitaire qui est un peu plus grand que le diamètre vertical de l'cil. - Ec.. l. long. 6.3 ou 66 ; 1. transr. 20 ou 21. - Les dorsales sont beaucoup moins hautes que le tronc; la base de la première dorsale est plus longue que l'espace postorbitaire; 
l'anale est moins longue que la seconde dorsale ; les pectorales ont leurs trois nu quatre rayons supérieurs crinoïlles; les ventrales sont grandes; leur membrane antérieure a des lobes à peu près aussi déreloppés que dans le Cíphalote.

Br. 5. - D. 6-1/13 011 14; 1. 1/10 on 11; C. 15 ; P. 19 ou $20 ;$ V. $1 / 5$.

En dessus el sur les côtés, la teinte est d'un gris jaunàtre arec de larges taches noirâtres; elle est jaunàtre en dessous. La tite est parfois d'une teinte brune uniforme, parfois elle est marquíe de taches noires ot de taches arrondies d'un blanc laiteux sur les joues et les pièces operculaires. La première dorsale est l'un gris jaunitre semé de taches noires, ou bien d'un ton brunitre, traversé de bandes plus claires, ses rayons ont la pointe blanchàtre ou d'un orangé assez clair; la seconde dorsale et la caudale sont grisàtres arec des taches noires; les pectorales sont d'un gris jaunatre arec des taches les unes noiràtres, les autres d'un gris clair; les rentrales sont tantol d'un blanc grisàtre, tantôt d'un brun assez foncé.

II existe, che\% ce fiobie, une ressie natatoire plus on moins développée et paraissant constante.

Habitat. Méditerranée, Nice, très rare; Cette, assez rare.

\section{LE GOBIE ENSANGLLITE. - GOBIUS CRUENTATUS, Gm.}

Poiss. France, t. II, p. 208.

N. vulg. : Gobou rouge, Nice; fiobie roujé, Toulon.

Long. : 0,12 à 0,16 .

La hauteur du tronc est comprise cinq fois et demie ì six fois et un tiers dans la longueur totale. - La tète est aussi haute que large; sa longueur est contenue quatre fois a quatre fois et demie dans la longueur totale; les màchoires sont garnies de pẹtites dents. Le diamètre de l'ail fait le quart, et parlois plus, de la longueur de la tète, le double de l'espace interorbitaire, il est à peu près égal à l'espace préorbitaire. - Ec., l. long. 88 a 62 ; 1. transr. 16 ì 18 . - La première dorsale est moins haute que le trone; les pectorales ont leurs rayons 
supérieurs crinoïdes; la membrane antérieure des rentrales est peu développée.

$$
\text { Br. 5.-D. } 6-1 / 14 \text {; A. } 1 / 13 \text { ou } 14 \text {; C. } 15 \text {; P. } 19 \text {; V. } 1 / 5 \text {. }
$$

La teinte générale est un gris rougeâtre avec des taches hrunâtres; des taches rouge de sang marquent les lèvres, le museau et les opercules; des lignes noires, étroites, formées par des séries de pores, se dessinent sur les joues, les opercules et la nuque. La première dorsale est de couleur ocre, avec des taches verdatres; la seconde dorsale, la caudale et l'anale sont brunâtres, tachetées de jaune et de roux ; parfois les dorsales et les pectorales sont d’un rouge orangé avec quelques taches plus claires; les ventrales sont d'un gris bleuâtre.

Habitat. Méditerranée, assez commun, Nice, Toulon, Martigues, Cette. Océan, excessivement rare, Arcachon.

Steindachner regarde le $G$. cruentatus et le G. geniporus, comme étant de mème espèce; les différences qui existent dans les proportions du corps, dans le nombre des écailles des lignes longitudinales, ne permettent guère d'adopter cette opinion.

\section{LE GOBIE A QUATRE BANDES. - GOBIUS QUADRIVITTATUS, Steind.}

Poiss. France, Suppl., p. 21.

Long. : 0,0 ä à 0, .

La hauteur du tronc est comprise six fois et demie à sept fois dans la longueur totale. - La longueur de la tête fait le quart de la longueur totale; la mandibule est plus avancée que la màchoire supérieure; elles sont, l'une et l'autre, garnies de dents pointues. Le diamètre de l'weil est à peu près égal à l'espace préorbitaire, il fait le triple au moins de l'espace interorbitaire; au-dessus et en arrière de l'œil se voient des séries de pores bordés de noir. - Ec., l. long. 50 environ. — Les dorsales sont à peu près de même hauteur; les pectorales sont un peu plus longues que les ventrales, leurs rayons supérieurs sont crinoïdes; les ventrales n'arrivent pas à l'anus; 
leur membrane antérieure est développée, avec un lobe de chaque côté,

D. $6-1 / 10$ ou $11 ; A .1 / 9$ ou $10 ;$ P. 17 a $19 ;$ V. $1 / 5$.

La leinte générale est d'un brun clair ou d'un rouge brunàtre, jaunâtre sous le ventre; de chaque côté, il y a quatre bandes blanchâtres verticales qui n'arrivent pas à la région ventrale. Les nageoires impaires sont noirâtres; les pectorales sont blanchâtres à leur base, noirâtres dans leur partie centrale, jaunâtres à leur bord; les ventrales sont jaunâtres.

Habitat. Méditerranée, Nice, excessivement rare.

6. LE GOBIE ZĖBRE. - GOBIUS ZEBRUS, RisS.

Poiss. France, t. II, p. 236.

N. vulg. : Gobou raiat, Nice, d'après Risso.

Long. : 0,040 à $0,0 \check{0} 0$.

Perugia, dans son Catalogue des Poissons de l'Adriatique; a donné deux jolies figures de ce petil Gobie. - La hauteur du tronc est contenue cinq fois et demie à six fois dans la longueur totale. - La tête est forte; sa longueur mesure le quart environ de la longueur totale, et semble faire quatre fois le diamètre de l'œil. - Ec., 1. long. 30 à 36. - La première dorsale compte six rayons.

$$
\text { D. } 6-1 / 10 \text { à } 12 ; A \text {. } 1 / 9 \text { ou } 10 \text {. }
$$

Le corps est d'un brun plus ou moins foncé; parfois tirant sur le vert; il est traversé par une douzaine de raies verticales d'un blanc argenté.

Habitat. Méditerranée, Nice, très rare.

7. LE GOBIE A LARGE TÊTE. - GOBIUS LATICEPS, Nób.

Poiss. France, t. II, p. 215, fig. 103; anim. vu de profil; fig. 104; auim. vu en dessus.

Long: : 0,040 . 
Le Gobius laticeps nest pas, comme le suppose Francis Day. identique au Gobius pictus de Malm; le premier a seulement quatre rayons branchiostèges et quatorze rayons au plus à la pectorale; le second est pourvu de cinq rayons branchiostèges et de vingt rayons à la pectorale; les proportions semblent ètre assez différentes dans chacun de ces Gobies. Chez le Gobie à large tête, la hauteur du tronc mesure le septième environ de la longueur totale; la longueur de la tête en mesure le quart; les màchoires sont garnies de dents très fines. Le diamètre de l'œil, sensiblement plus grand que l'espace préorbitaire, fait près du tiers de la longueur de la tète. - Ec..l. long. une quarantaine; l. transr. une dizaine. - La première dorsale est un peu moins haute que la seconde; elle porte une tache noiratre sur les deux ou trois derniers rayons; les rentrales vont jusqu'à l'anus, elles dépassent parfois les pectorales qui n ont pas de rayons crinoïdes.

Br. 4.-D. $6-1^{\prime} 9 ;$ A. $1 / 8$; C. $16 ;$ P. 13 ou 1 ; ; I. $1 / 5$.

La teinte générale est d'un beau vert olive uniforme.

Habitat. Manche, Saint-Valery-en-Caux, excessirement rare.

\section{LE GOB IE COLONIEN. - GOBIUS COLONIANUS, RisS.}

Poiss. France, t. II, p. 198.

Long. : 0,06 à 0,0 T.

La hauteur du trone est comprise six à sept fois dans la longueur totale. -- La tête est généralement un peu plus haute que large; sa longueur mesure, ou peu s'en faut, le quart de la longueur totale; la fente de la bouche dépassele bord antérieur de l'orbite. Le diamètre de l'œil fait le tiers de la longueur de la tète, le double de l'espace interorbitaire. - Ecail., l. long. 39 à $11 ; 1$ transr. 13 ou 1'r, entre la première dorsale et la rentrale, 11 би 12 entre la seconde dorsale et l'anale. - La première dorsale, chez le mâle adulte, est très déreloppée, d’un tiers environ plus haute que la seconde dorsale dont la hatuleur est égale à celle du tronc: aucun des rayons de la première dorsale n'est filamenteux; chez les femelles, la pre- 
mière dorsale nest pas plus élevée que la seconde dont la hauteur est à peine égale à celle du trone; les pectorales mesurent le cinquième au moins de la longueur totale; les rentrales sont longues, leur pointe arrive près de l'anus.

$$
\text { Br. 4. -D. G (i, Riss.) - 1/10; A. 1/10; C. 1/13/1; P. } 18 .
$$

La teinte générale est jaunâtre ou d'un brun rougeàtre arec une quantité de petits points noirs formant, à la région supérieüe, quatre ou ring larges bandes verticales, ef sur les crités des taches souvent asse' mal délinies; la bande la plus large part de la base de la première dorsale. Chezle mâle. la première dorsale est à fond jaunàtre teinté de bleu, avec des bandes transversales blanchatres; le dernier espace intraradiaire porte souvent un ocelle ovale, cerelé de blanc; la seconde dorsale est d'un jaune pille, tirant sur le gris; la caudale et les nageoires paires sont d'un jaune grisàtre.

Habitat. Méditerranée, Nice, assez rare.

\section{LE GOBIE A QUATRE TACHES. - GOBIUS QUADRIMACLLATUS,} Valenc.

Poiss. Frunce, t. II, p. 210.

Long. : 0,07 à 0,09 .

La hauteur du tronc est comprise de six fois à huit fois et demie dans la longueur totale. - Généralement la tête est un peu moins haute que large: sa longueur est contenue quatre fois à quatre fois et demie dans la longueur totale. Le diamètre de l'cil fait presque le tiers de la longueur de la tète, il est a peine plus grand que l'espace préorbitaire. - Ec., l. long. 37 à 40 ; l. Iransv. 8 ou 9. - La première dorsale chez les adulles, au moins dans les males, a le second rayon beaucoup plus allongé que les autres; elle est éloignée de la seconde d'une distance plus grande que la moitié de la longueur de sa base: la pectorale na pas de rayons crinoïdes, elle est bien développée ainsi que la ventrale, dont la pointe arrive ordinairement jusqu à l'anus.

Br. $4-D$ D. $6-1 / 9$ ou $10 ;$ A $1 / 9$ ou $10 ;$ C. 12 à $14 ;$ P. 1 i ou $18 ; \mathrm{V}, 1 / 5$. 
Sur le dos et les cités, la coloration est d'un gris jaunàtre clair avec un semis de petits points noiràtres; la gorge et le ventre sont blanchâtres; sur les flancs existent quatre taches noires arrondies, nettement dessinées; la première est placée ver's le milieu de la longueur de la pectorale; la quatrième à peu près au milieu du tronçon de la queue. Les dorsales et la caudale sont tachetées de points noirs formant des bandes nuageuses; les pectorales sont pointillées de noir vers leur base, elles sont d'un blanc jaunâtre ou gris clair dans le reste de leur étendue; l'anale et les ventrales sont blanchâtres.

Habitat. Méditerranée, Nice, assez commun, moins commun à Cette.

A propos du G. quadrimaculatus, le $\mathrm{D}^{\mathrm{r}}$ Sarato m'écrivait en 1887 : "Au musée de Nice, se trouvent deux males remarquables par la longueur du rayon effilé s'élevant à quinze millimètres au-dessus de la membrane de la nageoire, " et ajoutait que cttte forme lui paraissait ètre le G. nebulosus, Risso; " j'ai répondu à mon savant confrère que le G. nebulosus, Riss., Hist. nat., p. 281, est effectivement un Gobie à quatre taches. - Quant au G. nebulosus, Riss., Ichth., p. 161, il doit, d'après la disposition de sa première dorsale à six rayons, "dont les trois du milieu se terminent par de longs filaments noirâtres, " être rapporté au G. jozo.

Steindachner et Day regardent le G. Jeffressii de Günther comme identique au G. quadrimaculatus; cette opinion ne peut ètre acceptée; l'image donnée par Francis Day, pl.43, fig. 2, et faite d'après un spécimen venant des îles Shetland, ne convient en aucune façon au G. quadrimaculatus, pas plus du reste que la description qui l'accompagne。

10. LE GOBIE RÉTICULÉ - GOBIUS RETICULATUS, Valenc.

Poiss. Frinte, t. II, p. 217.

Long. : 0,0 à à 0,06 .

La hauteur du tronc est comprise cing fois et demie à six fois et quart dans la longueur totale. - La tète es t forte, à peine moins haute que large ; sa longueur est contenue quatre fois et demie dans la longueur totale. Le diamètre de l'œil mesure le quart de la longueur de la tête, il est égal à l'espace préorbi- 
taire. - Les dorsales ont la mème hauteur qui est un peu moindre que celle du tronc; les ventrales sont d'un quart environ plus longues que les pectorales qu'olles dépassent de moitié, étant insérées plus en arrière, elles vont à peu près jusqu'à l'anus; les pectorales n’ont pas de rayons crinoïdes.

$$
\text { D. } 6-1 / 9 ; \text { A. } 1 / 8 \text { ou } 9 \text {. }
$$

Sur le dos et les cotés, la coloration est d'un gris jaunatre clair, avec un pointillé noiràtre très tin, bordant les écailles et formant des espèces de petites mailles; le ventre est blanc argenté, la gorge blanchàtre; il y a généralement sous la mandidule une série de points noirâtres figurant une espèce de mentonnière interrompue. Les dorsales sont d'un jaune clair arec des points noiritres; la caudale est de mème teinte, avec une tache noire à la partie supérieure de sir base; les pectorales sont grisîtres, avec une tache noire sur le haul de leur base; les ventrales sont blanchàtres.

Habitat. Méditerranée, rare, Nice.

\section{GOBIE BUHOTTE. - GOBIUS MINUTUS.}

Poiss. France, t. II, p. 212.

N. vulg. : Bourguette, Buhotte, Normandie; Pescarlide, Roscoff; Boucaud, Nantes; Tout-Nu, Cabau, Vendée, Charente-Inférieure; Ilougnou, Cette.

Long. : 0,06 à 0,08 .

Le corps est courert de peitites écailles ; sa hauteur esí comprise sept à huit fois dans la longueur totale. - La tête est généralement plus large que haute; sa longueur est contenue quatre fois à quatre fois et demie dans īa longueur totale. Le diamètre de l'ceil fait le quart de la longueur de la tête, le triple, ou peu s'en manque, de l'espace interorbitaire, il est i peine plus grand que l'espace préorbitaire. - Ec., l. long. jö à 60 ; 1. transv. 11 à 13 . - Les dorsales ont ordinairement .ne mème hauteur, à peine moindre que celle du tronc; les jectorales sont un peu moins longues que la tête; les ventrales 
font à peu près le cinquième de la longueur totale; la membrane antérieure de la rentouse n'est pas lobée.

Br. $5 .-$ D. $6-1 / 10$ ou 11 ; A. $1 / 10$ ou 11 ; C. 13 à 15 ; P. 19 ou $20 ; V .1 / 5$.

Le système de coloration est le plus souvent gris jaunàtre nuancé parfois de brun clair ou finement pointillé de noiràtre, rarement il y a sur les côtés des bandes verticales ou des taches noirâtres assez semblables à celle du Gobie à quatre taches. Les deux dorsales et la caudale sont d'un gris clair avec des points brunatres formant des bandelettes; la première dorsale est généralement marquée d'une petite tache noirâtre à l'extrémité de ses derniers rayons; l'anale est grise, quelquefois teintée de brun à son bord libre; les pectoralesel les ventrales sont grisâtres.

Habitat. Ce fiobie est plus on moins commun sur toutes nos còtes.

12. LE GOBIE JOZO OU A HAUTE DORSALE. - GOBIUS JOZO, Linn.

Poiss. France, t. II, p. 194.

N. vulg. : Gobou variat, Nice; Gobi négra, Cette; Pignou, Agde.

Long. : 0,12 à 0,13 et mème 0,10 .

La hauteur du tronc est contenue six fois à six fois et un tiers dans la longueur totale. - La tête est à peine moins haute que large; sa longueur est comprise quatre fois et un quart à quatre fois el demie dans la longueur totale; la màchoire supérieure est un peu moins avancée que la mandibule, elles sont garnies de petites dents en cardes. Le diamètre de l'œil est contenu quatre fois et quart à cinq fois dans la longueur' de la tête; il est à peine moins grand que l'espace préorbitaire. il fait le double, ou peu s'en faut, de l'espace interorbitaire. Ec., l. long. 39 à 41 ; 1. transv. 9 à 11. - Suivant l'àge et le sexe. la première dorsale montre de très grandes différences dans son développement; chez les mâles adultes, elle est très haute, à rayons inégaux, les $3^{\mathrm{e}}, 4^{\mathrm{e}}, \check{5}^{\mathrm{e}}$ rayons, beaucoup plus grands que les autres, s'allongent en filaments minces et flexibles, ils sont sensiblement plus longs que la tête; chez les femelles, 
les màles non adultes les rayons médians sont plus déreloppés que les autres, ils sont rrinoïdes et libres dans une grande partie de leur hauteur, mais ils ont moins de longueur que la tète; la seconde dorsale est aussi plus haute chez les mâles adultes que chez les l'emelles; les pectorales sont bien déreloppées, elles font environ le cinquième de la longueur totale, les deux ou trois, parfois les quatre rayons supérieurs sont crinoïdes; les ventrales sont moins longues que les pectorales. Chez les jeunes sujets de $0,0 \check{\text { à }} 0,06$, la première dorsale n'est pas plus haute que la seconde; ses rayons médians ne sont pas crinoïdes.

Br. 5. - D. 6-1/11 ou 12, A. 1/11; C. 15 ou $16 ;$ P. 15 a $17 ;$ V. 1/5.

Le long des flanes se trouvent des taches noires; chez les màles adultes, la coloration est d'un gris noiràtre, elle est plus claire chez les femelles, parfois d'un gris jaunàtre chez les jeunes. La première dorsale est grisàtre arec filaments noirâtres; la teinte est plus claire chez les femelles et chez les jeunes : l'anale est grisâtre, bordée de noir; la caudale est brunàtre; les pectorales sont grisâtres à leur base, brunâtres dans le reste de leur longueur; les ventrales sont d un gris brunàtre.

\section{Vir. - Le Gubie à longs rayons. - Gobius longiradiatus.}

I.a hauteur du trone ne fait que le septième de la longueur totale. - Le diamètre de l'wil mesure le quart de la longueur de la tète. Ec., l. long. 36 à 40 ; l. transv. 10 à 12. - La coloration est d'un gris jaunàtre lavé de brun, moins foncé que dans le Jozo; la première dorsale est teintée de vert, de bleu, bordée de noir, avec une tache noire dans le premier espace intraradiaire le plus souvent; la seconde dorsale et l'anale sont grisatres, bordées de noir; les pectorales sont grisàtres, avec deux ou trois rayons crinoïdes. - La membrane antérieure des rentrales est basse, comme dans le Jozo.

Habitat. Manche, rare, Seine-Inférieure, Calvados. Océan, assez commun au sud de Ja Loire. Méditerranée, assez commun.

\section{GOBIE DL: LESLELR. - GOBIE LESUEURII, Riss.}

Poiss. France, t. II, p. 219.

N. vulg. : Gobou raiat, Nice.

Long. : 0,0ł⿱艹 à 0,07 et mème 0,09 (Riss.). 
La peau est couverte de grandes écailles plus larges ou plus hautes que longues; la hauteur du tronc ne fait ğuère que le septième d'e la longueur totale. - La tête est parcourue par des lignes de pores généralement nombreuses et bien dessinées; sa longueur est comprise quatre fois et demie à six fois dans la longueur totale. Le diamètre de l'œil mesure le quart et parfois le tiers de la longueur de la tête.-Ec., l. long. 26 ou 27 ; 1. transv. 4 à 7 . - La première dorsale a chez les adultes, d'après Canestrini, le premier rayon prolongé en filament, chez. les jeunes sujets c'est ordinairement le troisième rayon qui est le plus grand ; la seconde dorsale a souvent ses rayons postérieur's très allongés; la caudale, à rayons médians fort développés, est légèrement lancéolée; les ventrales sont longues, elles arrivent jusque sur l'anus.

\section{D. $6-1 / 13$ ou $14 ; A .1 / 13$ ou 14 .}

La teinte paraît variable, d'un blanc verdâtre ou plutòt d'un rose légèrement jaunâtre, avec un pointillé brun; la tête est d'un gris ou d'un brun rougeâtre; trois lignes d'un jaune nacré descendent obliquement sur les joues et sur les opercules. Les nageoires impaires sont d'un gris pâle arec des lignes transversales jaunâtres; la première dorsale montre une bordure noirâtre; la base de la caudale est marquée d'une tache nuirìtre; les pectorales sont roses; les ventrales grisâtres.

Habitat. Méditerranée, assez rare, Nice.

14. LE GOBIE A JOUE POREUSE. - GOBIUS GENIPORUS, Valenc.

Poiss. France, t. II, p. 222, fig. 104, anim.

Long. : 0,10 à 0,16 .

La hauteur du tronc est contenue sept à neuf fois dans la longueur totale. - La tête est moitié moins haute que longue; sa longueur est comprise quatre fois à quatre fois et un tiers dans la longueur totale. Du pourtour de l'orbite partent plusieurs lignes de pores; le diamètre de l'cil mesure à peu près le quart de la longueur de la tête, il fait le triple de l'espace interorbitaire, il est à peine moins grand que l'es- 
pace preurbilaire - Ec., l. long. 333 à 36 ; I. trausv. 13 u 14. la première dorsale est à peine plus haute que la seconde et que le trone; la caudale a les rayons médians plus développés que les autres; les ventrales sont un peu moins longues que les pectorales; la membrane antérieure de la ventouse parait manquer entièrement. la partie moyenne transversale n'existe récllement pas.

Br. 5. - D. 6-1/12 ou $13 ;$ A, $1 / 11$ ou $12 ;$ C. $16 ;$ P. 18.

Le systime de coloration est des plus variables, hrunâtre ou d'un brun rougeàtre, parfois jaunàtre teinté de gris ; sur les flanes, une douzaine de larges laches brunes forment une espèce de bande longitudinale; le ventre est blanchâtre ; la tète est grisàtre, teintée de jaune en avant; des taches arrondies d'un blanc laiteux marquent la nuque, les joues et les pièces operculaires. Les dorsales sont jaunâtres, avec des laches noires ou d'un jaune pàle; la caudale est d'un gris jaunatre arec des points noirs et une tache noirâtre vers sa base; les pectorales sont grisàtres, arec une tache noiràtre vers le tiers supérieur de leur base et quelques taches laiteuses; les rentrales et l'anale sont jaunâtres.

Habitat. Méditerranée, excessivement rare, Cette, Nice.

Le G. geniporus nest pas identique au G. cruentutus, ainsi que le suppose Steindachner.

13. LE GOBIE TROMPELR. - GOBIUS FALLAI, Sarato.

Poiss. France, Suppl., p. 23.

Long . : 0,060 à $0,07 \ddot{\text {. }}$.

Le corps est assez grèle ; sa hauteur qui est d'un tiers environ plus grande que son épaisseur est contenue six à sept fois dans la longueur totale. - La longueur de la tète est comprise quatre fois à quatre fois et demie dans la longueur totale; les mâchoires sont garnies de dents aigüüs, sur plusieurs rangées; celles de la rangée externe, surtout à la mandibule, sont plus fortes, plus crochues. Le diamètre de l'œil mesure à peu près le quart de la longueur de la tète; il est un peu plus grand que l'espace préorbitaire. - Ecail., l. long. 但à 14; 1. transr. 11 à 13. 
- La première dorsale a moins de hauteur que le trone, elle est formée de rayons à peu près égaux; la seconde dorsale est composée de quinze rayons le plus souvent ; l'anale prend naissance un peu plus en arrière que la seconde dorsale; les pectorales sont insérées sur une large base, elles ont deux petits rayons à peine crinoïdes; généralement les ventrales sont un peu moins longues que les pectorales; la membrane antérieure du disque manque absolument.

$$
\text { Br. 5. - D. 6. -1/13 ou } 14 \text {; A. 1/13; C. } 13 \text { ou 14; P. } 18 ; \text { V. } 1 / 5 .
$$

La coloration est d'un brun jaunâtre; sur les côtés, il y a généralement de petites laches noiràtres en série allant jusque vers la base de la caudale; les joues et les pièces operculaires sont marquées de petites taches plus ou moins arrondies, de gouttelettes d'un jaune pâle ou d'un blanc laiteux; de chaque côté de l'espace jugulaire, il y a une série de quatre à six taches. Les dorsales et la caudale sont grisàtres arec de petites taches brunâtres; l'anale est grisitre; les pectorales sont d'un gris jaunâtre pointillé de noir, sur la base des rayons supérieurs est une tache noire qui parait constante; les ventrales sont d'un gris pâle.

Habitat. Méditerranée, assez commun a Nice, assez rare à PortVendres.

16. LE GOBIE DORÉ. - GOBIUS AURITUS, RisS.

Poiss. France, t. II, p. 220.

N. vulg. : Gobou giaune, Nice.

Long. : 0,07 à 0,10 .

La hauteur du tronc est comprise cing fois et quart à six fois dans la longueur totale. - La tête est au moins aussi haute que large, sa longueur mesure le quart de la longueur tolale. Le diamètre de l'œil fait le quart de la longueur de la tête, le douhle de l'espace interorbitaire; il est à peu près égal à l'espace préorbitaire.-.-. Ecail., 1. long. 12 à 11; 1. transr. 12 à 10̈. - Les dorsales sont moins hautes que le trone; la caudale est arrondie; les pectorales ont deux ou trois rayons crinoïdes; les 
rentrales sont longues elles arrivent à l'anus; leur membrane antérieure est excessivement réduite, parait même quelquefois tout à fait manquer.

Br. 4 ou $5 .-D .6-1 / 13$ ou $14 ;$ A. $1 / 13$ ou $14 ;$ C. $3 / 14 / 3 ;$ P. 15 à 19.

Le système de coloration est jaune doré, avec des nuages et des points noiràtres, une tache noirâtre ou d'un bleu foncé marque la base des rayons supéricurs de la pectorale, moins celle des rayons crinoïdes; parfoís il existe une petite tache noire sur le milieu de la base de la caudale.

Habitat. Méditerranée, Nice, assez commun d'après Risso.

1 propos de ce Gobie, M. Vinciguerra, dans Croc. del Violante, p. 62, écrit : Cuvier nella seconda edizione del Règne animal afferma essere questa specie un' Eleotris $e$ non un Gobius... Tale separatione pero è del tutto erronea. - M. Vinciguerra est bien sévère pour Cuvier; i! aurait pu se dispenser d'insister sur une erreur, qu'il n'avait aucune raison de relever; Valenciennes avait pris soin de la rectifier V. Hist. nat. Poiss., t. XII. p. 31); ce que M. Vinciguerra se garde bien de faire connaitre.

\section{LE GOBIE NOIR. - GOBIUS NIGER.}

Poiss. France, t. II, p. 230.

N vulg. : Cabot, Normandie, Doucet à Cherbourg, d'après Jouan ; Boulerot, Goujon de mer, Poitou; Loche, Arcachon.

Long. : 0,08 à $0,1 \%$.

La hauteur du tronc est comprise cinq fois et un tiers a six fois dans la longueur totale, et la longueur de la tête quatre fois à quatre fois et quart; les mâchoires, à peu près égales, sont garnies de dents assez nombreuses, plus forles et plus crochues à la rangée externe. Le diamètre de l'œil fait à peine le quart de la longueur de la tête, le double de l'espace interorbitaire; il est généralement un peu plus grand que l'espace préorbitaire. - Ecail., l. long. 39 ou 40 ; l. transr. 13̈ou 16. - Les dorsales sont assez rapprochées; elles ont à peu près la même hauteur qui est moindre que celle du tronc; l'anale est opposée et semblable à la seconde dorsale; la caudale arrondie mesure le sixième environ de la longueur totale 
et la pectorale le cinquième, chez les sujets de grande taille elle a une huitaine de rayons crinoïdes; les ventrales sont de longueur variable, souvent d'un quart moins longues que les pectorales, elles ne vont généralement pas jusqu'à l’anus.

$$
\text { Br. 5. -D. 6-1/12 à } 14 ; \text { A. 1/11 à } 13 ; \text { C. } 13 ; \text { P. } 24 \text {. }
$$

La teinte générale est des plus variables; le plus souvent le fond est d'un brun jaunâtre avec des marbrures noirâtres, ou bien d'un gris plus ou moins foncé avec une bande latérale plus ou moins continue, formée de points noirs. Les nageoires chez les jeunes sont grisâtres, marquées de taches noires, excepté les ventrales qui sont ordinairement jaunâtres mouchetées de noir; chez les grands individus, les dorsales et l'anale sont d'un brun foncé avec des macules noires; les pectorales sont plus ou moins brunes, tachetées de noir ; les ventrales sont le plus souvent d'un blanc grisâtre, avec ou sans taches noires; la caudale est d'une teinte brune uniforme.

Habitat. Méditerranée, assez commun, Nice, Cette. Océan, assez commun. Nanche, commun, Roscoff, Cherbourg; lilus rare au nord de la Seine, Fécamp, Saint-Valery-en-Caux.

Francis Day a donné, comme étant celle du Gobius niger, une figure qui rappelle mieux le G. jozo, Day, Brit. Fish., I. I, pl. LII, fig. 3.

Gobiusater, Bellotti, Note ittiolog., dans Atti Soc. Ital. Sc. nat., Milano, 1888, t. XXXI, avec fig. - Sous le nom de Gobius ater, le $D^{r}$ Bellotti a décrit un Ciobie qu'il pense être de nouvelle espèce. Au mois de février 1888, mon savant confrère eut l'amabilité de m'envoyer plusieurs spécimens de ce Gobie, dont il avait recueilli une certaine quantité sur le marché de Nice. - Ces divers sujets sont identiques à ceux que j'ai reçus de Nice, de Celte, et dont j’ai rappelé l'habitat, t. II, p. 232. Dans mes notes, j’ai retrouvé le tableau des proportions prises, depuis de longues années, sur un de ces Gobies que j’ai rapporté de Nice en 1867 ; ces proportions, comparées à celles que j’ai relevées sur les individus offerts par M. Bellotti, sont exactement les mêmes. - Voulant expliquer la raison qui l'engage à faire de ce Gobie une espèce nouvelle, M. Bellotti s'appuie d'abord sur l'opinion suivante : l'esistensa nel Mediterraneo del Gobius niger L. fu negata da aleuni iltiologi : Steindachner,... etc. Pour nier, avec apparence de cerlitude, l'existence du G. niger dans 
la Méditerranée, il faut nécessairement que les ichthyologistes, dont parle M. Bellotti, aient examiné toutes les espèces du genre fiobie vivant dans cette mer; par conséquent ils ont eu sous les yeux des spécimens de son G. ater, qui a dù ètre recomnu et déterniné par eux et ne peut dans ces condilions ètre considéré comme le type d'une espèce nouvelle. - En admeltant d'ailleurs qu'il y ait deux espèces distinctes inscrites par Linné sous une mème dénomination, conviendrait-il l'enlever le nom spécifique au Gobie de la Méditerranée et de l'attribuer au Gobie des còtes de l'ouest de l'Europe? Non assurémenl; il existe un droit de priorité qui n'est pas dischilable, c'est liondelet qui a domné l'épithète de niger à un Gobie de la Méditerranée, ce nom doit lui ètre réservé, d'autant mieux que la figure accompagnant le texte, exéculée, suivant toute probabilité, de grandeur naturelle, paraît suffisamment exacte, ainsi que le remarque Valenciennes, qui jamais n’a mis en doute l'existence du G. niger dans la Méditerranée, comme le prétend M. Vinciguerra.

\section{LE GOBIE PAGANEL. - GOBIUS PAGANELLUS.}

Poiss. France, t. II, p. 22.;.

Long. : 0,10 it 0,12 .

La hautem du tronc fait environ le cinquième de la lonqueur totale; les écailles, plus développées que chez le Gobie à deux teintes, ont leur bord libre anguleux. - La longueur de la tète est comprise quatre fois à quatre fois et demie dans la longueur lotale; la mandibule est à peine plus avancée que la mâchoire supérieure; elles sont garnies l'une et l'autre de petites dents. Le diamètre de l'œil, contenu trois fois et un tiers à quatre fois dans la longueur de la tête, est un peu plus grand que l'espace préorbitaire qui généralement fait le double de l'espace interorbitaire. - Ecail., 1. long. 11 à 18; 1. transr. 1.jou 16. - Les dorsales paraissent égales, moins hautes que le tronc; l'anale finit plus tôt que la seconde dorsale; la caudale est arrondie; les pectorales ont un certain nombre de rayons crinoüdes; la membrane antérieure des rentrales est assez uéveloppée.

$$
\text { Br. ว. -1). 6-1/12 ou } 13 ; \text { A. } 1 / 10 \text { à } 12 .
$$

La coloration générale est très variable, ordinairement d'un 
brun assez foncé sur le dos, jaunâtre sur les flancs avec des taches brunes, jaunâtre sous le ventre, quelquefois d'un jaune teinté de gris. La première dorsale est d'une teinte brunâtre rarement uniforme, le plus souvent elle est marquée de petites taches arrondies ou de points d'un bleu très pâle; le bord de la nageoire porte une large bande d'un jaune citron tirant parfois sur le rouge vers la pointe des rayons antérieurs; la seconde dorsale est d'un gris assez foncé et semée de taches arrondies d'un jaune clair, au milieu desquelles s'en trouvent d'autres d'un bleu pâle ou d'un brun foncé; l'anale est brunâtre avec ou sans taches; la caudale est brunâtre avec des taches plus ou moins foncées; la pectorale est d'un gris foncé avec des taches jaunâtres ou assez pâles; vers la partie supérieure de sa base est une tache noirâtre qui s'étend parfois vers le bord inférieur; la ventrale est d'un gris plus ou moins prononcé, parfois jaunâtre.

Habitat. Méditerranée, assez commun, Nice, Toulon, Cette, PortVendres. Océan, très rare, Arcachon. Manche, rare, Roscoff, le Havre.

\section{LE GOBIE A DEUX TEINTES. - GOBIUS BICOLOR.}

Poiss. France, 1. II, p. 228.

Long. : 0,10 à 0,15 .

La hauteur est comprise cinq fois et deux tiers à six fois et quart dans la longueur totale: les écailles sont plus nombreuses que chez le Paganel, elles ont le bord libre presque droit. - La longueur de la tête est contenue environ quatre fois et quart dans la longueur totale; la mâchoire supérieure est un peu plus courte que l'inférieure, elles sont l'une et l'autre garnies de dents en velours ras avec une rangée externe de dents crochues, qui paraissent plus fortes que dans le Paganel. Le diamètre de l'œil est compris trois fois et demie à peu près dans la longueur de la tête, il est généralement un peu plus grand que l'espace préorbitaire, qui fait le double de l'espace interorbitaire. - Ecail., l. long. 50 à 57 ; la transv. 16 ou 17. - La première dorsale est ordinairement d'un tiers moins haute 
que le trone; la seconde a des rayons plus nombreux que chez le Paganel: la caudale parait plus longue; les pectorales ont des rayons crinoïdes; la membrane antérieure des rentrales est assez développée.

$$
\text { Br. 5.-D. } 6-1 / 14 \text { ou } 15 ; \text { A. } 1 / 13 \text { ou } 14 \text {. }
$$

La teinte générale est d’un brun noiràtre. La première dorsale porte ordinairement trois bandes longitudinales; à la base est une bande gris brunitre; la bande intermédiaire est d'un noir foncé ; la bande supérieure est blanchâtre chez les sujets conservés, sur le frais elle est rougeàtre; il n'y a pas de taches arrondies; la seconde dorsale est bordée le plus souvent d'un fin liséré blanchìtre. Toutes les nageoires, excepté la première dorsale, paraissent d'une teinte uniforme brunàtre ou noiràtre sans ancune tache arrondie.

Habitat. Véditerranée, Nice, Cette. Océan, excessivement rare jusqu'ì l'embouchure de la Gironde; moins rare sur la còte du Poitou; plus commun au-dessus de la Loire. Nanche, très commun à Roscoff; assez commun depuis la pointe de Primel jusqu'à la baie du Iont-Saint-Michel; moins commun sur les plages de Normandie.

Le Gobius paganellus et le Gobius bicolor ne sont-ils que des spécimens de mème espèce, ainsi que le prétendent la plupart des ichthyologistes? Cette opinion n'est pas admissible en raison de la zrande différence qui existe dans le nombre des écailles de la ligne longitudinale chezl'un et l'autre; dans le G. paganellus de Valenciennes, le nombre des écailles n'arrive pas à cinquante, chez le G. bicolor de Valenciennes qui est le G. paganellus de la plupart des auteurs, le nombre des écailles varie de cinquante à cinquante-sept. - Pour ne pas causer de complication nouvelle, j'ai cru devoir prendre comme sujets d'étude les types ayant servi à Valenciennes, et faisant partie de la collection du Muséum.

20. LE GOBIE DE RLTHENSPARRE. - GOBIUS RUTHENSPARRI, Euphr.

Poiss. France, t. 1I, p. 232 .

Long. : 0,0 t̀ ì 0,06 .

La hauteur du tronc mesure environ le sixième de la lon- 
gueur totale. - La tète est à peine plus haute que large ; sa longueur est comprise quatre fois et demie dans la longueur totale; les màchoires sont garnies de dents très aiguës, plus fortes à la mandibule̊. Le diamètre de l'œil est compris trois fois et un tiers dans la longueur de la tète; il est un peu plus grand que l'espace préorbitaire. - Ec., 1. long. 36 à 40. - La première dorsale a sept rayons; elle est, ainsi que la seconde, à peu près aussi haute que le tronc; les pectorales n'ont pas de rayons crinoïdes; elles sont égales aux ventrales dont la longueur est contenue environ cinq fois et demie dans la longueur totale; la membrane antérieure de la ventouse est très peu développée.

$$
\text { D. } 7-1 / 10 \text { ou } 11 ; \text { A. } 1 / 10 \text { ou } 11 ; \text { C. } 13: \text { P. } 15 ; \text { V. } 1 / 5 \text {. }
$$

La teinte est d'un grris rougeâtre avec une série longitudinale de petites taches blanchâtres sur les flanes, parfois ces taches sont peu visibles; il y a de chaque côté deux taches noirâtres, la première est vis-à-vis le tiers postérieur de la pectorale, elle manque quelquefois chez les femelles et les jeunes mâles ; la seconde tache, qui est plus grande, marque la base de la caudale. Les dorsales sont d'un gris teinté de rougeâtre, ainsi que l'anale; la caudale, d'un gris marron, est rayée de bandes brunâtres; les nageoires paires sont d'un gris blanchàtre.

Habitat. Assez commun sur nos plages de l'Ouest jusqu'à l'embouchure de la Gironde.

\section{LE GOBIE BORDÉ. - GOBIUS LIMBATUS, Valenc.}

Poiss. France, t. II, p. 23'

Long. : 0,1 à à 0,18 .

La hauteur du tronc est comprise quatre fois et demie à cinq fois dans la longueur totale. - La tête est un peu plus haute que large; sa longueur est contenue trois fois et trois quarts à quatre fois dans la longueur totale. Le diamètre de l'œil mesure le cinquième environ de la longueur de la tête; il fait un peu plus de la moitié de l'espace préorbitaire, il est égal à l'espace interorbitaire. - Les dorsales sont égales; elles sont 
d'un tiers ou d'un quart moins hautes que le trone; les pectorales sont bien développées, à rayons supérieurs crinoüdes; les ventrales semblent insérées un peu en avant des pectorales, elles sont courtes mais larges, arec leur membrane antérieure développée ayaut un lobe pointu sur chaque côté.

$$
\text { D. } ₹-1 / 13 ; \text { A. } 1 / 11 \text {. }
$$

La teinte générale est grisatre arec des laches noires el quelques points blanes, ou brunâtre avec un pointillé jaunàtre; la tète est brune. Les nageoires rerticales sont bruncttres, teintées de jaume et bordées de blane on de bleu (C.V.); les pectorales sont d'un brun assez foncé ou d'un gris plus ou moins clair.

Habitat. Méditerranée, très rare, Nice.

D’après Steindachner, le G. capito, le G. guttatus et le G. limbatus, C. I., sont des spécimens d'une seule et mème espèce qu'il rapporte au G. exanthematosus, Pallas. - V. P. Fr., t. II, P. 23', Canestrini.

\section{GEYRE APHYE. - APHId, Riss.}

Corps peu développé; écailles lisses, caduques.

Tête altongée; màchoire ayant les dents sur une seule rangée.

\section{LAPHYE PELLLCIDE. - IPHYA PELLUCIDA.}

Poiss. France, t. II, p. 238, fig. 106, et Suppl., p. 26.

N. vulg. : Nounat et Nonnat, Nice.

Long. : 0,0 ' à $0,0 \ddot{\text {. }}$.

La hauteur du trone fait le septième environ de la longueur totale; écailles relativement grandes mais si peu adhérentes que la peau semble toujours nue. - La longueur de la tête est comprise à peu près quatre fois et demie dans la longueur totale; la fente de la bouche est assez grande, oblique; les màchoires ont les dents sur une seule rangée, peu nombreuses mais relativement développées chez le mâle, excessivement petites chez. la femelle. Le diamètre de l'cril mesure le quart de la longueur de la tête; il est égal à l'espace in terorbitaire.-Ec., l. long. 24 ou 23 ; I. transv. 4. - La première dorsale est très 
fragile, moins haute que le tronc et généralement que l'autre dorsale; la caudale est à peu près carrée; les pectorales n'ont pas de rayons crinoïdes; les ventrales sont étroites, pointues.

Br. 5. - D. 5-1/12 ou 13 ; A. I/11 ou 12 ; C. $15 ;$ P. 16 ou 17 ; V. 1/5.

Le corps est transparent, d un jaune pâle sur le dos et les tlancs, pâle sous le ventre. Les nageoires impaires sont d'un jaune excessivement pâle, leur base est marquée d'un petit pointillé noiràtre; les pectorales sont blanchâtres à la base, puis d'un jaune très clair; les ventrales sont pâles.

Habitat. Méditerranée, excessivement commun d'Antibes à Menton. Manche, très rare, à l'embouchure de la Seine.

\section{Famille des Mullidés, Mullidx.}

Corps ovale, légèrement comprimé, couvert de grandes écailles à spinules excessivement faibles.

Téte à profil supérieur arqué, écailleuse, comprimée; museau arrondi; bouche petite, au-dessous du museau; màchoire supérieure plus longue et plus large que la mandibule, dentition faible, parfois incomplète; chevron du vomer portant deux plaques ovales garnies de petites dents. Sous la mandibule deux barbillons articulés avec l'os hyoüde.

Yeux latéraux, près du profil supérieur de la tète.

Appareil branchial; fente des ouies grande; quatre rayons branchiostèges; fausses branchies; pièces operculaires minces.

Ligne latérale bien marquée, formée d'écailles à large canal.

Nageoires; deux dorsales éloignées l'une de l'autre, assez courtes; anale semblable et opposée à la seconde dorsale; rentrales ayant un aiguillon et cinq rayons mous.

Vessie natatoire nulle dans notre genre. - Appendices pyloriques nombreux.

2. GENRE MULLE. - MULLUS, Linn.

Caractères de la famille.

a. Extrémité postérieure de la mảchoire supérieure arrivant au moins à l'aplounb du bord antérieur de

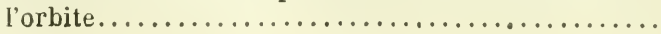


Extrémité postérieure de la màchoire supérieure n’arrivant pas à l'aplomb du bord antérieur de l'or-

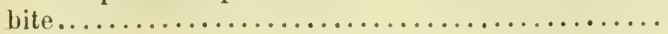

b. Longueur de la tête plus grande que la hauteur du

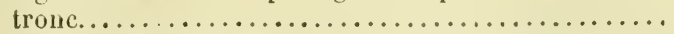

Longueur de la tête égale á la hauteur du tronc....

b.

1. SUHMULET.

3. BRIN,

1. LE MULLE SURMULET. - MULLUS SURMULETUS, Linn.

Poiss. France, t. II, p. ُْ4́, fig. 10z, écaille de la ligne latérale.

N. vulg. : Rougel, sur toutes nos còtes; Rouge d'Y port, fécamp; Barbarin, Barbeau, Barberin, Rouget-barbet, Vendée; Rujet-gros, Pyrénées-Orientales; Routget, Rouchet, Celte; Streglia de rocca, Nice.

Long. : 0,20 à 0,30 , quelquefois 0,40 .

La hauteur du tronc est comprise quatre fois et quart à cinq fois dans la longueur totale. - La tète a le profil arrondi : sa longueur, qui l'emporte sur la hauteur du corps, est contenue quatre fois à quatre fois et demie dans la longueur lotale; l'extrémité postérieure de la màchoire supérieure n'arrive pas à l'aplomb du bord antérieur de l'orbite. Le diamètre de l'ceil est compris trois fois et demie à quatre fois dans la longueur de la tête ; il est égal au moins à l'espace interorbitaire, il fait les deux tiers de l'espace préorbitaire. - Ec., l. long. 39 ou 40 ; l. transv. 10 ou 11. - La première dorsale a généralement huit épines et non pas sept.

Br. $4 .-$ D. 7 ou $8-1 / 8 ;$ A. $2 / 6$; C. $18 ;$ P. 17 ; V. $1 / 5$.

La leinte est rouge sur le dos, rosée sur les flancs, d'un blanc rosé sous le ventre; les côtés portent trois ou quatre bandes longitudinales jaunâtres. La première dorsale est parcourue, à la base, par une bande lilas très clair, au-dessus clle est jaune, sourent avec une bande noirâtre; la seconde dorsale est d'un jaune rougeàtre nuancé de brun; les pectorales sont d'un jaune rosé; les ventrales sont rosées.

Habitat. Toutes nos côtes. 
2. LE MULLE ROLGET. - MULLUS BARBATUS.

Puiss. France, t. II, p. 249.

N. vulg. : Streglia de fanga, Nice; Petit, Barbarin, Poitou.

Long. : 0,15 ì 0,23 .

La hauteur du tronc mesure le cinquième environ de la longueur totale.- La tète a le protil antérieur presque vertical: sa longueur est comprise quatre fois et demie à quatre fois et trois quarts dans la longueur totale; la màchoire supérieure se porte en arrière jusqu à l'aplomb du bord antérieur de l'orbite ot parfois nuème au delà. Le diamètre de l'œil fait le quart au moins de la longueur de la tête, la moitié de l'espace préorbitaire; il est un peu plus grand que l'espace interorbilaire qui est concave. - Ec., l. long. 38 à 40. - La première dorsale compte sept ou huit rayons.

$$
\text { D. i ou } 8-1 / 8 ; \text { A. } 2 / 6 ; \text { C. } 17 \text {; P. } 15 ; \text { V. } 1 / 5 \text {. }
$$

Le système de coloration est rouge plus ou moins foncé sur le dos, rose argenté sur les flanes et le ventre; pas de bandes jaunâtres sur les flancs. La première dorsale est d'un blanc rosé, sans macule noiràtre; les rayons sọt rougeâtres; les autres nageoires sont pàles ou d'un jaune rosé.

Habitat. Méditerranée, commun, Nice, Cette, Port-Vendres. Gcéan, assez rare Bayonne, Arcachon; rare entre la Gironde et la L.oire; très rare sur la còte de Bretagne. - Manche, excessivement rare.

Certains auteurs pensent que le $\boldsymbol{M}$. surmuletus et le $\boldsymbol{M}$. barbatus sont les sujets d'une mème espèce mais de sexe différent, le $\boldsymbol{M}$. surmuletus étant probablement la femelle, c'est l'opinion de fiünther, Introd. Stud. Fi.h., p. 404. - D'après Steindachner, le I. surmuletus et le $\boldsymbol{M}$. barbatus représentent les extrêmes limites des formes d'une mème espèce; Ichth. Ber. Span. Portug. Reise V, p. 33. -- Day considère le M. surmuletus comme une variété du M. barbatus, mais la fig. 1 , pl. VII, qui suivant lui est celle du $\mathbf{l}$. barbalus, se rapporte mieux au jeune du M. surmuletus; Brit. Fish., p. 22. 
3. LE MULLE BRUN. - MULLUS FUSCATUS, Rafin.

Poiss. France, t. II, p. 2. 2 , fig. 108, anim., et 109, écaille de la ligne latérale.

N. vulg. : Streglia de fanga, Nice.

Long. : 0,13 a $0,2 \ddot{\text { ö }}$

La hateur du trone est contenue quatre fois a quatre fois et quart dans la longueur totale; les écailles ont de cinq à sept rangées de spinules, tandis qu’elles n'en ont que trois ou quatre chez le surmulet. - La longueur de la tête est égale à la hauteur du tronc; l'extrémité postérieure de la màchoire supérieure n’arive pas à l'aplomb du bord antérieur de l'orbite. Le diamètre de l'wil est compris trois fois et demie à quatre fois et un tiers dans la longueur de la tête ; il mesure environ la moitié de l'espace préorbitaire, il est plus petit que l'espace interorbitaire. -- Les écailles de la ligne latérale ont leur canal moins large et moins divisé que dans le Surmulet. Ec., l. long. 38 ou 39 ; l. transv. 9 ou 10. - La première dorsale a sept ou huit aiguillons.

\section{7 ou $8-1 / 8 ;$ A. $2 / 6 ;$ C. $18 ;$ P. 17 ; V. $1 / 5$.}

Le dos et les coités sont rougeâtres; les écailles ont le bord libre marqué d’un pointillé brun plus ou moins foncé; le ventre est jaune rougeâtre, parfois tout à fait jaunàtre; trois ou quatre bandes longitudinales, assez larges, jaunàtres, s'étendent sur les côtés. La première dorsale est d'une teinte violacée avec une bande jaunâtre et une macule noiràtre; la seconde dorsale est d'un jaune rougeâtre, ainsi que l'anale et les nageoires paires; la caudale est jaunâtre avec une bordure noiràtre.

Habitat. Méditerranée, commun à Nice, à Cette.

\section{Famille des Triglidés, Triglidx, Bp.}

Corps oblong ou le plus sonvent allongé, rarement nu, généralement garni d'écailles, ou de pièces dures plus ou moins développées.

Téte de forme variable; dents ordinairement assez petites, manMoneau - Ichthyologie. 
quant parfois; joue plus ou moins cuirassée; "les sous-orbitaires, ou l'un d'entre eux, se portent assez loin sur la joue pour la couvrir plus ou moins sur sa longueur, et pour s'articuler par leur extrémité postérieuro arec le préopercule (C. V.).

Appareil branchial; opercule, sous-opercule souvent épineux; rayons branchiostèges au nombre de cinq à sept; pseudobranchies.

Nageoires; deux dorsales ou dorsale unique formée de rayons épineux et de rayons mous; pectorales séparées en plusieurs parties ou bien à rayons inférieurs simples, non branchus mais articulés; ventrales ayant souvent moins et jamais plus de cinq rayons mous.

Cette famille se partage en trois sous-familles.

a. Pectorales divisées en plusieurs parties......... non divisées.................... $b$.

1. Trighiniens.

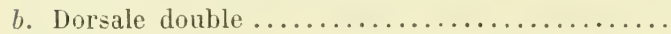
unique ..........................

2. Cottixiens.

3. SCORPÉxiNieNS,

\section{Sous-fanille des Trigliniens, Triglini, Bp.}

Corps allongé, arrondi ou formant une espèce de pyramide à pans inégaux. Peau courerte soit d'écussons plus ou moins développés, soit d'écailles de grandeur variable, tantòt plus ou moins rudes, tantòt lisses.

Téte grosse en forme de parallélipipède, cuirassée de plaques osseuses, remarquable surtout par le singulier développement de l'appareil sous-orbitaire, qui constitue en avant la plus grande partie du museau et s'articule en arrière arec le préopercule. Le bord supérieur du cràne est prolongé postérieurement par le surscapulaire, qui se termine en pointe plus ou moins saillante. Bouche en dessous; màchoire supérieure plus avancée.

Nageoires; deux dorsales pourant se loger dans le sillon médian de la région tergale; anale à peu près semblable à la seconde dorsale; pectorales bien développées, se divisant en deux parties parfaitement distinctes, l'une conservant toujours l'apparence d'une vraie pectorale, l'autre, ou la partie antérieure, réduite à quelques rayons ou doigts tantòt complètement libres, séparés les uns des autres, tantòt réunis par une membrane.

Vessie natatoire de forme variable, sans conduit pneumatophore.

Appareil digestif; estomac en cul-de-sac ; appendices pyloriques plus ou moins nombreux.

Cette sous famille se compose de trois genres. 
a. Division antérieure de la pectorale à doigts réunis

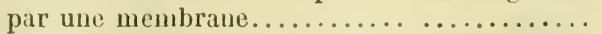

Division antérieure de la pectorale à doigts libres. b.

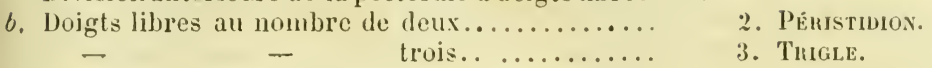

1. D.ictYloptéRE.

1. GEYRE DACTYLOPTERA. - DATTLOPTERUS, Lacép.

Corps allongé, couvert d'écailles très adhérentes, carénées ou striées.

Tête grosse, garnie de pièces osseuses; museau court; màchoires munies de dents granuleuses; palais lisse.

Appareil branchial; ouïes médiocrement fendues; préopercule armé d'une longue épine; six rayons branchiostèges.

Nageoires; première dorsale à rayons antérieurs détachés; seconde dorsale et anale à rayons peu nombreux; surscapulaire terminé en épine forte et longue; pectorales divisées en deux parties, sans rayons libres, la partie antérieure est relativement assez courte, la partie postérieure est excessivement léveloppée; ventrales ayant une épine et quatre rayons mous.

Vessie natatoire petite. - Appendices pyloriques nombreux, une trentaine dans le Dactyloptère volant. (D'après Valenciennes, chez le Cephalacanthus spinarella, que la plupart des auteurs, qui ont adopté l'opinion de Canestrini, regardent comme étant le jeune du Dactylopterus volitans, le pylore est enveloppé d'une quantité innombrable de cæcums fins et serrés; il n'y a pas de vessie natatoire.)

\section{LE DACTYLOPTÉRE VOLANT. - D.ACTYLOPTERUS VOLITANS.}

Poiss. France, t. II, p. 2̈33, fig. 110, anim., et 111 , jeune.

N. vulg. : Gallina, Nice; Ratapenada, Peï-boulant, Cette ; Ratepenade, Aronde, Arondelle, Landole, Rondole, Provence, Languedoc; Aulendia de mar, Roussillon.

Long. : 0,30 ou 0,40 , quelquefois 0,30 .

Suivant le développement des animaux, la hauteur du tronc est comprise de quatre à huit fois dans la longueur totale; les écailles, garnissant le dos et les côtés, portent une carène médiane plus ou moins saillante; les écailles de la région infripieure sont striées. - La tète est moins haute que larogre; elle est couverte d'une espèce de casque formé de pièces osseuses granulées; le museau est court, fendu sur le milieu; 
la bouche est petite, ouverte en dessous; sa muqueuse est d'un rouge jaunâtre éclatant; les mâchoires ont une bande de pelites dents mousses. Le diamètre de l'œil est moins grand que l'espace interorbitaire; le sous-orbitaire antérieur est fort développé. - Il n'y a pas de ligne latérale. Ec., l. long. 60 à 62 ; 1. transv. 23 ou 26 . - La première dorsale a sept rayons simples dont les deux premiers sont libres en grande partie; la seconde est soutenue par huit rayons articulés; la caudale est plus ou moins échancrée ; les surscapulaires sont excessirement déreloppés, ils s'unissent en dedans aux occipitaux externes et se terminent postérieurement en une épine très longue; la pectorale acquiert un développement extraorlinaire, elle est portée sur un pédoncule assez courl, mais gros; elle est profondément divisée en deux parties, l'une antérieure mesurant le cinquième environ de la longueur totale, l'autre postérieure beaucoup plus considérable, atteignant ì la base de la caudale, pouvant se déployer en une aile trìs large.

Br. $6 .-$ D. $7-8 ;$ A. 6 ; C. $2 / 8$ ou $9 / 2 ;$ P. $6+29$ ou $30 ;$ V. 1/4.

La teinte générale est sur le dos brunâtre ou rougeàtre avec des taches bleu de ciel : les còlés sont d'un rouge assez clair; le ventre est rosé. - La première dorsale est grisâtre; la seconde est d'un gris clair avec quatre ou cinq taches brunâtres, la caudale est à peu près de même teinte; la ventrale et l'anale sont d'un blanc rosé; la pectorale a sa petite division brunâtre, sa grande est brune en dessous, noirâtre ou olivâtre en dessus avec des taches bleuâtres.

Habitat. Méditerranée, assez rare, Nice, Cette.

Le professeur Canestrini a, dès 1861, émis l'opinion que le Cephalucanthus spinarella est le jeune du Dactyloptère, cette manière de voir a été pleinement justifiée par les recherches du Dr Chr. Lütken.

2. GENRE PÉRISTLDION. - IERISTEDION, Lacép.

Corps allongé, en pyramide octogone, cuirassé de larges pièces carénées; partie inférieure du trone garnie d'une espèce de plas. tron.

Tête couverte de plaques osseuses, prolongée en museau profon- 
dément hifurqué; bouche en dessous; màchoires et palais non dentés; barbillons filamenteux sous la mandibule.

Nageoires; dorsales rapprochées, la seconde de mème longueur que l'anale; deux rayons libres détachés de la pectorale.

Vessie natatoire simple. - Appendices pyloriques au nombre de sept à dix.

\section{IE MALARMAT. - PERISTEDION CATAPIRACTUM.}

Poiss. France, t. II, p. 261, fig. 112, anim.

N. vulg. : Pei fuorca, Nice; Maouarmat, Cette; Malaımat, Provence, Linguedoc; Mal armat, Roussillon.

Long. : 0,20 it 0,30 .

Du bout du museau à l'extrémité de la queue, ce Poisson est couvert d'une armure complite. Le corps a les angles hérissés d'épines, il est revètu de grandes écailles, de plaques épineuses; sa hauteur est comprise sept fois à sept fois et demie dans la longueur totale. - Le museau est lrès avancé, profondement fourchu, chacune des branches de la fourche est formée par la production considérable de l'un des sousorbitaires antérieurs; la bouche est ouverte en dessous, non dentée; sous la mandibule sont attachés plusieurs barbillons d’inégale longueur. Le diamètre de l'oeil est à peu près égal à l'espace interorbitaire qui est bordé d'épines. A la partie supérieure du museau sont trois épines assez fortes. L'opercule est muni en haut et en arrière d'une épine assez courte. - Ec., 1. long. 30. - La première dorsale est soutenue par sept ou huit rayons, plus ou moins allongés, à membrane intraradiaire excessivement délicate; la ventrale est attarhée sur la parlie latérale des deux boucliers antérieurs du plastron, et n’est libre que dans le quart de son étendue.

$$
\text { Br. ₹.-D. } 7 \text { ou } 8-1 / 18 \text { ou } 19 ; \text { A. } 18 \text { i } 20 \text {; C. } 11 \text {; P. } 12+2 \text {; V. 1/5. }
$$

Les parties supérieures ef latérales du corps sont d'un rose couleur chair; le ventre est d'un rose argenté. Les dorsales et la caudale sont rouges; l'anale et les rentrales sont d'un blane pàle.

Habitat. Mf́diterranée, assez commun, Nice, Celte. Océan, rare, Arcachon. Manche, excessivement rare, Boulogne. 


\section{GENRE: TRIGLE OU GIONDIN. - TRIGLA, Arted.}

Corps allongé, couvert d'écailles variables de forme et de grandeur: vertèbres au nombre de trente à trente-huit.

Tête développée, en forme de parallélipipède, à profil antérieur déclive, armée d'épines plus ou moins fortes, garnie de plaques osseuses striées; museau crénelé, ordinairement échancré dans son milieu; bouche ouverte en dessous; màchoire supérieure plus longue et plus large que la mandibule, munies l'une et l'autre de petites dents en velours; chevron du vomer denté; palatins et langue lisses.

Yeux ovales, placés vers le profil supérieur de la tête. Sourcil épineux. Premier sous-orbitaire excessivement développé.

Appareil branchial; fente des ouïes très grande; opercule épineux; préopercule élaryi dans sa région inférieure; interopercule et sous-opercule peu développés; sept rayons branchiostèges.

Ligne latérale relevée parfois de grosses écailles rudes.

Nageoires; deux dorsales logées dans un sillon bordé par les saillies des interépineux, la première plus courte et plus haute que l'autre; anale à peu près semblable à la secoude dorsale; pectorales à trois rayons libres; ventrales ayant une épine et cinq rayons mous.

Vessie natatoire très variable de forme et de grandeur, souvent pourvue de muscles à fibres striées.

Appareil digestif; estomac en cul-de-sac; cinc à douze appendices pyloriques.

Le genre Trigle comprend sept et mème huit espèces suivant la plupart des auteurs.

$a$. Sur le corps des stries transversales bien dessinées. $b$.

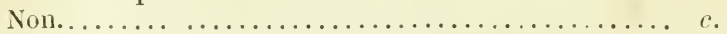

b. Stries marquées sur les côtés seulement..........

Stries faisant des cercles plus ou moins complets...

c. Première dorsale ì deuxième rayon filamenteux,

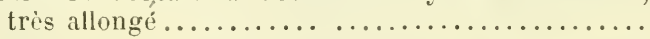

Première dorsale à deuxieme rayon pointu........

d. Ligne latérale formée de grosses écailles a crîte nıédiane denticulée.................... $e$.

Ligne latérale formée d’écailles sans crête médiane. $f$.

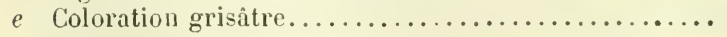

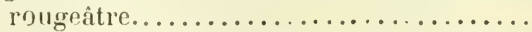

f. En arriere de l'orbite un sillon transversal profond.

1. PIN.

2. ІмвитаGо.

3. MORRUDE. I. e.

4. GORNAUD.

5. MILAN.

8. CAVILloNe. Non ................................. g. 
g. Museau très échancré, épine coracoïdienne fort

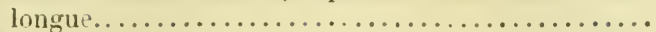

Museau peu échancré; épine coracoïdienne moins

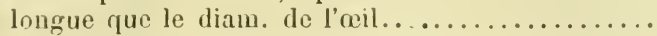

6. LYRE.

7. CORBEAU.

\section{I.E TRIGLE PIN - TRIGLA PINI, Bloch.}

Puiss. France, t. II, p. 266.

N. vulg. : Caraman, Galinella, Nice; Rouget, Grondin rouge sur nos còtes de l'Ouest, où les mèmes noms sout donnés à d’autres espèces.

Long. : $0,2 \ddot{z}$, ̀̀ 0,30 .

La hauteur du trone est contenue de six à sept fois dans la longueur totale; la peau, excepté dans la région abdominale qui est ì peu près nue, est couverte de très petites écailles faiblement ciliées sur le dos et les côtés, lisses à la région inférieure du corps. - La tète mesure le quart environ de la longueur totale; le museau est peu échancré; ses lobes latéraux. formés par les sous-orbitaires, sont garnis de cinq à sept épines ou crénclures, mousses chez les grands individus. Le diamètre de l'reil fait les deux tiers de l'espace préorbitaire, le double de l'espace interorbitaire; le sourcil porte deux ou troisépines en avant. - Les écailles de la ligne latérale sont des lamelles étroites, trìs hautes, qui cerclent en partie le corps de l'animal, ressemblant, d’après Bloch, à des feuilles de pin, elles sont percées d'un large canal central très ramifié en arrière, clles sont au nombre de 70 environ. - Le sillon des dorsales est bordé de chaque coté d’une série de vingt-sept à vingt-huit épines triangulaires; la première dorsale est plus haute que la seconde, son premier aiguillon a le bord antérieur parfois peu rugueus, le plus souvent dentelé en scie, généralement son deuxième aiguillon est plus haut que le tronc; lanale commence un peu plus en arrière que la seconde dorsale; les pectorales mesurent un peu moins du quart de la longueur totale, elles s'étendent en arrière de l'anus; les ventrales sont un peu moins longues.

Br. Ћ.-D. S i $10-18 ;$ A. 16 ou 17 ; C. 11 ; P. $10+\delta$; V 1/5.

Le dos el les côtés sont d'un rouge clair; le ventre est blanc 
rosé. Les nageoires sont orlinairement d'un rouge clair; les pectorales sont rougeâtres, teintées de violet jaunâtre, leur bord postérieur est liséré de jaune très pâle. - La vessie natatoire est ovale, échancrée en avant, avec deux lobes très petits. - Il y a dix appendices pyloriques.

Habitat. Commun sur toutes nos còtes.

\section{LE TRIGLE IMBRIAGO. - TRIGLA LINEATA.}

Poiss. France, t. II, p. 263.

N. vulg. : Belugan, Nice; Imbriaco, Imbriago, Languedoc; Ibrougna, Cette; Camard, còtes de l'Ouest.

Long. : 0,2 ว̈ à 0,3 ö.

La hauteur du tronc fait le sixième environ de la longueur totale; le corps est cerclé de lignes transversales el parallèles, formées par des replis cutanés, entre lesquels sont de petites écailles lisses ou ciliées, bien différentes de celles qui protègent le canal latéral. - Le museau est court; la tête est grosse, à profil antérieur très déclive, sa longueur est contenue quatre fois et un tiers environ dans la longueur tolale; la bouche est semi-circulaire. Le diamètre de l'ceil fait le quart de la longueur de la tête, un peu plus de la moitié de l'espace préorbitaire; il est d'un cinquième plus grand que l'espace interorbitaire; le bord antérieur de l'orbite est marqué de stries prolondes et porte cinq à sept dentelures. L'opercule a les épines excessivement courtes. - De grosses écailles carénées marquent la ligne latérale: elles sont très adhérentes, épineuses, au nombre de 64 à 70 . - De chaque côté du sillon dorsal, il y a emviron vingt-cinq épines triangulaires, plus saillantes en arrière, à bord supérieur mince, tranchant, chez les jeunes, denticulé chez les vieux individus. La première dorsale est beaucoup plus haute que la seconde; le premier aiguillon est crénelé sur l'angle antérieur ainsi que le bout du deuxième qui est le plus grand de tous; les pectorales sont développées, dépassant l'anus en arrière, leur longueur est comprise environ frois fois et un tiers dans la longueur totale; 
les ventrales ne font guère que le cinquième de la longueur totale.

D. 10 ou $11-15$ a $17 ; \Lambda .15$ ou $16 ;$ C. $12 ;$ P. $10+3 ; Y .1 / 5$.

La teinte est rougeàtre, sourent des taches noiratres s'étendent sur le dos el les côtés; le ventre est blanchâtre. Les dorsales, la caudale et les ventrales sont plus ou moins rougeàtres; assez fréquemment la première dorsale est marquée de taches noirûtres; l'anale est pâle ; les pectorales sont grisâtres en dehors avec des macules d'un noir bleuâtre; elles sont noiritres en dedans. - La vessie natatoire est ovale à un seul lobe creusé en avant d'un léger sillon. - Il y a dix appendices pyloriques généralement.

Habitat. Toutes nos còtes.

\section{LE TRIGLE MORRUDE. -- TRIGLA CUCULUS.}

Poiss. France, t. II, p. 272.

N. vulg.: Grondin barbarin, aux Sables d'Olonne; Galinetta, Port-Vendres ; Linota, Cette; Orghe, Orgue, Nice

Long. : 0,20 à $0,2 \pi$.

La hauteur du trone est contenue environ six fois et demie dans la longueur totale; les écailles, excepté celles de la ligne latérale, sont petites, généralement lisses. - La longueur de la tête est comprise à peu près quatre fois et demie dans la longueur totale; le museau est peu fourchu et peu armé. Le diamètre de l'ceil fait un peu plus du quart de la longueur de la têle, près des deux tiers de l'espace préorbitaire, un peu moins du double de l'espace interorbitaire. Les épines de la tête, des pièces operculaires et de l'épaule sont peu développées. - Les écailles de la ligne latérale sont grandes, très larges, marqquées de stries divergentes, au nombre de 68 à 70 . - Le sillon dorsal est bordé de très petites épines ì pointe dirigrée en arrière et peu saillante, au nombre de 27 ou 28 paires; la première dorsale a son deuxiène rayon presque sétiforme, excessivement allongé, faisant plus du tiers de la longueur totale; la cautale, un peu échancrée, mesure presque le cin- 
quième de la longueur tolale; la pectorale finit sous le commencement de la seconde dorsale, elle est égale à la ventrale, fait un peu moins du quart de la longueur totale.

$$
\text { Br. ₹.-D. } 10-18 ; \text { A. } 18 \text {; C. } 11 \text {; P. } 10+3 \text {; V. } 1 / 5 \text {. }
$$

Le dos et les côtés sont rougeàtres ou d'un brun rougeâtre; le ventre est gris blanchâtre. Les dorsales sont d'un grris rougeâtre assez clair; la caudale est rougeâtre ; les pectorales sont d'un bleu plus ou moins foncé; les ventrales et l'anale sont blanchâtres. - La vessie natatoire est ovale, grande, ì parois minces. - Les appendices pyloriques sont au nombre de huit.

Habitat. Méditerranée, assez commun, Nice, Cette. Océan, commun dans le golfe de Gascogne; assez commun sur les còtes de la Charente-Inférieure, de la Vendée; rare au nord de la Loire. Manche, excessivement rare.

\section{LE TRIGLE GORNAUD OU GRONIIN GRIS. - TRIGLA GUR NARDUS, I,Inn.}

Poiss. France, t. II, p. 2i4.

N. vulg. : Grugnao, Nice; Bélugan et Cabiouna, Cette; Grondin, Grondin gris, Gurnaud, Gurmard, Gronau, còtes de l'Ouest.

Long. : 0,30 à 0,40 et mème 0,60 .

La hauteur du tronc est comprise six ì sept fois dans la longueur totale; la peau est couverte de petites écailles ciliées, au moins sur le dos el les côtés. - La longueur de la tête est contenue quatre fois à quatre fois e! trois cinquièmes dans la longueur totale; le museau est relativement allongé ; chaque préorbilaire porte en avant trois ou quatre épines el quelques dentelures en arrière. Chez les sujets de grande taille, le diamètre de l'cril ne fait pas le quart de la longueur de la tête, il mesure la moitié environ de l'espace préorbitaire; il est égal à l'espace interorbitaire; le sourcil a deux ćpines en avant, el souvent quelques dentelures en arrière. L'épine horizontale de l'opercule est bien développée, elle atteint le milieu de l'épine coracoüdienne. - La ligne latérale est saillante, formée de grosses écailles granulées, relevées d'une arête 
portant deux à cinq dentelures et terminée en pointe, au nombre de 69 à $7 \%$. - Le sillon dor'sal est hordé par 28 ou 29 paires d'osselets granuleux; la première dorsale finit vers la sixième paire d'osselets; ses deux premiers aiguillons sont généralement très granuleux en avant et sur les cólés, le deuxième est très fort el très long; l'épine surscapulaire est rugueuse: l'́pine coracoïlienne est saillante, granulée, très pointue; les pectorales sont ordinairement un peu plus courtes que les ventrales, elles arrivent à peine à l'anus; les ventrales font le cinquième au moins de la longueur tolale.

$$
\text { D. i i } 9 .-19 \text { ou } 20 ; \text { A. } 18 \text { i } 20 \text {; C. } 11 \text {; P. } 10+3 ; \text { V. } 1 / 5 \text {. }
$$

Le plus souvent le dos et les côtés sont gris avec des taches blanchàtres; la gorge et le ventre sont blanchâtres; parfois le dos est bleuatre et le ventre blanc. Une tache noirâtre marque assez. souvent la première dorsale entre le troisième et le cinquième rayon. La ligne latérale forme une bande diun blanc nacré. - La ressie natatoire est grande, ovale, échancrée, presque bilobée en avant. - Il y a sept appendices pyloriques, le plus somvent.

Habitat. Méditerranée, assez rare. Commun sur nos còtes de l'Ouest.

\section{̈̈. LE TRIGLE MILAN. - TRIGLA MILVUS.}

Poiss. France, t. II, p. 278.

N. vulg. : Giano, Nice; Bélugo, Bélugar, Marseille; Bélugan, Cabiouna, Celle; Lloumbrigna, Port-Vendres.

Suivant Parnell, le Trigle milan ou le Grondin rouge n'est qu'une varifín du firondin gris; nous adoptons cette manière de voir; les différences, qui existent entre ces frondins, sont trop peu importantes pour ètre regardées comme de véritables caractères spécifiques; les crénelures des écailles de la ligne latérale sont moins prononcées dans le Grondin rouge que dans le Grondin gris, elles sont aussi généralement moins fortes sur les osselets bordant le sillon dorsal.

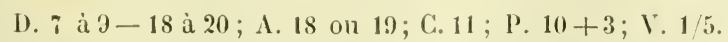

Chez le Milan, le dos et les flanes sont rouges; le rentre est 
d'un gris blanchâtre; quelquefois le dos est d'un violet assez foncé; la ligne latérale dessine une raie blanche: dans les jeunes, la teinte est d'un gris rougeâtre. La première dorsale porte, entre le troisième et le cinquième ou le sixième aiguillon, une tache noire bien limitée. - La ressie natatoire est semblable à celle du Grondin gris. - Les appendices pyloriques sont en nombre variable de cinq et plus.

Habitat. Toutes nos còtes; il parait plus commun que le Gornaud dans la Méditerranée.

\section{LE TRIGLE LYRE. - TRIGLA LYRA.}

Poiss. France, t. II, p. 280.

N. vulg. : Gallina, Nice; Pinaou, Cette; Grougnant, Languedoc; Bourreau, Soint-Jean-de-Luz; Cardinal, Poitou.

Long. : $0,2 \ddot{z}$ à 0,40 .

Le corps est très haut en arant, puis s'abaisse d'une facon sensible sous la première dorsale; sa hauteur est comprise six fois à six fois et quart dans la longueur totale; les écailles sont très petites, nettement ciliées, en rangées très obliques. - Ordinairement la tète est un peu plus haute que le trone; sa longueur fait le quart de la longueur totale; son profil antérieur est relativement allongé : le museau est profondément échancré; chaque préorbitaire se ternine en avant par une proéminence plus longue que l'espace interorbitaire, large, aplatie, armée d'épines plus ou moins pointues, en nombre variable de sept à quinze. Le diamètre de l'œeil est contenu trois fois à trois fois et quart dans la longueur de la tète, il mesure environ les deux tiers de l'espace préorbitaire. le double de l'espace interorbitaire; le sourcil porte en avant une épine bien déreloppée, une autre moins forte en arrière. Loperule est armé de deux épines; l'épine horizontale, dirigée en arrière, est très pointue, très longue. - La ligne latérale est un peu courbe à son origine; elle est formée d'écailles tubuleuses, étroites, dessinant une légère saillie. - Le sillon des dorsales est bordé par une série de vingt-cinq épines très développées, triangulaires, à pointe dirigée en arrière. La 
première dorsale a généralement le troisième aiģuillon plus allongé que les autres; la seconde dorsale est d'un tiers, ou plus, moins élevée que la première; la caudale est un peu échancrée; l'épine coracoïdienne est excessivement développée, elle se prolonge en arrière jusque vers le milieu de la pectorale; la pectorale, très développée, se porte en arrière jusque vers le cinquième ou le sixième rayon de l'anale, sa longueur est comprise trois fois et un tiers à trois fois el demie dans la longueur tolale, dont la ventrale ne fait guère que le cinquième, son extrémité arrivant à l'anus.

D. 9) ou $10-16$ ou 17 ; A. 16 ou 17 ; C. 11 on 12 ; P. 11 à $14+3 ;$ V. 1/5.

Le dos est d'un rouge assez clair ; les flanes et le ventre sont généralement rouges; la première dorsale est souvent marquée d'un bleu très foncé; les pectorales ont deux ou trois bandes d'un hleu fort sombre dans l'intervalle des plus grands rayons; les ventrales sont d'un hlanc violacé ou bleuâtre. - La vessie natatoire est large, ovoïde, légèrement échancrée en avant. - Les appendices pyloriques sont au nombre de six.

Habitat. Méditerranée, commun, Nice, Cette. Océan, golfe de Gascognne, commun et mème très commun à Arcachon; moins commun au nord de la Gironde. Manche, assez rare.

\section{LE TRIGIL CORBEAU OU PERLON. - TRIGLA CORAX.}

Poiss. France, t. II, p. 284.

N. Vulg. : Gallina, Gallinetta, Nice ; Cabouta boulanta et Boulaïda, Cette; Cabote, Galline, Provence, Languedoc ; Cabote, Port-Vendres; Perlon, Bordeaux; Perlan, Vendée; Pirlon, Rouget, còtes de Normandie.

Long. : 0,40 à 0,60 et plus.

La hauteur du tronc est comprise cing fois et un tiers a sept fois dans la longueur totale; les écailles sont petites, ovales, le plus souvent garnies de spinules excessivement fragiles. La tète est large; sa longueur mesure environ le quart de la longueur totale; le museau est peu échancré, coupé carrément, à lobes garnis de très petites pointes. Le diamètre de l'wil lail 
le cinquième environ de la longueur de la tête, les deux cinquièmes de l'espace préorbitaire; il est égal à l'espace interorbitaire; le soureil porte en avant deux ou trois épines. L'opercule a ses deux épines mousses et courtes; le préopercule n’a qu’une pointe peu développée. - La ligne latérale est peu saillante, formée d'écailles étroites, allongées, légèrement tubuleuses. - La partie libre des interépineux bordant le sillon dorsal est peu saillante; la première dorsale a son premier aiguillon à bord antérieur tranchant, peu ou pas dentelé; le deuxième aiguillon est le plus allongé; le coracoïdien est muni d'une épine assez courte; les pectorales sont très développées, elles sont ì peu près aussi larges que longues, leur longueur fait au moins le quart de la longueur totale.

D. 8 ou $9-16$ ou 17 ; A. 1 1 d 16 ; C. 12 ou 13; P. 10 ou $11+3$; V. 1 .

La teinte est très variable; ordinairement le dos est d'un rose jaunatre ou grisàtre, le ventre d'un blanc rosé, les flancs d'un rose doré; la lête est rougeâtre; parfois le corps est en dessus d'un gris brunàtre ou olivàtre, blanchâtre en dessous. Les dorsales sont roses; la première est parfois marquée d'une tache obscure entre le quatrième et le cinquième aiłruillon; la caudale est rougeàtre; les pectorales sont en dehors d'un violet foncé, à leur face interne d'un vert très-foncé grivelé de noir avec une assez large bordure bleuàtre, chez les jeunes, il y a une tache noire semée de taches bleues; les ventrales sont d'un blane rosé, ainsi que l'anale. - La ressie natatoire est trilobée, chez les individus de grande taille, elle se compose d'un lobe médian ovale, très volumineux et de deux longues cornes latérales; chez les jeunes, elle est échancrée antérieurement et chaque lobule se partage en deux petites cornes l'une dirigée en avant, l'autre rejetée sur le côté. - Les appendices pyloriques sont au nombre de huit à douze.

Jeune. - Le Petit Perlon à pectorales tachetées. - Trigla pæciloptera, Valenc.

Outre les deux épines que le sourcil porte en avant, comme chez l'adulte, il en a une troisième en arrière. Le sillon des dorsales est bordé d'épines très pointues. - La coloration 
est d’un gris vert lavé de rouille sur le dos el les flancs, blanchitre sous le ventre. Les pectorales ont la face externe violet blenatre, la face interne bleuatre ou noiratre avec une plaque d’un bleu foncé semé de petites taches pâles.

Habitat. Commun sur toutes nos còtes.

\section{S. LE TIIGLE CAVILLONE OU TRIGLE RLDE. - TRIGLA}

\section{C.AVILLONE IUT ISPERA.}

Loiss. Frence, t. II, p. 290, fig. 113, anim.

N. vulg.: Cavillom, Nice; Rascassou, Rascoun, Cette.

Long. : 0.08 à 0,12 .

Le corps est à peu près eonique; sa hauteur est contenue environ ciny fois et demic dans la longueur totale; ses écailles sont plus développées que dans les autres Trigles; elles sont grandes. plus hautes que larges, très rudes, garnies d'une rangée de spinules écartées. - La tète a le profil antérieur court. presque vertical; sa longueur mesure le quart environ de la longueur totale ; le museau est court, peu échancré. Le diamètre de l'ceil est contenu trois fois et demie à trois fois et deux tiers dans la longueur de la tète; il fait un peu moins des deux liers de l'espace préorbitaire; il est à peine plus grand que l'espace interorbitaire; le sourcil porte en avant deux petites épines, et une autre, en arrière, plus grosse, après laquelle est creusé un sillon transrersal, profond, qui entame le bord postérieur de l'orbite. L'opercule est armé d'une épine lıorizontale très piquante. - Les écailles de la ligne latérale nont pas de spinules à leur bord postérieur; elles sont très courtes et relativement assez hautes; il y en a de 30 à 60 . 11 y a de chaque côté du sillon dorsal vingt-trois à vingt-cinq épines très aiguës. La première dorsale est presque triangulaire, ses trois premiers aighuillons, qui sont les plus élevés, ont le bord antérieur généralement dentelé ; le coracoïdien est développé, armé d'une épine longue, très acérée; les pectorales sont fort grandes; leur longueur est contenue trois fois et demie à trois fois et deux tiers dans la longueur totale.

D. $9-15$ ou $16 ;$ A. 15 ; C. $11 ;$ P. 10 ou $11+3 ;$ V. $1 / 5$. 
Le dos est rouge, parfois d'un gris un peu jaunatre; le ventre est blanc ou d'un blanc teinté de jaune. - La vessie natatoire est développée ; elle est ovale, un peu échancrée à son extrémité antérieure.

Habitat. Méditerranée, Nice, assez rare; Cette, commun.

\section{Sous-famille des Cottiniens, Cottini, Bp.}

Tête large ; mìchoires dentées; palatins et langue lisses.

Appareil branchial : ouverture des ouies de grandeur variable; quatrième arc branchial ne portant qưune série simple de lamelles respiratoires; six rayons branchiostèges.

Nageoires; deux dorsales rapprochées; anale opposée à la seconde dorsale; pectorales développées, composées en tout ou en partie de rayons simples; ventrales étroites, ayant une épine et moins de cinq rayous mous.

Vessie natatoire nulle. - Appendices pyloriques peu nombreux.

Cette sous-famille comprend deux genres:

Corps nu ou n'ayant que des pièces écailleuses isolées.. 1. Corte. Corps revêtu de grandes écailles ou plutôt de boucliers. 2. Aspidopnone.

\section{GENRE COTTE. - cotTUS, Arted.}

Corps allongé; peau nue ou n'ayant que de rares tubercules. Tête forte; dents en velours sur les màchoires et le vomer.

Ligne latẻrale bien marquée.

Nageoires; seconde dorsale plus longue que la première et que l'anale; ventrale ayant une épine et trois ou quatre rayons mous.

Ce genre est composé de trois espèces:

a. Préopercule à une seule épine distincte....... Préopercule muni de plusieurs épines....... b.

b. Nembranes branchiostèges unies sous la gorge. Nembranes branchiostèges séparées l'une de

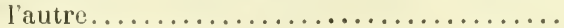

1. CHAвот.

2. SCORPION.

3. A LONGUES ÉPINES.

1. LE COTTE CHABOT oU CHABOT IE RIVIERE. - COTTUS GOBIO, Linn.

Poiss. France, t. II, p. 293.

N. vulg. : Cabot, Testard, Grosse-tête; Sassot, le Bourget, Annecy; 
Séchot, lac Léman; Vilain, Chaca, finavelet, Bavard, Lorraine; Bine, Jacquard, Gan,Cafard,Còte-d'Or;Chapsot, environs de Paris ; Chamsot, Normandie; Chaboiseau, Godet, Echabot, Anjou; Meunier, Mouné, Poitou; Chahaou, Asé, Gard; Tète d'aze, Lanquedoc; Botta, Nice.

Long. : 0,10 à 0,12 , rarement plus.

La hauteur du trone est comprise six fois et quart à sept fois dans la longueur totale ; en avant, au-dessus et au-dessous de la lignne litérale, la peau est souvent rugueuse, hérisséc de petites plaques épineuses. - La tète est couverte d'une peau molle; elle est rolumineuse, plus large que le corps; sa longueur est contenue quatre fois à quatre fois et quart dans la longueur totale; la bouche est grande; la mìchoire supérieure est protractile, elle porte des dents en velours ainsi que la mandibule et le vomer. Le diamètre de l'uil fait le cinquième de la longueur de la tète, les trois cinquièmes environ de l'espace préorbitaire ; il est plus petit que l'espace in terorbitaire. L'opercule se termine en arrière par une pointe mousse; le préopercule est armé d'une épine très pointue, dirigée en arrière et en haut ; au-dessous de cette épine, mais portée en sens contraire, en existe une autre beaucoup plus petite, difficile à sentir avec le doigt. - La ligne latérale est droite; elle est soutenue par deux rangées de petites pièces dures. - Les dorsales sont unies par une membrane triangulaire basse et courte; l'anale est plus courte que la seconde dorsale qui la dépasse en avant el en arrière; les pectorales sont bien développées, leur longueur est comprise quatre fois et quart dans la longueur tolale, les six ou sept rayons inférieurs sont simples, articulés, libres dans une partie de leur Iongueur, les rayons supérieurs sont généralement branchus, parfois ils restent simples comme les inférieurs; les ventrales ont une épine et quatre rayons mous.

Br. $6 .-$ D. 6 a $8-16$ à 18 ; A. 12 ou 13; C. 13 ; P. 13 ou $14 ;$ V. $1 / 4$.

La teinte est très variable ${ }_{2}$ le plus souvent grisittre avec de larges taches ou des bandes noirâtres sur le dos et les cótés : chez les jeunes, la teinte est souvent d'un gris roussâtre avec des marbrures d'un brun plus foncé; la tête est grise avec de petites taches noires. Les dorsales, la caudale et les pectorales sont généralement d'un gris plus ou moins brunâtre; les ven- 
trales et l'anale sont ordinairement d'un blanc grisâtre.- Les appendices pyloriques sont au nombre de quatre, de cinq parfois.

Habitat. Très commun dans la plupart de nos rivières.

\section{LE COTTE SCORPION. - COTTUS SCORPIUS.}

Poiss. France, t. II, p. 298.

N. vulg. : Vive de mousse, Arcachon; Barlan, Biarritz.

Long. : $0,1:$ à 0,20 .

La hauteur du trone est contenue de quatre fois à cinq fois et quart dans la longueur totale; la peau est ordinairement nue, parfois elle montre des écailles éparses à quatre ou cinq dentelures sur leur bord postérieur. - La tète est nue, armée d'épines; sa longueur est contenue trois fois à trois fois et quart dans la longueur totale; la bouche est grande; les màchoires et le vomer ont des dents en velours. L'ceil est rapproché du profil supérieur; son diamètre fait à peu près le cinquième de la longueur de la tête, les deux tiers de l'espace préorbitaire; il est plus grand que l'espace interorbitaire. Les membranes branchiostèges se réunissent sous la gorge; l'opercule est muni d'une épine aiguë, qui dépasse en arrière celle du préopercule; le préopereule est armé de trois épines, la plus développée se porte en arrière el en haut. - La ligne latérale est formée d'osselets saillants. - Les dorsales sont unies par une membrane assez courte et assez basse; la première est moins haute que le tronc; les pectorales mesurent le quart de la longueur totale, leurs rayons sont simples.

$$
\text { D. } 8 \text { ì } 10-1 / 13 \text { à } 15 ; \text { A. } 11 \text { ou } 12 \text {; C. } 12 \text {; P. 1i ; V. 1/3. }
$$

Le dos et les flanes sont d'un gris roussàtre ou verdàtre; le ventre est d'un gris jaunatre; des marbrures et des taches noirâtres se dessinent plus ou moins nettement sur le corps; la tête est ordinairement d'un brun ou d'un gris assez foncé arec des points ou des taches blanchatres. Les nageoires impaires et les pectorales sont grisàtres, marquées de taches noirâtres, assez somvent traversées de bandes noirâtres obli- 
ques; les ventrales sont d'un blanc grisatre avec des points brunâtres. - Les appendices pyloriques sont au nombre de huit environ.

Habitat. Manche, commun. Océan, assez commun sur les còtes de Brelagne, moins commun au sud de la Loire; assez rare entre la Gironde et l'Adour: très rare dans les Basses-Pyrénées.

\section{LE COTTE A IONGLES EPINES. - COTTUS BUBALIS.}

Poiss. France, t. II, p. 392, fig. 114, anim.

Long. : 0,10 à 0,13 .

La hauteur du tronc est comprise quatre fois et quart à quatre fois et demie dans la longueur totale. - La tète est armée de nombreuses épines; sa longueur mesure près du tiers de la longueur totale; les mâchoires portent une large rangée de dents en velours. Le diamètre de l'oril fait le quart de la longueur de la tête, le double de l'espace interorbitaire, il est un peu moins grand que l'espace préorbitaire. Les membranes branchiostèges ne se joignent pas sous la gorge, elles sont séparées l'une de l'autre par une distance égale au tiers de la hauteur de la fente branchiale; l'opercule est muni d'une épine; le sous-opercule a chacun de ses angles postérieurs terminé par une épine très aiguë; le préopercule est pourvu de quatre épines, celle de son angle postérieur et supérieur est très longue, elle mesure le tiers de la longueur de la tète; le préopercule a l’angle inférieur prolongé en une épine crochue. - La lignne latérale est rapprochée du profil du dos; elle est soutenue par de petits osselets épineux. - La première dorsale est basse.

D. 8 ou $9-12$ ou $13 ;$ A. 9 ou $10 ;$ C. 11 ou $12 ;$ P. 15 ou $16 ;$ V. $1 / 3$.

Le dos est gris brunâtre ou rougeâtre; le ventre, ainsi que la gorge, est d'un grris blanchàtre ou violacé; la tète et les parties supérieures du corps sont tachetées de inacules ou de points noirâtres. Les dorsales sont d'un gris blanchâtre ou rougeâtre avec ou sans taches; les pectorales, la caudale et sourent l'anale sont marquées de taches brumes disposées par 
séries; les ventrales sont d'un gris blanchâtre ou rosé. - 11 y a une huitaine de petits appendices pyloriques.

Habitat. Manche, commun. Océan, moins commun; assez rare entre la Loire et la Gironde; excessivement rare plus au sud.

\section{GENRE ASPIDOPHORE. - ASPIDOHHORUS, Lacép.}

Corps en forme de pyramide allongée; cuirassé de plaques écailleuses.

Tête large, couverte de pièces osseuses; museau épineux; dents sur les màchoires, pas sur le vomer.

Nageoires; deux dorsales courtes; anale sous la seconde dorsale.

\section{L'ASPIDOPHORE ARMÉ. - ASPIDOPHORUS CATAPHRACTUS.}

Poiss. France, t. II, p. 306, fig. 11ว̈, anim.

N. vulg. : Souris de mer.

Long. : 0,10 à 0,12 , quelquefois 0,15 .

Le corps, en forme de pyramide allongée, est courert de grandes écailles, de boucliers dont les angles forment des arêtes longitudinales très prononcées; sa hauteur est comprise six fois à sept fois et demie dans la longueur totale. - La tête est très large, triangulaire; sa longueur est contenue quatre fois et demie dans la longueur totale ; le museau est avancé, il est relevé de chaque côté par une éminence terminée par deux petites épines; la màchoire supérieure déborde la mandibule, ayant l'une et l'autre une bande assez étroite de dents en velours très ras; sous la mandibule et la gorge sont attachés des appendices cutanés sétiformes. Le diamètre de l'œil est compris quatre à cinq fois dans la longueur de la lête, il est d'un sixième moins grand que l'espace préorbitaire, il est plus petit que l'espace interorbitaire. Les membranes branchiostèges s'unissent sous la gorge; le préopercule a son angle postérieur et inférieur armé d'une forte épine. - La ligne latérale est marquée par une suite de petites saillies. - La première dorsale est courte; l'anale est placée assez loin de lanus, sous la seconde dorsale à layuelle elle ressemble: les 
pectorales, d'un quart plus longues que les ventrales, font le cinquième de la longueur totale.

Br. 6. - D. 5.-6 ou 7; A. 6 ou 7; C. 11; P. $15 ;$ V. $1 / 2$.

Le système de coloration est trìs variable; le dos et les côtés sont d'une teinte sombre assez uniforme ou bien d'un Ion rosé ou rougeàtre avec des bandes transversales brunes ou noiràtres; le dessous du corps est blanc jaunàtre en avant, grisàtre après l'anale. Les dorsales, la caudale et les pectorales sont d'un brun plus ou moins foncé; les ventrales sont d'un gris jaunatre avee quelques laches brunes.

Habitat. Manche, commun à l'embouchure de la Seine, plus rare au nord et au sud de ce fleuve. Océan, très rare, Charente-Inférieure.

\section{Sous-famille des Scorpéniniens, Scorpænini.}

Corps oblong, plus ou moins comprimé, couvert d'écailles.

Tête épineuse; dents sur les màchoires, le vomer, les palatins.

Appareil branchial; opercule et préopercule épineux; sept rayons branchiostèges; trois séries doubles et une série simple de lamelles respiratoires, rarement quatre séries doubles; pseudobranchies; sept rayons branchiostèges.

Nageoires; dorsale unique composée d'aiguillons et de rayons mous; anale assez courle, ayant trois épines et des rayons mous assez peu nombreux; pectorales à rayons inférieurs simples; ventrales ayant une épine et cinq rayons mous.

Appendices pyloriques peu nombreux.

Deux genres.

Tète nue ou n'ayant que des écailles sous-épidermiques.... 1. SGonpėne. Tète couverte d'écailles cténoïdes.................... 2. Sébaste.

1. GENRE SCORPENE. - SCORPANA. Linn.

Corps oblong, à lambeaux cutanés plus ou moins nombreux.

Tête forte, comprimée, non écailleuse ou n’ayant que des écailles sous-épidermiques, armée de piquants, généralement pourvue de franges cutanées ; région occipitale arec une dépression transversale ; dents en velours sur les màchoires, le palais.

Appareil branchial; le quatrième arc branchial ne portant qu’une série simple de lamelles respiratoires. 
Nageoires; dorsale très avancée, plus ou moins échancrée, à rayons épineux plus nombreux que les rayons mous.

Vessie natatoire nulle.

Ce genre comprend trois espèces :

a. Ligne longitudinale ayant moins de cinquante écailles. $b$.

Ligne longitudinale ayant plus de 50 écailles; sousorbitaire antérieur a deux épines...............

b. Bord antérieur du premier sous-orbitaire armé de trois épines............................

Bord antérieur du premier sous-obitaire armé de

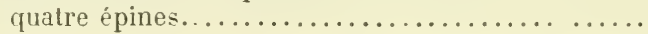

3. RASCASSE.

2. PUSTLLELSE.

1 TRUIE.

\section{LA SCORPENE TRLIE. - SCORPEIA SCROFA, Linn.}

Poiss. France, t. II, p. 310, fig. 116, anim.

N. vulg. : Capoun, Yice, Cette; Scorpène, Marseille ; Rascasse, Escorpit, Pyrénées-Orientales; Saccarailla et Saccoile, Saint-Jeande-Luz, Biarritz; Rascasse, Arcachon; Sabourolle, Charente-Inférieure.

Long. : 0,20 à $0, \dot{4} 0$, quelquefois 0, ว̈0.

La hauteur du tronc est comprise trois fois et demie, rarement quatre fois dans la longueur totale; le corps est courert d'écailles plus développées que dans la Rascasse, garnies à leur bord libre d'une rangée de spinules qui s'usent et disparaissent plus ou moins chez les sujets de grande taille; surles côtés se montrent des appendices cutanés, plus nombreux et plus allongés sur le trajet de la ligne latérale. - La longueur de la tète mesure généralement plus du tiers de la longueur totale; le dessus de la tète, le museau, le dessous de la mandibule sont garnis d’appendices cutanés plus ou moins nombreux. Le diamètre de l'œil fait le cinquième ou le sixième de la longueur de la tète, les deux tiers de l'espace préorbitaire, il est un peu plus grand que l'espace interorbitaire; le sourcil est armé de trois épines et porte deux tentacules; le premier sous-orbitaire a le bord inférieur muni de quatre épines en quelque sorte couplées à leur base; il donne insertion à un appendice cutané bien déreloppé. Le tentacule nasal esí plus

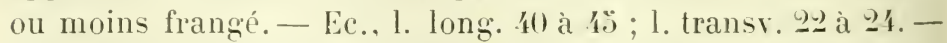
La dorsale est inégale, échancrée vers la fin de sa partie épineuse; l'anale est assez éloignée de l'anus; la caudale est 
large; la longueur de la pectorale fait le cinquiòme environ de la longueur totale.

D. $12 / 9$ ou $10 ;$ A. $3 / 5 ;$ C. $4 / 10$ ou 11/4; P. $19 ;$ V. $1 / 5$.

La teinte générale est variahle; le corps et la tête sont le plus souvent rougeàtres, tachclés de noir, parfois grisâtres avec des macules d'un brun plus ou moins foncé. Les nageoires impaires et les pectorales sont marquées de taches brunes, jaunàtres ou rougeâtres, suivant la teinte du corps; les ventrales sont roses ou d'un jaune grisatre aree des laches sombres; souvent la dorsale porte une tache noire s'étendant du sixième au neuvième ou dixième aiguillon.

Var. - La Scorpène jaune. - Scorprna lutea, Riss.

N. vulg. : Capoun giaune, Nice; Capoun tjaouné, Cette.

Le corps est jaunatre avec des marbrures brunàtres; les nageoires, également jaunàtres, sont marquées de zébrures noirâtres.

Habitat. Méditerranée, commune, Nice, Cette. Océan, commune à Saint-Jean-de-J.uz; assez commune, Arcachon; rare au nord de la Gironde.

\section{LA SCORPENE PUSTULEUSE. - SCORPENA USTULATA, Lowe.}

Poiss. France, Suppl., p. 26.

Long. : 0,10 à 0,13 , quelquefois plus.

La hauteur du tronc est comprise trois fois et quart ì trois lois et demie dans la longueur totale; les appendices cutanés sont fort grèles et généralement rares; les écailles sont grandes, très rudes. - La longueur de la tête mesure le tiers environ de la longueur totale; la michoire supérieure est un peu moins avancée que l'inférieure; elles sont munies l'une et l'autre de petites dents en velours ras; il n'y a que fort peu d'appendices cutanés. Le diamètre de l'ceil est contenu trois fois à trois fois el quart dans la longueur de la tête; il est un 
peu plus grand que l'espace préorbitaire, il fait le double de l'espace interorbitaire; le tentacule sus-orbitaire est petit, grêle, digité; le premier sous-orbitaire a le bord inférieur armé de trois épines, deux épines antérieures à base très rapprochée, une épine postérieure crochue, à pointe dirigée en bas et en arrière. Le tentacule nasal est peu déreloppé. - Ec., 1. long. 46 environ; 1. transr. 21 ou 29. - La dorsale est échancrée, très longue; l'anale a la seconde épine très développée; la longueur de la pectorale est comprise quatre fois à quatre fois et demie dans la longueur totale.

\section{D. $12 / 9$ ou $10 ;$ A. $3 / 5$; C. 2 à $4 / 12$ ou $13 / 3$ ou 4 ; P. 18 ou $19 ;$ V. $1 / 5$.}

La teinte générale est rosée arec des points ou des taches brunâtres. La dorsale est rosée; une tache noirâtre, bien marquée, se montre entre le huilième aiguillon et le neuvième, parfois elles'étend du huitième aiguillon au dixième; la partic molle porte de petites taches noirâtres; lanale a la même coloration que la dorsale; la caudale et les pectorales sont roses avec des taches noiràtres en séries verticales; les ventrales sont roses avec des taches noires assez rares. Les tentacules du soureil sont tantôt rosés, tantôt noirâtres.

Habitat. Méditerranée, Nice.

3. LA SCORPENE RASCASSE OU BRLNE. - SCORP ENA PORCUS, Linn.

Poiss. France, t. II, p. $31 \%$.

N. vulg. : Rascassa, Nice, Cette; Rascasse, Marseille; Gornito, Biarritz; Crapaud de mer, Arcachon, la Rochelle.

Long. : 0,15 à $0,20 \%$, rarement 0,30 .

La hauteur du tronc est comprise trois fois et quart dans la longueur totale; les écailles, qui ont été comparées à celles de certaines Couleuvres, sont beaucoup plus petites que dans les autres espèces, très peu cilices; les appendices cutanés sont assez peu nombreux, assez peu développés. - La lête a des appendices moins nombreux que dans la Scorpène truie; il n'y a pas de lambeaux charnus sous la mandibule. Le dia- 
mètre de l'iril fail le quart de la longueur de la tète, le double de l'espace interorbitaire, il est en général plus grand que l'espace préorbitaire; le sourcil porte deux tentacules plus ou moins développés. Il existe un tentacule à l'orifice nasal anté-

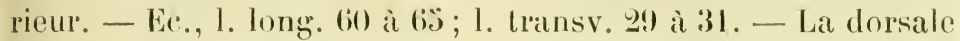
est échancrée, elle a ses rayons épineux plus réguliers que dans la Scorpène truie.

D. $12 / 9 ; \Lambda .3 / 5 ;$ C. $4 / 10$ ou $11 / 4 ;$ P. $18 ;$ V. $1 / 5$.

Généralement le dos et les côtés sont grisâtres, variés de noir; le ventre, les ventrales et les rayons inférieurs des pectorales ont une teinte rosée; la dorsale porte souvent sur les $7^{\mathrm{c}}, 8^{\mathrm{e}}, 9^{\mathrm{e}}, 10^{\mathrm{c}}$ aiguillons, et sur les espaces intraradiaires, une lache noiràtre.

Habitat. Méditerranée, très commune à Nice, Cette. Océan, commune dans le golfe de liascogne; assez rare au-dessus de la Gironde, la Rochelle, le Croisic. Manche, très rare, Caen? Dieppe.

2. GENRE SEBASTE. - SEBASTES, Guv.

Corps oblong, couvert d'écailles ciliées.

Tête écailleuse, plus ou moins épineuse, sans lambeaux cutanés; dents sur les màchoires, le vomer el les palatins.

Appareil branchial; fente des onïes très grande.

Nageoires; dorsale longue, échancrée; pectorale à rayons inférieurs à moitié libres, non branchus.

LA SÉBASTE DACTYLOPTERE. - SEBASTES DACTYLOPTER.1.

Poiss. France, t. II, p. 317, fig. 117, anim.

N. vulg. : Cardouniera, Nice; Vaca, Celle; Crabra (basque), Biarritz.

Long. : 0,20 à 0,30 .

Le corps est couvert d'écailles très rudes; sa hauteur est contenue trois fois et demie à trois fois et deux tiers dans la longueur totale. - La tète est garnie d'écailles; sa longueur st comprise trois fois à trois fois el quart dans la longueur lotale; la màchoire supérieure est à peine moins arancée que 
la mandibule; elles sont l'une et l'autre munies de dents en cardes; l'extrémité du maxillaire supérieur s'étend plus loin que le prolongement du diamètre vertical de l'cril. Le diamètre de l'oil mesure presque le tiers de la longueur de la tète; il est d'un quart plus grand que l'espace préorbitaire qui fait le double de l'espace interorbitaire. - Ec., l. long. 333 à 60 ; 1. transr. 26. - La dorsale est échancrée vers la fin de sa partie épineuse; le troisième aiguillon et le quatrième sont les plus allongés; la portion molle est plus élevée que l'autre; la deuxième épine de l'anale est au moins aussi forte que la troisième; la caudale est carrée ; les pectorales sont développées, leurs sept ou huit rayons inférieurs sont simples, libres dans le tiers ou la moitié de leur longueur; les rentrales arrivent jusqu'à l'anus et parfois mème plus en arrière.

Br. 7.-D. 12/12 ou $13 ;$ A. $3 / 5$ ou $6 ;$ C. $16 ;$ P. $19 ; \mathrm{V} .1 / 5$.

La teinte générale est tantôt d'un rouge plus ou moins vif avec des bandes verticales blanchâtres; tantôt elle est d'un rouge lavé de blanc, ou rosée avec des marbrures rougeâtres; parfois des bandes brunes descendent jusqu à la ligne latérale.

Habitat. Méditerranée, la Sébaste est commune à Nice; assez commune à Marseille; assez rare à Cette. Océan, assez commune à Saint-Jean-de-Luz; assez rare, Bayonne; excessivement rare, Areachon; parfois elle est apportée en certaine quantité sur le marché de Paris, expédiée, parait-il, de la Rochelle; en 1889, j’ai été surpris d'en voir pareil nombre à la Halle.

\section{La Sébaste de Bibron. - Sebastes Bibroni, Sauv.}

Poiss. France, t. II, p. 321.

A propos d'une nouvelle espèce de Sébaste, distinguée par le I) Sauvage parmi des Poissons que Bibron avait recueillis en Sicile, et nommée par lni S. Bibroni, M. Vinciguerra écrit (Croc. Vinlunte, note, p. 50) : è strano pero come il /, $^{\mathrm{r}}$ Bourjot (Liste des Poissons d'Alger, p. 30), che seguira il Bibron nei snoi viaggi in Sicilin, dica non ricordarsi essere mai stato da questi trovuto un Sebastes. Ce qui est plus étrange encore, c'est l'expédient auruel a recours M. Vinciguerra, qui, pour donner une apparence de rérité à son 
observation, ne craint pas de nodıfier la note publiée par l'auleur dont il invorfue le témoignage. - Jamais le Dr Bourjot n’a parlé, comme Vavance M. Vinciguerra, de ses voyages en Sicile, suoi viag!ji in Sicilia, avec Bibron; la citation du texte du $D^{\mathrm{r}}$ Bourjot, qui est fort explicite, en fournit la preuve la plus indiscutable: nous ne nous souvenons pas que nolre ami et premier camarade de voyage, f. Bibron... ait trouvé le Sebuste dans ses investigations sur les poissons de la Méditerranée. Ce voyage se reporte à 1824, ou à plus de quarante ans en arrière (Bourjot, loc. cit., p. 30). - En 1829, Bibron fut enroyé par le Muséum en Sicile, pour y faire une collection de Poissons.

\section{Famille des Bérycidés, Berycidx.}

Corps ovale, comprimé, couvert d'écailles.

Téte développée; houche bien lendue; màchoires dentées.

Appareil branchial; ouïes largement ouvertes; pièces operculaires plus ou moins épineuses.

Nageoires; dorsale unique; ventrales ayant un aiguillon et plus de eing rayons mous.

Cette famille est formée de deux genres :

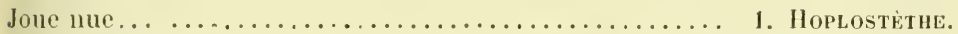

- écailleuse............................ Ве́ях.

1. GENRE HOPLOSTETHUS. - HOPLOSTETHUS, CUV.

Corps ovale, garni entre les ventrales et l'anus d'une cuirasse formée de pièces écailleuses carénées.

Tête nue, hérissée d’arètes ou de crètes osseuses limilant des cavités plus ou moins grandes, couvertes par la peau; museau court; bouche nou protractile, à grande fente oblique; màchoires à dents fort petites; vomer non denté.

Yeux grands, Jatéraux; sous-orbitaires caverneux, portant des arêtes divergentes, plus ou moins àpres.

Appareil branchial; huit rayons branchiostèges; pseudobranchies.

Ligne latérale composée d'écailles plus frandes que les autres.

Nageoires; dorsale à rayons épineux moins nombreux que les rayons mous.

Vessie natatoire grande. - Appendices pyloriques nombreux. 


\section{L'HOPLOSTETHE DE LA MÉDITERRANÉE. - HOPLOSTETHUS} MEDITERR A NEUS.

Poiss. France, t. II, p. 322.

Long. : 0,18 à 0,26 .

La hauteur du corps est comprise deux fois et deux tiers à trois fois dans la longueur totale; les écailles sont assez grandes, plus ou moins ciliées dans la région supérieure, lisses à peu près sur les côtés et le ventre; la partie qui s'étend de la base des ventrales à l'anus est garnie d'une espèce de cuirasse formée de huit à treize boucliers carénés. - La tête est nue, hérissée d'arêtes âpres; sa longueur est contenue trois fois et demie environ dans la longueur totale; la bouche est oblique, sa fente s'étend presque jusqu'au prolongement du diamètre vertical de l'œil; les mâchoires et'les palatins sont munis de dents excessivement fines; la muqueuse de la bouche est noirâtre ainsi que celle de la chambre branchiale. Le diamètre de l'ceil mesure le tiers au moins de la longueur de la tête, il fait presque le double de l'espace préorbitaire, il est plus grand que l'espace interorbitaire ; les sousorbitaires portent des arêtes divergentes qui limitent des collules irrégulières. - Ec., l. long. 60); 1. transs. 28 à 30. Aucune des nageoires ne parait écailleuse; la dorsale est en général assez régulièrement arquée; la caudale est fortement échancrée; la pectorale mesure, ou peu s'en faut, le quart de la longueur totale, elle arrive au-dessus du commencement de l'anale; la ventrale fait le sixième de la longueur totale, elle est formée d'une épine et de six rayons mous.

Br. $8 .-$ D. $6 / 12$ ou $13 ;$ A. $3 / 10 ;$ C. 5 à $8 / 19$ ou $20 / 8$ à $5 ;$ P. 14 ou $15 ;$ V. $1 / 6$

Le corps est d'un rose violacé, pointillé de brun sur le dos, d'un rose pâle sur les flanes; la tête est argentée, teintée de rose. Les nageoires sont d'un rouge jaunatre.

Habitat. Méditerranée, excessivement rare, Nice. 
2. GENIE BERYX. - BERYI, C. V.

Corps élevé, comprimé, convert d'écailles pectinées.

Tête; museau court; bouche i fente oblique; mandibule plus arancée que la màchoire supérieure, garnies l'une et l'autre de dents en velours; vomer et palatins dentés; joues écailleuses.

Yeux très grands; sous-orbitaires dentelés.

Appareil branchial; rayons branchiostèges, huit et plıs; préopercule dentelé, mais sins épine; opercule el sous-opercule couverts d'écailles.

Nageoires; anale à quatre épines; rentrale à plus de sept rayons.

\section{LE BERYY DÉCADICTYLE. - BERYI DECADACTYLUS, C. V.}

Puiss. France, Suppl. p. 30.

Long. : 0,30 à $0,0 ̈ 0$ et plus.

Le corps est ovale; sa hateur est comprise deux fois et trois quarts à trois fois et demie daus la longueur totale. - La longueur de la tête est contenue trois fois et demie à quatre fois dans la longueur totale; la mandibule est proéminente, relevée en avant; la màchoire supérieure se porte en arrière jusque sous le milieu de l'ceil. L'oeil est fort grand; son diamètre est compris deux fois et demie à deux fois et deux tiers dans la longueur de la tète; il est beaucoup plus grand que l'espace préorbitaire ; l'estrémité antérieure du préorbitaire est armée d'une épine à pointe dirig'ée en arrière. Les joues, l'opercule et le sous-opercule sont couverts d'écailles. - La ligne latérale suit le profil du dos. - Ec., l. long. 62 à 6̈; 1. transv. 32 à 34. - La caudale est profondément échancrée, elle est écailleuse; la ventrale a généralement dix rayons mous.

Br. 8. - D. 4/18 ou 19 ; A. 4/28 i 30 : C. 5 ou $6 / 18$ ou $19 / 4$ ou $5 ;$ P. 14 à 18 ; V. $1 / 9$ ou 10.

La teinte générale est rougeàtre.

Habitat. Méditerranée, accidentellement, Nice. 
๖. F'amille des Percidés, Percidx.

Corps de forme variable, couvert d'écailles presque toujours cténoïdes.

Tête rarement nue; màchoires à dents sur plusieurs rangées; vomer et palatins déntés le plus souvent.

Appareil branchial ; fente des ouies grande ; opercule épineux; rayons branchiostèges au nombre de sept, rarement de six; pseudobranchies généralement.

Nageoires; dorsale double ou unique, composée de rayons épineux et de rayons mous; anale ayant ordinairement deux ou trois aiguillons; ventrale avec un aignillon et cinq rayons mous.

Vessie natatoire simple. - A ppendices pyloriques peu nombreux.

Cette famille se divise en trois sous-familles.

a. Dorsale unique ou double, la $1^{\text {re }}$ ayant au moins huit aiguillons.................... $b$.

Dorsale double, la fre ayant moins de huit aiguil-

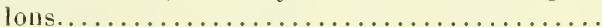

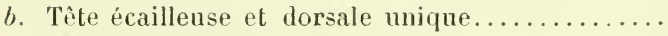

Tête écailleuse et dorsale double ou tète nue, creusée de fossettes, et dorsale unique..........

3. Apogoniniens.

2. Serranintens.

1. Perciniens.

\section{Sous-famille des Perciniens, Percini.}

Gorps oblong, couvert d'écailles de moyenne grandeur.

Tête allongée; bouche horizontale ou légèrement oblique; dents en velours ou en cardes aux leux màchoires; vomer denté le plus généralement.

Appareil branchial ; opercule épineux; sept rayons branchiostègres.

Nageoires; une ou deux dorsales avec huit rayons épineux au moins.

Cette sous-famille se compose de quatre genres:

a. Dorsale double............................. b.

- mique; tète nue, creusée de fossettes.......

$b$. Bouche terminale..........................

- sous le museau; joues écailleuses............

c. Opercule à deux épines; $1^{\text {re }}$ dorsale à $8-9$ épines...... une épine; 1re dorsale à 13-15 épines......

4. ACÉRINe.

3. APRON.

2. BAR.

1. Percie. 
1. GENRE PEIRCHE. - PERCA.

Corps oblong, courert d'écailles pectinées assez petites.

Tête allongée; crine el espace interorbitaire sans écailles; dents en velours sur tes machoires, le romer et les palatins; langue nue, lisse.

Appareil branchial ; opercule ayant une seule cpine et quelques dentelures sur le bord postérieur; préopercule dentelé.

Nageoires; deux dorsales rapprochées; la première ayant de treize à quinze aiguillons; anale a deux épines; pirces scapulaires dentelées.

\section{LA PERCHE DE RIVIERE. - PERCA FLUVIATILIS, Bell.}

Poiss. France, t. II, p. 328.

N. vulg. : Perchaude, Perdrix de rivière; Ifurlin, Vosges; Perca, Pyrenées-Orientales; Pergo, Card.

Long. $0,2: 3$ à $0, \dot{4} 0$, rarement plus.

La hauteur du tronc est comprise quatre à cinq fois dans la longueur totale; la peau est couverte d'écailles très adhérentes, très ciliées. - La longueur de la tète fait le quart environ de la longueur lotale; les màchoires sont à peu près égales, à dents loutes en velours ainsi que le vomer et les palatins. Le diamèlre de l'wil est contenu cing à six fois dans la longueur de la tèle. -- La lignne latérale est rapprochée du dos; Ec., l. long. 63 à 70 ; l. transs. 20 à 26 . - La première dorsale commence au-dessus de l’épine de l'opercule, olle est bien développée, d'un liers environ plus longue que la seconde; la caudale est échancrée; l’anale a deux fortes épines.

Br. ․ - I). 13 a $15-1 / 1$ a a $16 ;$ A. 28 ou $9 ;$ C. $17 ;$ P. 14; V.1/5.

Le système de coloration est très variable; en général la teinte est d'un vert doré, ou d'un grris azuré sur le dos et les crilés, avec cinq à sept bandes verticales, d'un brun plus ou moins foncé. La première dorsale est d'un goris teinté de brunâtre avec une tache noire dans les deux premiers espaces intraradiaires; la seconde dorsale est grisâtre ou jaune verdâtre; lanale, la caudale et les ventrales sont d'un rouģe assez 
vif; les pectorales sont d'un jaune pâle, parfois teinté de gris. - La ressie natatoire est déreloppée. - Ily a trois appendices pyloriques.

Habitat. La plupart de nos eaux douces.

Suivant Day, cette espèce est exposée à diverses épidémies. Ainsi, en 1867, des centaines de milliers de Perches succombèrent à une maladie causée, d'après le $\mathrm{D}^{\mathrm{r}}$ Forel et le $\mathrm{D}^{\mathrm{r}}$ du Plessis, par la présence de certaines bactéries dans le sang; Day, Brit. Fish., t. I, p. b.

\section{GENRE BAR. - LABRAT, Cir.}

Corps oblong, couvert d'écailles pectinées de moyenne grandeur.

Tête; cràne et espace interorbitaire écailleux; dents en veluurs sur les màchoires, le vomer, les palatins et la langue.

Appareil branchial; opercule armé đle deux épines; préopercule à bord postérieur dentelé et à bord inférieur muni d’épines recourbées en arant.

Nageoires; deux dorsales rapprochées; la première à huit ou neuf aiguillons; anale à trois épines; pièces scapulaires non dentelées.

Deux espèces.

Vomer avec des dents sur le chevron seulement.......... 1. counux. - et le corps.......... 2. poxctit.

\section{LE BAR COMMUN. -- LABRAX LUPUS, Cuv.}

Poiss. France, t. II, p. 333.

N. vulg. : Loubas, Nice ; Loup, Loupasson, Provence, Ianguedoc ; Llobarro, Pyrénées-Orientales; Pique, Ladatte, Basses-Pyrénées; Loubineau, Barreau, Poitou; Lubin, Loire-Infériemre ; Irigne, Digne, Finistère; Loubine, Louvine.

Long. : 0,30 à 0,70 , quelquefois 1,00 .

La hauteur du tronc est comprise quatre fois à cinq fois et quart dans la longueur totale. - La longueur de la tète mesure ì peu près le quart de la longueur totale; dents en velours sur les mâchoires, la langue, les palatins et le cherron du vomer seulement. Le diamètre de l'oil, chez les sujets de moyenne taille, ne mesure pas tout ì fait les deux tiers de 
l'espace préorbitaire; il est un peu moins grand que l'espace interorbitaire; les écailles qui garnissent l'espace interorbitaire sont toujours lisses. - Ec., l. long. $6 \ddot{3}$ a 70 ; l. transv. 2't à 27. - La première dorsale commence au-dessus, ou peu s'en faut, du milieu de la base de la ventrale qui est un peu en arrière de celle de la pectorale.

Br. 7. D. 8 ou $9-1 / 12$ ou $13 ; \Lambda .3 / 10$ ou $11 ;$ C. $17 ;$ P. 15 ou $16 ;$ V. 1/5.

Lit leinte est d'un gris plombé sur le dos, gris plus clair, argenté sur les flanes; le ventre est blane argenté. Les dorsales, l'anale et la caudale sont grisâtres; les pectorales et les ventrales sont blanchâtres. Une tache d'un brun foncé marque la partie postérieure de l'opercule. - Il y a généralement cinq appendices pyloriques.

\section{Var. - Le Bur noiratre. - Labrax nigrescens, Riss.}

N. vulg. : Loubas nègre, Nice.

La hauteur du trone est égale à la longueur de la tète; les épines du bord inférieur du préopercule sont plus fortes que dans le Bar commun. - Ec., l. long. 67; l. transv. 2̈. - La caudile est un peu plus échancrée que dans le Bar commun. - La coloration est d'un brun plus ou moins foncé.

Habitat. Le Bar est commun surtoutes nos còtes.

\section{LE BAR PONCTUE OU TACHETE. - LABRAX PUNCTATUS.}

Poiss. France, t. II, p. 337, fig. 118, màchoire supérieure et voùte palitine.

N. vulg. : Loubasson, Nice; Loup ticassat, Cette; Thyoure, Bayonne.

Long. : $0, ; 0$ a 0,70 et plus.

Chez le Bar ponctué, les formes semblent un peu plus épaisses que dans le Bar commun. - Le vomer porte des dents en velours sur toute sa face inféricure, aussi bien sur le corps que sur le cherron. Les écailles, garnissant l'espace interorbitaire, sont toujours cténoïdes; le diamètre de l'óil, 
chez les sujets de moyenne taille, est égal à l'espace préorbitaire. - Ec., l. long., 70 environ ; l. transv. 23 ou 26.

Le dos et les flancs sont marqués de petites taches noirâtres, ordinairement disposées par séries longitudinales; ces macules noirâtres se montrent chez beaucoup de Bars communs et ne sont pas suffisantes pour servir de caractère distinctif.

Habitat. Toutes nos còtes, moins commun que l'autre Bar.

\section{GENRE APRON. - ASPRO, Cuv.}

Corps allongé, arrondi, couvert d'écailles petites et rudes.

Tête aplatie; cràne et espace interorbitaire généralement écailleux; museau avancé au-dessus de la bouche; dents en velours sur les màchoires, le vomer et les palatins; langue lisse; joues non écailleuses.

Nageoires; deux dorsales assez éloignées l'une de l'auire.

\section{L'APRON COMMUN. - ASPRO VULGARIS; Cuv.}

Poiss. France, t. II, p. 339, fig. 119, anim.

N. vulg. : Dauphin, Dijon; Roi-poisson, bords de la Saòne; Sorcier, cours de l'Ain, du Rhòne; Anadélo, Ciard.

Long. : 0,12 à 0,15 , quelquefois 0,18 .

Le corps est allongé, fusiforme, couvert, excepté sous une partie de la poitrine, d'écailles ciliées; sa hauteur est contenue sept à huit fois dans la longueur totale. - La tête est déprimée; sa longueur est comprise environ quatre fois et un tiers dans la longueur totale; le museau est gros, nu, ainsi que les mâchoires et les joues; la bouche est retirée; les mâchoires, le chevron du vomer et les palatins sont armés de dents en velours. Le diamètre de l'œil est contenu cinq fois à cinq fois et demie dans la longueur de la tète, il fait à peu près la moitié de l'espace préorbitaire, il est à peine plus petit que l'espace interorbitaire. - La ligne latérale est à peu près droite. Ec., l. long. 68 à 80 ; 1. transv. 21 ou 22 . - Les dorsales sont assez éloignées l'une de l'autre; la première naît audessus du milieu des ventrales; l'anale commence dans le mème plan vertical que la seconde dorsale, mais finit un 
peu avant, elle a deux épines; la caudale est échancrée; les ventrales ont les rayons médians très développés; elles sont plus longues que les pectorales.

Br. 7. - D. 8 ou $9-1 / 11$ oll $12 ; \Lambda .2 / 9$ a $12 ;$ C. $2 / 17 / 2 ;$ P. $14 ;$ V. $1 / 5$.

La région supérieure du corps, d'un brun marron ou jaunàtre, est traversée, par lrois, quatre, quelquefois cinq bandes noirâtres descendant obliquement sur les côtés ; le dessous du corps est d'un grris blanchàtre. Les nageoires sont d'un jaune nuancé de gris.

Habitat. Le Ihhòne et ses affluents, Saòne, Ain, Isère, Gard.

4. GENRE ACÉRINE OU GREMLLE. - ACERINA, GUV.

Corps oblongs, couvert d'écailles assez petites, pectinées.

Tête non écailleuse, creusée de fossettes; dents en velours sur les màchoires.

Appareil branchial; opercule et sous-opercule épineux.

Nageoires; dorsale unique, échancrée; anale à deux aiguillons.

\section{LA GREMLLE COMNUNE. - ACERINA CERNUA, Cur.}

Poiss. France, t. II, p. 3't.

N. vulg. : Perche goujonnière, goujonnée, gardonnée, Perche à Goujon, Seine, Yonne, Aube; Goujon perchat, Aube, etc.; Chagrin, environs de Troyes ; Ciremille, Gremenille, Lorraine; Gremillet, SeineInférieure; Grimon, Gard.

Long. : 0,12 à 0,1 .

La hauteur du tronc est comprise quatre fois et quart à quatre fois et demie dans la longueur totale; la peau, excepté à la région pectorale, est couverte d'écailles fortement ciliées. - La tête est complètemenl nue; elle est creusée de fossettes assez larges, dans chacune desquelles est un bouton nerveux Irès développé; sa longueur mesure le quart environ de la longueur totale; le museau est assez gros; les màchoires portent une bande de dents en velours; le cherron du vomer a généralement quelques dents courtes, crochues; chez les grands individus il y a souvent sur la langue un petit groupe 
de dents. Le diamètre de l'wil est contenu environ trois fois et demie dans la longueur de la tête. L'opercule a l'angle postérieur armé d’une épine acérée; le préopercule a son limbe tout échancré, il est muni de nombreuses épines. - La ligne latérale est légèrement courbe en arant, elle est composée d'une quarantaine d'écailles à canal très large. Ec., l. long. 33 à 60 ; I. transv. 20 ou 21. - La dorsale, fort longue, est échancrée rers la fin de sa partie épineuse: la caudale est échancrée; les ventrales sont à peu près aussi longues que les pectorales.

D. 12 à $15 / 11$ à 1 f; A. $2 / 6$ à 8 ; C. 3 ou $4 / 1$ i/t ou 3 ; P. 13 ; V. $1 / 5$.

La coloration est en dessus brunàtre tirant sur le vert, d'un brun jaunàtre sur les flancs, d'un blanc argenté sous le ventre, d'un blanc rosé sous la poitrine et la gorge ; les pièces operculaires sont nuancées de teintes chatoyantes variant du rose au verdàtre; la tête, le dos et les côtés sont, chez les vieux individus surtout, marqués de petites laches noirâtres. La dorsale est d'un gris jaunâtre avec des macules noires; la caudale et les pectorales sont grisâtres souvent tachetées de noir; l'anale et les ventrales sont blanchâtres. - Il y a seulement deux ou trois appendices pyloriques.

Habitat. La Gremille est plus ou moins commune dans les départements du Nord, du Nord-Est, dans le bassin de la Seine, celui du Rhòne.

\section{Sous-famille des Serraniniens, Serranini.}

Corps oblong, plus ou moins comprimé.

Tête longue, plus ou moins écailleuse; dents sur les màchoires et le plus ordinairement sur le vomer et les palatins.

Nageoires ; dorsale unique à dix ou onze rayons épineux; anale à trois aiguillons.

Cette sous-famille se compose de cinq genres.

a. Opercule traversé par une arête finissant en pointe.

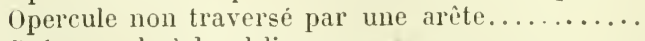

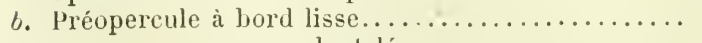

1. Cernier. b.

5. Callaxthias. 
c. Ventrale excessivement longue ordinaire.

1. Màchoire infériemre écailleuse. Jầchoire inférieure nue. d.

4. Anthlas.

3. MÉrou.

2. Serrix.

1. GENRE CERNIER OU POLYPION. - POLYPRION, Cuv.

Corps ovale, couvert de petites écailles cténoïdes très rudes.

Tète forte, hérissée d'arètes, de crénelures; museau court; bouche grande, fendue obliquement; dents en cardes ou en velours sur les màchoires, le vomer, les palatins el la langue.

Appareil branchial ; opercule épineux, traversé par une arête terminée en épine; pièces operculaires dentelées.

\section{LE CERNER BRUN. - POLYPRION CERNIUH, Valenc.}

Poiss. France, t. II, p. 3's, fig. 120, anin.

N. vulg. : Lernia, Nice; Cernier, Marseille; Fanfré rascas, Cette; Méro, Mérou, Sainl-Jean-de-Luz, Bayonne, Cap-Breton.

Long. : 0,60 , à 1,00 et mème 2,00 .

La hauteur du trone mesure le liers environ de la longueur totale. - La tète, dont la longueur fait le tiers de la longueur totale, est forte, hérissée d'aspérités, d’arêtes, d'épines, principalement chez les jeunes individus; le museau est court. Le diamètre de l'ceil est compris quatre fois et demie à cinq fois et demie dans la longueur de la tête ; il fait un peu plus de la moitić de l'espace interorbitaire. L'opercule est traversé par une arête qui se termine postérieurement en une épine robuste. - Ee. 1. long. 110 a 110 ; l. transv. 00 à $\ddot{20 . ~-~ L a ~ d o r s a l e ~ e s t ~}$ longue; la caudale est entiòre avec les angles arrondis; les aiguillons des nageoires sont plus ou moins àpres; la base des nageoires impaires, celle des pectorales, est courerte d'écailles.

Br. 7.-D. 11/11 ou $12 ;$ A. $3 / 8$ ou $9 ;$ C. 1/17/1; P. 17; V. 1/5.

La teinte générale est d'un gris brunâtre, parfois tirant sur le jaune, ou d’un brun violacé, lilas, varié de blanc el de noirâtre. Les nageoires sont d'un bleu noirâtre, ou d'un ğris brunatre: souvent la partie molle de la dorsale et de l'anale, le bord postérieur de la caudale et la pointe des rentrales sont 
blanchâtres. - Le nombre des appendices pylorique est rariable: deux, six ou plus.

Habitat. Méditerranée, assez commun à Nice; assez rare Marseille, Cette. Océan, commun à Saint-Jean-de-Luz; très rare audessus de la Gironde, Charente-Inférieure.

\section{GENRE SERRAN-SERRANUS.}

Gorps oblong, comprimé, couvert d'écailles pectinées.

Tête; des écailles sur le cràne et les joues; màchoires nues, munies de dents en velours ou en cardes, et de canines le plus souvent; vomer et palatins dentés; langue lisse.

Appareil branchial; pièces operculaires écailleuses; opercule armé de trois épines, généralement aplaties; préopercule à hord plus ou moins dentelé; sept rayons hranchiostiges; pseudobranchies.

Le genre Serran se compose de trois espèces:

a. Bord inférieur du préopercule dentelé sur sa moitié postérieure.......................... b

Bord inférieur du préopercule dentelé sur toute sa

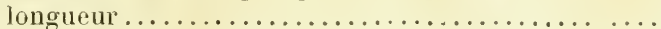

b. Trois bandes obliques, jaunes ou lilas, sur les côtés de

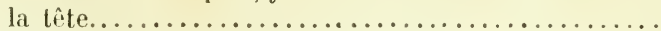

Lignes sinueuses, irrégulières, bleuâtres ou lilas, sur le museau, les joues.......................

3. HÉPATE.

2. CABRILLA.

1. ÉCRITURE.

\section{LE SERRAN ECRITURE. - SERRA NUS SCRIBA.}

Poiss. France, t. II, p. $35 \%$.

N. vulg. : Serran, Perca, Nice; Sarran, Cette; Baque-Sarranc, Port-Vendres.

Long. : $0,10 ̋$ ì 0,20 .

La hauleur du trone est contenue trois fois el un tiers à trois fois ot deux liers dans la longueme totale; la peau est couverte d'écailles de moyenne grandeur. - La longueur de la tète est comprise trois fois à trois fois of un quatr dans la longueur tolale; le museau est poinlu, il est nu, ainsi que les mâchoires, qui sont garnies l'une el l'aulre d'une bande assez large de dents en velours ou plutot en cardes lines; à la rangée externe, il y a des dents plus forles, plus crochues, des espèces de 
canines. Le diamètre de l'eril est contenu cing fois à cinq fois et demie dans la longueur de la tête; il est d'un quart au moins plus petit que l'espace préorbitaire et d'un cinquième environ plus grand que l'espace interorbitaire, qui est nu. L’opercule est armé de trois épines aplaties. dirigées en arrière ; le préopercule est finement crénelé sur le bord postérieur, sur l'angle postérieur, qui est très arrondi, et sur le tiers postérieur du bord inférieur; les écailles des joues sont petites et lisses. - Ec., l. long. 70 ; 1. transv. 20̈. - La dorsale est longue, régulière, ses aiguillons portent à leur bord postérieur un filament rougeâtre dépassant les rayons; l'anale commence sous le deuxième rayon mou de la dorsale; les pectorales mesurent presque le quart de la longueur totale.

D. $10 / 11$ ou $15 ;$ A. $3 / 7$ ou 8 ; C. 17 ; P. 13 ou $14 ;$ V. 1/5.

Le corps est d'un jaune rougeâtre, avec cinq ou six bandes noiràtres rerticales, descendant de la base de la dorsale vers les coites. Le dessus de la tête, le museau et les joues sont parcourus par des lignes sinueuses, entrecoupées, étroites, d’un bleu argentéou lilas à liséré noiràtre; ces lignes, qu’on appelle l'écriture, se dessinent sur un fond rougeàtre ou d'un brun roussitre. La dorsale est d'un gris jaune ou rose arec de petites taches rouges; les filaments membraneux, qui dépassent les épines, sont d'un rouge très vif ; l'anale et la caudale sont d'un gris rosé arec de petites taches rougeâtres; ces petites taches des nageoires impaires forment des séries de bandes: les pectorales sont d'un jaune nuancé de rose, arec une tache brune ì la base; les rentrales sont brunâtres, marquées parfois de macules rougeatres. - Il y a sept appendices pyloriques.

Habitat. Méditerranée, assez commun de Nice à Port-Veudres.

\section{LE SERRAN CABRILLE. - SERRANUS CABRILLA.}

Poiss. France, t. II, p. 360.

N. vulg. : Serran, côtes de la Méditerranée; Roussignoou, Cette; Crak, Biarritz; Cabre ou Crabe, Bayonne; Fougère, Brest; Sonneur, Violon, Cherbours.

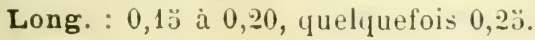


Le corps est garni d'écailles plus petites que chez le Serran écriture; sa hauteur est comprise de quatre à cinq fois dans la longueur totale. - La longueur de la tête est contenue trois fois et un tiers à trois fois et demie dans la longueur totale; le museau est légèrement obtus; la dentition est à peu près semblable à celle de l'espèce précédente, les mâchoires portent quelques dents plus fortes et plus crochues. Le diamètre de l'œil est compris quatre fois a quatre fois et deux tiers dans la longueur de la tête; il est égal à l'espace préorbitaire chez les jeunes, un peu plus court chez les adultes; il est plus grand que l'espace interorbitaire, qui est nu. Le préopercule a l'angle postérieur moins arrondi que dans le Serran écriture; les crénelures sont bien prononcées, elles viennent jusqu'au milieu du bord inférieur; les écailles de la joue ont leur bord libre garni de plusieurs rangées de spinules. - Ec., l. long. 8.j environ; 1. transv. 32 à 34. - Comme dans le Serran écriture, les nageoires paires ont de petites bandes d'écailles dans leurs espaces intraradiaires; la caudale est un peu échancrée; la longueur de la pectorale est comprise quatre fois et demı à einq fois dans la longueur totale.

$$
\text { D. } 10 / 14 ; \text { A. } 3 / 7 \text { ou } 8 ; \text { C. } 17 ; \text { P. } 14 ; \mathrm{V} .1 / 5 \text {. }
$$

Le système de coloration est très variable; la teinte générale est d'un gris jaunâtre, ou d'un rouge assez clair, avec sept à neuf bandes verticales d'un rouge brunatre et trois ou quatre bandes longitudinales jaunâtres ou d'un rouge vermillon; sur la tête, qui est d'un fond rougeâtre, se remarquent généralement trois bandes jaunes ou lilas dirigées obliquement de haut en bas et d'avant en arrière, la bande supérieure va de l'orbite, à l'angle de l'opercule. La dorsale est d'un rouge ocracé peu foncé avec des bandes longitudinales d'un azur très clair; dans sa région molle, elle présente deux rangées d'ocelles bleu clair et, au-dessous, une bande bleuâtre; l'anale a la même leinte que la dorsale dans sa partie épineuse; la caudale est d'un roux pâle avec trois rangées d'ocelles azur clair; les nageoires paires sont pâles avec les rayons d'un rouge jaunâtre. - Il existe trois appendices pyloriques.

Habitat. Toutes nos còtes. Méditerranée, commun. Océan, assez 
commun it Saint-Jean-de-Lız; rare au nord de la Gironde, CharenteInférieure, Loire-Infériemre. Manche, assez rare à hoscoff; rare, Cherbourg; excessivement rare en Picardie.

\section{LE SERRAN HEPATE. - SERRANUS HEPATUS.}

Poiss. France, t. II, p. 363, fig. 121, anim.

N. vulg. : Pétaydé, Cette.

Long. : 0,08 à 0,12 .

Le corps est couvert d'écailles relativement plıs grandes que dans les autres espèces; sa hauteur est comprise environ trois fois el demie dans la longueur totale. - La longueur de la tête est contenue trois fois à trois fois el un tiers dans la longueur tolale: les màchoires, à peu près égales, sont garnies de dents en cardes assez fortes; les dents de la rangée externe sont les plus développées surtout en avant, et à la mâchoire supérieure, sur laquelle se roient ordinairement plusieurs petites canines. Le diamètre de l'oeil fait le quart de la longueur de la tète, il est à peu près égal à l'espace préorbitaire, il est d'un quart ou d'un tiers plus grand que l'espace interorbitaire qui porte de petites écailles pectinées. Le préopercule est dentelé sur son bord postérieur et sur toute la longueur de son bord inférieur ; les joues sont courertes d'écailles à plusieurs rangées de spinules. - Ec., l. long. 11 à 14; 1. transv. 20 ou 21. - La dorsale est faiblement échancrée, elle a quelques rayons mous de moins que dans les autres espèces; la caudale est très peu échancrée, coupée presque verticalement.

$$
\text { I). } 10 / 11 \text { ou1 12; A. } 3 / 7 \text {; C. } 16 \text {; P. } 14 ; \text { V. } 1 / 5 \text {. }
$$

La coloration est très variable, parfois d'un gris blanchàtre uniforme, tantìt grisattre ou gris rougeàtre arec cinq bandes verticales noirâtres, parfois la teinte générale est d’un brun très foncé. La lorsale est grisâtre avec quelques points noirs dans sa région épineuse et une tache noiràtre arrondie vers la partie supérieure des trois premiers rayons mous; l'anale est grisâtre; la caudale est grise avec quelques points jaunes; les pectorales sont jaunatres, les rentrales noirâtres. - II y a cinc appendices pyloriques.

Habitat. Méditerranće, commun de Nice à Banyuls. 
3. GENRE MÉROU OU ÉPINÉPHÈLE. - EPINEPIIELUS, Bloch.

Corps ovale, couvert de petites écailles ciliées.

Tête garnie d'écailles excepté parfois sur la màchoire supérieure; màchoires armées de dents en cardes avec quelques petites canines; romer et palatins dentés.

Appareil branchial; opercule à trois épines; préopercule dentelé.

Ligne latérale formée d'écailles lisses.

Ce genre comprend deux espèces.

Candale arrondie........................ 1. Brex.

Caudale échancrée........................ 2. A yuseau aigu.

\section{LE MEROU BRUN OU EPINEPHÈLE GÉANT. -- EPINEPHELUS GIGAS.}

Poiss. France, t. II, p. 368.

N. vulg. : Anfousson, Nice; Mérou et Méron, Míarseille.

Long. : 0,30 à 0,60 et mème 1,00 .

La hauteur du trone est comprise trois fois et quart à quatre fois dans la longueur totale. - La tête est couverte d'écailles excepté sur la mâchoire supérieure; sa longueur est contenue deux fois et deux tiers à trois fois et quart dans la longueur totale; la mâchoire supérieure est moins avancée que la mandibule; clles sont l'une et l'autre garnies de dents en cardes; au côté interne de chacun des intermaxillaires, il y a une ou deux canines crochues; la mandibule a généralement une canine de chayue côté de la symphyse. Le diamètre de l'œil est contenu de cinq à sept fois dans la longueur de la tête ; il est plus petit que l'espace préorbitaire. Le sous-opercule et l'intcropercule ne sont pas crénelés: le préopercule a le bord postérieur légèrement courbe, à crénelures de plus en plus fortes à mesure qu'elles descendent rors l'angle postérieur sous lequel elles finissent; les écailles des pièces operculaires et des joues m ont toujours paru lisses. - Les écailles de la ligne latérale sont lisses. Ec., l. long. 100 environ; l. transr. 10 et plus. - Les nageoires sont toutes plus ou moins écailleuses à leur base; la dorsale est très longue; la caudale est arrondie.

Br. 7. - D. $11 / 15$ ou 16 ; А. $3 / 8$; C. 3 ou $4 / 15 / 4$ ou 3 ; P. 1 ; V. $1 / 5$. 
La teinte est d'un brun rougeàtre ou lie de vin. parfois brun jaunâtre arec des laches grises assez larges, parfois jaunâtre avec des nuages d'un brun plus ou moins foncé; le rentre est jaune. Les nageoires sont d'un brun lie de vin foncé, avee l'exlrémité des rayons mous blanchàtre.

Habitat. Méditerranée, rare, Nice, Marseille.

2. LE MEROU A MUSEIU MIGU. - EPINEPHELUS ICUTIROSTRIS.

Poiss. France., Suppl., p. 32.

Long. : 0,3 à 0,80 .

La hauteur du corps est comprise quatre fois el quart ì quatre fois et demie dans la longueur tolale. - La lête est couverte d’écailles, même sur le maxillaire supérieur; sa longueur est contenue 'nviron trois fois et quart dans la longueur totale; la màchoire supéricure est beaucoup moins avancée que linférieure; clles sont l'une et l'autre garnies de dents en cardes; chacun des intermaxillaires porte une canine plus développée que les autres dents. Le diamètre de l'ipil est compris de sept à neuf fois dans la longueur de la tète; il ne mesure gùère que la moitié de l'espace préorbitaire. Le bord postérieur du préopercule est finement dentelé, il porte une légère échancrure au-dessus deson angle postérieur et inférieur, qui est garni d'épines un peu plus fortes que les autres. Eeail., 1. long. 80 à $90 ; 1$. Lransr. 40 à 40 ö. - La base des nageoires impaires est plus ou moins écailleuse; la dorsale est longue; l'anale est hien développée, elle compte onze rayons mous; la caudale est nettement échancrée.

1). 11 ou $12 / 15$ on $16 ;$ A. $3 / 11$; C. $2 / 1$ i ou $18 / 2 ;$ P. 15 ou $16 ; \mathrm{V} .1 / \mathrm{s}$.

La teinte est généralement d’un brun plus ou moins foncé.

Habitat. Méditerranée, excessivement rare, Nice.

Plectropomus fasciutus, Costa, Poiss. France, t. II, p. 380 et Suppl., p. 36 (Epinephelus Costa). - M. Giglioli écrit : Plectropoma fasciatum (La Cép.), Messina, Malta... Buonissima specie (Cat. Pese. ital., p. 79, $\mathrm{n}^{\circ}$ 20). - A propos de celle espèce, M. Vinciguerra fait l'observation suivante: Giglioli la disse dapprima buonissima specie, ma ammisse in 
seguito l'opinione qui ïa identifica col S. Alexandrinus per l'individuo la lui indicato come proveniente da Messina, mentre l'esemplare di Maltu posseduto dal Museo di Firenze altro non è che il Serranus aneus, Geoffr. (Croc. Violante, p. 30). - Prendre le S. xneus pour un Plectropomus fasciatus, Costa, c'est assez extraordinaire; ce qu'il y a de plus surprenant encore c'est de voir M. Vinciguerra considérer le S. acutirostris, Perugia (Elenco Pesc. Adriat., p. 3, pl. 1), comme identique au S. Alexandrinus, C. V. - Si M. Vinciguerra avait profité des documents fournis par Valenciennes, il n'aurait pas commis cette nouvelle erreur; Valenciennes fait remarquer très judicieusement que chez le $\boldsymbol{S}$. Alexandrinus " le bord membraneux de l'opercule est droit ou mème un peu concave supérieurement ", ce qui est exact; dans le S. acutirostris, Perugia (non Cuv. Val.), le bord supérieur de l'opercule est très oblique de haut en bas et d'avant en arrière, de plus la caudale est échancrée, la pectorale courte; dans le S. Alexandrinus, C. V., la caudale est arrondie et la pectorale longue. - Le professeur Doderlein qui avait d'abord admis le Cernua Costx (Plectropomus fasciatus, Costa) et le C. Alexmdrina, comme espèces distinctes, les a réunies en une seule, Epincphelus Alexandrinus; enfin il a malheureusement adopté l'opinion de I. Vinciguerra, et dans la synonymie de son $\boldsymbol{E}$. alexumdrinus, il a inscrit le Serranus acutirostris de Perrugia, V. Doderlin, Man. ittiol. Medit., Teleostei, fasc. 4, p. 71, Palermo, 1889.

\section{GENRE ANTHIS OU BARBIER. - ANTIILAS.}

Corps ovale, couvert de grandes écailles ciliées.

Tête écailleuse; museau court; màchoire supérieure moins avancée que la mandibule, toutes deux écailleuses, munies des dents en velours et de canines; vomer et palatins dentés; lingue lisse.

Appareil branchial; opercule à trois épines; préopercule crénelé.

Nageoires; dorsale à troisième aiguillon beaucoup plus grand que les autres; caudale excessivement fourchue.

\section{LE BARBIER OU L'ANTIIAS SACRE. - ANTHIAS SACER.}

Poiss. France, t. II, p. 372, fig. 122, anim.

N. vulg. : Sarpanansa, Nice; Barbier, Montpellier.

Long. : 0,12 à 13 , parfois 0,18 .

La hauteur du trone fait environ le tiers de la longueur, 
caudale non comprise. - La tête est complètement écailleuse ; sa longueur est à peu près égale à la hauteur du tronc; le museau est court; la bouche est très oblique; les màchoires sont garnies de dents en velours; en outre la màchoire supérieure a deux canines, et la mandibule quatre ou six. Le diamètre de l'eril mesure le tiers de la longueur de la tète; il est d'un tiers plus grand que l'espace préorbitaire. L'opercule a trois épines. - Ec., l. long. 36 à 39 : 1. transv. 16 ou 17. - La dorsale est très longue; ses épines ont généralement en arrière une espèce de filament; le troisième aiguillon est très développé, sa longueur est parfois égale à celle de la tète; la caudale estexcessivement fourchue, ses rayons externes se terminent en filaments; la ventrale a ses deux premiers rayons mous remarquablement. allongés, parfois, leur extrémité alteignant et même dépas. sant la base de lanale.

Br. 7. -D. 10 ou $11 / 15$; A. $3 / 7$; C. 2 ou $3 / 17 / 3$ ou $2 ;$ P. $17 ;$ V. $1 / 5$.

La coloration est magnifique; c'est un rouge rosé sur le dos et les còtés, un rosé assez vif sur la partie inférieure des flancs, un rose pàle argenté sous le ventre; la tête est d'une teinte rosée, traversée par trois bandes jaunàtres, dirigées d'avant en arrière. Les pectorales sont rosées; les autres naggeoires sont d'une teinte safran ou rose et jaunâtre. - La vessie natatoire est très développée.

Habitat. Méditerranée, assez commun à Nice, et mème à Cette depuis quelques années.

3. GENRE CALIANTHAS. - CALLANTHIS, LOWe.

Corps assez allongé, couvert de grandes écailles ciliées.

Tête écailleuse; museau court; màchoires munies de canines et de pelites dents en velours.

Appareil branchial; opercule à deux épines; préopercule à bord non dentelé ; six rayons branchiostèges.

Ligne latèrale très rapprochée du profil supérieur, finissant à peu près dans le mème plan vertical que la dorsale.

Nageoires; caudale profondément échancrée. 
Poiss. France, t. II, p. 3\% , fig. 123, anim.

Long. : 0,13 à 0,28 .

Le corps est oblong, comprimé; sa hauteur est contenue trois fois et un tiers dans la longeur, caudale non comprise. La tête est écailleuse; sa longueur est égale à la hauteur du tronc ou à peine plus grande; le museau est très court; la mâchoire supérieure est légèrement protractile, elle est munie, ainsi quela mandibule, de petites dents et de quelques canines; les dents du vomer et des palatins semblent caduques. Le diamètre de l'ceil est compris deux fois et demie dans la longueur de la tête; il fait le double environ de l'espace préorbitaire; il est presque d'un tiers plus grand que l'espace interorbitaire. Il n'y a que six rayons blanchiostèges; lopercule a deux épines; le préopercule a le bord sans crénelures. - La ligne latérale cesse vers la fin de la dorsale; elle est composée de 22 à 24 écailles. Ec., l. long. 40 à 12; l. transv. 12 ou 13. - La dorsale commence un peu en avant de l'insertion de la pectorale; elle a onze aiguillons qui, du premier au dernier, s'allongent d'une façon régulière; les rayons mous sont plus élevés; la caudale est profondément échancrée ; ses rayons externes se terminent en filaments plus ou moins développés, mesurant parfois la moitié de la longueur du corps.

Br. 6. - D. $11 / 10$ ou 11 ; A. $3 / 9$ ou 10 ; C. 15 a 17 ; P. 19 a 21 ; V. 1/5.

En dessus la tête et le corps sont d'un rose rougeàtre; la partie inférieure de la tête et la région ventrale sont d'un rose pâle. Les nageoires sont d'un rose rougeâtre, excepté les rentrales qui sont d'un jaune très pâle.

Habitat. Méditerranée, excessivement rare, Nice.

\section{Sous-famille des Apogoniniens, Apogonini.}

Corps garni de grandes écailles assez peu adhérentes.

Tête; museau court; dents en velours sur les màchoires, le vomer les palatins; langue lisse. 
Appareil branchial; sept rayons branchiostèges.

Nageoires; deux dorsales écartées; la première à six ou sept aiguillons; anale à deux épines.

Deux grenres.

Espace interorbitaire et museau nus................ 1. Apogon.

Espace interorbitaire et museau écailleux............ 2. Poмatome.

1. GENIE APOGON. - APOGON, Lacép.

Corps ovale, comprimé.

Tête assez développée; espace interorbitaire et museau nus.

Appareil branchial; préopercule semblant à double rebord.

L'APOGON COMMUN. - IPOGON IMBERBIS.

Poiss. France, t. II, p. 38:, fig. 124, anim.

N. vulg. : Sarpanansa, Nice.

Long. : 0,10 à 0,15 .

La lauteur du tronc est comprise trois fois à trois fois et un tier's dans la longueur totale. - La longueur de la tête est égale, ou peu s'en faut, à la hauteur du corps ; la partic supérieure et antérieure du crâne, les mâchoires, le museau et l'espace interorbitaire sont nus; des dents en velours garnissent les mâchoires, le vomer et les palatins. Le diamètre de l'œil mesure le tiers de la tête; il est un peu plus grand que l'espace préorbitaire qui est égal à l'espace interorbitaire. L'opercule porte en arrière une épine peu saillante ; le préopercule a le bord postérieur légèrement dentelé, et séparé, par une dépression, d'une saillie antérieure, paraissant ainsi former un double rebord. - Ec., l. long. 28 à 32 ; 1. transv. 11. - La première dorsale est courte, assez basse, à six épines; sa base est un peu plus longue qre la distance qui la sépare de la seconde dorsale; la caudale est échancrée ; les pectorales arrivent à l'anale; les ventrales sont courtes.

$$
\text { Br. } 7 \text {. -D. } 6-1 / 8 \text { ou } 9 ; \text { A. } 2 / 8 \text {; C. } 1 \text { i ; P. } 10 \text { à } 12 \text {; V. } 1 / 5 \text {. }
$$

Le corps est d'un rougeâtre plus foncé vers le dos, plus clair vers le ventre, moucheté de petits points noirs; sur le troncon 
de la queue, est une tache noirâtre plus ou moins effacée. la tète est d'un rouge jaunâtre. Les nageoires sont rouges; la seconde dorsale est marquée d'une tache noire vers son extrémité.

Habitat. Méditerranée, assez rare, Nice, Marseille.

\section{GEXRE POMATONE. - POHATOMUS.}

Corps allongé, épais, couvert de grandes écailles.

Tête développée, écailleuse; dents en velours sur les màchoires, le vomer, les palatins.

Appareil branchal; préopercule à bord postérieur échancré.

\section{LE POMATOME TÉLESCOPE. - POMATOMUS TELESCOPIUM.}

Poiss. France, t. 11, p. 386, fig. 123.

Long. : 0,40 à $0, \ddot{0} 0$.

La hauteur du tronc est comprise quatre fois et demie à cinq fois et quart dans la longueur totale. - La tête est grosse, forte, aplatie en dessus; elle est, sauf aux lèrres et à l'intermaxillaire, complètement garnie d'écailles; sa longucur est contenue environ trois fois et demie dans la longueur totale; les mâchoires et les palatins sont munis de dents très firres en velours ras; une plaque arrondie de petites dents se trouvesur le vomer. Le diamètre de l'ceil fait plus du tiers de la longueur de la tète, il est d'un quarl au moins plus grand que l'espace préorbitaire. Le préopercule a le bord postérieur echancré; l'opercule est armé de deux petites épines ; la muqueuse de la chambre respiratoire est noirétre ainsi que celle de la cavité

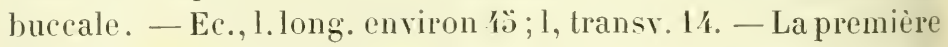
dorsale commence un peu en arrière de la fente branchiale; la caudale est très fourchue; les nageoires sont écailleuses.

Br. 7. - D. $7-1 / 9$ ou $10 ;$ A. $2 / 9$; C. 17 ou 18 ; P. 22 ou $23 ; \mathrm{V} .1 / 5$.

La teinte générale est d'un brunâtre plıs ou moins violacé. - Le péritoine est noiràtre; il y a de dix à vingt-deux appendices pyloriques.

Habitat. Méditerranée, très rare, Nice. 
6. Famille des Sciénides, Scianida.

Gorps oblong, couvert d'écialles pectinées.

Tête écailleuse; museau obtus; bouche médiocrement fendue; màchoires dentées; vomer et palatins sans dents. Système canaliculé latéral plus ou moins développé.

Appareil branchial; ouïes très ouvertes; opercule épineux; sept rayons brauchiostèges; pseudobranchies.

Nageoires; généralement deux dorsales rapprochées, la première à neuf ou dix épines; la seconde longue; parfois une seule dorsale; anale à deux ou trois aiguillons; ventrale à une épine et cing rayons mous.

Vessie natatoire de forme variable. - Appendices pyloriques, huit à dix.

Cette famille comprend quatre genres.

a. Dorsale double.......................... b.

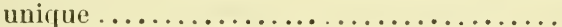

b. Barbillon à la màchoire inférieure, court et gros....

Pas de barbillon à la mandibule.. ............ c

c. Anale à $2^{e}$ aiguillon grêle $\ldots \ldots \ldots \ldots \ldots \ldots \ldots \ldots$ 2. Matgre.

4. Pristipone.

1. Ombrine.

3. Conb.

\section{GENRE OMBRINE. - UMBRINA, Cuv.}

Corps oblong, comprimé, couvert d'écailles assez grandes.

Tête à profil supérieur courbe ; museau arrondi, màchoire supérieure recouvrant l'inférieure, garnies l'une et l'autre de dents en velours; un barbillon court et gros sous la symphyse de la mandibule.

Deux espèces.

Diamètre de l'œil faisant environ moitié de l'espace préorbitaire.

Diamètre de l'œil ègal, ou peu s'en faut, à l'espace préorbitaire.

1. COMMUNE.

2. DE LAFONT.

\section{L'OMBIINE COMMUNE. - UMBRINA CIRROSA.}

Poiss. France, t. II, p. 391.

N.vulg. : Oumbrina, Nice; Caine, Clırau, Provence; Daïné, (Cette), Languedoc; Bourrugue, Verrue, Bayonne; Bomrugat, Arcachon.

Long. : 0,30 à 0,50 et même 0,70 .

Moreat. - Ichthyologie. 
La hauteur du trone est comprise trois fois et deux tiers à quatre fois dans la longueur totale. - La longueur de la tête, qui est à peu près égale à sa hauteur, est contenue quatre fois à quatre fois et demie dans la longueur totale; le museau est arrondi, son rebord est entamé de quatre ou cinq petites échancrures, il a trois pores assez larges, au-dessus desquels il en existe un ou deux plus petits; la mâchoire supérieure déborde la mandibule, elles sont l'une et l'autre garnies d'une bande assezlarge de dents fines en velours ras; sous la symphyse de la mandibule est attaché un barbillon charnu, tronqué. Le diamètre de l'cil est compris cinq fois et demie dans la longueur de la lête; il mesure la moitié de l'espace préorbitaire, les deux tiers environ de l'espace interorbitaire. - Ec., 1. long. 68 à $70 ; 1$. transv. $\frac{8}{19}+1=28$. - La seconde dorsale finit bien en avant de la base de la caudale, elle en est séparée par une distance supérieure à la hauteur du tronçon de la queue; la caudale a le bord postérieur droit ou légèrement échancré.

Br. 7. -D. $10-1 / 22$ ou 23 ; A. $2 / 7$; C. 18 ; P. 17 ; V. $1 / 5$.

Le dos et les flanes sont jaunâtres; de la région supérieure descendent vingt-cinq à trente bandes ondulées obliques d'arrière en avant; la membrane qui continue l'angle de l'opercule est noiràtre. La première dorsale est noirâtre, la seconde jaunâtre avec des lignes bleuâtres ; la caudale est brunâtre; l'anale et les nageoires paires sont jaunâtres avec des reflets rougeâtres. - La vessie natatoire est grande, sans appendices. - Généralement les appendices pyloriques sont au nombre de huit.

Habitat. Toutes nos còtes; ce Poisson est commun dans la Méditerranée. Océan, assez commun dans le golfe de Gascogne; plus rare au-dessus de la Gironde; rare, Bretagne. Manche, excessivement rare.

\section{L'OMBRINE DE LAFONT. - UMBRINA LAFONTI.}

Poiss. France, 1. II, p. 30ว̈, fig. 126, anim.

N. vulg. : Coucou, Borrugat nègre, A rcachon.

Long. : 0,30 à 0,4 ว̈. 
La hauteur du trone est comprise trois fois à trois fois et demie dansla longueur totale. - La têle est un peu plus hauto que longue; sa longueur est contenue quatre lois à quatro fois et demie dans la longueur totale; le museau est obtus, plus gros, plus court que dins l'Ombrine commune, il présente, sur le bord, trois larges pores, et, au-dessus, une rangée demicirculaire de trois pores beaucoup plus étroits ; le barbillon de la mandibule parait plus carré, plus épais que colui de l'Ombrine commune. Le diamètre le l'oeil fait le quart de la longueur de la tète, il est égal, ou peu s'en faut, à l'espace préorbitaire et à l'espace interorbitaire. La muqueuse tapissant la chambre branchiale et l'arrière-bouche est d'un lilas foncé presque noiraitre. - Ec., l. long. 30 a 32 ; la transv. $\frac{5}{12}+1=18$.

- La seconde dorsale est plus longue que dans l'autre espèce; ses derniers rayons, quand ils sont couchés, arrivent presque à la base de la caudale; la hauteur du troncon de la queue est plus grande que la distance séparant la base des deux nageoires; la caudale est carrée.

$$
\text { D. } 9 \text { ou } 19-1 / 27 \text { à } 29 ; \text { A. } 2 / 7 \text {; C. } 19 ; \text { P. } 17 ; \text { V. } 1 / 5 \text {. }
$$

La coloration générale est grisâtre avec un fin pointillé noirittre; des bandes brunes, plus ou moins foncées, ront d'avant en arrière, et un peu obliquement de bas en haut, des côtés vers le dos; sous la seconde dorsale, la partie supérieure du corps est teintée d'un vert doré assez brillant; la membrane postérieure des opercules est en haut d'un jaune grisìtre, en has d'un gris argenté pointillé de noir. La première dorsale est d'un gुris brunâtre; la seconde, d'un gris jaunâtre, ainsi que la caudale et les pectorales; l'anale est brunâtre avec une bande quise à sa hase; les ventrales sont blanchàtres. - Les appenlicespyloriques, au nombre de huit, sont beaucoup plus déreloppés que dans l'Ombrine commune; la longueur des plus zrands mesure plus des trois quarts de la longueur du cul-deiac de l'estomac.

Habitat. Océan, assez rare dans la Gironde; très rare, Charentenféricure. 
9. GENRE MAIGRE OU SCIẼNE. - SCIANA, Linn.

Corps oblong, couvert d'écailles obliques, plus larges que longues.

Tête grosse; museau mousse; màchoires ayant les dents de la rangée externe plus fortes que les autres, mais sans canines.

\section{LE MAIGRE COMMUN OU L'AIGLE. - SCIENA A QUILA, Cuv.}

Poiss. France, t. II, p. 398 et t. I, p. 7, fig. 3, vertèbre.

N. vulg. : Aigle, còtes de la Manche, Aigle de mer, Maigre, Nègre, Haut-Bar, côtes de l’Océan; Mégro, Arcachon, Bayonne; Tihoure (le jeune), Basses-Pyrénées; Peis rei, Languedoc; Daïné, Cette: Figou, Nice.

Long. : 0,40 à 0,80 , parfois 2,00 .

La longueur totale fait quatre à cinq fois la hauteur du tronc. - La tête est forte ; sa longueur est comprise quatre fois à quatre fois et demie dans la longueur totale; le museau est obtus; les mâchoires, à peu près égales, sont garnies de dents, elles en portent une rangée externe de plus fortes que les autres, écartées, un peu crochues. Le diamètre de l'œil fait le sixième de la longueur de la tête, un peu plus de la moitié de l'espace préorbitaire, les deux tiers de l'espace interorbitaire. Les épines de l'opercule sont séparées l'une de l'autre par une

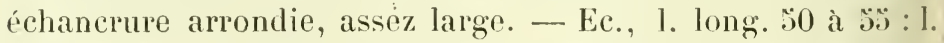
transr. 28 à 30. - Les dorsales peuvent se coucher dans un sillon plus creux en avant qu'en arrière; elles sont unies par une membrane; l'anale a sa première épine excessivemenl petite, cachée dans la peau; la caudale est carrée, ou très faiblement échancrée; les ventrales paraissent un peu moins longues que les pectorales.

Br. 7. - D. 9 ou $10-1 / 27$ à $29 ;$ A. ?/7 ou 8 ; C. 17 ou $18 ;$ P. 16 ; V. $1 /$ i.

Le dos est gris plombé teinté de brun ; les flancs et le ren-1 tre sont d'un gris argenté ; chez les jeunes, les côtés sont très? souvent marqués de taches arrondies d'un blanc argentéfort' brillant. Les nageoires paires, la première dorsale el l'analt sont rougeâtres; la seconde dorsale et la caudale sont grisí- 
tres. - La ressie natatoire est fortgrande, elle est remarquable par le développement de son corps rouge et la disposition de ses appendices branchus. - Il y a une dizaine d'appendices pyloriques.

Habitat. Méditerranée, assez commun. Océan, assez commun dans le golfe de Gascogne, plus rare en remontant vers le Nord. Manche, rare, Cherbourg, Arromanches, Dieppe, Dunkerque.

\section{GENRE CORB. - $\operatorname{coRVINA,~Cuv.~}$}

Corps oblong, couvert d'écailles de moyenne grandeur.

Téte forte; museau gros, arrondi ; màchoire supérieure plus longue et plus large que linférieure, garnies l'une et l'autre de dents en velours, avec une rangée externe de dents régulières plus développées que les autres.

Nageoires; anale à seconde épine très développée.

\section{LE CORB NOIR. - CORVINA NIGRA, Cuv.}

Poiss. France, t. II, p. 402, tig. 12\%, anim.

N. vulg. : Corbeau, Cuorp, Coracin de mer, Provence; Corb I nègré, Cette.

La hauteur du tronc est comprise trois fois et demie à quatre fois dans la longueur totale. - La longueur de la tète fait le quart environ de la longueur totale; le museau est gros, arrondi, montrant six ou sept pores disposés sur deux lignes; sous la mandibule, il y a généralement cinq pores. Le diamètre de l'ceil mesure le quart environ de la longueur de la tête; il est égal à l'espace interorbitaire, un peu moins grand que l'espace préorbitaire. - Ec., l. long. 58 à 60 ; l. transv. 28 à 30 . Les aiguillons de la première dorsale vont s'allongeant jusqu'au sixième ou septième formant une pointe plus ou moins prononcéc; l'anale, à base écailleuse, est beaucoup plus haute et plus courte que la seconde dorsale, sa seconde épine est très developpée, moins longue cependant que le premier rayon mou, elle est épaisse dans sa partie moyenne, parait courbe; les rentrales sont plus longues que les pectorales.

$$
\text { Br. 7. - D. } 10-1 / 23 \text { a } 25 ; \Lambda, 2 / 7 \text { ou } 8 \text {; C. } 17 \text { à } 19 ; \text { P. } 17 \text {; V. 1/5. }
$$


La teinte générale est brunàtre, d’un ton plus clair, jaunâtre piqueté de noir sous la gorge et le ventre. Les nageoires sont d'une coloration brunâtre; l'anale et les ventrales ont leurs rayons mous d'un noir foncé. - La vessie natatoire est grande, pointue en arrière, sans aucun appendice. Il y a huit appendices pyloriques.

Habitat. Méditerranée, assez commun à Nice, Marseille, Cette.

\section{GENRE PIISTIPOME. - PRISTIPOMA, Cuv.}

Corps oblong, comprimé, couvert d'écailles de moyenne grandeur.

Tête à peu près aussi haute que longue ; museau obtus; màchoires à peu près égales, garnies de dents en velours; une fossette sous le mienton.

Nageoires; dorsale unique, longue ; anale à trois aiguillons.

LE PRISTIPOME DE BENNETT. - PRISTIPOM.A BENNET 7I, Lowe.

Poiss. France, Suppl., p. 37.

Long. : 0,12 à 0,20 .

La hauteur du trone est comprise environ trois fois et demie dans la longueur totale; elle est à peu près égale à la longueur de la tête; le museau est obtus; les mâchoires sont à peu près égales, garnies de dentsen velours, un peu plus fortes à la rangée externe. Le diamètre de l'wil est contenu trois fois et demie à quatre fois dans la longueur de la tête; il est un peu moins grand que l'espace préorbitaire, un peu plus grand que l'espace interorbitaire. L'opercule porte en arrière une échancrure entre deux épines peu sensibles; le préopercule a le bord postérieur concave, garni de dentelures qui contournent l’angle postérieur qui est arrondi. - Ecail., l. long. ¿33 à 50 ; 1. transv. 22 à 24. -- La dorsale est longue, abaissée vers la fin de sa portion épineuse, relevée à l'origine de sa portion molle, échancrée par conséquent; son quatrième aiguillon est le plus élevé ; l’anale a trois aiguillons, le second est plus gros, mais pas plus long que le troisième; la caudale est très échancrée; les pectorales sont longues, presque falciformes; l'épine 
de la ventrale est d'un tiers moindre que le rayon mou adjacent.

Br. $7 .-\mathrm{D}) .12 / .5$ ou $16 ; 1.3 / 11$ ou $12 ;$ C. 16 ou $17 ;$ P. 16 à $18 ; \mathrm{V} .1 / 5$.

La teintegénérale est d'un gris plus foncé sur le dos, plus pàle sur les llancs. - La portion épineuse de la dorsale est d'un gris teinté de jaune, la portion molle est jaunâtre; l'anale ef les ventrales sont jaunâtres.

Habitat. Méditerranée, accidentellement, Cette, étang de Thau, 1888.

\section{Famille des Scombridés, Scombrida.}

Corps de forme variable; peau rarement nue, couverte ordinairement d'écailles petites et lisses, quelquefois de pièces rudes.

Tête plus ou moins développée; dentition généralement faible, parfois nulle, rarement forte.

Appareil branchial; ouïes largement ouvertes; le plus souvent sept rayons branchiostèges et pseudobranchies.

Nageoires; dorsale simple ou double; parfois la première dorsale est composée d'aiguillons plus ou moins libres; anale souvent précédée de quelques épines paraissant constituer une première nageoire; en arrière de la dorsale et de l'anale, il y a dans certains genres, dans certaines espèces, des rayons détachés appelés pinmules ou fausses nageoires; ventrales plus ou moins développées, parfois trẻs réduites et mème manquant comme dans certains faux-apodes (Espadon) ou chez les adultes (Stromatée).

Appendices pyloriques généralement nombreux.

La famille des Scombridés comprend quatorze sous-familles.

a. Disque sur la tête, ovale.................

Nol

८. Mluseau prolongé en lame................

Non .......................... $c$

c. Dorsale double....................... e.

unique ....................

e. Plusieurs fausses nageoires après la $2^{\mathrm{e}}$ dorsale et l'anale ..................... $f$.

Pas de fausses nageoires ou une seule..... g.

f. Crêtes ou carène sur le troncon de la queue.

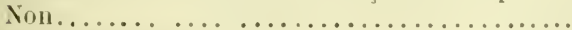

y. Anale double........................ h.

$-\operatorname{simple......................~} k$.
1'. ÉCHĖNÉLIENS.

13. Xipuétntevs.

1. Scombriniexs.

2. Thyositisiens. 


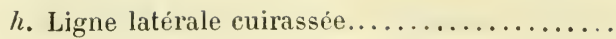

i. Écussons de chaque côté de la 2 e dorsale....

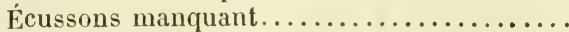

k. Caudale carrée ou arrondie................ - fourchue...................

l. Ventrale ayant au moins 14 rayons......... moins de 14 rayons......... $m$. Anus recouvert par les ventrales........... - non recouvert par les ventrales.......

$n$. Dorsale commençant sur la tête........... Dorsale commencant au-dessus ou en arrière des ouïes........................ o. Dents des mâchoires sur plusieurs rangées. - sur une seule rangée..
3. Caranginiens. $i$.

5. Zétxiess.

4. Centronotiniens.

6. Capriniens.

i. Cubicépiniens.

8. LAMPRINIENS. $m$. $n$.

11. Louvariniens.

12. CoRYPHE்niniens.

9. Braminiens.

10. Centrolophiniens.

\section{Sous-famille des Scombriniens, Scombrini.}

Corps fusiforme, couvert généralement de très petites écailles; dans certaines espèces, les écailles qui revètent la poitrine sont différentes des autres, forment une espèce de ceinture plus ou moins complète, plus ou moins large, désignée par les ichthyologistes sous le nom de corselet. Troncon de la queue portant de chaque côté deux petites crêtes et souvent une carène médiane.

Tête allongée; màchoires dentées; langue ordinairement lisse.

Yeux pourvus d'une paupière adipeuse.

Appareil branchial; sept rayons branchiostèges; joues couvertes d'écailles ou plutòt de pièces dures, plus ou moins osseuses.

Nageoires; deux dorsales; derniers rayons de la seconde dorsale et de l'anale séparés et formant les fausses nageoires ou pinnules; caudale fourchue ou en croissant.

La sous-famille des Scombriniens comprend quatre genres :

$a$. Dorsales éloignées l'une de l'autre.............. b.

- rapprochées..................... ...

b. Carène latérale sur le troncon de la queue nulle .... 1. Scombre.

- 5 - $\quad-\quad$ - $\quad$ - $\quad$ distiucte.. 2. Auxide.

c. Dents des màchoires fines, courtes.. . .......... 3. Tном.

longues, fortes............... 4. Pélamide.

\section{GENRE SCOMBRE. - SCOMBER.}

Corps allongé; tronçon de la queue grêle, ayant, de chaque côté, deux petites crètes entre les racines de la caudale.

Téte longue, plus ou moins conique; bouche grande; màchoires avec une rangée de petites dents pointues; vomer et palatins dentés. 
Nageoires; dorsales éloignées l'une de l'autre; anale précédée d'une petite épine crochue et suivie, ainsi que la seconde dorsale, de cinq ou six fausses nageoires.

Espace interorbitaire de teinte foncée, non transparent.. 1. Maquereau. blanchâtre, plus ou moins transparent. 2. Coliss.

\section{LE SCOMBRE MAQUEREAU. - SCOMBER SCOMBER.}

Poiss. France, t. II, p. 409.

N. vulg. : Auriou, Nice; Auriol, Marseille; Béiidat, Cette; Verrat, Languedoc; Barat, Roussillon; Brill, Brehel, Basse-Bretagne.

Long. : 0,30 à 0,40 , quelquefois plus.

Le corps est courert d'écailles excessivement pelites, semblant perdues dans la peau; sa hauteur est comprise cinq fois et demie à six fois et demie dans la longueur totale. - La longueur de la tête est contenue quatre fois et demie à cinq fois dans la longueur totale; les mâchoires portent une rangée de petites dents coniques régulières. Le diamètre de l'ceil est compris einq à six fois dans la longueur de la tête, il fait à peu près les deux tiers de l'espace préorbitaire. Les pièces operculaires sont lisses: les joues sont couvertes de longues écailles. - La ligne latérale est sinueuse, et marquée đ’écailles un peu plus grandes que celles du corps. - La première dorsale est légèrement falciforme.

D. 10 a $13-1 / 11+V ; 1.1-1 / 11+V$; C. 17 ; P. 19 ou $20 ; V .1 / 5$.

Le dos est verdâtre arec des lignes sinueuses d'un bleu très foncé; le ventre est d'un blanc argenté très brillant; le dessus de la tête est d'un bleu noirâtre. Les dorsales, la caudale et les pectorales sont d'un brun plus ou moins foncé; l'anale et les ventrales sont d'un gris blanchàtre. - Il n'y a pas de ressie natatoire. - Les appendices pyloriques sont nombreux.

Habitat. Toutes nos còtes, commun.

A Cette, la chair des Maquereaux, dont les pècheurs ont enlevé une pièce de la peau en forme de poisson, est plus estimée que celle des Maquereaux n'ayant pas subi cette petite opération. 
2. LE SCOMBRE COLIAS. - SCOMBER COLIAS.

Poiss. France, t. II, p. 412 , fig. 128 , anim.

N. vulg. : Cavaluca, Nice; Aourneaou-bias, Marseille ; Gros-Yol, Biar, Cette; Bizet, Roussillon.

Long. : 0,20 à 0,30 , parfois 0,33 .

La hauteur du tronc est comprise cinq fois et demie à six fois dans la longueur totale; chez les sujets de grande taille, les écailles de la région pectorale dessinent une sorte de corselet. -- La longueur de la tète est contenue quatre fois et quart environ dans la longueur totale; les dents sont plus fines et plus nombreuses que dans l'autre espèce. Le diamètre de l'oil fait le quart de la longueur de la tête, les deux tiers de l'espace préorbitaire; l'espace interorbitaire et la partie supérieure du museau, chez les jeunes principalement, sont blanchàtres, plus ou moins diaphanes. - La ligne latérale est bien marquée, mais elle a les écailles plus petites que celles du corselet. - La première dorsale est presque triangulaire.

$$
\text { D. } 10-1 / 11+V ; \Lambda .1-1 / 11+V .
$$

Le dos est d'un bleuâtre tirant sur le vert avec des bandes et des taches noirâtres; sur Jes côtés et le ventre sont des taches plus ou moins grandes d'un vert noirâtre. - La vessje natatoire est plus ou moins développée suivant l’àge.

Habitat. Méditerranée, assez commun. Océan, golfe de Gascogne, rare, Arcachon; très rare au-dessus de la Gironde, la Rochelle.

\section{GENRE AUXIDE. - AUIIS.}

Corps fusiforme; corselet bien dessiné; carène latérale sur le troncon de la queue.

Tête conique; màchoires à petites dents; vomer non denté.

Nageoires; dorsales éloignées l'une de l'autre; seconde dorsale et anale courtes, suivies de sept à neuf pinnules. 


\section{L'AUXIDE BISE. - AUXIS BISUS.}

Poiss. France, t. II, p. $\$ 15$.

N. vulg. : Bounicou, Bounitou, Nice.

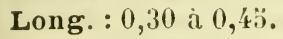

Le corps est fusiforme, plus ou moins renflé: sa hauteur est comprise de quatre à six fois dans la longueur totale; la peau semble lisse; les écailles, chez l'animal adulte, forment, dans la région pectorale, un corselet complet. - La tête est forte; sa longueur est contenue quatre fois à quatre fois et demie dans la longueur totale; la bouche est assez petite; les mâchoires sont garnies d'une rangée de dents courtes et fines. Le diamètre de l'wil est compris cinq à six fois dans la longueur de la tête; il mesure les trois quarts de l'espace préorbitaire. L'opercule a le bord cilié; le préopercule a les bords courbes dessinant une moitié d'ellipse. - La ligne latérale est bien marquée après la pointe du corselet. - La première dorsale est séparée de la seconde par une distance plus grande que la longueur de sa base ; la seconde dorsale est écailleuse, courte et basse ; la caudale est en croissant; les pectorales sont courtes; les ventrales, encore moins longues que les pectorales, sont séparées l'une de l'autre par un repli cutané à bord postéricur arrondi.

D. 10 ou $11-1 / 10$ ou $11+$ VIII ou $1 \mathrm{X} ;$ 1. $1 / 10$ à $12+$ VII ; C. 21 ; P. 20 a 22.

La coloration générale est assez variable; le dos est bleuâtre avec des bandes et des taches d'un bleu plus foncé; les tlanes et une partie du corselet sont d'un bleu très clair; le ventre est argenté; parfois les bandes et les taches sont effacées sur le dos, qui présente une teinte uniforme. Les nageoires sont grisitres. - Il n'y a pas de ressie natatoire.

Habitat. Néditerranée, assez rare, Nice, Cetle. Océan, Finistère, Concarneau.

\section{GENRE THON. - THYNNUS.}

Corps fusiforme ; corselet plus ou moins développé, ả échancrure sus-pectorale commencant sous le première dorsale; troncon de la 
queue portant, de chaque còté, une carène plus ou moins saillante et deux petites crêtes entre les racines de la caudale.

Tête; museau pointu; bouche assez grande; dents petites, fines, sur les màchoires et les palatins et généralement sur le vomer.

Narines; orifice postérieur de la narine dans une fente verticale.

Nageoires; dorsales rapprochées, la première ayant treize ì seize aiguillons; sept à dix pinnules; caudale en croissant.

Le genre Thon se compose de cinq espèces.

a. Pectorale ne dépassant pas la $1^{\mathrm{re}}$ dorsale....... $b$.

b. $1^{\text {re }}$ dorsale falciforme..........................

5. Germox.

triangulaire...................

c. Bandes noires longitudinales, 4 ou 5 , au-dessous de la ligne latérale.....................

Bandes noires longitudinales sous la ligne latérale manquant............................

d. Corselet se prolongeant en dessous plus en arriere que les ventrales.......................

Corselet étroit en dessous, finissant avant les ven-

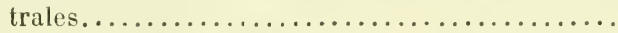

1. Bonite a venTRE RAYÉ.

2. Thonine.

3. COMMUN.

4. A PECtorales COURTES.

M. Chr. Lütken dans spolia Atlantica, p. ว̈95, écrit : Je conserve le nom de Thymnus pour "les petits thons", le bonito (Th. pelamys) et le Th. thunnina... je réserve celui d'Orcynus pour les "grands thons", c'est-i-dire pour le vrai thon (O. thynnus) et le germon (0.germo). Pourquoi ne pas ranger dans la division Oreymus, le Th. thunnina qui arrive à une taille à peu près égale à celle de 0 . germo?

\section{LA BONITE A VENTRE RAYE. - THYNNUS PELAMIS.}

Poiss. France, t. II, p. 419.

Long. : 0,40 à 0,70 .

La hauteur du trone fait le quart environ de la longueur totale; le corselet est développé, son angle pectoral dépasse de beaucoup la nageoire; son échancrure inférieure s'étend, vers la gorge, en avant de la base des ventrales. - La longueur de la tête est comprise trois fois à trois fois et un tiers dans la longueur totale; les màchoires et les palatins ont de petites dents; le vomer ne semble pas denté. Le diamètre de l'cil mesure à peine le septième de la longueur de la tête, plus de la moitié de l'espace préorbitaire. - Lapremière dorsale est 
falciforme; son premier rayon est plus haut et plus fort que le suivant, ses troisième, quatrième et cinquième rayons décroissent rapidement; la seconde dorsale est échancrée ; la caudale est en croissant très ouvert ; la pectorale est à peu près triangulaire, elle mesure un peu plus duseptièmede la longueur totale.

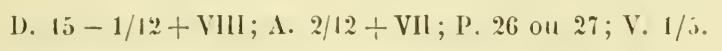

Le dos el le haut des llanes sont d'un bleu teinté de rose; le reste du corps est argente; quatre, parfois cinq bandes brunâtres, légèrement courbes, s’étendent sur les côtés à partir du corselet el remontent vers la ligne latérale en arrière de la seconde dorsale.

Habitat. Accidentellement, Méditerranée, Océan.

\section{IA THONINE. - THYNIUS THUNNINA.}

Poiss. France, t. II, p. 421.

N. vulg. : Touna, Nice; Thounina, Cette.

Long. : 0.70 à 1,00 .

La hauteur du tronc mesure le cinquième environ de la longueur totale: le corselet a des échancrures profondes, l'échancrure inférieure se porte un peu en avant de la base des rentrales. - La longueur de la tète est comprise quatre fois à quatre fois et un tiers dans la longueur totale; il y a des dents sur les màchoires, le vomer et les palatins. Le diamètre de l'ceil est contenu six fois à six fois et demie dans la longueur totale; il fait la moitić de l'espace interorbitaire, qui est à peine plus grand que l'espace préorbitaire. - La ligne latérale est bien marquée. - La première dorsale est falciforme; la première épine est plus haute que la deuxième, après la troisième les autres baissent rapidement jusqu'à la dixième; les pectorales sont triangulaires, courtes, leur longueur ne mesurant pas le septième de la longueur totale; les rentrales ont à peu près la même dimension.

D. 15 ou 16-1/12+ VIII, q.q.f. IX ; A. 2/12+ VII ou VIII; C. 35 ou $36 ;$ P. 26.

La coloration est bleue sur le dos arec des bandes noires 
flexueuses; elle est argentée sur les côtés et le ventre qui sont marqués de taches noirâtres peu nombreuses.

Habitat. Méditerranée, très rare, Nice, Marseille, Cette. Océan, excessivement rare, Concarneau, 1883.

\section{LE THON COMNUN. - THYNNUS THYNNUS.}

Poiss. France, t. II, p. 423.

N. vulg. : Thoun et Toun, Provence, Languedoc; Thoun, Cette ; Thon rouge, Bayonne.

Long. : 0,80 à 1,50 et même 2,00 .

La hauteur du tronc est comprise quatre fois et quart à cinq fois dans la longueur totale; le corselet est très grand, la pointe inférieure ou abdominale, entoure la base des ventrales, et se porte jusqu'à l'aplomb de l'extrémité des pectorales. - La longueur de la tête mesure le quart environ de la longueur totale; les mâchoires portent une rangée de pelites dents pointues, légèrement crochues; le vomer et les palatins sont aussi dentés. Le diamètre de l'œil est contenu de sept à neuf fois dans la longueur de la tête; il fait la moitié ou le tiers de l'espace préorbilaire. - En avant la ligne latérale est courbe; elle s'abaisse sous la seconde dorsale pour gagner le milieu du tronçon de la queue. - La première dorsale a généralement le premier aiguillon plus élevé que les autres, puis viennent les $2^{\mathrm{e}}, 3^{\mathrm{e}}$, $\mathbf{4}^{\mathrm{e}}$ et $\ddot{j}^{\mathrm{e}}$, qui sont beaucoup plus hauts que les suivants; la seconde dorsale semble pointue; les pectorales sont falciformes, leur longueur est généralement plus grande que celle de l'espace postorbitaire.

D. 14 ou $15-1 / 13+$ IX ou X; A. 2/12+ VIII ou IX ; C. $20 ;$ P. 30 ou 31.

La coloration est d'un bleu plus ou moins foncé sur le dos: elle est grisàtre sur les flancs et le ventre avec des taches nombreuses et rapprochées d'un blanchâtre argenté. La première dorsale, les pectorales et les rentrales sont d'un brun foncé; la caudale est d'un brun plus clair ; la seconde dorsale et l'anale sont d'un rouge jamàtre assez clair; les pinnules sont jaunâtres avec une bordure noire. Pas de vessie nata- 
toire, suivant beaucoup d'auteurs; elle existe au contraire d’après Malm, V. Lütlien, Spol., p. $\$ 96$.

Habitat. Commun sur toutes nos còtes de la Méditerranée. Océan, golfe de Ciascogne, assez commun, jusqu'à l'embouchure de l'Adour; rare entre l'Adour et la Gironde; très rare au nord de la Gironde. Manche, accidentellement, Boulogne.

\section{LE THON A PEGTORALES COURTES. - THYNNUS BRACHYPTERTS.}

Poiss. France, t. II, p. 426.

Long. : 0,50 à 1,00 .

La hauteur du trone est comprise quatre fois et demie environ dans la longueur totale; le corselet est assez peu développé, il laisse, autour de la base des ventrales, un grand espace libre. - La longueur de la tête mesure au moins le quart de la longueur totale; les màchoires ont des dents fines et pointues. Le diamètre de l'ceil fait environ le sixième de la longueur de la tête, la moitié au moins de l'espace préorbitaire. - La ligne latérale est légèrement sinueuse. - La première dorsale a son premier aiguillon plus fort et aussi haut que le deuxième; après le troisième les autres décroissent d'une façon régulière; la pectorale est triangulaire, courte, sa longrueur étant contenue de sept à huit fois dans la longueur totale, et moins grande que celle de l'espace postorbitaire, elle compte une trentaine de rayon.

D. 1 ' ou $15-1 / 13$ ou 1 ' $;+1 \mathrm{X}$; A. $2 / 12+$ VIII C C. $19 ;$ P. 31 .

Le dos et les côtés sont d'un bleu assez clair avec quatorze ou quinze larges bandes verticales d'un bleu plus foncé; la régrion abdominale est d'un blane argenté. Les nageoires sont d'un gris plus ou moins foncé, parfois teinté de marron.

Habitat. Méditerranée, assez commun, Nice, Marseille, Cette.

D'après Lütken, le Th. brachypterus n'est sans le moindre doute fu'une jeune forme de l'Orcynus thynnus (spol. Atlant., p. 583̈-187). - Fis l)ay partage cetle opinion et il met dans la synonymie du eune Thon (Brit. Fish., t. I, p, 9i) le Short-finned Tunny, Couch, qui, 
je l'ai démontré, est une Pélamide, P. Sarda (Poiss. France, t. II, 431). Day ne connaissait pas alors mon observation, plus tard il en tint compte. - D'après Cuvier et Valenciennes, le Th. bruchpyterus a une taille ordinaire de trois pieds; il est pourvu d'une petite vessie natatoire; son foie est petit et composé de deux lobes triangulaires (C. V., t. VIII, p. 100-102); chez le Th. vulgaris, le foie est assez volumineux et composé de trois lobes (C. V., I. c., p. 66).

\section{כ. LE GERMON. - THYNNUS ALALONGA.}

Poiss. France, t. II, p. 428.

N. vulg. : Thon, còtes de Bretagne, Belle-Ile; Germon et quelquefois Longue-Oreille, Thon aux longues ailes, Poitou, Guyenne; Thon blanc, Alut, Bayonne, Saint-Jean-de-Luz; Thoun, Audëyat, Cette, Alalonga, Nice.

Long. : 0,30 a 1,00 .

Ses grandes pectorales font de suite reconnaître le Germon. - La hauteur du tronc est comprise quatre fois et demie environ dans la longueur totale; le corselet est bien développé. La longueur de la tète est contenue trois fois et demie à quatre fois et quart dans la longueur totale; il y a de petites dents sur les mâchoires, les palatins, le vomer, la langue; le diamètre de l'ceil fait le cinquième ou le sixième de la longueur de la tète, les deux tiers ou les trois cinquièmes de l'espace préorbitaire. - La première dorsale est assez haute en arant, falciforme; la pectorale dépasse en arrière la seconde dorsale. sa longueur mesure le tiers environ de la longueur totale.

D. $14-3 / 12+$ VIII ; A. 3/12+ VII ou VIII; C. 21 ; P. 35 ou 36.

Le dos est d'un bleu très foncé; les côtés el les parties inférieures du corps sont d'un gris bleuâtre.

Habitat. Méditerranée, rare, Nice, Cette. Océan, commun de la Bidassoa à la Loire; assez commun à Belle-Ile et sur la còte de Bretagne jusqu'à la baie de Douarnenez. Manche, assez rare jusqu’à la baie de Morlaix, excessivement rare au delà.

\section{GEYRE PÉLAMYDE. - PELAMYS.}

Corps oblong; troncon de la queue portant de chaque còté une 
carène, plus deux petites crètes vers lit caudale; corselet peu développé.

Tête; dents fortes sur les màchoires; dents sur les palatins, pas sur le romer.

Nageoires; dorsales contiguës; six à neuf fausses nageoires.

f'e dorsale i plus de 20 rayons............... 1. sande.

- moins de 15 rayous............... 2. de Bon.aparte.

1. LA PELAMIDE SARIDE OL COMMUNE. - PELAMYS SARDA.

Poiss. Fiance, t. II, p. 430 .

N. vulg. : Palamida, Boussicou, Nice; Boniton, Bonite, Cette.

Long. : 0,30 à 0,50 el mème 0,70 .

La hauteur du trone est comprise cinq fois à cinq fois et demie dans la longueur totale; le corselet est étroit. - La longueur de la tète est contenue quatre fois à quatre fois et quart dans la longueur totale; les màchoires sont à peu près égales, munies, l'une et l'autre, d'une rangée de dents pointues, crochues. Le diamètre de l'œil mesure le sixième environ de la longueur de la tète, la moitié de l'espace préorbitaire. - La lignne latérale est légèrement sinueuse. - La première dorsale commence au-dessus de l’insertion de la pectorale; elle compte vingt-deux à vingt-quatre rayons; la seconde dorsale est petite, écailleuse à la base; l'anale prend naissance sous les derniers rayons de la seconde dorsale; la caudale a ses lobes très divergents; les pectorales sont triangulaires, peu développées, mesurant à peine le dixième de la longueur totale; les ventrales sont encore plus courtes.

Br. 7. - D. 22 à $24-2 / 12$ ou $13+$ VIII nu IX; 1 . $2 / 11$ à $13+V I$ à VIII C. $20 ;$ P. $16 ; \mathrm{V} .1 / 5$.

Chez les jeunes, le dos est bleuâtre, les côtés et le ventre sont argentés; dix à douze bandes verticales, d'un bleu clair, descendent de la région supérieure sur les flanes; chez les adultes, le dos est bleuâtre, marqué de douze à seize larges bandes noirâtres ou d'un bleu foncé, s'abaissant jusque sur le milieu des flancs et coupant des lignes brunâtres dirigées obliquement d'arrière en avant et de haut en bas. Les dorsales 
et la caudale sont d'un brun plus ou moins foncé; les pectorales sont d'un brun bleuatre; les ventrales et l'anale sont d'un gris clair ou légèrement jaunâtre.

Habitat. Méditerranée, assez commune à Nice; assez rare à Cette. Océan, rare. Manche, accidentellement.

2. LA PÉLAMYDE DE BONAPARTE. - PELAMYS BONAPARTII,
Vérany.

Poiss. France, t. II, p. 434.

Long. : 0, כ̈0 à 0,80 .

La hauteur du tronc mesure le cinquième environ de la longueur totale; le corselet est mieux dessiné que dans l'autre espèce. - La longueur de la tête est contenue cinq fois et quart dans la longueur totale; les mâchoires sont armées de dents coniques, fortes, écartées. Le diamètre de l'wil ne fait guère que le septième de la longueur de la tête, il fait un peu plus du tiers de l'espace préorbitaire. - La ligne latérale est un peu onduleuse, composée d'écailles bien distinctes. - La première dorsale est soutenue par une douzaine de rayons; l'anale commence sous les derniers rayons de la seconde dorsale; la carène latérale du tronçon de la queue est très prononcée; la pectorale est peu développée, sa longueur faisant à peine le huitième de la longueur totale; la ventrale est beaucoup plus courte.

D. 11 à $13-1 / 12+$ VIII ; A. $1 / 12+$ VII ; C. 20 à $22 ;$ P. 18 ou 19; V. 1/5.

La partie supérieure du corps est d'une teinte bleuâtre uniforme, sans aucune bande; le ventre est argenté. La première dorsale est d'un violet foncé; les autres nageòires sont beaucoup plus pâles.

Habitat. Méditerranée, excessivement rare, Nice.

\section{Sous-famille des Thyrsitiniens, Thyrsitini.}

Corps allongé, plus ou moins fusiforme, sans corselet; ni carène, ni crête sur le tronçon de la queue. 
Tête longue; bouche largement ouverte; màchoires armées de dents pointues; palatins dentés.

Nageoires; première dorsale commeneant plus en avant que la base de la pectorale; après la seconde dorsale et l'anale, quelques pinnules parfois réunies par une membrane.

GENRE ROUVET. - RUVETTUS, Valenc.

Corps garni de petites écailles et de grands écussons épineux.

Tête grande; màchoires munies de dents sur une seule rangée; à la màchoire supérieure, les dents antérieures et internes sont plus longues que les autres; série unique de dents sur les palatins, quelques dents sur le chevron du vomer.

Appareil branchial; fente des oules très grande; sept rayons branchiostèges.

\section{LE ROUVET PRÉCIEUX. - RUVETTUS PRETIOSUS.}

Poiss. France, Suppl., p. 41.

Long. : 0,70 à 1, ö0 et plus.

La hauteur du trone est comprise cinq fois à six fois et demie dans la longueur totale; la peau est hérissée d'écussons épineux; entre les rentrales et l'anus, il existe une carène excessivement rude, formée d'une quarantaine de boucliers à pointe tournée en arrière. - La longueur de la tète est contenue quatre fois à quatre fois et deux tiers dans la longueur totale; la màchoire supérieure est plus courte que la mandibule; elles sont garnies l'une et l'autre d'une rangée de dents aiguës. Le diamètre de l'œil, qui est moindre que l'espace préorbitaire, est, chez les sujets de moyenne taille, compris quatre fois et demie dans la longueur de la tête. - La première dorsale commence au-dessus de la fente branchiale; elle est basse, formée de rayons espacés, à peu près égaux; la seconde dorsale est haute en avant, assez basse en arrière; l'anale est un peu moins haute et un peu moins longue que la seconde dorsale; après ces nageoires vient une double pinnule ou bien une pinnule à deux rayons; la caudale est fortement échancrée; les nageoires paires sont courtes, elles 


\section{LE SAUREL COMMUN. - TRACHURUS TRACHURUS.}

Poiss. France, t. II. p. 437 ,

Syn. : Traciurus Lixnai, Malm, V. Lütken, Spol. Atlant., p. 196.

N. vulg. : Maquereau bàtard, Carangue, Normandie; Makerelle, Bretagne: Chinchard, Noirmoutiers; Chichard, Querelle, Poitou; Coustout, Coustut, Arcachon; Chicharou, Basses-Pérénées; Bizet, Roussillon; Gascon, Gascoun, Saurel, Sieurel, Languedoc, Provence ; Séveran et Souvareau, Provence; Suck-Cagnenck, Nice; Macreuse, Marché de Paris.

Long. : 0,20 à 0,30 , rarement 0,50 .

La hauteur du tronc est comprise cinq fois à cinq fois et demie dans la longueur totale. - La longueur de la tète est contenue quatre fois et quart à quatre fois et demie dans la longueur totale; la mâchoire supérieure est plus courte que la mandibule, elles sont l'une et l'autre munies de dents sur plusieurs rangées; le milieu de la langue porte une bande assez longue de dents en velour's d'une extrême finesse. Le diamètre de l'œil est compris trois fois et demie à quatre fois dans la longueur de la tête; il est un peu moins grand que l'espace préorbitaire; le premier sous-orbitaire est strié. La ligne latérale est marquée par une série de boucliers plus hauts que larges, à peu près lisses en avant; sous la seconde dorsale, la pointe des boucliers devient plus prononcée, et sur le tronçon de la queue leur épine est plus forte, plus acérée; le nombre de ces pièces est chez ce Saurel de 69 à 80 . — La première dorsale est précédée d'une épine fixe ; elle est triangulaire; deux épines, unies par une membrane, forment une petite nageoire avant l'anale; la caudale est fourchue; les rentrales sont de beaucoup plus courtes que les pectorales.

$$
\text { Br. 7.-D. 8. - 1/28 à } 32 ; \Lambda .2-1 / 25 \text { à } 29 \text {; C. } 17 \text {; P. } 21 ; \text { V. } 1 / 5 \text {. }
$$

La moitié supérieure du corps est d'un gris bleuàtre, l'autre d'un blanc argenté; une taclıe noire marque le bord postéricur de l'opercule; une petite tache noirâtre existe à l'aisselle de la pectorale. - La vessie natatoire est pourrue d'un canal 
qui vient s'ourrir dans la chambre branchiale du côté droit, ainsi que l'a démontré A. Moreau.

Habitat. Plus ou moins commun sur toutes nos còtes.

\section{LE SAUREL MEDITERRANEEN. - TRACHURUS MEDITERRANEUS.}

Syn. : Caranx trachures, Variatio mediterranea, Steindach., Ichth. Ber. Span. und Portug. Reis. V. Forts., p. 33, dans Silz. Alkad. Wissens., Wien, 1868, t. LVII.

Dans la liste des Saurels dont il a relevé le nombre des boucliers, Cuvier, dit-il, croit apercevoir deux sections distinctes de ceux de la Manche par des caractères qui, bien que peu apparents, pourraient ètre spécifiques, surtont à cause de leurs rapports avec les nombres des boucliers. La première de ces subdivisions comprend les individus qui ont de 80 à 88 boucliers; ces boucliers y sont moins élevés, la bande est plus étroite, elle fait une inflexion plus rapide, en sorte que sa partie postérieure et droite ne surpasse que de peu de chose sa partie antérieure; Cuv. Val., t. IX, p. 17.

Habitat. Méditerranée. Océan.

\section{LE SAUREL DE GUVIER. - TRACHURUS CUVIERI.}

Syn. : Caranx Guvieri, Lowe, dans Trans. Zool. Soc. Lond., 1841, p. 183.

Trachurus fallax, Brit. Capel., Cat. Peix. Portug., Lisb., 1867, Extr. Jorn. Scienc., nº 4, p. 4, et trad. franc., p. 13, - pl. V, fig. 2-3, langue, vomer et palatins du $T r$. truchurus et fig. $2^{\text {a }}$ et 3 a, langue et dents palatines du $T r$. fallax.

Le nombre des boucliers est très élevé, de 91 à 99 et mème 10ä. Les Saurels de cette subdivision ont, d'après Cuvier, le corps plus grèle, la ligne latérale plus étroite, son inflexion plus rapide, et sa partie postérieure, après l'inflexion, est égale en longueur à l'antérieure, dans laquelle il comprend la partie infléchie ou oblique (loc. cit., p. 17-18). Suivant de Brito Capello, la ligne latérale est composée de 91 à 105 boucliers : 37 à 43 de la tète à la courbure, 10 à 12 dans la portion inclinée et de 4 ty à 50 dans la portion droite extrème.

Habitat. Méditerranée, Nice. - Océan? - C'est à ce dernier Saurel qu'il faut rapporter le Trachurus Rissoi, Giglioli, qui est le 
Suck blaou de Risso, "de notre troisième subdivision " fait observer Cuvier (loc. cit., p. 19).

\section{GENRE CARANX. - CARANX, Guv.}

Corps de forme variable, couvert d'écailles lisses.

Ligne latérale n'ayant de boucliers qu'après sa courbure.

Ce genre se compose de trois espèces:

a. Fausse nageoire après la 20 dorsale nulle.......... b.
6. Boucliers au nombre de plut
la 2 e dorsale..................
3. SUATÉOU.
2. IUSEAU.
moins de $40 \ldots \ldots \ldots \ldots \ldots \ldots$. 1 . Lune.

1. LE GARANX LUNE. - CARANX LUNA, Geof.-St-IIil,

Poiss. France, t. II, p. 442.

N. vulg. : Pei Suvareou, Nice.

Long. : 0,2́ł à 0,40 et mème 0,60 d'après Risso.

Le corps est comprimé; sa hauteur est comprise trois fois à trois fois et demie dans la longueur totale. - La longueur de la tète est contenue quatre fois à quatre fois et demie dans la longueur totale; la mâchoire supérieure est un peu plus avancée que la mandibule; elles portent l'une et l'autre une rangée de petites dents; derrière les dents du milieu s'en trouvent d'autres plus petites encore; la partie médiane de la langue est munie d'une rangée de petites dents; le romer et les palatins sont lisses. - En arant la ligne latérale suit la courbure du tronc; elle devient droite sous le milieu de la seconde dorsale et se garnit de boucliers à carène plus ou moins saillante dont le nombre varie de 21 à 28. - La première dorsale est assez basse; le troncon de la queue est grêle; la caudale est fourchue; les pectorales sont falciformes, très longues, mesurant un peu moins du quart de la longueur totale; les rentrales sont courtes.

$$
\text { Br. 7. -D. } 8-1 / 24 \text { à } 27 ; \text { A. } 2-1 / 20 \text { a } 22 ; \text { C. } 17 .
$$

La teinte est d'un bleu verdâtre ou ardoisé sur le dos, blanc argenté sur les côtés, d'un blanc uni sous le ventre; le bord 
postérieur de l'opercule porte une tache noirâtre. Les nageoires sont d'un gris jaunâtre.

Habitat. Méditerranée, rare, Nice.

\section{LE C.ARANX FUSEAU. - CARA.YX FUSUS, Geof.-St-Hil.}

Poiss. France, t. II, p. 444 .

Long. : 0,28.

La hauteur du tronc mesure le quart de la longueur totale. - La tête a le profil supérieur convexe; sa longueur est comprise environ quatre fois et demie dans la longueur totale; la màchoire supérieure est à peine moins avancée que la mandibule; elle porte une petite bande de dents en velours et une série externe de dents plus fortes que les autres; la mâchoire inférieure n'en a qu'une rangée; le vomer, les palatins et la langue sont dentés. Le diamètre de l'œil fait le quart environ de la longueur de la tète, il est à peu près d'un quart moins grand que l'espace préorbitaire. - La ligne latérale est formée d'écailles, de petits el de grands boucliers; sur sa partie droite i) y a 13 grands boucliers: Ec., 1 "3 ou 16 ; boucliers, petits $1+$ grands, 洋. - Le bord du sillon de la seconde dorsale, ainsi que celui de l'anale, est releré par un repli de la peau; ces nageoires finissent dans le même plan, leur dernier rayon est un peu plus grand que les avant-derniers; les pectorales sont très longues, elles mesurent le quart de la longueur totale, elles dépassent la courbure de la ligne latérale; les ventrales n'arrivent pas à l'anus.

$$
\text { D. } 7 \text { ou } 8-1 / 24 ; \text { A. } 2-1 / 19 \text { ou } 20 ; \text { P. } 18 ; \text { V. } 1 / 5 \text {. }
$$

Le dos est gris bleuâtre; les côtés sont d'un gris blanchâtre; le ventre est argenté; en haut lopercule est marqué d'une tache noirâtre qui s'étend sur la ceinture scapulaire. Les nageoires sont d'un gris plus ou moins foncé.

Habitat. Méditerranée, excessivement rare, Nice. 
3. LE CARANX SUARÉOU. - CARANX SUAREUS, Riss.

Poiss. France, t. II, p. 447.

Long. : 0,40 à $0, \ddot{0} 0$.

La hauteur du tronc est comprise six fois dans la longueur totale, et la longueur de la tête quatre fois et demie; la mandibule est arancée. - La ligne latérale est droite sur les deux tier's postérieurs du tronc et y porte 16 boucliers aigus. - La seconde dorsale et l'anale sont suivies d'une fausse nagieoire; la pectorale, falciforme, mesure plus du quart de la longueur totale.

Br. 7. -D. $8-1 / 30+\mathrm{I} ;$ A. $2-1 / 24+\mathrm{I}$; C. 17 ; P. $25 ; \mathrm{V} .6$.

Le dos a des nuances gorge de pigeon; les côtés sont argentés; le ventre est d'un blanc mal. Il y a une tache noire à l'opercule.

Habitat. Méditerranée, excessivement rare, Nice.

\section{Sous-famille des Centronotiniens, Centronotini.}

Corps plus ou moins allongé, couvert de petites écailles lisses. Tête de forme variable; màchoires, romer et palatins dentés. Appareil branchial; ouies largement fendues.

Nageoires; première dorsale généralement assez basse et assez courte, formée parfois d'aiøuillons isolés, précédée souvent d'une épine dirigée en avant; seconde dorsale longue; deux épines après l'anus; caudale fourchue ou échancrée.

Cette sous-famille comprend quatre genres.

a. Carine latérale sur le trouçon de la queue longue... Pas de carène sur le tronçon de la quene......... $b$.

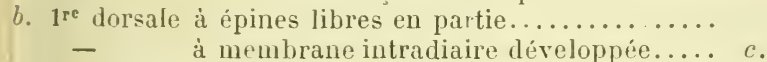

c. $1^{\text {re }}$ dorsale précédée d'une épine fixe................

- nou précédée d'une épine fixe......... 4. Temodon.

1. Naucrate.

1. Liche.

3. SÉRIOLE.

1. GENRE NAUCRATE. - NAUCRATES, Rafin.

Corps fusiforme; une carène latérale sur le tronẹon de la queue. Tête; dents en velours sur les màchoires, le vomer, les palatins et. a langue. 
Appareil branchial; sept rayons branchiostèges; pseudobranchies.

Nageoires; trois ou quatre épines libres, isolées, courtes, formant la première dorsale, précédées d'une épine fixe dirigée en avant. Vessie natatoire petite. - Appendices pyloriques au nombre de douze à quinze.

\section{LE PILOTE OU NAUCRATE PILOTE. - NAUCRATES DUCTOR.}

Poiss. France, t. II, p. 449, fig. 129, anim.

N. vulg. : Fanfré, Nice, Marseille; Fanfré, Galafat, Cette.

Long. : 0,20 à 0,30 et même 0,38 (Celte).

La hauteur du tronc est comprise quatre fois et demie à cinq fois dans la longueur totale, et celle de la tête quatre fois et demie; la mâchoire supérieure est à peine moins avancée que la mandibule. Le diamètre de l'wil fait environ le cinquième de la longueur de la tête, la moitié de l'espace interorbitaire qui est plus grand que l'espace préorbitaire. - Trois ou quatre épines libres constituent la première dorsale qui est basse ; la seconde dorsale est longue, elle finit dans le même plan que l'anale; le troncon de la queue porte de chaque cóté une carène développée, s'étendant jusqu’au milieu de la racine de la caudale qui est très échancrée; la pectorale ne mesure guère que le huitième de la longueur totale.

Br. 7. -D. 3 ou 4--1/25 à $28 ; \Lambda .2-1 / 16$ ou 17 ; P. 17 ou 18. V. 1/j.

La teinte est, sur le dos, d'un gris bleuâtre, d'un gris bleuàtre plus clair ou légèrement jaunâtre sur les flancs; le corps est traversé par cinq ou six larges bandes verticales d'un bleu foncé; la tête est d'un gris brunâtre à sa région supérieure. Les ventrales sont noiràtres, les pectorales d'un gris violacé; la caudale porte une espèce de bande verticale d'un bleu très foncé; la seconde dorsale et l'anale ont une coloration grisâtre; l'extrémité des lobes de la caudale, ainsi que la pointe des premiers rayons de la seconde dorsale et de l'anale, est blanchâtre.

Habitat. Méditerranée, assez commun, Nice, Toulon, Marseille, Cette. Océan, très rare. Manche, excessivement rare, Cayeux. 
2. GENIE LICHE. - IICHIA, Guv.

Corps oblong, comprimé, couvert de petites écailles lisses.

Téte; dents sur les màchoires, le vomer, les palatins et la langue.

Appareil branchial; huil ou neuf rayons branchiostèges.

Nageoires; une épine fixe, dirigée en arant, précède les aiguillons, qui, en partie libres, munis en arrière d'une petite membrane triangulaire, forment la première dorsale; seconde dorsale et anale longues, plus ou moins falciformes; caudale fourchue.

Vessie natatoire développée, bifurquée en arrière. - Appendices pyloriques en nombre variable.

Ce genre comprend trois espèces.

a. Màchoires à dents en velours................. b.
b. Ligne latérale à courbure
double......................
3. VADIGO.
simple................
2. AMIE.
1. GLIYCOS.

\section{LA LIGHE GLAYCOS. - LICHIA GLAUCUS.}

Poiss. France, t. II, p. 4ä4, fig. 130, anim.

N. vulg. : Lecca, Nice; Litcha, Nicha, Pélamida, Cette.

Long. 0,30 à 0,40 , quelquefois $0, \ddot{3} 0$.

La hauteur du tronc est contenue près de quatre fois dans la longueur totale, et la longueur de la tète cinq fois et demie; le museau est court; les mâchoires, à peu près égales, ont les dents en velours; l’extrémité postérieure du maxillaire supérieur arrive sous le bord antérieur de l’orbite ou à peine plus en arrière. Le diamètre de l'ceil est compris quatre fois et un tiers à quatre fois et demie dans la longueur de la tête; il mesure les deux tiers au moins de l'espace préorbitaire. Au-dessus de la pectorale, la ligne latérale est un peu ondulée, puis se continue directement jusqu'à la caudale. - La première dorsale a le plus souvent six aiguillons très courts, très acérés, pouvant s'abaisser dans une petite fossette; la caudale, ì base écailleuse, est très développée, sa longueur fait le quart le la longueur totale.

Br. 8. - D. 5 ou $6-1 / 24$ ou 25 ; A. 2-1/24 ou 25 ; C. 17 ; P. 17 ; V. $1 / 5$. 
La région supérieure est d'un gris ardoisé ou d'un bleu d'outremer; les flancs et le ventre sont d'un gris argenté; trois ou quatre taches, d'un gris ardoisé, forment sur les crités de courtes bandes verticales. La seconde dorsale et l'anale, qui sont d'un jaune assez clair, portent sur leurs rayons antérieurs une large tache noirâtre; la caudale est grisâtre avec la pointe des lobes noire; les pectorales sont d'un gris teinté de jaune; les ventrales sont blanchâtres. - Il y a douze ou treize appendices pyloriques.

Habitat. Méditerranée, assez commune, Nice, rare à Cette.Océan, excessivement rare.

\section{LA LICHE AMIE. - LICHIA AMIA.}

Poiss. France, t. II, p. 437.

N. vulg. : Leccia, Nice; Litcha, Cette.

Long. 0,50 à 0,60 , parfois 1,00 .

La hauteur du tronc est contenue trois fois et demie à quatre fois et demie dans la longueur totale. - La longueur de la tête mesure le cinquième environ de la longueur totale; la mâchoire supérieure est à peine moins avancée que la mandibule; les dents sont en velours; l'extrémité du maxillaire supérieur dépasse en arrière le bord postérieur de l’orbite. Le diamètre de l'œil est compris cinq fois et demie dans la longueur de la tête, il fait environ les deux tiers de l'espace préorbitaire, la moitié au moins de l'espace interorbitaire. La ligne latérale décrit une double courbure, une courbure convexe au-dessus de la pectorale, et sous la seconde dorsale une courbure à concavité supérieure. - La première dorsale a le plus souvent sept épines assez fortes; la caudale est très fourchue.

Br. \&.-D. 6 à $8-1 / 20$ ou 21 ; A. $2-1 / 20$ ou 21 ; C. 17 ; P. 19 à $21 ; \mathrm{V} .1 / 5$.

Le dos est d'un blanc verdâtre ou grisâtre assez clair; les côtés et le ventre sont d'un blanc argenté. Les nageoires ont une teinte jaunâtre plus ou moins foncée; la pointe de la seconde dorsale est brunâtre, ainsi que celle de l'anale.

Habitat. Méditerranée, assez rare à Nice; rare, Marseille, Cette. 


\section{LA LICHE VADIGO. - LICHIII VADIGO.}

Poiss. France, t. II, p. 't60.

N. vulg. : Leccia, Nice; Llampuga, Cette.

Long. : 0,40 à 0,70 .

La hateur du tronc est comprise quatre fois à quatre fois et demie dans la longueur totale, et la longueur de la tète environ cinq fois et quart; la màchoire supérieure est moins avancée que la mandibule, elles portent l'une et l'autre une seule rangée de dents pointues, légèrement crochues. Le diamètre de l'wil est contenu cinq tois et demie à six fois dans la longueur de la tète et une fois et demie à une fois et trois quarts dans la longueur de l'espace préorbitaire. - En avant la ligne latérale est légèrement courbe. - La caudale a une longueur à peine égale à celle de la tête.

Br. $8 .-$ D. $7-1 / 29$ a $31 ;$ A. $2-1 / 23$ ou $24 ;$ C. 22 ; P. 16 ou 17 ; V. $1 / 5$.

La teinte bleuâtre de la région supérieure n'est pas limitée, sur les flanes, par une ligne à peu près droite, elle forme une espèce de bande festonnée, dont les dentelures, assez larges et ondulées, se dessinent très nettement sur le fond argenté des côtés. Les nageoires sont d'un grisâtre plus ou moins foncé.

Habitat. Méditerranée, très rare, Nice; Cette.

\section{GENRE SÉRIOLE. - SERIOLA, Cuv.}

Corps ovale, comprimé, couvert de petites écailles lisses.

Tête; dents en velours sur màchoires, vomer, palatins, langue.

Appareil branchial ; sept rayons branchiostèges; pseudobranchies.

Nageoires; première dorsale précédée d'une épine fixe dirigée en avant, à membraue intraradiaire développée; seconde dorsale longue; deux épines avant l'anale; caudale fourchue.

Vessie natatoire simple.-Appendices pyloriques nombreux.

\section{IA SERIOLE DE DUMERIL. - SERTOLA DUMERILII.}

Poiss. France, t. II, p. 462, fig, 131, anim.

N. vulg. : Seriola, Nice; Sariola, Roussillon.

Long. : 0,40 à 0,90 . 
La hauteur du tronc est comprise trois fois et demie à quatre fois dans la longueur totale. - La longueur de la tête fait environ le quart de la longueur totale; le museau est convexe; les mâchoires sont à peu près égales. Le diamètre de l'œil mesure un peu plus du cinquième de la longueur de la tête, les deux tiers de l'espace préorbitaire. - La ligne latérale est composée d'écailles un peu plus grandes que les autres; elle décrit une double courbure en sens inverse. - La première dorsale est unie à la seconde par une petite membrane, elle est assez courte; la seconde dorsale est en avant beaucoup plus haute que l'autre, elle est très longue; l'anale commence à peu près sous le milieu de la seconde dorsale.

$$
\text { Br. 7. -D. } 7-1 / 30 \text { à } 32 ; A .2+1 / 19 \text { à } 21 ; \text { C. } 17 ; \text { P. } 19 \text { ou } 20 ; \text { V. 1/5. }
$$

Le système de coloration est gris argenté teinté de bleu ou de violet sur le dos, teinté de jaunảtre sur les flanes, gris argenté sous le ventre. Les ventrales sont jaunâtres; l'extrémité des lobes de la caudale est d'un brun assez foncé.

Habitat. Méditerranée, assez rare à Nice; très rare à Cette, deux spécimens.

4. GENRE TEMNODON. - TEMNODON, C. V.

Corps oblong, comprimé, couvert de petites écailles lisses.

Tête à profil supérieur légèrement déclive; màchoires dentées, intermaxillaire portant une rangée externe de dents aplaties ì pointe tournée en arrière, en dedans s'en trouvent de moins développées; vomer, palatins et langue à dents en velours ras.

Appareil branchial ; sept rayons branchiostèges; pseudobranchies.

Nageoires; première dorsale basse, non précédée d'une épine fixe; seconde dorsale et anale assez écailleuses.

\section{LE TEMNODON SAUTEUR. - TEMNODON SALTATOR.}

Poiss. France, Suppl., p. 4 วั.

Long. : 0,20 à 0,70 .

La hauteur du tronc est comprise quatre fois à quatre fois 
et demie dans la longueur totale et la longueur de la tête trois fois et demie à quatre fois; la màchoire supérieure est moins avancée que la mandibule. Le diamètre de l'wil mesure environ le cinquième de la longueur de la tête. L'opercule a le bord postérieur entamé d'une échancrure assez profonde. La ligne latérale est bien marquée, formée d’écailles plus hautes que longues. - La première dorsale est composée d'aiguillons assez grêles, unis par une membrane très mince; l'anale est opposée à la seconde dorsale; la caudale est fort échancrée ou plutôt fourchue; la pectorale est insérée vers le milieu de la hauteur du tronc; elle est assez courte.

Br. 7.-D. $8-1 / 25$ a 29 ; A. $2-1 / 27$ à 30 ; C. 20 ; P. 17 ou 18 ; V. 1/5.

La teinte est d'un blanc argenté ou plombé. Les nageoires impaires et les pectorales sont grisâtres; les ventrales semblent oâles.

Habitat. Méditerranée, accidentellement, Nice.

\section{כ. Sous-famille des Zéiniens, Zeini.}

Corps ovale; comprimé, couvert de petites écailles non imbriquées; carène du ventre formée de boucliers épineux.

Nageoires; deux dorsales contiguës; deux anales; la première lorsale ayant une dizaine d'aiguillons et de longs filaments soutenus ar des appendices sétacés ; seconde dorsale et seconde anale ayant, le chaque còté de leur base, une série d'écussons épineux ; première male à trois ou quatre aiguillons; ventrales insérées un peu en trant des ventrales.

GENRE ZÉE. - ZEUS, Arted.

Tête haute, comprimée, nue, excepté sur les joues; bouche très rotractile, à fente oblique; màchoire supérieure moins arancée ue la mandibule, garnies l'une et l'autre de dents fines; vomer enté.

Appareil branchial; sept rayons branchiostèges; une série imple de lamelles respiratoires sur le quatrième arc branchial; seudobranchies. 
Vessie natatoire très développée, ovoïde. - Appendices pyloriques fort nombreux.

Le genre Zée comprend deux espèces.

Épine du scapalaire très courte, à peine sensible..... 1. Forgeron. aussi longue que le diamètre de l'œil. 2. ÉPALLE ARMÉE.

1. LE ZÉE FORGERON. -- ZEUS FABER, Linn.

Poiss. France, t. II, p. 467.

N. vulg. : Dorée, Normandie; Poule de mer, Bretagne; Poisson Saint-Pierre, Poule de mer, Poitou; la Rose, Arcachon ; Gal, Peï San Pierré, Cette; Peï San Peire, Nice; Poisson Saint-Christophe.

Long. : 0,30 à 0,30 et mème 0,60 .

La hauteur du tronc est comprise deux fois et un tiers ì deux fois et demie dans la longueur totale; la carène du ventre est formée de treize ou quatorze paires d'écussons osseux. La longueur de la tête fait plus du tiers de la longueur totale. Le diamètre de l'oil est compris quatre fois à quatre fois et demie dans la longueur de la tête. - La première dorsale a neuf ou dix aiguillons; la seconde dorsale est bordée par une série de huit à dix, rarement sept, boucliers osseux, armés de deux épines; la première anale compte généralement quatre aiguillons; la seconde dorsale est bordée de chaque côté par une série de neuf boucliers à deux épines; le scapulaire et le coracoïdien ont chacun une épine.

D. 9 ou $10-2$ ? ou 23 ; A. 3 ou $4-21$ ou 22 ; C. 15 ; P. 13 ; V. $1 / 5$.

Le corps est d'un gris argenté lavé de jaune, avec une tache noirâtre, arrondie sur les flanes. Les nageoires sont d'une teinte brunâtre.

Habitat. Commun sur toutes nos còtes.

2. LE ZEE A ÉPAULE ARMÉE. - ZEUS PUNGIO, G. V.

Poiss. France, t. II, p. 472, fig. 132, anim.

Long. : 0,30 à 0,50 .

Le corps est peut-être un peu plus allongé que dans le Zée 
forgeron; la hauteur du tronc, chez un sujet de grande taille, est comprise deux fois et trois quarts dans la longueur totale; les écailles sont un peu plus développées que dans l'autre espèce. - La longueur de la tète fáit le tiers de la longueur totale; les dents sont plus fortes que dans l'autre espèce. - La première dorsale a le plus souvent onze aiguillons plus forts que dans le Zée forgeron; la seconde dorsale est, de chaque còté, bordée par une série de cinq à sept écussons osseux, plus volumineux que dans le Zée forgeron; la seconde anale a sur les côtés une rangée de sept ou huit écussons à deux épines fort saillantes: l'os scapulaire est pourvu d'une épine, à pointe dirigée en arrière, généralement plus longue que le diamètre de l'wil; le coracoüdien a son angle postérieur également muni d'un aiguillon robuste.

D. 10 ou $11-22$ à $24 ;$ A. $4-22$ ou 23 ; C. 13 ; P. 12 ; V. $1 / 5$.

La coloration est grisùtre; la tache arrondie des côtés manque souvent, quand elle existe, elle paraît moins marquée que dans l'autre espèce.

Habitat. Méditerranée, très commun à Cette. - Suivant Perugia, le Zeuspungio est la forme juvénile du Zeus faber, mais il ne se trouve presque jamais sur nos còtes de l'Ouest ; d'après Giglioli, le Zeus pungio doit ètre supprimé, il n’a jamais vu dans les mer's d'Italie un Zeus semblable à celui figuré par Cuvier et Valenciennes. Manche, accidentellement, le Havre, V. Suppl., p. 49.

\section{Sous-famille des Capriniens, Caprini.}

Corps ovale, comprimé, couvert d'écailles rudes à longues spinules.

Nageoires; deux dorsales réunies par une membrane assez courte, la première ayant neuf ou dix aiguillons; anale à trois épines et plus de vingt rayons mous, opposée à la seconde dorsale; caudale carrée.

GENRE CAPROS. - CAPROS, Lacép.

Téte longue, haute; bouche très protractile; dents fort petites sur les màchoires et le romer.

Appareil branchial; cinq rayons branchiostèges; pseudobranchies. 
Vessie natatoire bien développée. - Appendices pyloriques peu nombreux.

\section{LE CAPROS SANGLIER. - CAPROS APER.}

Poiss. France, t. II, p. 475, fig. 133, anim.

N. vulg. : Verrat, Nice; Peïpuorc, Cette.

Long. : 0,08 à 0,12 , rarement 0,15 .

La hauteur du trone est contenue environ deux fois et quart dans la longueur totale et la longueur de la tête, trois fois à trois fois et demie; la mâchoire supérieure est excessivement protractile. Le diamètre de l'cril est en général au moins aussi grand que l'espace préorbitaire et que l'espace interorbitaire, il est contenu deux fois et demie, ou peu s'en faut, dans la longueur de la tête. - La première dorsale a le plus souvent neuf aiguillons, qui sont robustes, rugueux; le troisième est le plus développé; l'anale prend naissance audessous de la dernière épine de la première dorsale; la caudale est coupée carrément ou légèrement arrondie; l'aiguillon des ventrales est généralement plus grand que les rayons mous, il est très robuste et fort rude.

$$
\text { Br. 5. -D. } 9 \text { ои } 10-23 \text { ou } 24 \text {; A. } 3 / 23 \text {; C. } 12 \text {; P. } 15 ; \text { V. } 1 / 5 \text {. }
$$

La région supérieure du corps est rougeâtre; la région inférieure, d'un rougeâtre glacé d'argent. Les nageoires sont d'un rouge assez pâle.

Habitat. Méditerranée, assez rare à Nice, Marseille; assez commun à Cette. Océan, très rare, Arcachon, la Rochelle, Concarneau. Manche, excessivement rare, Roscoff.

\section{Sous-famille des Cubicépiniens, Cubicepini.}

Corps oblong, couvert d'écailles minces, peu adhérentes.

Tête forte; museau court; bouche petite; màchoires à dents fines.

Nageoires; deux dorsales contiguës; anale opposée à la seconde dorsale; caudale fourchue; pectorales beaucoup plus longues que les ventrales. 
GENRE CUBICEPS. - CUBICEPS, Lowe.

Narines à deux orifices placés vers le bord supérieur du museau.

Appareil branchial; fente des ouies grande; pièces operculaires peu distinctes; six rayons branchiostèges; pseudobranchies.

\section{LE CLBICEPS GRÈLE. - CUBICEPS GRICILIS.}

Poiss. France, t. II, P. 479, fig. 134, anm., figg. 135, écaille.

Long. : (), 18 à 1,00 .

La hauteur du tronc mesure environ le cinquième de la longueur totale. - La tète est couverte d'écailles, excepté sur le museau et les mâchoires; sa longueur est comprise quatre fois et quart dans la longueur totale; les mâchoires sont égales; le vomer a des dents très fines; chez les jeunes animaux, il y a généralement des barbillons sous la gorge. Le diamètre de l'œil est contenu trois fois et demie à quatre fois dans la longueur de la tête; il est d'un quart plus grand que l'espace préorbitaire. La muqueuse de la chambre branchiale est noiràtre. - Ec., l. long. 60 à 66; l. transv. 18 à 20. - La première dorsale commence au-dessus de l’insertion des ventrales; la caudale est très fourchue; les pectorales sont longues, elles font un peu plus du quart de la longueur totale; lépine des rentrales est très courte.

Br. $6 .-$ D. $12-1 / 21 ;$ A. $3 / 19$ ou 20 ; C. 17 ; P. 18 a $20 ; \mathrm{V} .1 / 5$.

La teinte générale est d'un roux marron; la tète est d'un gris jaunàtre nuancé de roux. Les dorsales et les pectorales sont brunes; l'anale est d'un jaune grisàtre; la caudale est grisàtre, arec l'extrémité des lobes noiràtre; les rentralès sont d'un gris assez pâle. La coloration indiquée est celle d'un spécimen conservé dans l'alcool; elle paraìt très variable sur le frais.

Habitat. Méditerranée, excessivement rare, Nice, Cette.

\section{Sous-famille des Lampriniens, Lamprini.}

Corps ovale, comprimé, couvert de petites écailles caduques. Tête à profil arrondi; bouche petite; màchoires non dentres. 
Appareil branchial; six ou sept rayons branchiostèges.

Nageoires; dorsale uniquc, plus ou moins haute en avant, très longue; anale longue; caudale échancrée; pectorales à base horizontale; ventrales a rayons nombreux.

GENIE LAMPIS. - LAMPRIS, Retzius.

Caractères de la sous-famille.

\section{LE LAMPRIS LUNE. - LAIIPRIS LUNA.}

Poiss. France, t. II, p. 484.

N. vulg. : Peï d'Africa, Nice, Riss.

Long. : 0,40 à 1,00 .

Le corps est comprimé; sa hauteur est contenue deux fois et quart a deux fois et deux tiers dans la longueur totale. La tète est plus haute que longue; sa longueur est contenue trois a quatre fois dans la longueur totale; la bouche est petite, terminale. Le diametre de l'œil est variable, il fait le quart ou le cinquième de la longueur de la tête, suivant le développement des individus; il est égal, ou peu s'en manque, à l'espace interorbitaire qui est moins grand que l'espace préorbitaire. - La dorsale est très longue; ses rayons antéricurs forment une espèce de faux plus ou moins haute, parfois ils sont excessivement allongés; la caudale est en croissant, bien développée; les pectorales sont falciformes, relevées en général, ayant leur insertion presque parallèle à l'axe du corps el à peu près au milieu de la hauteur du tronc; les ventrales sont falciformes, très longues chez les jeunes sujets.

$$
\text { D. } 53 \text { à } 55 \text {; A. } 38 \text { à } 41 \text {; C. } 22 \text {; P. } 24 ; \text { V. } 14 \text { à } 16 \text {. }
$$

Le Lampris est bleuâtre sur le dos, violacé sur les côtés, rose sous le ventre; il a des taches argentées sur tout le corps. Les nageoires sont d'un rouge éclatant.

Habitat. Toutes nos còtes, mais rare, Marseille, Toulon, Nice; Royan, la Rochelle, Noirmoutiers, île d'Yeu, île de Ré; le Havre, Dieppe, Boulogne. 


\section{Sous-famille des Braminiens, Bramini.}

Corps ovale, comprimé, couvert d'écailles assez grandes.

Tête écailleuse, comprimée; bouche oblique ou plutòt courbe; dents en cardes sur les mìchoires, les palatins.

Appareil branchial; sept rayons branchiostèges; pseudobranchies.

Nageoires: nageoires impaires écailleuses; dorsale et anale longues, à premiers rayons épineux, à rayons mous antérieurs développés, falciformes; caudale échancrée; rentrales assez petites, à six rayons.

Vessie natatoire nulle. - Appendices pyloriques peu nombreux.

genre castagyole. - braha, Schneid.

Caractères de la famille.

\section{LA CASTAGNOLE. - BRAMA RAII, Schneid.}

Poiss. Frunce, t. II, p. 487, fig. 136, anim.

N. vulg. : Castagnolla, Nice; Castagnola, Cette; Blada, AiguesMortes.

Long. : 0,30 à $0, \pi 0$.

Le corps a le profil très arqué ; sa hauteur fail au moins le tiers de la longueur totale. - La tète est courbe, plus haute que longue; sa longueur est comprise quatre fois et demie à cinq fois dans la longueur totale; le museau est très court; les mâchoires sont arquées, elles sont garnies de dents en cardes fines. Le diamètre de l'oeil mesure environ le quart de la longueur de la tête; il est égal, ou peu s'en faut, à l'espace préorbitaire. - Ecail., l. long. 73 à $80 ; 1$. transs. 34 à 36 . Toutes les nageoires sont écailleuses à leur base, les nageoires impaires le sont presque dans leur surface entière ; les rayons de la dorsale et de l'anale se terminent en filaments noirâtres; la caudale est profondément échancrée; les pectorales sont longues, les ventrales très courtes.

Br. Ћ. - D. $3 / 31$ à $33 ;$ A. $2 / 27$ ou $28 ;$ C. 1 i ; P. 19 ou $20 ;$ V. $1 / 5$. 
La teinte générale est d'un blanc argenté teinté de gris; la dorsale et l'anale sont argentées dans leur partie écailleuse, noirâtres à leur bord libre; la caudale est d'un gris noirâtre; les nageoires paires sont d'un gris jaunâtre. - Il y a cinq appendices pyloriques.

Habitat. Méditerranée, rare, Nice, Cette. Océan excessivement rare. Manche, accidentellement, Caen.

\section{Sous-famille des Centrolophiniens, Centrolophini.}

Corps plus ou moins oblong.

Tête de forme variable; màchoire avec une rangée de dents.

Nageoires; dorsale, unique ; caudale échancrée ou fourchue.

Cette sous-famille se compose de trois genres:

a. Ventrales manquant ou fort courtes............. assez grandes................... b.

b. Ventrales insérées en avant des pectorales.......

3. Stronatée.

- $\quad$ - au-dessous des pectorales.....

2. SCHÉDOPHLLE.

1. Centrolophe.

\section{GENRE CENTROLOPIE. - CENTROLOPHUS.}

Corps plus ou moins écailleux; une rangée de dents sur les màchoires; pas de dents sur le vomer, ni les palatins.

Appareil branchial; sept rayons branchiostèges; pseudobranchies.

Nageoires; dorsale longue, écailleuse, à sa base, ainsi que l'anale; caudale plus ou moins échancrée.

Vessie natatoire très petite. - Appendices pyloriques au nombre de cinq à neuf.

Ce genre comprend quatre ou cinq espèces.

$a$. Ventrale a six rayons.................... $b$.

$b$. Longueur totale faisant quatre fois et plus la hauteur du tronc.....................

Longueur totale faisant moins de quatre fois la hauteur du tronc......................

$c$. Dorsale à moins de trente rayons............
à plus de trente rayons.............

d. Pores sur la tête peu visibles...............

très distincts.............

5. LIPARIS.

1. PONPILE. $c$.

2. De Valencienves. l.

3. OVALE.

4. ÉPAIS. 
1. LE CENTROLOPHE POMPILE. - CENTROLOPHUS POMPILUS.

Poiss. France, L. II, p. 492, fig. 137, anim.

N. vulg. : Fanfré d'Amérique, Nice, Riss.

Long. : 0,30 à 0,40 , rarement 0,60 .

La hateur du tronc est contenue quatre fois à quatre fois et un cinquième dans la longueur totale. - La longueur de la tête mesure le cinquième environ de la longueur totale; le museau est gros; les mâchoires portent une rangée de petites dents crochues; l'extrémité postérieure du maxillaire supérieur natteint pas au prolongement du diamètre vertical de l'ail. Le diamètre de l'ceil fait le quart de la longueur de la tète; il est un peu moins grand que l'espace préorbitaire, il est à peu près égal aux trois quarts de l'espace interorbitaire. - La rigne latérale est courbe au-dessus de la pectorale; elle est formée d'écailles saillantes. - La dorsale naît au-dessus ou un peu en arrière de l'insertion de la pectorale, elle est longue et assez basse; l'anale commence généralement sur la seconde moitié de la longueur totale, loin de la fin des pectorales.

$$
\text { Br. 7.-D. } 38 \text { à } 40 ; \text { A. } 23 \text { à } 25 \text {; C. } 17 \text {; P. } 21 \text {; V. 1/5. }
$$

Le dos et les côtés sont tantôt d'un bleu foncé avec des taches jaunâtres ou grisâtres, tantôt d'un bleu très foncé, noirâtre, sans taches; le ventre est bleu cendré. Les ventrales sont bleuâtres; les autres nageoires sont d'un brun plus ou moins foncé. - Le nombre des appendices pyloriques varie de six à neuf.

Habitat. Méditerranée, assez commun, Nice ; rare, Cette. Océan excessivement rare, la Rochelle, Noirmoutiers. Nanche, accidentellement, Fécamp.

\section{Le Centrolophe négre. - Centrolophus niger, Lacép.}

Au mois d'octobre 1890, des pècheurs de Cette ont trouvé dans leurs thonnaires un Poisson de teinte foncée, qui leur était inconnu. - Ce Poisson curieux, dont j’ai reçu l'extrémité antérieure de la 
tète et la caudale. est éridemment un Centrolophe: il doit ètre rapporté au type $C$. niger ou morio. - La muqueuse de la bouche, bien qu'après un long séjour dans l'alcool, est d'une coloration noiratre tres intense. Cette coloration est-elle naturelle. provient-elle d'un mélanisme accidentel ? Je n’en sais rien : en lout cas. elle n’est pas signalée chez les sujets de grande taille, étudiés soit par Savigny $10.6 \%$. soit par Laurillard 0.731 , cités dans C. Y., t. 9. p. 314. La forme du spécimen. pris à Cette, semble plus élancée que celle du C. pompilus; la hauteus est contenue un peu plus de cinq fois dans la longueur totale, ainsi quon peut en juger dapres les proportions qui mont été indiquées: Long. du bout du museau au milieu de la caudale 0,740 ou 0.755 a la pointe de l'un de ses lobes ; haut. à l'aplomb de l'anus 0,140; épais. 0.0s2. - Poids 3,730 gr. - Chair hlanche, molle.

2. LE CENTROLOPHE DE VALENCIExiES. - CENTROLOPHUS TALENCIENVESII. Nob.

Poiss. France, t. II, p. $\{96$, fig. 135, anim.

Long. : 0,13 à 0.30 .

La hauteur du tronc est comprise trois fois et un tiers dans la longueur totale. - La tète est aussi haute que longue. sa longueur est contenue trois fois et trois quarts dans la longueur totale; la fente de la bouche est oblique: les màchoires ont une rangée de dents pointues et crochues: l'extrémité postérieure du maxillaire supérieur dépasse un peu la verticale tangente au bord antérieur de lorbite. Le diamètre de l'øil fait le quart de la longueur de la tête: il est égal à lespace préorbitaire, un peu moins grand que l'espace interorbitaire: la récion postorbitaire est marquée de pores nombreux. - La lig̨ne laterale, courbe en avant. est formée d’écailles un peu plus grandes que les autres, au nombre de is environ. - La dorsale est longue et basse: lanale commence sur la première moitie de la longueur totale: vers la fin des pectorales; la caudale est légèrement échancrée.

D. \& 21:A. 3/16: C. 19; P. 22; V. 1;5.

La teinte est jaunâtre chez le jeune conservé. d'un noir bleuàtre chez ladulte frais. 
Habitat. Méditerranée excessivement rare, Marseille; un second spécimen, mesurant 0.30, a íté signalé a Vice par M. Sarrato, le savant conservateur du musée de cette ville; Y. Notes sur les Poissons de Nice, Sarato, Nice, 30 avril 1888.

3. LE CENTROLOPIE OVALE. - CENTROLOPIILS OYILIS, CUY.

Poiss. France, t. II, p. 498.

Long. : $0,3 \ddot{\text {. }}$

La hauteur du tronc mesure le tiers de la longueur totale; la longueur de lat tète en fiut le quart. Le diamètre de l'œil est contenu quatre fois dans la longueur de la tète. - Ec., l. long. environ 90. - La dorsale et l'anale sont basses: la caudale est un peu échancrée. sa longueur, suivant Cuvier, est du septième de la longueur totale.

$$
\text { D. } 6 / 32 \text { ou } 33 ; \text { A. } 3 / 24 \text {; C. } 17 \text {; P. } 22 ; \text { V. } 1 / 5 \text {. }
$$

La coloration est d'un brun marron sur le dos, d'un gris olivatre sous le ventre. Daprès Cuvier, le nombre des appendices pyloriques est de cinq.

Habitat. Méditerranée, excessivement rare, Nice.

4. LE CENTROLOPHE EP.IS. - CENTROLOPHUS CRASSLS, C. V.

Poiss. Franre, t. II, p. 499.

Long. : 0,30 ì 0,40 .

Lépaisseur du tronc fait la moitié de la hauteur qui est comprise deux fois et trois quarts ou un peu moins de trois fois dans la longueur totale. - La tète, aussi haute ou plus haute que longue, mesure le quart de la longueur totale; elle est criblée de pores; les màchoires portent une rangée de dents excessivement fines; l'extrémité postérieure du maxillaire supérieur n’arrive pas au prolongement du diamètre vertical de l'ceil. Le diamètre de l'wil fait le quart de la longueur de la tête. les trois cinquièmes de l'espace interorbitaire; il est égal à l'espace préorbitaire. - Ec., l. long. 100, environ. - La dorsale commence vers le tiers antérieur de la 
longueur totale, au-dessus de la fente branchiale; la caudale est échancrée à peu près jusqu'au quart de sa longueur, qui mesure le cinquième de la longueur totale; les ventrales sont placées un peu en arrière de la base des pectorales.

Br. 7. - D. 6 ou $7 / 30$ à $32 ;$ A. $3 / 22$; C. $19 ;$ P. 22 ; V. $1 / 5$.

Le dos est ardoisé ou brunâtre, le ventre argenté. Les nageoires sont noirâtres.

Habitat. Méditerranée, excessivement rare, Nice.

כ. LE CENTROLOPHE LIPARIS. - CENTROLOPHUS LIPARIS, Riss.

Poiss. France, t. II, p. 501.

Long. : 0,78 .

Suivant Risso, le corps est d'un beau bleu, terminé par une queue fort épaisse; la tête est oblongue, le museau arrondi; les mâchoires égales, armées de très fines dents; les yeux médiocres; la ligne latérale est droite.

$$
\text { Br. 7.-D. } 38 \text {; A. } 23 \text {; C. } 22 \text {; P. } 14 \text {; V. 7. }
$$

Les nageoires sont demi-transparentes.

9. GENRE SCIÉDOPHILE. - SCHEDOPHILUS; CocCo.

Corps oblong, comprimé, couvert de petites écailles.

Tête haute; màchoires garnies d'une rangée de dents.

Appareil branchial; préopercule à bord dentelé; six on sept rayons branchiostèges; pseudobranchies.

Nageoires; dorsale longue; ventrales avancées.

LE SCHÉDOPHILE MÉDUSOPHAGE. - SCHEDOPHILUS IEDUSOPHAGUS, Cocco.

Poiss. France, t. II, p. 502, fig. 139, anim.

Long. : 0,12 à 0,20 .

La hauteur du tronc mesure le tiers environ de la longueur totale. - La longueur de la tête est contenue trois fois et 
demie à quatre fois dans la longueur totale; les matchoires ont une rangée de dents égales, fines et pointues. Le diamètre de l'œil fail le quart de la longueur de la tête, près du double de l'espace interorbitaire; il est égal à l'espace préorbitaire. Le préopercule a sur le bord postérieur el le bord inférieur des dentelures assez longues. - La dorsale commence au-dessus de l'insertion de la pectorale; ses rayons mous ressemblent à des crins; la caudale est échancrée; les ventrales sont évidemment jugulaires.

D. $3 / 44$ a 48 ; A. $2 / 26$ a 28 ; C. 20 ; P. 18 ou 19 ; V. $1 / 5$.

La teinte est olivâtre, plus sombre vers la région dorsale, avec des taches noirâtres, variées de formes, rangées en séries longitudinales; la tète est d'un jaune verdâtre. La dorsale est noirâtre; l'anale porte à sa base quatre ou cinq taches noirâtres.

Habitat. Méditerranée, excessivement rare, Marseille, Marion, 1877.

\section{GENRE STROMATÉE. - STROMATEUS.}

Corps ovale, comprimé, couvert de petites écailles lisses.

Tête plus haute que longue; museau court; bouche petite; màchoire supérieure un peu moins avancée que la mandibule, ayant l'une et l'autre une rangée de dents fines et courtes; langue et palais lisses.

Appareil branchial; six rayons branchiostèges; pseudohranchies.

Nageoires; dorsale et anale longues, à parlie épineuse peu distincte, à base écailleuse; caudale fourchue; ventrales très petites oul manquant.

Vessie natatoire nulle. - Appendices pyloriques nombreux.

\section{LE STROMATEE FIATOLE. - STROMATEUS FIATOLA.}

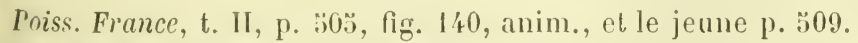

N. vulg. : Lampuge, Nice; Lippa, Celte.

Long. : 0,1 à à 0,30 .

La hauteur du tronc fail le tiers de la longueur totale. - La 
longueur de la tête. qui est d'un quart environ moins grande que la hauteur, est comprise quatre à cinq fois dans la longueur totale; la mâchoire supérieure est un peu moins avancée que la mandibule. Le diamètre de l'œil mesure le cinquième de la longueur de la tête, les deux tiers et plus de l'espace préorbitaire. - La ligne latérale décrit une longue courbure peu prononcée; elle est formée d'écailles plus distinctes que les autres. - La dorsale commence au-dessus du milieu des pectorales: la caudale est très développée, très fourchue, sa longueur est comprise trois fois et demie à quatre fois dans la longueur totale; les ventrales manquent complètement chez les sujets qui ont acquis toute leur croissance, à leur place il n'y a plus qu'un très léger bourrelet, dans lequel, par la dissection, on peut distinguer des restiges de rayons.

Br. 6. - D. $5 / 40$ à 43 ; A. $3 / 32$ à 34 ; C. 17 ; P. 23 à $25 ;$ V. 0.

La coloration est bleuâtre sur le dos, d'un blanc argenté sous le ventre, la gorge et sur les joues; des taches dorées. ovales, se montrent sur tout le corps. Au-dessus de la ligne latérale, il y a sourent trois ou quatre bandes longitudinales d'un brun légèrement doré.

Jeune. - Le Stromatée seserin ou microchire. - Stromateus microchirus.

Long. : 0,06 à 0,10 .

Chez le jeune Stromatée fiatole ou seserin, les ventrales sont très visibles, composées d'une épine et de cinq rayons mous. La teinte est jaunàtre chez les très jeunes animaux; elle est jaunàtre avec des bandes verticales noiràtres chez les sujets de moyenne taille.

Habitat. Méditerranée, rare, Nice, Marseille, les Martigues, Cette.

\section{Sous-famille des Louvariniens, Luvarini.}

Syn. : Proctostegini, Nardo; Luvarini, Trois.

Corps oblong; une carène latérale sur le tronçon de la queue; peau garnie de petits boucliers juxtaposés; anus avancé recouvert par une espèce d'opercule ou plutôt d'obturateur.

Tête haute, comprimée; museau court; bouche petite, terminale, à muqueuse rougeàtre; roile palatin excessivement développé, 
échancré sur son milieu, comme bilobé; màchoires non dentées chez les alultes; dents très fines, chez les jeunes, sur les màchoires, les palatins et la langue.

Narines à deux orifices très rapprochés.

Appareil branchial; cinq rayons branchiostèges; pseudobranchies.

Nageoires: dorsale et anale de longueur variable, finissant près de la caudale; caudale échancrée; ventrale plus ou moins longue, à cinq rayons ou réduite à un seul rayon épineux large, dentelé sur le bord exteme, formant avec celui du còté opposé l'appareil obturateur de l'anus.

Cette sous-famille est réduile à un seul genre.

GENRE LOUVAREOU. - LUVARUS, Rafin.

Caractères de la sous-famille.

Une ou deux espèces.

Dorsale commençant loin de la tête.............. 1. IMPériat.

-.. $\quad$ - $\quad$ sur la tête .................. 2. Astroder.ie.

1. LE LOUVAREOU IMPERIAL. - LUVARUS IMPERIALIS, Rafin.

Poiss. France, t. II, p. :311.

N. vulg. : Thon blanc, Cette; Pei barbaresch, Nice, Riss.

Long. : 0,60 à 1,00 et mème 1,73 .

Le corps est ovale, fusiforme; sa hauteur est comprise trois fois et un tiers à trois fois et trois quarts dans la longueur totale, et la longueur de la tête quatre fois et demie à cinq fois; les màchoires et le romer ne portent pas de dents, il en reste parfois sur les palatins. Le diamètre de l'œil fait le sixième environ de la longueur de la tête. - La dorsale est reculée, occupant une grande partie de la moitié postérieure du corps; l'anale est opposée et semblable à la dorsale; les ventrales, parfois réduites à deux épines, recouvrent l'anus.

$$
\text { Br. } 5 .- \text { D. } 13 \text {; A. } 14 \text {; C. } 16 \text {; P. } 18 \text {; V. } 1 \text { ou } 1 / 4 \text {. }
$$

Le dos est doré; les côtés sont d'un blanc teinté de bleu; le ventre est blanc argenté. La caudile est dorée; la ventrale est grisàtre; les autres nageoires sont rougeâtres. 
Habitat. Méditerranée, excessivement rare, Nice, Cette. - Un spécimen pèché à Cette, en aoùt 18\%̈, mesurait 1,7\%; un autre, capturé, en juin 1889, avait 0,72 de longueur.

\section{LE LOUVAREOU ASTRODERME. - LUVARUS ASTRODERMUS.}

Poiss. France, t. II, p. 514.

N. vulg. : Pei d'America, Nice, Riss.

Long. : 0,20 a 0,42 .

La tête, à crête tranchante, a sa longueur comprise trois fois et trois quarts ì quatre fois et demie dans la longueur totale; les màchoires portent une rangée de dents fines, caduques; les palatins, la langue sont généralement dentés. Le diamètre de l'ceil fait le sixième ou le septième de la longueur de la tête. - La dorsale, excessivement longue, commence au-dessus du bord postérieur du préopercule, et l'anale sous le tiers antérieur des pectorales; les ventrales sont parfois insérées un peu en avant des pectorales; ventrale avec une épine développée el quatre rayons mous de longueur variable.

D. 22 ou $23 ;$ A. 17 on $18 ;$ C. $17 ;$ P. $18 ;$ V. $1 / 4$.

La teinte est rose jaunâtre sur le dos et les côtés, avec des taches noirâtres circulaires; blanchâtre sous le ventre: chez les très jeunes, la teinte générale est d'un brun bleuâtre ou violacé, ou d'un blanc argenté.

Habitat. Méditerranée, excessivement rare, Nice, Cette.

Plusieurs naturalistes pensent que l'Astrodermus elegans est le jeune du Luvarus imperialis. - Daus un excellent travail (Ricerche zootom. istolog. Luvarus imperialis, Venezia, 1877), Trois a très justement attiré l'attention sur la similitude anatomique de certains organes chez le Luvarus et l'Astrodermus; le canal intestinal présente lesmèmes dispositions dans sa longueur qui est extraordinaire, dans le développement des papilles coniques garnissant la muqueuse de l'œsophage et celle de la région cardiaque, la forme de l'estomac, le nombre de ses appendices pyloriques; on pourrait en quelque sorte suivre la description, faite par Cuvier et Valenciennes, du tube digestif de l'Astrodermus, sur les figures de l'intestin du Luvarus dessinées par Trois. - Les scutelles ou les boucliers, qui recouvrent la 
peau de ces animaux, sont à peu près semblables chez l'un et chez l'autre, mais ils n'ont pas tout a fait la configuration indiquée par les auteurs; ce ne sont pas précisément des disques pédonculés; chacun de ces boucliers, espèce de bouton double, est constitué par deux disques superposés unis par un pédoncule grèle, cylindrique, relativement allongé; le disque externe est plus large que l'interne; il semble plus développé et plus découpé chez l'Astrodermus que chez le Luvarus; il est plus ou moins circulaire; le disque interne, plus étroit que l'autre, représente me sorte de plateau sur lequel s'appuie la tige centrale; je ne puis évidemment donner une description complète de ce dermosquelette. - Maintenant l'A strodermus est-il réellement le jeune du Luvurus? C'est possible; mais il serait imprudent de l'affirmer arant de connaitre les phases du développement cliez cet animal. Au lieu d'entamer une discussion, je me horne à rappeler les observations de Risso; Diana semilunata (Astro(lermus), long. 0,420, la femelle est pleine d'wufs en été (Riss., Hist. nat., p. 268, fig. 1't) ; Ausonia Cuvieri (Luvarus), long. 0,360 (Riss., l. c., p. 3\%2, fig. 28); les faits cités par Risso ne permettent gruère de conclure a l’identité spécifique de ces animaux, à moins d'en suspecter l'exactitude.

\section{Sous-famille des Coryphéniniens, Coryphxnini.}

Corps allongé, comprimé, couvert de petites écailles lisses.

Tête à profil supérieur plus ou moins arqué: museau court: màchoires, vomer, palatins et langue dentés.

Appareil branchial; sept rayons branchiostèges.

Nageoires; dorsale très longue, commençant sur la tète et finissant près de la caudale, à rayons simples flexibles; caudale fourchue; ventrale ayant $1 / \%$.

\section{GLNRE CORYPIENE. - CORYPIIENA.}

Caractères de la famille.

Ce genre se compose de deux espèces.

Hauteur du trone comprise plus de cinq fois et demie dans

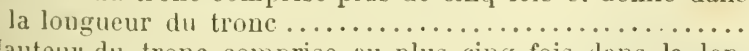
Hauteur du trone comprise au plus cinq fois dans la lon-

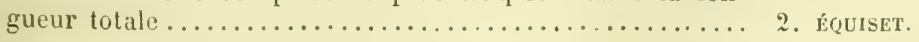




\section{LA CORYPHÈNE HIPPURUS. - CORYPHENA HIPPURUS.}

Poiss. France, t. II, p. 519, fig. 141 anim.

N. vulg. : Fera, Peï fouran, Nice.

Long. : 0,30 à 0,30 et mème 1,00 .

La hauteur du tronc est comprise cinq fois et troisquarts à six fois et deux tiers dans la longueur totale. etla longueur de la tête cinq fois et un tiers à six fois; la màchoire supérieure est plus courte que la mandibule, elles ont, l'une et l'autre, une bande de dents en cardes, celles de la rangée externe plus fortes que les autres, crochues, à pointe tournée en arrière; l'extrémité postérieure du maxillaire supérieur arrive à peu près sous le milieu de l'orbite. Suivant le déreloppement des sujets, le diamètre de l'œil est contenu trois fois et demie à cinq fois dans la longueur de la tête, il est aussi grand ou d'un tiers moins grand que l'espace préorbitaire. - La ligne latérale figure, au-dessus de la pectorale, une espèce de $\mathrm{V}$ renversé. La dorsale commence dans lintervalle de l'orbite au bord postérieur du préopercule; générâlement l'anale prend nais-sance sous le trente-sixième ou le trente-septième rayon de la dorsale, le premier rayon est une épine excessivement courte; la longueur de la caudale est comprise quatre fois et demie à quatre fois et trois quarts dans la longueur totale.

$$
\text { D. } 54 \text { à } 60 \text {; A. } 1 / 24 \text { à } 28 \text {; C. } 21 \text {; P. } 20 \text { ou } 21 \text {; V. } 1 / 5 \text {. }
$$

La région supérieure du corps est d’un gris argenté ou bleuâtre, arec une douzaine de grandes taches ovales, noiràtres, rangées en série; les côtés et le ventre sont d’un gris jaunâtre. Les nageoires impaires sont grisâtres; les ventrales sont jaunàtres à leur face externe, d un noir bleuâtre à leur face interne; les pectorales sont d'un jaune brunâtre.

Habitat. Méditerranée, très rare, Nice, Port-Vendres.

\section{LA CORYPHÈNE EQUISET. - CORYPHOENA EQUISETIS.}

Poiss. France, t. III, p. 6əコั.

Long. : $0,0 ̋ 0$ à 1,00 et plus. 
La hauteur du trone est contenue quatre fois et demie à cinq fois dans la longueur totale. - En général, la tête est plus haute que longue, sa longueur mesure le sixième environ de la longueur totale; la bouche est oblique; la màchoire supérieure est à peu près aussi avancée que la mandibule, elles sont munies de dents en cardes fines, plus grandes, plus fortes sur la rangée externe; l'extrémité postérieure du maxillaire supérieur dépasse le prolongement du diamètre vertical de l'oil. - Le diamètre de l'œil fait environ le sixième de la longueur de la tète, et la moitié de l'espace préorbitaire. - La dorsale est haute en avant, et va s'abaissant d'une façon régulière jusque près de la racine de la caudale; la longueur de la caudale mesure, ou peu s'en faut, le quart de la longueur totale.

$$
\text { Br. 7. - D. } 51 \text { à } 57 \text {; A. } 24 \text { à } 27 \text {; P. } 19 \text { à } 21 ; \text { V. 1/5. }
$$

Le dos est verdàtre à reflets dorés ou argentés; les côtés et le rentre sont arg’entés.

Habitat. Méditerranée, accidentellement, Cette.

13. Sous-famille des Xiphéiniens, Xipheini.

Corps allongé, fusiforme; peau nue ou couverte d'écailles, de tubercules peu développés; tronçon de la queue ayant de chaque còté une carène ou deux crètes superposées.

Tête fort longue; museau s'avançant en bec pointu, formé par l'allongement de la màchoire supérieure, ou plutòt par le vomer et les intermaxillaires; dents petites ou manquant.

Appareil branchial; sept rayous branchiostèges; pseudobranchies.

Nageoires; une ou deux dorsales; caudale en croissant; rentrale nulle, ou a rayons peu nombreux.

Vessie natatoire, plus ou moins déreloppée. - Appendices pyloriques très nombreux.

Cette sous-famille se compose de trois genres:

a. Ventrales manquant......................

ayant 11 ou plusieurs rayons...........

b. Carène latérale du troncon de la queuc double... unique....
3. Tétraptune.

2. MaKaIRA.

1. Espadon.

Moreav. - Ichthyologie. 


\section{GENRE ESPADON. - IIPHIAS.}

Gorps; tronçon de la queue ayant de chaque còté une seule carène. Nageoires; dorsale unique de forme variable; pas de ventrales.

\section{L'ESPADON EPEE. - XIPHIAS GLADIUS.}

Poiss. France, t. II, p. : 206 .

N. vulg. : Épée, Dard, Empereur; Peiz espasa, Pyrénées-Orientales; Peï emperur, Empedur, Cette; Emperatour, Nice.

Long. : 1,50 à 4,00 et plus.

Le corps est fusiforme, de proportions rariables suivant le développement des sujets; peau lisse chez les adultes, couverte, chez les jeunes, de scabrosités, de petits tubercules. - En dessus la tête est aplatie ou très légèrement bombée, sa longueur fait le tiers, et plus, de la longueur totale; les mâchoires et le vomer sont garnis de fort petites dents, peu distinctes à l'œil nu; la mandibule se termine en pointe aiguë; le museau ou plutôt le bec est épais à sa base qui est constituée par les frontaux, l'ethmoïde, les maxillaires supérieurs, le vomer et les intermaxillaires; ces dernières pièces forment la pointe du bec dont les bords sont minces et tranchants. L'oil est grand. Les lamelles respiratoires sont disposées en deux séries sur chaque arc branchial. - La dorsale est très longue: elle est entière chez les jeunes, plus ou moins usée dans son milieu, chez les vieux individus, simulant parfois deux nageoires distinctes; la carène du tronçon de la queue est fort saillante; les pectorales sont placées très bas.

$$
\text { Br. ๆ.-D. } 3 / 40 \text {; A. } 2 / 15 \text {; C. } 17 \text {; P. } 16 \text {. }
$$

La coloration est d'un bleu foncé sur le dos, d'un argenté brillant sur les côtés et le ventre.

Habitat. Toutes nos còtes; Méditerranée, assez commun, Nice, Cette. Océan, assez rare, Bayonne, Arcachon; rare entre la Gironde et la Loire, la Rochelle; très rare au nord de la Loire, Concarneau, 1888. Manche, excessivement rare, le Havre, Boulogne. 
2. GENRE MALAIRA. - MAKIIRA, Lacép.

Corps; troncon de la queue ayant de chaque coté une double carène ou une double crète.

Nageoires; deux dorsales; pas de ventrales.

Deux espèces.

Dorsale plus basse que le trone.................. 1. nomatre

haute que le tronc.................. 2. vomier.

1. LE MAKAIRA NOIRATRE. - MAKAIRA NIGRICA NS, Lacép.

Poiss. France, t. II, p. $\$ 30$.

Long. : 3,30 .

La hanteur du tronc est comprise trois fois et un tiers dans la longueur totale. - La mâchoire inférieure n'atteignait, suivant de Lacépède, qu'au milieu de la mâchoire supérieure qui faisait à peu près le cinquième de la longueur totale. - La première dorsale avait une hanteur moindre que celle du tronc; seconde dorsale égale à l'anale; pectorale étroite. Les deux boucliers (ou crêtes) qui se trouvaient de chaque côté, sur le troncon de la queue, étaient placés l'un au-dessus de l'autre.

Habitat. Océan, accidentellement, Charente-Inférieure.

\section{I.E MAKAIRA VOILIER, - MAKAIRA VELIFERA.}

Poiss. France, t. Il, p. 531.

Long. : 2,30 à 2,60 .

La hauteur du corps ne fait que le douzième de la longueur totale. - La longueur de la tête est trois fois et un tiers dans la longueur totale; l'épée est un peu déprimée, la partie qui est au-dessus de la màchoire inféricure a la forme d'un demicòne. - La première dorsale est, dans sa région la plus élevée, plus haute que le tronc; la seconde dorsale est séparée de la première par un intervalle nu; il y a deux anales; de chaque côté de la queue sont deux crêtes horizontales.

$$
\text { D. } 42 \text { à } 45-1 / 7 ; \text { A. } 3 / 9-7 \text {. }
$$


Habitat. Océan, accidentellement, île de Ré.

Suivant Lütken, le Makaira C. V. est, sous tous les rapports, un véritable Histiophore sans nageoires ventrales, et on ne peut s'empècher de soupconner que l'absence de ces dernières repose sur une erreur ou est due au préparateur (Spol. Atlant., p. 592-184).

\section{GENRE TÉTRAPTURE. - TETRAPTURUS, Rafin.}

Corps; deux crètes, de chaque còté, sur le troncon de la queue. Tête longue; bec effilé; màchoires dentées.

Nageoires; deux dorsales, la première beaucoup plus longue que l'autre; anale double; ventrale réduite à un seul rayon.

\section{LE TÉTRAPTUPE AIGUILLE OU ORPHIE. - TETRAPTURUS BELONE.}

Poiss. France, t. II, p. ว32.

Long. : 1,300 à 2,40 .

La hauteur du tronc est comprise huit à neuf fois dans la longueur totale; le tronçon de la queue porte de chaque côté deux petites crêtes superposées. - La longueur de la tête fait environ le quart de la longueur totale; le bec est plus ou moins effilé, il est arrondi en dessus; sa longueur est contenue cinq fois et demie à sept fois dans la longueur totale; les mâchoires et les palatins sont munis de dents en velours. La ligne latérale est sinueuse en avant. - La première dorsale commence au-dessus de l'opercule; elle est fort longue et généralement moins haute que le corps; la seconde dorsale est courte; la première anale est placée sous le tiers postérieur de la première dorsale; la seconde anale est opposée à la seconde dorsale; la caudale est en croissant, elle est bien développée; les ventrales ont un grand rayon.

$$
\text { Br. 7. -D. } 43-6 \text {; A. } 2 / 13-\text { ₹; C. } 17 \text {; P. } 18 \text {; V. } 1 .
$$

La coloration est brun bleuâtre sur le dos, blanchâtre sous le ventre.

Habitat. Excessivement rare; Méditerranée, Nice. Océan, la Rochelle. 


\section{Sous-famille des Échénéiniens, Echeneini.}

Corps allongé, en forme de fuseau ou plutòt de coin à angles arrondis, couvert de petites écailles lisses.

Tête large, aplatie, portant un disque ovale, composé d'un nombre variable de lamelles transversales, paires, épineuse ; museau assez allongé; bouche terminale, peu fendue; mandibule avancée; dents en velours sur les màchoires, le vomer, les palatins.

Appareil branchial; sept à neuf rayons branchiostèges.

Nageoires; première dorsale transformée en disque dorsocéphalique; seconde dorsale reculée, opposée à l'anale.

Vessie natatoire nulle. - Appendices pyloriques au nombre de six à huit.

\section{GeNRe ÉCHénéis. - ECHENEIS, Arted.}

Caractères de la sous-famille.

Anale ayant moins de 30 rayons.................. 1. RÉMOra.

plus de 30 rayons................... 2. vaucrate.

\section{L'ÉCHÉNÉIS RÉHORA. - ECHENEIS REMORA.}

Poiss. France, t. II, p. ร33̈, fig. 14?, anim.

N. vulg. : Sussapasa, Nice.

Long. : 0,20 à 0,3 ว̆.

La hauteur du tronc est comprise de sept à neuf fois dans la longueur totale et la longueur de la tête quatre fois et quart à cinq fois; la lèvre supérieure est bordée d'un grand nombre de denticules fort ténus. L'œil est placé au-dessous de l’intervalle qui s'étend de la cinquième à la huitième lamelle du disque, parfois un peu plus en arrière; son diamètre fait environ le cinquième de la longueur de la tête, la moitié de l'espace préorbitaire, le tier's de l'espace interorbitaire. - Le disque céphalique est la première dorsale modifiée; il est très développé, ovale; sa longueur, qui est le double de sa largeur, mesure, chez les jeunes, le tiers de la longueur totale, un peu moins chez les grands; la caudale est légèrement échancrée; la 
pectorale commence sous la treizième lamelle du disque chez les jeunes, un peu plus en arrière chez les adultes.

Br. 7. -D. 16 à $19-18$ à $22 ;$ A. 20 à 22 ; C. 16 ; P. 23 a $25 ;$ V. $1 / 5$.

La coloration est d'un brun ardoisé, teinté de violet.

Habitat. Méditerranée, rare, Nice, Cette, 1882. Océan, excessivement rare, la Rochelle.

\section{L'ÉCHÉNÉIS NAUCRATE. - ECHENEIS NAUCRATES.}

Poiss. France, t. II, p. 339.

Long. : 0,30 à 0,70 .

La hauteur du tronc est comprise huit à treize fois dans la longueur totale et la longueur de la tête six fois à six fois et demie. L'wil est sous l'espace compris entre la sixième et la neuvième lamelle du disque; son diamètre fait le tiers de l'espace préorbitaire, il est contenu environ six fois et demie dans la longueur de la tète et trois fois et demie dans la longueur de l'espace interorbitaire. - La longueur du disque, qui fait le triple de sa largeur moyenne, est comprise quatre fois et demie à cinq fois dans la longueur totale; il y a vingt ou plutôt vingt et une à vingt-quatre paires de lamelles; la caudale est légèrement échancrée chez les sujets de grande taille, sinueuse ou faiblement convexe chez les jeunes.

Br. 9. -D. 20 à $24-35$ à 40 ; A. 34 ả 39 ; C. 14 ; P. 18 à 21 ; V. $1 / 5$.

La teinte est d'un bleuâtre très foncé, qui passe au noirâtre sur le dos; une bande étroite, blanchàtre ou jaunâtre, s'étend le long de la région abdominale. Les nageoires impaires sont brunes, bordées de jaune.

Habitat. Méditerranée, excessivement rare, Nice.

\section{Famille des Trichiuridés, Trichiuridx.}

Corps très comprimé; peau sans écailles.

Tête longue, pointue; màchoire supérieure plus courte que la mandibule, garnies l'une et l'autre de dents plus ou moins fortes, 
armées sur le devant de quelques dents crochues fort développées; palatins dentés.

Appareil branchial; ouies largement ouvertes; sept ou huit rayons branchiostègres; pseudobranchies.

Nageoires; dorsale unique très longue; anale de longueur variable; ventrale nulle ou réduite à un fort petit rayon écailleux.

Cette famille comprend deux genres:

Caudale échancrée ou fourchue................ 1. LÉpIdope.

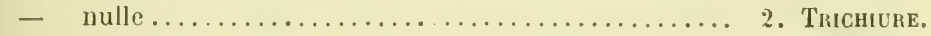

1. GENRE LÉPIDOPE. -- LEPIDOPUS, Goüan.

Nageoires; dorsale commençant sur la nuque et finissant près de la caudale à rayons tous épineux; anale courte; caudale fourchue; ventrale réduite à une écaille.

\section{LE LEPIDOPE ARGENTE. - LEPIDOPUS ARGENTEUS.}

Poiss. France, t. II, p. 544, fig. 143, anim.

N. vulg. : Arggentin, Nice; Peij d'archén, Cette.

Long. : 0,40 à 1,50 et mème 2,00 .

La hauteur du tronc est comprise quinze à vingt fois dans la longueur totale, et la longueur de la tête sept fois environ. La màchoire supérieure est beaucoup plus courte que la mandibule, elles sont armées l'une et l'autre de dents tranchantes, pointues; en avant se montrent des dents beaucoup plus développées que les autres, il y en a, sauf accident, de quatre à six en haut, deux à la mandibule. Le diamètre de l'œil mesure le cinquième à peu près de la longueur de la tête, la moitié de l'espace interorbitaire. - La dorsale est basse, excessivement longue; après l'anus est une écaille ou plutòt une espèce d'épine crochue, à la suite de laquelle s'en trouve une série de fort petites, l'anale à rayons unis est reportée fort en arrière, elle est très basse; la caudale est fourchue; la ventrale est représentée par une écaille mobile.

Br. 8. - D. 100 à $105 ;$ A... + 18 à 25 ; C. 17 ou 18 ; P. 12 ; V. 1.

Le corps est couvert d'une espèce de pigment poisseux blanc 
argenté; les joues et le dessus de la tête sont d'un blanc clair. - Le péritoine est noiràtre; la ressie natatoire est fusiforme, très longue; les appendices pyloriques sont nombreux.

Habitat. Méditerranée, commun à Nice; assez rare à Cette. Océan, très rare, la Rochelle, Ouessant.

\section{GENRE TRICHIURE. - TRICHIURUS.}

Gorps très allongé; queue longue, mince, sétiforme.

Nageoires; dorsale très longue; anale constituée par des épines courtes et libres; pas de caudale ni de ventrales.

\section{LE TRICHIUE LEPTURE. - TRICHIURUS LEPTURUS.}

Poiss. France, t. II, p. 347 .

Long. : $0, \ddot{3} 0$ à 1,00 .

La hauteur du tronc est comprise seize à dix-sept fois dans la longueur totale; le dos et le ventre ont le bord fort mince; la queue est longue, très grêle, terminée en cheveu. - La longueur de la tête fait environ le huitième de la longueur totale; la mâchoire supérieure est plus courte que la mandibule; elles sont l'une et l'autre armées de dents aiguës, tranchantes; en avant il y a quatre longues dents crochues à la màchoire supérieure et deux à la mandibule; ces longues dents sont souvent moins nombreuses, peurent même manquer, surtout à la mandibule. Le diamètre de l'œil mesure en moyenne le sixième de la longueur de la tête, un peu moins de la moitié de l'espace préorbitaire. - En avant la ligne latérale est courbe. - La dorsale commence en avant de l'angle de la fente branchiale, elle finit à une certaine distance de la pointe de la queue; l'anale a ses épines, excepté la première, excessivement petites; les pectorales sont relevées, courtes mais assez larges.

$$
\text { Br. 7.-D. } 130 \text { à } 136 \text {; A. } 115 \text { à } 118 \text {; P. } 11 .
$$

Le corps est d'un blane argenté; la dorsale est d'un gris assez foncé.

Habitat. Océan, excessivement rare. 
9. Famille des Trenioïdés, Tienioidx.

Corps allongé, très comprimé, plus ou moins ensiforme.

Tête de forme variable: màchoires dentées.

Appareil branchial; ouïes largement fendues; six ou sept rayons branchiostèges; pseudobranchies.

Nageoires; dorsale très étendue, régnant parfois sur toute la longueur du corps; anale manquant parfois; ventrales présentes.

Cette famille se compose de trois sous-familles.

a. Anale nulle $\ldots \ldots \ldots \ldots \ldots \ldots \ldots \ldots \ldots \ldots \ldots \ldots \ldots \ldots$ 3. Trachiptériniens.

- existante...................... $b$.

$b$. Anale très longue..................... 2. Cépolixiens.

- très courte.................... 1. Lophotiniens.

1. Sous-famille des Lophotiniens, Lophotini.

Corps allongé, comprimé; peau nue; anus très reculé.

Tête surmontée d'une crète triangulaire très haute, sur laquelle s'arlicule une longue épine; museau court; màchoires, vomer et palatins dentés.

Nageoires; dorsale allant du sommet de la crète de la tète jusque près de la caudale; anale très reculée; caudale peu déreloppée.

GEYRE LOPHOTE. - LOPHOTES, Giorna.

Caraclères de la sous-fitmille.

LE LOPHOTE DE IACEPEDE. - LOPHOTES CEPEDIANUS.

Poiss. France, t. II, p. כ̈亡 9.

N. vulg. : Argentin, Nice, Riss.

Long. : 1,00 à 1,40 .

La hauteur du tronc fait environ le septième de la longueur totale. - La tète est relevée en avant par une crête triangulaire fort saillante, armée d une épine longue et comprimée qui est le premier rayon de la dorsale; les mâchoires sont garnies de dents en cardes. Le diamètre de l'œil semble mesurer le tiers environ de la longueur de la tète. - La dorsale va de la tète 
à la caudale; l'anale est courte, très reculée; les pectorales sont relevées; les rentrales sont très petites.

$$
\text { Br. 6. -D. } 230 ; \text { A. } 17 \text {; C. } 17 \text {; P. } 15 ; \text { V. } 1 / 5 \text {. }
$$

Le corps est d'un gris argenté, avec des taches arrondies d'une teinte argentée plus brillante. Les nageoires sont d'un rose assez foncé.

Habitat. Méditerranée, excessivement rare, Nice.

\section{Sous-famille des C'époliniens, Cepolini.}

Corps allongé couvert de fort petites écailles cycloïdes.

Tète assez courte, obtuse; bouche fendue obliquement, assez protractile; màchoires munies de dents; vomer et palatins non dentés.

Nageoires; dorsale allant de la nuque à la caudale; anale très longue; ventrale ayant une épine et cinq rayons mous.

\section{GENRE CÉPOLE. - CEPOLA, Linn.}

Caractères de la sous-famille.

\section{LA GÉPOLE ROUGEATRE. - CEPOLA RUBESCENS.}

Poiss. France, t. II, p. 5̋̈2, fig. 14千, anim.

N. vulg. : Calegnairis, Nice; Roudgeole, Marseille; Doumaïzella, Cette; Foutet, Port-Vendres.

Long. : 0,30 à 0,40 et mème 0,300 .

La hauteur du corps est contenue quinze à dix-huit fois dans la longueur totale; la peau est couverte de très petites écailles lisses, non imbriquées. - La longueur de la tête est comprise onze à treize fois dans la longueur totale; le museau est tronqué; la mandibule se relève au-devant de la mâchoire supérieure, elles portent l'une et l'autre une rangée de dents assez longues, aiguës, légèrement crochues. Le diamètre de l'ceil mesure à peu près le tiers de la longueur de la tête; il est d'un tiers au moins plus grand que l'espace préorbitaire, qui est égal à l'espace interorbitaire. Les pièces operculaires sont nues. - La dorsale commence sur la nuque et se termine 
en arrière par une inembrane qui s'attache à la base de la caudale; l'anale commence sous le neuvième rayon de la dorsale et finit comme cette nageoire; la caudale est pointue, elle fait le septième ou le huitième de la longueur totale.

$$
\text { Br. } 6 .- \text { D. } 67 \text { à } 69 ; \text { A. } 60 \text {; C. } 10 \text { ou } 11 ; \text { P. } 18 \text {; V. } 1 / 5 .
$$

Le dos et les côtés sont rouges; la région inférieure est d'un rouge jaunâtre. Les nageoires sont d'un rouge jaunàtre assez clair. La membrane qui unit l'intermaxillaire au maxillaire supérieur est marquée d'une tache noire assez grande. -La vessie natatoire est fort grande, pointue en avant, large en arrière. - Il y a une huitaine d'appendices pyloriques.

Habitat. Méditerranée, assez commun. Océan, très rare, Biarritz, Arcachon, la Rochelle. Manche, accidentellement, Roscoff.

\section{Sous-famille des Trachypteriniens, Trachypterini.}

Corps allongé, comprimé; vertèbres nombreuses.

Tête; bouche médiocre, protractile; màchoires à dents aiguës, généralement peu développées; maxillaire supérieur large.

Nageoires; dorsale commençant sur la tête et finissant à ou vers la caudale, a premiers rayons formant panache; anale nulle; caudale de forme variable.

Cette sous-famille comprend deux genres.

Ventrale à un seul rayon..................... 1. RÉGalec.

- plusieurs rayons.................... 2. Trachyptére.

1. GEYRE RÉGALEC. - REGALECUS, Brünn.

Corps très allongé, en forme de ruban, garni de petits tubercules écailleux.

Tète á profil oblique en arant; museau court; bouche presque verticale; màchoires à dents excessivement fines.

Nageoires ; pas d'anale; caudale peu développée ou nulle; ventrale réduite à un seul rayon fort allongé.

Ce genre se compose de deux espèces.

Inus ouvert après le quart antérieur du corps............ 1. ÉPÉE.

- sous le quart antérieur du corps............. 2. IRis. 
1. LE RÉGALEG EPEE. - REGALECUS GLADIUS, Walb.

Poiss. France, t. II, p. כ̋วّ.

N. vulg. : Argentin, Nice, Riss.

Long. : 2,00 à 2,75 et même 3,40 .

La hateur du trone est contenue environ dix-neuf fois dans la longueur totale, caudale non comprise. - La longueur de la tête est sensiblement égale à la hauteur du tronc; la mandibule est relevée en avant de la mâchoire supérieure; elles ont l'une et l'autre une rangée de dents excessivement fines; la joue est garnie de pièces écailleuses semblables à celles du corps. Le diamètre de l'œil mesure un peu moins du quart de la longueur de la tête; l'œil est séparé du profil supérieur par un espace plus grand que son diamètre. - La dorsale commence au-dessus du bord antérieur de l'orbite; les premiers rayons forment, sur la tête, un panache très élevé, les derniers rayons sont très près de la caudale; généralement la caudale est plus ou moins brisée; les pectorales sont courtes; les ventrales ont un rayon unique, terminé par une petite expansion cutanée.

$$
\text { Br. 6. -D. } 340 ; \text { A. } 0 \text {; C... ; P. } 14 \text {; V. } 1 \text { (C. V.). }
$$

Le corps est argenté avec des taches grisâtres.

Habitat. Méditerranée, excessivement rare, Nice; un sujet mesurant 3,40 a été trouvé à Palavas en 1872, S. Jourdain.

2. LE REGALEG TRAIT. - REGALECUS TELUM, C. V.

Poiss. France, t. II, p. $\$ 37 \%$

Long. 2,00.

La hauteur du trone est contenue environ vingt-quatre fois dans la longueur totale, caudale non comprise. Lanus, comme le fait remarquer Valenciennes, eșt sous le quart antérieur de la longueur du corps chez le Régalec trait, plus en arrière chez le Régalec épée; la longueur de l'œsophage et de l'estomac n’égale pas la moitié de la longueur du corps chez le Régalec 
trait, elle en mesure plus de la moitié chez le Régalec épée. - L'oil est plus petit et plus haut placé que chez le kégaleo épée; il est séparé du profil supéricur par un espace égal à son diamètre.

$$
\text { D. 398. (C.V.). }
$$

Habitat. Méditerranée, excessivement rare, Nice.

\section{GENRE TRACHYP'LEE. - TRACHYPTERUS, Goüan.}

Corps allongé, très comprimé ; peau ordinairement nue.

Tète à crète tranchante; museau court, tronqué; bouche à fente oblique; maichoires munies de petites dents aiguës.

Ligne latérale presque droite, àpre, formée, en arrière surtout, par des espèces d'écussons armés d'une épine plus ou moins développée.

Nageoires; anale nulle; caudale fragile, rarement entière; pectorale peu développée; rentrale à plusieurs rayons.

Ce genre comprend quatre ou cinq espèces.

a. Profil inférieur du corps régulier.......... b

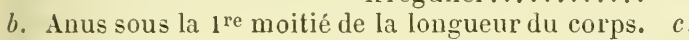
- $\quad 2^{\mathrm{e}}$ moitié de la longueur du corps.
4. De Spinola.

c. Dorsale à rayons rudes.

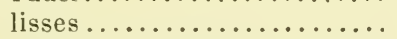

d. Longueur, sans la caudale 9 faisant plus de sept fois la hauteur........................

Longueur, sans Ia caudale, faisant moins de sept fois la hauteur...................

5. A CRÈTE.

d.

3. A RAYONS LISSES.

2. IRIS.

1. FAUX.

\section{LE TRACHYPTERE FAUX. - TRACHYPTERUS FALX.}

Poiss. France, t. II, p. 538.

N. vulg. : Gros-Argentin, Nice, Riss.; Peï d'Artjen, Flamba, Cette.

Long. : 0,30 à 1,00 et mème 1,50 .

Le corps présente la furme d'une lame qui, d'avant en arrière, diminue d'une façon régulière; sa hauteur est contenue cinq fois et demie à six fois et quart dans la longueur totale, caudale non comprise; la longueur de la tête fait environ le huitième de cette longueur. L'anus est placé sous la première moitié de la longueur du corps. La mâchoire supérieure est 
fort protractile; elle est armée, ainsi que la mandibule, de six à huit dents, courtes et pointues; il y a sur le vomer trois ou quatre dents semblables. Le diamètre de l'œil mesure à peu près le tiers de la longueur de la tête ; il est un peu plus grand que l'espace préorbitaire. - La ligne latérale est à peu près droite. - Sur la tète, les huit premiers rayons de la dorsale forment un panache, plus ou moins développé; la caudale est généralement plus ou moins mutilée; la ventrale est plus ou moins longue; elle est très fragile.

Br. 6 -D. $8+160$ à 172 ; C. 6 à $8+5$ ou 6 ; P. 11 ; V. $1 / 7$.

Le corps brille d'un éclat argenté très vif; il est marqué. au-dessus de la ligne latérale, de trois taches noirâtres, assez régulièrement espacées les unes des autres. Les nageoires sont roses.

Habitat. Méditerranée, très rare, Nice, Cette, Port-Vendres.

\section{LE TRACHYPTÈRE IRIS. - TRACHYPTERUS IRIS.}

Poiss. France, t. II, p. 561.

Long. : 0,70 à 1,40 .

La hauteur du corps est contenue huit fois et demie à neuf fois dans la longueur totale, caudale non comprise; dans son tiers postérieur, la queue est armée d'une douzaine de fortes épines crochues. - La longueur de la tête est comprise environ dix fois et demie dans la longueur totale, sans la caudale; en général, les màchoires ont chacune six à huit dents courtes et pointues; le nombre des dents paraît diminuer chez les sujets de grande taille. Le diamètre de l'mil est compris trois f́ois et demie dans la longueur de la tète, il est à peine moindre que l'espace préorbitaire. - La ligne latérale fait en avant une courbure légère; elle est âpre surtout en arrière où elle est formée d'écussons épineux. - La dorsale commence, sur la tête, par un panache composé d'une huitaine de rayons; la caudale a huit grands rayons le plus souvent; les ventrales ont six à huit rayons.

Br. 6. - D. $8+164$ à 168 ; C. $70118+3$ à 6 ; P. 11 ; V. $1 / 5$ à 7. 
La teinte est d'un blanc argenté fort brillant, avec trois taches noires larges, arrondies, placées sur la partie supérieure du corps. Les nageoires sont d'un blane rosé.

Habitat. Méditerranée, assez rare, Nice? Banyuls.

\section{LE TRACHYPTĖRE A RAYONS I.ISSES. - TRACHYPTERUS LEIOPTERLS, C.V.}

Poiss. Frunce, t. II, p. 363.

Long. : 1,20 à 1,50.

Ce Trachyptère est probablement une variété du Tr. iris. La hauteur du tronc fait le neuvième environ de la longueur totale, caudale non comprise; la longueur de la tête en fait le dixième; la mandibule est armée de dents plus fortes que celles de la màchoire supérieure, ces dents, au nombre de huit, quatre de chaque côté, sont réunies deux par deux; le romer porte deux ou trois dents courtes et pointues. Le diamètre de l'œil, qui est un peu moins grand que l'espace préorbitaire, mesure presque le tiers de la longueur de la tête. La ligne latérale est àpre; ses boucliers postérieurs ont une épine crochue, à pointe tournée en avant. - Jes rayons de la dorsale sont lisses; les six ou sept premiers forment panache; les rentrales sont insérées au-dessous, mais un peu en arrière des pectorales.

D. 6 ou $7+169$ à 174 ; C. $8+6$; P. 12 ; V. 8 .

Le corps est d'un blanc argenté avec une tache noirâtre sur le premier cinquième de sa longueur; il y a généralement une seconde tache au tiers de la longueur totale.

Habitat. Méditerranée, très rare, Nice.

4. LE TRACHYPTËRE DE SPINOLA. - TRACHYPTERUS SPINOLE.

Poiss. France, t. II, p. 56ว̈, fig. 14ว̆, anim.

N. vulg. : Flamba, Cette.

Long. : (1,09 à 0,22. 
La hauteur du tronc est contenue trois fois et demie à quatre fois dans la longueur totale, sans la caudale; l'anus est fort reculé, à la fin du second tiers de la longueur du corps. - La longueur de la tête ne fait pas tout à fait le quart de la longueur totale, caudale non comprise. Le diamètre de l'œil mesure presque le tiers de la longueur de la tète; il est un peu moins grand que l'espace préorbitaire. - Le panache est composé de cinq à sept rayons; chez les sujets non mutilés, la caudale est fort développée et les rentrales ont une longueur supérieure au tiers de la longueur totale.

$$
\text { D. } 5 \text { à } 7+120 \text { à } 139 \text {; C. } 8 \text { à } 12 \text {; P. } 10 \text { ou } 11 \text {; V. } 1 / 5 \text {. }
$$

Le corps est argenté; il est marqué de trois ou quatre taches noirâtres, placées au-dessus de la ligne latérale; quelquefois il en porte une autre sur les flancs. Les nageoires sont d'un rouge plus ou moins clair.

Habitat. Méditerranée, assez rare, Nice, Cette.

Suivant Emery, le $T r$. iris et le $T r$. Spinolx sont des $T r$. falx en voie de développement; cependant on trouve des spécimens de Tr. iris beaucoup plus grands que ceux de certains spécimens de Tr. falx.

כั. LE TRACHYPTĖRE A CRÊTE. - TRACHYPTERUS CRISTATUS, Bonel.

Poiss. France, t. II, p. $56 \%$.

Long. : 0,30 à 0,90 .

Ce Trachyptère a été décrit sous le nom de $T r$. Bonellii par C. V., et sous celui de Gymnetrus Mullerianus par Risso. L'abdomen semble lobé; le bord inférieur du tronc derient mince en arrière, forme une espèce de crête qui remonte brusquement et se termine sur le bourrelet qui entoure l'anus; après, le corps se rétrécit graduellement et se termine en une queue assez grêle; de chaque côté, vers le profil inférieur, il est garni d'une série de boucles qui marquent le trajet de la ligne latérale; sa hauteur fait environ le sixième de la longueur, caudale non comprise. La peau est couverte de tubercules 
plus ou moins larges. - La longueur de la tête est à peu près égale à la hauteur du corps; sur chacun des intermaxillaires sont fixées une dizaine de petites dents, at pointe dirigée en arrière; la mandibule porte de chaque còté six à huit dents. Le diamètre de l'œil est compris deux fois et demic dans la longueur de la tête ; il est plus grand que l'espace préorbitaire. - La ligne latérale commence vers le bord postérieur de l'orbite, puis se dirige obliquement de haut en bas et d'avant en arrière; sur le trone, clle est formée d'osselets rugueux ou mème épineux; après l'anus, elle est composée d'écussons ou de boucles supportant une épine erochue plus ou moins forte. - Osselets 13 ì $4 \hat{4}$, boucles 40 . - Les six ou sept premiers rayons de la dorsale forment panache; les ventrales sont insérées un peu plus en avant que les pectorales.

$$
\text { J. } 6 \text { ou } 7 \text {; }+114 \text { à } 121 \text {; C. } 8+5 \text {; P. } 11 \text {; V. } 3 \text { à } 6 \text {. }
$$

Le nombre des rayons semble variable à la caudale et à la pectorale. Les nageoires sont rougeâtres; en général, il y a deux taches noires sur le panache de la tête et cinq autres sur la moitié postérieure de la dorsale; la eaudale est teintée de noirâtre dans une assez grande étendue.

Habitat. Méditerranée, très rare; Nice.

\section{Famille des Sparides, Sparide.}

Corps oblon ¿̌, couvert d'écailles généralement cténoïdes.

Téte de forme variable; bouche le plus souvent terminale, pas ou peu protractile; màchoires dentées, palais lisse.

Appareil branchial; ouïes largement fendues; pièces opercuaires écailleuses, sans épines; rayons branchiostèges au nombre de iny à sept; pseudobranchies.

Ligne latérale bien marquée, ne se continuant pas sur la caulale.

Nageoires; dorsale unique, composée de dix à quinze aiguillons t de neuf à seize rayons mous; anale formée de trois épines et de ept à seize rayons mous; caudale généralement fourchue.

Cette famille est composée de cinq sous-familles :

Moreac. - Ichthyologie. 
$a$. Incisives tranchantes..................... $b$.

coniques.....................

b. Dents latérales mousses, arrondies........... 1. SArginiens.

- pointues ou coupantes......... 2. Obiadinievs.

c. Dents latérales arrondies ou mousses......... 3. Spariniens.

pointues................... $d$.

4. Canthariniens.

5. Denticiniens.

\section{Sous-famille des Sarginiens, Sargini.}

Gorps comprimé, ovale, couvert d'écailles pectinées.

Tête plus haute que longue; bouche peu fendue; dents incisives plus ou moins aplaties, tranchantes, généralement au nombre de huit à chaque màchoire; molaires arrondies; joues écailleuses.

Nageoires; dorsale ayant onze ou douze, rarement treize aiguillons, et douze à quinze rayons mous; pectorales longues.

Vessie natatoire plus ou moins développée. - Appendices pyloriques peu nombreux.

Cette sous-famille comprend deux genres:

Molaires sur plusieurs rangées.................. 1. Sargue.

- sur une seule rangée........................ 2. Сharax.

1. GenRe SARgue. - Sargus, Cuv.

Tête; molaires arrondies sur plusieurs rangées.

Le genre Sargue comprend quatre espèces:

$a$. Bande noirâtre sur le tronçon de la queue seulement.............................. b.

Bande noirâtre sur le tronçon de la queue se prolongeant sur la dorsale....................

$b$. Sur le corps sept on huit bandes brunàtres verti-

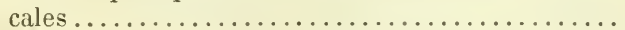

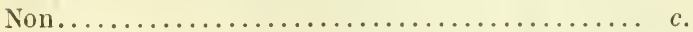

c. Ventrales noiràtres....................... 3. vieiLLE.

jaunâtres........................ 5. ANNULAIRE.

1. LE SARGUE ORDINAIRE. - SARGUS VULGARIS, Geof.-St-Hil.

Poiss. France, t. III, p. 2, fig. 146, anim.

N. vulg. : Sargou rascas, Nice; Sarguét négré, Cette.

Long. : 0,18 à $0,2 \%$.

La hauteur du corps est comprise deux fois et demie à deux 
fois et trois quarts dans la longueur totale. - La longueur de la tète mesure environ le quart de la longueur totale; les mâchoires, à peu près égales, sont munies l'une et l'autre de huit incisives, légèrement proclives, sur les côtés elles portent deux rangées de molaires arrondies. Le diamètre de l'œil fait le quart à peu près de la longueur de la tête, les deux lier's de l'espace préorbitaire. - La ligne latérale est parallèle au dos. Ec., l. long. 30 à 33 ; l. transv. 17 ou 18. - Généralement la deuxième épine de l'anale est un peu plus longue que la troisième; la pectorale ne fait pas tout à fait le tiers de la longueur totale, elle atteint à l'aplomb de la seconde épine de lanale.

$$
\text { Br. } 5 .- \text { D. } 11 / 14 \text { ou } 15 ; \text { A. } 3 / 14 ; \text { C. } 17 \text {; P. } 15 ; \text { V. } 1 / 5 \text {. }
$$

Sur le troncon de la queue se remarque une bande noiràtre qui gagne les rayons mous de la dorsale, et même ceux de l'anale chez les jeunes animaux. La dorsale est tachetée de noirâtre dans sa partie épineuse; l'anale est d'un brun foncé; la caudale est blanchàtre, sans bordure noire; les pectorales sont grisâtres; les ventrales sont noires à la face externe, grisâtres à la face interne. Le corps est d'un gris argenté avec des bandes verticales d'un gris doré, peu distinctes, et des bandes longitudinales de teinte jaunâtre au nombre de quatorze à seize. Une tache dorée se voit au-dessus de l'orbite. De la base de la dorsale descend une large bande noirâtre, qui s'étend sur le scapulaire et le bord postérieur de l'opercule. La ressie natatoire est grande. - Il y a quatre appendices pyloriques.

Habitat. Méditerranée, commun, Nice, Cette, Port-Vendres.

2. LE SARGUE DE RONDELET OU SAR PROPREMENT DIT. SARGUS RONDELETII, C. V.

Poiss. France, t. III, p. ̈̈.

N. vulg. : Sargou, Nice; Sarguet, Chique-tabac, Cette; Mouchon, Bayonne.

Long. : 0,20 à 0,30 . 
La hauteur du tronc est contenue deux fois et demie à deux fois et trois quarts dans la longueur totale. - La longueur de la tête est comprise quatre fois à quatre fois et demie dans la longueur totale; les màchoires, à peu près égales, portent chacune huit incisives plus ou moins verticales; il y a généralement trois rangées de molaires à la mâchoire supérieure. Le diamètre de l'œil fait le quart de la longueur de la tête, les deux tiers de l'espace préorbitaire. - Ec., l. long. 63 ou 66; 1. transr. 22 à 27. - L'anale a la deuxième épine aussi forte que la troisième et peut-être un peu plus longue; les pectorales sont falciformes, leur longueur est comprise environ trois fois et demie dans la longueur totale; les ventrales n'en font guère que le sixième.

Br. $5 .-$ D. 11 ou $12 / 12$ à $14 ;$ A. $3 / 13$ ou $14 ;$ C. $17 ;$ P. $16 ;$ V. $1 / 5$.

Le dos et les flancs sont d'un gris brunàtre; le ventre est argenté. Sur les côtés sont tracées vingt à vingt-cinq lignes longitudinales brunâtres; sept ou huit bandes verticales, d'un brun plus ou moins foncé, descendent de la région dorsale vers les flancs; le troncon de la queue porte une large bande noire formant une demi-ceinture fermée en dessus; cette bande ne sétend ni sur la partie inférieure du tronçon de la queue, ni sur les rayons mous de la dorsale. La dorsale est d'un gris jaunâtre; l'anale d'un brun foncé; la caudale, d'un brun jaunâtre, est bordée de noir; les pectorales sont grises, avec une large tache noire à la base; les ventrales sont noiràtres. - Il y a cinq à sept appendices pyloriques.

Habitat. Méditerranée, commun sur toute la còte, et mème très commun à Cette, au mois d'août. Océan, assez commun, Bayonne, Arcachon; je ne l'ai pas trouvé au nord de la Gironde.

3. LE SARGUE VIEILLE. - SARGUS VETULA, G. V.

Poiss. France, t. III, p. 7.

Long. : 0,13 à 0,23 , quelquefois 0,30 .

La longueur totale fait à peine deux fois et demie la hauteur du tronc. - La longueur de la tête mesure le quart au moins 
de la longueur totale; la màchoire supérieure est un peu plus avancée que la mandibule; elles ont l'une et l'autre huit incisives plates et larges; les molaires, grosses et arrondies, sont disposées en quatre rangées ì la màchoire supérieure, sur trois à la mandibule. Le diamètre de l'oeil fail environ le quart de la longueur de la tête, les trois cinquièmes de l'espace préorbitaire. - Ec., l. long. 70 à 80 . - La longueur de la pectorale est comprise trois fois et demie à trois fois et trois quarts dans la longueur totale, sa pointe dépasse en arrière les rayons épineux de l'anale.

$$
\text { D. } 11 / 14 \text {; A. } 3 / 13 \text {; C. } 17 \text {; P. } 17 \text {; V. } 1 / 5 \text {. }
$$

La coloration est grisitre sur le dos, plus claire sur les flancs, qui portent dix-huit à vingt bandes longitudinales d'une teinte foncée. Une tache noirâtre existe souvent sur la partic dorsale du tronçon de la queue. En général l'aisselle de la pectorale est marquée d'une tache noire. Une tache en croissant d'un jaune pâle s'étend sur les sourcils. Les nageoires impaires et les ventrales sont noirâtres. - Il y a quatre ou cinq appendices pyloriques.

Habitat. Méditerranée, excessivement rare, les Martigues.

Steindachner regarde le $S$. vetula comme étant la forme adulte du S. Rondelttii (Ichth. Ber. Span. Port. Reis., IV Forts. p. 42, Wien, 186i); mais on trouve des spécimens de $S$. vetula beaucoup moins développés que des spécimens de $S$. Rondeletii; de plus, la formule des écailles est différente : S. Rondeletii, long, 0,212, écailles sur la joue quatre ou cinq rangées, et 65 ou 66 dans une ligne Iongitudinale; S. vetula, long. 0,172 , écailles, six rangées sur la joue, et 70 à 80 dans une ligne longitudinale, nageoires impaires noiratres. Il est probable que Steindachner n'a pas vu de $S$. vetula; il indique ainsi la formule des écailles: 1. lat. 64-66, qui se rapporte seulement au $S$. Rondeletii.

\section{LE SARGUE ANNULAIRE OU SPARAILLON. - SARGUS A NNULARIS.}

Poiss. France, t. III, p. 9.

N. vulg. : Sparaillon, Port-Vendres; Paräyou, Celte; Pataclet, Aigues-.Iortes; Sparlin, Antibes ; Esperlin, Nice.

Long. : 0,12 à $0,1 \%$, quelquefois 0,18 . 
La hauteur du tronc est comprise deux fois et demie à trois fois dans la longueur totale. - La longueur de la tête est contenue trois fois et deux tiers à quatre fois dans la longueur totale; les mâchoires sont égales; elles portent chacune huit incisires; il y a deux ou trois rangées de molaires arrondies à la mandibule et trois ou quatre à la màchoire supérieure. Le diamètre de l'œil est compris trois fois et quart à trois fois et demie dans la longueur de la tête: il est d'un cinquième moins grand que l'espace préorbitaire: il est égal à l'espace interorbitaire. - Ec. l. long. $\dddot{3} \ddot{~ a ̀ ~} 60$; l. transv. 20. - L'anale a généralement sa deuxième épine plus développée que la dernière; les pectorales sont falciformes, leur longueur est comprise trois fois et demie dans la longueur totale; les ventrales natteignent pas à l'anus.

\section{Br. 6. - D. $11 / 12$ ou 13 ; A. $3 / 10$ ou $11 ;$ C. $17 ;$ P. $14 ;$ V. $1 / 5$.}

La région dorsale est d'un jaune doré; les côtés sont d'un jaune clair ; il n'y a pas de bandes verticales foncées, à l'exception dune large bande noirâtre qui entoure le tronçon de la queue seulement, sans gagner les rayons mous de la dorsale; l'espace interorbitaire et les sourcils sont jaunàtres: le préopercule a le bord postérieur rosé ou argenté. La dorsale, la caudale et les pectorales sont d'un gris légèrement teinté de jaune; l'anale et les rentrales sont d'un jaune orangé. - Il y a quatre appendices pyloriques.

Habitat. Méditerranée, très commun de Nice à Port-Vendres. Océan, excessivement rare, Bayonne, Arcachon.

\section{GENRE CHARIX. - CHARAX, Riss.}

Gorps orale, comprimé, couvert d'écailles de moyenne grandeur. Tête à profil oblique; màchoires ayant une seule rangée de dents; incisives tranchantes, proclives; molaires fort petites.

Appareil branchial; fente des ouies grande; pièces operculaires et joues écailleuses; six rayons branchiostèges. 


\section{LE CHARAX PUNTAZZO. - CHARAX PUNTAZZO.}

Poiss. France, t. III, p. 11.

N. vulg. : Mourre-agut, Nice.

Long. : 0,12 à $0,2 \%$, quelquefois 0,33 .

La hauteur du tronc est contenue deux fois et demie à trois fois dans la longueur totale. - La longueur de la tête fait le quart environ de la longueur totale; le museau est pointu; les mâchoires sont proéminentes, à peu près égales; les incisives sont plus ou moins longues, dirigées en avant; les molaires sont très développées. Le diamètre de l'œil mesure le quart de la longueur de la tète, les trois quarts de l'espace interorbitaire, les deux tiers de l'espace préorbitaire. - Ec., l. Jong. כ̋0 à 60 ; l. transv. 23. - La longueur de la pectorale fait environ le quart de la longueur totale.

$$
\text { Br. 6. - D. } 11 / 13 \text { ou } 14 ; \text { A. } 3 / 12 \text {; C. } 19 ; \text { P. } 15 \text { ou } 16 ; \text { V. } 1 / 5 \text {. }
$$

Le corps est d'un gris argenté, traversé par sept à neuf bandes verticales noirâtres; une large bande noirâtre se montre sur le troncon de la queue; les flanes portent des bandes longitudinales dorées. La dorsale, l'anale et les ventrales sont d'un brun foncé ; la caudale est jaunâtre à bordure noire; les pectorales sont noirâtres à la base, pâles dans le reste de leur étendue. -- Il y a sept appendices pyloriques, C. V.

Habitat. Méditerranée, assez commun à Nice, assez rare à Cette. Océan, Arcachon, assez commun parfois au mois d'aoùt.

\section{Sous-famille des Obladimiens, Obladini.}

Corps oblong, couvert d'écailles de moyenne grandeur.

Tête de dimension variable; bouche petite; incisives aplaties; pas de molaires arrondies; dents latérales coupantes ou pointues.

Appareil branchial; six rayons branchiostèges.

Nageoire; dorsale ayant onze à quatorze, rarement quinze épines assez faibles .

Vessie natatoire terminée en arrière par deux longues cornes. - Appendices pyloriques peu nombreux. 
Cette sous-famille comprend deux cenres:

Pas de dents en arrière des incisives ................ 1. Bogte. Lne rangée de petites dents en arrière desincisives....... 2. Oblade.

\section{GENRE BOGLE. - BOX, Cur.}

Tête; bouche petite; dents plates sur une seule rangée; à la màchoire supérieure, elles ont le bord tranchant plus ou moins échancré ou crénelé: à la mandibule, elles sont terminées en pointe avec ou sans talons latéraux.

Ce genre se compose de deux espèces:

Tache noire a la base de la pectorale nulle............. 1. conscs.

- - - bien marquée....... 2. sacpe.

\section{LE BOGLE COMMLX. - BOA BOOPS.}

Priss. France. t. III, p. 1 t.

N. vulg. : Poli, Arcachon; Boga, Saint.Jean-de-Luz; Bogas et Brgea, Roussillon; Boga, Cette; Bogue, Languedoc, Prorence; Buga. Nice.

Long. : 0.20 à 0,30, quelquefois 0,33 .

Le corps est oblong. ou plutiot légèrement fusiforme; sa hauteur est comprise quatre fois et un tiers à cinq fois dans la longueur trotale. - La longueur de la tête est contenue environ quatre fois et demie dans la longueur totale: les mâchoires sront égales: il n y a qu une seule rangée de dents: elles ont le brord libre coupant et crénelé à la mâchoire supérieure: à la mardifule elles sont prointues, à double talon. Le diamètre de l'seil fait le tiers de la longueur de la tête, il est égal, au moins. à l'espace préorbitaire. - Ec.. l. long. 70 ḋ 7'́l. transr. 19. - La dorsale a généralernent le quatrième aiquillon plus allongí que les autres: l'anale prend naissance sous le deuxième ou le troisième rayon rnou: les pectorales mesurent environ le cinquième de la longueur trotale.

$$
\text { Br. 6. - D 14/15 ou 16:1.3/150u 16; C. 17; P. I6 ou 17; V. 1/5. }
$$

Le dos est gris bleuâtre: les flances et le ventre sont argentés: au-dessous de la ligne latérale se voient trois ou 
quatre bandes longitudinales dorées. Toutes les nageoires sont pâles. - Il ỵ a cinq appendices pyloriques.

Habitat. Toutes nos còtes; Méditerranée, très commun. Dcéan. assez commun, jusqu'à la Gironde; rare entre la Gironde et la Loire; très rare sur la còte de Bretagne. Manche. excessirement rare.

\section{LE BOGUE SAUPE oc LA SAUPE. - BOI SALPA.}

Poiss. France, t. III, p. 17, fig. 1't, anim.

N. vulg. : Salpe, Port-lendres: Saoupa, Cette: Sarpa, Nice: Saopi et Sopi, sur différents pnints de la Méditerranée.

Long. : 0,20 à 30 , quelquefois 0.40 .

Le corps est ovale. comprime : sa hauteur est comprise trois fois et un tiers à trois fois et demie dans la longueur totale: la longueur de la tète en fait environ le cinquième: la màchoire supérieure, légèrement plus avancée que la mandibule. porte une rangée de dents aplaties, à bord tranchant et échancre: la mandibule est munie de dents assez larges. triangulaires. pointues. Le diamètre de l'exil mesure à peu près le quart de la longueur de la tète, les deux tiers de lespace prénbitaire. - Ec.. l. long. 70 à $8(0$; l. transr. 22. - La dorsale est basse: la quatrième ou la einquième épine. qui est la plus elevée, ne fait guère que le quart de la hauteur du trone : l'anale a. comme chez le Bogue, la troisième ipine plus longue yue les autres: les pectorales ne mesurent pas le cinquième de la longueur totale.

Br. 6. -D. 11 ou 1? 12 a 1 it: A. 3/1t ou $15:$ C. $18 ;$ P. 15 ou $16 ; 1: 15$.

Le dos est teinte d'un gris bleuatre: les flanes et le rentre sont d'un blane argente: les cotés sont pareourus par une dizaine de lignes longitudinales d'un beau jaune doré. La pectorale est marquée d'une tache noiratre, vers la partie supérieure de sa hase. - Il y a quatre appendices pyloriques.

Habitat. Océan, excessivement rare, la Rochelle; assez rare au sud de la Cironde, Areachon. Méditerranée, commun de portVendres a Nice. 


\section{GENRE OBLADE. - OBLADA.}

Tête assez forte; màchoires munies en avant d'incisives aplaties, échancrées, et latéralement de dents pointues sur une seule rangée; derrière les incisives, une série de dents très petites, comme grenues.

\section{L'OBI.ADE ORDINAIRE. - OBLADA MELANURA.}

Poiss. France, t. III, p. 19.

N. vulg. : Nèblada, Cette; Blade, Oblado, Marseille; Blada, Nice. Long. : 0,15 à $0,2 \ddot{\text { ä. }}$

La hauteur du tronc est comprise trois fois et demie à quatre fois dans la longueur totale, et la longueur de la tête, quatre fois et quart à quatre fois et demie; les mâchoires, à peu près égales, sont garnies en avant d'incisives plus ou moins aplaties, à bord échancré, latéralement de dents coniques légèrement recourbées; en arrière des incisives se trouve une série de dents grenues plutôt que pointues, parfois très petites à la mandibule. Le diamètre de l'ceil mesure le quart de la longueur de la tête, il est égal à l'espace interorbitaire, à peine plus grand que l'espace préorbitaire. - Ec., 1. long. 64 à 67 ; l. transr. 22 ou 23. - La dorsale est basse; l'anale a sa première épine beancoup moins développée que les autres; les pectorales sont falciformes; leur longueur, qui est égale à celle de la caudale, fait le quart de la longueur totale.

Br. 6. -D. $11 / 14$; A. $3 / 13$ ou 14 ; C. 17 ; P. $15 ;$ V. $1 / 5$.

Le dos est brunâtre ou d'un bleu foncé ; les côtés sont d'un gris argenté nuancé de bleuâtre avec une dizaine de bandes longitudinales noirâtres ou d'un bleu foncé; une bande assez large, noirûtre, entoure plus ou moins complètement le tronçon de la queue; chez les jeunes animaux, les bandes longitudinales des llanes sont peu ou pas marquées. La caudale est brunâtre; les autres nageoires sont d'un gris plus ou moins 
foncé; chez les jeunes, les ventrales et l'anale sont d'un gris tirant sur le jaune. - Il y a six appendices pyloriques.

Habitat. Médilerranée, commune.

\section{Sous-famille des sparimiens, Sparini.}

Téte variable de forme; màchoires à dents antérieures coniques, à molaires arrondies, placées sur plusieurs rangées.

Appareil branchial; six rayons branchiostèges.

Nageoire; dorsale ayant onze à treize rayons épineux.

Cette sous-famille se compose de trois genres:

a. Dents antérieures en velours ou en cardes fines....... fortes, coniques au nombre de + à 6 . $b$.

$b$. Ligne longitudinale ayant moins de 65 écailles...... 2. PaGRe. plus de 70 écailles....... 3. Daurade.

1. GENRE PAgel. - PAgELLU, Cuv.

Corps oblong, couvert d'écailles ciliées.

Tête; màchoires garnies en avant de dents en velours ou en cardes fines, latéralement de molaires arrondies sur plusieurs rangées; molaires généralement en séries moins nombreuses chez les jeunes que che\% les adultes.

Nageoires; dorsale ayant le plus souvent douze aiguillons et neuf à treize rayons mous; anale arec trois épines et neuf à douze rayons mous.

Vessie natatoire assez grande. - Appendices pyloriques au nombre de quatre ou cinc le plus ordinairement.

Le genre Pagel compte sept espèces.

a. Tache foncée sur l'épaule ou à l'aisselle de la pectorale...........................

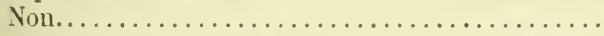

b. Dix a douze bandes verticales noirâtres sur le

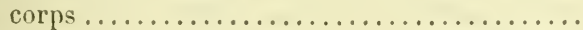

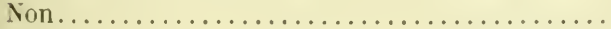

c. Diamètre de l'œil plus petit que l'espace préorbitaire

Diamètre de l'œil plus grand que l'espace préorbitaire

$e$.

$b$.

4. MORMYRE.

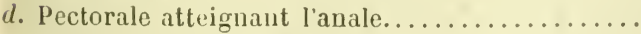

Pectorale n'atteignant pas l'anale............

e. 'Tache noiràtre à l'origine de la ligne latérale.. c.

1. ÉRYTHRin.

d.

2. A huseau court.

3. BOGUERA VEL.

5. CENTRODONTE. 
Pas de tache noirâtre à l'origine de la ligne latérale ..................... $f$. $f$. Joue ayant moins de sept rangées d'écailles... Joue garnie de plus de sept rangėes d'écailles.

6. ACARNE.

7. De Philippe.

\section{LE PAGEI, COMMUN ou ÉRYTHRIN. - PAGELLUS ERYTHRINUS.}

Poiss. France, t. III, p. 23.

N. vulg. : Pageau, île de Ré : Rousseau, Bayonne ; Pagell, PyrénéesOrientales; Patjel et Pachel, Cette; Pageo ou Pageu, Nice.

Long. : 0,20 à 0,50 et plus.

La hauteur du tronc est comprise trois fois à trois fois et trois quarts dans la longueur totale, et la longueur de la tête trois fois et trois quarts à quatre fois; la mâchoire supérieure est un peu plus courte que la mandibule; les dents antérieures sont en cardes, celles de la rangée externe sont un peu plus développées que les autres ; latéralement, et en arrière surtout, les molaires de la rangée interne sont les plus grosses. Le diamètre de l'œil est contenu trois fois et quart à trois fois et deux tiers dans la longueur de la tête; il fait les deux tiers, parfois les quatre cinquièmes de l'espace préorbitaire, il est égal à l'espace interorbitaire, chez les sujets de moyenne taille. La joue est garnie de six rangées d'écailles. - Ec., l. long. 60 à 63 ; l. transv. 21 ou 22. - En général le quatrième aiguillon de la dorsale est le plus allongé; les pectorales sont falciformes, étroites; leur longueur est contenue environ trois fois et demie dans la longueur totale.

$$
\text { Br. 6. -D. } 12 / 10 \text {; A. } 3 / 9 \text { ou } 10 \text {; C. } 17 \text {; P. } 15 \text { ou } 16 ; \text { V. } 1 / 5 \text {. }
$$

Le dos est d'un rouge assez vif; les côtés sont d'un rouge plus pâle; le ventre est d'un blanc rosé. Les nageoires verticales sont roses; les nageoires paires sont d'un blanc rosé. - Il y a quatre appendices pyloriques.

Habitat. Manche, très rare. Océan, còtes de Bretagne assez rare ; còtes du Poitou, assez commun; commun au Sud de la Gironde. Méditerranée, commun de Port-Vendres à Nice. 


\section{LE PAGEL I MUSEAU COURT. - PAGELLUS BREIICEPS.}

Poiss. France, t. III, p. 26, fig. 148, anim.

N. vulg. : Cieucla ou Chieucla, Nice; Bourabèou, Cette.

Long. : 0,10 à $0,10 ̈$.

Le Pagel à nuseau court est bien l'Aurata bilumuluta de lísso. Il est probable que Risso, dans sa description du Sparus berda, a réuni les caractères appartenant au $P$. breviceps et au $P$. acarne.

La hateur du tronc est contenue trois fois et deux tiers dans la longueur totale; la longueur de la tête en fait le quart; la mâchoire supérieure est un peu moins avancée que la mandibule; le inuseau est.gros, court; sur le devant des mâchoires, les dents sont assez fortes, aiguës, légèrement crochues; en arrière s'en trouvent d'autres, un peu plus courtes, presque mousses; sur les côtés il y a généralement deux séries de petites molaires arrondies. Le diamètre de l'œil fait le tiers au moins de la longueur de la tête; il est d'un tiers plus grand que l'espace interorbitaire, qui est légèrement convexe. La joue est garnie de cinq rangées d'écailles. - Ec., l. long. ̋̈8 ou 59 ; I. transr. 28. -- Le quatrième aiguillon de la dorsale est généralement plus élevé que les autres ; l'anale a des épines aplaties, robustes; la troisième un peu plus longue que la deuxième; la caudale est échancrée; les pectorales sont falciformes, elles mesurent environ le quart de la longueur totale; elles arrivent jusqu'à l'aplomb de la première épine de l'anale.

$$
\text { Br. } 6 .- \text { D. } 12 / 12 ; \text { A. } 3 / 11 \text { ou } 12 \text {; C. } 15 ; \text { P. } 14 ; \text { V. } 1 / 5 .
$$

Le dos et les côtés ont une teinte d'un blanc argenté glacé de rose; le ventre est d'un blanc nacré; la tète est couverte d'argent gaufré, principalement sur les parties non écailleuses; le sourcil est marqué d'une espèce de croissant argenté légèrement bruni. La dorsale est transparente grisàtre; la caudale et les pectorales sont d'un gris pàle, teinté de rose; l'anale et les rentrales sont blanchâtres.

Habitat. Méditerranée, très rare. Nice, Cette. 


\section{LE PAGEL BOGUERAVEL. - PAGELLUS BOGARAVEO.}

Poiss. France, t. III, p. 29, fig. 149, anim.

N. vulg. : Bugoravella, Nice; Bougrabéou, Cette.

Long. : 0,8 à 0,15 , quelquefois 20 .

La hauteur du tronc est comprise trois fois et demie à trois fois et trois quarts dans la longueur totale; la longueur de la tête trois fois et quart à quatre fois. Le museau est court, obtus; les incisives sont fines ; les molaires arrondies sont placées sur deux rangées. Le diamètre de l'œil fait le tiers environ de la longueur de la tête; il est à peine plus grand que l'espace préorbitaire qui est égal à l'espace interorbitaire. Il y a sur la joue cinq ou six rangées d'écailles. - Ec., l. long. 52 à 50 ; l. transv. 20 à 22. - La dorsale commence au-dessus de la pectorale; de même longueur que la caudale, la pectorale ne mesure guère que le cinquième de la longueur totale, elle n'arrive pas à l'aplomb de l'origine de l'anale; la ventrale est d'un tiers plus courte que la pectorale.

\section{D. $12 / 11$ ou $12 ;$ A. $3 / 10$ ou $11 ;$ C. 17 ; P. $15 ;$ V. $1 / 5$.}

Le corps est d'un brun assez clair teinté de rougeâtre. Les nageoires verticales sont d'un gris rosé; les nageoires paires sont d'un blanc tirant sur le jaune; l'aisselle de la pectorale est un peu brunâtre.

Habitat. Méditerranée, rare, Nice, Cette, Port-Vendres. Océan?

Le Pagellus bogaraveo de Fis Day (Brit. Fish., t. Ier, p. 37, pl. XIV), est évidemment un $P$. acarne.

\section{LE PAGEL MORMYRE. - PAGELLUS MORMYRUS.}

Poiss. France, t. III, p. 31 .

N. vulg. : Tenillé et Tinié, Cette; Morme, Provence; Mourmena, Nice.

Long. : 0,20 à 0,32 .

La hauteur du tronc est comprise, en général, trois fois et un cinquième dans la longueur totale. - Chez les individus de 
grande taille, la longueur de la tête est contenue trois fois et trois quarts à quatre fois dans la longueur totale; les máchoires sont égales; les dents antérieures sont en cardes fines; chez les adultes, les molaires de la màchoire supérieure sont placées sur quatre rangées; celles de la mandibule, sur deux, trois et mème quatre rangées. Le diamètre de l'œil est compris cinq fois à cinq fois et demie dans la longueur de la tète; il fait moins de la moitié de l'espace préorbitaire. - Il y a le plus souvent six rangées d'écailles sur la joue. Ec., l. long. environ 64 ; l. transv. 16 à 19. - La eaudale est très échancrée; la pectorale n’atteint pas l'anale, elle mesure le cinquième de la longueur totale.

D. 11 ou $12 / 12 ;$ A. $3 / 10$ ou 11 ; C. 17 ou $18 ;$ P. $16 ;$ V. $1 / 5$.

Le corps est d’un gris argenté, traversé par dix à douze bandes noirâtres verticales, qui descendent de la région dorsale. Les nageoires sont d'un jaune brunàtre.

Habitat. Méditerranée, assez commune à Nice, Cette. Océan, assez commun à Arcachon, pendant l'été.

วั. LE PAGEL CENTRODONTE ou ROUSSEAU. - PAGELLUS CENTRODONTUS.

Poiss. France, t. III, p. 33.

N. vulg. : Besugo, Nice; Arvasseii, Biarritz; Pilonneau, la Rochelle; Rousseau, Vendée; Brème ou Brène, Cherbourg; Gros-yeux, Marché de Paris.

Long. : 0,30 à 0,30 .

La hauteur du tronc est comprise trois fois à trois fois et trois quarts dans la longueur totale; et la longueur de la tête trois fois et deux tiers à quatre fois; le museau est court; la muqueuse de la bouche, comme celle de la chambre branchiale, est d'une coloration rouge saumon ou orange; sur le devant des mâchoires, les dents sont en cardes fines, un peu plus fortes, plus crochues à la rangée externe; les molaires sont à la màchoire supérieure sur trois, quatre, cinq rangées, à la mandibule sur deux, trois, quatre, rarement cinq rangées. Le diamètre de l'ceil mesure le tiers de la longueur de la tête; 
il est aussi grand, ou même plus grand que l'espace préorbitaire, qui est ordinairement égal à l'espace interorbitaire. Il y a sept rangées d'écailles sur la joue. - Ec., l. long. 7 à 80 ; 1 . transv. 22 à 21. -- Les pectorales sont falciformes, très longues; elles mesurent le quart de la longueur totale; leur pointe dépasse l'anus; les ventrales sont beaucoup plus courtes que les pectorales.

D. $12 / 12$ ou $13 ;$ A. $3 / 12$; C. 17 ; P. 16 ou 17 ; V. $1 / 5$.

Le ton est gris plus ou moins rosé sur le dos, gris argenté sur les llancs; une grande tache noire s'étend sur l'épaule et le commencement de la ligne latérale ; elle manquę parfois chez les jeunes. Les nageoires impaires sont d'un jaune rosé; les nageoires paires d'un blanc rose clair. - La vessie natatoire est très déreloppée. - Il y a quatre appendices pyloriques, parfois trois seulement.

Habitat. Méditerranée, commun. Océan, commun pendant l'été, Arcachon, Lorient, Concarneau. Manche assez commun, et mème très commun au Havre; assez rare en Picardie. - Ce Paggel, ainsi que nous l'avons fait remarquer, est fort probablement le Pilonneuu de Duhame].

\section{LE PAGEL AGARNE. - PAGELLUS ACARNE.}

Poiss. France, t. III, p. 36, fig. 150, anim.

N. vulg. : Pageo de plana, Nice.

Long. : 0,20 à 0,3 s̆.

La hauteur du tronc est comprise trois fois et demie à qualre fois dans la longueur totale; la longueur de la tête, trois fois et demie à trois fois et trois quarts; le museau est obtus; la muqueuse de la bouche, ainsi que celle de la chambre branchiale, est d'une teinte rouge saumon ou orange; la mâchoire supérieure est un peu plus avancée que la mandibule; elles portent, l'une et l'autre, en arant des dents en cardes plus ou moins fortes, et sur les côtés plusieurs rangées de molaires arrondies; le nombre des rangées de molaires, surtout à la mâchoire supérieure, varie, suivant l'âge des sujets, de deux 
à quatre, parfois il y a une rangée de plus d'un cóté que de l'autre; la mandibule a deux ou trois rangées de molaires. Le diamètre de l'oil mesure le quart environ de la longueur de la tête, les deux tiers de l'espace préorbitaire, il est égal, ou peu s'en manque, à l'espace interorbitaire ; chez les jeunes animaux, le diamètre de l'œil est relativement plus grand. Les joues sont courertes de cinq rangées d'écailles. - Ec., l. long. 70 à 72; 1. transv. 19 ou 20. - La pectorale est falciforme; sa pointe dépasse l'anus; sa longueur fait le quart environ de la longueur totale; la ventrale est sensiblement plus courte que la pectorale.

Br. 6.--D. $12 / 11 ;$ A. $3 / 9$ ou $10 ;$ C. $17 ;$ P. 15 ou $16 ;$ V. $1 / 5$.

Le dos et les côtés sont colorés d'un rougeâtre argenté, parfois assez clair; le ventre est argenté ; le dessus de la tête est d'un gris rougeâtre. La partie épineuse de la dorsale est rosée; la caudale, les rayons mous de la dorsale et ceux de lanaie sont d'un rougeâtre clair; la pectorale est d'un rouge très pâle; à l'aisselle de la nageoire, et sur la base de ses rayons supérieurs, se remarque une tache d'un gris rougeâtre; les ventrales sont blanchâtres.

Habitat. Méditerranée, assez commun de Nice à Port-Vendres. Océan, golfe de Gascogne, rare, Saint-Jean-de-Luz, Bayonne, Arcachon; très rare au nord de la Gironde, la Rochelle. Manche, excessivement rare, Abbeville.

Day a décrit le Pagel acarne osus trois noms différents.

7. LE PAGEL DE PHILIPPE. - PAGELLUS PHILIPPI. Nob.

Poiss. France, t. III, p. 39.

Long. : $0,1 \div 7$.

La hauteur du trone mesure le tiers de la longueur totale. - La tête est un peu plus haute que longue; sa longueur fait le quart de sa longueur totale; la muqueuse, tapissant la bouche et la chambre branchiale, est d'un jaune rougeâtre, safran; les dents antérieures sont petites, égales, très aiguës; les dents de la série externe sont pointues, excepté en arrière

Moreau. - Ichthyologie. 
où se trouvent deux rangées de molaires arrondies. - Le diamètre de l'œil mesure le tiers de la longueur de la tête; il est égal à l'espace préorbitaire, qui lui même est égal à l'espace interorbitaire. Il y a sur la joue huit ou neuf rangées d'écailles. - La ligne latérale est large brunàtre. - Ec., l. long. 67 à 70; l. transv. 24 à 26. - La dorsale a douze ou treize aiguillons; le quatrième, ou le cinquième, qui est le plus long, fait le tiers de la hauteur du tronc; la pectorale est comrte; sa longueur est contenue environ six fois et demie dans la longueur totale, elle dépasse à peine celle de la ventrale.

\section{12 ou $13 / 10$ ou $11 ;$ A. $3 / 10$ ou $11 ;$ C. $17 ;$ P. 16 : V. 1/5.}

Le dos est d'un brun jaunâtre; les côtés sont d'un gris jaunâtre; la joue et les pièces operculaires sont jaunâtres. La dorsale est brunâtre; la caudale d'un gris rougeâtre; les ventrales et l'anale sont d'un gris jaune assez pàle; la pectorale est grise; à l'aisselle de la nageoire est une tache noirâtre, qui ne s'étend pas sur la base des rayons.

Habitat. Méditerranée, Celte, deux spécimens, 1878, 1887.

\section{GLNRE PAGRE. - PAGRUS.}

Gorps ovale, couvert d'écailles ciliées.

Tête développée; màchoires armées en arant de quatre ou six dents fortes, coniques, derrière lesquelles sont des dents en cardes; grosses molaires arrondies sur deux rangées principales.

Ligne longitudinale ayant moins de 63 écailles.

Nageoires; dorsale à rayons épineux plus nombreux que les rayons mous; anale à trois épines et huit ou neuf rayons mous.

Deux espèces.

Espace interorbitaire de teinte uniforme............. 1. ORDinare. marqué d'un croissant bleuâtre..... 2. oRpIIE.

\section{LE PAGRE ORDINAIRE. - PAGRUS VULGARIS.}

Poiss. France, t. III, p. 40.

N. vulg. : Padre, Nice; Pagré, Padré, Cette; Bagre, Port-Vendres. Long. : 0,20 à 0,40 , quelquefois 0,73 . 
La hauteur du trone est comprise trois fois et un tiers à trois fois el trois quarts dans la longueur totale. - La longueur de la lète est contenue trois fois et demie à quatre fois et un liers dans la longueur totale; la màchoire supérieure, légèrement proéminente, est armée en arant de quatre dents longues et fortes, espèces de canines, en arrière desquelles sont des dents en cardes; sur les côtés, à la suite des canines, se trouvent quatre à sept dents coniques, à pointe mousse, puis viennent des molaires complètement arrondies; en dedans de cette rangée, il en existe une seconde composée de douze à dix-sept molaires plus grosses en arrière; chez les jeunes animaux, il n’y a que deux rangées de molaires; chez les grands spécimens, en dedans de la rangée interne se voient de petites dents grenues sur deux ou trois séries, plus ou moins régulières. La mandibule porte en avant quatre à six longues dents pointues, derrière lesquelles sont des dents en cardes; sur les coilés, elle a deux rangées de molaires développées, en outre, chez les sujets de grande dimension, elle a une ou deux séries de molaires grenues. Suivant la taille des individus, le diamètre de l'œil est compris trois fois et trois quarts à quatre fois et deux tiers dans la longueur de la tête, faisant tantôt plus, tantôt moins de la moitié de l’espace préorbitaire. Il y a, en général, six rangées d'écailles sur la joue. - Ec., l. long. ö et 60 ; l. trans. 20 à 24 . - La dorsale commence ordinairement en avant de la base de la pectorale; le quatrième aiguillon est le plus allongé chez la plupart des spécimens, mais ne fait pas le tiers de la hauteur du trone; le plus souvent la deuxième épine de l'anale est la plus développée; les pectorales sont longues, faisant plus du quart de la longueur totale, leur pointe atteint ou dépasse la troisième épine de l'anale.

$$
\text { Br. 6. - D. } 12 / 10 \text {; A. } 3 / 8 \text {; C. } 17 \text { a } 19 \text {; P. } 15 \text {; V. } 1 / 5 \text {. }
$$

Le dos est rosé ou d'un rouge tendre; les flancs sont argentés; les nageoires sont d'un rose pâle.

Habitat. Méditerranée, assez rare, Nice, Cette, Port-Vendres. Océan, excessivement rare, Concarneau. 
2. LE PAGRE ORPHE. - PAGRUS ORPHUS.

Poiss. France, t. III, p. 42.

N. vulg. : Pageu ou Pageo testas, Nice.

Long. : 0,15 à 0.23 et 0.36 .

Les proportions sont à peu près les mêmes que dans le Pagre ordinaire; il n'y a pas non plus de différence bıen appréciable dans la disposition du système dentaire. Chez les jeunes animaux, le diamètre de l'œil fait le tiers de la longueur de la tête, le quart chez les sujets de grande taille; il mesure toujours plus de la moitié de l'espace préorbitaire. Il y a sur la joue six ou sept rangées d'écailles. -- Ec., l. long. 60 ; l. transv. 26. - La dorsale est insérée un peu en arrière de la base des pectorales; son quatrième aiguillon, qui paraît le plus développé, mesure le tiers au moins de la hauteur du tronc, chez un sujet ayant une taille de 0,330 ; le troisième aiguillon de l'anale est le plus grand; les pectorales sont falciformes, elles arrivent au-dessus de la région épineuse de l'anale, elles font plus du quart de la longueur totale.

Br. 6. - D. $12 / 10$ ou $11 ;$ A. $3 / 8$ ou $9 ;$ C. 17 ou $18 ;$ P. $15 ;$ V. $1 / 5$.

La teinte générale est rose, plus pâle sous le ventre, à reflets bleuâtres au-dessus de la ligne latérale. Dans l'espace interorbitaire est un croissant bleuâtre qui passe au-dessus des narinos. Le bord postérieur de l'opercule est d'un brun foncé ou d'un noir rougeâtre. Les pectorales, la dorsale et la caudale sont d'un rose assez vif; les ventrales sont roses à la base et pâles dans le reste de leur étendue, parfois lilas; l'anale est d'un rose pâle avec un pointillé noirâtre excessivement fin. Sur un sujet bien développé je n’ai trouvé que trois appendices pyloriques.

Habitat. Méditerranée, assez rare; Nice, Toulon, Cette. Océan, très rare, Arcachon, le Pouliguen.

Le Pagre hurta, P. hurta, C. V., Sparus hurta, Linn., n'est pas la Dorade hurta, A. hurta, Riss., V. Poiss. France, t. III, p. 44. 


\section{GENRE DAURAIE. - CHRYSOPHRYS.}

Corps oblong, couvert d'écailles assez petites, peu ciliées.

Tête forte; incisives ou dents antérieures coniques développées, au nombre de six généralement à chaque màchoire; molaires arrondies sur trois à cinq rangées à la màchoire supérieure, sur deux rangées, ou plus, à la mandibule.

Ligne longitudinale ayant plus de 70 écailles.

Nageoires; dorsale à rayons épineux pas plus nombreux que les rayons nous.

Ce genre comprend deux espèces.

Dorsale marquée d'une bande longitudinale brunâtre. 1. vulgaIne.

Dor'sale d'une teinte uniforme, sans bande brunàtre. 2. a museau rexflé.

\section{LA DAURADE VULGAIRE. - CHRYSOPHRYS AURATA.}

Poiss. France, t. III, p. 43.

N. vulg. : Morade, Dorée, Dorette, còtes de l'Ouest; Daurade, Roussillon; Saouquèna, Cette; Aourade, Daurade, Provence; Aurada, Nice.

Long. : $0,3 \ddot{a}$ à $0,3 \ddot{z}$, quelquefois 0,30 .

La hauteur du tronc est comprise trois fois à trois fois et demie clans la longueur totale. - La tête est plus haute que longue; sa longueur est contenue quatre à cinq fois dans la longueur totale; la màchoire supérieure est plus avancée que l'inférieure; elles portent ordinairement l'une et l'autre six fortes incisives coniques, légèrement crochues, à pointe mousse, parfois il s'en trouve quatre seulement à la mandibule; les molaires sont placées sur quatre à cinq rangées à la mâchoire supérieure, sur trois ou quatre ì la mandibule; au fond de la bouche et sur chaque mâchoire, il y a toujours une et souvent deux molaires à couronne très large, à surface ovale plus ou moins plane; les séries dentaires sont plus nombreuses chez. les vieux individus que chez les jeunes. Le diamètre de l'ail est contenu quatre fois et demie à cinq fois et quart dans la longueur de la tète, il mesure à peu près la moitié de l'espace préorbitaire. La joue est garnie de sept ou huit rangées d'écailles. - Ec., 1. long. 76 à 80 ; 1. transr. 29 ou $2 \%$. - La caudale est 
fourchue; la pectorale mesure environ le quart de la longueur totale.

Br. $6 .-$ D. $11 / 13$; A. $3 / 11$ ou 12 ; C. 17 ; P. 16 . V. $1 / 5$

La région dorsale est d'un bleu foncé; les cotés sont d'un jaune argenté, avec des lignes longitudinales d'un brun clair, une bande dorée forme une espèce de croissant entre les yeux; une tache couleur rouille marque le bas de l'opercule; une tache rougeàtre se voit à l'aisselle de la pectorale. La dorsale est bleuâtre avec une bande longitudinale bruuâtre ; les pectorales, la caudale et l'anale sont grisâtres; les ventrales sont d'un violet grisâtre ou jaunâtre. - Il y a quatre appendices pyloriques.

Habitat. Méditerranée, fort commune. Océan, golfe de Gascogne, commune; assez commune entre la Gironde et la Loire; assez rare sur les còtes de Bretagne. Manche, excessivement rare.

\section{LA DAURADE A MUSEAU RENFLÉ. - CHR ISOPHRYS CRASSIROSTRIS, C. V.}

Poiss. France, t. III, p. 47 .

Long. : 0,30 à 0,50 .

La hauteur du tronc est comprise trois fois à trois fois et demie dans la longueur totale. - La longueur de la tête fait environ le quart de la longueur totale; la mâchoire supérieure est munie de six grosses incisives coniques, elle a trois ou quatre rangées de molaires; la mandibule a six incisives fortes, coniques et deux ou trois rangées de molaires. Le diamètre de l'œil mesure le sixième environ de la longueur de la tête, le tiers de l'espace préorbitaire ; le sous-orbitaire a le bord inférieur plus échancré que dans la Daurade vulgaire. Les joues sont garnies de sept rangées d'écailles. - Ec., l. long. 83 à $8 \%$; l. transv. 20. Les pectorales sont deux fois plus longues que les ventrales; leur longueur est contenue trois fois et demic dans la longueur totale.

$$
\text { D. } 11 / 13 ; \text { A. } 3 / 11 ; \text { C. } 17 \text {; P. } 15 ; \text { V. } 1 / 5 \text {. }
$$

Le dos est bleu foncé; le llanc bleu jaunâtre; le ventre gris 
foncé; des bandes longitudinales d'un brun bleuâtre s'étendent sur les côtés; une large tache noiràtre s'étale sur l'épaule et sur l'opereule. Les joues sont d'une teinte euivrée; un croissant doré marque l'espace interorbitaire. Les nageoires sont d'un gris assez foncé; la dorsale n'a pas de bande noirâtre; la caudale paraît avoir une bordure très brune.

Habitat. Méditerranée, excessivement rare, Nice.

Steindachner considère le Chrysophrys crassirostris, Cuv. Val., comme étant l'adulte dı Pagrus (Chrysophrys) auratus (Iehth. Ber. Span. Port. Reis., IV. Forts., p. 36, Wien, 1867); mais à part d'autres caractères qu'il serait trop long de rappeler, il faut faire observer que chez le C.crassirostris, le nombre des écailles des rangées verticales est moindre que chez le $C$. auratu.

\section{Sous-famille des Canthariniens, Cantharini.}

Corps ovale, couvert d'écailles plus ou moins ciliées.

Tête; bouche petite; dents toutes en velours ou en cardes.

Appareil branchial; six rayons branchiostèges.

Nageoires; dorsale à onze rayons épineux en général.

GENRE CANTHERE. - CANTHARUS, Guv.

Caractères de la sous-famille.

a. Sous-orbitaires échancrés...

1. C. GRIs.

- non échancrés............. b

b. Hauteur du corps contenue plus de trois fois dans la longueur totale.......................

Ilauteur du corps contenue moins de trois fois dans la longueur totale..................

2. C. BRÈME.

3. C. orbiculatre.

\section{LE CANTHÈRE GRIS. - CANTHARUS GRISEUS.}

Poiss. France, t. III, p. 49.

N. vulg. : Brême commune, Boulogne; Pilonneau, Daurade, Seine-Inférieure; Brème de rochers, Sarde, Cherbourg; Mangegoëmon, Vendée; Bouchon, Bayonne; Gallet, Port-Vendres ; Cantarèla, Cantha négra, Cette; Canthéno, Languedoc, Canthàro, Canthèna, Tanuda, Provence; Canthèno (jeune), Tanudo, Tanuda (adulte), Nice.

Long. : 0,20 à $0, \dot{4} 0$, quelquefois $0, \ddot{3} 0$. 
Le Canthère gris et le Canthère commun ne forment qu'une seule espèce. - La hauteur lu tronc est comprise trois fois à trois fois et quart dans la longueur totale, rarement moins, rarement plus. La longueur de la tête est contenue quatre fois à quatre fois et trois quarts dans la longueur totale; les mâchoires sont égales ; elles sont munies, l'une et l'autre, de dents en cardes assez fines, régulières; les dents de la rangée externe sont un peu plus fortes que les autres, surtout en avant, où elles sont un peu crochues. Le diamètre de l'œil, suivant la taille des sujets, est compris trois à quatre fois dans la longueur de la tête; chez les jeunes, il est aussi grand que l'espace préorbitaire, il est moins grand, chez les adultes; le sous-orbitaire antérieur est échancré sur le bord inférieur, à la réunion de deux pièces qui le composent. Les joues sont couvertes de six à huit rangées d'écailles. - Ec., l. long. 62 à 703 ; l. transv. 2' à 28 . - Le deuxième aiguillon de l'anale est généralement plus développé que les autres; la caudale mesure environ le cinquième de la longueur totale; les pectorales sont de longueur variable : tantôt elles arrivent à la première épine de l'anale, tantôt elles n'atteignent pas à l'anus ; la longueur des ventrales est comprise cinq fois et demie à six fois dans la longueur totale.

D. $11 / 11$ ou $12 ;$ A. $3 / 9$ ou $10 ;$ C. 15 a $17 ;$ P. $15 ;$ V. 1/5.

Le corps est ordinairement gris brunàtre sur le dos, argenté sur les côtés, avec quinze à vingt-deux lignes longitudinales d'un jaune doré; parfois les flanes paraissent d'un gris teinté de brun avec les lignes longitudinales noirâtres; l'opercule est bordé de brunâtre. La dorsale et l'anale sont d'un gris violacé ou d'un bleu noirâtre; la caudale est grise, bordée de brun foncé; les pectorales sont grises; les ventrales plus ou moins brunâtres. - La vessie natatoire, développée, est terminée en arrière par deux prolongements coniques.

Habitat. Toutes nos còtes. 
2. LE GANTHËLE BRÊME. - CANTHARUS BRAMA.

Poiss. France, t. III, p. 82.

Long. : 0,23 à 0,3 .

La hauteur du tronc est comprise trois fois et deux tiers dans la longueur totale, et la longueur de la tête quatre fois et un tiers à quatre fois et demie; la nuque est tranchante; la ligne du profil supérieur de la lête est légèrement concave; la màchoire supérieure paraît un peu plus avancée que la mandibule, elles sont garnies l'une et l'autre de dents en cardes, plus fortes à la rangée externe. Le diamètre de l'oil mesure le quart de la longueur de la tête, les trois quarts de l'espace préorbitaire. Les joues portent neuf rangées de petites écailles. Ec., l. long. 62 ; 1. transv. 28 à 30. - La caudale est fourchue, elle mesure le quart de la longueur totale; les pectorales arrivent à l'aplomb de la région épineuse de l'anale, elles font plus du quart de la longueur totale; les ventrales sont d'un tiers au moins plus courtes que les pectorales.

$$
\text { D. } 11 / 12 ; \text { A. } 3 / 10 ; \text { C. } 17 \text {; P. } 15 ; \text { V. } 1 / 5 \text {. }
$$

Le corps est d'un gris arg’enté avec des bandes longitudinales dorées.

Habitat. Méditerranée, excessivement rare. Océan? Arcachon; Charente-Inférieure, Vendée. Hanche? Cherbourg.

3. LE GANTHËRE ORBICULAIRE. - CANTHARUS ORBICULARIS,

Poiss. Frunce, 1. III, p. 34 .

N. vulg. : Cantha rounda, Cette.

Long. : 0,30 à 0,40 , quelquefois plus.

La hauleur du tronc est comprise deux fois et un sixième ì deux fois et trois quarts dans la longueur totale. La longueur le la tète est contenue trois fois et un tiers à quatre fois dans a longueur tolale; la mâchoire supérieure est égale à la manlibule, garnies l'une et l'autre de dents en cardes, plus fortes à 
la rangée externe. Le diamètre de l'œeil est compris, suivant le développement des sujets, trois fois à quatre fois et demie dans la longueur de la tête, il est parfois d'un tiers moins grand que l'espace préorbilaire. Il y a sur la joue sept rangées d'écailles. Ec., 1. long. 66; 1. transv. 23 ou 26. - L'anale a la troisième épine plus forte que les autres; la pectorale est développée, sa longueur fait le quart, ou peu s'en faut, de la longueur totale; la longueur de la ventrale en fait à peine le sixième.

$$
\text { Br. 6. - D. } 11 / 12 \text {; A. } 3 / 10 \text {; C. } 17 \text {; P. } 13 \text {; V. } 1 / 5 \text {. }
$$

Le corps est d'un gris argenté, avec des bandes longitudinales d'un brun à reflets jaunâtres; les écailles sont généralement marquées d'un trait vertical jaunâtre et bordées de gris. Les ventrales sont brunâtres; les autres nageoires sont d'un bleu violacé plus ou moins foncé.

Habitat. Méditerranée, excessivement rare, Nice; Cette, très rare.

\section{วั. Sous-Famille des Denticiniens, Denticini.}

Corps ovale, comprimé, couvert d'écailles pectinées.

Tête forte; dents pointues, en velours et en crochets; à chaque màchoire, au moins quatre dents plus développées que les autres, des canines; chez les grands spécimens, il existe de très petites molaires arrondies sur le bord interne des màchoires.

A ppareil branchial; six rayons branchiostègres.

Nageoires; dorsale ayant dix à douze aiguillons et neuf à douze rayons mous; anale à trois épines et huit ou neuf rayons mous; caudale fourchue.

- Vessie natatoire échancrée en arrière. - Appendices pyloriques peu nombreux.

GENRE DENTÉ. - DENTET, Cuv.

Caractères de la sous-famille.

Diamètre de l'œil plus petit que l'espace préorbitaire. 1. овdrnarne. plus grand que l'espace préorbitaire. 2. AUX GROS YecX. 


\section{LE DENTÉ ORDINAIRE. - IIENTEX VULG.IRIS.}

Poiss. France, t. III, p. כ̋6.

N. vulg. : Dente et Dentou, Port-Vendres; Dentanu, Denté, Celte; I.ente, Nice.

Long. : 0,30 à 0,30 , quelquefois 1,00 .

La hauteur du tronc est comprise trois fois et un cinquième à trois fois et trois quarts dans la longueur totale. - La longueur de la tête est contenue environ trois fois et trois quarts dans la longueur totale; en avant, les mâchoires sont armées chacune de quatre longues canines fortes et crochues; les canines externes sont les plus développées; à la suite, il y a des dents pointues, parfois en dedans se trouvent de petites molaires arrondies. Chez les jeunes sujets, le diamètre de l'œeil mesure le quart de la lonğueur de la tête, les trois cinquièmes de l'espace préorbitaire; chez les adultes, il fait le cinquième, et moins encore, de la longueur de la tête, la moitié à peine de l'espace préorbitaire. Il y a huit à neuf rangées d'écailles sur la joue. - Ec., l. long. כ̆ à 60 ; l. transv. 22 à 24 . - La longueur de la caudale est comprise environ quatre fois et demie dans la longueur totale; les pectorales en mesurent le quart.

Br. 6 . -D. $11 / 11$ ou 12 ; A. $3 / 7$ ou 8 ; C. 18 ; P. 14 ou 15 ; V. 1/5.

Le dos ést d'un bleu assez pâle; les flanes sont d'un jaune légèrement doré, à reflets argentés, et sont parcourus par des bandes longitudinales grisâtres. Le préopercule est jaunâtre. La dorsale est d'un gris rosé, avec des taches bleues; l'anale et les ventrales sont jaunâtres; la caudale est d'un gris rosé ou rouge pâle; la pectorale est rougeàtre; à l'aisselle est ordinairement une tache d'un bleu foncé. - La vessie natatoire est très grande. - Il y a cinq appendices pyloriques.

Habitat. Méditerranée, assez commun à Nice; assez rare, Cette, Port-Vendres. Océan, golfe de Gascogne, très rare, Arcachon; Charente-Inférieure, excessivement rare, la Rochelle, ile de Ré; Finistère, accidentellement, Concarneau. 


\section{LE DENTÉ AUX GROS VEUX. - DENTEX MACROPHTHALMUS.}

Poiss. France, t. III, p. ว9, fig. 131 .

N. vulg. : Boucca-rouga, Nice.

Long. : $0,2: 3$ à 0,40 .

La hauteur du tronc est comprise trois fois à trois fois et demie dans la longueur totale, et la longueur de la tête environ trois fois et deux tiers; le museau est gros et court; la muqueuse des lèvres et de la bouche est rougeâtre; à la mâchoire supérieure, il y a quatre canines; à la mandibule, en avant, il y a généralement une rangée de huit à douze dents crochues assez fortes, et après une bande de petites dents en velours. Le diamètre de l'œil mesure le tiers de la longueur de la tête; il est plus grand que l'espace préorbitaire. Il y a sur la joue sept rangées d'écailles. - Ec., 1. long. 54 à 56 ; 1. transv. 20. - La caudale fait un peu moins du cinquième de la longueur totale; la longueur de la pectorale, qui est falciforme, est contenue trois fois et demie à trois fois et deux tiers dans la longueur totale.

D. $12 / 9$ ou $10 ;$ A. $3 / 7$ ou 8 ; C. 17 ; P. 15 ou $16 ;$ V. $1 / 5$.

Le dos et les côtés sont rosés; le ventre est argenté, marqué d'un pointillé noirâtre, formant des espèces de losanges sur les saillies. La caudale est rougeàtre; les autres nageoires sont rosées.

Habitat. Méditerranée, très rare, Nice, Cette.

Parfois le Denté du Maroc, Dentex Maroceanus se trouve sur le marché de Marseille, avec des Poissons expédiés d'Algérie; V. Suppl., p. 134 .

\section{Famille des Ménidés, Marnidx.}

Corps; oblong ou cylindroïde, couvert d'écailles cténoïdes.

Tête assez développée; bouche très protractile; intermaxillaire à branche montante très longue; màchoires garnies de dents envelours, ou en cardes fines, avec ou sans canines.

Appareil branchial; ouies largement fendues; opercule ter- 
miné postérieurement en pointe assez aiguë; pièces operculaires et joues écailleuses; six rayons branchiostèges; pseudobranchies.

Nageoires; dorsale unique, composée généralement de vingtdeux rayons $11+$, pouvant s'abaisser lans un sillon; anale à trois aiguillons; caudale échancrée ou légèrement fourchue ; ventrales à six rayons; au bord externe de ces nageoires est une écaille axillaire plus ou moins longue, entre leur bordinterne estune écaille impaire.

Vessie natatoire grande, ordinairement bifurquée en arrière. Appendices pyloriques au nombre de quatre à sept, rarement de trois.

Cette famille comprend deux genres.

Vomer denté............................. Mendole.

- non denté........................... Pránel.

1. GENRE MENDOLE. - I ENA, Guv.

Tête assez longue; vomer denté.

Ce genre est composé de quatre espèces.

a. Dents du vomer en groupe sur le chevron......... bande longitudinale......... b.

6. Canines de la mandibule nulles ou fort courtes..... - $\quad$ - assez grandes.............

c. Écaille externe de la ventrale faisant plus de la moitié

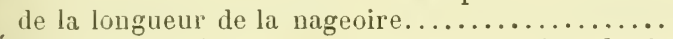

Écaille externe de la ventrale faisant moins de la moitié de la longueur de la nageoire........... 1. comuune.

\section{LA MENDOLE COMMUNE. - MEYA VULGARIS.}

Poiss. France, t. III, p. 64, fig. 142, anim.

N. vulg. : Mata-souldat, Port-Vendres, Cette ; Amendoula, Nice.

Long. : 0,1 à à 0,20 .

La hauleur du tronc est comprise trois fois et demie à trois fois et trois quarts dans la longueur totale, et la longueur de la tête quatre fois el un cinquième à quatre fois et demie; la mâchoire supérieure est garnie de dents assez fines, plus fortes à la rangée externe; outre ses dents en velours, la mandibule porte en avant deux canines assez développées; sur le romer est une rangée longitudinale de dents en velours. Le diamètre de l'cil mesure à peu près le quart de la longueur 
de la tête, il est à peine moins grand que l'espace préorbitaire. Il y a généralement cing grandes rangées d'écailles sur la joue, plus une très courte. - Ec., l. long, 74 à 76 ; l. transv. 20. L'épine, la plus développée de la dorsale, est d'une longueur sensiblement égale au tiers de la hauteur du tronc; l'écaille axillaire externe de la ventrale ne fait guère plus du liers de la longueur de la nageoire.

$$
\text { Br. 6. -D. } 11 / 11 \text {; A. } 3,9 \text {; C. } 17 \text { ou } 18 \text {; P. } 15 \text {; V. } 1 / 5 \text {. }
$$

Le dos est grisâtre ou gris plombé, marqué de cinq ou six raies longitudinales brunâtres; les flancs sont jaunâtres, semés de taches.bleues; le ventre est argenté; une grande tache noire s'étale sous la ligne latérale, au-dessus du tiers postérieur de la pectorale. La dorsale est couleur olive avec quelques taches rougeàtres; l'anale et la caudale sont jaunâtres, tachetées de bleu; les nageoires paires sont rougeâtres ou gris rougeâtre.

Habitat. Méditerranée, assez commune de Nice à Port-Vendres. Océan? Bayonne.

\section{LA MENDOLE D'OSBECK. - MENA OSBECKII.}

Poiss. France, t. III, p. 66.

N. vulg. : Gora, Nice.

Long. : 0,13 à 0,20 , quelquefois 0,23 .

La hauteur du tronc est comprise trois fois et un tiers à quatre fois clans la longueur totale, et la longueur de la tête, quatre fois et un tiers à quatre fois et deux tiers; la mandibule est armée de canines relativement fortes, dirigées en avant. Le diamètre de l'wil est contenu quatre fois à quatre fois et un tiers dans la longueur de la tête; il fait environ les deux tiers de l'espace préorbilaire. La joue porte cinq rangées principales d'écailles plus une petite. - Ec., l. long. 70; 1. transv. 19 à 21. - L'écaille axillaire externe de la ventrale est très grande, faisant plus de la moitié de la longueur de la nageoire.

$$
\text { D. } 11 / 10 \text { ou } 11 \text {; A. } 3 / 9 ; \text { C. } 17 \text {; V. } 1 / 5 \text {. }
$$


Le corps est lacheté de bleu; il est d'un jaune brunâtre plus ou moins foncé vers le dos, argenté sur les flanes; la tache noire du côté est ordinairement au-dessous des derniers rayous épineux el des premiers rayons mous de la dorsale. Les nagreoires impaires sont presque noires, ou bien olivâttres, marquées de taches bleues; les nageoires paires sont jaunàtres.

Habitat. Méditerranée, assez commune, Nice, Cette.

\section{LA MENDOLE JUSCLE. - MENA JUSCULUM.}

Poiss. France, t. III p. 67.

Long. : 0,13 à 0,18 .

La hauteur du corps est contenue quatre fois à quatre fois et quart dans la longueur totale et la longueur de la tête quatre fois et un tiers à quatre fois et trois quarts; les màchoires sont munies de très petites dents; à la mandibule, les dents antérieures ne sont pas saillantes, elles sont à peine différentes des autres. Le diamètre de l'oil est compris trois fois et demie dans la longueur de la tète, il est à peu près égal à l'espace préorbitaire. Il y a sur la joue cinq rangées d'écailles, plus une petite série. -- Ec., l. long. 70 ì $\dddot{̋}$; 1. transv. 20 à 23. - La rentrale est courte; sa longueur mesure à peine le sixième de la longueur totale; l'écaille axillaire externe fait à peu près la moitié de la longueur de la nageoire

$$
\text { D. } 11 / 11 ; \text { A. } 3 / 9 ; \text { C. } 17 \text {; P. } 15 ; \text { V. } 1 / 5 \text {. }
$$

Le dos est brunâtre; les flanes sont d'un gris argenté avec quatorze ou quinze lignes longitudinales brunattres souvent peu distinctes; la tache noire du cóté est bien marquée, elle longe le bord inférieur de la ligne latérale, répondant au $6^{\mathrm{c}}, 7^{\mathrm{e}}$ ou $8^{\mathrm{e}}$ aiguillon de la dorsale. Les nagreoires sont d'une teinte grise uniforme sans taches.

Habitat. Méditerrannée, le Juscle est assez commun à Nice, plus rare à Cette. 


\section{LA MENDOLE VOMÉRINE. - MENA VOMERINA.}

Poiss. France, t. III, p. 69.

Long. : $0,12,0,20$.

La hauteur du tronc est contenue trois fois et deux tier's à quatre fois et un tiers dans la longueur totale, et la longueur de la tête quatre fois et demie; la mâchoire supérieure est garnie de dents en cardes; la mandibule est armée de quatre à six canines crochues, plus développées que les autres dents, chez les adultes; le vomer porte sur le chevron un groupe de dents fines, pointues, dont la rangée externe circonscrit une espèce d'ovale. Le diamètre de l'œil est compris trois fois à trois fois et demie dans la longueur de la tête; il est égal à l'espace préorbitaire. La joue est couverte de cinq rangées d’écailles. - Ec., l. long. 60 à 62; l. transv. 23. - L'écaille axillaire externe de la ventrale ne fait guère que le tiers de la longueur de la nageoire.

\section{D. $11 / 11 ;$ A. $3 / 9 ;$ C. 17 ; P. $15 ;$ V. $1 / 5$.}

Le dos est jaunâtre; les flanes sont grisâtres; la tache du côté est souvent peu marquée. Les nageoires sont d'une teinte uniforme, sans taches; elles sont jaunâtres, excepté les pectorales, qui sont grisâtres.

Habitat. Méditerranée, la Vomérine est assez commune à Nice, plus rare à Marseille; assez commune à Celte.

\section{GENRE PICAREL. - SMARIS.}

Tête plus ou moins allongée; vomer nou denté.

Ce genre est composé de cinq espèces.

a. Hauteur du trone contenue moins de cinq fois dans la longueur totale..................

Hanteur du tronc contenue cinq fois et plus dans la longueur totale. ............... $d$.

$b$. Écailles de la ligne longitudinale au nombre de

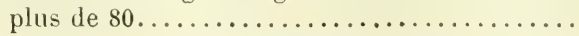

Écailles de la ligne longitudinale, moins de 80. $c$.

1. ORDINAIRE. 
c. Tache noire dans le $1^{\text {er }}$ espace intraradiaire de

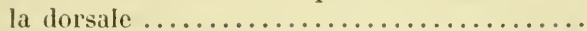

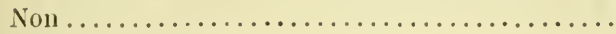

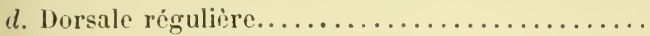

Dorsale très échancréc.

2. MARTIN-PÉCHEUR.

3. CHRYSĖLE.

4. De Mauri.

5. INSIDATEUR.

\section{LE PIGAREL ORDINAIRE. - SHARIS VULGARIS.}

Poiss. France, t. III, p. 70.

N. vulg. : Mata-souldat, Port-Vendres; Vernieira, Berniëyda, Celte; Picarel, Giarret, Gerret, Languedoc, Provence.

Long. : 0,13 à 0,18 .

La hauteur du tronc est comprise quatre fois et quart à quatre fois et trois quarts dans la longueur totale, elle est sensiblement égale à la longueur de la tête; les mâchoires portent une bande de petites dents en velours ou en cardes fines; de plus à l'extrémité de la mandibule sont deux petites canines crochues. Le diamètre de l'œil est contenu trois fois à trois fois et deux tiers dans la longueur de la tête; il est égal, ou peu s'en faut, à l'espace préorbitaire. Il y a sur la joue quatre rangées d'écailles, plus une petite série vers le bord du préopercule. - Ec., I. long. 86 à 92; 1. transv. 19 ou 20. - La ventrale est moins développée que la pectorale.

$$
\text { Br. } 6 .- \text { D. } 11 / 11 \text {; A. } 3 / 9 \text {; C. } 17 \text {; P. } 15 ; \text { V. } 1 / 5 \text {. }
$$

La teinte générale est un gris jaunâtre, plus rembruni à la région dorsale; la tache du côté est très marquée. La coloration des nageoires est très variable; ordinairement la dorsale et la caudale sont grisâtres, l'anale et les nageoires paires sont d'un gris jaunâtre; parfois il y a des points rouges sur la dorsale et la caudale.

Habitat. Méditerranée, assez commun à Nice, moins commun à Cette.

Steindachner considère le Sm. gagarella, C.V., et le Sm. chryselis C.V., comme étant l'un le màle, l'autre la femelle d'une même espèce dont le Sm. vulyaris serait encore une femelle; mais chez le Sm. vulgaris, le nombre des écailles dans une lignelongitudinale est de 86 à 92 , il n'est que de 70 environ chez le Sm. chryselis dont le Sm. gagarella est probablement la femelle, d'après C. Bonaparte.

Moreat. - Ichthyologic. 
2. LE PIGAREL MARTIN-PEACHEUR. - SHARIS ALCEDO.

Poiss. France, t. III, p. 73, fig. 133 anim.

N. vulg. : Gerle blavié, Nice; Varlet de ville, Marseille.

Long. : 0,15 à 0,20 .

La hauteur du tronc est contenue quatre fois à quatre fois et trois quarts dans la longueur totale, la longueur de la tête quatre fois et quart à quatre fois et deux tiers; l'extrémité de la mâchoire supérieure arrive un peu en arrière du bord antérieur de l'orbite. Le diamètre de l'œil est compris trois fois et un tiers à quatre fois dans la longueur de la tête; il est moins grand que l'espace préorbitaire. Il y a quatre rangées d'écailles sur la joue, plus une rangée fort étroite, peu distincte vers le limbe inférieur du préopercule. - Ec., l. long. 70 ; l. transv. 18. - Les ventrales sont de longueur variable, tantôt aussi longues, tantôt plus courtes que les pectorales.

$$
\text { Br. } 6 .- \text { D. } 11 / 11 \text {; A. } 3 / 9 \text {; C. } 17 \text {; P. } 15 \text {; V. } 1 / 5 \text {. }
$$

Le dos est d'un brun fort clair à reflets jaunâtres; les côtés sont gris avec trois bandes longitudinales d'un bleu assez clair et d'autres bandes jaune doré ; les pièces operculaires et la tête sont ordinairement traversées par des bandes bleuâtres; la tache noire du côté est grande, plus ou moins marquée. Les nageoires impaires sont d'un jaune très pâle avec des taches bleu assez clair; une tache foncée se voit entre les deux premières épines de la dorsale; les pectorales sont d'un jaune orange, les rentrales sont d'un bleu mêlé de roux avec une bordure jaunâtre.

Habitat. Méditerranée, assez commun à Nice ; commun à Cette.

D'après Steindachner, le Sm. gracilis, Bp., est la femelle du Sm. alcedo, Riss., dont le Sm. Maurii, Bp., est une variété màle; ils ne seraient nullement, ainsi que l'avait indiqué $\mathrm{C}$. Bonaparte, le màle et la femelle d'une espèce distincte. - Regarder, comme étant les màles du Sm. gracilis, deux spécimens d'aspect aussi dissemblable, est une opinion qu'il est difficile d'accepter. - Assurément si le $S m$. alcedo doit ètre rapproché d'une des espèces admises par les auteurs, c'est du Sm. chryselis; en effet chez ces Picarels, le nombre 
des écailles des lignnes longitudinales, les proportions du corps, de la tète, etc., sont à peu près les mèmes; la tache noire, qui marque le premier espace intraradiaire de la dorsale du Sm. alcedo, qui manque dans le Sm.chryselis, est le principal caractère différentiel, caractère, il fautbien le reconnaitre, d'assez mince valeur.

\section{LE PIGAREL CHRYSELE. - SMARIS CHRYSELIS.}

Poiss. France, t. III, p. 7ว.

N. vulg. : Vernieïra, Cette.

Long. : $0,1 \ddot{\text { à }} 0,20$.

Le Picarel chrysèle et le Picarel gagarel sont de mème espèce. La hauteur du tronc est contenue trois fois et quatre cinquièmes à quatre fois et quart dans la longueur totale, la longueur de la tète en mesure le quart environ; les mâchoires ont une bande de petites dents en velours ou en cardes fines, et souvent, près de leur symphyse, de faibles canines. Le diamètre de l'œil est compris trois fois et quart à trois fois et demie dans la longueur de la tête; il est égal, ou peu s'en faut, à l'espace préorbitaire. Les écailles de la joue sont disposées comme dans les espèces précédentes. - Ec., 1. long. 69 à 71 ; l. transv. 18 . - Les nageoires paires sont geénéralement d’égale longueur.

$$
\text { D. } 11 / 11 \text {; A. } 3 / 9 \text {; C. } 1 \text { i; P. } 15 \text { ou } 16 \text {; V. } 1 / 5 \text {. }
$$

Le dos est grisâtre; les côtés sont d'une teinte plus claire à reflets jaunâtres, parcourus par des bandes longitudinales d'un bleu fort pàle; de petites taches bleuâtres sont disséminées sur le corps; la tache des flanes est plus ou moins marquée. La dorsale est d'un bleu clair, elle est semée de taches bleues; l'anale est d'un jaune bleuâtre arec des taches azurées; la caudale est généralement marquée de taches d'un bleu foncé; les pectorales et les ventrales sont d'un jaune ̧̧risâtre.

Habitat. Médilerranée, assez commun à Nice, très commun à Jette. 


\section{LE PICAREL DE MAURI. - SVARIS MAURII.}

Poiss. France, t. III, p. 77, fig. 13̈4, anim.

N. vulg. : Ni Vogué ni Verniera, Gerlé, Cette; Jaret, Marseille.

Long. : 0,12 à 0,18 .

Chez le mâle, la hauteur du tronc fait le cinquième de la longueur totale, le sixième chez la femelle. La longueur de la tête est comprise quatre fois et un tiers à quatre fois et demie dans la longueur totale; les mâchoires sont garnies de fort petites dents; à l'extrémité de la mandibule sont deux canines très peu développées. Le diamètre de l'œil est contenu trois fois à trois fois et quart dans la longueur de la tête, il est à peu près égal à l'espace préorbitaire. Sur la joue, il semble n'y avoir que trois rangées d'écailles. - Ec., l. long. 80; 1. transv. 18 ou 19. - Les derniers rayons de la dorsale et de l'anale sont courts dans la femelle (Sm.gracilis, Bp.), allongés chez le mâle (Sm. Maurii, Bp.).

\section{D. $11 / 11$ ou $12 ; \mathrm{A} .3 / 9$.}

Le dos est d'un bleu argenté à reflets jaunâtres; les côtés sont d'une teinte plus claire; le ventre est blanchâtre; la tache des flancs est grande et très distincte, chez la femelle surtout. Les nageoires sont rosées ou d'un rouge jaunàtre plus ou moins teinté de gris.

Habitat. Méditerranée, assez rare, Cette, Marseille.

\section{LE PICAREL INSIDIATEUR. - SUARIS INSIOLATOR.}

Poiss. France, t. III, p. 78 et Suppl., p. 48.

Long. : 0,13 à 0,20 .

La hauteur du tronc est comprise cing fois et trois quarts à six fois et demie dans la longueur totale, la longueur de la tête quatre fois à quatre fois et quart; l'extrémité de la mâchoire supérieure se porte en arrière au-delà du bord antérieur de l'orbite; le diamètre de l'cil mesure à peu près le tiers de la 
longueur de la tête, il est égal, ou peu s'en manque, à l'espace préorbitaire. Il y a cinq rangées d'écailles sur la joue. - Ec., 1. long. 8.; à 90 (?); l. transv. 18 à 19. - La dorsale est profondément échancrée; elle est soutenue par treize aiguillons et neuf rayons mous.

$$
\text { D. } 13 / 9 \text {; A. } 3 / 10 \text {; C. } 17 \text {; P. } 15 \text {; V. } 1 / 5 \text {. }
$$

La coloration est d'un brun plus ou moins rougeâtre sur le dos, blanc argenté sous le ventre; la tache noirâtre des flancs parail toujours manquer; il y a souvent une tache brune à la base de la pectorale. - D'après Curier et Valenciennes, la ressie nalatoire est simple, non bifurquée en arrière; il y a seulement trois appendices pyloriques.

Habitat. Méditerranée, excessivement rare, Nice.

\section{Famille des Labridés, Labridx.}

Corps ovale, plus ou moins allongé, couvert d'écailles cycloïdes. Tête; màchoires dentées; langue et palais lisses.

Appareil branchial; cinq ou six rayons branchiostèges; quatrième arc branchial ne portant en général qu'une série simple de lamelles respiratoires; pseudobranchies; pharyngiens inférieurs soudés en une seule plaque dentée.

Nageoires; dorsale longue, à rayons antérieurs épineux; ventrales thoraciques, ayant une épine et cinq rayons mous.

Vessie natatoire développée, sans conduit pneumatophore. Appendices pyloriques manquant.

Cette famille se subdivise en deux sous-familles.

Dents des màchoires séparées.................... 1. Labriniens.

- $\quad$ - soudées...................... 1. Scariniens.

1. Sous-famille des Labriniens, Labrini.

Tête; dents des màchoires isolées;

Cette sous-famille est composée de sept genres.

$a$. Joue et opercule écailleux................. b.

b. Préopercule lison écailleux............... $f$.

$b$. Préopercule lisse......................... 1. Labre.

dentelé.................... $c_{\text {. }}$ 
$c$. Dents des màchoires sur une seule rangée..... d.

- - plusieurs rangées. $e$.

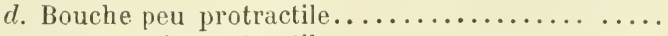

2. Crénilabre.

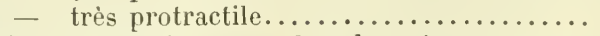

e. Épines de l'anale au nombre de trois...........

3. Sublet.

4. Ctténolabre.

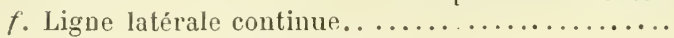

quatre au moins. 5. Acantholabre.

interrompue $\ldots \ldots \ldots \ldots \ldots \ldots \ldots$

6. Girelle.

7. Rason.

\section{GENRE LABRE. - IABRUS, Arted.}

Gorps oblong, portant plus de 40 écailles dans une ligne longitudinale (Blkr.).

Tête ; museau nu, allongé ; bouche moyenne, à lèvres épaisses et plissées; màchoires ayant une seule rangée de dents coniques.

Appareil branchial ; cinq rayons branchiostèges; interopercule nu, ou n’ayant en général que fort peu d'écailles; opercule, sousopercule et joue couverts d'écailles; au moins sept rangées d'écailles sur la joue.

Ligne latérale bien marquée, non interrompue.

Nageoires; dorsale ayant de quinze à vingt et un rayons épineux et de huit à douze rayons mous; anale à trois aiguillons et huit à douze rayons mous; un lambeau charnu dépasse ordinairement la pointe des épines, surtout à la dorsale ; caudale carrée, avecles angles arrondis, à base écailleuse.

Le genre Labre se compose de huit espèces.

a. Tache bleue sur l'angle postérieur et supérieur de l'o-

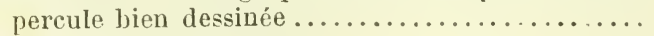

Tache bleue manquant.................. $b$. b. Longueur de la tête égale à la hauteur du tronc.. $c$.

Longueur de la tête d'un quart environ plus grande que la hauteur du tronc................ $f$.

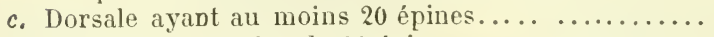

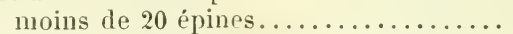

d. Bandes longitudinales brunâtres, sous la ligne laté-

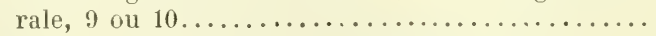

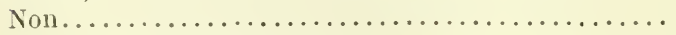

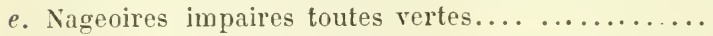

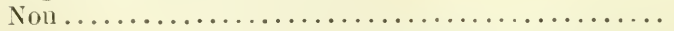

f. Traits noirs (parfois un seul) autour de l'orbite...

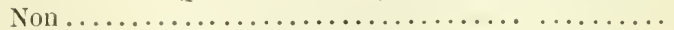

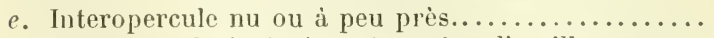
Interopercule ì plusieurs rangées d'ecailles........

8. DES ROCHES.

1. Vieille. d.

4. LINE์OLÉ. e.

2. TOURD.

3. MERLE.

5. PARÉ.

6. VERT.

7. MÈLÉ. 


\section{LE LABRE VIEILLE OU VIEILLE COMNUNE. - LABRUS} BERGYLTA, Ascan.

Poiss. France, I. III, p. 81, et t. I, p. 164, fig. 19, os hyoïde.

N. vulg. : Vieille, Vieille verte, jaune, tachetée; Carpe et Tanche de mer; Perroquet de mer, còtes de Normandie; Grande Vieille, Fécamp ; Vras, Cherbourg; Vrac, Granville; Crahotte, Còtes-du-Nord.

Long. : 0,30 à 0,40 et mème 0,30 .

La hauteur du tronc est comprise trois fois et demie à quatre fois dans la longueur totale, la longueur de la tête trois fois et deux tiers à quatre fois. Le diamètre de l'weil est conlenu quatre fois et un tiers à cinq fois et demie dans la longueur de la tête; chez les grands, il mesure la moitié de l'espace préorbitaire, les deux tiers chez les jeunes. Il y a généralement deux ou trois écailles sur l'interopercule et neuf ou dix rangées sur la joue. -- Ec., l. long. 41 à 47;1. transv. 19 à 23. - La dernière épine de la dorsale répond à la première de l'anale.

D. 20 ou $21 / 10$ ou 11 ; A. $3 / 8$ à 10 ; C. 14 ; P. 14 ou 15 ; V. $1 / 5$.

Le système de coloration est des plus variables. La teinte est rarement uniforme; le corps et les nageoires sont marquées de taches plus ou moins arrondies, plus ou moins régulières; souvent le corps est d'un ton rerdâtre, traversé par des lignes, plus ou moins régulières, d'une teinte rouge brique, limitant des mailles, arec les nageoires rouge brique, la dorsale portant un plus ou moins grand nombre d'ocelles; parfois le corps est verdâtre avec des taches nacrées et toutes les nageoires sont vertes; parfois le corps est bleuâtre avec des taches rougeâtres, etc.

$$
\text { VAR. a. - Le Labre pesiquit. }
$$

Dans cette variété, qui se trouve parfois à Biarritz, la tète et le corps sont d'une teinte uniforme, rouge assez pàle, avec les nageoires d'un jaune rougeàtre; une petite tache noire marque la base des deux derniers rayons de la dorsale. 
Var. b. - La Vieille Verte. - Labrus Donovani, Valenc.

La tête, le corps et les nageoires sont d'une teinte verdàtre; une petite bandelette blanche part de l'œil et se porte jusqu'à la caudale ; il n'y a pas d'ocelles sur les nageoires.

Habitat. Toutes les còtes de l'Ouest. Manche assez commun,Picardie, Normandie; commun, Còtes-du-Nord; très commun dans le Finistère. Océan assez commun, jusqu'à l'embouchure de la Loire; moins commun au-dessous.

\section{LE LABRE TOURD. - L.ABRUS TURDUS, Linn.}

Poiss. France, t. III, p. 8 3̈.

Long. : 0,1 à à 0,30 .

La hauteur du tronc, qui est sensiblement égale à la longueur de la tête, est comprise trois fois et demie à quatre fois dans la longueur totale. Le diamètre de l'œil mesure environ le cinquième de la longueur de la tête, il est d'un tiers moins grand que l'espace préorbitaire. Il y a deux ou trois écailles sur l'interopercule; il y en a une huitaine de rangées sur la joue. - Ec., I. long. 42; l. transv. 18. - Les ventrales sont courtes.

D. 17 ou $18 / 11$ à $14 ; A .3 / 10$ à 12 ; C. 13 ou $14 ;$ P. 14 ; V. $1 / 5$.

La coloration est d'un beau vert plus foncé sur le dos que sur les flancs; une bande blanchâtre, parfois un peu lilas, part de l'ceil et se termine à la caudale; le rentre et la gorge sont d'un vert jaunâtre avec des taches blanches. II ne semble pas y avoir d'ocelles sur les nageoires; les nageoires impaires sont vertes; la dorsale porte une seule tache noire à la base de ses deux ou trois derniers rayons mous; l'anale est bordée d'un petil liséré lilas; la pectorale est d'un vert légèrement jaunâtre avec une bordure rougeâtre, et un trait brun vers la base; la ventrale est d'un verdâtre tirant sur le jaune. Parfois, chez les jeunes surtout, il n'existe pas de bande visible sur les côtés, mais la tache brune qui marque la base des derniers rayons de la dorsale ne paraît jamais manquer.

Habitat. Méditerranée, assez commun, Nice, Cette. 
3. LE LABRE MERLE. - LABRUS MERULA, Linn.

Poiss. Franre, t. III, p. 87.

N. vulg. : Roucaou, Cette.

Long. : 0,20 à 0,30

La longueur du tronc est comprise trois fois et deux tiers à quatre fois et trois quarts dans la longueur totale. La longueur de la tête présente à peu près les mêmes proportions. Les lèvres sont épaisses, d'un lilas foncé; les dents sont régulières ; de chaque còté, il y en a huit ou neuf à la mâchoire supérieure et dix à douze à la mandibule. Le diamètre de l'wil est contenu quatre fois et demie à six fois dans la longueur de la tête; autour de l'orbite se trouvent des pores assez étroits. Le sousopercule n’a parfois qu'une seule rangée d'écailles; l'interopercule porte une ou deux écailles à sa partie supérieure; la joue est couverte de sept à dix rangées d'écailles. - Ec., l. long. 12 à $46: 1$. transv. 18 ou 19. - Les ventrales sont insérées un peu après le tiers antérieur de la longueur des pectorales.

D. 17 à $19 / 11$ ou $12 ; A .3 / 8$ ou 9 ; C. 13 à $15 ;$ P. 15 ; V. $1 / 5$.

Le dos est d'un bleu foncé; les côtés sont d'un bleu plus clair; le ventre est d'un brun violacé ou lilas. Les nageoires impaires et les pectorales sont d'un bleu très foncé; l'anale porte une bordure d'un bleu assez clair; les ventrales sont brunâtres avec un liséré bleu clair ou violacé.

\section{VAr. a. - Le Labre livide. - Labrus livilus.}

La teinte est d'un gris plus ou moins sombre vers la région supérieure, un peu clair sur les còtés et le ventre. La dorsale est grisàtre; l'anale olive arec une bordure noiràtre; les pectorales sont d'un gris jaunàtre; les ventrales noiràtres, sans bordure; parfois une tache marque la base des derniers rayons mous de la dorsale.

\section{VAR. b. - Le Labre borlé. - Labrus limbalus.}

La teinte générale est grisàtre avec une bande brune allant de la tète à la caudale; les nageoires impaires sont brunàtres; l'anale est bordée de noir ; la dorsale porte une petite tache noire sur ses deux 
premiers aiguillons et une autre plus grande à la base de ses deux derniers rayons mous; ordinairement il existe une tache noiràtre à la base de la pectorale.

Habitat. Méditerranée, assez commun, Nice, Toulon, Marseille, les Martigues, Cette.

\section{LE LABRE LINÉOLÉ.- LABRUS LINEOLA TUS, G.V.}

Poiss. France, t. III, p. 89.

Long. : 0,20 à 0,30 .

La hauteur du tronc est contenue trois fois et demie environ dans la longueur totale; et la longueur de la tête trois fois et deux tiers à quatre fois; le diamètre de l'œil est compris cinq fois et demie à six fois dans la longueur de la tête; vers le bord supérieur de l'orbite se trouvent des pores assez nombreux; il ne paraît y avoir aucune écaille sur l'interopercule; la joue est garnie de huit rangées d'écailles. - Ec., l. long. 43; 1. transv. 18. - La portion molle de la dorsale semble aussi haute que longue.

D. $18 / 11$ ou $12 ;$ A. $3 / 9$; C. $14 ;$ P. $15 ;$ V. $1 / 5$.

Le dos est brunâtre; le ventre et la gorge sont argentés; au-dessous de la ligne latérale, il y a une dizaine de rayures longitudinales brunâtres, plus ou moins marquées, séparées les unes des autres par des taches blanchâtres. Les nageoires sont d'une teinte pâle.

Habitat. Méditerranée, très rare, Nice, Toulon.

5. LE LABRE PARÉ. - LABRUS FESTIVUS, Riss.

Poiss. France, t. III, p. 91.

N. vulg. : Sera, Nice; Roussignoou, Cette.

Long. : 0,20 à 0,40 .

La hauteur du tronc est comprise quatre fois et demie à cinq fois dans la longueur totale. La longueur de la tête, qui l'emporte d'un quart environ sur la hauteur, est contenue trois fois et un tiers à trois fois et deux tiers dans la longueur totale. 
Le diamètre de l'ail est compris six à sept fois dans la longueur de la tête; il est sensiblement égal à l'espace interorbitaire. Il y a sur la joue huit rangées d'écailles. - Ec., l. long. Æ̈; l. transv. 17 à 19. - La dorsale a sa portion épineuse d'un tier's au moins plus basse que sa portion molle.

\section{18 ou $19 / 12$ ou $13 ;$ A. $3 / 10$ ou 11 ; C. 13 ; P. 14 ou 15 ; V. 1/5.}

La coloration est très variable. De la tête à la caudale s'étend une bande qui est ordinairement d'un blanc lilas, mais parfois elle est verdâtre, bleuâtre ou rougeâtre. Le dos est d'un vert jaunâtre ou brunâtre ou d'un bleu sombre arec des taches noires; les flancs sont d'un vert assez clair ou d'un gris jaunâtre, arec des macules blanches ou bleues; le ventre est blanc tacheté de jaune, de vert, d'orange ou marqué de points rouges. La tète est verdâtre ou d'un brun rougeâtre; autour de l'ceil se voient plusieurs traits noirâtres; les opercules et la joue montrent quelques ocelles. - La dorsale est jaunâtre ou d'un grris verdâtre avec des ocelles lilas ou verdâtres; elle porte généralement une tache noirâtre à la base du dernier ou des deux derniers rayons mous; l'anale est jaune verdâtre avec des ocelles verdâtres; la caudale est orangée ainsi que la ventrale, souvent marquée d'ocelles verdâtres; la pectorale a la membrane intraradiaire pâle et les rayons d'un orange clair.

Habitat. Méditerranée, assez commun, Nice, Toulon, Marseille ; assez rare, Cette.

\section{VAr. - Le Labre louche. - Labrus luscus Linn.}

Poiss. France, t. III, p. 93.

Le Labre louche est une simple variété du Labre paré dont il ne diffère que par l'absence de macules, d'ocelles sur les nageoires impaires. - La région supérieure du corps est verdàtre ou rougeâtre avec des macules foncées et des taches nacrées; la région inférieure est blanchàtre, traversée par des bandes orangées; la bande longitudinale est dorée ou blanchàtre, parfois peu distincte. Le sourcil marqué d'un ou deux traits plus ou moins foncés.

Habitat. Méditerranée; assez commun, Nice, Villefranche, TouIon ; plus rare, les Martigues. 
6. LE LABRE VERT. - LABRUS VIRIDIS, Linn.

Poiss. France, t. III, p. 94.

N. vulg. : Rouchié, Séra, Nice; Berdoun ou Verdoun, Celle, Aigues-Mortes.

Long. : 0,20 à 0,30 .

La hauteur du tronc est contenue cinq fois et quart à cinq fois et demie dans la longueur totale, et la longueur de la tête trois fois et demie à quatre fois; le museau est avancé; le diamètre de l'ceil est compris quatre fois et demie à six fois dans la longueur de la tête, suivant la taille des sujets. L'interopercule est nu ou ne porte qu'une, deux écailles; les joues sont garnies de sept à neuf rangées d'écailles. - Ec., l. long. 42 à 13 ; l. transv. 16 à 19 . - La portion molle de la dorsale est d'un tiers ou d'un quart moins haute que longue.

D. 17 à $19 / 10$ à $12 ;$ A. $3 / 10$ ou 11 ; C. 14 ou 15 ; P. 14 ou $15 ;$ V. $1 / 5$.

Le dos et les côtés sont d'un vert magnifique; le ventre est d'un vert jaunâtre avec des points ou des taches d'un bleu plus ou moins foncé; sur les flancs s'étend, de l'œil à la caudale, une bandelette, à fond blanchàtre ou vert clair. Les nageoires sont vertes arec des ocelles lilas; un petit point noir existe à la base des deux derniers rayons mous de la dorsale ; les pectorales sont lègèrement teintées de roux.

\section{VAR. : Le Labre nérée. - Labrus nereus, Riss.}

Chez le Nérée, la dorsale est d'un vert clair avec une bordure jaune rougeàtre; l'anale est d'un vert jaunàtre; la caudale, ainsi que la pectorale, est verte ả la base, rougeàtre à l'extrémité. Les pièces operculaires sont d'un vert tendre, avec des bandes jaunàtres, qui se coupent en formant une espèce de réseau. La bande longitudinale est d'une teinte nacrée ou bleu verdàtre, souvent peu distincte.

Habitat. Méditerranée ; assez commun, Nice, Marseille, les Martigues, Cette. 
7. LE LABRE MÊLE OU VARIÉ. - LABRCS MIXTUS, Fries et Ekstr.

Poiss. France, t. III, p. 96.

N. vulg. : Violon, Cherbourg ; (m.) Vieille rayée, Cherbourg; Roussignaou, Cette; Tenca, Verdoun, Nice; (f.) Coquette, Brest; Counict, le Croizic; Roucaou, Cette; Tenca, Nice.

Long. : 0,18 à 0,30

Ainsi que l’ont démontré Fries et Ekström, le Labre mélé el le Latbre ì trois taches sont l'un le màle, l'autre la femelle d'une mème espèce.

La hauteur du tronc est comprise quatre fois et demic à cinq fois dans la longueur totale, la longueur de la tête trois fois et quart à trois fois et demie; le museau est pointu. Le diamètre de l'ceil est contenu quatre fois et demie à cinq fois et demie dans la longueur de la tête. En arrière, l'interopercule porte plusieurs rangées d'écailles; il y en a huit à douze séries sur la joue. - Ec., 1. long. 30 à $60 ; 1$. transr. 23 à 20 ; le nombre des écailles est sensiblement plus grand que dans les autres espèces.

D. 16 à $18 / 1$ ? a $14 ;$ A. $3 / 10$ ou 11 ; C. 15 ; P. 16 ; V. $1 / 5$.

Chez le màle, la moitié supérieure du corps est le plus souvent d'un brun verdâtre avec quatre ou einq bandes longitudinales bleuâtres, au-dessous d'elles le côté est jaunâtre; parfois la région dorsale est rougeâtre, et au-dessous des handes bleuâtres, le ventre est d'un rouge jaunâtre clair. La dorsale est jaunâtre, arec une longue tache bleue, qui s'étend sur les sept ou huit premiers aiguillons et parfois se prolonge jusqu'au douzième; l'anale et les ventrales sont jaunâtres bordées de bleu; la caudale est un peu jaunâtre à la base, bleue dans le reste de son étendue; les pectorales sont tantôt orangées, tantòt d'un jaune clair, quelquefois d'un rose pâle avec une tache d'un noir bleuàtre à la base. - Chez la femelle, la teinte générale est d'un rouge plus ou moins vif; en arrière, il y a trois taches noires, une sur le troncon de la queue, et deux i la base de la portion molle de la dorsale. Les nageoires sont rougeâtres; les nageoires impaires ont une bordure blanchàtre. 
Habitat. Manche, très rare, Boulogne, Cherbourg. Océan, assez rare, Brest, la Rochelle, Arcachon. Méditerranée, assez commun, Cette, Nice.

\section{LE LABRE DES ROCHES. - LABRUS SAXORUM, C.V.}

Poiss. France, t. III, p. 100, fig. 15\%, anim.

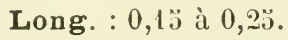

La hauteur du tronc mesure le quart environ de la longueur totale. - La longueur de la tête est comprise trois fois et trois quarts dans la longueur totale; le museau est allongé. Le diamètre de l'œil est contenu cinq fois et demie dans la longueur de la tête. Sept ou huit rangées d'écailles couvrent la joue. - Ec., l. long. 42 à 403 ; l. transv. 13 à 17 . - La ventrale est aussi longue que la pectorale.

$$
\text { D. } 16 \text { à } 19 / 11 \text {; A. } 3 / 9 \text {; C. } 13 \text {; P. } 14 \text {; V. } 1 / 5 \text {. }
$$

Le dos est d'un brun rougeâtre; les còtés, d'un brun lilas, sont marqués de losanges irréguliers; le ventre et la gorge sont d'un lilas assez clair. La tête est d'un brun lilas; sur l'angle postérieur et supérieur de l'opercule, se montre une tache d'un bleu foncé; des taches d'un noir foncé se dessinent sur les pièces operculaires et vers l'orbite; le museau et la lèvre supérieure sont d'une teinte lie de vin. La dorsale et la caudale sont brunes; il y a parfois quelques taches noires sur la dorsale; l'anale est d'un brun rougeâtre, avec quelques ocelles lilas; les ventrales sont noirâtres; les pectorales sont d'un brun peu foncé.

Hab. Méditerranée, très rare, Nice, Marseille.

2. GENRE CRENILABRE. - CRENILABRUS, Cuv.

Corps ovale, ayant au plus 40 écailles dans une ligne longitudinale (Blkr.).

Tête assez forte; dents des màchoires sur une seule rangée.

Appareil branchial; cinq rayons branchiostèges; préopercule à bord postérieur dentelé ou crénelé; pièces operculaires et joue écailleuses; moins de sept rangées d'écailles sur la joue. 
Ligne latérale bien marquée, non interrompue.

Nageoires; dorsale à rayous épineux plus nombreux que les rayons mous; caudale arrondie ou coupée carrément.

Le genre Crénilabre se compose de nombreuses espèces.

a. Tache isolée sur l'opercule bien marquée.... b.

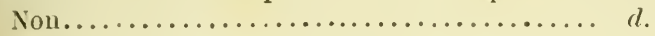

b. Dorsale avec 2 à 5 grandes taches noires.... $c$.

c. Écailles de l'interopercule sur plusieurs ran-

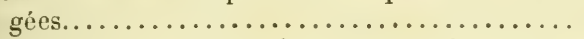

Écailles de l'interopercule sur une seule rangee.

d. Tache noire arquée derrière l'œil générale-

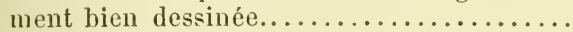

Tache noire arquée derrière l'œil nulle.....

e. Troncon de la queue sans tache noire, ni double trait........................ $f$.

Tronçon de la queue avec tache ou double trait noiraitre.

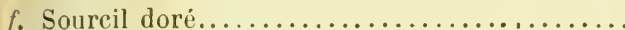

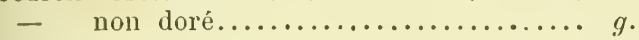

g. Dents égales....................

Dents inégales, incisives supérieures saillantes.

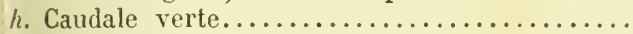

- plus ou moins noirâtre............

i. Tache sur la base de la pectorale plus ou moins

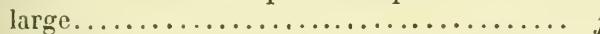

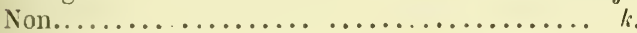

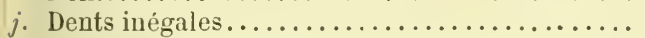

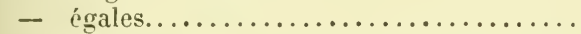

$k$. Tache sur le troncon de la queue, au-dessus de

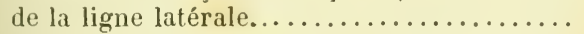

Tache sur le troncon de la queue, au-dessous

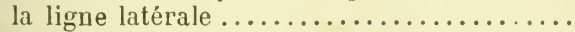

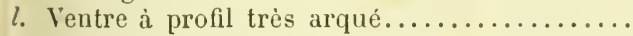
-
ordinaire
...................

$m$. Tache du tronçon de la queue limitée.........

Tache gagnant le bord inférieur du tronçon de

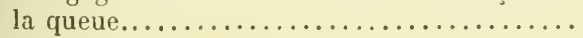

1. oCELIÉ.

2. Rolssal.

3. TIGRÉ.

4. MÉLOPE.

e. f.

$i$.

5. SOURCIL DORÉ.

8. hédtTerRaNéEN.

7. de Batllon.

6. QUEUK NOIRE.

8Dis MÉnIterraNéeN.

9. Petite tanche.

$l$.

$m$.

10. ARQUÉ.

11. VERT-TENDRE.

12. PAON.

13. MASSA.

1. LE CRÉNILABRE OCELLE. - CRENILABRUS OCELLATUS, Forsk.

Poiss. France, 1. III, p. 104.

N. vulg. : Vachetta.

Long. : 0.07 à $0,0,10$, quelquefois 0,12 .

La hauteur du tronc est comprise trois fois et quart à trois fois et deux tiers dans la longueur totale et la longueur de la 
tête trois fois et demie à trois fois et trois quarts; les incisives sont un peu plus fortes que les autres dents et légèrement proclives à la mâchoire supérieure. Le diamètre de l'œil fait le quart environ de la longueur de la tête, il est un peu moins grand que l'espace préorbitaire. Le préopercule est marqué de fines dentelures sur le bord postérieur et sur le bord inférieur; les joues sont couvertes de trois rangées d'écailles. - Ec., l. long. 30 à 34 ; l. transv. 14. - La dorsale est basse en avant; ses épines vont grandissant d'une façon régulière de la première à la dernière.

$$
\text { Br. 5. -D. } 12 \text { a } 15 / . \text { ou } 10 \text {; A. 3/9; C. } 13 \text {; P. 11; V. 1/5. }
$$

La teinte générale est d'un brun jaunâtre ou olive; sourent une bande nacrée s'étend de la fente branchiale à la base de la caudale; la joue et la gorge sont traversées par des bandes verdàtres ou par des raies jaunàtres; la partie postérieure de l'opercule est marquée d'une belle tache bleue entourée d'une bordure rouge. Une tache noire se trouve sur le tronçon de la queue, sous la ligne latérale. La dorsale est de couleur rouille avec ou sans taches azurées; la caudale est jaunâtre, semée de taches bleuâtres; les autres nageoires sont d'un jaune rouğeâtre assez pâle.

\section{VAr. a. - Le Crénilabre olivaitre. - Crenilabrus olivaceus.}

La teinte générale est vert jaunàtre ou vert olive sur le dos et les còtés, blanchàtre sous le ventre, l'opercule est marqué d'une tache assez large, mal définie, d’un vert grisàtre ou bleuàtre; une bande jaunàtre va de l'wil sous la gorge. La dorsale et la caudale sont verdàtres; il y a des taches roussàtres sur l'anale et la portion molle de la dorsale; la pectorale est d'un jaune clair.

\section{VAr. b. - Le Crénilabre littoral. - Crenilubrus littoralis, Riss.}

La teinte est verdàtre, interrompue par de grandes bandes longitudinales argentées; l'opercule porte une tache bleue non ocellée; une dizaine de raies bleues traversent la gorge et l'extrémité des opercules.

Habitat. Méditerranée, très commun, Nice, Port-Vendres; assez commun, Marseille; assez rare, Cette. 
2. LE CRÉNILABRE ROISSAL. - CRENILABRUS ROLSSALI, RisS.

Poiss. France, t. III, p. 107.

N. vulg. : Langaneu, Nice.

Long. : 0,12 ì 0,16 .

La hauteur du trone mesure le tiers environ de la longueur totale, dans laquelle la longueur de la tête est comprise trois fois et quart a trois fois et demie; la bouche est protractile; les dents antérieures sont légèrement proéminentes. L’iris est rougeâtre; le diamètre de l'oil est contenu quatre fois à quatre fois et trois quarts dans la longueur de la tête; il fait à peu près les deux tiers de l'espace préorbitaire. Le bord postérieur de l'opercule est seul dentelé chez les vieux individus; il y a sur la joue quatre à six rangées d'écailles, occupant un espace égal au diamètre de l'cil; il y en a deux ou trois rangées sur l̈interopercule, - Ec, , 1, long. 33 ; 1. transv. 13 .

\section{15 ou $16 / 8$ ou $9 ; A .3 / 8$ ou 9 .}

La coloration est très variable. Le corps est verdâtre teinté de marron, de jaunatre, ou bien parcouru de bandes longitunales bleues et jaunes. L'opercule est marqué d'une tache noire; en avant de l'weil est une courte bande noirâtre. Souvent la queue porte une tache grisàtre, peu marquée. La dorsale est d'un rert clair teinté de roux; dans sa portion molle, elle a deux taches noires entourées d'une bordure orange ou rougeàtre, l'une sur les deux ou trois rayons antérieurs, l'autre sur les trois derniers ou sur les deux avant-derniers rayons; pariois les deux taches se confondent en une bande assez large sur la base de la région molle. L'anale et la caudale sont vertes. La pectorale est d'un vert jaunàtre; à la base est un lrait marron linité par une petite bande verte.

\section{VAR. - Le Crénilabre à cinq tuches. - Crenilabrus quinquemaculatus, Riss.}

Le dos est verditre, le ventre argenté; l'opercule, porte une tache isolée; une tache noiràtre, bien distincle, existe sur le troncon de la queue. La dorsale est marquée de cinq taches noiràtres, la première 
sur les deux premiers aiguillons, la seconde sur les cinquième, sixième et septième; la troisième sur les dixième, onzième et douzième; la quatrième sur les trois premiers rayons mous, la cinquième sur les trois derniers. L'anale a deux taches noiràtres. La caudale et les pectorales sont verdàtres; les ventrales bleuàtres.

II. Sarato considère les Cr. quinquemaculatus, tiyrinus, arcuutus, Riss., comme les femelles du $\mathrm{Cr}$. Roissali.

Habitat. Méditerranée, très commun, Toulon, Marseille; assez commun, Port-Vendres. Océan, le Croisic (C.V.).

\section{LE CRÉNILABRE TIGRÉ. - CRENILABRUS TIGRINUS, Riss.}

Poiss. France, t. III, p. 109.

N. vulg. : Rouquie, Nice.

Long. : 0,08 à 0,12 .

La hauteur du trone est comprise trois fois à trois fois et demie dans la longueur totale; elle est à peu près égale à la longueur de la tête. Les dents antérieures, un peu plus longues que les autres, sont légèrement proclives. Le diamètre de l'œil mesure le quart environ de la longueur de la tête; les trois quarts de l'espace préorbitaire. Il y a sur la joue quatre rangées d'écailles, une seule ordinairement sur l’interopercule. Ec., l. long. 30 ; l. transv. 14.

\section{14 ou $15 / 9 ;$ A. $3 / 8$ ou 9 .}

Le corps est jaune rerdàtre, semé de taches noires; il y a plusieurs taches noirâtres sur les pièces operculaires, il s'en trouve une assez grande vers l'angle postérieur de l'opercule; une bande noirâtre, allant de l'œil au museau, se réunit en arant à celle du côté opposé; une raie noire descend de l'orbite sous la gorge où elle rencontre celle du côté opposé. La dorsale, d'un gris rosé, est traversée par trois bandes de taches dirigées obliquement d'arant en arrière; une tache couleur rouille se montre sur les trois premiers rayons mous et sur l'intervalle qui les sépare du dernier aiguillon. Lanale porte une tache noire assez grande sur le troisième, le quatrième et le cinquième rayon mou, une autre plus petite dans le dernier espace intraradiaire; parfois les taches sont plus nombreuses. 
Le troncon de la queue est marqué d'une pelite tache noire bien circonscrite, au-dessous de la ligne latérale; la caudale est plus ou moins tachetée. Un trait noiràtre marque la base de la pectorale. La ventrale a sur le milieu une tache formant bande transversale.

Habitat. Méditerranée, assez commun, Nice.

4. LE CRENILABRE MÉLOPE. - CRENILABRUS MELOPS, Linn.

Poiss. France, t. III. p. 111.

N. vulg. : Fournie, liouquie, Nice; Clabiëyda rouquièyda, Cette; Pesquit, Biarritz.

Long. : 0,1 à à 0,18 .

La hauteur du tronc est comprise deux fois et trois quarts à trois fois et demie dans la longueur totale, et la longueur de la tête trois fois et demie à quatre fois. Les mâchoires sont égales; les dents sont petites. Le diamètre de l'œil fait plus de la moitié de l'espace préorbitaire, il est contenu quatre fois et demie à cinq fois et demie dans la longueur de la tête. L'interopercule porte une huitaine d'écailles, disposées en deux séries le plus ordinairement. Le préopercule a des crénelures régulières sur le bord postérieur et le bord inférieur. Les joues sont couvertes de cinq ou six rangées d'écailles. - Ec., l. long. 32 à $34 ;$ l. transv. 14 à 16 .

$$
\text { Br. 5.--D. } 14 \text { à } 17 / 8 \text { ou } 9 ; \text { A.3/9; C. } 14 ; \text { P. } 14 ; \text { V. } 1 / 5 \text {. }
$$

Il est impossible d'indiquer les divers systèmes de coloration que présente cette espèce. Le plus souvent la teinte du corps est d'un jaune tirant sur le vert avec des bandes longitudinales foncées et des points bleus sur les côtés; parfois elle est rerte, soit avec des taches ou de courtes bandes marrons, soit arec des macules noires et rougeâtres. Il y a généralement au tronçon de la queue, sous la ligne latérale, une tache noire bien circonscrite. La tête est traversée latéralement de lignes vertes ou bleuâtres; en dessus, elle est d'un brun marron; les lèves sont légèrement verlâtres; derrière l'ceil est une tache arquée, d'un noir bleuâtre, qui manque rarement; du bas de 
cette tache, part souvent une bande brunâtre, qui s'unit sous la gorge à celle du côté opposé. La portion épineuse de la dorsale est d'un rerdâtre clair, tantôt uniforme, tantôt avec une suite de taches orangées; la portion molle est souvent brunâtre à la base, verdâtre au milieu, orange en haut avec quelques petits ocelles d'un vert très-pâle; les trois premiers rayons mous ont souvent une large tache brune. L'anale est parfois d'un vert pâle avec des taches orangées, parfois elle est jaunâtre avec des traits bleuâtres, parfois encorc elle est parcourue par trois bandes obliques de teintes différentes. La caudale est ordinairement jaunâtre avec des traits bleus; parfois elle est verdàtre, teintée d'orange. Les pectorales ont la base bleuâtre ou d'un brun marron; elles sont plus ou moins jaunâtres. Les ventrales sont jaunâtres avec des traits bleuâtres, ou d'un bleu très clair, etc.

Habitat. Toutes nos còtes. - Méditerranée, assez commun de Nice à Port-Vendres. Océan, très commun, Biarritz ; commun, Arcachon ; assez commun, Poitou ; très commun, Noirmoutiers; commun, còtes de Bretagne. Manche, très commun, Roscoff, Cherbourg; assez rare au nord de la Seine, le Havre.

A propos de cette espèce, M. Vinciguerra écrit.... il... Cr. melops (Linn.) sembra esisttre certumente nei nostri mari, benché poco frequente e non indicato da autori precedenti a Günther, Steindachner e Giglioli; forse era prima di questi confuso col Cr. quinquemaculatus (Vincig., Crociere del Violante, p. 84). - Il sst probable que M. Vinciguerra ne connait pas l'ourrage de Cuvier et Valenciennes; s'ill'avait consulté, il aurait pu lire t. XIII, p. 167 : Crénilabre mélope... Nous en arons reçu de nombreux individus de Martigues, par M. Delalande; de Marseille, par M. Cuvier; de Nice, par M. Laurillard; de Gènes, par I. Viviani; de Naples, par M. Savigny. - Risso, Guichenot, C. Bonaparte, etc., avaient depuis longtemps signalé la présence du Cr. melops dans la Méditerranée; l'Ichthyologie de Nice a été publiée en $\mathbf{1 8 1 0}$, bien avant la naissance des auteurs auxquels $\mathbf{H}$. Vinciguerra attribue la découverte de ce Crénilabre dans la Méditerranée.

ว̈. LE CRÉYILABRE SOURCIL DORÉ. - CRENILABRUS CHRYSOPHRYS, Riss.

Poiss. France, t. III, p. 113. 
N. vulg. : Rouquie, Nice.

Long. : 0,10 à 0,13 .

La hauteur du tronc est comprise environ trois fois et quart dans la longueur totale, dont la longueur de la tête mesure le quart, ou peu s'en manque; la mâchoire supérieure est un peu plus avancée que l'inférieure; les incisives sont fortes, portées en avant.

$$
\text { D. } 13 \text { ou } 14 / 10 ; \text { A. } 3 / 8 \text { à } 10 \text {. }
$$

La teinte est vert-pré sur le dos et les côtés; le ventre est argenté ou d'un blanc verdâtre. Le sourcil est marqué d’une bande dorée. Les nageoires sont vertes; d'après Risso, la dorsale, chez la femelle, a sur les derniers rayons quelques petites taches noirâtres.

Habitat. Méditerranée, rare, Nice. Océan, golfe de Gascogne, excessivement rare, Arcachon?

\section{LE CRÉNILABRE QUEUE NOIRE. - CRENIL. BRUS} MELANOCERCUS, Riss.

Poiss. France, t. III, p. 116, fig. 15\%6, anim.

N. vulg. : Rouquie, Nice.

Long. : 0,08 à 0,10 et mème 14, suivant Risso.

La hauteur du tronc est contenue trois fois et demie à quatre fois et quart dans la longueur tolale, et la longueur de la tète environ quatre fois et demie. La mâchoire supérieure est à peine plus courte que l'inférieure, garnies l'une et l'autre de petites dents égales. Le diamètre de l'œil mesure le quart de la longueur de la tête; il est égal à l'espace préorbitaire. Le préopercule a des crénelures sur le bord postérieur et le bord inféricur: l'interopercule porte une rangée d'écailles : il y a sur la joue quatre rangées d'écailles. - Ec., l. long. 3 1 à 38 ; 1. transv. 12 ou 13.

$$
\text { D. } 16 \text { ou } 17 / 6 \text { à } 9 ; \text { A. } 3 / 8 \text { ou } 9 \text {; C. } 14 ; \text { P. } 12 \text { a } 14 ; \text { V. } 1 / 5 \text {. }
$$

Le corps est d'une teinte foncée, brun rougeâtre; le pourtour de l'orbite est souvent marqué d'une ligne bleuâtre. La 
dorsale est d'un bleu foncé ou rougeâtre arec des taches bleues; l'anale est brunâtre ou rougeâtre, marquée de quelques taches bleues; la caudale est noiràtre, tachetée de bleu, son extrémité a souvent une bordure blanche; la pectorale est. d'un jaune pàle ou rougeâtre, elle est bordée, vers la pointe de ses rayons supérieurs principalement, d'une bande noirâtre assez large ; la ventrale est d'un jaune orange clair.

Habitat. Méditerranée, assez rare, Nice, Toulon, Marseille.

\section{Le Crénilabre bleu. - Crenilabrus cœruleuৎ, Riss.}

Poiss. France, t. III, p. 118, fig. 15\%, anim.

N. vulg. : Rouquie, Nice.

Long. : 0,08 à 0,10 .

Le Crénilabre bleu représente soit une variété, soit l'un des sexes du Crénilabre queue noire.

La hauteur du tronc est comprise trois fois et demie à quatre fois dans la longueur totale; la longueur de la tète en mesure le quart, ou peu s'en faut; les màchoires sont de mème longueur, munies de petites dents égales. Le préopercule n’a généralement de crénelures que sur le bord postérieur; l'interopercule porte une rangée d'écailles; sur la joue, je trouve seulement trois séries d'écailles. Ec., l. long. 38 ; l. transv. 12.

\section{D. $16 / 7$ ou $8 ;$ A. $3 / 8$; C. 12 à 14 .}

Sur le frais, le corps est d'une belle couleur bleue qui devient foncée chez l'animal conservé. La dorsale et l'anale sont d'un bleu très foncé; la caudale, d'un brun jaunâtre à la base, prend une teinte noiràtre très sombre, et porte en arrière une bordure claire, soit blanche, soit jaunàtre; les nageoires paires sont pàles; la pectorale n'a pas de bordure noire à son extrémité.

Habitat. Méditerranée, assez rare, Nice, Toulon, Marseille; très rare, Port-Vendres.

Le charmant Crenilatrus coruleus, Risso, non Cuv. et Val, écrit M. Sarato, est du sexe masculin; nous n'avons jamais trouvé d'œufs que dans l'espèce du mème auteur, le $\mathrm{Cr}$. melanocercus, Risso, $\mathrm{Cr}$. cœruleus, G. et $\mathrm{V}$. Cette forme moins coquette doit ètre la femelle du petit poisson bleu. - Suivant M. Sarato, la nageoire caudale du cœruleus est rembrunie avec des taches bleues; celle du melanocercus, jaunâtre à la base, liserée de blanc à l'extrémité, est d'un noir sans 
mélange dans tout l'espace intermédiaire. V. Genre Crénilahre, Sarato, dans Monitur cles Etranyers, Nice, 28 avril 1889.

7. LE CRENILABRE IIE BAIILON. -- CRENILABRUS BAILLONI, Valenc.

Poiss. France, t. III. p. 119.

Long. : 0,15 à 0,22 .

La hauteur du trone est contenue trois fois et demie à trois fois et trois quarts dans la longueur totale, dont la longueur de la tête mesure le quart environ; les màchoires sont égales, garnies de petites dents régulières. Le diamètre de l'œil fait le cinquième de la longueur de la tête, les trois cinquièmes de l'espace préorbitaire. L’interopercule est écailleux. Le préopercule est assez finement crénelé sur le bord postérieur; les dentelures descendent sur l'angle postérieur qu'elles dépassent un peu, mais ne s'étendent pas sur le bord inférieur plus loin que l'aplomb du bord postérieur de l'orbite; il y a, sur la joue, trois rangées d'écailles, occupant un espace de hauteur égale, à peu près, à la longueur du diamètre de l'oeil. - Ec.,

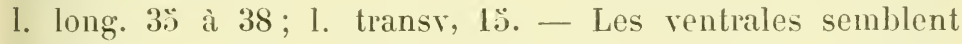
pointues.

D. $11 / 9$ ou $10 ;$ A. $3 / 9$ ou $10 ;$ C. $14 ;$ P. $15 ;$ V. $1 / 5$.

Le corps est d'un gris bleuâtre, passant au violet sur les flanes; cing ou six larges taches d'un bleu foncé descendent de la région dorsale; cinq ou six rangées de taches ou de traits jaunes s'étendent le long des flancs. La tête est ornée de bandes orangées: il y en a de trois à cinq de l'oeil au museau. L'opercule est bordé de rose. La dorsale est violacée, arec une bordure, rose; à la base de ses aiguillons est une bande jaune ou jaune verdâtre; souvent à. la base de ses premiers rayons mous il existe une ou deux taches noires. L'anale est teintée de rose et de violet, arec quelques points jaunes. La cauclale est verte avec une tache rose foncé sur l'angle postérieur et supérieur; il n’y a pas de tache noire sur le troncon de la queue. La pectorale est violacée, avec trois bandes rerti.- 
cales jaunâtres et une tache bleue bordée d'orange. La ventrale est marquée de points jaunes (Valenc.).

Habitat. Manche, excessivement rare, Saint-Valery-sur-Somme. Océan, très rare, la Rochelle.

\section{LE GRÉNILABRE MÉDITERRANÉEN. - CRENILABRUS MEDITERRANEUS.}

Poiss. France, t. III, p. 121.

N. vulg. : Sublaire, Rouquie, Nice; Bourdagas, Port-Vendres.

Long. : 0,10 à $0,13 ̈$.

La hauteur du tronc est' comprise trois fois et quart à trois fois et trois quarts dans la longueur totale; la longueur de la tête y est contenue trois fois et demie à trois fois et trois quarts; à la mâchoire supérieure les deux premières incisives sont plus fortes que les autres dents, portées en avant. Le diamètre de l'oril mesure le quart ou le cinquième de la longueur de la tête, la moitié ou les deux tiers de l'espace préorbitaire. Chez les sujets de grande taille, le bord postérieur du préopercule paraît seul dentelé. Il y a sur la joue quatre rangées d'écailles, rarement trois. - Ec. 1. long. 30 à 34; l. transr. 12 à 14 .

D. 15 à $17 / 9$ ou $10 ;$ A. $3 / 9$ à 11 ; C. 13 ou $14 ;$ P. 13 ou $14 ;$ V. $1 / 5$.

Le corps est rose, ou rouge jaunâtre clair, avec des bandes longitudinales d'un brun assez pàle; les joues sont de teinte jaunâtre; à droite et à gauche, sur la tête, une bande jaunâtre rejoint celle du côté opposé. La dorsale et les ventrales sont d'un rouge assez clair; l'anale est d'un jaune pâle ; la caudale est d'un rouge jaunâtre clair ; une g'rande tache noire se montre sur le troncon de la queue, limitée en bas par la ligne latérale, s'étendant jusque vers le profil du dos. La pectorale, d'un rose pâle, porte à sa base et sur l'articulation une tache noire, bordée de jaune sur la nageoire seulement.

VAr. a. - Le Crénilabre de Bory. - Crenilabrus Boryanus, Riss.

N. vulg. : Rouquie nègre, Nice.

Souvent les dentelures du préopercule s'avancent sur le bord infé- 
rieur presque vers le prolongement du diamètre vertical de l'œil. Le dos et la tète sont brun verdàtre; le ventre est jaunàtre; des lignes bleues se voient sur la tète, li gorge, le long des flancs. Les nageoires impaires, d'un jaune plus ou moins rougeàtre, sont bordées de bleu ; la pectorale, d'un brun rougeàtre, porte à la base, une grande tache noire bordée de jaune.

\section{Var. b. - Le Crénilabre de Brünnich. - Crenilabrus Brunnichii.}

Le corps est rougeàtre avec des bandes longitudinales vert cuivré assez clair; des bandes bleuàtres forment sur la tête des dessins ondulés. Les nageoires sont jaunàtres; l'anale est bordée de bleu; la pectorale a la base marquée d'une grande tache d'un bleu très foncé. Il n'y a pas de tache noire sur le tronçon de la queve.

Habitat. Méditerranée, assez commun, Nice, Marseille, Cette, Port-Vendres.

\section{LE GRENILABRE PETITE TANCHE. - CRENILABRUS TINCA.}

Poiss. France, t. III, p. 124.

N. vulg. : Roucairou, Nice.

Long. : 0,07 à 0,10 .

La hauteur du tronc est comprise trois fois et demic à quatre fois dans la longueur totale, et la longueur de la tête, trois fois et demie à trois fois et trois quarrs; le museau est gros; les mâchoires ont les dents égales, non portées en avant. Le diamètre de l'oil fait le quart de la longueur de la tête, les deux tiers de l'espace préorbitaire. Le préopercule est crénelé sur le bord postérieur seulement. Il y a trois rangées d'écailles sur les joues. - Ec. 1. long. 30 à 32 ; l. transv. 13.

D. 14 ou $15 / 9$ ou $10 ; A .3 / 8$ ou 9 ; C. 14 ou $15 ;$ P. 13 ou $14 ; \mathrm{V} 1 / 5$.

Le corps est d'un rouge peu foncé; ordinairement une bande verdâtre s’étend du museau, en s’interrompant au niveau de l'œil, jusqu'ì la caudale; au-dessus, une bande rougeâtre va s'unir à celle du còté opposé, en formant un angle sur le museau, elle sépare la bande verdâtre d'une autre bande qui commence au-delà de l'espace interorbitaire et suit la ligne du dos. Le troncon de la queue est marqué d'une petite tache 
noire, qui est au-dessus de la ligne latérale. Les nageoires sont en partie jaunâtres; une tache bleue se montre à l'aisselle de la pectorale.

Habitat. Méditerranée, assez rare à Nice; assez commun, Toulon, Marseille.

10. LE CRÉNILABRE ARQUÉ. - CRENILABRUS ARCUATUS, Riss.

Poiss. France, t. III, p. 125.

N. vulg. : Rouquie, Nice.

Long. : 0,10 à 0,17 .

La hauteur du tronc mesure le tiers au moins de la longueur totale. - La longueur de la tête est comprise trois fois et demie dans la longueur totale; les mâchoires sont égales; les dents antérieures sont plus longues et plus fortes que les autres. Le diamètre de l'ceil fait le quart de la longueur de la tête, les quatre cinquièmes de l'espace préorbitaire. Il y a des crénelures sur le bord postérieur du préopercule seulement. Les joues portent quatre ou cinq rangées d'écailles. - Ec., l. long. $32 ; 1$. transv. 13.

D. $16 / 8$ ou 9 ; A. $3 / 8$ à 10 ; C. 14 ; P. 14 ; V. $1 / 5$.

Le dos est rougeâtre; les côtés et le ventre sont d'un bleu grisâtre; des raies ou des bandes rougeâtres se montrent sur les opercules. Le tronçon de la queue est marqué d'une tache noire, placée au-dessus de la ligne latérale. Les pectorales et la caudale sont de couleur ocre ou jaune roussâtre; les autres nageoires sont semées de taches noirâtres.

Habitat. Méditerranée, rare, Nice.

\section{LE GRÉNILABRE VERT TENDRE. - CRENILABRUS CHLOROSOCHRUS, Riss.}

Poiss. France, t. III, p. 126.

N. vulg. : Langaneu, Nice.

Long. : 0,10 à 0,15 .

Ce Crénilabre est probablement une variété du Cr. Roissal 
ou du Cr. paon. - Suivant Risso, la tête est aiguë; la bouche est garnie de fines dents: deux longues dents isolées sur le devant de la mâchoire supérieure.

$$
\text { I. } 16 / 8 \text {; A. } 3 / 10 \text {; C. } 14 \text {; P. } 14 \text {; V. } 1 / .3 .
$$

Le corps est verdâtre nuancé de rouge, avec de petites lignes obscures; une tache noire vers la partie dorsale de la queue. Les nageoires sont variées; la dorsale parsemée de points rouges; la caudale traversée d'une bande noire à la base, pointillée de rouge à l'extrémité. - La femelle a des couleurs plus ternes.

Habitat. Méditerranée, Nice.

\section{LE CRÉNILABRE PAON. - CRENILABRLS PAVO.}

Poiss. France, t. III, p. 127.

N. vulg. : Ronquie, Blavie, Nice; Roucaou, Marseille, Cette; Claviera, Cette; Loubiou (musicien), Ploumarenc-de-Nid, Port-Vendres.

Long. : 0,1 à à 0,20 et mème 0,30 .

La hauteur du tronc est contenue trois fois et quart à trois fois et demie dans la longueur totale, et la longueur de la tête, trois fois et quart à trois fois et deux tiers; le museau est gros: les lèvres sont fort épaisses. Le diamètre de l'œil mesure la moitié de l'espace préorbitaire. L’interopercule porte quelques écailles; il y en a cinq rangées sur la joue; le préopercule est dentelé sur le bord postérieur seulement; parfois les crénelures sont peu sensibles et même semblent manquer. - Ec., l. long. 34 à $3 \ddot{3} ; 1$. transr. 10 .

$$
\text { D. } 14 \text { i } 16 / 11 \text { ou } 12 ; \Lambda .3 / 9 \text { ou } 10 \text {; C. } 13 \text {; P. } 14 ; \text { V. } 1 / 5 \text {. }
$$

Le plus souvent le corps est d'un vert jaunâtre, avec des taches rouges et bleues, formant sur les côtés trois ou quatre bandes longitudinales. Une tache bleuâtre se montre en avant de l'œil; une tache brunâtre, ou brun rerdàtre, assez étendue. se trouve un peu au-dessus de la pectorale; au-dessous de la ligne latérale, le tronçon de la queue porte une tache brunâtre, au milieu de laquelle existe parfois un ocelle bleu de ciel. La 
dorsale est d'un vert jaunâtre à la base, rougeâtre dans la région supérieure; l'anale est rougeâtre, tachetée de bleu, ou bien bleuâtre avec des taches ocracées, et une bande étroite, jaune verdâtre à sa base; la caudale est jaunâtre, semée de taches bleues; les pectorales sont jaunâtres; les ventrales sont d'un bleu plus ou moins foncé, quelquefois elles sont pâles.

Habitat. Méditerranée, commun de Nice à Port-Vendres, Océan, Arcachon (Lafont)?

13. LE CRÉNILABRE MASSA. - CRENILABRUS MASSA, Riss.

Pciss. France, t. III, p. 129.

N. vulg. : Langaneu, Nice.

Long. : 0,12 à 0,16 .

La hauteur du tronc est comprise trois fois et trois quarts ì quatre fois dans la longueur totale, qui contient environ quatre fois la longueur de la tête; les incisives sont à peu près égales, non proclives. Le diamètre de l'œil fait à peu près le cinquième de la longueur de la tête, les trois cinquièmes de l'espace préorbitaire. Le préopercule n’a de crénelures que sur le bord postérieur; les écailles de la joue paraissent toujours disposées sur deux rangées seulement. - Ec., l. long. 32; 1. transv. 12.

Br. 5. - D. 13 à $15 / 9$ ou $10 ;$ A. $3 / 9$ ou 10 .

Le corps est tantôt d'un gris jaunâtre ou verdâtre, tantôt d'un brun rougeâtre; le dos et les côtés sont semés de macules brunâtres; le ventre et la gorge sont jaunâtres; au-dessus de la ligne latérale s'étendent deux bandes longitudinales brunâtres, plus ou moins marquées. L'espace interorbitaire est noirâtre; du bord postérieur et inférieur de l'orbite descend une large bande brunâtre qui, sous la gorge, rejoint celle du côté opposé; sous la mandibule se voit une autre bande noirâtre; il y a sur la joue quelques bandes brunâtres; sur le tronçon de la queue, au-dessous de la ligne latérale, est une large tache foncée, qui s’étale un peu sur les rayons de la caudale, et joint en dessous celle du côté opposé. La dorsale est, 
à la base, d'un rose jaunàtre assez clair, avec des taches roussâtres; plus haul, elle présente une large bande verdâtre ou bleuàtre, teintée de brun; en avant elle est marquée d'une tache noire, bien distincte dans le premier espace intraradiaire. L'anale est blanchâtre à la base, verdâtre dans le reste de son étendue arec quelques macules brunâtres. La caudale est verdàtre, pointillée de brun. La pectorale est d'un jaune clair, marquée à la base d'une tache foncée. La ventrale a les rayons jaunàtres, et les espaces intraradiaires verdâtres.

Habitat. Méditerranée, commun, Nice, Toulon, Marseille, Cette. Océan, je l’ai trouvé à Bayoune et assez souvent à Arcachon.

\section{GEXRE SUBLET. - CORICUS, Cuv.}

Tête allongée; museau proéminent; bouche très protractile.

Appareil branchial; préopercule dentelé; pièces operculaires et joues écailleuses; cinq rayons branchiostèges.

\section{LE SUBLET GROIN. - CORICUS ROSTRATUS.}

Poiss. France, t. III, p. 131.

N. vulg. : Sublaire, Nice; Canadelle, Marseille; Sublaïré, Cette; Barre-stret (bouche étroile), Port-Vendres.

Long. : 0,08 à 0,12 .

La hauteur du tronc est comprise trois fois et demie à quatre fois dans la longueur totale. - La longueur de la tête, qui l'emporte d'un tiers environ sur la hauteur, est contenue trois fois à trois lois et demie dans la longueur totale; le museau est relevé et pointu; la bouche est très protractile à lèvres assez minces; la mandibule est légèrement relevée, un peu plus avancée que la màchoire supérieure, portant l'une et l'autre une rangée de petites dents aiguës régulières. Le diamètre de l'xil fait à peu près le cinquième de la longueur de la tête, la moitié de l'espace préorbitaire. Le bord postérieur du préopercule est finement dentelé; les écailles de la joue sont disposées sur plusieurs rangées, deux, trois et mème quatre. - Ec., l. long. $30 ; 1$. transi. 1 '.

Br. 5.-D. 14 à $16 / 10 ;$ A. $3 / 9$; C. $13 ;$ P. $12 ;$ V. $1 / 5$. 
Rien de plus variable que le système de coloration. Les teintes les plus ordinaires sont: le rouge orangé, verdâtre avec des points rouges; jaune vert avec des points plus foncés; rert plus ou moins clair, bleuâtre sur le dos avec des points rouges; brun rougeâtre avec des points brun marron et une bande de points brunâtres allant de l'œil à la fin de la courbure de la ligne latérale ; il y a parfois une tache noire sur le commencement de la dorsale.

Habitat. Méditerranée, très commun, Nice ; assez commun, Toulon, Marseille; assez rare, Cette, Port-Vendres.

\section{GENRE CTÉNOLABRE. - CTENoLABRUS, Valenc.}

Corps oblong, comprimé, couvert d'assez grandes écailles.

Tête; mâchoires garnies de dents sur plusieurs rangées; une série externe de dents coniques assez fortes, en dedans une bande de petites dents en velours.

Appareil branchial; préopercule dentelé; joues et pièces operculaires écailleuses; cinq rayons branchiostèges.

Nageoires; dorsale ayant seize à dix-huit aiguillons et sept à douze rayons mous; anale à trois épines et sept à dix rayons mous.

Deux espèces :

Tache noire sur le commencement de la dorsale...... 1. DEs Rocues. Non............................... IRIs.

\section{LE CTÉNOI.ABRE DES ROCHES. - CTENOLABRUS RUPESTRIS.}

Poiss. France, t. III, p. 134, fig. 145, anim.

Long. : 0.10 à 0,1 วั.

La hauteur du tronc est comprise trois fois et demie à quatre fois et demie dans la longueur totale, et la longueur de la tète trois fois et deux tiers à quatre fois; les mâchoires sont munies, l'une et l'autre, de quatre incisives crochues, plus longues que les autres dents; elles portent sur les côtés une rangée de dents, légèrement crochues; en dedans de cette série externe, il y a une bande étroite de dents excessivement fines. Le diamètre de l'wil fait lequart de la longueur de la tête. Le préopercule a le bord dentelé. Les joues sont couvertes de quatre 
ou einq rangées d'écailles. - Ee., l. long. 34 à 38 ; I. transv. 14 à 16 .

D. 16 is $18 / 8$ à 10 ; A. $3 / 7$ ou 8 ; C. 13 à 15 ; P. 14 ; V. $1 / 5$.

Le dos est d'un grris rosé ou d'un rouge verdâtre, le ventre d’un blanc rosé. Il y a sur les côtés dix à douze bandes longitudinales d'un gris verdâtre ou brunâtre, parfois peu distinctes. Une tache noire bien marquée se trouve sur le haut du troncon de la queue; parfois il existe une macule noirâtre sur l'opercule. La dorsale est d'un gris verdâtre, avec une tache noirâtre sur les trois ou quatre premiers espaces intraradiaires. L'anale et la caudale sont verdâtres. La pectorale est rougeâtre, a vec une bande verdâtre et une bande noirâtre à la base. La ventrale est d'un vert pâle.

\section{VAr. - Le Cténolabre bordé. - Ctenolabrus murginatus, Valenc.}

La récrion supérieure du corps est jaune verdàtre, l'inférieure est blanchàtre. Les nageoires impaires sont bordées de noir; la tache noire de la dorsale se prolonge jusqu'à la dixième épine; une tache noiràtre marque la base de la pectorale.

Habitat. Manche, très rare, le Havre, Saint-Malo. Océan, très rare, Arcachon. Méditerranée, rare, Cetle, Marseille, Toulon, Nice.

\section{LE CTÉNOLABRE IRIS. - CTENOLABRUS IRIS, Valenc.}

Poiss. France, t. III, p. 137.

Long. : 0,10 à 0,13 .

La hauteur du tronc mesure environ le cinquième de la longueur tolale; la longueur de la lète en fait le quart au moins. A chacune des mâchoires, il y a quatre incisives crochues; les dents latérales sont fines, égales; en arrière des incisives, sont de fort petites dents. Le diamètre de l'ceil est contenu trois fois et demie à quatre fois dans la longueur de la tète, il est à peu près égal à l'espace préorbitaire. Le bord postérieur du préopercule est finement crénelé. Les écailles de la joue sont disposées en quatre séries. - Ec., l. long. 32 à 34; 1 . transv. 13 à 16.

I) 16 ou $17 / 10$ a $12 ;$ A. $3 / 10 ;$ C. $13 ;$ P. 14 a $16 ;$ V. $1 / 5$. 
La teinte générale est d'un rouge écarlate, qui devient plus clair à la région inférieure du corps; un trait brunâtre part de l'orbite, traverse le battant operculaire et disparaît sur l'épaule. Les nageoires sont rougeâtres. La dorsale porte en général une tache noirâtre sur les premiers rayons mous. A la partie supérieure du troncon de la queue, il y a souvent une macule noirâtre; les rayons moyens de la caudale sont marqués d'une lache noirâtre, qui s'étale parfois jusqu'à l'extrémité de la nageoire.

Habitat. Méditerranée, assez rare, Cette.

5. GENRE ACANTHOLABIE. - ACANTHOLABRUS, Valenc.

Gorps oblong, comprimé, couvert d’assez grandes écailles.

Tête; dents des màchoires sur plusieurs rangées, plus fortes à la rangée externe.

Appareil branchial; préopercule plus ou moins dentelé; pièces operculaires et joue écailleuses; cinq rayons branchiostèges.

Nageoires; anale ayant au moins quatre aiguillons.

\section{L'AGANTHOLABRE PALLONI. - ACANTHOLABRUS PALLONI.}

Poiss. France, t. III, p. 139, fig. 159 anim.

N. vulg. : Tenca, Nice; Clabiéyda bastarda, Cette.

Long. : 0,15 à 0,20 .

La hauteur du tronc est comprise quatre fois et un tiers dans la longueur totale, dont la longueur de la tête mesure le quart environ; en général les incisives sont plus développées que les autres dents, elles sont un peu crochues; les dents latérales sont aiguës et régulières; à la rangée interne, les dents sont assez fortes. Le diamètre de l'ceil fait à peu près le quart de la longueur de la tête; il est sensiblement égal à l'espace préorbitaire. Le préopercule est crénelé au moins sur le bord postérieur; il y a sur la joue quatre ou cinq rangées d'écailles. - Ec., l. long. 43 à 13 ; l. transv. 16. - Lanale a le plus souvent cinq épines, quelquefois elle en a quatre seulement, quelquefois elle en a six.
D. 20 ou $21 / 8$ ou 9 ; A. 4 a $6 / 5$ à 8 ; C. 15 ; D. 15 ; V. $1 / 5$. 
La teinte est bleuàtre ou violacée sur le dos, rose pàle sur les flanes, blanchâtre sous le ventre; la partic dorsale du troneon de la queue est marquée d'une tache noirâtre; il pxiste parfois une macule noire à la base des rayons mous de la dorsale. Sur le frais, d'après Risso, la dorsale est d'un vert jaunàtre, l'anale blanche; les pectorales sont jaunâtres, les ventrales roses.

Habitat. Méditerranće, assez rare, Nice, Cette.

6. GENRE GIRELI. - JULIS, Guv.

Corps oblong, couvert d'écailles de grandeur variable.

Tête à peu près complètement nue; màchoires dentées; les dents antérieures sont plus fortes et plus longues que les autres.

Appareil branchial; membranes branchiostèges réunies sous la gorge; six rayons branchiostèges.

Nageoires; dorsale ayant huit ou neuf épines et une douzaine de rayons mous; anale à trois aiguillons et onze ou douze rayous mous.

Ce genre compte trois espèces.

a. Écailles de la ligne longitudinale au nombre de plus

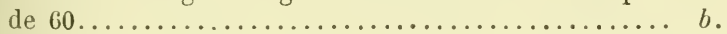

Écailles de la ligne longitudinale au nombre d'une

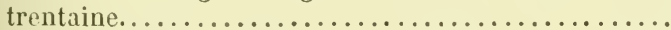

3. Dorsale à $1^{\mathrm{er}}$ espace intraradiaire sans tache......... tacheté....... 1. семmune.

\section{LA GIRELLE COMMUNE. - JULIS VULGARIS.}

Poiss. France, t. III, p. 141 ; Suppl., p. ว̈0.

N. vulg. : Girella, Nice; Donzella, Marseille; Giréla, Chidella, Vette; Girelle, Port-Vendres.

Long. : 0,15 à 0,20 , quelquefois 0,23 .

Le corps est couvert de petites écailles; sa hauteur est comrise cinq fois à cinq fois et quart dans la longueur totale. a tête est allongée; sa longueur est contenue trois fois et rois quarts à quatre fois dans la longueur totale; les mâhoires sont égales; à la rangée externe les dents sont coniues, régulières et courtes sur les coités; les dents antéieures, qui sont généralement au nombre de deux ou quatre, Moreav, - Ichthyologie. 
en haut et en bas, sont des espèces de canines, longues et fortement crochues; sur le côté interne des mâchoires, se trouvent des dents arrondies très petites ; à la mâchoire supérieure, tout à fait en arrière, se montre une dent allongée, à pointe tournée en avant. Le diamètre de l'wil est contenu cinq à sept fois dans la longueur de la tête; il fait la moitié ou les deux tiers de l'espace préorbitaire. - Ecail., l. long. 74 à 79 ; 1. transv. 28.

Br. 6. - D. $9 / 12$ on 13 ; A. $3 / 11$ ou 12 ; C. 14 ; P. 13 ou 14 ; V. 1/5.

La teinte geénérale est très variable; la partie supérieure de la tête et la région dorsale sont d'un brun bleuâtre; de l'épaule au tronçon de la queue s'étend une bande généralement dentelée, le plus souvent orange, parfois d'un jaune rosé; audessous de cette bande, est une longue tache d'un noir bleuâtre; les flancs et le ventre sont d'un blanc jaunâtre; une large. ligne bleue va de la bouche jusque sur l'opercule et se prolonge parfois sur les côtés; une petite tache bleue marque l'angle du battant operculaire. La dorsale a sur les deux ou trois premiers espaces intraradiaires une tache bleu foncé, généralement bordée de rougeâtre; elle est en outre teintée de couleurs variées; vers la base, elle est d'un jaune verdàtre. à la partie supérieure elle porte une bande rougeâtre ou d'un rouge orangé; ordinairement l'anale est d’un rouge orangé assez clair; la caudale est d'un gris verdâtre teinté de roux; les nageoires paires sont d'un jaune pâle nuancé de rougeâtre.

\section{VAR. - La Girelle élégante. - Julis speciosa, Riss.}

La dorsale a ses premiers rayons de mème longueur que les suivants; elle porte en avant une tache bleu indigo, ocellée de rouge clair.

Habitat. Méditerranée, ce Poisson est commun à Nice, Toulon; très commun à la Ciotal; assez commun à Marseille, Cette; commun à Port-Vendres. Océan, très rare, golfe de Gascogne, Arcachon; còtes du Poitou.

2. LA GIRELLE GIOFREDI. - JULIS GIOFREDI, Riss.

Poiss. France, t. III, p. $14 \%$, fig. 160, anim.; Suppl., p. 50.

Long. : 0,15 à 0,20 , quelquefois 0,25 . 
Brïnnich regardait cette Girolle comme une varićlé de la Girelle commune. - La hauteur du trone est comprise quatre fois et trois quarts à cing fois et deux tiers dans la longueur totale, et la longueur de la tête trois fois et trois quarts à quatre fois; la mâchoire supérieure est un peu plus avancée que la mandibule; elle porte en arrière une espèce de canine assez forte, moins erochue que dans la Girelle commune; les màchoires ont en arant des dents plus développées que les autres. Le diamètre de l'ouil fait le cinquième ou le sixième de la longueur de la tète; il est d’un tiers moins grand que l'espace préorbitaire. - Eeail., 1. long. \$0; 1. transv. 206 ou 27. - Les trois premières épines de la dorsale ne sont pas plus hautes que la quatrième.

$$
\text { Br. 6. - D. } 9 / 12 \text { ou } 13 ; \text { A. } 3 / 12 \text {; C. } 1 \text {; ; P. } 14 ; \text { V. } 1 / 5 \text {. }
$$

Le système de coloration est des plus variables; il semble changer suivant le développement des animaux, suivant leur habilat. La partie supérieure de la tête et du corps est rougeàtre; le ventre est rose; du museau partent souvent trois bandes longitudinales, qui s'étendent jusque vers la base de la caudale, la supérieure est noiràtre ; l’intermédiaire est bleue en avant, rouge en arrière; l'inférieure est jaunâtre. L'angle postérieur du battant operculaire est marqué d'une tache bleue. La dorsale ne porte pas ordinairement de tache en arant, elle est d'un orangé clair, avec un liséré bleu assez. pâle : l'anale est d'un rouge orangé; les autres nageoires sont d'un jaune pâle varié de rose.

\section{VAR. - La Girelle corquetle. - Julis festiva, Valenc.}

Les nageoires sont rouges; la caudale seule est bordée d'orangé (Valenc.).

Habitat. Méditerranée, cette Girelle est commune à Nice, à TouIon; assez rare à Marseille, à Cette; elle est très commune à PortVendres. Ocían, golfe de Gascogne, assez rare, Saint-Jean-de-Luz.

La Girelle coquette a été prise à Brest.

Steindachner regarde la Julis vulyaris et la J. Giofredi comme eprésentant les formes sexuelles d'une seule et mème espèce, la I. vulgaris étant le màle, la J. Giofredi étant la femelle. - Cette 
opinion a été adoptée sans contròle par divers ichthyologistes, ce qui est fort regrettable. - Je l'ai déjà signalé (V. Suppl., p. 50), il y a des màles et des femelles dans li $J$. vulgaris aussi bien que dans la $J$. Giofredri. - Maintenant la J. Giofredi est-elle une espèce nettement séparée de la $J$. vulgaris, comme le pensait Risso? N'est-elle qu'une variété de Labrus julis (J. vulgaris), ainsi qu'avant Risso l'avait indiqué Brünnich? C'est une question que je n’ai pas à discuter ici.

\section{LA GIRELLE PAON. - JULIS PAVO.}

Poiss. France, t. III, p. 148.

N. vuig. : Girella turca, Nice.

Long. : 0,15 à 0,20 .

La hauteur du tronc est comprise quatre fois à quatre fois et demie dans la longueur totale. - La longueur de la tête présente la même proportion; les mâchoires ont sur le devant chacune deux dents plus longues et plus fortes que les autres. Le diamètre de l'œil mesure à peine le sixième de la longueur de la tête, la moitié de l'espace préorbitaire. - Ec., l. long. 29 à 31 ; 1. Lransv. 13 ou 14. - La caudale est arrondie chez les jeunes, profondément échancrée ou fourchue chez les sujets de grande taiile.

Br.6.-D. $9 / 12$ ou $13 ;$ A. $3 / 11$ ou 12 ; C. 13 ou $14 ;$ P. $15 ;$ V. $1 / 5$.

La teinte générale est verdâtre; un trait vertical rougeâtre marque la plupart des écailles; des trois premiers aiguillons de la dorsale descend une bande verdâtre qui rejoint en dessous celle du côté opposé et forme une espèce de ceinture à la partie antérieure du corps; des bandes azurées partent de l'orbite et se portent en sens divers sur la tête, les pièces operculaires. La dorsale est verte en avant, puis teinte d'un bleu plus ou moins foncé avec une bordure blanchâtre ou verdâtre; l'anale est bleuâtre à la base, blanchâtre dans sa partie moyenne, bordée de vert; la caudale est marquée de lignes vertes et rouges ; la pectorale, qui est rerdâtre, montre une tache jaunâtre à la base, et une large tache d'un bleu' noirâtre à l'extrémité; la ventrale est blanchâtre ou vert pâle.

Habitat. Méditerranée, assez rare, Nice. 
7. GENRE RASON. - XYRICHTHYS, Guv.

Corps oblong, très comprimé, couvert de graudes écailles.

Téte tranchante, à profil antérieur plus ou moins vertical, à peu près complètement nue; màchoires à dents sur une seule rangée.

Appareil branchial; préopercule lisse; joue et pièces operculaires peu ou pas écailleuses; six rayons branchiostèges.

Ligne latérale interrompue sous la fin de la dorsale.

Nageoires; dorsale ayant généralement neuf aiguillons et une douzaine de rayons mous.

\section{LE RASON ORDINAIRE. - XIRICHTHYS NOVACULA.}

Poiss. France, t. III, p. 1ว̈1, fig. 161, anin.

N. vulg. : Rasoir, Rason, Provence, Languedoc; Rat de mer, Cette.

Long. : 0,1 ä à 0,20 , quelque 0,30 .

Le dos parait tranchant; la hauteur du trone est comprise trois fois à trois fois et demie dans la longueur totale, et la longueur de la tète trois fois et trois quarts à quatre fois et quart; les inàchoires ont de chaque côté une dizaine de petites dents pointues, légèrement crochues, et en avant deux canines longues et fortes; les canines supérieures sont crochues, fort pointues, écartées, recerant, dans leur intervalle, les canines inféricures, qui sont un peu moins crochues. Le diamètre de l'cil est compris quatre fois et demie à cinq fois et demie dans la longueur de la tête; il mesure le tiers ou la moitié de l'espace préorbitaire. Il y a quelques écailles vers le bord supérieure de l'opercule. La ligne latérale est interrompue sous les derniers rayons mous de la dorsale. Ec., 1. long. 26 à 28.; 1. transv. 11. - La dorsale est longue, égale.

$$
\text { Br. 6. - D. } 9 \text { ou } 10 / 12 \text {; A. } 3 / 12 ; \text { C. } 13 \text { ou } 14 ; \text { P. } 11 \text {; V. } 1 / 5 .
$$

Le corps est d'une coloration rougeâtre, plus foncée vers le dos; chacune des écailles est marquée d’un trait vertical bleuâtre; des lignes bleuâtres descendent de la région orbitaire sur les joues et les pièces operculaires. Toutes les naģeoires ont une leinte jaunâtre, relerée, sur les nageoires rerticales, par des lignes ondulées violettes ou bleuâtres. 
Habitat. Méditerranée, très rare, Nice, Marseille, les Martigues, Cette.

\section{Sous-famille des Scariniens, Scarini.}

Corps ohlong, comprimé, couvert de grandes écailles cycloïdes. Tête; en partie écailleuse; bouche au bout du museau, horizontale; màchoires à dents sondées.

Appareil branchial; ouies largement fendues; cinq rayons branchiostèges; pharyngiens inférieurs soudés en une seule plaque dentaire; les dents pharyngiennes inférieures et supérieures sont à couronne quadrilatérale, pressées les unes contre les autres, comme de petits pavés, formant une espèce de mosaïque.

\section{GENRE SCARE. - SCARUS, Forsk.}

Corps revètu de grandes écailles, assez peu nombreuses, moins de trente dans une série longitudinale.

Tête; une seule rangée d'écailles sur les jones.

Ligne latérale bien marquée.

Nageoires; dorsale ayant généralement neuf épines et dix rayons mous; anale ayant le plus souvent deux aiguillons plus ou moins recouverts par la peau el neuf ou dix rayons mous.

\section{LE SGARE DES MERS DE GRĖE. - SCARUS CRETENSIS.}

Poiss. France, Suppl., p. 亏̌l.

Long. : 0,15 ì 0,20 .

La hauteur du tronc est comprise trois fois et un tiers à quatre fois dans la longueur totale dont la longueur de la lète mesure le quart environ; les mâchoires ressemblent à un bec de Perroquet; elles sont l'une et l'autre bordées de petites dents soudées. Le diamètre de l'ceil fait à peu près le cinquième de la longueur de la tête, un peu plus de la moitié de l'espace préorbitaire. Les pharyngiens supérieurs s'articulent à la base du crâne. - La ligne latérale n’est pas toujour's interrompue, comme le prétendent quelques auteurs; elle décrit une courbe régulière de l'épaule jusque sous la fin de la dorsale, puis descend sur le milieu du tronegon de la queue et 
gagne directement la base de la caudale; elle est composée de vingt-cinq à vingt-sept écailles. Ec., l. long. 22 à 24 ; 1. transv. 9. - La dorsale est longue; l'anale a deux épines grèles; le tronçon de la queue est à peu près carré; la caudale est coupée carrément.

$$
\text { Br. } 5 .- \text { D. } 9 / 10 ; \text { A. } 2 / 9 \text {; C. } 13 \text { ou } 14 ; \text { P. } 12 \text {; V. } 1 / 3 \text {. }
$$

Chez les sujets conservés la teinte est d'un brun rougeâtre.

Habitat. Méditerranée, Nice, très rare.

13. Famille des Pomacentridés, Pomacentridi.

Corps oblong, comprimé, couvert d'écailles pectinées.

Appareil branchial; pharyng̣iens inférieurs sondés; pseudobranchies.

Ligne latérale interrompue ou finissant sous la partie molle de la dorsale.

Nageoires; dorsale unique; ventrale ayant une épine et cinq rayons mous.

GENRE CHROMS. - CHROHIS, Cuv.

Tête écailleuse; bouche protractile; màchoires à dents en velours; vomer et palais lisses.

Appareil branchial; opercule arant son angle postérieur épineux; ares branchiaux portant les trois premiers une série double, le quatrième une série simple de lamelles respiratoires; six rayons branchiostèges.

Ligne laterale interrompue sons la fin de la dorsale.

\section{LE CIIROMIS GaSTAGNEAT. - CHROMIS CASTANEA, Cuv.}

Poiss. Frunce, t. III, p. 13\%, fig. 162, anim.

N. vulg.: Castagnole, Castagnolla, Nice; Quoue-fourkat, PortVendres.

Long. : 0,08 ì 0,12 .

Le corps est couvert de grandes écailles, fortement ciliées; sa hauteur est comprise deux fois et trois quarts à trois fois et un tiers dans la longueur totale, et la longueur de la tête 
quatre fois à quatre fois et demie: les mâchoires sont garnies de dents en velours, un peu plus fortes à la rangée externe. Le diamètre de l'œil mesure le tiers environ de la longueur de la tête, il est plus grand que l'espace préorbitaire. - La ligne latérale suit le profil supérieur jusque vers l'extrémité de la dorsale, au-dessous de laquelle elle est seulement interrompue; elle reprend sur le milieu du troncon de la queue et se continue jusqu'à la caudale. Ec., l. long. 28 à 30 ; 1. transv. 10 ou 11. - La seconde épine de l'anale est développée; la caudale est fourchue, elle mesure le quart environ de la longueur totale; la ventrale a la moitié externe de son premier rayon mou fort allongée.

Br. 6. - D. 13 ou $14 / 8$ à 11 ; A. $2 / 8$ à 11 ; C. 17 ; P. 17 ; V. $1 / 5$.

Le corps est brun violacé, marron, glacé d'argent; sur les côtés s'étendeut cinq à lıuit bandes d'une teinte noirâtre. Toutes les nageoires sont d'un brun violacé; la caudale a le bord interne des lobes plus ou moins blanchâtre; à l'aisselle de la pectorale est une tache d'un noir très foncé. - La vessie natatoire est très développée. - Il y a deux appendices pyloriques.

Habitat. Méditerranée, très commun, Nice, Antibes; assez commun, Toulon, Marseille; très rare, Port-Vendres.

\section{I. TRIBU DES ACANTHOPTÉRYGIENS ABDOMINAUX. ACANTHGPTERYGII ABDOMINALES.}

Cette tribu est composée de sept familles.

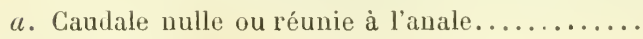

b. Première dorsale formée d'épines libres......... ayaut les épines unies par

une membrane........................

c. Museau prolongé en tube................... ordinaire.................... d

d. Tronçon de la queue à carènes latérales.......

$e$. Première dorsale à quatre rayons épineux...

f. Dents des mâchoires très petites..............

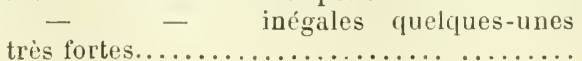

6 .

1. Notacanthides.

2. Gastérostéidés.

$c$.

3. Aulostonidés.

d.

4. Tétragonuridés. $e$.

5. JuGilidés.

6. ATMÉRINidés.

i. SPHYRÉNIDÉS. 


\section{Famille des Notacanthidés, Notacanthidie.}

Corps allongé, comprimé, couvert de petites écailles cycloïdes.

Tête plus ou moins écailleuse; museau avancé; bouche fendıe obliquement sous le museau; màchoires et palatins dentés.

Nageoires; dorsale constituée par des aiguillons libres, avec ou sans rayon mou après la dernière épine; anale longue, unie à la caudale; ventrales composées d'aiguillons et de rayons mous.

Vessie natatoire plus ou moins développée, pourvue d'un conduit pneumatophore (Vaill.), en manquant (Günth.).

GENRE NOTACANTIE. - NOTACANTHUS, Bloch.

Caractères de la famille.

a. Dorsale ayant plus de vingt épines..... moins de douze épines... . b.

b. Orifices de la narine distants............ j. DE RISso.

2. de bonaparte.

1. de la Méditerranée.

1. LE NOTACANTHE IE I.A MÉDITERRANÉE. - NOTACANTHUS MEDITERRANEUS, Fil. et Vér.

Poiss. France, t. III, p. 158, fig. 163, anim.

Syn. : Notacanthus mediterraneus, Vaill., Exp. sc. Travail. ct Talism., p. 323̈, pl. 27, fig. 2 , anim., $2^{\text {a }}$ cràne vu de còté, $2^{\text {b }}$ ceinture scapulaire, 2 c $2^{d}$ sagitta.

Long. : 0,140 à 0,320 .

La hauteur du trone est comprise de sept à douze fois dans la longueur totale, et la longueur de la tête cinq fois et quart ¿ sept fois; le museau est avancé en forme de pyramide quadrangulaire; les màchoires sont garnies de dents étroites, pointues, assez longrues. Le diamètre de l'oeil est contenu cinq lois à cing fois el demie dans la longueur de la tête; il mesure lés trois quarts environ de l'espace préorbitaire; il est aussi grand ou plus grand que l'espace interorbitaire. Les orifices des narines sont très rapprochés l'un de l'autre; ils paraissent confondus dans une petite fossette noiraitre. - La dorsale commence en avant du milieu de la longueur totale; elle a six ou sept aiguillons et un rayon mou; lianale est longue et 
basse, continue à son extrémité avec la caudale; la ventrale compte de deux à quatre aiguillons et six rayons mous.

$$
\text { D. } 5 \text { ou } 6+1 / 1 ; \text { A. } 12 / 132 \text { ?; P. } 14 ; \text { V. } 2 / 6 \text {. }
$$

Br. VIII+D. VI, 1; A. XI, 120 ?; V. III, 6, (Vaill.).

Le corps est d'un brun rougeâtre; l'anale est bordée de brun foncé; les ventrales sont noirâtres; l'intérieur de la chambre branchiale est noirâtre. -- Suivant le professeur Vaillant, sur le frais, la teinte générale est d'un brun sépia.

Habitat. Méditerranée, Nice, excessivement rare.

A propos du Notacanthus de la collection du Muséum que j’ai décrit (P. Fr.t. III, p. 1כ8) sous le nom de N. Mediterraneus, le Dr Vaillant (Exp. sc. Trav. et Talism., Poiss., p. 322) dit que ce Notacanthus appartient à un type qui lui paraìt ètre le $N$. Bonapartii, Risso; je regrette infiniment que les raisons suivantes m'empèchent de partager l'opinion de mon savant confrère: dans le $N$. Mediterraneus, les orifices de la narine, j'en ai fait l'observation, sont très rapprochés l'un de l'autre, ils sont contigus; au contraire, ils sont chez le N. Bonapartii, séparés par une distance relativement assez grande, de plus le nombre des épines est de 6 ou 7 à la dorsale, 11 ou 12 à l'anale chez le $N$. Wediterraneus, tandis qu'il est de 8 ou 9 à la dorsale, de 1 ä à 18 à l'anale chez le $N$. Bonapartii. - Quant aux spécimens du Muséum, je faisais cette réserve (loc. cit., p. 160), " ces deruiers sont-ils bien de mème espèce que celui du Musée de Turin »? Peutètre les Notacanthes du Muséum de Paris sont-ils le type d'une espèce nouvelle et doivent-ils receroir une autre dénomination que celle sous laquelle je les ai désignés?

\section{LE NOTACANTHE BONAPARTE. - NOTACANTHUS BONAPARTII, Riss.}

Poiss. France, t. III, p. 161.

Syn. : Notacanthus Bonapartii, Günth., Challeng. Decp-Sea Fish., t. XXIl, p. 249, pl. 61, fig. C. anim.

Long. : 0,140 à 0,300 .

La hauteur du tronc est contenue de six à dix fois dans la longueur totale. La longueur de la tête, suipant Günther, est comprise six fois et demie environ dans la longueur totale; la mâchoire supérieure (mandibule, Risso) est garnie d’une 
rangée de dents tranchantes, au nombre de vingl à ringtdeux; la mâchoire inférieure est munie d'un seul rang de dents plus lisses, plus petites que les dents du palais qui sont disposées sur deux rangées. - Le diamètre de l'œeil fait environ le cinquième de la longueur de la tète, les deux tiers de l'espace préorbitaire, il est moindre que l'espace interorbitaire (iiunth.). Les orifices de la narine sont éloignés l'un de l'autre; la distance qui les sépare est, d'après la figure donnée par Günther, égale, ou peu s'en faut, à la moitié de la lonģueur du diamètre de l'oxil.

$$
\begin{gathered}
\text { D. } 9 ; \Lambda .15 / 120 ; \text { P. } 16 ; \text { V. } 3 / 11 \text { (Riss.). } \\
\text { D. } 8 ; \Lambda .18 / x(150) ; \text { C. } 3 ; \text { P. } 9 ; \text { V. } 1 / \text { i (Günth.). }
\end{gathered}
$$

La partie postérieure des nageoires paires et la partie inférieure de l'anale sont noires; la cavité de la bouche, comme celle de la chambre branchiale est noire (Günth.).

Habitat. Méditerranée, excessivement rare, Nice.

Suivant le prince de Canino, le Notacanthe Bonaparte de Risso et le Nolacanthe nez de Bloch sont de mème espèce; opinion que semble partager le Pr. Vaillant. Il y a deux espèces distinctes suivant le Dr Günther.

3. LE NOTACANTHE DE RISSO. - NOTACANTHUS RISSOANUS. Fil. Vér.

Poiss. France, t. III, p. 16\%.

Syn. : Notacanthus Rissoanus, Fil. et Ver., Vaill., Fxp. sc. Truvail. et Tulism., p. 33.̈, pl. 27, fig. 1 .

Long. : 0,1 à à 0,26 .

La hauteur du tronc est contenue douze à treize fois dans la longueur totale; l'anus est en avant du milieu de la lonzzueur totale. - La longueur de la tête fait à peu près le huitième de la longueur totale; le museau est proéminent, probosciforme (F. V.), sa longueur est au moins égale au tiers de la longueur de la tète: les màchoires sont munies de dents fines et serrées; les dents, qui garnissent le palais, forment une courbe semblable à celle de l'arcade maxillaire supérieure. L'wil est petit; l'espace préorbitaire est, d’après les figures, 
que je puis examiner, un peu moindre que l'espace postorbitaire. -- La dorsale compte de trente-trois à trente-sept épines, plus un rayon mou; l'anale a de vingt-sept à trente-trois aiguillons et un assez grand nombre de rayons mous.

Br. VIII+D. XxxVII, I; A. XxVII, $n+$ V. 1,9 (Vaill.).

La teinte sur le frais était d'un blạnc laiteux avec la tête noire (Vaill.).

Habitat. Méditerranée, Nice, excessivement rare. - L'étrange Notacanthe dédié à Risso, qui l'avait découvert et déjà nommé (Notacanthus lacerta, Riss., dans album inédit), ressemble, écrit M. Sarato, aux Mastacembélidés par son museau probosciforme, non moins que par sa longue rangée de 32 épines dorsales. Le spécimen type du $N$. Rissoanus existe au Muséum de la ville de Turin. On a recueilli sur notre marché, il y a 7 ou 8 ans, un second individu, et cet exemplaire a été envoyé au Muséum de Florence. Le troisième et dernier spécimen connu, trouvé à Nice, le 14 avril 1887, est resté dans notre ville et figure au Musée d'Histoire naturelle (Sarato, Notes sur les Poissons de Nice, janvier 1888). - MM. Gal frères ont eu l'obligeance de me donner une esquisse de ce dernier spécimen et de me fournir les renseignements suivants: long. totale 0,190 ; long. de la tète $0,020 \%$; distance du museau à l'anus 0,0725; au palais, les dents forment un arc pareil à celui des màchoires; dorsale à 33 épines dures et libres; anale à 33 épines libres et 38 à 40 rayons unis par une membrane; queue finissant en pointe.

Le spécimen, recueilli par le Talisman, a été pris sur la còte du Maroc, par 2212 mètres de profondeur; il mesure 0,260 de longueur, tronc, hauteur 0,020 ; tête long. 0,031 ; museau, long. 0,011 ; wil, diam. 0,00' (Vaill.). - D'après II. L. Vaillant, le N. Rissoanus Fil. et Ver., est différent du poisson du Japon décrit et figuré sous le mème nom spécifique par M. Gïnther, pl. LXI, B, (Vaill., loc. cit., p. 387$)$.

\section{Famille des Gastérostéidés, Gasterosteidie, Bp.}

Corps plus ou moins allongé, nu, ou bien ayant, au lieu d'écailles ordinaires, des pièces osseuses sur les flancs et parfois sur les còtés de la queue.

Tête nue; mandibule plus avancée que la màchoire supérieure, garnies de dents l'une et l'autre; palais et langue lisses. 
Yeux latéraux; sous orbitaires recouverts seulement par la peau, formant une chaine continue, le dernier s'articulant avec le préopercule.

Appareil branchial; ouĩes bien fendues; trois rayons branchiostèges.

Nageoires; première dorsale formée par des épines isolées, munies en arrière d'une membrane triangulaire; seconde dorsale ayant une épine et des rayons mous; anale semblable et opposée à la seconde dorsale; caudale entière ou peu échancrée; pectorale à rayons simples articulés, non branchus; os du bassin uni au squelette de la pectorale; ventrale peu développée, n'ayant qu'une épine et un ou deux rayons mous.

Vessie natatoire oblongue. - Appendices pyloriques peu nombreux.

Cette famille se compose de deux genres.

Première dorsale à moins de douze épines............ 1. Épinoche.

- $\quad$ à plus de douze épines.................. 3. Gastré.

1. GENRE ÉPINOCHL. - GASTEROSTEUS, Linn.

Nageoires; première dorsale ayant moins de douze épines.

Deux genres ou deux divisions.

Première dorsale ayant moins de cinq épines......... 1. Éprxoche.

- $\quad-\quad$ plus de cinq épines.............. 2. Épinochette.

\section{SOUS-GENRE ÉPINOCHE. - GASTEROSTEUS.}

Nageoires; avant les rayons mous de la seconde dorsale, il y a généralement trois aiguillons, rarement deux ou quatre.

Il n'y a réellement qu'une seule espèce et des variétés plus ou moins nombreuses.

L'ÉPINOGHE AIGUILLONNÉE. - GASTEROSTEUS ACULEATUS, Linn.

Poiss. France, t. III, p. 163.

N. vulg. : Épinoche à trois épines; Grande Épinoche; Épinarde; Picot, Rippe; Épinglotte; Épinarde; Savetier; Cordonnier; Arite, Charente-Inférieure; Estrangla-cat, Hérault; Crébro-Varlé, Espignaube, Estranglo Ca, Gard; Sabatié, Nice.

Long. : 0,0 à à 0,08 . 
Le corps est comprimé; sa hauteur est comprise quatre fois et demie à cinq fois dans la longueur totale; il y a sur le dos, entre la tête et les rayons mous de la seconde nageoire, cinq ou six plaques osseuses, et sur les côtés une série d'écussons en nombre variable de deux à trente-deux; le tronc est entouré d'une cuirasse qui est constituée par des plaques dorsales, des écussons latéraux, les cubitus et les os du bassin. La longueur de la tête est contenue trois fois et demie à quatre fois dans la longueur totale; les mâchoires portent une bande étroite de petites dents crochues. Le préopercule a deux branches unies en un angle droit dans lerfuel est reçue la partie postérieure et inférieure du grand sous-orbitaire. A l'élat normal, deux épines isolées représentent la première dorsale.

D. 1 à $3-1 / 10$ à $12 ;$ A. $1 / 8$ ou 9 ; C. 12 ; P. 10 à 12 ; V. 1/1.

La coloration est très variable, le plus souvent verdâtre. La vessie natatoire est argentée, ovoïde, pourvue de deux corps rouges. - Il y a deux appendices pyloriques.

Habitat. L'Épinoche se trouve dans la plupart de nos départements, manque en Savoie.

\section{Variètés:}

1. L'Épinoche à queue nue. - Gasterosteus leiurus, C.V.

2. L’Épinoche à queue armée. - Gasterosteus trachurus, C. V.

3. L'Epinoche demi-armée. - Gasterosteus semiarmatus, C. I.

4. L'Épinoche demi-cuirassée. - Gasterosteus semiloricatus, C. V.

5. L’Épinoche à deux épines. - Gasterosteus biaculealus, Cresp.

6. L'Épinoche à quatre épines. - Gasterosteus tetracanthus, C. V.

\section{2. SOUS-GENRE ÉPINOCHETTE - GASTEROSTEA.}

Nageoires; une dizaine d'épines arant les rayons mous de la seconde dorsale.

\section{L'ÉPINOCHETTE. - GASTEROSTEA PUNGITIA.}

Poiss. France, t. III, p. 169.

N. vulg. : Marichaud, Poitou (Lemarié).

Long. : 0,0't à 0,06 , rarement 0,07 . 
La hateur du tronc est comprise cing fois à cinc fois el demie dans la longueur lotale; les flanes ne sont pas garnis de lamelles verticales osseuses: le troneon de la queue est lantôt lisse, tantôt armé de pièces dures, plus ou moins carénées; en avant des rayons mous de la seconde dorsale, est une série de petits écussons. La longueur de la tète est contenue environ quatre fois et demie dans la longueur totale.
D. 8 a $10-1 / 3$ ou $10 ;$ A. $1 / 8$ ou $9 ;$ C. $12 ; \mathrm{l}$. 10 ou $11 ; \mathrm{V} .1 / 1$.

La teinte est variable, le plus souvent d'un vert jaunâlre.

Habitat. L'Épinochette se trouve dans la plupart de nos départements qui sont au nord du $43^{\circ}$ de latilude.

\section{Variétés :}

1. L'Épinochette piquante. - Gasterosteus pungitius, Blanch.

2. L'Epinochette bourguignomne. - Gasterosteus Burgundianus, BI. 3. L'Épinochette lisse. - Gasterosteus lœvis, Cuv.

4. L'Épinochelte lorraine. - Gasterosteus Lotharingus, Blanch.

כ. L'Épinochette à tète courte. - Gasterosteus breviceps, Blanch.

2. GLNRE GASTIÉ OU SPINACHE. - SPINACHIA, GUV.

Corps allongé, anguleux; écussons osseux sur le dos, les llancs. Tête longue, pointue; mandibule avancée.

Nageoires; quinze épines avant les rayons mous de la seconde dorsale; os du bassin ne formant pas un bouclier médian.

\section{LE GASTRÉ OU ÉPINOCHE DE MER, - SPIN.ICHIA VULGARIS.}

Poiss. France, t. III, p. 171, fig. 164, anim.

N. vulg. : Quinze épines; Étrangle-chat, Poitou (Lemarié).

Long. : 0,09 à 0,12 , quelquefois $0,1 \%$.

Le corps est prismatique; sa hauteur est comprise dix à douze fois dans la longueur totale; il y a sur les côtés une rangée de plaques carénées; le tronçon de la queue est, dans une certaine partie de sa longueur, enveloppé par quatre séries do boucliers, deux séries latérales, une série supérieure, une série inférieure. La longueur de la tête mesure le fuart 
environ de la longueur totale; les màchoires sont garnies de dents en velours.

$$
\text { D. } 14-1 / 6 \text { ou } 7 \text {; A. } 1 / 6 \text {; C. } 14 \text {; P. } 9 \text { ou } 10 ; \mathrm{V} .1 / 1 \text {. }
$$

Le dos est verdâtre, le ventre blanchâtre. - Les nageoires sont d'un gris plus ou moins clair; une tache noirâtre marque généralement, à la partie antérieure, la seconde dorsale ainsi que l'anale.

Habitat. Manche, assez rare au nord de la Seine, moins rare au sud, mème commun près de Cherbourg; commun à Roscoff. Océan, assez rare vers le continent, plus commun vers les ìles; rare au sud de la Gironde, Arcachon.

Les Gastérostéidés construisent avec grand soin les nids dans lesquels leurs œufs doivent éclore.

\section{Famille des Aulostomidés, Aulostomidx.}

Corps de forme variable; écailleux, parfois nu.

Tête avancée; museau tubuleux, constitué par le prolongement du vomer, de l'ethmoïde, des ptérygoïdiens, des préopercules et des interopercules, terminé par une petite bouche.

Appareil branchial ; rayons branchiostèges peu nombreux; pseudobranchies.

\section{GENRE CENTRISQUE. - CENTRISCUS, Linn.}

Corps ovale, comprimé, couvert de petites écailles rugueuses. Tête écailleuse; bouche non dentée, terminale.

Nageoires; deux dorsales, la première courte, très reculée, à deuxième aiguillon dentelé et fort développé; ventrales petites, rapprochées, à quatre ou cinq rayons mous, épine nulle ou rudimentaire.

Vessie natatoire grande.-Appendices pyloriques manquant.

LE CENTRISQUE BÉGASSE. - CENTRISCÚS SCOLOPAX, Linn.

Poiss. France, t. III, p. 17\%, fig. 16ö, anim.

N. vulg. : Trombetta, Nice; Cardilagno, Marseille ; Peï Troumpeta, Becassa, Cette; Bécasse de mer, Soufflet.

Long. : 0,10 à 0,15 . 
Le corps est comprimé; sa hauteur est contenue environ quatre fois et un tiers dans la longueur tolale; la carène du ventre est presque tranchante en avant; entre les ventrales et l'anale, il y a trois épines minces, aiguës. - La tête a une longueur ég̨ale au moins aux deux cinquièmes de la Jongueur totale, sans la caudale; elle se prolonge en un museau étroit, presque cylindrique; la bouche est très petile; la mandibule est relevée, à bord mince et tranchant, plus avancée que la mâchoire supérieure. Le diamètre de l'œil est compris cing fois et demie environ dans la longueur de la tète. - La première dorsale commence sur le tiers postérieur de la longueur totale, caudale non comprise; sa deuxième épine est excessivement développée, à bord postérieur creusé d’un sillon et garni de dentelures.

Br. 3 ou 4. - D. $5-1 / 10$ ou 11 ; A. 15 a 20 ; C. 9 ; P. 16 ou 1 i;

V. $1 / 4$ ou 5 .

La coloration est d'un rose doré ou d'un gris doré sur le dos, d'un rose argenté sur les còtés et le ventre.

Habitat. Méditerranée, assez rare, Nice, Marseille, Cette. Océan, excessivement rare, Bayonne; accidentellement, còtes du Poitou.

\section{Famille des Tétragonuridés, T'etragonuridie.}

Corps allongé, couvert d'écailles dures, ciliées, disposées en verticilles obliques; deux crètes ou carènes saillantes de chaque còté clu troncon de la queue.

Tête allongée; museau assez gros, arrondi; mảchoire supérieure plus avancée que l'inférieure, ayant l'une et l'autre des dents sur une seule rangée; vomer et palatins dentés.

Appareil branchial; fente des ouïes grande; cinq rayons branchiostèges; joue et pièces operculaires écailleuses.

Nageoires; deux dorsales très rapprochées l'une de l'autre; la première longue, basse, épineuse; la seconde plus courte et plus haute; anale semblable et à peu près opposée à la seconde dorsale.

Vessie natatoire nulle. - Appendices pyloriques nombreux.

GENRE TÉTRAGOYURE. - TETRAGONURUS, Riss.

Caractères de la famille.

Monead. - Ichthyologie. 
LE TÉTRAGONURE DE CUVIER. -- TETRAGONURUS CUVIERI, Riss.

Poiss. Frunce, t. III, p. 178, fig. 166, anim.

N. vulg. : Courpata, Nice.

Long. : 0,23 à 0,30 , quelquefois $0,3 \ddot{3}$.

Le corps est à peu près cylindrique en avant de l'anus, légèrement conique en arrière; sa hauteur est comprise six lois et un tiers à sept fois et demie dans la longueur totale, dont la longueur de la tète mesure le cinquième ou le sixième; la bouche est grande; la mandibule a le bord dentaire arqué, elle porte une rangée de dents comprimées figurant une espèce de lame de scie; le vomer et les palatins ont les dents placées en une série longitudinale. Le diamètre de l'weil fait le cinquième environ de la longueur de la tête. - La ligne latérale est légèrement courbe jusqu'au-dessus de l'anale, droite ensuite. Ec., l. long. 100 à 120 ; 1. transs. 30 environ. - La première dorsale naìt au-dessus de la fin des pectorales, elle peut se cacher dans le sillon du dos, elle est contiguë à la seconde; le troncon de la queue est épais, il s'enfonce dans la base de la caudale et porte, de chaque côté, deux fortes carènes hérissées d'écailles; la caudale, à lobes à peu près égaux, ne mesure guère plus du septième de la longueur totale.

Br. 5. -D. 15 à $21-1 / 11$ à 13 ; A. 11 ou 12 ; C. 23 à 30 ; P. 16 ; V. $1 / 5$.

La teinte est d’un lilas très foncé sur le dos, plus clair sur les côtés arec des reflets rougeâtres.

Habitat. Méditerranée, très rare, Nice, Toulon, Marseille.

\section{¡. Famille des Mugilidés, Mugilidie.}

Corps allongé, couvert d'écailles.

Tête écailleuse; bouche en travers, peu fendue; maxillaires supérieurs grèles ; màchoire inférieure à tubercule médian, plus ou moins saillant.

Nageoires; deux dorsales éloignées l'une de l'autre, la première à quatre aiguillons; ventrales ayant une épine et cinq rayons mous. 


\section{GENRE MUGE. - MUGIL, Arted.}

Corps allongé, légèrement comprimé, couvert de grandes écailles très finement ciliées.

Tête large en dessus; museau obtus; bouche terminale, fendue transversalement, mais un peu arquée; lèvre supérieure plus ou moins grosse, avec une échancrure médiane dans laquelle s'enfonce le tubercule de la màchoire inférieure; maxillaire supérieur grèle ; intermaxillaire et dentaire munis d'appendices dentiformes, ressemblant à des soies, ordinairement cachés dans la lèvre inférieure, mais dépassant le bord de la lèv'e supérieure.

Appareil branchial; oües largement ouvertes; six rayons bran. chiostègres; pseudobranchies; pièces operculaires écailleuses, peu distinctes les unes des autres; l'interopercule et la branche correspondante de la mandibule circonscrivent, avec les pièces similaires du còté opposé, un espace plus ou moins étroit, c'estl'espace jugulaire ou intramandibulaire.

Ligne latérale manquant.

Nageoires; seconde dorsale ayant uné épine et sept à neuf rayons mous; anale composée de trois épines et de sept à onze rayons mous ; caudale échancrée.

Vessie natatoire grande, sans conduit pneumatophore. - Appendices pyloriques au nombre de deux à huit; estomac à parois très épaisses, espèce de gésier bulbiforme; péritoine pariétal noiràtre. Les Poissons de ce genre sont appelés Muges, Mujons sur les bords de la Méditerranée; Meuils ou Meuilles sur les còtes de l'Océan ; Mulets par les pècheurs de la Manche.

Le genre Muge comprend sept espèces.

¿. Espace jugulaire ovale.................... b.

b. Paupière double, presque nul..................

b. Paupière double, verticale.................. 1. CÉphale.

- circulaire, étroite................... $c$.

c. Maxillaire supérieur caché par le sous-orbitaire.... 2. DORÉ.

d. Sous-orbitaire à bord antérieur droit............. d. ${ }^{2}$ 3. Capiton.

-
e. Anale ayant onze rayons mous.............................

f. Hauteur du trónc faisant moins du quart de la lon-

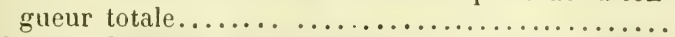
Ilauteur du tronc faisant le quart aumoins de la lon-

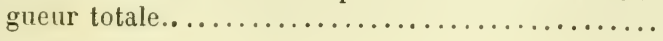

6. CIIÉLUN.

7. raccourci. 


\section{LE MUGE CEPHALE. - HUGIL CEPHALUS.}

Poiss. France, t. III, p. 183.

N. vulg. : Carida, Nice; Cabot, Cette et dans tout le Languedoc; Sautereau, Bayonne.

Long. : 0,30 à 0,50 , quelquefois 0,70 .

La hauteur du tronc mesure le cinquième environ de la longueur totale. - La longueur de la tête est comprise quatre fois et demie à quatre fois et trois quarts dans la longueur totale; les appendices sétiformes des màchoires dépassent les lèvres; l'espace jugulaire est ovale, assez large en avant. L'œil est pourvu de deux paupières verticales, s'écartant vis-à-vis de la pupille; son diamètre est contenu quatre fois et demie à cinq fois dans la longueur de la tète, il est à peu près égal à l'espace préorbitaire. - Ec., l. long. 43 à 亿0: 1. transr. 14 ou 1\%. - Généralement la première dorsale est un peu plus haute que longue; l'appendice écailleux, qui se trouve à l'aisselle de la pectorale, est triangulaire, caréné, faisant à peu près le tiers de la longueur de la nageoire; la ventrale est à peu près aussi longue que la pectorale.

$$
\text { D. } 4-1 / 8 \text { ou } 9 \text {; A. } 3 / 8 \text {; C. } 14 \text { ou } 15 \text {; P. } 17 \text {; V. } 1 / 5 \text {. }
$$

Le corps est gris plus ou moins foncé sur le dos et les flancs, argenté sous le ventre; six ou sept bandes brunâtres parallèles s'étendent le long des flancs. Les dorsales et la caudale sont d'un gris foncé; l'anale et les pectorales d'un gris pâle; les ventrales sont blanchàtres. Il y a seulement deux appendices pyloriques.

Habitat. Méditerranée, très commun, Nice, Cetı. Océan, assez commun de Saint-Jean-de-Luz à l'embouchure de la Gironde; rare sur la còte du Poitou, la Rochelle, les Sables d'Olonne. Je ne l'ai pas trouvé au nord de la Loire.

\section{LE MUGE DORÉ. - MUGIL AURATUS, Riss.}

Poiss. France, t. III, p. 18̈̈, fig. 167, tète vue en dessous.

N. vulg. : Mugou daurin, Nice; Gaouta-roussa, Calaga, Cette.

Long. : 0,30 à 0,4 . 
La hauteur du tronc est comprise cinq fois et un tiers à six fois dans la longueur totale, et la longueur de la tête cinq fois à cing fois et demie; la màchoire supérieure est pourvue de petites dents sétiformes; le maxillaire supérieur est courert à peu près complètement par le sous-orbitaire quand la bouche est fermée, parfois il est tout à fait caché d'un côté et un peu visible de l'autre; l'espace jugulaire est ovale, plus long que l'espace préorbitaire. La paupière adipeuse est étroite, circulaire; le diamètre de l'oeil est compris qualre fois et quart à quatre fois et demie dans la longuenr de la tète, il mesure la moitié environ de l'espace interorbitaire; le bord antérieur du sous-orbitaire est droit, pas échancré ni dentelé. - Ec., l. long. 43 à $4 \ddot{3}$; l. transr. 14 ou 10 . - La pectorale est beaucoup plus grande que la ventrale, sa longueur est contenue six fois et un tiers environ dans la longueur totale; l'écaille axillaire est nulle ou excessivement réduite.

$$
\text { D. } 4-1 / 8 ; \text { A. } 3 / 9 \text {; C. } 14 ; \text { P. } 17 \text {; V. } 1 / 5 \text {. }
$$

Le dos est brunâtre, le flanc gris foncé, avec six ou sept bandes longitudinales d'un brun assez foncé; le ventre est blanc argenté. Il y a derrière l'wil une tache jaune; il s'en trouve une plus grande et plus brillante sur l'opercule. L'anale et les ventrales sont blanchâtres; les autres nageoires sont d'un gris brunâtre.

Habitat. Méditerranée, très commun, Nice, Cette. Océan, golfe de fiascogne, assez commun à Arcachon; rare au-dessus de la Gironde. Manche, très rare, Dieppe, Saint-Valery-sur-Somme.

\section{LE MUGE CAPITON, - MUGIL CAPITO, Cuv.}

Poiss. France, t. III, p. 188.

N. vulg. : Ramada, Nice; Yol nègre et parfois Gaouta-roussa, Cette.

Long. : 0,30 à 0,30 , quelquefois plus.

La hauteur du tronc est comprise quatre fois et trois quarts à cinq fois et trois quarts dans la longueur totale, et la longueur de la tête quatre fois et demie à cinq fois; la lèrre supé- 
rieure est bordée de cils à peine visibles; l'extrémité du maxillaire supérieur est courbe, dépasse le sous-orbitaire et se montre à nu derrière la commissure des lèvres, même quand la bouche est fermée; l'espace jugulaire est ovale, il est environ deux fois et demie plus long que le diamètre de l'œil. La paupière est circulaire; le diamètre de l'œil est compris quatre fois et demie à six fois dans la longueur de la tête, deux fois et demie et plus dans la largeur de l'espace interorbitaire; le bord antérieur du sous-orbitaire est en partie dentelé, il est droit, sans échancrure arrondie. - Ec., l. long. 44 à 46; 1. transr. 14 ou 15. - La pectorale est courte, sa longueur ne mesure guère que le septième ou le huitième de la longueur totale; l'appendice écailleux fait presque le quart de la longueur de la pectorale; la ventrale est en général plus courte que l'autre nageoire paire.

$$
\text { D. } 4-1 / 7 \text { ou } 8 ; \Lambda .3 / 8 \text { ou } 9 ; \text { C. } 17 ; \text { P. } 17 \text {; V. } 1 / 5 \text {. }
$$

Le dos est brunătre, le côté grisâtre arec six ou sept bandes longitudinales brunâtres, le ventre gris argenté. - L'anale est grisâtre; les ventrales sont blanchâtres; les autres nageoires sont d'un gris brunâtre plus ou moins foncé; une tache noire marque presque toujours l'angle supérieur de la pectorale. - Il y a six à huit appendices pyloriques généralement égaux.

Habitat. Méditerranée, très commun. Océan, très commun jusqu'à l'embouchure de la Gironde; commun, côtes du Poitou, de Bretagne. Manche, moins commun.

\section{Var. - Le Muge blanc. - Mugil albus.}

La pectorale est assez large, presque triangulaire; son appendice écailleux est très réduit; l'appendice écailleux de la ventrale est développé, il mesure presque la moitié de la longueur de la nageoire.

$$
\text { D. } 4-1 / 8 ; \text { A. } 3 / 9 \text {. }
$$

Le dos est gris brunàtre; les côtés et le ventre sont argentés; les bandes longitudinales des flancs sont grises, peu marquées.

Habitat. Océan, Basses-Pyrénées. 
4. LE MUGE SAUTEUR, - MUGIL SHLIENS, RiSS.

Poiss. Frunce, t. III, p. 192.

N. vulg. : Mugou flavetoun, Flaretin, Flùte, Nice; Bayounetta, Russa, Celte.

Long. : 0,20 à 0,30 , quelquefois 0.40 , d'après Risso.

La hauteur du trone est comprise cind fois et demie à six fois et quart dans la longueur tolale, et la longueur de la tête quatre fois et demie à cinq fois et demı; le museau est étroit relatirement; les lèrres sont peu épaisses, semblant toujours dépourvues d’appendices sétiformes; le maxillaire supérieur est plus à découvert que chez le Muge capiton; le sous-orbitaire est entamé d'une échancrure arrondie sur la moitié externe de son bord antérieur; l'espace jugulaire est ovale, faisant à peine, en général, le double du diamètre de l'œil. Le diamètre de l'oil mesure environ le cinquième de la longueur de la tête, la moitié au moins de l'espace interorbitaire; le sous-orbitaire est dentelé sur le bord inférieur et sur le bord antérieur principalement au niveau de l'échancrure. - Ec., 1. long. 44 à $46 ; 1$. transv. 14 ou 13 . - La pectorale est assez courte, sa longueur ne mesurant généralement pas le septième de la longueur totale: l'appendice écailleux est très peu déreIoppé; la ventrale semble à peine moins longue que la pectorale.

$$
\text { D. } 4-1 / 8 \text {; A. } 3 / 9 \text {; C. } 14 \text {; P. } 15 \text { à } 17 \text {; V. } 1 / 5
$$

Le dos est brunàtre, le còté grisâtre, avec cinq ou six bandes azurées sur le frais; les pièces operculaires ont plusieurs taches dorées. Une tache noire marque parfois, en haut, la base de la pectorale. - Il y a en général huit appendices pyloriques, divisés en deux groupes, cinq assez courts, trois deux fois plus longs.

Habitat. Méditerranée, assez commun, Nice; peu commun, Cetle. Océan, golfe de Gascogne, rare, Arcachion. 
5. LE MUGE LABÉON. - MUGHL LABEO, Cuv.

Poiss. France, t. III, p. 193.

N. vulg. : Sabounié, Nice.

Long. : 0,13 à 0,20 .

La hauteur du tronc est comprise quatre fois et un tiers à cinq fois dans la longueur totale, el la longueur de la tête cinq fois et trois quarts; le museau est gros; la lèvre supérieure est fort épaisse, très échancrée dans son milieu, à bord un peu crénelé, garni de cils très fins; le maxillaire supérieur dépasse de beaucoup le sous-orbitaire; l'espace jugulaire est moins long que le diamètre de l'ceil; il est linéaire, presque nul. Le diamètre de l'œil est contenu trois fois et demie à quatre fois dans la longueur de la tête, il est aussi grand, parfois plus grand, que l'espace préorbitaire, il mesure environ la moitié de l'espace interorbitaire; le sous-orbitaire est fort échancré pour loger l'extrémité de la lèvre supérieure. L'anale compte onze rayons mous; la pectorale a une longueur ¿ peu près égale au sixième de la longueur totale; il ne paraît pas y avoir d'écaille axillaire bien formée.

$$
\text { D. } 4-1 / 9 ; \text { A. } 3 / 11 \text {; C. } 19 \text {; P. } 16 \text {, V. } 1 / 5 \text {. }
$$

Le dos et les côtés sont brunatres; le rentre est grisâtre; les côtés sont parcourus par six lignes dorées longitudinales. -- Il y a sept appendices pyloriques (C.V.).

Habitat. Méditerranée, assez rare, Nice, Cette. Océan, Arcachon?

\section{LE MUGE A GROSSES LÈVRES. - MUGIL CHELO, Cuv.}

Poiss. France, t. III, p. 193.

N. vulg. : Mugon Labru, Labru, Nice; Pansard, Marseille; Canuda, Lissa nigra, Sama, Cette.

Long. : 0,30 à 0,15 , quelquefois 0,60 .

La hauteur du tronc est comprise quatre fois et deux tiers à cing fois et un tiers dans la longuemr lotale, et la longueur de la tête cinq fois et un tiers à einq fois el demie; la lèvre supé- 
rieure est épaisse, elle a le bord garni de cils très visibles; l'espace jugulaire est presque linéaire, moins long que le diamètre de l'oil. Le diamètre de l'ceil est compris cinq à six fois dans la longueur de la tète, deux fois à deux fois et trois quarts dans l'espace interorbitaire; il mesure la moitié ou les trois quarts de l'espace préorbitaire; le premier sous-orbitaire a le bord externe taillé obliquement. - Ec., l. long. 4 ou 46 ; 1. transv. 16. - L'appendice écailleux de la première dorsale n’atteint pas en général au bord postérieur de la nageoire.

$$
\text { D. } 4-1 / 8 ; \text { A. } 3 / 9 \text {; C. } 16 \text {; P. } 17 \text {; V. } 1 / 5 \text {. }
$$

Le dos est gris bleuâtre, ainsi que les côtés qui sont parcourus par six ou sept handes longitudinales d'un brun parfois jaunatre; le ventre est argenté. Les pectorales sont ordinairement jaunâtres avec une tache foncée sur la partie supérieure de leur base. - Il y a six ou sept appendices pyloriques.

Habitat. Commun sur toutes nos còtes.

\section{LE MUGE RACGOURCI, - MUGIL CURTUS, Yar.}

Poiss. France, t. III, p. 198, figg. 168, anim., fig. 169, tête vue en dessous.

N. vulg. : Aubour mugé, Muge noir, Bayonne.

Long. : 0,20 à 0,28 .

La hanteur du tronc est comprise trois fois et demie it quatre fois dans la longueur totale, et la longueur de la tête quatre fois à quatre fois et un tiers; le museau est court; la lèvre supérieure est épaisse, elle porte une rangée de cils excessivement fins; l'espace jugulaire est linéaire presque nul, moins long que le diamètre de l'œil. Le diamètre de l'oeil est contenu quatre fois et trois quarts environ dans la longueur de la tête, il mesure les deux tiers de l'espace préorbitaire, un peu moins de la moitié de l'espace interorbitaire; le sous-orbitaire a le bord antérieur légèrement échancré et le bord externe finement dentelé. L'opercule est entamé d'une échancrure assez. lirrge an niveau de la base de 
la pectorale. - Ec., l. long. 38 ou 39; 1. transv. 14. - La première dorsale commence sur la seconde moitié de la longueur totale, caudale non comprise; l'appendice écailleux est bien développé, il dépasse en arrière la membrane de la nageoire; la longueur de la pectorale fait le sixième environ de la longueur totale, son extrémité est plus près de la base de la caudale que du bout du museau.

$$
\text { D. } 4-1 / 8 ; \text { A. } 3 / 9 ; \text { C. } 16 ; \text { P. } 17 \text {; V. } 1 / 5 \text {. }
$$

Le dos est d'un brun assez foncé; les côtés sont gris ou d'un brun rougeâtre; le ventre est argenté. Les nageoires sont brunes, excepté les ventrales qui sont pâles.

Habitat. Manche, excessivement rare, baie de la Somme. Océan, golfe de Gascogne, très rare, Arcachon; peu commun, Bayonne; commun, suivant Lafont, sur la còte d'Espagne.

\section{Famille des Athérinidés, Atherinida.}

Corps allongé, fusiforme, couvert d'écailles cycloïdes.

Tête aplatie en dessus; bouche très protractile, fendue obliquement; màchoire supérieure plus courte que l’inférieure, n’ayant l'une et l'autre que de fort petites dents; la langue et le vomer sont généralement dentés.

Appareil branchial; ouïes largement fendues; six rayons branchiostèges; pseudobranchies; joues et pièces operculaires écailleuses.

Ligne latérale nulle.

Nageoires; deux dorsales éloignées l'une de l'autre, la première commençant au-dessus ou plutòt un peu en arrière de l'insertion des ventrales; seconde dorsale opposée à l'anale qui comple souvent un ou plusieurs rayons mous de plus; caudale fourchue; ventrale ayant une épine et cinq rayons mous.

Vessie natatoire allongée. - Appendices pyloriques manquant.

Coloration; une bande argentée très brillante sur les còtés.

\section{GENRE ATIĹRINE. - ATHERIN $A$.}

Caractères de la famille.

Ce genre comprend cinq espèces. 


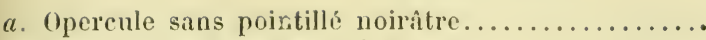
pointillé de noirâtre.................

b. Diamètre de l'oil ne faisant pas le liers de la lon-

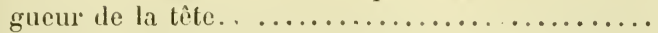

Diamètre de l'eil faisant le tiers au moins de la lon-

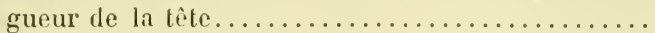

c. Ligne longitudinale composée de moins de f́s éeailles. comptant plus de 18 écailles....

d. Longueur de la tête firisant le se $^{\mathrm{e}}$ de la longueur

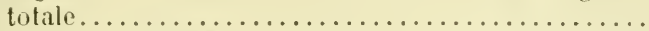

Longueur de lì tìte ne faisant pas le 5e de la lon-

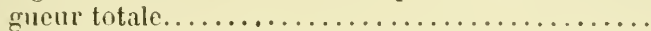

5. DE Risso. b.

1. HEPSET.

$$
c \text {. }
$$
l.

2. yocHov.

3. DE BOYER.

4. PRÈTRE.

1. LATHÉRINE HEPSET oU SALCLET. - ITIERINA IIEPSETUS, Linn.

Poiss. France, t. III, p. 202, fig. 170, anim.; Suppl., p. วั7.

N. vulg. : Mellet, Nice; Cabassoun, Toulon; Siouclet, Marseille; Saouclet, Cette; Joneil, Port-Vendres.

Long. : 0,10 à 0,12 , quelquefois 0,1 '

La hauteur du tronc est comprise six fois et demie à sept fois dans la longueur totale, et la longueur de la tête cinq fois à cing fois et demie; la mandibule ne semble pas dentée, elle n'a que des dents excessivement petites, non visibles à l'cril nu. Le diamètre de l'oeil est compris trois fois et demie dans la longueur de la tête; il est à peine plus grand que l'espace préorbitaire, il est égal à l'espace interorbitaire. - Ec., l. long. 60; l. transv. 11 ou 12, parfois 1\%. - La première dorsale commence à peu près au-dessus du milieu de la longueur des ventrales; la distance qui sépare l'anale de la pointe les ventrales esł au moins égale à la distance qui sépare le bord postérieur du battant operculaire du bord antérieur de l'orbite.

$$
\text { Br. 6. -D. } 8 \text { au } 9-1 / 11 \text { ou } 12 \text {; A. } 1 / 12 \text {; C. } 17 \text {; P. } 15 \text { ou } 16 \text {; V. 1/5. }
$$

Le dos est grisàtre, tacheté de points noirs formant un trait régulier à la base des écailles; les côtés et le ventre sont blanchìtres. La bande argentée occupe, sous la première dorsale, la moitié inférieure de la quatrième rangée d'écailles, la cinquième rangée et la moitié supérieure de la sixième rangée. 
L'opercule est marqué d'un pointillé noirâtre plus ou moins abondant.

Habitat. Méditerranée, très commune.0céan, assez rare, Arcachon.

\section{L'ATHERINE MOCION. - ATIIERINA HOCHON.}

Poiss. France, t. III, p. 209 .

Long. : 0,06 à 0,08 .

La hauteur du trone est contenue six fois et demie à sept fois dans la longueur totale et la longueur de la tète quatre fois et demie à quatre fois et trois quarts; la mandibule a de petites dents, visibles à l'œil nu et très sensihles au toucher. Le diamètre de l'ceil est compris deux fois et demie à deux fois et deux tiers dans la longueur de la tête; il est d'un quart ou d'un tiers plus grand que l'espace préorbitaire, il mesure à peine un cinquième de plus que l'espace interorbitaire, parfois moins encore. - Ec., l. long. 43 à 45 ; l. transv. 8. - La première dorsale commence au-dessus du liers postérieur de la longueur des ventrales; la distance qui sépare l'anale de la pointe des ventrales est à peu près égale à l'espace postorbitaire, elle ne paraît jamais dépasser la distance qui sépare le bord postérieur du battant operculaire du diamètre vertical de l'oeil.

$$
\text { D. } 7 \text { ou } 8-1 / 11 \text {; A. } 1 / 14 \text { à } 17 \text {; C. } 17 \text {; P. } 15 ; \text { V. } 1 / 5 \text {. }
$$

L'opercule est marqué de points noirs assez nombreux. La bande argentée est placée, entre la première dorsale et les ventrales, sur la quatrième, la cinquième et la sixième rangée d'écailles, parfois sur la troisième, la quatrième et la cinquième.

Habitat. Méditerranée, très commune, Marseille, Cette; elte est généralement confondue avec l'Athérine hepset.

3. L'ATHÉRINE DE BOYER OU JOÊL. - ATHERINA BOYERI.

Poiss. France, t. III, p. 205.

N. vulg. : Cabasuc, Nice; Tjol, Chol, Cette; Cabot, Port-Vendres. Long. : 0,08 à 0,10 . 
La hauteur du trone est contenue cinq fois et demie à six fois dans la longueur lotale, et la longueur de la tête quatre fois et demie à cinq fois; les dents, très visibles, forment une bande étroite sur les màchoires. Le diamètre de l'oil est compris deux fois et demie dans la longueur de la tète; il est d'un tiers au moins plus grand que l'espace préorbitaire; il est égal à l'espace interorbitaire. - Ec., l. long. $\ddot{0} 0$ à $5 \%$; 1 . transy. 10 ou 11 ; les écailles des flancs portent sur leur's bords verticaux une échancrure plus ou moins profonde. - La première dorsale commence au-dessus du tiers postéricur de la longueur des ventrales; la distance qui sépare l'anale de la pointe des ventrales est généralement plus grande que la distance qui sépare l'insertion des ventrales de l'anus, parfois les deux distances ne présentent pas de différence.

D. 7 ou $8-1 / 12 ;$ A. $1 / 13$ ou 14 ; C. 17 ; P. 14 ou $15 ;$ V. $1 / 5$.

Le dos est gris clair, pointillé de noirâtre, le ventre est gris blanchàtre. La partie supérieure de l'opercule est marquée de points noirs. La bande argentée des flanes est quelquefois bordée inférieurement par une ligne de points noirs.

Habitat. Méditerranée, cette espèce est moins commune que la précédente, se pèche de Menton à Banyuls. Océan, Arcachon?

Nous l'avons démontré (V. Suppl., p. 5̃ i) l’Athérine de Boyer n’est pas, comme le croyait Steindachner, la forme jeune de l'Athérine prètre. - C'est le Cabassoun des Marseillais.

\section{L'ATHERINE PRÊTRE. - ATIERINA PRESBYTER.}

Poiss. France, t. III, p. $20 \%$.

N. vulg. : Capelan, Eperlan, Faux-Éperlan, Seine-Inférieure; Roseret, Calvados; Prètre, Grados, Manche, Ille-et-Vilaine, Loire-Inférieure; Prètre, Aubusseau, Abusseau, Vendée, Charente-Inférieure ; Troyne, Noirmoutiers, Arcachon, Bayonne; Troque, Bayonne.

Long. : 0,10 à $0,1 \%$, quelquefois $0,1 \%$.

La hauteur du tronc est comprise cing fois et demie à sept fois dans la longueur totale, et la longueur de la tête cinq fois et demie environ; les dents des mâchoires sont distinctes. Le diamètre de l'ceil mesure le licrs au moins de la longueur 
de la tète; il est d'un tiers ou d'un quart plus grand que l'espace préorbitaire; il est égal à l'espace interorbitaire. - Ec., l. long. 88 à $63 ; 1$. transv. 11 ; les écailles des flancs n'ont pas leurs bords verticaux échancrés ou à peine; leur bord antérieur ou radical est pourvu d'un mamelon médian beaucoup plus développé que celui des écailles du Joël. - La première dorsale commence à peu près au-dessus du milieu de la longueur des ventrales; la distance qui sépare l'anale de la pointe des ventrales est moindre que la distance qui sépare l'anus de l'insertion des ventrales.

1). 7 ou $8-1 / 11$ à $13 ;$ A. $1 / 14$ à 16 ; C. 17 ; P. $15 ;$ V. $1 / 5$.

Le dos est verdàtre, semé d'un pointillé noiràtre moins fourni que dans les autres espèces; le ventre est blanchàtre. L'opercule est, à sa partie supérieure, marqué de petits points noirs. La hande argentée des flancs est d'une teinte excessiment brillante.

Habitat. Ce Poisson est plus ou moins commun sur toutes nos côtes de l'Ouest; il est excessivement commun dans les marais salants de Noirmoutiers, où l'on peut en prendre facilement de toutes les tailles.

5. L'ATHERINE DE RISSO. - ITHERINA RISSO, C.V.

Poiss. France, t. III, p. 210.

Long. : 0,07 à 0,09 .

La hauteur du tronc est comprise cinq fois à cinq fois et demie dans la longueur totale, et la longueur de la tête cinq fois. Le diamètre de l'œil mesure le tiers de la longueur de la tête; il est à peine plus grand que l'espace préorbitaire; il est égal à l'espace interorbitaire. - La première dorsale commence audessus ou à peine en arrière du milieu de la longueur des ventrales.

$$
\text { D. } 7-1 / 10 ; \text { A. } 1 / 11 \text { ou } 12 ; \text { C. } 17 ; \text { P. } 15 ; \text { V. } 1 / 5 \text {. }
$$

La teinte générale est d'un brun un peu roug'eâtre sur le dos, plus pâle sous le ventre. L'opercule est d'une couleur 
argentée uniforme, sams pointillé noiràtre. La bande argentée est très brillante.

Habitat. Méditerranée, très rare, Nice.

7. Famille des Sphyrénidés, Sphyranida.

Corps allongé, arroudi, couvert de petites écailles cycloïdes.

Tête longue; museau pointu; fente de la bouche à peu près horizontale; màchoire supérieure plus courte que la mandibule qui a ver's la symphyse un tubercule saillant; màchoires et palatins dentés, armés de quelques dents aiguës tranchantes plus développées que les autres; vomer non denté.

Appareil branchial; ouïes largement ouvertes; pièces operculaires écailleuses; sept rayons branchiostèges.

Nageoires; deux dorsales éloignées l'une de l'autre; la première répondant aux rentrales, la seconde opposée à l'anale; caudale fourchue; ventrales ayant une épine et cinq rayons mous.

Vessie natatoire grande, pointue en arrière, bifurquée en avant. - Appendices pyloriques nombreux.

GENRE SPHYR ENE. - SPHYRANA, Klein.

Caractères de la famille.

\section{LE SPET OU SPHYRENE SPET. - SPHYRE.YA SPET.}

Poiss. France, t. III, p. 212, fig. 171, anim.

N. vulg. : Lussi, Nice; Espest, Poisson-cheville, Marseille; Spet, Languedoc; Broutchet de mar., Pëy escoumé, Cette; Peix escomer, Pyrénées-Orientales.

Long. : 0,30 ì 0,40 et parfois 1,00 .

La hauteur du tronc est comprise neuf à dix fois dans la longueur totale, et la longueur de la lête trois fois et quart à quatre fois; le museau est allongé, étroit; la mâchoire supérieure a le bout tronqué; la mandibule la dépasse d'une longueur égale au tiers ou parfois à la moilié du diamètre de l'ceil, elle est terminée par un tubercule élastique continuant la ligne du profil supérieur de la tête, quand la bouche est 
fermée; les intermaxillaires sont armés en avant de deux longues dents tranchantes, latéralement, ils ont des dents courtes et fines; les palatins portent en avant trois ou quatre dents longues, et tranchantes, suivies de petites dents; à la mandibule, il y a parfois deux longues dents pointues, inclinées en arrière. Le diamètre de l'œil est contenu six à sept fois dans la longueur de la tête; il mesure le tiers environ de l'espace préorbitaire, il est à peu près égal à l'espace interorbitaire. - La ligne latérale est bien marquée, légèrement saillante. Ec., 1.long. 150 environ; 1. Iransv. 2̈ environ. - La première dorsale commence au-dessus des ventrales; la seconde est placée au-dessus et un peu en avant de l'anale; la caudale est fourchue; les nageoires paires sont courtes.

$$
\text { Br. 7. -D. } 5-1 / 9 ; \text { A. } 1 / 9 ; \text { C. } 17 \text {; P. } 13 ; \text { V. } 1 / 5 \text {. }
$$

La région supérieure du corps est d’un brun verdàtre, la région inférieure d’un blanc argenté. - Les dorsales et la caudale ont une teinte brunâtre; l'anale et les nageoires paires sont d'un gris plus ou moins clair.

Habitat. Méditerranée, assez rare, Nice, Cette.

\section{Sous-ordre des Malacoptèrygiens, Malacopterygii.}

Nageoires; dorsale et anale dépourvues de véritables aiguillons ; ventrale n'ayant pas de rayon épineux, et manquant parfois.

Vessie natatoire nulle ou plus ou moins développée, avec ou sans conduit pneumatophore.

Le sous-ordre des Malacoptérygiens est composé de trois tribus, caractérisées d'après l'absence ou la présence et la position des ventrales.

a. Ventrales manquant.

1. Psecdapones.

plus ou moins développées........... $b$.

$\iota$. Ventrales placées en avant ou au-dessous des pec-

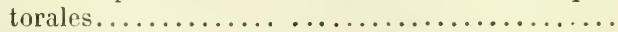

Ventrales placées en arrière des pectorales .....

2. Subrachlexs.

1. Aвoominaux.

I. TRIBU DES MALACOPTÉRYGIENS PSEUdAPODES. MALACOPTERYGII PSEUDAPODES.

Cette tribu comprend deux familles. 


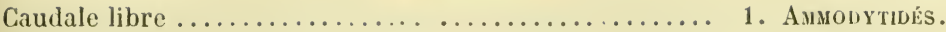

- unie aux nageoires impaires.............. 2. Orniblntés.

\section{Famille des Ammodytidés, Ammodytidie.}

Corps allongé, à peu près cylindrique, tantòt couvert de très petites écailles en séries obliques, tantòt paraissant plus ou moins nu; anus reculé.

Tête longue; bouche grande; màchoires non dentées; màchoire supérieure plus courte que la mandibule, qui est terminée en pointe.

Appareil branchial; fente des ouïes très grande; sept rayons branchiostèges; pseudobranchies.

Ligne latérale placée très haut, près de la base de la dorsale.

Nageoires; dorsale fort longue, composée, ainsi que l'anale, de rayons articulés, simples, non branchus, pouvant se loger dans un sillon; caudale libre, fourchue; pectorales assez peu développées.

Vessie natatoire nulle. - Appendice pylorique unique.

GENRE AMMODYTE. - A.MODYTES, Arted.

Caractère de la famille.

a. Màchoire supérieure non protractile............. 1. LAxços,

protractile ............. b.

b. Peau couverte d'écailles disposées en séries obliques. 2. ÉQvìlte.

- nue ou peu éeailleuse................... 3. Cicerelle.

1. L'AMMODYTE LANCSON. - AMMODYTES LANCEOLATUS, Lesauv.

Poiss. France, t. III, p. 217.

Long. : 0,15 à 0,30 .

La hauteur du tronc est comprise treize fois et demie à dixsept fois dans la longueur totale ; les écailles sont excessivement petites, formant un nombre de séries plus considérable que chez l'Equille. - La longueur de la tète est contenue cinq fois à cinq fois et demie dans la longueur totale; la màchoire supérieure n'est pas protractile; la pointe de la mandibule est fort allongée; le romer est armé de deux dents crochues. Le diamètre de l'ceil ne mesure guère que le septième de la longueur de la tête. - Ec., 1. long. $16 \%$ à 180 séries. - La dorsale Moreau. - Ichthyologie: 
commence au-dessus ou un peu en arrière de la pointe de la pectorale.

$$
\text { D. } 55 \text { à } 61 \text {; A. } 29 \text { à } 33 \text {; C. } 15 \text { à } 17 \text {; P. } 13 \text { à } 15 \text {. }
$$

Le clos est verdâtre; il n'existe pas de tache cuivreuse près de l'anus.

Habitat. Manche, rare, Seine-Inférieure; moins rare, Calvados, Manche, còtes de Bretagne. Océan, rare, Sables-d'Olonne, Arcachon.

\section{L'AMMODYTE ÉQUILLE. - AMMODYTES TOBIANUS, Lesauv.}

Poiss. France, t. III, p. 218, fig. 168. anim., et t. 1, p. 113, fig. 12, coupe de l'œsophage.

N. vulg. : Allançon, Sables-d'Olonne; Traouque-Sable, Arcachon.

Long. : 0,12 à 0,20

La hauteur du tronc est contenue douze à treize fois dans la longueur totale, et la longueur de la tète cinq fois à einq fois et demie; la mâchoire est très protractile; les intermaxillaires ont leur branche montante fort longue; le vomer n'est pas denté. - Ec., I. long. 114 à 130 séries. - La dorsale commence presque toujours avant la fin de la pectorale.

$$
\text { D. } 54 \text { à } 60 \text {; A. } 26 \text { a } 30 \text {; C. } 15 \text {; P. } 12 .
$$

Le dos est verdâtre; les flancs portent une large bandelette nacrée; il y a souvent près de l'anus une tache cuivreuse.

Habitat. Manche, très commun. Océan, Irès commun jusqu'à l'embouchure de la Gironde; moins commun dans le golfe de Gascogne.

3. L'AMMODYTE CICERELLE. - AMMODYTES CICERELLUS, Rafin.

Poiss. France, t. III, p. 219 ; Suppl., p. 58.

N. vulg. : Lussi, Nice; Jolivet, Saint-Malo.

Long. : 0,10 à 0,15 .

La hauteur du tronc est contenue treize à seize fois dans la longueur totale; la peau n'est pas marquée de plis obliques; 
chez beaucoup de spécimens, elle parait avoir des écailles vers le trongon de la queue seulement, chez d'autres, elle semble en manquer absolument; mais ça et là, on distingue des plaques légèrement saillantes, formées d'écailles qui présentent une grande diflérence dans leur développement. - La longueur de la tète est comprise quatre fois et deux tiers à cinq fois et trois quarts dans la longueur totale; la mâchoire supérieure est protractile, son extrémité arrive, ou peu s’en manque, sous le bord antérieur de l'orbite; le vomer n'est pas denté. - La dorsale commence généralement en arrière de l'extrémité de la pectorale.

$$
\text { D. } 5.3 \text { ì } 59 ; \Lambda .28 \text { à } 30 ; \text { C. } 19 ; \text { P. } 14 \text {. }
$$

Le dos est bleuâtre ; une bande argrentée, for't brillante, s'étend sur tout le côté; une lache bleue se roit fréquemment sur la partie supérieure du crâne.

Habitat. Méditerrannée, assez rare, Nice, Marseille. Océan? Manche, assez commun, Saint-Malo, baie de Cancale. Cette espèce a été apportée sur le marché de Paris, en 1891.

\section{Famille des Ophidiidés, Ophidiidx.}

Corps allongé, nu ou couvert de petites écailles cycloïdes. Tête petite; museau court; dents sur les màchoires, le vonıer.

Appareil branchial; fente des ouies grande; sept rayons branchiostèges.

Nageoires; dorsale très longue; nageoires impraires réunies.

Vessie natatoire sans conduit pneumatophore, maintenue par des apophyses vertébrales (V. t. III, p. 22:2).

Celte famille se compose de deux genres.

Barbillons sous la gorge, quatre............... 1. Ophide.

- $\quad$ manquant................ 2. Fí́rasfer.

1. GENRE OPHIDIE OU DONZELLE. - OPHIDIU $\boldsymbol{H}$, Arted.

Corps comprimé, ensiforme, couvert de petites écailles cycloïdes. Tête pelite; dents sur les màchoires, le voner et les palatins; sous la gorge, quatre barbillons disposés par paires, insérés sur une 
protubérance, ce sont les rayons des ventrales ayant subi un déplacement.

Ligne latèrale rapprochée du profil supérieur du corps.

Espace postorbitaire nu...................... 1. BARBU.

écailleux.................... 2. de VAssal.

\section{L'OPHIDIE BARBU. - OPHIDIUM BARBATUM, Linn.}

Poiss. France, t. III, p. 223, fig. 173, anim.

N. vulg. : Caligneiris, Nice; Donzèla, Doumaïzella, Dama, Cette.

Long. : 0,1 à à $0,2 \partial ̈$, quelquefois 0,30 .

La hauteur du tronc est comprise sept à neuf fois dans la longueur totale. - La lète est complètement nue; sa longueur est contenue cinq fois et un tiers à cinq fois et trois quarts dans la longueur totale; les màchoires portent une large bande de dents à peu près égales; l'extrémité de la mâchoire supérieure n'arrive pas à l'aplomb du bord postérieur de l'orbite; les barbillons sont très inégaux, les antérieurs étant d'un tiers plus longs que les autres. Le diamètre de l'œil fait environ le quart de la longueur de la tète; l'espace postorbitaire est nu. La dorsale commence ordinairement en arrière de l'extrémité de la pectorale; la pointe des rayons de la pectorale, retournée en avant, n'atteint pas l'extrémité de la màchoire supérieure.

$$
\text { Br. 7.-D. } 135 \text { à } 140 ; \text { A. } 120 \text {; P. } 20 .
$$

Le dos est couleur chair; le côté est argenté; tout le corps est pointillé de noir. Les nageoires impaires sont bordées de noir.

Habitat. Méditerranée, commun, Nice, Cette. Océan?

2. L'OPHIDIE DE VASSALI. - OPHIDIUM VASSALI, Riss.

Poiss. France, t. III, p. 224.

N. vulg. : Caligneiris, Nice.

Long. : 0,13 à 0,23 .

La hauteur du tronc est comprise huit fois et trois quarts à neuf fois et trois quarts dans la longueur totale, et la longueur 
de la tête six fois à six fois et demie; les màchoires sont à peu près égales, garnies de dents fines; l'extrémité de la mâchoire supérieure dépasse la perpendiculaire tangente au bord postérieur de l'orbite; les barbillons sont à peu près égaux. Le diamètre de l'œil est contenu quatre fois et demie à cinq fois dans la longueur de la tête; l'espace postorbitaire est écailleux. - Le plus souvent la dorsale commence un peu avant la terminaison de la pectorale; la pointe de la pectorale, renversée en avant, atteint à l'extrémité postérieure de la mâ. choire supérieure.

\section{130 à 137 ; A. 100 à 110 ; P. 16 ou 1 .}

La teinte générale est jaunâtre, excepté sous la gorge et le ventre qui sont d'un blanc rosé. Les nageoires sont d'une couleur jaune rougeâtre, sans bordure noire.

Habitat. Méditerranée, assez commun, Nice.

\section{GENRE FIÉRASFER. - FIERASFER, Cuv.}

Corps allongé, comprimé; peau nue; anus très avancé.

Tête nue; bouche grande; dents sur les màchoires, le vomer, les palatins; pas de barbillons sous la gorge.

Nageoires; anale commençant très en avant.

Màchoires garnies en avant de dents en cardes........... 1. гмвщввE.

- armées en avant de dents en crochets......... 2. DExté.

\section{LE FIÉRASFER IMBERBE. - FIERASFFR IMBERBIS.}

Poiss. France, t. III, p. 226, fig. 174, anim.

N. vulg. : Aurin, Nice.

Long. : 0,12 à 0,13 .

La hauteur du tronc mesure le douzième ou le treizième de la longueur totale; le corps est ensiforme ; la queue se termine en une pointe très allongée ; l'anus est en avant de l'insertion de la pectorale. - La tête est mince; sa longueur est comprise sept à huit fois dans la longueur totale; le museau est arrondi ; la bouche est fendue obliquement; les mâchoires sont garnies de dents en cardes, courtes et crochues; la saillie du romer 
est armée de dents assez fortes. Le diamètre de l'œil est contenu quatre fois à quatre fois et demie dans la longueur de la tête. - La dorsale est plus basse et moins longue que l'anale, elle commence après l'extrémité de la pectorale; l'anale prend naissance presque sous l'insertion de la pectorale qui est assez déreloppée.

$$
\text { Br. 7. - D } 140 \text {; A. } 170 \text {; P. } 18 \text { (Riss.). }
$$

Le cops est jaunâtre avec des points roses et quelques bandelettes de couleur ocre; sur les côlés, il y a une quinzaine de plaques vert doré; le ventre est d'un blanc nacré.

Habitat. Méditerranée, assez rare, Nice.

Suivant Gïnther le Porobranchus linearis, Kaup, est le jeune du Fierasfer acus (F. imberbis); d'après Emery, le Vexillifer de Filippii, Gasco, en est la forme larraire.

\section{LE FIÉRASFER DENTÉ. - FIERASFER DENTATUS, Cuv.}

Poiss. France, Suppl., p. 89.

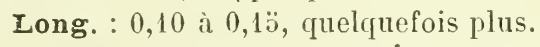

Le corps est mince, effilé; sa hauteur est contenue de quatorze a vingt et une fois dans la longueur totale; l'anus est au-dessous ou un peu en arrière de la base de la pectorale. La longueur de la tête est comprise de huit à neuf fois dans la longueur totale; le museau est obtus; en général, chacun des intermaxillaires est armé en arant d'une longue dent crochue, il est garni sur les côtés de fort petites dents, courtes, en relours cu en cardes très fines; la mandibule porte à son extrémité, et de chaque côté, une dent forte, crochue, en arrière elle est munie de petites dents courtes, semblables à celles de la màchoire supérieure; le nombre des crochets n'est pas toujours limité au nombre de quatre, il y en a parfois six, quelquefois huit. Le diamètre de l'ceil mesure le cinquic̀me de la longueur de la tête; il est égal à l'espace préorbitaire. - La dorsale commence généralement un peu plus en arrière que l'anale, après l'insertion de la pectorale; les deux nageoires impaires se confondent en une espèce de caudale, à rayons 
médians plus allongés que les autres, formant une espèce de pointe; la pectorale est assez courte; d'après Thompson, les nageoires impaires sont soutenues par 370 à 372 rayons.

D. $180 ; \Lambda .180 ;$ C. $12 ;$ P. 15 ou 16.

La teinte générale est rougeâtre. Le buttant operculaire est argenté.

Habitat. Méditerranée, très rare, Níce.

Les Fiérasfers vivent en parasites chez divers animaux marins; ils se logent de prétérence dans la cavité respiratoire de certains Échinodermes. Daprès Costa le Fierasfer imberbis se tient dans la cavité de l'Holothuria tubulosa, entre les viscères et les parois du corps.

\section{TRIBU DES MLALACOPTÉRYGIENS SUBRAGIIENS. IALACOPTERYGII SUBRACHII.}

Ventrales placées en avant ou au-dessous des pectorales.

Cette tribu est cómposée de cinq familles:

Ventrales réunies en disque.................

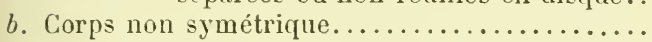

c. Peau couverte d'écailles rudes, pectinées......

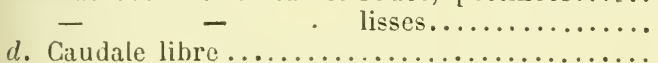
- unie aux nageoires impaires..........
5. Cycloptéridés.
4. Pleuronecidés. c.
3. MaCrovtridés. d.
2. GADIDÉS.
1. PtÉRIDIDÉs.

\section{Famille des Ptéridiidés, Pteridiidx.}

Corps allongé, assez comprimé, couvert de petites écailles cycloïdes.

Tête bien développée, écailleuse; màchoires et vomer dentés.

Appareil branchial; ouïes largement fendues; huit ayons branchiostèges; pseudobranchies.

Ligne latérale double en avant.

Nageoires; nageoires impaires réunies; ventrales filiformes.

Vessie natatoire ovoüle, sans conduit pneumatophore. - Appendices pyloriques, deux.

GEXRE PTRAIDION. - PTERIDIUM, Scopoli.

Ciaractères de la famille. 


\section{LE PTÉRIDION NOIR. - PTERIDIUM ATRUM.}

Poiss. France, t. III, p. 228, fig. 17\%̈, anim.

N. Vulg. : Fanfré négré, Nice.

Long. : 0,08 à 0,10 , parfois 0,133 , Bellot.

La hauteur du tronc est comprise cinq à six fois dans la longueur tolale; la queue se termine en pointe. - La tête est forte; sa longueur mesure le quart de la longueur tolale; le museau est arrondi ; les màchoires sont à peu près égales, elles portent, chez le mâle, une rangée de dents aiguës, bien séparées, peu nombreuses, au milieu d'autres dents très petites et très serrées; le vomer est armé de deux à quatre grosses dents crochues, il en a d'autres petites; chez la femelle, ainsi que le fait judicieusement observer le $D^{r}$ Cr. Bellotti, la dentition est différente, il n'y a pas de dents saillantes aux mâchoires, ni au vomer. Le diamètre de l'œil ne fait guère que le huilième de la longueur de la tête. - La ligne latérale figure une espèce d'Y ou de $\mathrm{V}$ allongé. - La dorsale commence audessus du milieu de la longueur des pectorales, elle s'unit à l'anale et forme arec elle une caudale pointue; la pectorale est insérée sur un pédoncule écailleux; les ventrales sont jugulaires, ayant chacune deux rayons filiformes.

$$
\text { Br. 8.-D. } 64 \text {; A. } 44 \text {; C. } 14 \text {; P. } 20 \text { (Riss.); V. } 2 .
$$

Le corps est d'un noir plus ou moins foncé, parfois uniforme, le plus souvent teinté de rougeâtre ou de marron. Les nageoires sont noirâtres.

Habitat. Méditerranée, très rare, Nice.

\section{Famille des Gadidés, Gadidx.}

Corps plus ou moins allongé, couvert d'écailles lisses, parfois caduques.

Tête; dents sur les màchoires et généralement sur le romer.

Appareil branchial; ouies bien fendues.

Nageoires; une, deux ou trois dorsales; une ou deux anales; caudale libre; ventrales jugulaires. 
Vessie natatoire manquant assez rarement; pas de conduit pneumatophore.

Cette famille comprend cinq sous-familles:

a. Dorsale triple.

1. Gadiniens.

6. Anale double.

2. Morinievs.

unique.

c. Barbillon à la mandibule nul......................

d. $1^{\text {re }}$ dorsale à plus de trois rayons................

trois rayons au plus..............

3. Mer Luciniens. d.

4. LOTINIENS.

5. RANicÉPINIENS.

\section{Sous-famille des Gadiniens, Gadini.}

Appareil branchial; sept rayons branchiostèges.

Nageoires; trois dorsales; deux anales.

Cette sous-famille est composée de deux genres :

Mandibule arec un barbillon..................... 1. Gade.

- sans barbillon........................... 2. Nerlan.

\section{GENRE GADE. - GADUS.}

Tête; un barbillon à la màchoire inférieure; dents sur les màchoires et le romer.

Ce genre comprend quatre espèces :

a. Ventrales ả deux rayons externes très allongés, dépassant l'anus ............................. b.

Ventrales à deux rayons exterines ordinaires............ $c$.

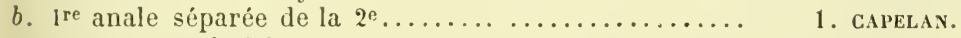

- unie à la $2^{2} \ldots \ldots \ldots \ldots \ldots \ldots \ldots \ldots \ldots$ 2. tacaud.

c. Tache sur le côté, au-dessous de la $1^{\text {re }}$ dorsale, nulle.. 3. yorue.

Tache sur le côté, au-dessous de la lre dorsale, bien

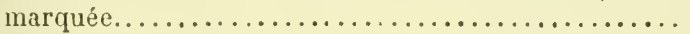

\section{LE GADE CAPELAN. - GADUS MINUTUS.}

Poiss. France, l. III, p. 231.

N. Vulg. : Capelan, cỏtes de la Méditerranée.

Long. : $0,1: \ddot{j}$ à $0,2 \ddot{3}$.

La hauteur du tronc est comprise trois fois et trois quarts à quatre fois et quart dans la longueur totale; les écailles sont 
peuadhérentes; l'anus est sous le milieu de la première dorsale. - La longueur de la tête est contenue trois fois et trois quarts à quatre fois el un tiers dans la longueur totale; les màchoires portent plusieurs rangées de dents fines, très acérées; le barbillon de la mandibule est d'une longueur à peu près égale à celle du diamètre de l'œil. Le diamètre de l'œil est égal, ou peu s'en faut, à l'espace préorbitaire, il est compris environ trois fois et demie dans la longueur de la tête. - La première dorsale est plus courte que la suivante; la première anale, complètement séparée de la seconde, prend naissance sous la fin de la première dorsale ou sous le commencement de la deuxième; la caudale est carrée ou légèrement échancrée; la ventrale a ses deux rayons externes sétiformes, très allongés, le deuxième arrivant à l'origine de la première anale.

Br. 7. - D. 12 à $14-19$ à $21-17$ à $20 ;$ A. 27 à $30-17$ à $20 ;$ C. 27 ; P. 17 ;
V. 6.

Le corps est brun rougeàtre, piqueté de noir sur le dos et les côtés, gris argenté sous le ventre; souvent une tache noirâtre se montre à l'aisselle de la pectorale; les nageoires impaires sont brunâtres; les ventrales sont d'un gris rosé.

Habitat. Méäiterranée, très commun. Océan, excessivement rare. Manche?

Sous le nom de Gadus mimutus, F. Day a donné, pl. LXXXI, une figure qui ne se rapporte nullement à l'espèce qu'il a voulu représenter.

\section{LE GADE TACAUD. - GADUS LUSCUS.}

Poiss. France, t. III, p. 233.

N. Vulg. Barraud-Godde, Godde ou Code, Mollet, Morue borgne, petite Morue; Poule de mer, Normandie; Moulet, Roscoff; Officier, Bretagne; Tacaud, còtes de l'Océan, Kiankiarquia, Biarritz.

Long. : 0,20 à 0,30 .

La hauteur du tronc mesure le quart environ de la longueur totale; les écailles sont adhérentes; l’anus est placé sous le tiers antérieur de la première dorsale. - La longueur de la tête est comprise quatre fois à quatre fois et deux tiers dans 
la longueur totale ; la bouche est relatirement petite ; les mâchoires sont munies de dents en cardes, plus fortes à la rangée externe; la longueur du barbillon est à peu près égaile à celle du diamètre de l'œil, qui est contenu trois fois à trois fois et demie dans la longueur de la tête, et qui est ordinairement un peu plus grand que l'espace préorbitaire. - La première anale commence sous le milieu de la première dorsale ; elle est longue. elle est unie à la seconde anale par une membrane assez développée: la caudale est carrée ou peu échancrée; les deux rayons externes de la ventrale sont très grands; le second est ordinairement le plus développé.
D.
$12-$
20 a $23-19$ ou 20 ;
1.17 à $31-27$ à 20 ;
C. $25 ;$ P. $17 ;$ V. 6.

Le corps est d'un jaune noiràtre ou plutôt brunàtre, plus clair sous le rentre, arec trois larges bandes verticales d'un gris blinnchâtre. Une tache noirâtre marque l'aisselle et la base de la pectorale.

Habitat. Manche, excessivement commun. Océan, commun. Médiditerranée, très rare, Nice, Cette.

Jaai nettement démontré que le G. minutus n'est pas, comme le prétend Steindachner, la forme jeune du G. luscus, c'est une espèce distincte; V. Suppl., p. 6 t.

\section{IE GADE MORUE. - GADUS MORHUA, Linn.}

Poiss. France, t. III, p. 23ä, et t. I, p. 166, fig. 20, appareil hyoïdien; t. 3 , p. II, fig. 83, squelette de la tète, et p. 10̈, fig. 8', squelette des nageoires paires.

N. Vulg. : Morue franche; Cabeliau, Cabillaud; Moulue, Poitou.

Long. : 0,50 ì 0,80 , quelquefois 1,50 .

La hauteur du tronc mesure environ le quart de la longueur totale; l'anus est placé sous les premiers rayons de la deuxième dorsale. - La longueur de la tête est comprise trois fois et demie à quatre fois et quart dans la longueur totale; la bouche est grande; les mâchoires sont armées de dents en fortes cardes; le barbillon est de longueur assez variable, tantôt plus long, tantôt plus court que le diamètre de l'œil. Chez les sujets très développés, le diamètre de l'ocil est contenu six à sept 
fois dans la longueur de la tête ; il fait près de la moitié de l'espace préorbitaire. - La première dorsale est plus haute et moins longue que les autres; les anales sont bien séparées l'une de l'autre; la caudale est carrée ou à peine échancrée ; la ventrale est généralement moins longue que la pectorale.

D. 13 à $15-17$ à $19-18$ à 21 ; A. 17 à $19 ;-16$ ou 17 ;C. 28 ; P. 16 à 19 ;
V. 6 .

La teinte générale est verdâtre ou d'un gris olive avec de nombreuses taches jaunâtres ou brunes sur le dos et les côtés. Ordinairement les dorsales et la caudale sont d'un gris jaunâtre ainsi que les pectorales : les anales sont d'un blanc pointillé de brun: les ventrales sont blanchâtres.

Habitat. Mer du Nord, la Morue, surtout la Morue de petite taille, est très abondante à Dunkerque. Manche, assez commune. Océan, rare, còtes de Bretagne; très rare, còtes du Poitou; excessivement rare, golfe de Gascogne.

On est parvenu, écrit de Lacépède, à rapporter vivantes en Europe des Morues pèchées à Terre-Neuve, et placées dans de grands vases à travers les parois desquels pénétrait l'eau salée; il ajoute que pour assurer l'existence de ces Morues, des pècheur's anglais les maintenaient au fond des vases, en prenant la précaution de leur percer la vessie natatoire au moyen d'une aiguille.

\section{LE GADE ÉGLEFIN. - GADUS RGLEFINUS.}

Poiss. France, t. III, p. 23\%.

N. vulg. : Egrefin, Morue de Saint-Pierre, Morue noire.

Long. : 0,3 à à 0,60 .

La hauteur du corps est comprise quatre fois et demie à six fois dans la longueur totale; l'anus est en général placé sous le commencement de la deuxième dorsale. - La longueur de la tête est contenue quatre fois à quatre fois et demie dans la longueur totale; le museau est arrondi ; les mâchoires sont garnies de dents en cardes; le barbillon est ordinairement très court. Le diamètre de l'œil mesure environ le quart de la longueur de la tête, chez les sujets de moyenne taille; il fait les deux tiers de l'espace préorbitaire. - La première dorsale 
commence le plus souvent au-dessus de l'insertion de la pectorale, elle est plus haute que longue, plus élevée que les autres dorsales; la deuxième dorsale est la plus longue des trois, elle finit à peu près dans le même plan vertical que la première anale; la caudale est légèrement éclıancrée ; les ventrales sont assez courtes, d'un tiers ou d'un quart moins longues que les pectorales.

D. 14 a $16-21$ a $23-19$ ou 20 ; A. 24 ou $25-20$ a 22 ; C. 29 ; P. 18 ; V. 6.

La partie supérieure du corps est d'un gris foncé; la partie inférieure est blanchâtre, légèrement teintée de gris. Sous la base de la première dorsale entre la ligne latérale et la pectorale est une tache noire très marquée, elle s'étend parfois audessus de la ligne latérale, elle est très persistante. Les dorsales et la caudale sont d'un bleu foncé ; les anales et les nageoires paires, d’un gris pàle.

Habitat. Mer du Nord, commun, Dunkerque. Manche, assez commun. Océan, assez commun jusqu'à l'embouchure de la Gironde, assez rare dans le golfe de Gascogue.

\section{GENRE MERLAN. - MERLANGUS.}

Tête; Dents sur les màchoires et généralement sur le vomer, pas de barbillon à la màchoire inférieure.

Le genre Merlan se compose de cinq espèces:

a. Diamètre de l'œil plus petit que l'espace préorbitaire. $b$.

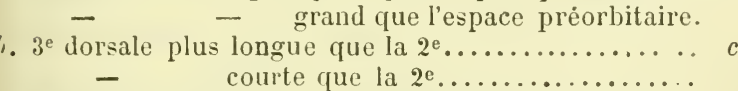
5. ARGENTÉ.
$c$.
4. Poutassou.
1. Connun.
c. Màchoire supérieure plus longue que l'inférieure...
Mảchoire supérieure plus courte que l'inférieure...
c. Ligne latérale courbe en avant...............

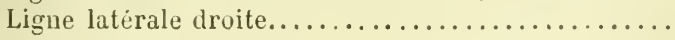 d.
2. JAUNE.
3 . NOIR,

\section{LE MERLAN COMMUN. - MERLANGUS VULGARIS.}

Poiss. France, t. III, p. 239.

N. vulg. : Léaud, île de Ré (I.emarié).

Long. : 0,2 à $0,3 \%$, quelquefois $0,40 ̈$. 
La hauteur du tronc est comprise cinq à six fois dans la longueur totale; l'anus est sous le milieu de la première dorsale. - La longueur de la tête mesure le quart environ de la longueur totale; la bouche est grande; la mâchoire supérieure est plus longue que l'inférieure; elles sont munies l'une et l'autre de dents fort inégales, de longues dents crochues, écartées, entre lesquelles s'en trouvent d'autres plus petites et beaucoup plus nombreuses. Le diamètre de l'œil est contenu quatre fois à quatre fois et demie dans la longueur de la tête; il fait les deux tiers ou peu s'en manque de l'espace préorbitaire. - La ligne latérale dessine en avant une longue et faible courbure jusque sous la deuxième dorsale, puis se continue directement jusqu’à la caudale; sur le frais elle paraît jatunâtre. - La deuxième dorsale est beaucoup plus longue que les autres.

D. 1 '́ à $16-18$ à $22-19$ à 21 ; A. 30 à $34-20$ à 24 ; C. 30 ; P. 19 ou 20 ; V. 6.

Le dos est gris verdâtre ou jaunâtre; le côté d'un blanc souvent teinté de jaune; le ventre d'un blanc argenté. Les dorsales sont d'un pâle légèrement jaunâtre; les anales sonl pâles avec un fin pointillé brunâtre et une bordure blanchâtre; la pectorale est d'un jaune très clair nuancé de brun a son extrémité; à la partie supérieure de sa base, il y a généralement unetache brune qui remonte sur le flanc.

Habitat. Mer du Nord, excessivement commun. Manche très commun. Océan, très commun jusqu'à l'embouchurc de la Gironde; moins commun dans le golfe de Gascogne. Méditerranée, accidentellement; un spécimen a été pêché à Cette, en 1882.

L'absence ou la présence d'un barbillon à la mandibule est un caractère de peu d'importance pour $\mathbf{M}$. Steindachner, qui regarde le G. merlangus (Merlan commun) et le G. Euxinus comme étant de même espèce.

\section{LE MERLAN JAUNE OU LIEU. - MERLANGUS POLLACHIUS.}

Poiss. France, t. III, p. 241.

N. vulg. : Colin, Cherbourg, Granville; Égrefin, marché de Paris. Long. : 0,30 à 1,00 , quelquefois 1,30 . 
La hauteur du tronc est contenue quatre fois et quart à cinq fois dans la longueur totale; l'anus est placé sous la moitié antérieure de la première dorsale. - La longueur de la tête est comprise quatre fois à quatre fois et demie dans la longueur totale; la màchoire supérieure est plus courte que l'inférieure, elles ont l'une et l'autre des dents assez fines, très aiguës. Le diamètre de l'œil, chez les sujets de moyenne taille, est compris quatre fois et quart à cinq fois dans la longueur de la tête; il mesure les trois cinquièmes de l'espace préorbitaire. - De la tète à la deuxième dorsale, la ligne latérale décrit une courbe allongée, puis se continue directement vers le milieu de la base de la caudale. - La première dorsale commence un peu en arrière de la verticale élevée sur le milieu de la longueur de la pectorale; la première anale prend naissance sous la moitié postérieure de la première dorsale.
D. 11 a $13-16$ à $19-15$ à 17
; A. 24 à $26-16$ a 18 ;
C. $32 ;$ P. 17 ; V. 6.

La coloration est assez variable; chez les adultes, le dos est d'un vert jaunâtre, ou d'un gris foncé à reflets jaunâtres; les flanes sont gris argenté; le ventre estblanchàtre. Les nageoires sont d'un g'ris brunâtre plus ou moins foncé.

Habitat. Nanche, commun. Océan, très commun, Bretagne, Poitou: golfe de Gascogne, assez commun, Arcachon, Saint-Jeande-Luz.

3. LE MERLAN NOIR OU COLIN. - MERLAYGUS CARBONARIUS.

Poiss. Frunce, t. III, p. 243.

N. vulg. : Charbonnier; Grélin; Merlan vert.

Long. : 0,2 ä à 0,60 , quelquefois 0,80 .

Il existe entre le jeune, ou le Sey, et l'adulte, ou Colin, certaines différences qui les avaient fait regarder comme étant deux espèces distinctes. - La hauteur du tronc est contenue quatre fois à quatre fois et quart dans la longueur totale ; l'anus est sous la fin de la première dorsale, quelquefois même un peu en arrière. - Chez les adultes, la longueur de la tête est ordinairement plus grande que la hauteur du corps; 
chez les jeunes, il n y a parfois aucune différence ; la muqueuse tapissant la bouche et la chambre respiratoire est noirâtre ou d'un bleu très foncé ; la màchoire supérieure, au moins chez les adultes, est plus courte que la mandibule, elles sont munies, l'une et l'autre, de dents en cardes; le diamètre de l'œil mesure les deux tiers ou les quatre cinquièmes de l'espace préorbitaire; il est contenu quatre fois et demi environ dans la longueur de la tête. La ligne latérale est droite, bien marquée, blanchâtre. - La première anale parait commencer à peine plus en avant que la deuxième dorsale.

D. 12 à $14-20$ à $22-20$ à $22 ; \Lambda .24$ à $27-20$ a $22 ;$ C. $26 ;$ P. 20 ou $21 ;$ V. 6.

La région supérieure du corps est noirâtre, la région inférieure est d 'une teinte moins foncée ; les dor'sales, la caudale et la pectorale sont d'un brun plus ou moins foncé; les autres nageoires sont grisâtres; il y a généralement une tache noirâtre à l'aisselle de la pectorale. Chez les jeunes, la coloration est verdâtre ou d'un gris jaunâtre.

Habitat. Manche, assez rare. Océan, assez commun sur la còte de Bretagne, baie d'Audierne; beaucoup plus rare au sud de la Loire; il est quelquefois pris dans le golfe de Gascogne, Arcachon.

F. Day figure le Gardus virens avec un petit barbillon sous le menton. V. Brit. Fish., pl. 84.

\section{LE MERLAN POUTASSOU. - MERLANGUS POUTASSOU.}

Poiss. Fiance, t. 1II, p. 2łö, fig. 176, anim.

N. vulg. : Gros Poutassou, Nice; Merlan, Cette.

Long. : 0,20 à 0,35 .

Lahauteur du corps est contenue cinq fois et trois quarts à six fois et demie dans la longueur totale; l'anus est placé plus en avant que la première dorsale. - La longueur de la tête est comprise quatre fois à quatre fois et quart dans la longueur totale; la muqueuse de la bouche est bleuâtre ou d'un violet très foncé; la màchoire supérieure est généralement moins avancée que l'inférieure; elles portent l'une el l'autre une bande de très petites dents et une rangée externe de dents 
assez fortes, crochues, espacées. Le diamètre de l'oril mesure le quart, au moins, de la longueur de la tète; il est aussi grand, ou peu s'en faut, que l'espace préorbitaire. Chez les adultes, la muqueuse de la chambre branchiale est d'un violet très foncé, presque noiràtre; elle est, chez les jeunes, d'un violet pâle, rosé. - La ligne latérale est droite. - Il existe entre les nagreoires du dos une distance à peu près égale, ou supérieure à la longueur de la base de la seconde dorsale qui est plus courte que celle des autres; la première anale est trèsavancée, très longue.

D. 12 ou $13-12$ ou $13-22$ à $24 ;$ A. 34 à $38-20$ i $25 ;$ C. $25 ;$ P. 20 ; V. 6 .

La teinte est d'un gris brunâtre sur le dos, argenté sur les coités et le ventre. Une tache noirâtre, peu marquée, se trouve sur l'opercule. Les dorsales sont grisâtres, les anales d'un gris pâle; la pectorale est brunâtre; une tache noirâtre se voit assez sourent à l'aisselle de la pectorale.

Habitat. Méditerrauée, assez commun, Nice, Cette. Océan, excessivement rare. Le Poutassou n'est pas, comme l'indique Giglioli, caractéristique de la Faune méditerranéenne, pusqu’il remonte jusque sur les còtes de la Norvège.

\section{ว̈. LE MERLAN ARGENTÉ. - IERLANGUS ARGENTEUS.}

Poiss. France, Suppl., p. 61.

Long. : 0,06 à 0,12 , rarement plus.

La hauteur du tronc est comprise quatre fois à six fois et demie dans la longueur totale; l'anus est placé sous la fin de la première dorsale, ou à peine en arrière, à peu près vers le milieu de la longueur totale; les écailles sont minces, très caduques. - La longueur de la tète est contenue trois à quatre fois dans la longueur totale; la mâchoire supérieure est un peu moins avancée que la mandibule; elles sont garnies l'une et l'autre de petites dents pointues, sur plusieurs rangées; tantôt le vomer est denté, tantòt il est lisse. - L'œil est très grand; son diamètre est compris deux fois et quart à deux fois et trois quarts dans la longueur de la tète; il est d'un tiers au moins Moreau. - Ichthyologie. 
plus grand que l'espace préorbitaire, qui, chez les jeunes, est à peu près égal à l'espace interorbitaire. — Les nageoires paires sont à peu près de même longueur; les ventrales ont six rayons, comme chez la plupart des autres Merlans.

D. 9 à $13-14$ à $17-15$ ou 16 ; A. 17 ou $18-15 ;$ C. 20 ou 21 ; P. 14 ou 15 ; V. 6.

La coloration, suivant le professeur Vaillant, est rosée, sauf le ventre et les joues qui sont argentés. Les nageoires sont grisâtres, transparentes.

Habitat. Méditerranée, excessivement rare, Nice.

2. Sous-famille des Moriniens, Morini.

Corps oblong, couvert d'écailles relativement grandes.

Tête écailleuse; bouche grande; dents en velours ou en cardes très fines sur les màchoires, le chevron du vomer, les palatins; un barbillon à la mandibule.

Appareil branchial; ouies largement ouvertes; sept rayons branchiostèges.

Ligue latérale bien marquée.

Nageoires; deux dorsales; deux anales; ventrale à six rayons.

GENRE MORA. - MORA, Riss.

Caractères de la famille.

\section{LA MORA DE LA MÉDITERRANÉE. - MORA MEDITERRANEA.}

Poiss. France, t. III, p. 248, fig. 177, anim.

N. vulg. : Mora, Moro, Nice.

Long. : 0,30 à 0,50 , quelquefois 0,6 ö.

La hauteur du tronc est comprise quatre fois et demie à cinq fois dans la longueur totale; elle est à peu près égale à la longueur de la tête; la bouche est tapissée, ainsi que la chambre branchiale, d'une muqueuse noirâtre ou d'un bleu très foncé; dents en velours ou en cardes très fines sur les mâchoires, le chevron du vomer et l'extrémité antérieure des palatins; les dents palatines semblent caduques; la mandibule 
porte un barbillon beaucoup plus court que le diamìtre de l'cil. Le diamètre de l'oil est contenu deux fois el deux tiers à trois fois et demie dans la longueur de la tète; il est plus grand que l'espace préorbitaire. - Ec., l. long. 7̈ à 8̈̈; 1 . transr. 24 à 26. - La première dorsale est triangulaire, plus haute. que longue; la seconde est très longue; la première anale est plus longue que la seconde ; la caudale est fourchue; la ventrale a son deuxième rayon plus allongé que les autres.

$$
\text { D. } 7 \text { ou } 8-42 \text { a } 45 \text {; A. } 16 \text { à } 19-15 \text { à } 20 \text {; C. } 25 \text {; P. } 18 \text { a } 20 \text {; V. } 6 \text {. }
$$

La teinte générale est un brun violacé à reflets argentés. La première dorsale est noire, la seconde d'un bleu sombre; les anales sont d'un bleu violacé; la caudale est d'un brun violacé; les pectorales sont noirâtres; les ventrales, brunes à la base, ont leur deuxième rayon d'un gris blanchâtre.

Habitat. Méditerranée, assez rare, Nice.

\section{Sous-famille des Merluciniens, Merlucini.}

Corps allongé, couvert d'écailles lisses.

Tête plus ou moins écailleuse; màchoires dentées; pas de barbillon.

Appareil branchial; onies largement fendues; sept rayons branchiostèges.

Ligne latèrale bien marquée.

Nageoires; deux dorsales; seconde dorsale et anale très longues. Cette sous-famille est composée de deux genres:

Anale commençant après la seconde dorsale........... 1. Merucus. Anale commençant avant la seconde dorsale........... 2. Uralepte.

1. GEYRE MERLUS OU MERLUCHE. - MERLUCIUS, CUV.

Corps plus ou moins arrondi, couvert d'écailles de moyennne grandeur.

Tête longue; dents en plusieurs séries sur les màchoires et le vomer.

Nageoires; seconde dorsale plus longue que l'anale. 


\section{LE MERLUS ORDINAIRE. -- MERLUCIUS VULGARIS.}

\section{Poiss. France, t. III, p. 231.}

N. vulg. : Merlan, côtes de la Méditerranée; Merlus, Merluche, còtes de l'Ouest; Colin, marché de Paris.

Long. : 0,30 à 0,70 .

La hauteur du tronc est comprise six fois et quart à huit fois dans la longueur totale, et la longueur de la tête quatre fois à quatre fois et un tiers; la bouche est grande, sa muqueuse est noirâtre, ainsi que celle de la chambre branchiale; chez les jeunes animaux, la muqueuse est ordinairement grisàtre; la màchoire supérieure est plus courte que la mandibule; elles sont munies, l'une et l'autre, de dents placées généralement sur deux rangées, celles de la série externe sont fixes et assez courtes, celles de la rangée interne sont mobiles, beaucoup plus longues et plus aiguës que les autres; les dents du vomer présentent les mêmes dispositions. Le diamètre de l'ceil mesure le sixième ou le septième de la longueur de la tète, la moitié à peu près de l'espace préorbitaire. - La première dorsale est plus haute que la seconde ; la caudale est carrée ; les pectorales sont plus longues que les ventrales.

$$
\text { Br. 7.-D. } 10-36 \text { a } 40 \text {; A. } 36 \text { a } 38 \text {; C. } 23 \text {; P. } 12 \text {; V. } 7 .
$$

Le dos et les côtés sont grisâtres; le ventre est blanc. - Le péritoine pariétal est noirâtre; il n'y a qu'un appendice pylorilique, court et gros.

Habitat. Méditerranée, très commun. Océan, très commun. Manche, commun, còtes de Bretagne; assez commun, Normandie, Picardie.

\section{GEYRE URALEPTE. - URALEPTUS, Costa.}

Corps allongé, effilé en arrière, couvert d'écailles, petites, caduques.

Tête longue, aplatie en dessus; màchoires dentées.

Nageoires; anale plus longue que la seconde dorsale. 
L'URALEPTE DE MARAIDI. - URALEYTUS MARALII, hisS.

Poiss. France, t. III, p. 233, fig. 178, anim.

N. vulg. : Moustella negra, Nice.

Long. : 0,20 à 0,30 .

Le corps est épais en avant, comprimé et très effilé en arrière; sa hauteur est comprise cinq fois à cinq fois el demie dans la longueur totale; l'anus est sous la première dorsale. - La têle est grosse, sa longueur est contenue qualre fois et quart environ dans la longueur totale; la mâchoire supérieure est un peu plus avancée que l'inférieure, elles portent l'une et l'autre une rangée de fortes dents crochues espacées; en outre, la mâchoire supérieure est munie d'une série interne de très petites dents; le vomer n’est pas armé. Le diamètre de l'œil mesure, ou peu s'en faut, le quart de la longueur de la tête; il est un peu moins grand que l'espace préorbilaire. - Ec., 1. long. 120 à 130 . - L'anale prend naissance sous la moitié postérieure de la première dorsale; ses derniers rayons, ainsi que ceux de la seconde dorsale, arrivent, quand ils sont couchés, vers l'insertion de la caudale ; le troncon de la queue est grêle; la caudale est en forme de spatule; la ventrale est moins longue que la pectorale.

$$
\text { Br. 7.-D. } 9 \text { ou } 10-56 \text { a } 58 ; \text { A. } 58 \text { à } 60 \text {; C. } 14 ; \text { P. } 20 \text {; V. } 7 \text {. }
$$

Le dos et les cutés sont d'un rougeâtre lavé de brun; la gorge, le ventre, le museau et les lèvres sont noirâtres. Les nageoires impaires sont grises, bordées de noir; la pectorale est noirûtre à la base, grise dans le reste de son étendue.

Habitat. Méditerranée, assez rare, Nice. Cette?

\section{Sous-famille des Lotiniens, Lotini.}

Corps plus ou moins allongé, couvert d'écailles lisses.

Téte de forme variable; dents sur la màchoire et généralement sur le vomer; un barbillon à la màchoire inférieure. 
Appareil branchial; fente des onies grande; sept ou huit rayons branchiostèges.

Nageoires; deux dorsales; seconde dorsale et anale longues. Cette sous-famille se divise en quatre genres:

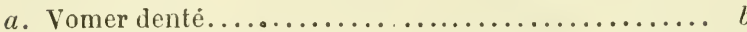

- non deuté........................ 4. Pirysicule.

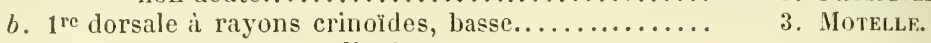

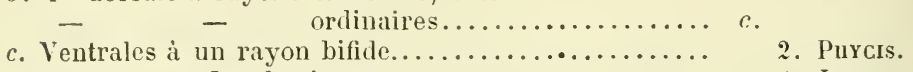

- plus de cinq rayons................ 1. Lote

\section{GENRE LOTE OU LOTTE. - LOTA, Guv.}

Corps allongé, arrondi en avant, comprimé en arrière, couvert de petites écailles cycloïdes.

Tête; dents sur les màchoires, le vomer.

Nageoires; seconde dorsale et anale très longues ;

Le genre Lole se compose de quatre espèces.

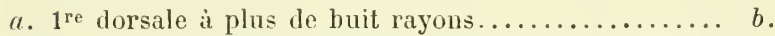

- à quatre rayons, le premier très allongé..

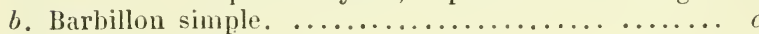

4. LÉPIDION.

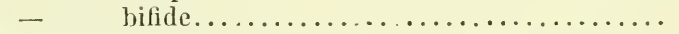

3. ALLONGÉE.

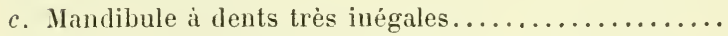

2. MOLVE.

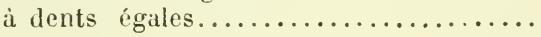

1. CoMHUNe.

\section{LA LOTE COMMUNE. - LOTA VULGARIS.}

Poiss. France, t. III, p. 2อั6.

N. vulg. : Barbot ou Barbotte, Motelle on Moutelle; Palmo, Gard; Azé, Avignon.

Long. : $0,33 ̈$ à 0,70 , rarement plus.

Le corps est couvert de petites écailles non imbriquées; sa hauteur est contenue six fois et demie à sept fois et quart dans la longueur totale. - La tête est déprimée; sa longueur est comprise cinq fois à cing fois et demie dans la longueur totale; la mâtchoire supérieure est généralement plus avancée que l'inférieure; elles sont l'une et l'autre garnies de dents en cardes fines; le vomer montre une large bande de dents en cardes très courtes; le barloillon de la mandibule est ordinairement beaucoup plus grand que le diamètre de l'wil. Chez les 
sujets de grande taille, le diamètre de l'œil est contenu sept à neuf fois dans la longueur de la tète; il mesure un peu plus du tier's de l'espace préorbitaire. L'orifice antérieur de la narine est muni d'un tentacule assez allongé. - La seconde dorsale est très longue, elle commence avant et finit après l'anale, vers la base de la caudale; le deuxième rayon de la ventrale est filiforme, plus allongé que les autres.

$$
\text { Br. 7. -D. } 12 \text { à } 14-68 \text { à } 72 ; \text { A. } 60 \text { à } 70 ; \text { C. } 40 ; \text { P. } 21 \text {; V. } 7 .
$$

Le système de coloration est excessivement variable, jaunàtre arec des marbrures brunâtres, ou bíen gris jaunatre avec des taches noires arrondies. Certains sujets sont atteints d'albinisme.

Habitat. Eaux douces; commune dans les lacs de Genève, d'Annecy, du Bourget; la Lote parait se trouver dans la plupart de nos cours d'eau. "La Lotte,écrit le comte de Sinéty, est moins commune dans l'Yonne que dans la Seine, où on en prend une grande quantité dans les mois de novembre et de décembre. ")(Faune, Seineet-IIarne, 18\%3). - Elle se pèche dans le Rhòne et ses principaux affluents. Elle parait manquer dans le Var et dans la plupart des rivières qui se jettent au nord de la Somme et au sud de la Gironde. - Suivant le $D^{r}$ L. Companyo, elle est quelquefois pèchée dans les Pyrénées-Orientales. -- Cette distribution géographique mérite d'ètre mieux fixée.

\section{LA I.OTE MOLVE OU LINGUE. - LOTA MOLVA.}

Poiss. France, t. III, p. 238.

N. vulg. : Julienne; Grande Morue barbue; Morue longue; Molve.

Long. : 1,00 à 1,30 .

La hauteur du tronc est contenue sept à huit fois dansla longُueur totale; l'anus est sous la partie antérieure de la première dorsale. - La longueur de la tête mesure le cinquième de la longueur totale; la bouche est grande; la mâchoire supérieure déborde linférieure, elle est garnie de dents en velours ou plutôt en cardes fines; la mandibule porte des dent’s en velours el une série de longues dents coniques, écartées les unes des 
autres, plus ou moins mobiles; le vomer a sur le chevron une bande de petites dents en velours, et une rangée interne de longues dents espacées au nombre de douze à quatorze; le barbillon de la mandibule est en général beaucoup plus grand que le diamètre de l'œil. Le diamètre de l'œil est compris six à sept fois dans la longueur de la tête ; il fait la moitié environ de l'espace préorbitaire. - La seconde dorsale finit, en arrière, dans le même plan vertical que l'anale; les pectorales et les ventrales sont à peu près de mème longueur.

Br. Ћ. -D. 14 à $16-63$ à 68 ; A. 58 à 65 ; C. 36 ; P. 19 ; V. 6.

La coloration est jaunâtre, quelquefois d'un brun jaunâtre sur le dos et les côtés, blanchâtre sous le ventre. Excepté la caudale qui est brunâtre, les nageoires sont d'un gris jaunâtre; les nageoires impaires sont bordées de blanc; la seconde dorsale et l'anale ont généralement une tache noire sur leurs derniers rayons.

Habitat. Ce Poisson se pèche sur toutes nos còtes de l'Ouest, où il est assez rare, surtout dans l'Océan. Méditerranée, excessivement râre; M. Bellotti en a trouvé quelques spécimens sur le marché de Nice.

3. LA LOTE ALLONGÉE. -- LOTA ELOVGATA, Riss.

Poiss. France, t. III, p. 260, fig. 179, anim.

N. vulg. : Stocofic, Nice.

Long. : 0,30 à 0,300 et mème 0,90 , Riss.

La hauteur du tronc, chez ce Poisson anguilliforme, est comprise douze à quatorze fois dans la longueur totale, et la longueur de la tête cinq fois et demie à six fois; la bouche est largement fendue; la màchoire supérieure est moins avancée que l'inférieure, elle est munie de dents en cardes assez faibles; outre ses petites dents, la mandibule en a une rangée d'autres forles et pointues; le vomer est garni de dents, les unes très fines, les autres fort développées ; le barbillon de la mandibule est bifide. Le diamètre de l'ceil est contenu trois fois et quart à quatre fois et demie dans la longueur de la tête; il est à peu 
près égal à l'espace préorbitaire. - L'anale commence plus en arrière que la seconde dorsale; la caudale est à peu près arrondie; le deuxième rayon de la ventrale est le plus grand, il dépasse, en arrière, l'extrémité de la pectorale.

D. 10 ì $12-77$ a $82 ; \Lambda .70$ a 77 ; C. 38 a $45 ;$ P. 18 ; V. 6.

Le dos est d'un gris rougeâtre, pointillé de noir, le ventre d'un blanc grisatre. Les nageoires sont grisâtres; une tache noire marque les rayons postérieurs de la seconde dorsale; la caudale porte deux larges taches noires placées l'une au-dessus de l’autre. - Le péritoine est noirâtre.

Habitat. Cette Lote se pèche assez sourent à Nice.

\section{LA LOTE LÉPIDION. - LOTA LEPIDION, Riss.}

Puiss. France, t. III, p. 262, fig. 180, anim.

N. vulg. : Moustella de fount, Nice.

Long. : 0,20 à 0,30 .

La hauteur est contenue quatre fois et demie à cinq fois et deux tiers dans la longueur totale, et la longueur de la tête environ quatre fois et demie ; la mâchoire supérieure est plus longue que la mandibule; les dents sont en cardes sur les mâchoires et sur le vomer; le barbillon de la mandibule parait de longueur assez variable. Le diamètre de l'œil est compris trois fois et demie à quatre fois dans la longueur de la tête; il est à peu près égal à l'espace préorbitaire. - Le rayon antérieur de la première dorsale se développe en un filament très ténu, mesurant parfois les deux cinquièmes de la longueur totale; les ventrales sont très longues, arrivant jusqu'à l'anus.

$$
\text { D. } 4-5 \text {; } ; \text { A. } 48 ; \text { C. } 22 ; \text { P. } 20 ; \text { V. } 6 .
$$

La teinte générale est d’un gris brunâtre; le pourtour des pieces operculaires est noiràtre.

Habitat. Méditerranée, assez rare, Nice. 
2. GLNRE PIIYCIS. - PHycis, Arted.

Corps allongé; écailles lisses, pas très adhérentes.

Tête plus ou moins écailleuse; dents en velours sur les mâchoires et le chevron du vomer; un barbillon à la mandibule qni est plus courte que la màchoire supérieure.

Appareil branchial; ouïes largement ouvertes; sept rayons branchiostèges.

Nageoires plus ou moins enveloppées dans une peau délicate; seconde dorsale très longue, commençant avant l'anale; ventrale paraissant formée d'un rayon bifide.

$1^{\text {re }}$ dorsale beaucoup plus haute que la $2^{\mathrm{e}} \ldots \ldots \ldots \ldots$ 1. BLennö̈pe.

- de même hauteur que la $2^{2} \ldots \ldots \ldots \ldots \ldots$. 2. MÉditerranéen.

\section{LE PRYCIS BLENNOIDE. - PHYCIS BLENNOIDES.}

Poiss. France, t. III, p. 26't.

N. vulg. : Moustella blanca, Moustella de Roca, Nice; Moula, Mouna, Cette.

Long. $\cdot 0,20$ à 0,40 , quelquefois $0, \breve{5} 0$.

La hauteur du tronc est contenue quatre fois et demie à cinq fois dans la longueur totale, et la longueur de la tête quatre fois à quatre fois et demie; la muqueuse tapissant la bouche et la chambre brancbiale est bleuâtre; les mâchoires sont garnies de dents fines et pointues; le barbillon est grêle, ordinairement moins grand que le diamètre de l'œil, qui mesure le quart au moins de la longueur de la tête et qui est égal, ou peu s'en manque, à l’espace préorbitaire. - La première dorsale a son troisième ou quatrième rayon filiforme beaucoup plus allongé que les autres; la ventrale est en réalité formée de trois rayons. le deuxième rayor est excessivement développé, atteignant parfois le milieu de l'anale.

$$
\text { D. } 9 \text { a } 11-56 \text { à } 60 ; \Lambda .52 \text { à } 5 \text { f C. } 21 \text {; P. } 18 ; \text { V. } 1 \text { (3). }
$$

Le dos et les côtés sont d’un gris rosé ou violacé, le ventre est d'un gris argenté. Les nageoires impaires sont grisâtres, bordées de noir, toutefois les derniers rayons de la première 
dorsale gardent une teinte uniforme; les nageoires paires sont grises, pointillées de noir.

Habitat. Méditerranée, commun, Nice, Cette. Océan? Manche (Lennier).

2. LE PHYCIS MÉDITERRANÉEN. - PHYCIS MEDITERRANEUS.

Poiss. France, t. III. p. 266.

N. vulg. : Moustella bruna, Nice.

Long. 0,30 à 0,40 .

La hateur du corps est comprise quatre fois et trois quarts a cinq foiset demie dans la longueur totale, et la longueur de la tête quatre fois à quatre fois et demie; les màchoires portent de petites dents en velours ; chez. des animaux conservés dans l'alcool, la muqueuse de la bouche, ainsi que celle de la chambre respiratoire, m'a paru d'un gris blanchâtre; le barbillon est grềle et généralement à peu près de même longueur que le diamètre de l'oeil. Le diamètre de l'ceil est contenu quatre fois et demie à cinq fois dans la longueur de la tête, il est moins grand que l'espace préorbitaire. - La première dorsale est triangulaire, de même hauteur que la seconde; la ventrale a une longueur égale, ou peu s’en manque, au quart de la longueur totale, son premier rayon n'est pas beaucoup moins allongé que le second qui se termine vers le commencement de lanale.

D. 9 à $11-57$ à $65 ; A .55$ à 60 ; C. 27 à 29 ; P. 17 à 19 ; V. 1 (2 ou 3).

Le corps est d'un brun noirâtre ou rougeàtre, plus foncé à la région dorsale. La première dorsale est brunâtre ; les autres nageoires impaires sont brunes et bordées de blane; l'extrémité de la pectorale est blanchâtre.

Habitàt. Méditerranée, assez rare, Nice, Marseille; très rare, Cette.

3. GENRE MOTELL OU MUSTËL. - MOTELLA, Gur.

Corps oblons, arrondi en avant, comprimé en arrière, à partir de l'anus, couvert de petites écailles lisses. 
Tête aplatie en dessus, écailleuse; màchoire supérieure plus avancée que l'inférieure; dents en velours ou en cardes fines sur les màchoires et le chevron du vomer; barbillons au nombre de trois au moins: un sous l'extrémité de la mandibule, un à l'urifice antérieur de chacune des narines; en outre, chez certaines espèces, il existe un ou deux barbillons au bout du museau.

Appareil branchial; fente des ouies grande; membrane branchiostège s’unissant sous l'isthme du gosier à celle du còté opposé; sept rayons branchiostèges le plus souvent.

Nageoires; deux dorsales; la première logée, plus ou moins cachée dans un sillon, très basse, formée de petits rayons crinoïdes très déliés, excepté le premier, qui est plus développé que les suivants; seconde dorsale et anale longues, finissant près de la caudale; ven/rale ayant de trois à huit rayons.

Les Motella glaura, Motella argenteola sont de jeunes animaux et non des espèces distinctes.

Le genre Motelle comprend quatre espèces :

$a$. Barbillons au nombre de trois........... $b$.

b. Longueur de la tête contenue moins de cinq fois dans la longueur totale............

Longueur de la tête contenue plus de cinq fois dans la longueur totale............ $c$.

c. Taches brunes sur le corps bien marquées..

Taches brunes sur le corps manquant .....

4. MUSTÈLE.

I. A TROIS BARBILLONS.

2. TACHETÉE.

3. BRUNE.

\section{LA MOTELLE A TROIS BARBILLONS. - MOTELLA TRICIRRATA.}

Poiss. France, t. III, p. 268.

N. vulg. : Loche, Renard, Cherbourg (Jouan).

Long. : 0,20 a 0,30 , quelquefois 0,33 .

La hauteur du tronc est comprise cinq fois et demie à sept fois et demie lans la longueur totale, et la longueur de la tête quatre fois à quatre fois et demie; la bouche est fendue jusque sous le bord postérieur de l'orbite; la mâchoire supérieure est beaucoup plus avancée que la mandibule, sa longueur fait généralement plus de la moitié de la longueur de la tête; outre leurs dents en velours, les mâchoires ont une série de dents plus fortes, crochues; le barbillon mandibulaire est plus ou moins allongé. Le diamètre de l'weil mesure environ le septième 
de la longueur de la tête, la moitié de l'espace préorbitaire. Sur le bord postérieur de l'orifice antérieur de la narine estun barbillon ou plutòt un tentacule bien développé. - La base de la première dorsale est courte, sa longueur est moindre que celle de l'espace postorbitaire; généralement la ventrale est sensiblement plus grande que la pectorale et compte sept rayons.

$$
\text { D. }-55 \text { ì } 60 ; \Lambda \text {. } 45 \text { à } 50 \text {; C. } 26 \text {; P. } 20 \text {; V. 7. }
$$

Les parties supérieures du corps sont d'un rouge orange finement pointillé de noir; la gorge et les parties longeant l'anale sont roses; le ventre est rose nuancé de bleu; sur le dos et les cotés se montrent des taches noirâtres plus ou moins grandes, plus ou moins nombreuses. Toutes les nageoires sont rougcitres chez les sujets de grancie taille, et la seconde dorsale plus ou moins marquée de laches noirâtres.

Habitat. Méditerranée, commune, Nice, Cette, Port-Vendres. Océan, assez rare, Arcachon, le Croizic. Manche, assez commune, Roscoff, Cherbourg; plus rare, le Havre.

\section{LA MOTELLE TACHETÉE. - MOTELLA MACULATA, Riss.}

Poiss. Erance, t. III, p. 270.

N. vulg. : 0,20 à 0,30 .

La hauteur du trone est comprise cinq fois et demie à six fois dans la longueur totale, et la longueur de la tête cinq fois et demie environ; la fente de la bouche n'arrive pas jusque sous le bord postérieur de l'orbite: les màchoires portent une bande de dents à peu près égales; la longueur de la mâchoire supérieure ne mesure pas tout à fait la moitié de la longueur de la tête. Le diamètre de l'reil fait le sixième de la longueur de la tète, les trois quarts environ de l'espace préorbitaire, il est à peu près aussi grand que l'espace interorbitaire. - La base de la première dorsale est plus longue que la région postorbitaire; la ventrale est à peine plus longue que la pectorale.

$$
\text { D. }-55 \text { à } 60 ; \text { A. } 45 \text { à } 50 \text {; C. } 22 \text { ì } 24 \text {; P. } 17 \text {; V. } 5 \text { ou } 6 .
$$

Le corps est d'un gris jaunàtre, semé de taches brunes as- 
sez grandes, et sourent marqué de points blanchâtres. Les nageoires, excepté parfois la première dorsale, sont plus ou moins brunâtres.

Habitat. Méditerranée, assez commune, Nice, Cette. Océan, rare.

3. LA MOTELLE BRUNE. - MOTELLA FUSCA, Riss.

Poiss. France, t. III, p. 272; v. Suppl., p. 133̈, Onus biscayensis. N. vulg. : Mouna négra, Cette; Furet, Port-Vendres.

Long. : 0,1 à 0,2 ö.

La hauteur du tronc est contenue cinq fois et demie à six fois et demie dans la longueur totale, et la longueur de la tête environ cinq fois et demie; les mâchoires ont les dents assez inégales; la longueur de la màchoire supérieure est moindre que la moitié de celle de la tête. Le diamètre de l'œil est compris de six à huit fois dans la longueur de la tête, il ne fait guère que la moitié de l'espace préorbitaire, chez les sujets développés, il est moins grand que l'espace interorbitaire. - La longueur de la base de la première dorsale est aussi grande ou plus grande que la longueur de l'espace postorbitaire; la ventrale est à peine plus longue que la pectorale.

$$
\text { D. }-52 \text { ou } 53 \text {; A. } 42 \text { a } 44 \text {; C. } 26 \text {; P. } 16 \text { ou } 17 \text {; V. } 6 .
$$

La femelle est d'une teinte uniforme, brun noirâtre; chez le mâle, le corps est d'un brun foncé, tirant parfois sur le marron; il porte sur le côté une ou deux séries de petites taches blanchâtres arrondies.

Habitat. Méditerranée, Nice, Cette.

4. LA MOTELLE MUSTĖLE OU MUSTÈLE A CINQ BARBILLONS. MOTELLA MUSTELA.

Poiss. France, t. III, p. 273.

N. vulg. : Loche de mer.

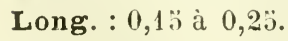

La hauteur du tronc est contenue cinq fois et demie à six fois 
dans sa longueur totale; elle est à peu près égale à la longueur de la tète; la màchoire supérieure est plus avancée que la mandibule; elles ont l'une et l'autre une bande de dents en velours ras, et parfois une rangée externe de petites dents erochues; il y a einq barbillons, un barbillon mandibulaire, deux tentacules nasaux, deux barbillons à la lèvre supépérieure. Le diamètre de l'œil mesure le sixième environ de la longueur de la tète; il est d'un tiers moins grand que l'espace préorbitaire. - La base de la première dorsale està peine plus longue que la région postorbitaire.

$$
\text { D. }-50 \text { à } 52 \text {; A. } 40 \text { ou } 41 \text {; C. } 19 \text { à } 21 \text { : D. } 14 \text { à } 16 \text {; V. } 8 \text {. }
$$

La teinte générale est d'un brun assez foncé sur le dos et les côtés, grisàtre sous le ventre, quelquefois la région supérieure du corps est d'un brun jaunàtre avec un pointillé noiràtre très serré.

Habitat. Manche, commune, très abondante dans les endroits rocailleux. Océan, assez commune.-La Motelle glauque, Motellaglauca, est l'état jeune de la Mustèle à cinq barbillons, M. Mustela.

\section{GENRE PIIYSICULE. - PHYSICULUS, Kaup.}

Corps allongé, couvert de petites écailles lisses; anus avancé.

Tête forte; dents sur les màchoires, pas sur le vomer; un barbillon à la mandibule.

Appareil branchial; oujes largement ouvertes; membranes branchiostèges réunies sous la gorge ; sept rayous branchiostèges.

Nageoires ; deux dorsales; la première courte; la seconde longue ainsi que l'anale; ventrales étroites.

LE PHYSICULE DE DALWIGK. - PHYSICULUS DALWIGKII,
Kaup.

Poiss. France, Suppl., p. $6 \ddot{3}$.

Long. : 0,18 à $0,2 \ddot{2}$.

Chez les sujets de grande taille, la hauteur du trone est comprise cinq fois et quart à cinq fois et demie dans la longueur totale, et de six fois et demie à sept fois chez les petits. - La 
longueur de la tête est contenue environ quatre fois et demie dans la longueur totale; la mâchoire supérieure recouvre la mandibule; les màchoires sont garnies de dents en velours ou en cardes fines; le vomer en manque; le barbillon est moins grand que le diamètre de l'ceil. Le diamètre de l'œil fait presque le tier's de la longueur de la tête; il est au moins égal à l'espace préorbitaire. - La première dorsale est presque triangulaire ; la seconde dorsale a ses derniers rayons allongés, arrivant, lorsqu’ils sont abaissés, sur la base de la caudale; la ventrale est insérée sous la gorge; elle est formée de deux longs rayons et de trois autres plus courts; la caudale est assez étroite, arrondie.

Br. 7. -D. 7 -64 à 67 ; A. 68 à 22 ; C. 22 à 24 ; P. 20 à 23 ; V. 5.

La teinte générale est un brun marron plus ou moins foncé.

Habitat. Méditerranée, très rare, Nice.

ə. Sous-famille des Ranicépiniens, Ranicepini, Bp.

Corps épais en avant, comprimé en arrière, couvert de très petites écailles.

Tête développée, aplatie en dessus; dents en cardes inégales sur les màchoires et le vomer; un barbillon a la mandibule.

Nageoires; deux dorsales; la première très réduite; la seconde très longue, comme l'anale ; caudale libre; ventrale effilée.

GENRE RANICEPS. - RANICEPS, Cuv.

Caractères de la famille.

LE RANICEPS TRIFURQUÉ. - RANICEPS TRIFURCATUS.

Poiss. France, t. III, p. 275 .

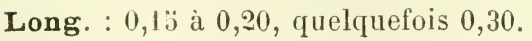

La hauteur du tronc est comprise quatre fois et demie environ dans la longueur totale. - Chez les jeunes la longueur de la tête est contenue quatre fois à quatre fois et demie dans la longueur totale, et trois fois et demie seulement chezles grands spéci- 
mens; la bouche est grande; la mâchoire supérieure est plus avancée que l’inférieure; les mâchoires etle vomer sont garnis de dents inégales en cardes; un petit barbillon est attaché à la mandibule. Le diamètre de l'ceil mesure le septième de la longueur de la tête, la moitié ou les deux tier's del'espace préorbitaire. - La première dorsale est souvent peu distincte, elle a deux ou trois rayous plus ou moins enveloppés dans la peau; la caudale est arrondie; la ventrale a le deuxième rayon très développé.

Br. 7. - D. 2 ou $3-65$ ou $66 ;$ A. 60 ; C. 30 à $35 ;$ P. 21 oul 22 ; V. 6.

La coloration est uniforme, d'un brun jaunâtre ou ggris foncé tirant sur le marron.

Habitat. Manche, excessivement rare, Cherbourg (Jouan), le Harre (Lennier), Bülogne (Sauvage); rare, Saint-Waast (E. Perrier).

\section{Famille des Macrouridés, Macrurida.}

Gorps allongé, terminé en lame pointue, couvert d'écailles.

Tête de forme variable; màchoires dentées; palais lisse; un barbillon à la mandibule.

Appareil branchial; fente des ouïes grande; six ou sept rayons branchiostèges; pas de pseudobranćhies.

Nageoires; deux dorsales; la première arancée, courte; la seconde très longue, ainsi que l'anale, avec laquelle elle se confond à la pointe de la queue; ventrale ayant six à huit rayons.

Cette famille se compose de deux genres:

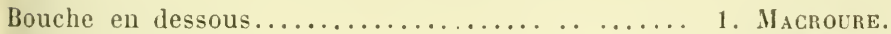

- terminale...................... HYuÉNocÉPHAL...

1. GEYRE MACROURE. - MaCRURUS, Bloch.

Corps garni d'écailles de forme variable, carénées, épineuses.

Tête grosse, hérissée de crètes plus ou moins saillantes; museau déhordant la bouche qui est arquée; màchoires munies de dents très fines, en velours; un barbillon à la mandibule.

Nageoires; ventrales en avant ou au-dessous des pectorales.

Le genre Macroure est formé de trois espèces:

Moread, - Ichthyologie. 
a. Ventrales placées sous les pectorales..........

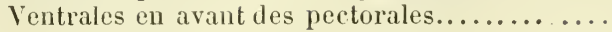

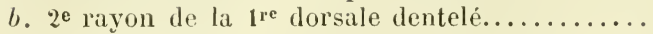

3. TRACHYRIYNQUE.

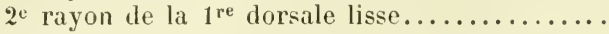

2. SCLEROIHYNQUE.

1. CÉlorhyNQUe.

\section{LE MACROURE CÉLORHYNQUE. - MACRURUS COELORHYNCHUS.}

Poiss. France, t. III, p. 278, fig. 181, anim.

N. vulg. : Granadié, Nice.

Long. : 0,20 à $0,3 \ddot{\text {. }}$

La hauteur lu corps est contenue six fois et quart à sept fois et demie dans la longueur totale; la peau est couverte d'écailles saillantes, qui sont, excepté en arrière, d'une extrême rudesse; l'anus est ouvert un peu après la terminaison de la première dorsale. - La tête est développée, garnie de pièces hérissées d'épines, formant une crête fort prononcée de l'extrémité du museau au préopercule; sa longueur mesure le quart environ de la longueur totale; la bouche est en dessous, arquée; le museau est triangulaire; la mâchoire inférieure est plus étroite que la supérieure, munies l'une et l'autre de très petites dents; le barbillon est grêle, beaucoup moins long généralement que le diamètre de l'œil. Chez les adultes, le diamètre de l'œil fait presque le tiers de la longueur de la tête; il est à peu près égal à l'espace préobitaire. La muqueuse de la chambre respiratoire est teintée de noir. - Ec., 1. long. 90 environ; 1. transv. 19 à 21. - La première dorsale est courte ; elle est séparée de la seconde par un espace plus grand que le diamètre de l'ceil ; son deuxième rayon est lisse; il est moins haut que le tronc; il n'arrive pas, quand il est abaissé, à l'origine de la seconde dor'sale; les ventrales sont insérées sous les pectorales.

$$
\text { Br. 6. -D. } 9-65 \text { à } 68 ; \text { A. } 75 \text { à } 83 \text {; P. } 18 \text {; V. 7. }
$$

Le dos est gris violacé; les flancs sont gris argenté; le ventre est brunâtre. Les nageoires sont grisâtres ; les dorsales et l'anale sont bordées de noirâtre.

Habitat. Méditerranée, Nice, rare; Cette, très rare. 
2. LE MACROURE SCLERORITNOUE. - MACRURUS SCLERORHYNCHUS, Val.

Poiss. France, t. III, p. 629.

Long. : 0,13 à $0,2 \%$.

La hauteur du trone mesure un peu moins du septième de la longueur totale; peau couverte d'écailles cténoïdes, à spinules inégales. - La longueur de la tète est ì peine supérieure à la hauteur du corps; le musea!n est court, tétraédrique, très épineux à son extrémité, qui est peu saillante; la bouche est infère, garnie de fines dents en velours; le barbillon est beaucoup moins long que le diamètre de l'œil. Le diamètre de l'œil fait un peu plus du tiers de la longueur de la tête; il est plus grand que l'espace préorbitaire. - Ec., l. long. 211 environ; 1. transr. 24. - La première dorsale est courte, élevée; le second rayon a le bord antérieur denticulé, il a une longueur supérieure à la hauteur du tronc, abaissé en arrière, il dépasse, de près de moitié de sa longueur, le point dorigine de la seconde dorsale; l'anale commence presque vers la perpendiculaire abaissée de la terminaison de la première dorsale; les rentrales sont insérées sous les pectorales.

$$
\text { Br. 7. - 1). } 10-187 ? ; \text { A. } 122 ? ; \text { P. 13; V. 7. }
$$

La coloration est argentée, un peu rougeâtre; la gorge, ainsi que la région antérieure de l'abdomen, est d'un bleu foncé presque noir.

Habitat. Océan, golfe de Gascogne, excessivement rare; un spécimen a été pèché par 1,160 mètres de profondeur dans l'Expédition ¿lu Travailleur. Méditerranée, accidentellement, Nice; d'après M. Sarato, le Poisson, que Risso a peint dans son album sous le nom de Lepidoleprus Gioma, est celui que Valenciennes a fait connaître plus tard sous la désignation de Macrurus sclerorhynchus. V Sarato, Notes sur les Poissons de Nice, Nice, 1888, p. 3. 


\section{LE MACROURE TRACHYRHYNQUE. - MACRURUS TRACHYRHYNCHUS.}

Poiss. France, t. III, p. 284, fig. 182, anim.

N. vulg. : Granadié, Nice.

Long. : 0,30 à 0,4 ว̆.

La hauteur du tronc est comprise sept à huit fois dans la longueur totale; la peau est courerte d'écailles excessivement rudes, épineuses; l'anus est placé sous le commencement de la seconde dorsale. - La tête est garnie d'écailles relevées en carènes denticulées; sa longueur est contenue trois fois et quart à trois fois et trois quarts dans la longueur totale; le museau est très proéminent, triangulaire; la mâchoire supérieure déborde l'inférieure; elles sont l'une et l'autre munies de très petites dents en velours; la muqueuse de la bouche, comme celle de la chambre branchiale, est noirâtre; le barbillon est très court. Le diamètre de l'âil mesure environ le cinquième de la longueur de la tête, et pas tout à fait la moitié de l'espace préorbitaire. - Ec., l. long. 120 environ; l. transv. 18. - Les dorsales sont très rapprochées, sourent peu distinctes l'une de l'autre; l'anale commence en arrière de la seconde dorsale; les ventrales sont insérées en avant des pectorales.

Br. 7. - D. 10 à $12-100$ à $110 ;$ A. 93 à $95 ;$ P. 18 ou $19 ; \mathrm{V}$.

Le corps est d'une teinte uniforme, il est gris nuancé de brunâtre. Les dorsales sont noirâtres; l'anale est brune; les nageoires paires sont girisâtres.

Habitat. Méditerranée, rare, Nice; très rare, Antibes. Océan, en 1882, un spécimen a été pris à Biarritz.

GENRE HYMÉNOCÉPHALE. - MYMENOCEPHALUS, Gigl.

Corps très effilé en arrière, couvert de petites écailles.

Tête grosse, sans crêtes saillantes; museau court, épais, tronqué; bouche terminale; mâchoires garnies de dents égales en velours ou en cardes (Vaill.); barbillon simple à la mandibule. 
Nageoires; première dorsale beaucoup plus haute que la seconde: ventrales jugulaires.

M. Giglioli n'a indiqué, ni dans Nature, ni dans Pelagos, aucun des caractères distinctifs du genre IIymenocephalus; c'est le professeur Vaillant qui a pris soin de les déterminer.

\section{L'HYMENOCÉPHALE D'ITALIE. - HYHENOCEPHALUS ITALICUS,} Giglioli.

Poiss. France, t. III, p. 28.́. Le Malacocéphale lisse, fig, 183, anim.

Syn. : Malacocephalus lavis, Gigl., Cat., Pesc. Faun. ital., sp. 306, et dans Nature, London, 1882, t. XXV, p. 333.

Hymenocephalus italicus, Gigl., New Deep.-Sea Fish from the Mediterranean, dans Nature, Lond., 1883, t. XXVII, p. 198-199; id. dans Pelagos, Genora, 188́, p. 228, fig.; Vaillant, Exp. se. Travail. et Talism., p. 211, pl. 19, fig. 1, anim., $1^{\mathrm{a}} 1^{\mathrm{b}}$ sagitta, $1^{\mathrm{C}} 1^{\mathrm{d}}$, écailles.

Maerurus italicus, Günth., dans Challeng., Deep-Sea Fish., t. XXII, p. 140 .

Long. : 0,1 ä à.

Le corps est couvert de petites écailles pectinées; il est grèle, très effilé en arrière, se terminant comme un crin; sa hauteur est comprise huit à dix fois dans la longueur totale; l'anus est sous le commencement de la première dorsale. - La tête est forte; sa loṇgueur mesure le sixième environ de la longueur totale; la bouche est terminale; la mâchoire supérieure est un peu plus large, mais pas plus longue que l'inférieure, munies de dents l'une et l'autre; le barbillon est assez long, mais fort grêle. Le diamètre de l'œil est contenu trois fois à trois fois et quart dans la longueur de la tête; il est un peu plus grand que l'espace préorbitaire. La muqueuse de la chambre respiratoire est brunâtre. - La première dorsale est très haute en avant; son deuxième rayon, qui est le plus développé, a parfois une longueur égale à celle de la tête; la seconde dorsale est fort basse, surtout en avant; l'anale est très longue, elle commence sous la première dorsale; les ventrales sont insérées en avant des pectorales.

Br. $8 .-$ D. $14-\ldots$; V. 8.

Le corps est d'un gris jaunâtre, la gorge est brunâtre. Les nagreoires sont brunes. 
Habitat. Méditerranée, excessivement rare, Nice.

Jans Pelagos, p. 228, M. Giglioli ne rappelle pas sa note publiée dans Nature, où est cité le Malacocephalus lavis capturé par lui; il écrit seulement... un piccolo Hacruride argenteo, a me allora sconosciuto e che ritenni essere tipo di genere e speeie nuovi. Ebbe poi da me il nome Hymenocephalus italieus, ed é cun piacere che ne do qui l'effigie; ne cbbi poi vari di Messina; il dolt. Günther che ne ebbe uno anni fa da Nizza, lo credette il giovane del Malacocephalus lævis. - Deux années après lapublication de son travail sur les Poissons recueillis par le Challenger, le $D^{\mathrm{r}}$ A. Günther indique ainsi l'habitat du Macrurus lavis, Lowe : Not uncommon in the Mediterranean..., dans Ann. Magaz. nat. History, London, 1889 (Ser. 6), t. IV, p. 418. - M. Vaillant fait remarquer, à propos de ce Poisson, que la seconde dorsale s'avance beaucoup plus en avant qu'elle n'a été fiģurée dans mon travail. Cette observation est parfaitement juste; le dessin n'a pas été exécuté suivant les indications que j’ai fournies et qui sont reproduites dans le tableau des proportions que j'ai relevées (p. 283̈) : "Distance du bout du museau à : $1^{\text {re }}$ dorsale, $0,023 \% 2^{\circ}$ dorsale, 0,048 ; anale $0,033$. " - Le spécimen de Nice qui a servi à ma description est-il bien identique aux sujets recueillis dans les Expéditions scientifiques du Travailleur et clu Talismun? Je n'oserais l'affirmer. La ventrale, chez l'individu pèché à Nice, est étroite, effilée, allongée, sa longueur mesure les quatre cinquièmes de la longueur de la tète.

\section{Famille des Pleuronectidés, Pleuronectidit.}

Gorps très comprimé, bordé sur une longue étendue par la dorsale et par l'anale ; coloré à l'état normal d'un seul côté, du còté correspondant à celui où se trouvent les yeux, blanchàtre du còté opposé; peau ordinairement couverte d'écailles, parfois de tubercules; anus très avancé.

Tête non symétrique; os plus ou moins inégalement développés sur chacun des côtés de la tète; dents parfois sur une seule moitié des màchoires, celle qui est du còté aveugle.

Yeux placés du mème còté, soit à droite soit à gauche, excepté chez les très jeunes animaux, qui les ont d'abord symétriques.

Narines à deux orifices.

Appareil branchial; six à huit rayons branchiostèges; pseudobranchies.

Ligne latérale généralement bien marquée du còté coloré.

Nageoires; dorsale commençant sur la tète et finissant très en 
arrière, ainsi que l'anale, qui est fort longue; rarement ces deux nageoires sont unies à la caudale; nageoires paires généralement peu développées; pectorales manquant parfois d'un còté ou mème des deux còtés.

Vessie natatoire manquant presque toujours. - Gavité abdominale se prolongeant de chaque côté des hémapophyses.

La famille des Pleuronectidés se compose de neuf genres:

a. Yeux à droite.

it gauche.

b. Dorsale commençant au-dessus de l'œil supérieur

- _ - en arant de l'œil supérieur. c. Base de la dorsale hérissée de tubercules épineux.

d. Dents larges coupantes.............................

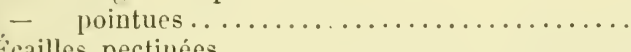

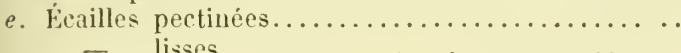

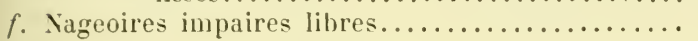

g. Espace interorbitaire plus petit que le diamètre vertical de l'wil.........................

Espace interorbitaire égal au moins au diamètre vertical de l'œil.. ...................... $h$. Côté gauche garni d'écailles lisses ou de tuber-

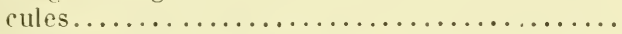

Côté gauche garni d'écailles pectinées........... $b$.

$f$.

$c$.

5. Sole.

4. FLET .

d.

3. PLIE.

$e$.

2. Limande.

1. Hirpoglosse.

g.

9. Plaguesie.

6. Pleuronecte.

$h$.

i. Rnonbe.

8. Botils.

\section{GENRE HIPPOGLOSSE. - IIPPOGLOSSUS, Cuy.}

Corps oblong, couvert de petites écailles lisses.

Téte à peu près aussi haute que longue; màchoires armées de dents pointues, écartées; dents pharyngiennes aiguës.

Yeux ì droite.

Nageoires; dorsale commençant au-dessus de l'œil supérieur.

\section{LE FLÉTAX. - HIPPOGLOSSUS VLLGARIS.}

Poiss. France, t. III, p. $28 \%$.

N. vulg. : Flétan, Fléton, Faiton, Holibut.

Long. : 1,00 à 2,00 et plus.

La hauteur du tronc est contenue trois fois à trois fois et quart dans la longueur totale, et la longueur de la tête quatre fois ì quatre fois et demie; la mâchoire supéricure est un peu moins 
avancée que la mandibule; elles sont munies l'une et l'autre de dents crochues, pointues. Les yeux sont à droite; leur diamètre est moindre que l'espace préorbitaire; il est un peu plus grand que l'espace interorbitaire, qui est aplati. - La ligne latérale est courbe au-dessus de la pectorale. - La dorsale commence au-dessus du milieu de l'œil supérieur; elle a, ainsi que l'anale, ses rayons médians plus élevés.

$$
\text { Br. 7. - D. } 100 \text { à } 107 \text {; A. } 75 \text { à } 82 \text {; C. } 18 \text {; P. } 14 \text { à } 17 \text {; V. } 6 .
$$

Le còté droit est d'un brun jaunâtre; le gauche est blanc grisâtre.

Habitat. Manche, assez rare, Boulogne. Océan, excessivement rare, Biarritz. Méditerranée, accidentellement, un spécimen a été pèché à Marseille en 1883 (Marion).

9. GENRE LIMANDE. - LIMANDA, Gottsche.

Corps ovale; écailles pectinées, très rudes du còté des yeux.

Tête; bouche oblique, peu fendue; mandibule avancée; dents petites, aiguës sur les màchoires et les os pharyngiens.

Yeux à droite, séparés par une crète osseuse; wil inférieur plus avancé.

Ligne latérale à forte courbure au-dessus de la pectorale.

Nageoires; dorsale commençant au-dessus de l'œil supérieur; anale précédée d'une épine.

LA LIMANDE COMMGNE. - LIMANDA VULGARIS, Gottsche.

Poiss. France, t. III, p. 289.

N. vulg. : Lime.

Long. : 0,20 ì 0,30 .

La hauteur du corps est comprise deux fois et un tiers à deux fois et trois quarts dans la longueur totale; les écailles sont minces, plus longues que larges, très adhérentes, excessivement rudes sur le côté droit. - La longueur de la tète mesure le cinquième environ de la longueur totale; le nuseau est court; les màchoires sont munies de dents assez courtes, pointues. Une crête osseuse, étroite, sépare les yeux; en avant elle 
se partage en deux branches venant former une partie du bord antérieur de chacune des orbites. L'ceil inférieur est plus a vancé; son diamètre est compris quatre fois et quart à cinq fois dans la longueur de la tête, il est plus grand que l'espace préorbitaire. - La dorsale commence au-dessus du milieu de l'ceil supérieur; l'anale est précédée d'une épine fort aiguë; le troncon de la queue mesure un cinquième ou un quart de plus en hauteur qu'en longueur; la pectorale droite est un peu plus développée que l'autre; les ventrales sont à peu près d'égale longueur.

Br. 7. - D. 65 ì 76 ; A. 50 à 56 ; C. 14; P. 10 ou $11 ; 9$ oll 10 ; V. $6,6$.

Du côté des yeux, le corps est gris ou brun jaunâtre, marqué souvent de petites taches blanchâtres et de petites taches orangées; du còté aveugle, il est blanchâtre.

Habitat. La Limande est très commune de Dunkerque à Brest. Océan, commune sur nos còtes de l'Ouest jusqu'à l'embouchure de la Gironde; moins commune dans le golfe de Gascogne.

3. GeNRE PLIE. - PLATESSA, Guv.

Corps ovale ou rhomboïdal; écailles généralement petiles et lisses.

Tête; museau court; bouche assez peu fendue; màchoire supérieure moins longue que la mandibule, portant l'une et l'autre, au moins sur le còté gauche, une rangée de dents aplaties plus ou moins coupantes.

Yeux à droite.

Appareil branchial; sept rayons branchiostèges.

Ligne latérale droite ou à faible courbure en avant.

Nageoires; dorsale commençant au-dessus de l'œil supérieur. Ce genre se compose de trois espèces.

$a$. Tubercules osseux sur la ligne postorbitaire bieu

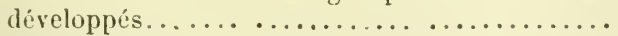

Tubercules osseux sur la ligne postorbitaire mail-

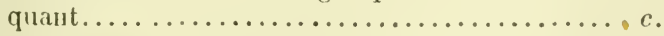

c. Épine avaut l'anale nulle................... M. 2. MocépHaLe.

1. FRANGHE.

apparente. ............... 3. GYNOGLOSSE. 


\section{LA PLIE FRANCHE OU CaRRELET. - PlatesSa VUlgaris.}

Poiss. France, t. III, p. 291.

N. vulg. : Floteau, Plie, Carrelet; Lizen, Bretagne; Fléau, Tardineau, Piaise, Hotant, Poitou (Lemarié).

Long. : 0,80 à 0,50 , quelquefois 0,70 .

Le corps est de forme rhomboïdale, sa hauteur étant contenue deux fois et demie environ dans la longueur totale, couvert de petites écailles lisses, discoïdes, non imbriquées.-- La tête est développée, sa longueur mesurant le quart environ de la Iongueur totale; entre la fin de l'espace interorbitaire et le commencement de la ligne latérale, elle porte une série de cinq à sept tubercules osseux; la bouche est oblique, largement ouverte du côté gauche; les mâchoires portent l'une et l'autre une rangée de dents, qui commence sur le devant du côté droit, el se continue sur lout le côté gauche; les dents sont égales, aplaties, coupantes; chez les sujets de grande taille, il y en a cinq à neuf sur l'intermaxillaire droit, de vingt à vingt-six sur le gauche; la mandibule en a de trois à cinq à droite et de vingt-six à trente et une à gauche. Une crète mousse, fort saillante, sépare les yeux; l'œil inférieur est un peu plus avancé que le supérieur; son diamètre ne fait guère, chez les très grands spécimens, que le neuvième de la longueur de la tête, les trois quarls de l'espace préorbitaire. - La ligne latérale est un peu sinueuse au-dessus de la pectorale, droite ensuite. - La dorsale commence au-dessus du milieu de l'œeil supérieur; une épine fort aiguë précéde l'anale; les rayons de ces deux nageoires ne sont pas écailleux; le tronçon de la queue a généralement un peu plus de hauteur que de longueur; la caudale est arrondie; ses rayons sont plus ou moins garnis de petites écailles; les pectorales sont à peu près égales.

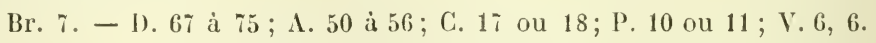

Du côté des ye̊ux, le corps est gris hrunàtre, avec plusieurs séries de taches ovales ou arrondies, d'une teinte rougeâtre ou orangée; des taches semblables se montrent ordinairement sur les nageoires impaires; le côté aveugle est blanchâtre. 
Habitat. La Plie est tris commune sur toutes nos còtes de l'Ouest jusqu’à l'embouchure de la Gironde.

2. LA PLIE MICROCÉPHALE. - PLATESSA MICROCEPHALUS.

Poiss. France, t. III, J. 29't.

N. vulg. : Limande-Sole, Plie-Sole.

Long. : 0,20 à 0,33 .

Le corps est couvert de petites écailles lisses, de forme presque rhomboïdale; sa hauteur est comprise deux fois et un tiers à deux fois et deux tiers dans la longueur totale. - La longueur de la tête est contenue six fois à six fois et demie dans la longueur totale; la bouche est peu fendue; les dents sont tranchantes; généralement l'intermaxillaire droit n’a aucune dent, l'autre en porte douze à quinze; sur le côté droit de la mandibule, il existe une ou deux dents, et douze à quinze sur le côté gauche. Les yeux sont ì peu près sur la même ligne, séparés par une crête lisse, étroite; leur dianètre mesure le quart environ de la longueur de la tête; il est plus grand que lespace préorbitaire. - La ligne latérale décrit une légère courbure au-dessus de la pectorale, elle est droite ensuite. La dorsale commence en avant du prolongement du diamètre vertical de l'œil supérieur; l'anale n’est précédée d’aucune épine; le tronçon de la queue a beaucoup plus de hauteur que de longueur; la caudale est arrondie.

Br. 7. - D. Ss à 93 ; A. 70 à ít ; C. 14 à 16 ; P. 10 ou 11 , 9 ou 10 ; V. 6,5 ou 6.

Du côté des yeux, le corps est d'un jaune tirant un peu sur l'acajou très clair; les nageoires ont la même teinte, excepté la pectorale qui est d'un blanc rosé; une bande jaune orange s'étend sur le bord du battant operculaire et sur la ceinture scapulaire au-dessous de lïnsertion de la pectorale.

Habitat. Manche, assez rare, Abbeville, Cherbourg. Océan, rare, la Rochelle, Arcachon, Bayonne. Méditerranée? M. Bellotti m'a écrit en aroir trouvé un spécimen sur le marché de Nice (1888). En 1891, dans Appunti all opera etc., p. 130, M. Bellotti reprend : Questa specie giunge in numerosi esemplari durante l'inverno sul mercalo di Nizzl proceniente d'all' Allantico francese. Come può dirsi rara nell 
Oceaao? M. Bellotti a confondu celte espèce avec une autre, et selon toute probabilité, avec Limanda vulgaris.

\section{LA PLIE CYNOGLOSSE. - PLATESSA CYNOGLOSSUS.}

Poiss. France, t. III, p. 296.

Long. : 0,30 à 0,50 .

Le corps, semblable à peu près à celui de la Sole, est couvert d'écailles imbriquées, plus ou moins caduques; sa hauteur est contenue trois fois et quart à trois fois et trois quarts dans la longueur totale, et la longueur de la tête six à sept fois; la bouche est oblique, peu fendue; les mâchoires sont garnies de petites dents égales, coupantes, plus nombreuses du côté gauche; chez un sujet d'assez grande taille, il y a quatorze dents sur l'intermaxillaire droit et vingt à vingt-deux sur l'autre; le côté droit de la mandibule en porte une douzaine, le gauche une vingtaine; la partie gauche de la tête est creusée de nombreuses fossettes. Les yeux sont grands, séparés l'un de l'autre seulement par une crête mince, non tuberculeuse; l'cil inférieur est le plus avancé; le diamètre est compris trois fois et demie à quatre fois dans la longueur de la tête, il est beaucoup plus grand que l'espace préorbitaire. - La ligne latérale est droite, décrivant à peine une très légère sinuosité au-dessus de la pectorale. - La dorsale commence au-dessus du milieu de l'ceil supérieur; elle se termine, comme l'anale, à une certaine distance de la caudale; l'anale est précédée d'une épine très aiguë; le tronçon de la queue a environ deux fois plus de hauteur que de longueur; la caudale est arrondie; les pectorales sont peu développées, la droite est la plus longue; les ventrales sont petites.

Br. 7. - D. 102 à $116 ;$ A. 87 à 102 ; C. 18 ; P. 10 à 1 ?, 10 à $12 ;$ V. 5 ou 6,5 ou 6 .

Le corps est d'un jaune brunâtre; du côté droil les nageoires impaires semblent brunâtres.

Habitat. Manche, très rare, còles de Picardie, Abbeville (Baillon). Océan, excessivement rare, Arcachon (Lafont). 


\section{GENRE FLET. - FLESUS.}

Corps ovale, couvert d'écailles assez petites.

Tète traversée par une crète osseuse, plus ou moins rugueuse, allant de l'espace interorbitaire ì la ligne latérale; bouche oblique; mandibule plus avancée que la màchoire supérieure, portant l'une et l'autre une rangée simple de dents presque cylindriques, mousses.

Yeux à droite.

Appareil branchial; sept rayons branchiostèges.

Ligne latérale dessinant une légère sinuosité au-dessus de l'cil supérieur.

Nageoires; dorsale commençant au-dessus de l'œil supérieur, ayant ì la base, ainsi que l'anale, une série de tubercules épineux; anale précédée d'une épine.

Ce genre est formé de deux espèces.

Ligne latérale bordée d'écailles rudes............... 1. connun .

- $\quad$ non bordée d'écailles rudes............... 2. moineau.

\section{LE FLET COMMUN. - FLESUS VULGARIS.}

Poiss. France, t. III, p. 299.

N. vulg. : Flet, Fléton, Flondre d'eau douce, Picaud.

Long. : 0,20 à 0,33 , quelquefois 0,43 .

A l'état normal le corps est tourné à droite; il est généralement couvert d'écailles lisses, excepté près de la ligne latérale et un peu au-dessus de la pectorale; la hauteur du tronc est comprise deux fois et demie à trois fois et quart dans la longueur totale. - La longueur de la tête est contenue quatre fois et un tiers à quatre fois et trois quarts dans la longueur totale; les mâchoires ont une rangée de dents cylindriques, plus nombreuses à gauche. Les yeux sont séparés par une crète qui se bifurque en avant; l'ceil inférieur est souvent un peu plus avancé que le supérieur; le diamètre de l'ceil varie, il mesure du cinquième au septième de la longueur de la tête, il est à peu près égal à l'espace préorbitaire. - La ligne latérale, soit dans la partie antérieure, soit dans toute la longueur de son trajet, est bordée d'écailles fort rudes. - La dorsale commence au-dessus du milieu de l'ceil supérieur; elle a, près 
de l'insertion de ses rayons, ainsi que l'anale, une série de tubercules garnis de petites épines; ces tubercules peuvent manquer sur le côté aveugle; le troncon de la queue a généralement un peu moins de hauteur que de longueur; la caudale est arrondie; chez certains sujets, elle est couverte, à la base, d'écailles pectinées.

Br. 7. - D. 58 à 64 ; A. 39 à 45 ; C. 14 ; P. 10 ou 11,10 ou 11; V. $6,6$.

Du côté des yeux, le corps estd'un brun verdâtre ou d'un gris jaunâtre; à certaines époques, surtout au printemps, il est marqué de taches jaunâtres, parfois orangées ou rougeâtres.

Habitat. Très commun sur toutes nos côtes de l'Ouest, de Dunkerque a l'embouchure de la Gironde; assez commun dans le golfe de Gascogne.

\section{LE FLET MOINEAU. - FLESUS PASSER.}

Poiss. France, t. III, p. 301.

N. vulg. : Plana, Cette.

Long : 0,20 à 0,3 ă quelquefois 0,4 ว̆.

Le corps du Flet moineau est partout couvert d'écailles cycloïdes; il présente à peu près les mêmes proportions que celui du Flet commun. - La Jongueur de la tête est comprise quatre fois et demie à cinq fois et demie dans la longueur totale; les dents sont cylindriques, obtuses, plus nombreuses à gauche. Quclquefois l'œil supérieur est un peu plus avancé que l'inférieur, dont il est séparé par une crête étroite; le diamètre de l'œil est compris cing à six fois dans la longueur de la tête, il est à peu près égal à l'espace préorbitaire. - La ligne latérale n'est, sur aucun point de son trajet, bordée d'écailles rudes. - Les tubercules épineux, qui sont à la base de la dorsale et de l'anale, paraissent moins développés que dans l'autre espèce; le troncon de la queue a généralement un peu plus de hauteur que de longueur.

Br. 7. - D. 58 ì 64 ; A. 45 à 48 ; C. 16 ; P. 10 ì 12,10 ou 11 ; V. $6,6$.

Le côté des yeux est gris brunâtre, parfois brun olive, quel- 
quefois marqué de laches rondes assez claires; les nageoires impaires ont souvent des macules brunatres, irrégulières.

Habitat. Méditerranée, commun, Nice; très comnun, Cette. Océan, golfe de Gascogne, commun, Bayoune, Arcachon; rare au nord de la Gironde. Manche?

Les Flets entrent dans les eaux douces, qu'ils remontrent parfois à une assez grande distance de la mer.

L'albinisme n'est pas rare chez les Flets. - Sur un F. vulgaris atteint d'albinisme partiel, la ligne latérale est bordée d'écailles rudes seulement dans la région colorée. - Steindachner n’admet qu'une seule espèce.

马. GENRE SOLE. - SOLEA, Cuv.

Corps très comprimé, plus ou moins ovale, couvert d'écailles ciliées.

Tête ayant sur le côté gauche des villosités plus ou moins nombreuses; museau arrondi, avancé; bouche arquée, irrégulière; màchoire supérieure plus longue que l'inférieure, formant à gauche une espèce de courbure prononcée dans laquelle s'engage l'arc dentaire de la mandibule; pas de dents sur le còté des màchoires correspondant aux yenx; sur le còté gauche un groupe ou une bande de petites dents en relours.

Yeux à droite; œil supérieur plus avancé que l'autre.

Appareil branchial; sept ou huit rayons branchiostèges.

Ligne latérale droite sur le tronc.

Nageoires; nageoires impaires libres, plus ou moins écailleuses; dorsale excessirement longue, commençant sur le museau en arant de l'wil supérieur.

Le genre Sole se divise en trois sous-genres.

a. Pectorale existant de chaque còté.............. b.

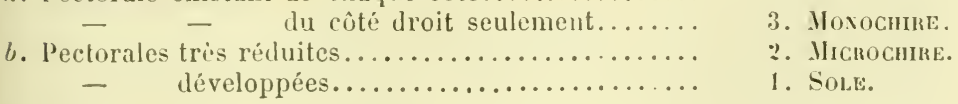

\section{SOUS-GENRE SOLE. - SOLEA, CuY.}

Nageoires; pectorales bien développées l'une et l'autre; pectorale gauche ayant toujours plus de quatre rayons.

Le sous-grenre Sole compte six espèces. 
a. Taches ocellées sur le corps manquant..... - $\quad$ - $\quad$ - plusieurs bien marquées...

b. Hauteur du trone comprise plus de trois fois et un tiers dans la longueur totale...... Hauteur du tronc comprise al plus trois fois et un tiers dans la longueur totale....... $c$. Ligne latérale dessinant sur la tète un angle. - $\quad-\quad$ - une courbe.

d. Orifices de la nariue gauche dissemblables; l'antérieur très large................. Orifices de la narine gauche à peu près semblables .......................

e. Base de la pectorale droite noirâtre en dedans. - _ _ - grisâtre en dedans.

$b$.

6. ocelLée. $c$.

d.

$\therefore$ SÉTAU.

4. DE KLEIN.

3. LaSGARIS.

e.

2. A pectorale NoIRE.

1. CoMmine.

\section{LA SOIE COMMUNE. - SOLEA VULGARIS.}

Poiss. France, t. III, p. 304 .

N. vulg. : Perdrix de mer; Sole franche; Sacillet, Garlizen, Finistère; Ruarde (Catal.), Pyrénées-Orientales; Palaïga., Sola, Hérault; Sola, Nice.

Long. : 0,25 à 0,40 et plus.

Le corps est couvert d'écailles rudes, à spinules développées; sa hauteur est comprise trois fois à trois fois et un tiers dans la longueur totale, et la longueur de la tête cinq fois et trois quarts à six fois et quart; du côté gauche sont de nombreuses villosités; la fente de la bouche se termine sous le milieu de l'œil inférieur; les mâchoires portent sur le côté gauche des dents en velours. Le diamètre de l'wil ne mesure guère que le huitième de la longueur de la tête; il est moins grand que l'espace interorbitaire, et chez les sujets de grande taille ne fait pas moitié de l'espace préorbitaire. L'orifice postérieur de la narine gauche est sur la ligne menée du quatrième rayon de la dorsale à l'angle de la bouche. - La pectorale droite est un peu plus grande que l'autre; sa longueur est comprise deux fois et demie ì deux fois et deux tiers dans la longueur de la tête.

$$
\begin{gathered}
\text { Br. } 7 \text { ou } 8 .- \text { D. } 74 \text { à } 87 \text {; A. } 60 \text { à } 69 \text {; C. } 15 ; \text { P. } 8 \text { à } 10,8 \text { ou } 9 \text {; } \\
\text { V. } 5 \text { ou } 6,5 \text { ou } 6 \text {. }
\end{gathered}
$$


En général le côté des yeux est brunâtre, parfois brun olivâtre, avec des taches noirâtres, souvent mal limitées.

Habitat. Cette espèce est très commune sur toutes nos côtes.

\section{LA SOLE A PECTORALE NOIRE. - SOLEA IELA NOCIIIRA,}

Poiss. France, t. III, p. $30 \ddot{\text {. }}$.

N. vulg. : Sole brusque, Arcachon.

Long. : 0,2 ä à $0,3 \ddot{\text {. }}$.

La hauteur du tronc est comprise trois fois à trois fois et quart dans la longueur totale; les écailles sont étroites, beaucoup moins larges que dans la Sole commune; le rachis est composé de quarante-cinq ou quarante-six vertèbres, deux ou trois de moins que dans l'autre espèce. - La longueur de la tête est contenue cinc fois et un tiers à cinq fois et demie dans la longueur totale; sur le côté gauche, les villosités sont plus déliées et beaucoup moins nombreuses que dans la sole commune; la fente de la bouche s'étend un peu plus loin en arrière que le prolongement du diamètre vertical de l'œil inférieur. Chez les sujets de grande taille, le diamètre de l'œil est compris six fois à six fois et demie dans la longueur de la tète; il est égal à l'espace interorbitaire; il mesure plus de la moitié de l'espace préorbitaire. L'orifice antérieur de la narine gaauche est placé sur le tiers antérieur d'une ligne menée de la commissure de la bouche au museau, en passant sur l'orifice mème, tandis que, chez la Sole commune, il est reculé vers le milieu de la ligne indiquée. Le tube de l'orifice antérieur de la narine droite a sa base noiràtre en arrière. - Les pectorales sont relativement longues; la pectorale droite mesure environ la moitić de la longueur de la tête; la rentrale droite a généralement cinç rayons, la gauche quatre seulement.

$$
\text { Br. 7. - D. } 77 \text {; A. } 62 \text { ou } 63 \text {; C. 14; P. } 8,8 \text {; V. } 5,4 .
$$

La coloration, du côtédroit, est d'un gris brunâtre, parfois assez foncé, arec des taches azurées qui disparaissent assez. rapidement. Les nageoires impaires sont d'un gris jaunâtre Moreau. - Ichthyologie. 
avec une bordure blanchâtre; la pectorale droite a les rayons teintés d'un noir bleuâtre, son bord est blanchâtre, en dedans sa base est noiràtre.

Habitat. Océan, golfe de Gascogne; celte espèce se trouve principalement à l'entrée des passes du bassin d'Arcachon; elle paraît frayer en mai et juin.

\section{LA SOLE LASGARIS. - SOLEA LASCARIS, Riss.}

Poiss. France, t. III, p. 307.

N. vulg. : Sole-pole, le Havre; Verruga, Berruga, Cette.

Long. : 0,20 à 0,40 .

La hauteur du tronc est comprise deux fois et trois quarts à trois fois et un cinquième dans la longueur totale, et la longueur de la tête cinq fois et demie à six fois et demie; les dents sont excessirement petites. Le diamètre de l'œil est contenu cing fois et demie à six fois et demie dans la longueur de la lête, il mesure la moitié environ de l'espace préorbitaire, il est un peu plus grand que l'espace interorbitaire. Du côlé opposé aux yeux, est une sorte de verrue évidée, large, ayant un diamètre à peu près égal à celui de l'ceil, ou plutôt une cupule frangée, qui est l'orifice antérieur de la narine gauche; cette disposition de l'orifice de la narine est suffisante pour faire distinguer cette Sole des autres espèces.

Br. 7. - D. 65 à $89 ;$ A. 52 à 70 ؛ C. 15 ou $16 ;$ P. 9 ou 10,8 ou $9 ;$ V. 5 ou 6,5 ou 6

La teinte est des plus variables; du côté des yeux, elle est d'un jaune pâle arec de petites taches noires fort nombreuses, ou bien d'un brun jaunâtre, ou encore d'un cendré assez clair varié de verdâtre, tachetéde points noirs. La pectorale est jaunâtre ou grisâtre à la base et sur les còtés, blanche à l'extrémité; elle est marquée dans sa partic moyenne et postérieure d'une tache noire, arrondie, bien circonscrite.

Habitat. Manche, assez rare, Abbeville; assez commune, le Havre, Trouville. Océan, assez rare, la Rochelle; assez commune, Arcachon, et mème commune en juillet, aoùt. Níditerranée, assez commune, Cette: plus rare, Nice. 
4. I.I SOLE DE KLEIN. - SOLEA KLEINII, RisS.

Poiss. France, t. III, p. 310.

Iv. vulg. : Rhombou, Nice.

Long. : 0,14 iो $0,: 0$.

Le corps est de forme oblongue, non arquée, diminuant d’une façon régulière jusqu ì la caudale; sa hauteur est comprise trois fois et deux cinquièmes à trois fois et qualre cinquièmes dans la longueur totale, et la longueur de la tête, cinq fois et un tiers à cinq fois et trois quarts; Je profil supéricur de la lète est plus courbe que dans le Séteau. Le diamètre de l'ceil mesure le cinquième environ de la longueur de la tête, il est plus petit que l’espace préorbitaire, plus grand que l'espace interorbitaire. L'orifice anterieur de la narine gauche est vers le milieu de la mâchoire supérieure, il est entouré d'un bourrelet fort saillant, très épais, dont le diamètre fait le tiers environ du diamètre de l'œil. - Au-dessus du prolongement du diamètre horizontal de l'œil supérieur, la ligne latérale décrit une courbe régulière. - La dorsale et l'anale sont unies par une petite membrane à la base de la caudale; le troncon de la queue manque en quelque sorle; la caudale est arrondie; sa longuenr fail le neuvième environ de la longueur lotale.

D. 80 à $9: 1$; A. Gí di i0; C. 19 ; P. 8,7 ou 8 ; V. 5,5 .

Du côté des yeux, le corps est brunâtre, marqué de points noirs et semé de petites taches ğrisâtres. Les nağeoires impaires sont diune teinte brunitre; la pectorale droite porte une grande tache noiritre. - In spécimen, pêché à Celte, est comme zébré ; il a le côté droit d’un brun marron traversé par une dizaine de bandes verlicales noirâtres assez larges.

Habitat. Méditerranee, assez rate, Nice, Cette.

3. LA SOLE SETIU. - SOLEA CLNEAT'I, la Pylaie.

Poiss. France, t. III, p. 312. 
N. vulg. : Séteau, Séton, Sables d'Olonne, la Rochelle; Languette, Langue d'avocat, Areachon.

Long. : 0,20 à 0,30 .

Le corps est couvert, à droite comme à gauche, d'écailles à plusieurs rangées de spinules; il est cunéiforme; sa hauteur est comprise trois fois et demie à quatre fois et un cinquième dans la longueur totale, et la longueur de la tête cinq fois et demie à six fois et quart. Le diamètre de l'oil mesure le sixième environ de la longueur de la tête, il est un peu moins grand que l'espace préorbitaire et un peu plus grand que l'espace interorbitaire. Du côté gauche, les orifices de la narine ont le bord légèrement renflé. - De la caudale à la tête, la ligne latérale est droite, arrivée sur le prolongement du diamètrelongitudinal de l'œil supéricur, elle se porte obliquement d'arant en arrière et de bas en haut, monte près de la base de la dorsale qu'elle suit, après avoir changé de direction, jusque vers l'œil supérieur; elle dessine de cette façon un angle très aigu dont le sommet est en arrière. - La dorsale et l'anale finissent près de la caudale; les rayons de ces nageoires sont couverts d'écailles.

D. 85 ou $86 ; \Lambda .69$ à 72 ; C. 16 à 18 ; P. 8,7 ou 8 ; V. 6,5 ou 6 .

Du côté des yeux, le corps est gris rosé chez les jeunes, brun grisâtre chez les adultes, avec des taches noirâtres; les nageoires imparres ont les rayons d'un gris brunatre, les espaces intraradiaires rosés, teintés de gris; la pectorale est grisître, arec une tache noire vers le tiers postérieur des deux plus grands rayons, et sur deux espaces intraradiaires.

Habitat. Océan, le Séleau est rare au-dessus de la Loire; il est commun sur la còte du Poitou et dans le golfe de Gascogne. Méditerranée, Cette?

\section{LA SOLE OCELLEE. - SOLEA OCULATA.}

Poiss. France, t. III, p. 313.

N. vulg. : Pegouse, Marseille; Sola de fount, Nice.

Long. : 0,15 à 0,20 . 
Le corps est couvert d'écailles très adhérentes, très rudes, plus grandes que celles de la Sole commune; il est ovale; sa hauteur mesure le tiers environ de la longueur totale. - La tête est forte; sa longueur est contenue cinq fois à cinq fois et un quart dans la longueur totale; la fente de la boache arrive à peine sous le bord antérieur de l'orbite inférieure. Le diamètre de l'œil est compris quatre ì cinq fois dans la longueur de la tête; il est égal à l'espace préorbitaire; il est beaucoup plus grand que l'espace interorbitaire. - Les écailles de la ligne latérale sont un peu plus développées que les autres. - La dorsale et l'anale sont pourvues de rayons robustes, courerts d'écailles; elles finissent à la base de la caudale.

$$
\text { D. } 66 \text { à } 70 ; \text { A. } 55 \text { à } 58 \text {; C. } 19 ; \text { P. } 7,5 \text { ou } 6 \text {; V. } 6,6 .
$$

Du còté des yeux, le corps est gris jaunàtre assez foncé, à reflets rougeâtres, marqué de taches noirâtres, généralement au nombre de sept; les nageoires impaires sont d'un gris foncé, teinté de roux; la pectorale est grise, puis noirâtre vers sa terminaison.

Habitat. Méditerranée, assez rare, Nice, Marseille.

\section{SOUS-GEYRE MICROCHIRE. - MICROCIIRUS; GBp.}

Nageoires; pectorales peu déreloppées, surtout celle de gauche, qui généralement à moins de quatre rayons.

Deux espèces.

Dorsale et anale sans taches noires................ 1. JAUNE.

- marquées de taches noires............. 2. panacié.

1. LE MICROCHIRE JAUNE. - MICROCHIRUS LUTEUS, Riss.

Poiss. France, t. III, p. 316, fig. 184, anim.

N. vulg. : Sola, Nice, Sola chaouna, Cetle.

Long. : $0,0 \mathrm{~s}$ à 0,12 .

La hauteur du tronc fait le liers environ de la longueur totale. - Ia longueur de la tète est contenue cinq fois à cinq fois et un tiers dans la longueur totale; le museauestarqué ; les 
dents sont excessivement petites. Le diamètre de l'œil mesure le cinquième de la longueur de la tête; il est un peu moins grrand que l'espace préorbitaire. L'orifice antérieur de la narine droite est à l'extrémité d'un appendice tubuleux. - Ec., l. long. 70 ou 71. - La dorsale commence en quelque sorte sur le prolongement du diamètre longitudinal de l'œil supérieur; elle finit, ainsi que l'anale, fort près de la base de la caudale.

D. 67 à $22 ; \Lambda .53$ d $56 ;$ C. $15 ;$ P. 5,2 ou $3 ;$ V. 5.

Du côté des yeux, le corps est jaune doré ou gris jaunâtre, lankit d'une coloration uniforme, tantôt marqué de fort petites taches noirâtres; la dorsale et l'anale ont la plupart de leurs rayons d'un brun jaunàtre ou roussâtre, séparés d'espace en espace, par des rayons d'un bleu très foncé presque noirâtre.

Habitat. Méditerranée, assez rare, Nice, Cetle.

\section{LE MICROCHIRE PANACHE. - MCROCHIRUS VARIEGATUS.}

Poiss. France, t. III, p. 317

Long. : 0,10 à 0,13 quelquefois 22 .

Le corps est couvert d'assez grandes écailles très rudes; sa hauteur est contenue trois fois à trois fois et demie dans la longueur totale. - La longueur de la tète mesure le tiers environ de la longueur totale; les dents sont très petites, peu visibles. Le diamètre de l'oxil est compris cinq à six fois dans la longueur de la tête; il est moins grand que l'espace préorbitaire, il est à peu près égal à l'espace interorbitaire. - La ligne latérale est droite. - Les pectorales sont très peu déreloppées, la gauche surtout est excessivement réduite, elle mesure souvent moins du vingtième de la longueur totale; les ventrales sont aussi fort courtes.

$$
\text { D. } 63 \text { а } 22 ; \Lambda .53 \text { а } 56 ; \text { C. } 15 \text {; P. } 5,3 ; \text { V. } 5,5 .
$$

Le corps, à droite, est d'un gris brunâtre ou brun châtain ; presque toujours il montre des bandes transversales ou de grandes taches noirâtres peu limitées; la dorsale el lanale sont marquées de laches noires s'élendant sur les parties roi- 
sines du corps; en arrière, elles sont bordées d'un liséré blarchâtre ; la caudale est teintée de noirâtre, souven t elle porte une bande noirâtre; la pectorale est d'un grisjaunâtre. - Duhamel avait donné à cette espèce le nom de Pole panachée à cause de son système de coloration. Le côté gauche est d'un gris blanchitre.

Habitat. Méditerranée, commun, Nice, Marseille, Cetle. Océan, golfe de Gascogne, commun, Arcachon; excessivement rare au-dessus de la Gironde, Concarneau. Manche?

3. SOUS-GEYRE MONOCHRE, - MONOCHIRUS, Rafiu.

Nageoires; une seule pectorale, la droite.

LE MONOCHIRE VELU, - HONOCHIRUS HISPIDUS, Ratin.

Poiss. France, 1. III, p. 319.

N. vulg. : Solla d'arga, Nice; Bourruda, Pialuda (Sole velue ou couverte de bourre), Cette.

Long. : 0,10 ì $0,1 \%$.

La hauteur du tronc est contenue deux fois et trois quarts i trois fois dans la longueur totale; à droite surtout, la peau est couverte d'écailles à spinules fort saillantes qui la rendent comme velue. - La longueur de la tète est comprise cinq fois et demie environ dans la longueur totale; la bouche est fendue jusque sous le tiers antérieur de l'œil: les dents sont excessivement petites. A peine si l'ceil supérieur est plus avancé que l'inférieur ; ils sont rapprochés l’un de l'autre; leur diamètre mesure le cinquième environ de la longueur de la tète; il est moins grand que l'espace préorbitaire. - La ligne latérale est droite. - La dorsale commence à peu près au-dessus du milieu de l'espace qui sépare l'ceil supérieur du museau; il n’y a qu une seule pectorale, ì droite, il n'existe, à gauche, aucune trace de rayons.

$$
\text { D. } 53 \text { à } 56 \text {; A. } 40 \text { à } 4 \text { 4; C. } 12 \text {; P. } 6 \text { out } 7,0 \text {; N. } 5,5 .
$$

Le còté droit est d'un brun rougreâtre ou marron avec des taches noires plus ou moins nombreuses, parfois confluentes. 
La dorsale et Janale sont d'une teinte marron avec des macules noirâtres; les espaces intraradiaires sont noirâtres des deux côtés; la caudale est marron; la pectorale est noirâtre, surtout vers son extrémité; la ventrale droite est presque noirâtre, l'autre est blanchâtre, ainsi que la partie gauche du corps.

Habitat. Méditerranée, très rare, Nice; rare, Cette.

\section{GENRE PLEURONECTE. - PLEURONECTES.}

Corps de forme ovale ou rhomboïdale.

Tête plus ou moins déreloppée; mandibule plus avancée que la màchoire supérieure, munies l'une et l'autre de dents pointues, disposées sur une ou plusieurs rangées; vomer tantòt lisse, tantòt denté.

Yeux à gauche; espace interorbitaire étroit, plus petil que le dianıètre de l'wil.

Nageoires; dorsale commencant au-dessus ou en avant du bord antérieur de l'orbite supérieure.

Ce genre comprend huit ou neuf espèces.

a. Ventrales unies à l'anale.

1. TARGEUR.

b. Dorsale ì rayons antérieurs très inégaux...... $c$.

à peu près égaux.. $d$.

c. $1^{\text {er }}$ rayon de la dorsale plus allongé.............

$2^{e}-\quad-\quad-\ldots \ldots \ldots$

d. OEil supérieur plus avancé que l'inférieur......

- pas plus avancé que l'inférieur..

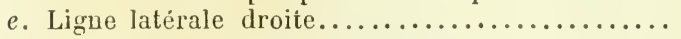

- courbe en avant............... $f$.

$f$. Épine géminée avant l'auale distincte.......... g.

2. UNIMACULE்.

3. ne Grollhass.

S. Guitare.

$e$.

9. ÉLÉGANT. h.

g. Nageoires impaires sans taches................

4. ARNOGLOSSE.

5. MOUCHETÉ.

$h$. Deux grandes taches sur la dorsale et l'anale en

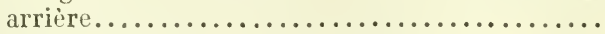

Pas de graudes taches sur la dorsale ni sur l'anale.

6. DE Bosc.

7. MÉGASTOME.

A Cette, Agde, Aigues-Mortes, le nom vulgaire de Perpeÿdé est donné aux Pleuronectes. 
1. LE PLEURONECTE TARGEUR. - PLEURONECTES HIRTUS, Abilg.

Poiss. France, t. III, p. 321 .

N. vulg. : Grosse Plie, Targeur; Targie; Sole de rochers, Cherbourg.

Long. : 0,1 à à 0,30 , quelquefois 0,30 .

Du côté gauche, le corps est couvert de petites écailles, dont les spinules relevées donnent à la peau l'apparence d'un velours très rude; sa hauteur est contenue deux fois à deux fois et quart dans la longueur totale, et la longueur de la tête trois fois et demie; la mandibule est relevée; elle est, ainsi que la màchoire supérieure, munie de dents en velours, fines, aiguës, légèrement crochues. Liœil inférieur est plus arancé que le supérieur, dont il est séparé par une crête rugueuse; son diamètre mesure le cinquième environ de la longueur de la tète, il est un peu moins grand que l'espace préorbitaire. - La ligne latérale, assez peu visible, est courbe au-dessus de la pectorale, droite dans le reste de son trajet. -- La dorsale commence au-dessus de la màchoire supérieure, et finit, comme l'anale, sur le côté droit du troncon de la queue; les rayons postérieurs de ces nageoires cachent en partie la base de la caudale, et au premier abord les nageoires impaires semblent réunies; lanale est jointe aux ventrales, et ferme, en arrière, l'espace dans lequel se troure l'anus; la caudale est arrondie; la ventrale gauche est plus avancée et plus relevée que la droite; les rayons, surtoul ceux des nageoires impaires, sont couverts d'écailles très rudes.

Br. 7. - 1). 87 à 99 ; A. 70 à 80 ; C. 1 t' à 16 ; P. 11 ou 12,10 ou 11 ; V. $6,6$.

Du côté gauche la teinte générale est d'un brun lie de vin, avec des taches, arrondies ou ovales, d'un noir d'ébène; sur la tête se voient des bandes noires partant les unes des yeux, les autres des opercules et allant sur le corps. Des taches noires mal limitées marquent les nageoires impaires.

Habitat. Manche, très rare, Boulogne, le Havre, Cherbourg, Ros coff. Océan, Bayonne (U. Darracq). 
2. LE PLEURONEGTE UNIMACULÉ. - PLEURONECTES UNIMACULATUS.

Poiss. France, t. III, p. 323.

N. vulg. : Rombou, Nice.

Long. : 0,10 à 0,1 ว̈.

La hauteur du tronc est comprise deux fois et quart à deux fois et demie dans la longueur totale; la peau est couverte d'écailles pectinées, très rudes sur le côté gauche. - La longueur de la tête mesure le quart environ de la longueur tolale; la bouche est petite, la mâchoire supérieure est moins avancée que la mandibule; elles portent l'une et l'autre, une bande étroite de petites dents coniques; le vomer est lisse. Les yeux ne sont séparés que par une crête étroite, haute, arquée, couverte d'écailles semblables à de petites épines; l'ceil inférieur est le plus arancé; son diamètre fait le quart de la longueur de la tête; il est égal à l'espace préorbitaire. - La ligne latérale est courbe au-dessus de la pectorale, droite ensuite. - La dorsale commence sur le museau; ses deux premiers rayons sont en partie libres; le premier est plus allongé que le deuxième, sa longueur mesure le tiers, et plus, de la longueur de la tête; la dorsale et l'anale finissent du côté droit vers la base de la caudale, qui est arrondie; les rayons des nageoires impaires sont écailleux. La pectorale gauche est beaucoup plus développée que la droite; son rayon supérieur est sétiforme, très allongé, sa longueur est souvent plus grande que celle de la tète; les rentrales sont fort rapprochées de l'analé, mais ne la joignent pas, comme chez le Targeur.

D. 70 à $80 ; \Lambda .65$ à lis; C. 14 ; P. 10 à 12,10 ou $11 ;$ V. 6,6 .

Du côté des yeux, le corps est le plus sourent gris chàtain ou rougeâtre arec quelques taches noires et parfois arec des points d'un rouge brunâtre; à peu près au tiers postérieur de la longueur totale, sur la ligne latérale, se dessine une tache ocellée arrondie à pourtour noir, ̀̀ centre blanchàtre ou rougeâtre, parfois elle a le centre brunâtre et tranche mal sur le fond, qui estalors d'un brun plus ou moins foncé. Les nageoires 
sont diun gris rougeatre; la dorsale et l'anale ont de place cn place des rayons noirâtres.

Habitat. Médilertanée, rare, Nice; moins rare, Cetle. Océan? Manche, Dieppe, Boulogne.

\section{LE PLEURONEGTE DE GROHMANN. - PLEURONECTES} GROHMANNI, Bp.

Poiss. France, t. III, p. 326, fig. 18̈̈, anim.

N. vulg. : Perpeïra, Celte.

Long. : 0,10 ì $0,1 \%$.

Le corps est couvert de larges écailles, très imbriquées, fort carluques; sa hauteur est contenue deux fois et demie à trois fois dans la longueur totale, el la longueur de la tête quatre fois et demie à cinq fois et quart; la bouche est oblique, petite; la màchoire supérieure est moins avancée que la mandibule, portant l'une et l'autre une rangée de dents fines et pointues. Les yeux ne sont séparés que par une crète étroite; l'œil inférieur est le plus arancé; son diamètre mesure le quart environ de la longueur de la tète; il est à peu près égal à l'espace préorhitaire. - La ligne latérale est formée d'écailles un peu plus grandes que les autres; elle est très courbe au-dessus de la pectorale, droite ensuite. - La dorsale commence sur le cùté areugle, très près de la màchoire supérieure; elle a le deuxième rayon beaucoup plus allongé que les autres; l’anale est précédéc d'une épine double, petite, à pointe dirigée en arrière.

$$
\text { I. } 84 \text { à } 90 ; A \text {. } 55 \text { à } 67 \text {; C. } 15 \text { à } 17 \text {; P. } 9 \text { ou 10,9; V. } 6,6 \text {. }
$$

Du côté des yeux, le corps est gris cendré ou rougeàtre, marbré de brun ; il est blane rosé du côté aveugle. Les nageoires impaires sont ordinairement marquées de points noiràtres ; souvent les rayons antérieurs de la dorsale sont d'un brun très foncé.

Habitat. Nédilerranée, assez commun, Nice, Celte. 
4. LE Pleuronegte ARNoglosse. - PLEURONECTES ARNOGLOSSUS.

Poiss. France, t. III, p. 328.

N. vulg. : Rombou, Nice; Perpeïra, Cette.

Long. : 0,10 à 0,15 , quelquefois 0,18 .

Le corps a de grandes écailles, très minces, finement pectinées, très peu adhérentes; sa hauteur est comprise trois fois ì trois fois et un tiers dans la longueur totale, et la longueur de la tête quatre fois à quatre fois et demie; la bouche est grande, très oblique; les mâchoires sont munies de dents égales, très aiguës, disposées sur une seule rangée; le vomer est lisse. Généralement l'oeil inférieur est un peu plus avancé que le supérieur, dont il n'est séparé que par une crête mince; le diamètre de l'oil est contenu quatre à cinq fois dans la longueur de la tète; il est égal ou peu s'en manque à l'espace préorbitaire. La ligne latérale est courbe au-dessus de la pectorale, droite ensuite. - La dorsale commence au-dessus de la narine droite; la caudale est arrondie; en avant de l'anus est une épine double ou géminée à pointe tournée en arrière.

Br. 7. - D. 8 i a 90 ; A. 64 à 68 ; C. 12 ; P. 10 ou 11,8 ou 9 ; V. (', 6 .

Sur le côté gauche, la teinte est gris jaunâtre ou gris rosé; le côté aveugle est gris blanchâtre. Les nageoires ne sont pas lachetées.

Habitat. Néditerranée, assez commun, Nice, Cette. Océan? Manche, très rare, je l'ai trouvé au Havre.

3. LE PLEURONECTE MOUCHETÉ. - PLEURONECTES CONSPERSUS, Canestr.

Poiss. France, t. III, p. 329.

Long. : 0,08 à 0,14 .

Ce Pleuronecte diffère de l'Arnoglosse par un peu moins de longueur dans la mandibule, qui fait à peine moitié de la longueur de la tête, et par son système de coloration. Du côté des 
yeux, le corps est cendré ot semé, ainsi que les nagcoires rerticales, de points noiratres.

Habitat. Méditerranée, j'en ai trouvé plusieurs spécimens à PortVendres.

6. LE PIEURONECTE DE BOSC. - PLEURONECTES BOSCII.

Poiss. France, t. III, p. 330.

N. vulg. : Pampaloti, Nice; Perpeïra, Cette.

Long. : 0,20 à 0,3 ว̈.

La peau est courerte d'écailles caduques, finement ciliées du côté des yeux, plus grandes que celles de la Cardine; la hauteur du tronc est comprise trois fois à trois fois et un tiers dans la longueur totale; le nombre des vertèbres est de 39. La longueur de la tète est contenue quatre fois à quatre fois et un tiers dans la longueur totale; la bouche est très oblique, largement fendue; les màchoires portent une bande de dents en velours, plus nombreuses, moins fortes que dans la Cardine; à la mandibule, le dentaire gauche a le bord alvéolaire ou buccal un peu ondulé, couvert de dents; le dentaire droit a le bord mince, presque rectiligne. - Le cherron du vomer est denté. A peine si l'œil inférieur est plus avancé que le supérieur, dont il est séparé par une espace fort étroit; le diamètre de l'oil est contenu environ trois fois et demie dans la longueur de la tête, il est plus grand que l'espace préorbitaire. - La ligne latérale dessine au-dessus de la pectorale un quart de cercle. - La dorsale prend naissance au-dessus de la narine droite et finit ainsi que l'anale à une certaine distance de la caudale, qui est arrondie; les ventrales sont insérées très en avant; la pointe de la pectorale gauche, renverséc sur la tête, arıive au bord postérieur de l'orbite.

$$
\text { Br. 7. - D. } 75 \text { ì } 82 \text {; A. } 62 \text { à } 66 \text {; C. } 17 \text { à } 19 \text {; P. } 11,9 \text { à } 11 \text {; V. } 6,6 \text {. }
$$

Le cóté des yeux est d'un gris jaunâtre ou cendré; le côté droit est jaunâtre. La dorsale et l'anale portent, en arrière, chacune deux taches noires, arrondies, placées symétriquement. 
Habitat. Méditerranée, assez commun, Nice, Cette.

Dans la synonymie de l'Arnoglossus megastomn, Day (Brit. Fish., 1. II, p. 21) cite le $\mathrm{Pl}$. Boscii, Riss., qu’il considère, d'après Gigglioli, comme étant de mème espèce : pr Giglioli first drew my attention to -Arno flossus Boscii being this species; c'est une erreur. - Cette espèce, dont le vomer est denté, ne peut ètre comprise dans le genre Arnoglossus, tel que M. Günther l'a déterminé : Vomerine... teeth none.

\section{LE PLEURONEGTE MEGASTOME OU GARDINE. PLEURONECTES MEGASTOIA.}

Poiss. Franee, t. III, P. 322.

N. vulg. : Pole, le Havre; Limandier, Cherloourg (Jouan); Liame, Poitou; Mère des Soles, Areachon.

Long. : $0,2: 3$ à 0,40 , quelqueîis 0,30 .

Le corps est courert d'écailles minces, ciliées du côté des yeux, généralement lisses du côté opposé ; sa hauteur est comprise trois fois a trois fois et demie dans la longueur totale; le nombre des vertèbres est ordinairement de 40. - La tête est eftilée; sa longueur est contenue quatre fois à quatre fois et un tiers dans la longueur totale; la bouche est oblique, largement ouverte; la mâchoire supérieure est relativement fort protractile, elle est ainsi que la mandibule, munie d'une bande étroite de dents en velours, un peu crochues; à la mandibule, le dentaire gauche a le bord buecal étroit, entamé, en arant, d'une échancrure courbe, allongée; le dentaire droit est semblable à lautre, à bord seulement un peu moins échancré. Le romer a le chevron denté. L'wil inférieur cst sensiblement plus arancé que le supérieur; son diamètre est compris trois fois el quart à trois fois et demie dans la longueur de la tète; il est en général plus grand que l'espace préorbitaire; l'espace interorbilaire est trìs étroit. - Au-dessus de la pectorale, la ligne latérale dessine une courbe allongée. - La dorsale est très arancée: son premier rayon est en quelque sorte placé audessus de l'orifiee postérieur de la narine droite; elle finit dans le mème plan que l'anale; ses douze ou ruinze premiers rayons sont libres dans une assez grande partie de leur hau- 
teur; la caudale est arrondie; la pointe de la pectorale gauche renversée sur la tête dépasse le bord postéricur de l'orbite; l'insertion des ventrales commence sous le tiers antérieur de l'interopercule.

$$
\text { Br. 7. - D. } 85 \text { a } 89 ; \text { A. } 67 \text { is } 70 \text {; C. } 15 \text {; P. } 110312,10 \text { i } 12 \text {; Y. } 6,6 .
$$

Le corps, du côté yeux, est gris jaunâtre teinté de brun ou gris rosé. Les nageoires sont pâles.

Habitat. Manche, assez rare, le Ilavre. Océan, très rare au nord de la Loire; rare entre la Loire et la Gironde, la Rochelle; golfe de liascogne, assez commun à Arcachon. Méditerranée, excessivement rare, je l'ai trouvé à Cette.

\section{S. LE PLEURONEGTE GUITARE. - PLEURONECTES CITHARUS.}

Poiss. France, t. III, p. 334, fig. 186, anim.

N. vulg. : Pampoliti, Nice; PerpeÏra, Prétré, Cette.

Long. : 0,13 à 0,30 .

Le corps est ovale, couvert de grandes écailles, assez peu adhérentes, munies, principalement sur le côté gauche, de spinules fort nombreuses; sa hauteur est contenue trois fois et un cinquième à trois fois et demie dans la longueur tolale, et la longueur de la tête quatre fois et demie; le museau est pointu, la bouche grande; la mandibule porte un bubercule à la symphỳse, elle est plus avancée que la mâchoire supérieure; elles sont garnies l'une et l'autre de dents crochues, inégales, disposées, le plus souvent, en rangée simple, parfois irrégulière on double en avant; sur le cherron du romer est un groupe de dents crochues. Le diamètre de l'reil est compris quatre fois et demie à six fois dans la longueur de la tête; il est moins grand que l'espace préorbilaire; l'ceil supérieur est le plus arancé; l'espace interorbitaire est très étroit. - La lignne latérale forme une courbe au-dessus de la pectorale; clle est composée d'écailles en quelque sorte carénées, portant ì leur bord postéríeur trois orifices. - La dorsale commence à droite rers le point correspondant au bord antérieur de l'orbite supérieure; 
elle finit, ainsi que l'anale, près do la base de la caudale qui est arrondie; less pectorales sont à peu près égales.



Le côté des yeux est gris teinté de jaune; parfois le tronçon de la queue est marqué d'une double tache noirâtre; le côté aveugle est blanchâtre. En général les nageoires n’ont pas de taches.

Habitat. Méditerranée, assez commun, Nice, Cette, Port-Vendres.

\section{LE PLEURONECTE ÉLÉGANT. - PLEURONECTES CANDIDISSIMUS.}

Poiss. France, t. III, p. 337.

Long. : 0,06 .

D’après Risso, ce petit Turbot, semblable à de la gelée, a le corps ovale, arrondi, couvert de très petites écailles d'un blanc transparent; la hauteur du tronc est comprise environ deux fois et demie dans la longueur totale. Le museau est protractile, arrondi; la bouche petite; les yeux sont placés sur une mème ligne. - La ligne latérale est droite. - La caudale est arrondie.

$$
\text { Br. 3. - D. } 46 \text {; A. } 28 \text {; C. } 11 \text {; P. } 9 \text {; V. } 5 .
$$

La dorsale et l'anale sont ornées chacune de cinq taches rouges, avec un liséré de la même couleur. Suivant Risso, la ligne latérale est droite, d'un blanc opaque, avec une tache de même couleur à son origine.

Habitat. Méditerranée, excessivement rare, Nice.

A. Costa, suivant l'observation de Canestrini, a donné la figure de ce Poisson dans Anmuario del Museo Zool. di Napoli, 1862, anno 1, tav. 1, fig. 1.

\section{GENRE TURBOT OU RHOMBE. - RHOMBUS, Klein.}

Corps de forme ovale ou rhomboïdale; du côté des yeux, peau couverte de tubercules ou d'écailles lisses.

Tête; bouche oblique; màchoire inférieure avancée, munie ainsi 
que la supérieure de dents en velours ou en cardes fines; vomer denté.

Yeux à gauche; espace interorbitaire plus grand que le diamètre vertical de l'vil.

Ligne latérale courbe au-dessus de la pectorale, droite ensuite.

Nageoires; dorsale commeneant sur le museau, en arant de l'wil supérieur, et tinissant, comme l'anale, près de la caudale.

Sur le côté gauche des tubercules................... 1. Tureot.

des écailles lisses................. 2. Baburu.

\section{LE TURBOT. - RHOHBUS HAXIHUS.}

Poiss. Fronce, t. III, p. 33 s.

N. vulg. : Grand Turbot; Faisan d'eau; Berlonneau; Tréboutet, Finistère; Eturbo, Poitou; Rum-clavellat (catalan), Pyrénées-Orientales; Roun clavélat, Cette; Rombou clavelat, Nice.

Long. : 0,40 à 0,70 et plus.

Du côté des yeux, le corps est courert de tubercules coniques plus ou moins rugueux; il a la forme d'un losange assez régulier; sa hauteur est comprise une fois et demie à deux fois dans la longueur totale, et la longueur de la tête trois fois et demic à quatre fois; les màchoires portent une bande, assez large en arant, étroite en arrière, de petites dents aiguës, en cardes fines; sur le romer est un pelil groupe de dents crochues. En général, l’oil supérieur est un peu plus reculé que l'inférieur; le diamètre longitudinal de l'ceil est contenu six à dix fois dans la longueur de la tête, une fois et deux tiers à deux fois et demie dans la longueur de l'espace préorbitaire, il est à peu près égal à l'espace interorbitaire, qui est aplati et plus ou moins courert de tubercules. - La dorsale commence sur le museau, un peu en avant de l'orifice antérieur de la narine droite; la caudale est arrondie; la ventrale gauche paraît toujours plus grande que la droite.

Br. 7. - D. 61 i $72 ; 1.45$ i 56 ; C. 15 ou 16 ; P. 11 ou 12, 11 ou 12; V. 6,6 .

Du còté des yeux, la coloration est d'un gris ou d'un brun jaunâtre, arec de fort petites taches, les unes blanchâtres, les autres noires. Le côté aveugle est blanchâtre, parfois il est

Mloreau. - Ichthyologie. 
coloré, el le Turbol est appelé double. - Il y a deux appendices pyloriques gros et courts.

Habitat. Toutes nos côtes.

\section{LA BARBUE COMMUNE. - RHOMBUS LOEVIS.}

Poiss. France, t. III, p. 340, fig. 187, anim. var. ; rayons antérieurs de la dorsale: fig. 188, Barbue commune; fig. 189, Barbue, var.

N. vulg. : Turbot sans piquants; Barbache, Barbuche; quelquefois Carrelet; Rum, Pyrénées-Orientales; Passar, Round, Cette; Rombou, Nice.

Long. : $0,2 \ddot{\partial}$ à $0, \ddot{0} 0$ et plus.

Des deux côtés, le corps est couvert de petites écailles cycloïdes très adhérentes; il est de forme ovale; sa hauteur est contenue deux fois et un cinquième à deux fois et un tiers dans la longueur totale, et la longueur de la tète trois fois et trois quarts à quatre fois et demie; les mâchoires portent une bande assez étroite de dents en cardes fines; le vomer est armé de dents crochues. L'œil inférieur est généralement plus arancé que l'autre; le diamètre de l'œil est compris six fois et demie à neuf fois dans la longueur de la tête, il est plus petit que l'espace préorbitaire, plus grand que l'espace interorbitaire, qui est aplati. - La dorsale commence un peu en avant de l'orifice antérieur de la narine droite, elle a ses premiers rayons plus ou moins divisés; le tronçon de la queue a beaucoup plus de hauteur que de longueur, comme chez le Turbot; la caudale est arrondie.

Br. 7. - D. 73 à 83 ; A. 50 à 61 ; C. 17 à 20 ; P. 11 ou 12,10 à 12 ; V. 6,6 .

Du côté des yeux, la coloration est d'un gris jaunâtre ou châtain avec des taches inégales, plus ou moins nombreuses, plus ou moins foncées. Le côté areugle est blanchâtre.

Kabitat. Toutes nos còtes.

Variété. - Il existe dans la Méditerranée une variété de Barbue qui a les premiers rayons de la dorsale à divisions beaucoup moins nombreuses que chez la Barbue commune; la crête interorbitaire est fort sitillante relativement; du còté des yeux, la teinte est uniforme, 
lie de vin, très foncée. Nous avons examiné divers spécimens venant de Nice el de Cette.

\section{GENiE BothUS. - BOTIUUS, CBp.}

Corps ovale, couvert d'écailles pectinées sur le còté gauche et généralement lisse sur le còté droit.

Tête; bouche petite, oblique; màchoires à dents fines; vomer lisse.

Yeux à gauche, très écartés l'un de l'autre; œil inférieur plus arancé.

Ligne latérale décrivant sur le còté gauche une courbure très prononcée très courte, finissant avant l'extrémité de la pectorale.

Nageoires; dorsale commencant sur le museau, et se termiuant, comme l'anale, près de la racine de la caudale; base de la rentrale gauche beaucoup plus longue que celle de la ventrale droite.

Largeur de l'espace interorbitaire contenue dans la longueur de la tête moins de trois fois............. 1. Rnonвö̈on. Largeur de l'espace interorbitaire contenue dans la longueur de la tête plus de trois fois.............. 2. PODas.

\section{LE BOTIIUS RHOMBOIDE. - BOTHUS RHOMBOIDES.}

Poiss. France, t. III, p. 34t, fig. 190, anim.

N. vulg. : Rombou, Nice.

Long. : 0,10 à 0,20 .

La hauteur du corps est contenue deux fois environ dans la longueur totale, et la longueur de la tête quatre fois et demie ì cinq fois; le museau est court; la bouche est à peine fendue jusque sous le bord antérieur de l'orbite inférieure; les mâchoires ont des dents pointues. très fines ; le maxillaire supérieur gauche porte à son extrémité supérieure un tubercule épineux faisant une saillie prononcée. Les yeux sont très écartés l’un de l'autre; le diamìtre de l'œil est compris trois fois et deinie à cincf fois dans la longueur de la tète, il est plus grand que l'espace préorbitaire, mais beancoup moins que l'espace interorbitaire, dont la largeur est contenue une fois et demie à deux fois et demie dans la longueur de la tête. - La dorsale commence sur le museau; elle a, ainsi que l'anale, la base garnie 
d'une série de petites épines, fort aiguës; la même disposition se remarque dans l'espèce suivante.

Br. 7. - D. 85 à 92 ; A. 66 à 72 ; C. 15 ; P. 10 ou 11, 11; V. $6,6$.

Le côté des yeux est brunâtre ou brun verdâtre, semé de taches arrondies, inégales, de couleur jaune clair, à contour brunâtre; sur la tête, il y a souvent des points assez nombreux d'un jaune doré ; parfois la teinte est uniforme ; le côté aveugle est blanc rosé.

Habitat. Méditerranée, rare, Nice, Cannes, Cette.

\section{LE BOTHUS PODAS. - BOTHUS PODAS.}

Poiss. France, t. III, p. 346.

N. vulg. : Rombou, Nice.

Long. : 0,10 à 0,20 .

Les proportions du corps et de la tête sont sensiblement les mèmes que dans l'autre Bothus; mais la saillie de l'extrémité supérieure du maxillaire supérieur gauche est beaucoup moins prononcée. Le diamètre de l'œil est compris environ trois fois et demie dans la longueur de la tête, il est généralement plus grand que l'espace préorbitaire; l'espace interorbitaire est plus déprimé que chez le Rhomboïde, et sa largeur est contenue trois fois et demie à quatre fois dans la longueur de la tête. - Souvent la ligne latérale est double au-dessus de la pectorale gauche; elle est plus rapprochée de la base de la dorsale que chez le Rhomboïde. - La caudale est à peu près arrondie.

D. 76 à 88 ; A. 68 à 70 ; C. 14 ou 15 ; P. 9 ou 10,9 ou 10 ; V. 6,6 .

Du côté gauche, la teinte est d'un brun olivâtre ou rougeâtre, avec des taches d'un blanc jaunâtre, parfois ocellées, bordées de bleu; parfois une tàche noirâtre se montre sur la ligne latérale vers le tiers postérieur du corps. Le côté droit est blanchâtre.

Habitat. Méditerranée, très rare, Nice. 
D'après Steindachner, il n'y a qu'une seule espèce dont le B. rhomhoüdes est le mile et le B. podas, la femelle. V. Steindachn., Ichth. Ber. Span. Portug. Reis., VII. Forst., P. 717, dans Sitz. Alad. Wissensch., Wien, 1868, t. 57.

\section{GeNRE plagusil. - PhaG USta, Browne.}

Corps peu développé, couvert d'écailles ciliées.

Tête; pas de villosités sur le còté aveugle; màchoires dentées sur le còté droit; dentition incomplète ou nulle du còté des yeux.

Yeux à gauche, très rapprochés.

Ligne latérale manquant des deux còtés.

Nageoires; nageoires impaires unies; pas de pectorales; une ventrale, la gauche.

\section{LA PLAGUSiE LACTEE OU DOUTEUSE. - PLAGUSIA LACTEA AUT ANCEPS.}

Poiss. France, t. III, p. 627.

Long. : 0,08 à 0,12 .

La hauteur du tronc est contenue trois fois et demie à quatre fois dans la longueur totale; de chaque côté, la peau est couverte d'écailles garnies de plusieurs séries de spinules, minces, plus longues que larges; l'anus est ouvert à droite. - La tète n’a pas de villosités sur le côté droit; sa longueur mesure le cinquième environ de la longueur totale; la bouche est petite, peu arquée; les mâchoires portent sur le còté droit de petites dents aiguës. Les yeux sont dans le mème plan rertical, très rapprochés l'un de l'autre; le diamètre de l'œil fait à peu près le huitième de la longueur de la tête; plus de la moitié de l'espace préorbitaire. Du côté gauche, l'orifice antérieur de la narine est un peu en avant de l'œeil inférieur; l'autre est vers l'extrémité de l'espace interorbitaire. La fente des oües est peu étendue; le bord postérieur dı battant oporculaire est échancré. - Il ñy a pas de ligne latérale. Ecailles, l. long. 6ö à 7ö; l. transv. 21 environ. - Les nageoires impaires sont unies; elles n’ont pas d'écailles sur leurs rayons; la caudale est pointue; il n'existe qu'une seule rentrale, la gauche; je m'en suis assure par la dissection.

D. 89 a 92 ; A. 70 ; C. 13 ou 14 ; V. i. 
Le côté gauche est d'un blanc laiteux ou d'un blanc jaunâtre teinté de gris; le côté droit est blanchâtre. A gauche, les nageoires impaires sont marquées de taches noirâtres plus ou moins étendues.

Habitat. Méditerranée, excessivement rare, Cette.

A propos de l'Ammopleurops lacteus, M. Vaillant (Exp. sc. Trav. et Talism., p. 192) fait observer qu’à première vue tous les individus paraissent présenter une ligne latérale nette, tandis qu'il n’a pas trouvé d'écailỉes portant le tube caractéristique, et qu’on peut se demander si ce n'est pas lí une simple apparence. - Cette remarque s’applique justement au spécimen pèché a Cette, que j’ai décrit sous le nom de Plagusia lactea (t. III, p. 167\%; de prime abord j’avais cru voir une ligne latérale, ce qui tenait sans doute à l'état dı sujet, qui était un peu desséché; plus tard, examinant le nıème individu, je n'en trouvai plus aucune trace; ce que j'avais regardé comme une ligne latérale n’est évidemment que la dépression fornée par le sillon séparant les muscles latéraux, et allant directement de la ceinture scapulaire à la base de la caudale; il n'existe, en effet, ni du còté gauche ni du còté droit, aucune écaille tubuleuse. - La dentition est aussi différente de celle qui est signalée dans le Plagusia lactea, Bp., qui a les deux màchoires garnies de petites dents à gituche comme à droite, an lieu que chez le sujet venant de Cette, les màchoires sont dentées seulement du còté aveugle; ce qui m’avait fait supposer que les màchoires sont munies de dents sur les deux còtés, c'est qu'en examinant au microscope les dents qui sont placées en zigzas, j'avais rapporté les dents internes des màchoires droites aux màchoires du còté des yeux; c'est une simple illusion, comme je m’en suis assuré plus tard. J'ai voulu constater si le mème arrangement se rencontrait sur les sujets recueillis dans les Expéditions du Travailleur et du Talisman, que le P. Vaillant eut l'amabilité de mettre à ma disposition; sur l'un d'eux, le plus développé, mesurant 0,094 de long, je n'aperçus d'abord à la loupe aucune dent sur le còté gauche des màchoires; je priai M. Vaillant de vérifier le fait; à l'aide d'un grossissement plus fort, il décourrit sur le còté gauche une petite dent conique, dont je pus aussi constater la présence; à còté de cette dent, il y en avait une ou deux autres visilles seulement au microscope; ces dents paraissent mobiles et caduques. - Notre Pleuronecte doit sans aucun doute ìtre placé dans le genre Plagusia, Browne, qui est caractérisé par le manque de ligne latérale à gauche comme à droite. - Il est sin- 
gulier de voir certains auteurs rapporter au genre Plagusia des espèces que Browne n’a pas connues, habitant les eaux des IndesOrientales, et meltre dans le genre Aphoristia, Kaup, l'espèce de la Jamaïque décrite par Browne dont le travail n'est pas bien connu et dont le nom est mal orthographié (Browne, Patrick, The civil and natural History of Jumuica, London 1736 et 1789, Plagusia, p. 4\$3).

\section{̋. Famille des Cycloptéridés, Cyclopteridx.}

Corps de forme variable; peau nue, ou couverte de granulations, de lubercules.

Tête large; màchoires garnies de petites dents en velours ou en cardes fines; palais lisse.

Appareil branchial; fente des ouïes peu étendue; cinq à sept rayons branchiostèges; quatrième arc branchial n'ayant qu'une seule rangée de lamelles respiratoires.

Nageoires; dorsale unique ou double; pectorale à base plus ou moins étendue; sous l'abdomen, un appareil acétubulaire ou cotyloüde, formé d'un discue simple ou double, faisant office de ventonse, servant aux animaux à se fixer aux corps solides; dorsale et rentrale n’ayant aucun rayon épineux.

Deux sous-familles.

Disque abdominal simple................. 1. Cycroptériniens.

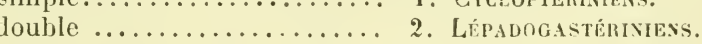

1. Sous-famille des Cycloptériniens, Cyclopterini.

Disque simple formé par les ventrales seulement. Deux genres.

Peau couverte de tubercules................ 1. Cycloptène.

- nue............................ 2. Liparis.

\section{GENRE CYCLOPTÈre. - CYCLOPTERUS, Arted.}

Corps trapu, plus ou moins prismatique; peau épaisse, couverte de granulations et de Lubercules; squelette d'une très faible consistance.

Tête large, aplatie en dessus; museau court; bouche terminale; michoires garnies de petites dents en velours; palais lisse.

Appareil branchial; six rayons branchiostèges; pseudobranchies. 
Nageoires; deux dorsales (la première est atrophiée chez l'animal adulte); seconde dorsale au-dessus de l'anale; ventrales ayant chacune six rayons semblables, formant par leur réunion un disque ovale.

Vessie natatoire nulle. - Appendices pyloriques nombreux.

\section{LE LOMPE. - CYCLOPTERUS LUMPUS, Linn.}

Poiss. France, t. III, p. 349.

N. vulg. : Gros-Mollet; Lièvre de mer; Gros-Seigneur, Cherbourg (Joulan).

Long. : 0,30 à 0,70 .

La hauteur du tronc est contenue deux fois et quart à trois fois dans la longueur totale; la peau est très dure, garnie de petites granulations coniques, ou de tubercules à base plus ou moins étoiléc; il y a de chaque coté trois rangées de tubercules très déreloppés, presque triangulaires. - La tête est plus haute que longue, large en dessus; sa longueur est comprise trois fois et trois quarts à cinq fois dans la longueur totale; les mâchoires, à peu près égales, sont munies de dents en velours, fines et pointues. Le diamètre de l'ceil est contenu six à sept fois dans la longueur de la tête; il ne mesure pas la moitié de l'espace préorbitaire; il fait le quart ou un peu plus de l'espace interorbitaire. Les pièces operculaires ne sont pas distinctes. Il n'y a pas de ligne latérale apparente. -- La première dorsale, visible chez les jeunes animaux, disparaît chez les grands, elle est atrophiée, et sa base comme perdue dans la peau qui forme la crête du dos; la seconde dorsale est reculée, elle finit un peu moins en arrière que l'anale; la caudale est arrondie: les rentrales se composent chacune de six rayons semblables, cachés dans la peau, disposés autour des os du bassin el formant arec eux la charpente d'un disque simple, ovale, légèrement concave, plus long que large. Les rayons des nageoires libres sont garnis de petils tubercules.

Br. 6. - D. 6 ou $7-9$ i 11 ; A. 9 ou 10 ; C. 10 ou 11 ; P. 20 ou 21 ; V. 6 .

La teinte est parfois d'un gris brunâtre à peu près uniforme; parfois la région supéricure du corps est d'un bleu assez clair 
nuancé de rouge, la région inférieure et les nageoires sont d’un jaune peu foncé. - Les appendices pyloriques sont au nombre d une quarantaine.

Habitat: Manche, assez rare, Boulogne, le Havre, Cherbourg, lioscoff. Océan, rare, Vendée, Noirmouliers, Charente-Inférieure, la Rochelle; très rare, grolfe de Gascogne, Arcachon.

Desvaux signale le Cyclopterus spinosus, Schneid., comme ayant é té trouvé sur nos còtes, V. Desv., Essai d'Ichthyologie, Angers, $183 ̈ 1$.

2. GENRE LIPARIS. - LIPARIS, Arted.

Corps plus ou moins allongé, épais en avant, comprimé en arrière de l'anus; couvert d'une peau nue, gluante.

Tête forte; bouche terminale; màchoires garnies de dents en velours.

Appareil branchial; ouies peu fendues; six ou sept rayons branchioslèges.

Nageoires; lorsale unique, longue, ainsi que l'anale; disque abdominal simple, formé par les ventrales, en partie bordé par les rayons inférieurs des pectorales.

\section{LE LIPARIS COMMUN. - LIPARIS VULGARIS.}

Poiss. France, t. III, p. 333 .

N. vulg. : Marmotte, Honfleur.

Long. : 0,07 à 0,12 , quelquefois $0,1 \%$.

La hauteur du tronc est comprise quatre à cinq fois dans la longueur totale; la longueur de la tête présenteà peu près les mèmes proportions; la bouche est fendue transversalement; la màchoire supérieure est un peu plus arancée que la mandibule, portant l'une ef l'au tre une bande de dents en velour's très nombreuses. Le diamètre de l'bil est contenu cinq fois et deux tiers à sept fois dans la longueur de la tête; il mesure environ la moitié de l'espace préorbitaire, qui est égal à l'espace interorbitaire. Il y a généralement sept rayous branchiostèges. - Les nageoires impaires sont contiguës; la dorsale est unie à la base de la caudale par une petite membrane; la caudale est arrondie; les pectorales ont une base très étendue; elles sont échancrées près 
de leur bord inférieur; le disque ventral est à peine moins large que long; il a le bord épais, garni de treize ou quatorze boutons aplatis.

$$
\text { D. } 32 \text { à } 36 \text {; A. } 26 \text { à } 30 \text {; C. } 10 \text {; P. } 27 \text { à } 30 \text {; V. } 6 \text {. }
$$

Le corps est d'un brun pâle, marqué de lignes d'une teinte plus foncée qui manquent parfois, surtout chez les jeunes animaux dont la teinte est jaunâtre.

Habitat. Manche, très rare, Abbeville, ou baie de la Somme; le Havre, Trouville, Honfleur. - Parmi les Poissons recueillis dans l'estuaire de la Seine par II. Gadeau de Kerville, et qu'il me pria de lui déterminer, j’ai trouvé un certain nombre de spécimens de cette espèce.

\section{Sous-famille des Lépadogastériniens, Lepadogasterini.}

Corps peu développé; peau nue, très lisse.

Tête de forme variable: màchoires dentées: palais lisse.

Appareil branchial; fente des ouies étroite; quatre à six rayons branchiostèges.

Nageoires; dorsale unique, à rayons antérieurs articulés; cau. dale arrondie; pectorales unies aux ventrales; ventrale à quatre rayons articulés, assez forts, plus, en avant, un rayon court, enveloppé dans la peau. - Appareil acétabulaire composé de deux disques, séparés par un sillon transversal.

Vessie natatoire nulle. - Appendices pyloriques manquant. Deux genres.

Dorsale et anale à rayons très distincts........... 1. LÉpadogastỉre. peu distincts........... 2. Goüanie.

1. GENRE LÉPA DOGASTÈR. - LEPADOGASTER, Goüan.

Corps cunéiforme, aplati en dessous, relevé et arrondi vers le dos. Tête large, déprimée; bouche relativement bien fendue.

Nageoires; dorsale et anale à rayons distincts; caudale arrondie. Quatre ou cinq espèces.

a. Caudale unie à la dorsale et à l'anale.......... b. - libre.......................... $c_{\text {. }}$

৮. Tentacule nasal bifide................... 1. GoüAN. - simple................. ?. DE BRow. 
c. Dorsale plus longue que l'anale. 3. DE C.INDOLLE.

l. Dorsale ayant cinq à sept rayons................

- it trois rayons sculement............ d.

4. A DEUX TACHES.

5. GRÊLE.

1. LE LÉPADOGASTERE GOÜAN. - LEPADOGASTER GOUANII.

Poiss. France, t. III, p. 33̈6, fig. 191, anim., appareil acétabulaire.

N. vulg. : Pei puorc, Nice; Marchand d'esca (Narchand d'amadou), Cette; Appèchart, Guéthary.

Long. : $0,0 \ddot{3}$ it 0,08 .

La hauteur du tronc est contenue cinq fois et demie à neuf fois dans la longueur totale, et la longueur de la tête deux fois et demie à deux fois et trois quarts; la tète est plus large que le corps; le museau est allongé ; la bouche grande; la mâchoire supérieure plus développée que la mandibule, munies, l'une et l'autre, de dents rangées sur plusieurs séries en avant, sur une seule en arrière. Le diamètre de l'œil est compris cing fois et demie à huit fois dans la longueur de la tète; il ne mesure pas la moitié de l'espace préorbitaire, il est moins grand que l'espace interorbitaire. A l'orifice antérieur de la narine est un appendice plus ou moins développé, divisé en deux tentacules; le tentacule antérieur est plus court et plus grèle que le postérieur, qui se partage souvent en ramifications secondaires.

- La dorsale commence en avant de l'anus; elle est, ainsi que l'anale, jointe, par une membrane assez làche, à la caudale, qui est arrondie; les pectorales sont bien développées, unies aux rentrales par une membrane résistante; le disque antérieur est ovale; le disque postérieur a le pourtour assez épais; il présente une dépression à peu près quadrilatérale; il parait tout garni de petites franges.

$$
\text { Br. 6. -D. } 15 \text { à } 20 ; 4.9 \text { à } 12 \text {; C. } 20 \text {; P. } 20 \text { à } 22 \text {; V. } 4 .
$$

Le corps est gris verdâtre ou gris rosé avèc des points rougeâtres, ou bien il estrougeâtre, rouge jaunâtre sur le dos, semé de points brunàtres; le ventre est d'un jaune clair. Sur la tète, il y a souvent, en arrière des yeux, des bandes en croissant d'un brun assez clair, ou deux taches ocellées à centre bleu, à contour rougeâtre; parfois la nuque est d'une teinte brunâtre. 
Habitat. Méditerranée, assez rare, Nice, Toulon, Marseille, Cette. Océan, assez commun, Guéthary, Brest. Manche, assez commun, Roscoff, Cherbourg; rare, le Havre.

2. LE LEPADOGASTĖRE DE BROWN. - LEPADOGASTER BROWNII, Riss.

Poiss. France, t. III, p. 33 9.

Long. : 0,04 à 0,06 .

SuivantRisso, le tentacule nasal est simple, et, d'après Canestrini, plus grand que le diamètre de l'œil; le disque antérieur est ovale; le disque postérieur est carré et divisé en trois parties: une antérieure granuleuse, et deux postérieures lisses (Canestr.). Les opercules sont ornés de deux taches oblongues, violettes, cerclées de bleu et placées sur un fond noirâtre; le corps est d'un jaune transparent, finement pointillé de noir et parsemé de taches d'un rouge aurore (Riss.).

Br. 3. - D. 22 ; A. 10 ; C. 14 ; P. 18 ; V. 4 (Riss.).

Br. 6.-D. 19; A. 12; C. 23; P. 23; V. 4 (Canestr.).

Habitat. Méditerranée, excessivement rare, Nice.

3. LE LÉPADOGASTĖRE DE CANDOLLE. - LEPADOGASTER CANDOLLII, Riss.

Poiss. France, t. III, p. 360, fig. 192, anim.

N. vulg. : Pei Sant-Peire, Nice; Appèchart, Guéthary.

Long. : 0,06 à 0,10 .

La hauteur du trone est contenue de six à dix fois dans la longueur totale, et la longueur de la tête deux fois et deux tiers a trois fois et demie; le museau est semi-circulaire en avant: les mâchoires, à peu près égales, ou la mâchoire supérieure à peine plus avancée que la mandibule, portent en avant des dents en velours, inégales et sur une seule rangée en arrière. Le diamètre de l'œil est compris cinq à sept fois dans la longueur de la tête; il mesure la moitié de l'espace préorbitaire, qui est un peu plus grand que l'espace interorbitaire. Les tentacules des narines sont très petits, parfois même peu visibles; 
ils sont ramifiés. - Les nageoiles impaires sont libres; le disque anterieur est circulaire; le disque postérieur est demicirculaire.

D. 14 à $16 ;$ A. 9 à 11 ; C. 16 à 18 ; P. 21 à $24 ;$ V. 4 .

Le système de coloration est très variable; le corps est gris jaunâtre avec des taches rougeâtres, parfois olive avec des taches blanches; quelquefois il y a sur l'opercule une tache rouge plus ou moins grande; quelquefois il existe une bande noirâtre sur la tête. La dorsale et l'anale sont tachetées de rouge; l'anale est d'un jaune clair; chez certains individus, les nageoires sont rouges entièrement.

Habitat. Méditerranée, assez commun. Nice, Toulon, Cette, Port-Vendres. Océan, golfe de Gascogne, assez rommun, Guéthary.

\section{LE LEPADOGASTÈRE A DEUX TACHES. - LEPADOGASTER BIMACULATUS, Penn.}

Poiss. France, t. III, p. 362.

N. vulg. : Pei Sant-Peire, Nice.

Long. : 0,03 ä à 0,060 .

La hauteur du tronc est contenue six fois et demie à neuf fois et demie dans la longueur totale, et la longueur de la tête trois fois et quart à quatre fois; le museau est assez court, terminé en pointe arrondie; la màchoire supérieure est un peu plus avancée que la mandibule. Le diamètre de l'œil mesure environ le cinquième de la longueur de la tête. Les tentacules des narines sont rudimentaires, parfois peu visibles. - La dorsale et l'anale sont très reculées, à rayons peu nombreux; la caudale est complètement libre, relativement longue et large; le disque antérieur est cordiforme, le disque postérieur est losangique.

J. 5 ì $i ; A .4$ à 6 ; C. 12 à 1 ; ; P. 18 olı 19 ; V. 4 .

Le système de coloration est le plus souvent rougeâtre, parfois brun clair; il y a souvent du bleu près des orbites; ordinairement les côtés portent une tache arrondie, violacée, entourée de blanc; celte tache n'est pas toujours bien marquée; 
elle manque chez les jeunes animaux. Dans la variété, Lépadogastère réticulé de Risso, le dos est brun jaunâtre ; les côtés inférieurs et la gorge sont d'un blanc nacré, varié de petites lignes noires.

Habitat. Méditerranée, assez rare, Nice, Marseille. Océan, assez rare, Arcachon. Manche, très rare, Cherbourg?

5. LE LÉPADOGASTĖRE GRÊLE. - LEPADOGASTER GRACILIS.

Poiss. France, t. III, p. 363.

Long. : 0,03 .

Suivant Canestrini, le museau est pointu; en arant et en arrière de chaque oeil existe une arète longitudinale; la dorsale et l'anale sont opposées, elles ont trois rayons; l'appareil aeétabulaire n a pas de granulations.

$$
\text { Br. 6. -D. } 3 \text {; A. } 3 \text {; C. } 10 \text {; P. } 14 \text {; V. } 4 \text {. }
$$

Le corps de ce Poisson, conservé dans l'alcool, est rouge violet avec des points blancs.

Habitat. Méditerranée, excessivement rare, Nice.

M. Cr. Bellolli a trouvé à Nice, en mars 1889, un spécimen de Lepadogaster dentatus, Facciolà. V. Bellotti, Appunti all opera del Dr E. Moreau: Ilistoire naturelle des Poissons de la France, Estr. Atti Soc. 1tal. sc. nat., Milano, t. XXXIII, 31 maggio 1891, p. (130) $2 \dot{t}$.

\section{GENRE GOÜANIE. - GOUANIA, Nardo.}

Corps allongé, plus ou moins arrondi en avant.

Tête courte; museau très peu arancé, large, arrondi.

Nageoires; dorsale et anale très basses, à rayons peu distincts, unies à la caudale; appareil acétabulaire peu développé.

\section{LA GOÜANIE DE VILDENOW. - GOUANIA VILDENOWII.}

Poiss. France, t. III, p. 364.

N. vulg. : Pei Sant-Peire, Nice.

Long. : 0,0 '́ à 0,06 . 
Le corps est assez arrondi jusqu'à la dorsale; sa hauteur, qui est égale à sa largeur, est contenue neuf à dix fois dans la longueur totale. - La tète est courte; sa longueur est comprise quatre fois à quatre fois et demie dans la longueur totale; le museau est large, déprimé en avant; la mâchoire supérieure est à peine plus avancée que la mandibule; elles sont, l'une et l'autre, munies de dents sur plusicurs rangées, plus fortes et plus pointues à la rangée externe. Le diamètre de l'cril est contenu six à sept fois dans la longueur de la tête; il fait environ la moitié de l'espace préorbitaire, qui est à peu près égal à l'espace interorbitaire. A l'orifice antérieur de la narine est un appendice assez court, parfois difficile à distinguer. - Les nageoires paires sont unies; la dorsale et l'anale sont très basses, à rayons peu visibles; la caudale est peu développée; les pectorales sont très courtes; lappareil acétabulaire est avancé sous le premier tier's de la longueur totale, il est étroit, il a une longueur moindre que la distance qui le sépare de l'anus; le disque antérieur a, de chaque côté, deux plis arrondis ; le disque postérieur est ovale.

$$
\text { D. } 13 \text { a } 15 \text {; A. } 10 \text { à } 12 \text {; C. } 17 \text {; P. } 16 \text {; V. } 4 \text {. }
$$

La coloration est grisâtre, gris jaunâtre, ou feuille morte arec un pointillé rougeâtre.

Habitat. Méditerranée, très rare, Nice.

\section{I. - TRIBU DES MALACOPTÉRYGIENS ABDOMINALX. MALACOPTERYGII ABDOUINALES.}

Nageoires; ventrales en arrière des pectorales.

Cette tribu compte onze familles.

a. Dorsale unique, rarement suivie de pinnules. $b$.

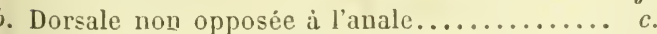

- opposée a l'anale ............... g.

c. Bord de la màchoire supérieure formé par les intermaxillaires seuls.............. Bord de la màchoire supéricure formé par les intermaxillaires et les maxillaires......

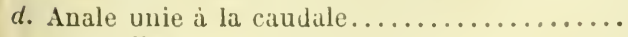




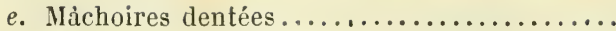

- non dentées..........................

f. Barbillons, six au moins ................... quatre au plus ou manquant....

$g$. Barbillon sous la gorge développé............ nul............... $h$.

$h$. Carène écailleuse de chaque côté du ventre. Pas de carène latérale vers le ventre........

$i$. Opercule écailleux.......................

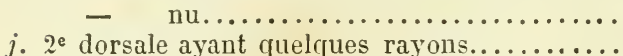
- adipeuse, parfois atrophiée .......
3. Cyprinodontidés.

2. Cobitroés.

1. Cyprinidés.

9. Stomiatidés.

8. EXocÉTIDÉs. $i$.

7. Ésocétides.

6. AlÉpocépHialidés.

10. SCOPÉLIDÉS.

11. SalMonidés.

\section{Famille des Cyprinidés, Cyprinidx.}

Corps de forme ovale ou allongée, couvert d'écailles cyclö̈des.

Tête nue; bouche petite; bord de la mâchoire supérieure formé par les intermaxillaires; màchoires dépourvues de dents; il n'existe de dents que sur les pharyngiens inférieurs; une plaque dure, épithéliale, est fixée dans une dépression de l'occipital basilaire.

Yeux latéraux; orbite à voùte élargie par un os sur-orbitaire.

Narines à deux orifices.

Appareil branchial; pièces operculaires nues; trois rayons branchiostèges; quatre arcs branchiaux complets; pharyngiens inférieurs déreloppés, munis de dents placées sur une, deux ou trois rangées, opposées à la plaque de l'occipital basilaire.

Ligne latérale, bien marquée en général.

Nageoires; dorsale unique; anale plus en arrière que la dorsale.

Vessie natatoire grande, divisée en deux lobes par un étranglement prononcé; lobe antérieur en rapport avec les osselets de Vieber; lobe postérieur communiquant avec l'œesophage par un conduit pneumatophore. - Appendices pyloriques manquant; estomac sans cul-de-sac.

Trois sous-familles.

a. Des barbillons à la bouche ou un rayon dentelé à l'anale........................

Ni barbillons à la bouche, ni rayon dentelé i l'anale ...........................

b. Lèvres molles .........................

- cartilagineuses.................

1. Cypriniviens.

b.

2. Leuciscinifys.

3. Chondrostominiens. 


\section{Sous-famille des Cyprininiens, Cyprinini, Bp.}

Barbillons à la bouche, ou rayon dentelé à l'anale et à la dorsale. Cette sous-famille comprend quatre genres.

a. Rayon dentelé ì l'anale plus ou moins fort...........

b. Barbillons au nombre de quatre....................

- $\quad$ - deux.................. c.

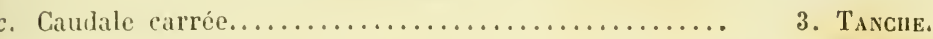

- trìs échancrée ..................... 4owo. 4.

\section{Cyptin.}

2. BARBEAU.

\section{GENRE CIPRIN. - CIPRINUS.}

Corps généralement ovale, couvert de larges écailles.

Nageoires; dorsale longue, ayant, ainsi que l'anale, un rayon dentelé avant le premier rayon branchu.

Le genre Cyprin se divise en deux sous-genres.

Barbillous a la bouche plus ou moins développés......... 1. Carpe.

$$
\text { manquant ................ 2. Canassix. }
$$

\section{SOUSGENRE CARRE. - CFPRINUS.}

Tête développée; barbillons généralement au nombre de quatre.

Appareil branchial; opercule strié; dents pharyngiennes le plus souvent au nombre de cinq, et placées sur deux ou trois rangées.

\section{LA GARPE COMNUNE. - CIPRINUS CARPIO.}

Poiss. France, t. III, p. 368.

N. vulg. : Escarpa, Escarpo, Gard, Hérault.

Long. : 0,30 à 0,30 et plus.

La hauteur du tronc est comprise trois fois à quatre fois et demie dans la longueur totale, et la longueur de la tête quatre fois à quatre fois et deux tiers; la mâchoire supéricure est un peu plus avancée que la nandibule; de chaque còté il y a deux barbillons, le postérieur est le plus développé. Le diamètre de l'cil est contenu quatre fois et demie à six fois et deux tiers dans la longueur de la tête; il mesure environ la moitié de Moreat. - Ichthyologie. 
l'espace préorbitaíre, qui est à peu près égal à l'espace interorbitaire. Les dents pharyngiennes sont des espèces de molaires, au nombre de cinq de chaque côté, et placées sur deux ou plutôt sur trois rangées; la première rangée se compose de trois dents bien développées; la deuxième et la troisième n’ont qu'une dent chacune. - La ligne latérale est bien marquée,

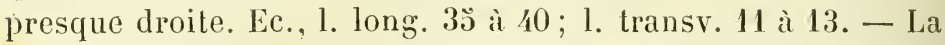
dorsale est longue, formée de trois ou quatre rayons simples et de dix-sept à vingt-deux rayons branchus dont le premier est le plus allongé ; l'anale est reculée, elle a trois rayons simples; le dernier rayon simple de chacune de ces nageoires est très robuste; il est, en arrière, creusé en gouttière ayant les bords garnis d'épines ou de dentelures; la caudale est fort échancrée.

D. 3 ou $4 / 17$ à 22 ; A. $3 / 5$; C. 17 à 19 ; P. $1 / 15$ à 17 ; V. $2 / 7$ ou 8.

La coloration est très variable, généralement d'un brun verdâtre à reflets bleuâtres sur le dos, dorés sur les côtés; parfois la teinte est blanchâtre. Le C'yprin Anne-Caroline de Lacépède est doré avec quelques taches noirâtres; en Auvergne se trouve une Carpe jaune.

Habitat. La Carpe est très commune dans les eaux douces courantes et stagnantes.

Variètés. - Monstruosités. - Carpe à miroir, Reine des Curpes, écailles excessivement développées. - Carpe nue ou Carpe à cuir, écailles atrophiées, peau épaisse, ayant l'apparence du cuir. - Carpe bossue, dos très élevé. - Carpes dauphins ou Carpes à tête de Dauphin, spécimens monstrueux à face raccourcie, la partie antérieure du cràne fuisant saillie en avant des yeux, au-dessus du museau.

\section{Hybnide. - La Carpe de Kollar. - Cyprinus kollurit.}

Poiss. France, t. III, p. 372.

N. vulg. : Carousche blanche, Lorraine; Carreau, Paris.

Long. : 0,20 à $0,: i 0$.

La hauteur du corps est contenue deux fois et trois quarts à quatrc fois dans la longueur totale, et la longueur de la tête quatre à cinq fois; les barbillons sont peu développés; chez certains individus, les barbillons antérieurs manquent ou sont fort peu visibles; les barbillons postérieurs semblent généralement les plus allongés; par- 
fois il n'existe qu'un très petit rudiment de barbillon à la commissure des lèvres. Le diamètre de l'wil mesure environ le cinquì̀me de la longueur de la tète, les deux tiers de l'espace préorbitaire, la moitié de l'espace interorbitaire. Les dents pharyngiennes sont ordinairement, de chaque còté, au nombre de cinq placées sur deux rangées; il $y$ en a quatre dans la longue rangée; chez quelques individus, le pharyngien ne porte qu'une seule rangée de quatre dents. - La ligne latérale est bien marquée. Ec., I. Jong. 33 à 38; l. transv. 11 a $1 \%$. - Parfois le rayon dentelé de la dorsale, comme celui de lanile, est assez faible; il en est de mème du rayon simple de la ventrale.

D. 3 oll $4 / 17$ à $21 ;$ A. $3 / 5$ ou 6 ; C. 17 ou 18 : P. $1 / 15$ à 17 ; V. ?/ร ou 8.

Ordinairement le dos et les còtés sont d'un brun verdàtre à reflets dorés; le ventre est blanc rougeàtre ou d'un jaune assez clair; parfois les parties latérales ou inférieures du corps sont d'un gris jaunàtre.

Habitat. Ce Poisson est assez rare; il existe dans quelques départements de l'Est et du Nord, dans le département de la Somme, particulièrement aux enrirons de Péronne. - C'est un hybride de la Carpe commune et dı Carassin commun.

\section{SOUS-GLNRE CaRASSIN. - CARASSIUS, Nilsson.}

Barbillons manquant, - Dents pharyngiennes au nombre de trois ou quatre de chaque còté, placées sur une seule rangée.

Deux espèces.

Hauteur du tronc comprise dans la longueur totale moins

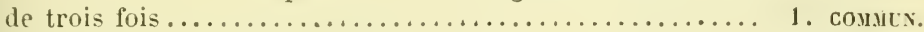

Hauteur du tronc comprise dans la longueur totale au moins

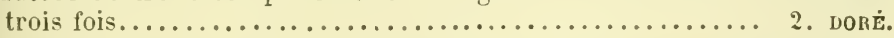

\section{LE CARASSIN COMMUN. - CARASSIUS VULGARIS.}

Poiss. France, t. III, p. 374.

N. vulg. : Carasche, Carousche, Carousche noire, Carrean, Lorraine.

Long. : 0,20 à 0,30 .

La hauteur du corps est contenue deux fois et un septième à deux fois et trois quarts dans la longueur totale, et la lon- 
gueur de la tête quatre fois et un tiers à quatre fois et trois quarts; la mâchoire supérieure est à peine plus avancée que la mandibule. Le diamètre de l'œil mesure le cinquième ou le sixième de la longueur de la tête, les deux tiers de l'espace préorbitaire, qui est d'un tiers moins grand que l'espace interorbitaire. Sur chacun des pharyngiens est une série de quatre dents dont la première est généralement conique et les autres à couronne comprimée. - La ligne latérale est presque droite; au-dessus de la base des ventrales, elle est plus rapprochée du profil inférieur que du profil supérieur. Ec., l. long. 31 à $3 \ddot{3}$; 1. transv. 13 à 16. - La dorsale est longue; elle commence au-dessus des ventrales et finit au-dessus de l'anale; la caudale est échancrée.

D. 3 ou $4 / 15$ à 20 ; A. $3 / 5$ ou 6 ; C. 18 à 20 ; P. $1 / 12$ à 16 ; V. $2 / 7$ ou 8.

Ordinairement le dos et les côtés sont d’un brun verdâtre; le ventre est jaunâtre, parfois d'un jaune rougeâtre.

Habitat. Il est rare; il se trouve dans quelques départements de l'Est et du Nord, Meurthe, Misne, etc.

Variétés : Carpe gibèle; Carpe meule, etc.

\section{LE CARASSIN DORE. - CARASSIUS AURATUS.}

Poiss. France, t. III, p. 377.

N. vulg. : Poisson rouge; Daurat, Nice.

Long. : 0,10 à 0,20 .

La hauteur du tronc est contenue trois à quatre fois dans la longueur totale, et la longueur de la tête quatre fois à quatre fois et trois quarts; les mâchoires sont égales. Le diamètre de l'œil mesure le quart environ de la longueur de la tête; il est plus petit que l'espace interorbitaire; il est égal, ou peu s'en faut, à l'espace préorbitaire. Les dents pharyngiennes, placécs sur une seule rangée, sont au nombre de trois ou de quatre le plus souvent; la dent antérieure est presque cylindri(pue; les suivantes ont la couronne comprimée. - En avant, la ligne latérale décrit une faible courbure, un peu plus rapprochée du 
dos que du ventre. Ec., l. long. 26 à $30 ; 1$ transv. 12 à 14. -La dorsale est longue; la caudale très échancrée.

D. 3 ou $4 / 16$ à $18 ; \Lambda .3 / 50116$; C. 17 à 19 ; P. $1 / 15$ à 17 ; V. $2 / 70118$.

La teinte est généralement d'un beau rouge vermillon, parfois elle est rosée; il y a des sujets blanchâtres, d'autres verdàtres plus ou moins marqués de noir.

Habitat. Il se trouve dans les bassins des jardins publics, et, à l'état libre, dans certains cours d'eau, dans la Seine et ses affluents, d'après M. Blanchard. - Il est parfois apporté sur le marché de Paris. - Il croise facilement avec la Carpe commune, et ne donne que des métis de mauvaise qualité. -- Il est apte à subir les modifications les plus extraordinaires.

\section{GENRE BARBEAU. - barbUS, Cuv,}

Corps allongé, fusiforme; couvert d'écailles minces, lisses.

Tête longue; bouche en dessous; quatre barbillons généralement bien développés.

Appareil branchial; dents pharyngiennes au nombre de neuf ou dix de chaque côté, disposées sur trois rangs $\breve{b}-3-1$ ou 2 , plus ou moins coniques, crochues à leur extrémité.

Nageoires; dorsale à dernier rayon simple tantôt dentelé, tantòt non dentelé; anale courte, sans rayon dentelé; caudale fourchue.

Deux espèces.

Dorsale avec un rayon dentelé.................. 1. coumux.

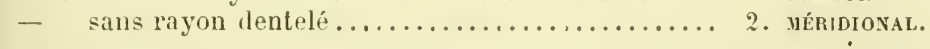

\section{LE BARBEAU COMMUN. - BARBUS FLUVIA TILIS.}

Poiss. France, t. III, p. 379.

N. vulg. : Barbillon, Barbio, Barbet, Barbarin.

Long. : 0,20̀ à 0,50 , quelquefois 1,00.

La hauteur du tronc est contenue cinq fois et trois quarts à six fois et demie dans la longueur totale, et la longueur de la tète quatre fois à quatre fois et trois quarts; le museau est proéminent; la bouche est tout à fait en dessous, à lèvres 
épaisses, avec deux barbillons, de chaque côté; le barbillon antérieur est vers l'extrémité du museau. Le diamètre de l'cril est compris cinq fois et demie à six fois dans la longueur de la tête; il mesure le tiers ou les deux cinquièmes de l'espace préorbitaire chez les sujets de moyenne taille. Chaque pharyngien porte neuf ou dix dents $\ddot{3}+3+1$ ou 2. - La ligne latérale est à peu près droite. Ec., l. long. ऑ̋̈ à 70 ; l. transv. 19 à 26. - Ordinairement la dorsale commence au-dessus de l'insertion des ventrales, et finit avant l'origine de l'anale; son dernier rayon simple est fort dentelé en arrière.

D. 3 ou $4 / 8$ ou 9 ; A. $3 / 5$ ou 6 ; C. 19 ou $20 ;$ P. $1 / 14$ ou $15 ;$ V. $2 / 7$ ou 8.

Le plus souvent le dos est gris bleuâtre ou verdàtre; les côtés sont d'un blanc argenté nuancé de gris ou de jaune; le ventre est blanchâtre; quelquefois la ieinte générale est d'un gris perle plus foncé vers le dos, plus clair vers le ventre. La dorsale est grisâtre avec quelques points bruns; l'anale, la caudale et les ventrales sont d'une teinte orangée.

Habitat. Commun dans la plupart de nos cours d'eau.

\section{LE BARBEAU MÉRIIIONAL. - BARBUS MERIDIONALIS.}

Poiss. France, t. III, p. 381, fig. 193, anim.

N. vulg. : Durgan, Nice; Barbéon, Cette; Barp, Pyrénées-Orientales.

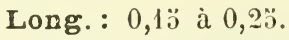

La hauteur du tronc est comprise quatre fois el trois quarts ì cing fois et demie dans la longueur totale, la longueur de la tête quatre fois et demie à cinq fois; le museau est assez gros, arrondi; les barbillons sont de longueur très variable, parfois grêles, courts, pariois très développés, surtout les postérieurs qui, ramenés en avant, peuvent dépasser l'extrémité du museau. Le diamètre de l'œil est compris quatre à six fois dans la longueur de la tête, il est d'un tiers ou de moitié plus petit que l'espace préorbitaire. - La ligne latérale est à peu près droite. Ec., l. long. 48 à : 29 ; l. transv. 17 à 21 . L Le dernier rayon simple de la dorsale est flexible, sans dentelures en arrière.

D. $3 / 7$ ou 8 ; A. $3 / 5$; C. 16 ; P. $1 / 15$ a 17 ; V. $2 / 8$. 
Les parties supérieures du corps sont d'un gris rerdàtre ou teinté soit de rose, soit de jaune; les parties inférieures sont argentées; le tronc et la tète sont marqués de gros points ou plutiot de laches noiratres. Les nageoires impaires sont jaunâtres avec des taches noires disposées en séries transversales; les nageoires paires sont blanchatres, avec quelques taches noirâtres souvent peu distinctes.

Habitat. Issez commun dans le département des Alpes-Maritimes, dans le département de l'Hérault, il est pèché parfois dans l'élang de Thau; il est très commun dins le département des Pyrénées-Orientales.

\section{GENRE TANCIE. - TINCA, Cuv.}

Corps trapu, couvert de petites écailles, très adhérentes.

Tête; bouche terminale; un pelit barbillon à l'angle de la bouche.

Appareil branchial; dents pharyngiennes légèrement claviformes, munies d'un pelit crochet à leur angle interne, placées, de chaque cóté, sur une seule rangée au nombre de quatre ou cinq.

Nageoires; dorsale et anale courtes, arrondies, ainsi que les nagreoires paires; caudale à peu près carrée.

\section{LA TANCHE VUlgaIRE. - TINCA VULGARIS.}

Puiss. France, t. III, p. 383.

N. vulg. : Tinche, Poitou (Lemarić); Tenca, Tenco, Gard, Hérault. Long. : 0,20 ì 0,33 .

La hauteur du corps est contenue trois fois et trois quarts à quatre fois et demie dans la longueur totale, et la longueur de la tête quatre fois el un tiers à cinq fois; le museau est oblus: de chaque côté, vers la commissure des lèvres, est un petit barbillon. Chez les sujels de grande taille, le diamètre de l'oril est compris six à sept fois dans la longueur de la tête: il ne mesure guère que la moitié de l'espace interorbitaire, qui est un peu plus grand que l'espace préorbitaire. Les dents pharyngiennes son! généralement au nombre de quatre de chaque còte, rarement de cinq; partois, il s'en trouve quatre d'un côté et cinq de l'autre. - Ec., l. long. 90 ì 120; l. transv. 
403 à 89 . - La dorsale commence au-dessus de la fin de l’insertion des ventrales et finit arant l'origine de l'anale; la caudale est carrée, ou très légèrement échancrée.

D. 4 /8 ou 9 ; A. 3 ou $4 / 6$ ou 7 ; C. 19 ; P. $1 / 16$ à 18 ; V. $2 / 8$ ou 9.

Le système de coloration est olivâtre, plus foncé sur le dos, plus clair sur les côtés, blanc jaunàtre ou vert clair sous le ventre; quelques sujets sont d'une couleur dorée très belle avec des taches noires, ainsi la Dorép d'stang de Bloch.

Habitat. La Tanche est répaudue dans la plupart de nos rivières ; elle peut vivre dans les eaux vaseuses et mème dans les eaux saumàtres, étang de Maguelonne.

\section{GEYRE GOEJON. - GOBIO, Cuv.}

Corps plus ou moins allongé et arrondi, couvert d'assez grandes écailles.

Tête grosse; museau arrondi; bouche en dessous; de chaque còté à l'angle de la bouche, un barbillon plus ou noins développé.

Appareil branchial; dents pharyngiennes coniques ou légèrement crochues, placées de chaque còté sur deux rangées, au nombre de sept on huit, 3 - 2 ou 3 .

Nageoires; dorsale et anale courtes; caudale fourchue.

\section{LE GOUJON DE RIVIERE. - GOBIO FLUVIATILIS.}

Poiss. France, t. III, p. 386.

N. vulg. : Goiffon ou Goeffon, Lyon; Boffi, Gofi, Gard; Jol, Ilérault (Crespon); Gobi dé ribiëyda, Cette; Tragan (Catal.), PỹrénéesOrientales; Chabroua, Biarritz.

Long. : 0,10 à 0,1 ö quelquefois 0,20 .

La hauteur du tronc est contenue cinq fois à six fois et quart dans la longueur totale, et la longueur de la tête quatre fois et demie à cinq fois; la bouche est protractile; vers la commissure des lères est un barbillon de longueur très variable. Le diamètre de l'veil mesure du quart au cinquième de la longueur de la têle, la moitié ou les deux tiers de l'espace préorbitaire, Les dents pharyngiennes, disposées en deux séries, 
sont généralement de chaque coité au nombre de sept ö-2, parfois il y en a trois à la petite rangée. - La ligne latérale est bien marquée, à peu près droile. Ee., 1. long. 36 à 42 ; l. transv. 9 à 13. - Presque toujours la dorsale commence un peu en avant de l'insertion des ventrales.

D. 2 ou $3 / 7$ ou 8 ; A. 2 ou $3 / 5$ i 7 ; C. 17 à 19 ; P. $1 / 12$ à $16 ;$ V. $2 / 6$ à 8 .

Le dos est d'un brun verdàtre et marqué de six ou sept taches noiritres; au-dessous de la ligne latérale le corps est argenté: le ventre est grisatre; le long des coités se montrent dix à douze taches noires. La dorsale et la caudale sont grisatres avec des points noirâtres; l'anale est pâle, ainsi que les ventrales; les pectorales sont d'un giris rosé.

Habitat. Commun dans la plupart de nos rivières.

\section{Sous-famille des Leucisciniens, Leuciscini.}

Téte de forme variable; pas de barbillons; lèvres molles.

Nageoires; dorsale et anale sans rayon dentelé.

Cette sous-famille se conıpose de huit genres.

a. Ligne latérale incomplète................... b.

๖. Corps ovale.........................................

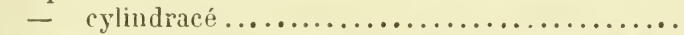

c. Dorsale commencant en arrière de l'insertion des ven-

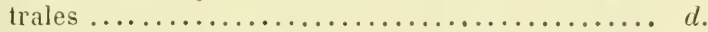

Dorsale commençant all-dessus de l'insertion des ven-

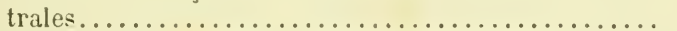

d. Bord de lit carine abdominale, entre les ventrales et l'anus, nu ou sans écailles imbriquécs........... Bord de la carène abdominale, entre les ventrales ot l'anus, garni d'écailles imbriquées..............

ค. Hàchoire supérieure avancée...................

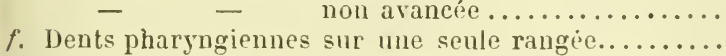
- $\quad$ - sur deux rangées............. g. Dents pharygiennes au nombre de liuit $5-3 \ldots \ldots \ldots$. - $\quad$ six ou sept 4 ou $5-2$.

1. Bouvière .

2. VAIRON. t. e.

5. Rotengle.

3. Brèue.

4. Ablette.

6. Garidos. $g$.

7. IDE.

8. Chevaine.

1. GEXRE BOUVIURE. - RHODEUS, Agass.

Corps ovale, comprimé, couvert de grandes écailles. Tête petite; museau court; màchoire supérieure avancée. 
Appareil branchial; oules bien fendues; dents pharyngiennes comprimées, au nombre de cinq de chaque còté, disposées sur une seule rangée.

Ligne latérale très courte, finissant à la cinquième ou sixième écaille.

Nageoires; dorsale et anale ayant chacune une douzaine de rayons; caudale échancrée.

\section{LA BOUVIERE COMMUNE. - RHODEUS AMARUS.}

Poiss. France, t. III, p. 389.

N. vulg. : Carpe de Vallières, Lorraine; Pelletet, Peultet, HauteBourgogne; Rosière, Picardie; Péteuse, environ de Paris; Piastro, liard.

Long. : 0,06 à 0,08 .

La hauteur du tronc est contenue trois fois à trois fois et demie dans la longueur totale. - La tète est petite, cunéiforme; sa longueur est comprise cinq fois à cinq fois et demie dans la longueur totale; la bouche est peu fendue. Le diamètre de l'œil est contenu trois fois et quart à quatre fois dans la longueur de la tête; il est égal à l'espace préorbitaire; il mesure les deux tiers de l'espace interorbitaire. Les dents pharyngiennes, au nombre de cinq de chaque côté, sur une seule rangée, sont comprimées, légèrement sécuriformes. - La ligne latérale ne semble jamais dépasser la sixième écaille, elle s'arrête parfois à la cinquième. Ec., l. long. 34 à 38 ; 1. transr. 9 à 12. - La dorsale commence au-dessus des ventrales et son huitième rayon correspond généralement à l’origine de l'anale; la caudale est plutôt échancrée que fourchue.

D. $3 / 9$ on $10 ;$ A. $3 / 8$ a 10 ; C. 19 ou 20 ; P. $1 / 10$ ou 11 ; V. $2 / 6$ ou 7.

Le dos est verdàtre ou brunâtre, le ventre argenté; la caudate et l'anale sont grisàtres: l'anale est d'un gris très pâle. A l’époque du frai, le màle est paré d’une brillante livrée; le corps est rosé; une bandelette d'un bleu verdâtre s'étend sur le milieu du troncon de la queue; la lorsale et l'anale ont une teinte rouge orange. Chez la femelle la coloration est toujours moins vive; au moment de la ponte, il se développe, en arrière 
de l'anus, un appendice tubuleux paraissant la continuation de l'oviducte.

Habitat. Ce Poisson, qui est le plus petit de nos Cyprinidés, est assez commun dans la Seine et ses aifluents; il se trouve dans la plupart des cours d'eau de l'Est, du Nord-Ouest, d'une partie du centre de la France, dans les départements du Gard, de l'Hérault.

9. GENRE VAIRON ou VÉRON. - PIIOXINUS, Agass.

Corps allongé, cylindracé, couvert de très petites écailles.

Tête grosse; museau arrondi; bouche terminale.

Appareil branchial; dents pharyngiennes crochues, au nombre, de chaque còté, de six ou sept, placées sur deux rangées, 4 ou 30 - 2.

Ligne latérale incomplète le plus souvent, au moins d'un côté. Nageoires; dorsale et anale courtes; caudale fourchue.

\section{LE VAIRON COMMEX. - HHONINUS LEVIS.}

Puiss. France, t. III, p. 392.

N. vulg. : Véron, Verdon, Arlequin; Gravier, Aube; Erling ou Edingle, Vosges; Lebette, Meilleraie; Sardine, Annecy; Verdelel, Auverone; Loco, Loco-Vernière, Roujhë, Gard; Cippe, Cippa, Bassesl'yrénées.

\section{Long. : 0,07 à 0,10 .}

La hauteur du tronc est contenue quatre fois et demie ì cing fois et trois quarts dans la longueur totale, et la longueur de la tête quatre fois et demie à cinq fois; la màchoire supérieure est un peu plus arancée et plus large que la mandibule. Le diamètre de l'œil mesure le quart environ de la longueur de la tète: il est à peine moindre que l'espace préorbitaire, qui est égal à l'espace interorbitaire. Les dents pharyngiennes sont grèles, crochues; de chaque còté, elles sont au nombre de six ou sept. placées sur deux rangs 4 ou 3 -2. - Généralement la ligne latérale est incomplète, au moins d'un còté; elle finit tantòt avant, tantôt après l’anale. Ec., l. long. 80 à 90 ; l. transv. 28 it 31 . - La dorsale commence en arrière de l'insertion des pectorales, elle est haute en avant; l'anale ressemble ì la dorsale; la caudale est fourchue, bien développée.

$$
\text { D. } 36 \text { ou } 7 ; A .3 / 7 \text { ou } 8 \text {; C. } 19 ; \text { P. } 1 / 14 \text { ou } 15 ; \text { V. } 2 / 6 \text { a } 8 \text {. }
$$


Le système de coloration est des plus variables; en général. le dos est gris bronzé; les flancs sont verdâtres; le ventre est d'un gris blanchâtre: des lignes ou bandelettes noirâtres descendent de la région dorsale vers les flancs: une bande azurée s'étend parfois de la tête à la queue. La dorsale et l'anale sont d'un gris assez clair; la caudale est d'un gris clair avec une large tache noirâtre au milieu de la base et une petite tache brune à la racine de ses rayons supérieurs.

Habitat. Très commun dans le bassin de la Seine; plus ou moins commun dans les petits cours d'eau, les lacs, les étangs.

Varièté. - Le Vairon montagnard. - Phoxinus montanus.

$$
\text { D. } 9 \text {; A. } 8 \text {; C. } 19 \text {; P. } 10 \text {; V. } 7 \text {. }
$$

Suivant Bonnaterre, il a trente-quatre vertèbres et seize còtes.

Habitat. Lozère, Jura. - Aux environs de Briançon, II. le $\mathrm{D}^{\mathrm{r}} \mathrm{R}$. Blanchard a capturé des Vairons à une altitude de 1800 mètres.

\section{GEXrE bR ÈE. - ABRAHIS, Cuv.}

Corps ovale, comprimé, couvert d'assez grandes écailles; carène abdominale, entre l'insertion des ventrales et l'anus, à bord non garni d'écailles imbriquées et pliées en chevron.

Tête ; màchoire supérieure protractile, plus arancée que la mandibule.

Appareil branchial; dents pharyngiennes comprimées, échan. crées ou crochues, placées, de chaque côté, sur une ou deux ranģées.

Ligne latérale bien marquée, à convexité rapprochée du profil inférieur.

Nageoires; dorsale commençant en arrière de l'insertion des ventrales; anale longue; caudale fourchue.

Dents pharyngiemnes sur une seule rangée........... 1. Commune.

- $\quad$ - deux rangées................. 2. Bordeuène.

\section{LA BRÈME COMMUNE. - ABRAMIS BRAHA.}

Poiss. France, t. III, p. 396.

N. vulg. : Brèmo, Idàourado d'aou Rosé, Gard (Crespon).

Long. : $0,2 \partial ̈$ à $0, \ddot{3} 0$. 
La hauteur dutrone est contenue trois fois à trois fois et deux tiers dans la longueur totale; la crête du dos est nue en avant; la carène abdominale, entre l'insertion des ventrales et l'anus, n'a pas le bord garni d'écailles imbriquées. - La longueur de la tête est comprise cinq à six fois dans la longueur totale. Le diamètre de l'cil est contenu quatre fois et demie à cinq fois et demie dans la longueur de la tête; il mesure environ les deux tiers de l'espace préorbitaire, qui est plus petit que l'espace interorbitaire. De chaque côtè, les dents pharyngiennes sont au nombre de cinq, placées sur une seule rangée. Ec., l. long. $ّ 0$ à $\dddot{3} ;$; l transv. 18 à 20 . - La dorsale commence un peu en arrière de l'insertion des ventrales, et finit ordinairement au-dessus des premiers rayons de l'anale, elle est plus haute que longue; l'anale est presque falciforme, elle est d'un tiers environ moins haute que longue.

$$
\text { D. } 3 / 9 \text {; A. } 3 / 24 \text { à } 28 \text {; C. } 19 \text {; P. } 1 / 15 \text { à } 17 \text {; V. ?/8. }
$$

Le dos est brunâtre ou brun verdàtre; le côté gris bleuâtre, le ventre blanc argenté; le tout finement pointillé de noir. Les nageoires sont plus ou moins brunâtres.

Habitat. Ce Poisson est assez commun dans la plupart de nos eaux douces, excepté en Savoie et dans les Alpes-Maritimes.

Variété. - La Brème de Géhin. - Abramis Gehini, Blanch.

Les nageoires impaires sont très développées.

\section{LA BRÈME BORDELIERE. - ABRAMIS BJOERKYA.}

Poiss. France, t. III, p. 398.

N. vulg. : Brème blanche, Brémette, Brème gardonnée, Petite Brème, Harriot, Hazelin; Sans-Nom, Anjou; Brèmo, Brama, Gard.

Long. : $0,1 \ddot{\text { à }} 0,2 \ddot{\text { jo }}$

La hauteur du trone est comprise trois fois et quart à trois fois et quatre cinquièmes dans la longueur totale; la carène, qui s'étend de l'insertion des ventrales à l'anus, n'est pas courerte d'écailles imbriquées. - La longueur de la tête est contenue cinq fois et quart à cinq fois et trois quarts dans la longueur totale. Le diamètre de l'œil est compris trois fois a 
trois fois et demie dans la longueur de la tête; il est plus grand que l'espace préorbitaire, égal, ou peu s'en manque, à l'espace interorbitaire. Les dents pharyngiennes sont, de chaque côté, disposées sur deux rangées $\ddot{\jmath}-2, \ddot{3}-3$, ou $4-2, \breve{b}-2$; il s'en trouve parfois une de plus ou de moins. - Ec., l. long. 43

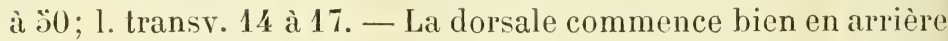
de l'insertion des ventrales; l'anale est presque falciforme, elle prend naissance sous la fin de la dorsale.

D. $3 / 8$; A. $3 / 19$ à 23 ; C. 17 a 19 ; P. $1 / 14$ ou 15 ; V. $2 / 8$.

Ia dos est d'un gris bleuàtre ou verdàtre; les côtés sont d’un gris blanc rosé, légèrement pointillé de noirâtre. La dorsale et la caudale sont pointillées de noir avec une bordure noire; l'anale est noirâtre en avant, blanchâtre en arrière; les nageoires paires sont rougeâtres, teintées de noir.

Habitat. La Bordelière se troure dans la plupart de nos rivières.

Hyвride. - La Brème de Buggenhagen. - Abramis Buggenhagii.

Poiss. France, t. III, p. 400.

N. vulg. : Omblais, Anjou (Soland).

Long. : 0,10 à 0,30 .

Ce Poisson paraît être un hybride de la Brème commune et du frardon commun. - La hauteur du tronc est contenue trois fois et trois quarts à quatre fois et quart dans la longueur totale; en avant, la crète du dos est garnie d'écailles. - La longueur de la tète est comprise quatre fois et demie à cinq fois et demie dans la longueur totale; le front est bombé. Le dianıètre de l'œil est contenu trois fois à trois fois et deux tiers dans la longueur de la tète; il est au moins égal à l'espace préorbitaire, à peine moins grand que l'espace interorbitaire; l'iris est rougeàtre. En général, les dents pharyngiennes sont, de chaque còté, sur une rangée, au nombre de cinq, parfois il y en a six. - Ec., 1. long. 40 à 52; 1. transv. 13 à 17. - La dorsale commence en arrière de l'insertion des ventrales et finit en avant de l'origine de l'anale qui est reculée.

D. 3 ou $4 / 10$; A. $3 / 1$ t a 18 ; C. 19 ; P. $1 / 15$ à 17 ; V. $2 / 7$ ou 8.

Le dos et les nageoires sont d'un gris verdàtre assez foucé; les còtés sont d'un gris argenté ; la tète el le corps sont semés de points brunàtres. 
Habitat. Rare, se pèche dans la Moselle, la Meuse, la Somme, la Loire, la Mayenne, la Sarthe, le lac de Sylins, près de Nantua.

IIrbride. - La Brème-rosse. - Abramis abramo-rutilus, Holand.

Poiss. France, t. III, p. 101.

Long. : $0,13 ̋$ à 0,20 .

Snivant quelques auteurs, la Brème-rosse est un hybride de la Bordelière et du Gardon ou du Rotengle; elle a les mèmes proportions, à peu près, que la Brème de Buggenhagen. La partie antérieure du dos paraît écailleuse et pas ou peu tranchante; la carène abdominale, entre linsertion des ventrales et l'anus, a le bord tantòt nu, tantòt couvert d'écailles imbriquées et pliées en chevron. - Les dents pharyngiennes sont, de chaque còté, au nombre de sept ou huit, placées sur deux rangées 5 - 2 ou ä -3 ; suivant II. Ciünther, il peut n'y avoir qu'une seule rangée de dents. - Valenciennes pense que la Brème-rosse (Holandre) et la Brème de Heckel (Selys-Longchamps) ne sont que des variélés de la Brime de Buggenhagen. - Ec. l. long. 41 à 50 ; l. transv. 13 à 16.

D. $3 / 8$ à $10 ;$ A. $3 / 1$ t́ à $16 ; \mathrm{C} 19 ; \mathrm{P}, 1 / 15$ à $17 ; \mathrm{V}$. $2 /$ i ou 8 .

D'après Holandre, le dos est d'un vert bleudtre; les còtés sont blenàtres, les flancs el le ventre argentés; la dorsale est bleu noiràtre; la caudale et les pectorales sont d'un gris noiràtre; les ventrales et l'anale d'un orangé rougeàtre.

Habitat. Rare, Moselle, Somme, Mayenne.

\section{GENRE ABLETTE. - ALBURNUS.}

Corps plus ou moins allongé et comprimé, garni d'écailles minces; entre l'insertion des ventrales et l'anus, la carène de l'abdomen est tranchante, et n'a pas le bord couvert d'écailles imbriquées.

Tête de forme variable; bouche fendue obliquement; màchoire supérieure moins avancée ou pas plus longue que la mandibule.

Appareil branchial; dents pharyngiennes comprimées, crochues, au nombre do sept de chaque còté, placées sur deux rangées.

Ligne latérale á courbure convexe en bas, rapprochée du profil du ventre.

Nageoires; dorsale courte, commençant en arrière de l'insertion des ventrales; anale généralement assez longue; caidale fourchue.

Deux espèces. 
Ligne latérale ordinaire ....................... 1. Connuse. - placée entre deux séries de points noirs.... 2. spiklix.

\section{L'ABLETTE COMMUNE. - ALBURNUS LUCIDUS.}

Poiss. France, t. III, p. 404 .

N. vulg. : Ovelle, Blanchet, Blanchaille, Ablet, Aublet, Còte-d'Or; Sardine, Mirandelle, lac du Bourget, lac de Genève; Zyeux de verre, Harlipantin, Isère (Charvet); Nablo, Vaucluse; Ravanënco, Gard.

Long. : 0,10 à 0,20 .

Le profil du dos est presque droit, celui du ventre arqué; la hauteur du tronc est contenue cing fois et quart à six fois ef quart dans la longueur totale; et la longueur de la tête cinq fois et demie à six fois et quart; la mâchoire supérieure, moins avancée que l’inférieure, présente en arant une échancrure dans laquelle est recu le tubercule de la symphyse mandibulaire. Le diamètre de l'ceil est compris trois fois à trois fois et demie dans la longueur de la tête; il est ordinairement un peu plus grand que l'espace préorbitaire, et mème que l'espace interorbitaire, chez les sujets de moyenne taille. Les dents pharyngiennes sont minces, finement deritelées sur le bord concave, au nombre de sept de chaque côté, sur deux rangées 5 - 2. Ec., l. long. 48 à $\breve{0}$; l. transv. 11 à 14. - La dorsale commence au-dessus de la moitié postérieure des ventrales; l'anale prend naissance sous la fin de la dorsale; sa longueur et sa hauteur sont à peu près égales.

D. $3 / 7$ ou $8 ;$ A. $3 / 16$ à $20 ;$ C. 19 ou $20 ;$ P. $1 / 15$ ou $16 ;$ V. $2 / 7$ ou 8.

Généralement le dessus de la tête et le dos sont d'un gris verdâtre; les côtés, le ventre el les joues sont d'une teinte argentée. La dorsale est grise, la caudale brunâtre, bordée de noir; l'anale et les nageoires paires sont pâles.

Habitat. LiAblette se trouve dans la plupart de nos rivieres of de nos lacs; elle est très abondante dans la Seine et dans l'Tonne.

L'enduit nacré, tapissant la face interne des écailles, fournit l'essence d'Orient qui sert à la fabrication des fausses perles. 


\section{L'ABLETTE SPIRLIN. - ALBURNUS BIPUNCTATUS.}

Poiss. France, t. III, p. 400.

N. vulg.: Able grise, Concie, hiolte, Sarthe; Rieland, Eure; Eperlan de Seine, Seine; Louvolle, Yonne; Luretle, Aube; Mezaigne, Blanc, Lorraine; Vairon de Saòne, Lignotle, Able bordé, Able rayé, Còte-d'Or ; Mirli, Jura; Solio plato, Vaucluse; Sofio, Gard.

Long. : 0,0 ì $0,1 \%$.

Le profil du dos et celui du ventre sont arqués; la hauteur du tronc est contenue quatre à einq fois dans la longueur totale ; entre les ventrales et l'anus, le bord de la carène abdominale porte, chez certains sujets, quelques écailles pliées en cherron, mais non imbriquées. - La longueur de la tête est comprise cinq fois à cinq fois et demie dans la longueur totale; généralement la mâchoire supérieure est un peu moins avancée que la mandibule. Presque toujours le diamètre de l'cil est un peu plus grand que l'espace préorbitaire, égal à l'espace inetrorbitaire, mesurant, ou peu s'en manque, le tiers de la longueur de la tête. Chaque pharyngien est muni de dents minces, parfois légèrement dentelées sur le bord interne, au nombre de sept, sur deux rangées $\ddot{3}-2$, rarement il y a seulement quatre dents à la grande rangée. - Ec., l. long. 44

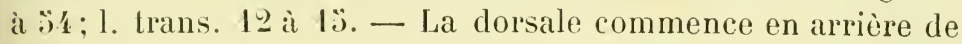
linsertion des rentrales; l'anale a presque toujours moins de hauteur que de longueur.

D. $3 / 7$ ou $8 ; \Lambda .3 / 15$ à 17 ; C. $19 ;$ P. $1 / 12$ a $14 ;$ V. $2 / 7$ ou 8.

Ordinairement le dos est gris rerdìtre; les côtés et le ventre sont argentés; chez certains individus, une bande cuivrée ou brunâtre s'allonge au-dessus de la ligne latérale. La ligne latérale est bordée, sur tout son trajet, d'une double série de petites taches ou de trails noirâtres.

Habitat. Le Spirlin est comniun dans la plupart de nos cours d'eau.

II ybride. - L'Alette hachelle. -- Allurnus dolabratus, Holand.

Poiss. France, t. III, p. 408.

N. vulg. : Hachette, Lorrainr.

Moreav. - Ichthyologie. 
Long. : 0,10 à 0,15 .

Selon nos pêcheur's, écrit Géhin, la Hachette est un métis de l'Ablette, Alburnus lncilus, et de la Vandoise, Squalius leuciscus. Suivant certains auteurs c'est un hybride de l'Ablette et du Chevaine, Squalius cephalus; suivant d'autres, un hybride de l'Ablette et du Rotengle, Scardinius erythrophthalmus. - La hauteur du tronc est contenue cinq fois et quart à six fois dans la longueur totale; le plus souvent la carène abdominale, entre les ventrales et l'anus, a le bord garni d'écailles imbriquées et pliées en chevron. - La longueur de la tète est comprise cing fois à cinq fois et trois quarts dans la longueur totale; les màchoires sont à peu près égales. Le diamètre de l'œil mesure à peu près le tiers de la longueur de la tête; il est égal à l'espace préorbitaire, qui est à peine moins grand que l'espace interorbitaire. D'après Holandre, il y a de chaque cỏté cinq dents crochues, et un peu crénelées le long de leur bord intérieur, sur un seul rang; une seule dent fixe, plus petite, intérieurement; suivant M. Blanchard, les dents sont au nombre de sept sur deux rangées $5-2 .-E c ., 1$. long. 430 à 54 ; l. transv. 11 à 13. - La dorsale commence en arrière de l'insertion des ventrales et finit au-dessus ou plutòt un peu en avant de l'origine de l'anale, qui paraît plus haute que longue.

D. 3,7 à $9 ;$ A. $3 / 9$ à 16 ; C. 19 ; P. $1 / 14$ ou $15 ;$ V. $2 / 8$ ou 9.

Sur le dos, la teinte est d'un gris bleuàtre à reflets métalliques; d'un gris assez clair sur les còtés; d'un gris argenté sous le ventre. La dorsale et la caudale sont d'un gris assez clair; la caudale est brunàtre; les nageoires paires sont pàles.

Habitat. Rare, Moselle et ses affluents.

\section{GENRE ROTENGLE. - SCARDINIUS, Bp.}

Corps ovale, comprimé, couvert de larges écailles; bord de la carène abdominale garni d'écailles imbriquées et pliées en chevron.

Tête; museau obtus; màchoire supérieure moins avancée que l'inférieure.

Appareil branchial; dents pharyngiennes au nombre de huit de chaque còté, placées sur deux rangées $̋$ - 3 , à couronne plus ou moins comprimée, dentelée sur le bord interne, terminée en crochet.

Nageoires; dorsale courte, commençant en arrière de l'insertion des ventrales et finissant au-dessus ou peu en avant de l'origine de l'anale. 


\section{IE ROTENGIE. - SC.IRDINIUS ERYTHROPHTHALMUS.}

Poiss. France, t. III, p. 410.

N. vulg.: Rosse, Rousse, Roche, liossette, Gardon rouge, Cardon de fond; Rousseau, Rossat, Yonne; Chérin, Charin, Còted'Or, Jura; Rotengle, Sarre, Salougne, Lorraine; Platelle, Plate, lac Léman; Sangar, Ciard; Sergent, Landes, Basses-Pyrénées.

Long. : 0,1 ä ì 0,30 .

Chez le Rotengle le profil du dos est beaucoup plus convexe que chez le Gardon; la hauteur du tronc est contenue trois fois à trois fois et deux tiers dans la longueur totale et même quatre fois chez les jemnes. - La longueur de la tête est comprise cinq fois et quart à six fois dans la longueur totale. Le diamètre de l'œil est contenu trois fois et demie à quatre fois et quart dans la longueur de la tête; il est à peu près égal à l'espace préorbitaire, plus petit que l'espace interorbitaire; l“iris est généralement d'un roug̃e vif. De chaque côté, les dents pharyngiennes sont au nombre de huit sur deux rangées $\ddot{3}-3$; parfois à la grande rangée il y a six dents; la couronne est comprimée, très dentelée sur le bord interne, terminée en crochet. - La ligne latérale est courbe, rapprochée du profil inféricur, à l'aplomb des ventrales. Ec., l. long. 10 à $4 \ddot{3}$; l. transr. 11 à 1\%. - La dorsale ne commence guère quaudessus de la moitié postérieure des ventrales.

1). $3 / 8 ;$. . $3 / 10$ à 12 ; C. 18 ou 19 ; P. $1 / 14$ à $16 ; \mathrm{V} .2 / \mathrm{i}$ ou 8 .

Le système de coloration est brun verdàtre sur le dos, plus clair sur les flancs, argenté sous le ventre. La dorsale et la caudale sont grisàtres à la base avee l'extrémité des rayons rougeatres; lanale et les ventrales sont rouges; les pectorales, jaunâtres ou d'un gris rosé.

Habitat. Commun dans la plupart des rivières, des lacs.

\section{GEXRE GIRDOX. - LEUCISCUS.}

Corps ovale, plus ou moins comprimé, couvert d'assez grandes écailles. 
Tète; màchoire supérieure généralement plus avancée que la mandibule.

Appareil branchial; dents pharyngiennes sur une seule rangée, et le plus souvent au nombre de six du côté gauche, de cinq du còté droit.

Nageoires; dorsale conmençant au-dessus de l'insertion des ventrales.

\section{LE GARdON COMMUN. - LEUCISCUS RUTILUS, C. V.}

Poiss. France, t. III, p. 413.

N. vulg. : Gardon blanc, Roche, Rousse, Rossette; Français, Blanchet, Evian.

Long. : 0,15 à 0,30 .

La hauteur du corps est comprise trois fois el trois quarts a quatre fois et deux tiers dans la longueur totale, rarement plus. - La longueur de la tête est contenue cinq fois et quart à cinq fois et trois quarts dans la longueur totale; le museau est arrondi, un peu saillant. Le diamètre de l'œil est compris trois fois et demie à quatre fois et demie dans la longueur de la tète; il est égal, ou peu s'en faut, à l'espace préorbitaire; il mesure les deux tiers environ de l'espace interorbitaire; l'iris est jaune doré, parfois rougeâtre. Les dents pharyngiennes sont placées sur une seule rangée, au nombre généralement de six à gauche, cinq à droile, parfois elles sont au nombre de cinq ou six sur chaque pharyngien, parfois il y en a seulement quatre à droite ou à̀ gauche; la première dent est conique, légèrement crochue à la pointe. - La ligne latérale est courbe, rapprochée du profil inférieur, entre elle et l’insertion de la ventrale, il y a, le plus souvent, trois grandes écailles plus une petite. Ec., l. long. 12 à 43 ; l. transv. 12. - La dorsale commence à peu près au-dessus du milieu de l’insertion des ventrales et finit avant l'origine de l'anale.

D. $3 / 8$ à 10 ; A. $3 / 3$ ì 11 ; C. 18 ou 19 ; P. $1 / 15$ à 18 ; V. $2 / 7$ ou 8 .

Le dos est verdàtre, le ventre argenté. La dorsale et les pectorales sont d'un vert grisâtre; la caudale est verdàtre, teintée de rouge à son extrémité; l’anale et les ventrales sont généra- 
lement d'un rouge jaunâtre. Le système de coloration varie suivant les eaux et surtout suivant la saison.

Habitat. Rivieres, lacs.

Var. a. - Le Vangeron. - Leuciscus prasinus, Agass.

Poiss. France, t. III, p. 413 .

N. vuig. : Français, Evian (Jurine).

La hauteur du corps est contenne cinq fois à cing fois et demie dans la longueur totale. -- Le dos est vert-pomme foncé, le còté vert clair, le ventre argenté; la dorsale et la caudale sont d'un brun verdàtre, l'anale et les nageoires paires sont jaunàtres; d'après Jurine, l'anale, la caudale et les nageoires paires sont toujours d'une couleur jaunatre.

Habitat. Lac Léman.

Var. b. - Le Gardon de Sclys. - Leuciscus Selysii, Ileck.

La hauteur du tronc est comprise quatre fois et demie à cinq fois dans la longueur totale. - La couleur est bleu d'acier à reflets argentés; les ventrales et l'anale sont blanchàtres, les autres nagenires sont grises. D’après Selys-Lonchamps, les nageoires sont d'un rouge moins vif que celles du Lcuciscus rutilus.

Habitat. Meuse.

V.ı. c. - Le Gardon rutilö̈de. - Leuciscus rutiloides, Selys.

Poiss. France, t. III, p. 416.

Les nageoires sont d'une teinte jaune de gomme-gutte terne.

Habitat. Somme, les rivières de l'Anjou.

Var. d. - Le Gardon pâle. - Leuciscus pallens, Blanch.

N. vulg. : Vairon, Annecy.

Les dents pharyngiennes sont en nombre variable, tantòt il y en a six de charque còté, tantòt six d'un còté et cinq de l’autre. - La coloration des nageoires change suivant la saison, tantòt d'un jaune pàle, ou d'un jaune grisàtre, tantòt elle est grisàtre.

Habitat. Très commun dans le lac d'Annecy.

7. GENRE IDE. - IDUS, Heck.

Corps ovale couvert d'écailles de moyenne grandeur.

Tête; màchoire supérieure un peu plus longue que l'inférieure. 
Appareil branchial; dents pharyngiennes au nombre de huit de chaque còté, placées sur deux rangées $\ddot{b}-3$; la première dent de la série interne est à peu près conique à pointe mousse, les suivantes sont légèrement comprimées, terminées par un petit crochet.

Nageoires; dorsale assez courte ainsi que l'anale.

\section{L'IDE JESSE. - IDUS JESES, AUT MELANOTUS.}

Poiss. France, t. III, p. 417.

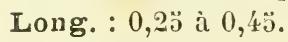

La hauteur du trone fait environ le quarl de la longueur totale. - La longueur de la tète est contenue einq fois à cinq fois et demie dans la longueur totale; le museau est épais, arrondi; l'extrémité de la mâchoire supérieure parait, en général, placée un peu au-dessous du prolongement du diamètre horizontal de l'wil. Le diamètre de l'ouil est compris quatre à cinq fois dans la longueur de la tète; chez les sujets de moyenne taille, il est égal à l'espace préorbitaire, il mesure les trois einquièmes de l'espace interorbitaire. Les dents pharyngiennes sont, de chaque côté, au nombre de huit, sur deux rangées $\tilde{\jmath}-3$; chez les jeunes sujets, les dents de la courte rangée ne sont pas toujours au complet, elles peuvent même manquer. - La ligne latérale déerit une courbe assez faible, à concavité supérieure. Ec., 1. long. 82 à $61 ; 1$. transv. 14 ou 10 $\frac{9}{40 u \unlhd}+1$ - - Généralement la dorsale commenee au-dessus de la fin de l’insertion des rentrales; l'écaille de l'aisselle de la ventrale est bien développée.

$$
\text { D. } 3 / 8 \text { ou } 9 ; \text { A. } 3 / 10 \text { ou } 11 \text {; C. } 19 \text {; P. } 1 / 15 \text { à } 18 ; \text { V. } 2 / 8 \text {. }
$$

Chez les jeunes, la partic supérieure du corps est rouge doré, et les nageoires sont d'un rouge plus ou moins vif. Chez les sujets développés, le dos est d'un brun bleuâtre, le ventre argenté ; la dorsale et la caudale sont d'un rose grisâtre, l'anale et les ventrales, d'un beau rouge avee un peu de jaune vers le bord, les pectorales d'un rose jaunâtree.

Habitat. Rare, la Somme, la Meuse, la Moselle et peut-ètre le Doulss. 


\section{GENRE CHEVAINE. - SQUALIUS.}

Corps, allongé, plus ou moins fusiforme, légèrement comprimé.

Tête de forme variable; màchoire supérieure généralement plus avancée que la mandibule.

Appareil branchial; dents pharyngiennes un peu comprimées, crochues à leur extrémité, ordinairement au nombre de sept de chaque còté, placées sur deux rangées ä-2.

Nageoires; dorsale commencant au-dessus de l'insertion des ventrales.

Le genre Chevaine comprend trois espèces.

a. Bande brune sur les flancs bien dessinée............ nulle................ b.

$b$. Diamètre de l'ceil faisant la moitié de l'espace interor-

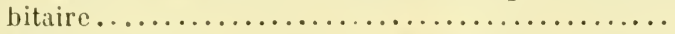

Diametre de l'œil faisant lesdeux tiers de l'espace interorbitaire...............................

1. SOUFIE.

2. commus.

3. VANDUISE.

\section{LE CHEVAINE SOUFIE. - SQUALIUS SOUFFIA.}

Poiss. France, t. III, p. 420, fig. 194, anim.

N. vulg.: Seuffe, Blanc, Còte-d’Or; Sars, lac du Bourget, Aix; Blageon, Annecy; Soufia, Alpes-Maritimes; Soffi, Vaucluse, Dròme, Gard.

Long. : 0,12 à 0,20 .

La hauteur du tronc est contenue quatre fois à cinq fois et demie dans la longueur totale, et la longueur de la tête cinq tois à cinq fois et demie; le museau est court, arrondi. Le diamètre de l'veil mesure le quart environ de la longueur de la tête; il est un peu moins grand que l'espace préorbitaire, qui est égal à l'espace interorbitaire. Les dents pharyngienues sont de chaque côté placées sur deux rangées au nombre de sept ¿̈-2; parfois les rangées ne sont pas complètes et ont une dent en moins soit des deux côtés, soit d'un côté seulement: 1-1,

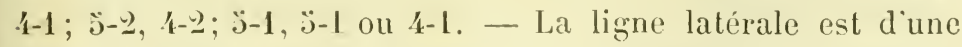
teinte jaunìtre; elle est légèrement courbe. Ec., l. long, 4ว à 36 ; 1. transv. 13 à $1 \%$. - La dorsale commence au-dessus de l'insertion des ventrales.

D. 2 ou $3 / 7$ ou 8 ; A. 2 ou $3 / 8$ ou 9 ; C 18 à 20 ; P. $1 / 13$ ou 1 ; ; V. $2 / 7$ ou 8 . 
Le dos est gris cendré ou violacé, le ventre argenté. Une large bande brunâtre s'étend de l'opercule à la base de la caudale; chez certains sujets, existe une bande jaunâtre, assez peu marquée, commençant un peu au-dessus de la fente branchiale et finissant sur le troncon de la queue. La dorsale et la caudale sont pâles, légèrement teintées de gris; l'anale et les pectorales sont pâles, nuancées de jaune très clair. - Le péritoine est noir.

Habitat. Le Soufie se trouve dans le Var, le Rhòne et ses affluents; il est commun dans le lac du Bourget, le lac d'Annecy; il est très commun dans l'Ouche, à Velars près de Dijon.

\section{LE CHEVAINE COMMUN oU MEUNIER. - SQUALIUS CEPH.ALUS.}

Poiss. France, t. III, p. 422.

N. vulg. : Cabot, Chabot, Chaboisseau, Chavanne, Chevanne, Chevauneau, Chevasson, Juène, Testard ; Cavergne, Somme; Rotisson, Yonne; Vilain, Vilna, Aube; Vilain, Voiron, Franche-Comté ; Rouxy, Toul (Meurthe); Cherenne, Bonneville (Haule-Saroie); Cabès, Arestou, Gard; Cabeda, Nice ; Laiche-à-Tout, Nantua (Ain).

Long. : 0,30 à 0,50 .

La hauteur du tronc est comprise quatre fois et un tiers à cinq fois et quart dans la longueur totale. - La tête est grosse, large en dessus; sa longueur est contenue quatre fois et trois quarts à cinq fois dans la longueur totale; le museau est obtus, arrondi; la bouche est légèrement oblique; l'extrémité de la mâchoire supérieure est sur le prolongement du diamètre horizontal de l'ocil. Le dernier sous-orbitaire est le plus déreloppé; le diamètre de l'ceil est compris cinq fois à cinq fois et demie dans la longueur de la tête; chez les individus de moyenne taille, il mesure un peu plus de la moilié de l'espace préorbitaire, qui est un peu moins grand que l'espace interorbitaire. En général, l'opercule est finement strié; les dents pharyngiennes sont, de chaque côté, au nombre de sept sur deux rangées ว̈-2; elles sont assez longues; quelques-unes d'entre elles portent de pelits tubercules sur leur bord supérieur. - La ligne latérale est séparée de la base de la ven- 
trale par trois écailles, quelquefois par quatre. Ec., l. long. 43 à 18 ; l. transr. 11 à 13. - La dorsale commence au-dessus et en arrière du milieu de l'insertion des ventrales; à l'aisselle de la ventrale est une écaille pointue de moyenne longueur.

$$
\text { D. } 3 / 8 \text {; A. } 3 / 7 \text { ì } 9 \text {; C. } 18 \text { ou } 19 \text {; P. } 1 / 1 \text { i a } 17 \text {; V. } 2 / 8 \text {. }
$$

Le dos est d'un brun verdàtre plus ou moins foncé; le ventre argenté; les côtés sont grisâtres; la ceinture seapulaire est assez souvent marquée d'une bande noiràtre. La dorsale et la caudale sont d'un vert sombre, les pectorales d'un gris verditre; l'anale et les ventrales sont rosées.

Habitat. C'est un des Poissons les plus communs, dans nos eaux douces.

\section{LE CHEVAINE VANDOISE. - SQUALIUS LEUCISCUS.}

Poiss. France, t. III, p. $42 \%$.

N. rulg. : Seuffe, Còte-d'Or; rravelet, Dard, Lorraine; Sorffe, Doubs; Cabolin, Jura; Suiffe, Rhòne; Soiffe, Boururet; Véron à Laffrey, Suiffe, Isère (Charvet); Sofio, Arignon ; Gandoise, Landoise, Gard, Vaucluse; Turgan. Gard; Sofi, Hérault; Aubour, Landes, Basses-Pyrénées; Dard, Aubourne, Saintonge; Accourci, Poitou; Dari, Anjou.

Long. : 0,20 à $0,3 \ddot{3}$.

La hauteur du tronc est comprise quatre fois et quart à cinq fois dans la longueur totale. - Beaucoup plus étroite que celle du Meunier, la tète de la Vandoise a le profil supérieur courbe : sa longueur est contenue quatre fois el trois quarts à cinq fois et demie dans la longueur totale; le museau est en pointe mousse; l'extrémité de la mâchoire supéricure est au-dessous du prolongement du diamètre horizontal de l'œil. Le premier sous-or. bitaire est en général le plus développé; le diamètre de l'oil est compris quatre fois et un tiers à quatre fois et trois quarts dans la longueur de la tète; il est moins griand que l'espace préorbitaire, qui est ordinairement plus petit que l'espace interorbitaire. De chaque coté, il y a sept dents pharyngiennes sur deux rangées $\ddot{3}-2$. - 11 y a quatre ou cinq écailles entre la ligne 
latérale et la base de la ventrale. Ec., l. long. 47 à $34 ; 1$ transv. 12 à 10 . - La dorsale commence au-dessus de l'insertion des ventrales.

$$
\text { D. } 3 / 7 \text {; A. } 3 / 8 \text { ou } 9 \text {; C. } 19 \text {; P. } 1 / 15 \text { à } 17 \text {; V. } 2 / 8 \text { ou } 9 .
$$

Le dos est gris verdàtre lavé de bleu; les flancs sont d'un vert pâle argenté; le ventre est d'un blanc fort éclalant. La dorsale et la caudale sont grisâtres ou d'un gris verdâtre teinté de jaune; l'anale est d'un jaune rosé ; les nageoires paires sont couleur chair.

Habitat. La Vandoise est commune dans la plupart de nos eaux douces; elle parait manquer dans le lac d'Annecy.

VAR. a. - La Vandoise rostrée. - Squalius rostratus, Agass.

Poiss. France, t. 1II, p. 427.

Le museau est allongé, pointu; la nuque est brusquement relevée et fait paraître l'animal plus ou moins bossu; le diamètre de l'œil mesure à peine les deux tiers de l'espace préorbitaire, qui est au moins aussi grand que l'espace interorbitaire.

Habitat. Basses-Pyrénées, Nive, rare.

VAr. b. - La Vandoise de la Gironde. - Leuciscus Burdigalensis, Val.

N. vulg. : Siéjo, Toulouse.

La tète est effilée, le museau poinlu; le diamètre de l'œil mesure les deux tiers de l'espace préorbitaire, qui est presque toujours plus grand que l'espace interorbitaire. La caudale et les pectorales sont ordinairement plus développées que dans la Vandoise commune.

Habitat. Ce Poisson est fort commun dans la Garonne; il est commun dans le département des Landes, dans celui des BassesPyrénées.

\section{Sous-famille des Chondrostominiens, Chondrostomini.}

Corps allongé, garni d'écailles assez grandes.

Tête; museau avancée; bouche en dessous à fente transversale et arquée; màchoires à bord tranchant, couvert d'un étui corné ou cartilagineux.

Appareil branchial; dents pharyngiennes sécuriformes, sans 
dentelures, au nombre de cinq à sept de chaque còté, placées sur une seule rangée.

Nageoires; dorsale et anale courtes; caudale fourchue.

GLNRE CHONDROSTOME. - CHONDRoSTOHA, Agass.

Caractères de la sous-famille.

Deux espèces.

Dents pharyngiennes au nombre de $6 \ldots \ldots \ldots \ldots \ldots \ldots \ldots$ 1. Xase.

de $5 \ldots \ldots \ldots \ldots \ldots \ldots \ldots$........ De Gene.

\section{LE CHONDROSTOME NASE. - CHONDROSTOMA NASUS.}

Poiss. France, t. III, p. 429.

N. vulg. : Nez, Ecrivain; Nulet, Yonne; Aloge, Ame noire, Seuffle grise, Còte-d Or; Ancon, Nase, Chiffe, Hotu, Lorraine; Siège, Hérault.

Long. : 0,20 à 0,40 .

La hauteur du tronc est contenue quatre fois et un tiers à cinq fois et demie dans la longueur totale. - La tète mesure environ le sixième de la longueur totale; la bouche est tout à fait en dessous; les màchoires, ou plutôt les lèvres, ont le bord mince, tranchant, couvert d'un étui corné, qui se détache facilement après la mort de l'animal. Le diamètre de l'œil est compris quatre à cinq fois dans la longueur de la tète; il est moins grand que l'espace préorbitaire qui, lui-mèmeaussi, est moins grand que l'espace interorbitairc. Les dents pharyngiennes sont comprimées, sécuriformes, sans dentelures, sur une seule rangée de chaque côté el généralement au nombre de six, parfois il y a une dent de plus ou de moins sur l'un des pharyngiens. - Ec., 1. long. "̈ł à 62 ; l. transs. 14 à 16 ; la ligne la térale est courbe, rapprochée du profil inférieur vers la base des ventrales. - La dorsale commence au-dessus et presque toujours un peu en arant de l'insertion des ventrales; sa hauteur fait le plus souvent les deux tiers environ de la hauteur du tronc, rarement les trois quarts.

D. $3 / 8$ ou $9 ; A 3 / 9$ à 11 ; C. 19 à $21 ;$ P. $1 / 14$ à $16 ;$ V. $2 / 7$ à 9 . 
Le dos est gris foncé, parfois brunàtre; les côtés sont d'un gris clair; le ventre est argenté. La dorsale est brune; la caudale est ordinairement rougeâtre vers la base, brunâtre sur les bords; l'anale et les nageoires paires sont d'une teinte rougeâtre, passant quelquefois au jaune. - Le péritoine est d'un noir très foncé.

Habitat. Le Chondrostome se trouve dans la plupart de nos cours d'eau du Nord et de l'Est, dans Je bassin de la Seine, le bassin du Rhòne. Il a été signalé daus l'Yonne pour la première fois en 1860. - Étang de Thau.

2. LE CHONIROSTOME DE GENÉ. - CHONdROSTOMA GENEI, CBp.

Poiss. France, Suppl., p. 68.

Long. : 0,14 à 0,30 .

La hauteur du trone est comprise cinq fois et trois quarts à six fois dans la longueur totale, elle est sensiblement égale à la longueur de la tête. Le diamètre de l'œil, qui est à peu près égal à l’espace préorbitaire, est contenu trois fois et demie à quatre fois dans la longueur de la tête. Les dents pharyngiennes sont généralement au nombre de cinq de chaque còté : parfois il s'en trouve six d'un côté et cinq de l'autre. - Ec., 1. long. 92 à 57 ; l. transv. 14 à 16. - Ja dorsale a une hauteur à peine moindre que celle du tronc; elle commence ordinairement très peu en arrière de l'aplomb de l’origine de la ventrale.

$$
\text { D. } 3 / 3 \text { ou } 9 \text {; A. } 3 / 3 \text { à } 10 \text {; C. } 17 \text { ol } 18 \text {; P. } 15 \text { ou } 16 \text {; V. } 2 / 8 \text {. }
$$

La teinte générale est d'un gris assez pâle. La dorsale et la caudale sont d'un gris pâle; les autres nageoires sont d'un jaune très clair.

Habitat. Var.

2. Famille des Cobitidés, Cobitidx.

Corps allongé, couvert de très petites écailles.

Tête nue; bouche en dessous, petite, entourée de six à dix bill- 
billons; maichoires non dentées; bord de la màchoire supérieure formé par les intermaxillaires.

Appareil branchial; fente des ouïes étroite; trois rayous branchiostèges; dents pharyngiennes aiguës, surr une seule rangée de cliaque còté.

Nageoires; dorsale unique, inséréc au-dessus des ventrales.

GENRE LOCIE. - COBITIS, Arted.

Vessie natatoire simple, enfermée dans une capsule osseuse adliérente à la colonne vertébrale. - Ganal intestinal, court, saus appendices pyloriques.

Ce genre comprend trois espèces.

a. Barbillons au nombre de six................ b.
6. Sous-orbitaire épineux....
dix.....................
3. D’ÉTANG .
2. DE RAVIĖliE.
1. FRANCHE.

\section{LA LOCIIE FRANCIIE. -- COBITIS BARBATULA.}

Poiss. France, t. III, p. 432.

N. vulg. : Loche franche, Barbette, Barbolte, Barbotin, Petit Rarbot; Mouteulle, Moutaille, Lorraine; Moulette, Cote-d'Or; Moustache, Saòne-et-Loire; Moutelle, Berling, Saint-Claude (Jura); Dormille, Endormille, Savoie: Dormille fine, Lanceron, Isère; Lochon. Provence; Locho, Loquo-Trenquo, Gard; Loulchia el Loursoua (basque), Balsses-P’yrénées.

Long. : 0,08 ic $0,1: 2$.

La hauteur du trone est contenue six à huit fois dans la longueur lotale, et la longueur de la tète cing fois à cing fois et demie; le museau est mousse; la bouche est entourée de six barbillons. Le diamètre de l'uil est compris eing à sept fois dans la longueur de la tête; il est beaucoup plus petit que l'espace prérbitare; le sous-orbitare n’a pas d'épine faisant saillie à travers la peau. Les dents pharyngiennes sont excessirement fines, crochues, sur une seule ranģée, au nombre de huit à dix de chaque còté. -- La ligne latérale est droile, composée d'écailles plus visibles que les autres. - La caudale est coupée à peu près carrément, ou à peine échancrée; 
les pectorales sont d'un tiers environ plus longues que les ventrales.

D. 3 ou $4 / 6$ ou 7 ; A. $3 / 5$; C. 15 à 17 P. $1 / 10$ à $12 ; \mathrm{V} .1 / 7$ ou 8 .

La coloration est très variable; tantôt le corps est gris jaunâtre, marqué de taches d'un brun très foncé sur le dos et les côtés; tantôt, il est jaune rougeâtre avec des taches nuagueuses; quelquefois les taches brunes sont disposées par rangées écartées, formant des bandes, qui descendent sur les flancs. Les nageoires impaires sont pâles; les nageoires paires sont jaune rougeâtre assez clair.

Habitat. Excepté dans les Alpes-Maritimes, la Loche franche est commune dans nos eaux douces.

\section{LA LOCHE DE RIVIERE. - COBITIS T ENIA.}

Poiss. France, t. III, p. 43'.

N. vulg. : Satouille, Lorraine; Moutelle de rivière, Dormille, Moustache, Petit Barbot, Jura ; Lotza, Haute-Loire; Loque-Tencho, la Tëncho, Gard.

Long. : 0,08 à 0,12 .

Le corps est comprimé, surtout en arrière de la dorsale; sa hauteur est contenue six fois et demie à neuf fois dans la longueur totale, et la longueur de la tête cinq à six fois; la bouche est garnie de six barbillons; la lèvre inférieure est échancrée sur le milieu. Le diamètre de l'œil est compris cinq à six fois dans la longueur de la tête. En arrière et au-dessous de l'orifice postérieur de la narine, est une petite fente que traverse, au gré de l'animal, une épine fourchue, constituant l'extrémité de l'os sous-orbitaire, d'où la dénomination d'aculeata donnée par Rondelet à cette Loche, dénomination qui aurait dû être conservée. Chaque pharyngien est muni de huit à dix petites dents aiguës. - La caudale est à peu près carrée arec les angles arrondis.

D. $3 / 6$ à 8 ; A. $3 / 5$; C. 15 ou $16 ;$ P. $1 /$ i ou 8 ; V. $1 / 5$ ou 6 .

Le dos est gris verdâtre avec des taches noirâtres plus ou moins 
rapprochées; les côtés et le ventre sont grisâtres, pointillés de brun; le long des flanes est une série de douze à dix-huit taches noirâtres. Ordinairement une tache noire existe sur la base des rayons supérieurs de la caudale, qui est, comme la dorsale, marquée de laches foncées en séries plus ou moins régulières; les nageoires paires sont d'un jaune blanchàtre.

Habitat. Cette Loche se trouve dans la plupart de nos rivières.

\section{LA LOCHE D'ETANG oU MISGURNE. - COBITIS FOSSILIS.}

Poiss. France, t. III, p. 436.

N. vulg. : Grande lierliche, environs de Douai; Palmo, Gard.

Long. : 0,15 à 0,25 , quelquefois $0,3 \ddot{\text {. }}$.

Le corps est en forme de prisme très allongé; sa hauteur est contenue sept fois et demie à neuf fois et demie dans la longueur totale, et la longueur de la tête sept à huil fois: la bouche est entourée de dix barbillons; la lèvre inférieure est fortement échancrée dans son milieu, et chacun de ses lobes est divisé en deux appendices formant de petits barbillons. Le diamètre de l'oeil est compris six fois à sept fois et quart dans la longueur de la tête. Chaque pharyngien porte dix à douze petites dents fines et crochues. - Généralement la dorsale est entièrement sur la seconde moitié de la longueur totale ; la caudale est arrondie.

$$
\text { D. } 3 / 5 \text { ou } 6 \text {; A. } 3 / 5 \text {; C. } 14 \text {; P. } 1 / 10 \text {; V. } 1 / 5 \text { ou } 6 .
$$

La région dorsale est d'un brun verdàtre, avec des taches noires; le long des flancs est une large bande noire, elle est ordinairement séparée par une bande jaune, d'une autre bande noiràtre, assez étroite, qui suit le profil inférieur du corps; le ventre est jaunâtre, arec des taches noires plus ou moins nombreuses. La dorsale et la caudale sont marquées de points noirâtres.

Habitat. La Loche d'étang est très rare en France; elle se rencontre dans quelques localités de la Lorraine, aux environs de Toul; elle a été signalée dans le département du Gard par Crespon, dans celui de Maine-et-Loire (étang de Saint-Nicolas) par M. de 
Soland; dans le département du Nord, elle se trouve dans le Marais d'Aubigny; M. Delplanque, directeur du Musée de Douai, a eu l'obligeance de m’en procurer quelques spécimens de cette localité.

\section{Famille des Cyprinodontidés, Cyprinodontidx.}

Corps trapu, couvert de grandes écailles lisses.

Téte écailleuse; museau courl; bouche peu fendue, oblique; màchoire supérieure à bord constitué par les intermaxillaires, munie, ainsi que la mandibule, de dents tricuspides, en série unique.

Appareil branchial; quatre ou cinq rayons branchiostèges; pharyngiens supérieurs et inférieurs garnis de petites dents pointues.

Nageoires; dorsale unique, reculée sur la seconde moitié du corps; anale plus en arrière que la dorsale; caudale arrondie.

Vessie natatoire simple. - Appendices pyloriques manquant; estomac sans cul-de-sac.

GENRE CYPRINODON. - CYPRINODON, Lacép.

Caractères de la famille.

LE GYPRINODON DE CAGLIARI. - CYPRINODON CALARITANLS.

Poiss. France, Suppl., p. 71.

Long. : 0,0 '́ à 0,06 .

La hauteur du tronc est contenue quatre fois et un cinquième à cinq fois dans la longueur totale. - La tête est large, aplatie; sa longueur mesure, ou peu s'en faut, le quart de la longueur totale; la màchoire supérieure est un peu plus avancée que la mandibule, elles ont l'une et l'autre une rangée de dents égales, à couronne tridentée. Le diamètre de l'œil est compris trois fois à trois fois et deux tiers dans la longueur de la tête; il est égal au moins à l'espace préorbitaire, il fait les deux tiers de l'espace interorbitaire. - La ligne latérale n'est pas marquée. Ec., l. long. 26 à 29 ; l. transv. 8 ou 9. La dorsale est à peu près carrée avec les angles arrondis; l'anale est un peu moins développée que la dorsale.

Br. 4 ou 5. -D. 10 à 12 ; A. 10 à 12 ; C. 16 ou 17 ; P. 13 à 16 ; V. 6 a 8. 
Chez les femelles, la moitié supérieure du corps est d'un vert brunâtre et la partie inférieure d'un blanc jaunâtre ou argenté; le long des flancs, il y a neuf à seize bandes verticales noiràtres; la dorsale et l'anale sont grisâtres, les pectorales d'un gris jaunâtre, les ventrales et l'anale pàles. Chez les mâles, la teinte générale est d'un gris jaunâtre ou roussatre; sur les côtés descendent des raies verticales d'un blane jaunâtre, au nombre de huit à dix, quelquefois douze, limitant de larges bandes brunàtres; les nageoires impaires et les ventrales sont d'un jaune citron, les pectorales d'un jaune pâle ; le bord antérieur de la dorsale est liséré de noir.

Habitat. Excessivement rare, Alpes- Maritimes.

La chair des Cyprinodontes, qui empoisonne les petits Mammifères, n’est pas vénéneuse pour la Musaraigne d'eau (Sorex fodiens), quii, d’après Giglioli, détruit ces Poissons, dans les lagunes de Venise.

\section{Famille des Siluridés, Siluridx.}

Corps; peau nue ou garnie de plaques osseuses.

Tête; bord de la màchoire supérieure formé par les intermaxillaires; maxillaire supérieur très réduit; barbillons plus ou moins développés.

Appareil branchial; pas de sous-opercule.

GEYRE SILURE. - SILURUS, LIIn.

Corps allongé, couvert d'une peau complètement nue.

Tête nue, déprimée; maxillaire supérieur rudimentaire, portant un barbillon développé; deux ou quatre barbillons à la mandibule; dents en cardes sur les màchoires et le vomer; palatins non dentés.

Nageoires; dorsale unique, courte, sans rayon osseux, insérée en avant des ventrales; anale très longue unie à la caudale; pectorale armée d'une forte épine dentelée à son extrémité.

Vessie natatoire grande, en rapport avec les osselets de Weber: - Appendices pyloriques minquant.

\section{LE SILURE GLANIS. - SILURUS GLANIS.}

Poiss. Frunce, t. III, p. 439, fig. 19ö, anim.

Long. : 0,80 à 2,00 et plus.

Morext. - Ichthyologie. 
La hauteur du tronc est contenue six à huit fois dans la longueur totale; l'anus est placé entre les rentrales, un peu en arrière de leur insertion. - La longueur de la tête est comprise cinq à six fois dans la longueur totale; le museau est court, arqué; la bouche est largement fendue en travers; la mandibule est plus arancée que la mâchoire supérieure; elles sont munies, l'une et l'autre, d'une large bande de dents en cardes; il y a six barbillons, deux à la mâchoire supérieure, quatre sous la mandibule; les barbillons supérieurs sont excessivement développés, mesurant parfois le quart et plus de la longueur totale. Chez les sujets de grande taille; le diamètre de l'œil ne fait guère que le treizième de la longueur de la tête. - La ligne latérale est rapprochée du dos, et à peu près droite. - La dorsale est courte; l'anale est très longue, elle prend naissance sous le tiers postérieur des rentrales et va s'unir à la caudale; la pectorale est munie d'un rayon osseux bien développé, finement dentelé vers l'extrémité de son bord interne.

Br. 16. - D. 1/4; A. 90 à 92 ; C. 16 à 18 ; P. $1 / 15$ à 17 ; V. 11 à 13.

Le corps est brun verdâtre sur le dos ou plutôt olive, gris jaunâtre sur les flancs avec ou sans taches brunes; l'abdomen est gris blanchâtre, souvent tacheté de brun. Les nageoires sont plus ou moins brunàtres.

Habitat. Le Silure est quelquefois pèché dans le Doubs.

\section{Famille des C'lupéidés, Clupeidæ.}

Corps allongé, couvert d'écailles lisses, généralement caduques ; ventre, excepté chez. l'Anchois, à carène dentelée.

Tête nue, comprimée ; màchuire supérieure, à bord libre formé par les intermaxillaires et les maxillaires, ordinairement composés de trois pièces, et, excepté chez l'Anchois, plus courte que la mandibule.

Appareil branchial ; fente des oües très longue; appendices lamelliformes des arcs branchiaux fort développés; pseudobranchies.

Nageoires; dorsale unique, opposée aux rentrales; caudale fourchue. 
Vessie natatoire allongée, communiquant avec le tube digestif. - Appendices pyloriques nombreux; estomac en forme de sac coniulue.

Cette famille se compose de six genres.

a. Carène du ventre dentelée................ b.
6. Vomer denté.....

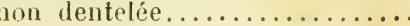
6. Anchois.
1. Hareng.

Dorsale commenca

la base de la caudale......................

Dorsale commençant plus près du museau que de

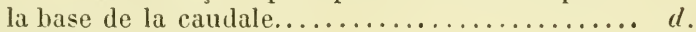

d. Opercule non strié....................

2. Melette.

5. Alose.

3. Harengule.

e. Bord antérieur de la ceinture scapulaire courbe...

4. Sardinelle.

1. GENRE IIARENG. - CLUPEA, Cuv.

Corps comprimé, à carène abdominale dentelée.

Tête; màchoire inférieure plus longue; dents sur le vomer, la langue, et en général sur les màchoires, les palatins.

Nageoires; dorsale commencant un peu avant les ventrales.

Deux espèces.

Opercule non strié.................... 1. Comnun.

- strié...................... de la MER Noire.

\section{LE HARENG COMMUN. - CLUPEA HARENGUS.}

Poiss. France, t. III, p. 443 .

Long. : 0,20 à 0,30 .

La liauteur du tronc est comprise quatre fois et trois quarts à six fois dans la longueur totale, et la longueur de la tête cinq fois à cinq fois et demie; la màchoire supérieure est moins avancée que la mandibule, elle est légèrement échancrée; les dents sont très petites, s'arrachent assez facilement, peuvent même complètement manquer; le maxillaire supérieur se porte en arrière jusque sous le milieu de l'orbite. Le diamètre de l'œil est contenu trois fois et deux tiers à quatre fois et quart dans la longueur de la tète, il est à peu près égal à l'espace préorbitaire, un peu plus grand que l'espace interorbitaire. 
L'opercule n'est pas strié; son bord postérieur n'est pas échancré ; son bord inférieur est très oblique. - Ec., l. long. 53 à $\check{9} 9$. — La dorsale est reculée; elle est sur le commencement de la seconde moitié de la longueur totale, caudale non comprise; ses premiers rayons sont insérés un peu plus en avant que la base des ventrales.

$$
\text { Br. } 8 .- \text { D. } 18 \text { ou } 19 \text {; A. } 17 \text { à } 19 \text {; C. } 17 \text { a } 19 \text {; P. } 17 \text {; V. } 9 .
$$

Le dos est vert bleuâtre; les flancs sont argentés.

Habitat. Mer du Nord, très commun; les jeunes sont apportés en grande abondance sur le marché de Dunkerque pendant les mois d'aoùt, septembre. Manche, très commun au large pendant l'automne et l'hiver. Océan, assez commun sur la còte de Bretagne; il ne dépasse guère l'embouchure de la Loire; cependant il est pris de temps à autre à Noirmoutier, à l'île de Ré, et mème dans le golfe de Gascogne, Arcachon. - Au Havre, le frai est appelé GEillet; c'est le Whitebait des Anglais, la Rogénie blanche, Rogenia alba, C. V.

2. LE HARENG DE LA MER NOIRE. - CLUPEA PONTICA, Eichw.

Poiss. France, Suppl., p. 7̈.

Long. : 0,20 à 0,30 .

La hauteur du tronc est comprise quatre fois et trois quarts á cinq fois et demie dans la longueur totale, et la longueur de la tête quatre fois et quart à quatre fois et trois quarts; la mâchoire supérieure est échancrée dans sa partie médiane ; l'extrémité du maxillaire supérieur arrive à peu près sous le bord postérieur de l'orbite; il y a des dents sur les mâchoires, le vomer, les palatins, la langue. Le diamètre de l'œil mesure environ le cinquième de la longueur de la tête; il est un peu moindre que l'espace préorbitaire, et même que l'espace interorbitaire, chez les grands spécimens. L'opercule est sillonné de stries prononcées, qui sont dirigées d'avant en arrière et de haut en bas. - La dorsale] commence en général un peu plus près du bout du museau que de la base de la caudale.

D. 15 à 17 ; A. 20 ou 21 ; C. 20 ; P. 15 ; V. 9.

La teinte générale est à peu près celle du Hareng commun. 
Ordinairement une tache noire marque l'épaule, vis-à-vis de l'angle supérieur de la fente branchiale.

Habitat. Méditerranée, excessivement rare, Cette, étang de Thau,

\section{GENRE MELETTE. - MELETTA, Valenc.}

Corps peu développé, couvert d'écailles caduques.

Tête; màchoire supérieure plus courte que la mandibule, légèrement échancrée dans son milieu; vomer non denté; langue lentée; quelquefois de petites dents, ou plutòt des rugosités, sur les maxillaires, les palatins.

Appareil branchial; sous-opercule plus long que haut.

Nageoires; dorsale commençant au-dessus ou en arrière de la base des rentrales, sur la seconde moitié de la longueur totale, caudale non comprise; la caudale est fourchue.

Deux espèces.

Sous-opercule environ deux fois moins haut que long.. 1. PHalérique.

- trois fois moins haut que long... 2. commuxe.

\section{IA MELETTE PHALERIQUE. - MELETTA PHALERICA.}

Poiss. France, t. III, p. 445 .

N. vulg. : Meleta, Nice; Meletta, Cette.

Long. : 0,09 à 0,12 .

La hauteur du tronc est contenue cing fois et un tiers à cinq fois et trois quarts clans la longueur totale; la carène du ventre, a dentelures fort saillantes, est formée d'une trentaine de boucliers. - La longueur de la tête mesure environ le cinquième de la longueur totale; la région frontale est transparente; le maxillaire supérieur est bien développé, il atteint au moins au bord antérieur de l'orbite. Le diamètre de l'œil est compris trois fois et quart à quatre fois dans la longueur de la tête; il est sensiblement égal à l'espace préorbitaire. L'opercule porte sur le bord postérieur une échancrure assez profonde; le sousopercule est allongé, environ deux fois plus long que haut. la ligne latéraje est difficile à voir. - La dorsale commence sur la seconde moitié de la longueur totale, caudale non comprise, au-dessus ou à peine en arrière de l’insertion des ven- 
trales. L'anale est basse, elle est séparée de la caudale par un espace aỵant en général une longueur moindre que la hauteur du troncon de la queue. Les rentrales sont fort petites.

$$
\text { Br. 7. -D. } 16 \text { à } 18 \text {; A. } 18 \text { à } 21 \text {; C. } 16 \text {; P. } 14 \text {; V. } 8 \text {. }
$$

Le dos est bleu ardoisé, le côté gris argenté. Le bout du museau, ainsi que celui de la mandibule, est noirâtre.

Habitat. Ce Poisson est assez commun dans la Méditerranée, Nice, Toulon, Cette.

\section{LA MELETTE COMMUNE oU ESPROT. - MELETTA VULGARIS SIVE SPRATTUS.}

Poiss. France, t. III, p. 447.

N. vulg. : Esprot, Melet, Harenguet, OEillet, còtes de la Manche. Long. : 0,08 à 0,12 et mème 0.16 .

Chez l'Esprot, la hauteur du tronc, généralement plus grande que chez la Melette de la Méditerranée, est comprise quatre fois et demie à cinq fois et quart dans la longueur totale; la carène du ventre est formée de trente à trente-trois boucliers. - La longueur de la tête mesure le cinquième environ de la longueur totale; le diamètre de l'œil est compris trois fois et demie à trois fois et trois quarts dans la longueur de la tête; le bord postérieur de l'opercule est plus droit, moins échancré que chez la Melette de la Méditerranée; le sous-opercule a deux fois et trois quarts à trois fois plus de longueur que de hauteur. - La dorsale commence au-dessus ou un peu en arrière de lïnsertion des ventrales.

Br. 6 ou 7. -D. 16 à 18 ; A. 18 à 20 ; C. 17 à 19 ; P. 14 ou 15 ; V. i.

Le dos est d'un bleu verdâtre très clair; les flancs sont argentés.

Habitat. Manche, commun. Océan, assez commun jusqu'à l'embouchure de la Loire ; assez rare, còtes de Vendée, Charente-Inférieure; excessivement rare au-dessous de la Gironde.

Assurément la Melette de la Méditerranée et la Melette commune ont entre elles la plus grande ressemblance, mais sont-elles réelle- 
ment identiques? Pour démontrer leur identité quelques naturalistes s'appuient sur l'accident auquel sont exposées ces Melettes, qui ont l'œil attaqué par un parasite, une Lernée ; cette Lernée d’ailleurs est-elle bien différente de celle qui se fixe à l'wil de la Sardine? Il ne m'appartient pas de juger cette question. - Fait très curieux et très intéressant, aucune Melette ne parait exister sur les còtes du Portugal; de Brito Capello n’en a pas sigrnalé la présence dans ses catalogues.

\section{GENRE IHAREGULE. - HARENGULA, Valenc.}

Corps peu développé, haut, couvert d'écailles adhérentes.

Tête; dents sur les màchoires, les palatins, la langue et sur les ptérygoïdiens (Valenc.), pas sur le vomer.

Nageoires; dorsale commençant sur la moitié antérieure du corps; bord antérieur de la ceinture scapulaire courbe.

\section{LA HARENGULE BLANQUETTE. - HARENGULA LATULUS, Valenc.}

Poiss. France, t. III, p. 449.

N. vulg. : Blanquette, Menise, Menuise, Normandie.

Long. : 0,07 à 0,10 .

La hauteur du trone est contenue quatre fois à quatre fois et demie dans la longueur totale ; la carène du ventre est garnie de dentelures plus développées que dans le Hareng et surtout que dans l'Esprot. - La longueur de la tète mesure, ou peu s'en manque, le quart de la longueur totale; les maxillaires supérieurs sont larges, ils ont quelques dents très faibles; les intermaxillaires, les palatins, les ptérygoüdiens, la langue portent de petites dents; le romer est lisse. Le diamètre de l'œil est compris trois fois à trois fois el demie dans la longueur totale. L'opercule est entamé, sur le bord postérieur, d'une échancrure assez profonde. - La ligne latérale est à peu près droite. Ec., l. long. 13; 1. transv. 13 à 17. - La dorsale commence un peu après le tiers antérieur de la longueur lotale, en avant de l'insertion des rentrales. 
Le dos est d'un verdâtre très clair, le ventre argenté. Toutes les nageoires sont blanches.

Habitat. Ce Poisson se trouve sur nos còtes de l'Ouest; Manche, assez commun. Océan, moins commun, la Rochelle, Arcachon, Bayonne.

4. GENRE SARDINELLE. - SARDINELLA, Valenc.

Corps allongé, couvert de grandes écailles caduques.

Tête; dents en général sur les palatins, les ptérygoïdiens et la langue, manquant sur les màchoires et le romer.

Nageoires; dorsale commençant plus près du bout du museau que de la racine de la caudale; ventrales insérées sous le milieu de la dorsale. Ceinture scapulaire à bord antérieur vertical.

\section{LA SARDINELLE AURICULEE. - SARDINELLA AURITA.}

Poiss. France, t. III, p. 4300, fig. 197, anim.

N. vulg. : Arenc, Nice; Alléchart, Allacha, Cette.

Long. : 0,15 à 0,30 .

La hauteur du tronc est contenue cinq fois à cınq fois et trois quarts dans la longueur totale, et la longueur de la tête cinq fois environ ; le museau est étroit, l'extrémité du maxillaire supérieur s'étend en arrière un peu au delì du bord antérieur de l'orbite; la langue est un peu noirâtre sur le bord, elle est garnie d'une plaquette de très petites dents; le plus souvent les palatins portent une plaque de dents très fines se continuant sur les ptérygoïdiens; ils en manquent parfois chez les sujets de grande taille. Le diamètre de l'œil mesure le quart environ de la longueur de la tête, il est à peine moins grand que l'espace préorbitaire, il est égal au moins à l'espace interorbitaire; la paupière adipeuse est très développée. Les parois de la chambre branchiale sont noirâtres, au moins chez les sujets d'une certaine taille. - La ligne latérale est peu distincte. Ec., l. long. 40 à 32 ; 1. transv. 10 à 12. - La dorsale est assez arancée, commençant vers la fin du tiers antérieur de la longueur totale.

Br. 6. - D. 20 ou 21 ; A. 15 ou 16 ; C. 21 ; P. 16 ; V. 9. 
Le dos est bleuâtre; les llanes sont argentés; une petite tache noire, plus ou moins marquée, se trouve à l'échancrure de l'opercule. La dorsale est brunàtre; la caudale est d'un gris rayé de noir ; l'anale et les nagreoires paires sont blancliàtres.

Habitat. Méditerranée, assez rare, Nice, Cetle.

\section{ร. GeNre Alose. - $A$ LOSA, Cuv.}

Corps plus ou moins allongé, comprimé, écailles cadıques.

Téte; pas de dents sur la langue, le romer, les palatins.

Appareil branchial ; opercule marqué de stries divergentes.

Nageoires; dorsale commencant au-dessus ou en avant des ventrales, sur la première moitié de la longueur totale, caudale non comprise.

Ce genre est représenté par trois espèces.

a. Boucliers de la carène du ventre au nombre de 37 et plus, à épine fort saillante...................

Boucliers de la carène du ventre au nombre de 30 environ. 3. SArdine. ८. Appendices lamelliformes du $1^{\mathrm{er}}$ arc branchial au nombre de moins de $50 \ldots \ldots \ldots \ldots \ldots \ldots \ldots \ldots \ldots \ldots \ldots \ldots \ldots \ldots \ldots \ldots \ldots$

Appendices lamelliformes du $1^{\mathrm{er}}$ arc branchial au nombre de plus de $50 . \ldots \ldots \ldots \ldots \ldots \ldots \ldots \ldots . . . \ldots$.

2. FEINTE.

1. CoMnL:Ne.

\section{LALOSE COMMUNE. - ILOSA VULGARIS.}

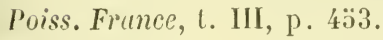

N. vulg. : Poisson de mai, Lorraine ; Lacia, Nice ; Alàouso, Gard; Alaousa, Laousa, Hérault; Coulacqua (basque), Basses-Pyrénées ; Gutte, Mlouse, Vienne; quelquefois Sabre, Loire-Inférieure.

Long. : 0,30 ì 0,70 , et plus.

Le corps est comprimé; sa hauteur est contenue quatre à cinq fois dans la longueur totale; la carène du ventre, forte. ment dentelée, est composée de 37 à 12 boucliers, dont 10 à 17 en arrière de l'insertion des ventrales. - La longueur de la tête est comprise environ cinq fois et demie dans la longueur totale; la mâchoire supérieure a dans le milieu une petite échancrure; l'extrémité postérieure du maxillaire supéricur se porte plus loin que le dianètre rertical de l'œeil: les 
mâchoires n’ont que de fort petites dents, qui disparaissent ordinairement chez les sujets adultes. Le diamètre de l'œil est contenu cinq fois et demie environ dans la longueur de la tête; il est d'un cinquième ou d'un tiers plus petit que l'espace préorbitaire, qui est à peu près égal à l'espace interorbitaire. Les appendices lamelliformes, qui garnissent le bord interne de l'arc branchial antérieur, sont plus nombreux que chez la Feinte, il y en a plus de cincquante. - Ec., l. long. 70 à 80. La dorsale commence au-dessus ou à peine en avant de la base des ventrales.

Br. 8.-D. 19 à 21 ; A. 20 a 24 ; C. 19 ou 20 ; P. 15 ou $16 ;$ V. 9 ou 10.

Le dos est d'un vert bleuâtre; les flanes et le ventre sont d'un vert clair argenté. Une tache irrégulière d'un vert très foncé, ou plutôt noirâtre, se montre vers l'épaule ; quelquefois cette tache se partage en deux; elle est souvent suivie, principalement chez les jeunes, de taches plus petites.

Habitat. Au commencement du printemps, l'Alose quitte les eaux saumàtres pour aller frayer dans les eaux douces; elle se trouve sur toutes nos còtes, dans tous nos fleuves.

\section{L'ALOSE FEINTE OU FINTE. - ALOSA FINTA.}

Poiss. France, t. III, p. 4306.

N. vulg. : Catioa, ile de Ré; Jacquine, Vendée; Mouse de Chàtellerault, Vienne (Lemarié).

Long. : 0,30 ì 0,50 .

La Feinte est très semblable à l'Alose. Le nombre des boucliers constituant la carène abdominale est de 38 environ; il y en a $1: 3$ à 17 entre l’insertion des rentrales et l'anale. - Parfois les mâchoires ont des dents très fines. L'extrémité du maxillaine supérieur se porte en arrière à peu près jusque sous le bord postérieur de l'orbite. Le diamètre de l'cil est compris quatre fois et demie à cinq fois et quart dans la longueur de la tête; il est d'un quart on d'un cinquième plus petit que l'espace préorbitaire qui semble toujours plus grand que l'espace interorbitaire. -.- Il y a sur le premier arc branchial de 
trente et un à quarante-trois appendices lamelliformes. - Les ventrales sont petites, elles commencent sous le troisième ou le quatrième rayon de la dorsale.

Br. S. -D. 18 à 21 ; A. 21 à 25 ; C. 19 à 21 ; P. 15 ou 16 ; V. 9.

Le dos est d'un gris bleuâtre plus ou moins foncé; les flancs et le ventre sont argentés. Une grande tache noire s'étale sur l'épaule, elle est suivie de quatre à six taches plus pelites, d'un noir plus ou moins foncé.

Habitat. La Feinte se trouve dans les mèmes eaux que l'Alose ; elle paraît faire sa montée plus tard.

Les màles sont aptes à la reproduction de très bonne heure; ainsi M. P. Vincent m’a donné un jeune spécimen, dont il s'était servi pour des fécondations artificielles et qui mesurait seulement 0,196 de longueur totale.

\section{L'ALOSE SARDINE. - ALOSA SARDINA.}

Poiss. France, t. III, p. $40 \% 8$.

N. vulg. : Célan, Célerin, quelquefois Pilchard, Hareng de Bergues, Picardie, Normandie; Royan, Charente-Inférieure, Gironde Sarda, Sardinyola, Pyrénées-Orientales; Sarda, Celte, AiguesMortes; Sardina, Nice.

Long. : 0,12 à 0,20, quelquefois, 0,2 ว̈.

La hauteur du tronc est contenue cing à six fois dans la longueur totale; les boucliers de la carène du ventre sont dans une gouttière écailleuse, et sont peu saillants, il y en a une trentaine, onze à quatorze entre l'insertion des ventrales et l'anus. - La longueur de la tète est comprise quatre fois et trois quarts à cinq fois et demie dans la longueur totale; la mâchoire supérieure est peu ou pas échancrée. - Le diamètre de l'œil mesure le quart environ de la longueur de la tête; il est à peu près égal à l'espace préorbitaire qui est plus grand que l'espace interorbitaire. - La dorsale commence un peu avant le milieu de la longueur totale, caudale non comprise; les ventrales sont insérées sous la moitié antérieure de la base de la dorsale.

Br. 7. D. 17 ou 18 ; A. 17 à 21 ; C. 18 o: 19 ; P. 1 i a 17 ; V. 6 à 8. 
Le dos est d'un rept olivâtre, arec une bande bleue; les côtés sont blanchàtres.

Habitat. La Sardine se trouve sur toutes nos cótes.

A Nice, d’après Risso, le Poisson à peine né est connu sous le nom de Poutina; quand il a pris quelque accroissement on le nomme Palaia, et Sardina, quand il est adulte, V. Hist. nat., p. 4 3̈3. — Suivant M. Marion, les œufs de la Sardine flottent à la surface. Consulter les intéressants travaux publiés par les Prs Pouchet, Marion sur la pèche et le développement de la Sardine.

\section{GENRE ANCIIOIS. - ENGRAULIS, Cuv.}

Corps allongé, plus ou moins arrondi; ventre sans carène dentelée.

Tête; museau avancé; bouche très fendue; màchoire supérieure débordant l'inférieure; l'une et l'autre généralement dentées.

Appareil branchial; une douzaine de rayons branchiostèges.

\section{L'ANCHOIS VULGAIRE. - ENGRAULIS ENCRASICHOLUS.}

Poiss. France, t. III, p. 460.

N. vulg. : Amplova, Nice; Antchoia, Anchöya, Ladrot (jeune), Cette; Anxova, Pyrénées-Orientales; Goulard, Poitou.

Long. : 0.13 à 0,20 .

Le corps est légèrement conique; sa hauteur est comprise sept à huit fois dans la longueur totale, et la longueur de la tête, quatre fois et demie à cinq fois; le museau est pointu, très proéminent; la fente de la bouche dépasse le bord postérieur de l'orbite; la mâchoire supérieure est beaucoup plus avancée que la mandibule. L'œil n’a pas de paupière adipeuse; son diamètre mesure environ le quart de la longueur de la tìte, il est plus grand que l'espace préorbitaire, qui est à peu près égal à l'espace interorbitaire. - Ec., l. long. environ 30. La dorsale commence vers le milieu de la longueur totale, caudale non comprise, un peu en arrière de l'insertion des ventrales; la caudale porte de chaque côté, près de ses rayons médians, deux grandes écailles oblongues.

Br. 12 ou 13 . - D. 15 à 18 ; A. 16 a $18 ;$ C. 21 ou $22 ;$ P. 15 à $17 ;$ V. i. 
Le dos est verdâtre, le ventre aronenté, quand l'animal vient d'ìtre pèché; peu de temps après, la région supérieure du corps devient d'un bleu plus ou moins foncé.

Habitat. L'Ancliois se trouve sur toutes nos còtes; il est surtout fort commun dans la Méditerranée, où il s'en fait parfois des pèches abusives ; ainsi au mois d'octobre 1890 , il a été pris, dans le canal de Cette, au moment de leur descente de l'étang de Thau ì la mer,

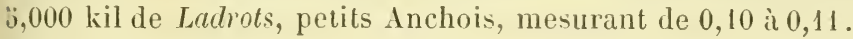

6. Famille des Alèpocéphalidés, Alepocephalidax.

Corps oblong, comprimé, garni d'écailles minces, lisses, peu adhérentes.

Tête nue; bord de la màchoire supérieure formé par les intermaxillaires et les maxillaires; mandibule, intermaxillaires et pala.tins dentés.

Appareil branchial; fente des ouies très longue; six rayons branchiostèges.

Nageoires; dorsale unique, opposée à l'anale, insérée sur le tier's postérieur de la longueur totale; caudale échancrée.

Vessie natatoire nulle. - Appendices pyloriques, une douzaine.

GENRE ALÉPOCÉPHALE. - ALEPOCEPUALUS, Riss.

Caractères de la famille.

LALÉPOCEPHALE A BEG. - ALEPOCEPHALUS ROSTRATUS.

Poiss. France, t. III, p. 463, fig. 198.

N. vulg. : Caussinié, Nice.

Long. : 0,20 à 0,33 .

La hauteur du tronc est contenue cind fois et deux liers it six fois et demie dans la longueur totale, et la longueur de la tèle trois fois el deux tiers environ; la bouche est de moyenne grandeur, sa muqueuse est noiràtre, comme celle de la chambre branchiale; les intermaxillaires, les palatins et la mandibule ont une rangée de dents excessivement fines; les maxillaires supérieurs en sont dépourvus, ainsi que le romer et la 
langue. L'œil est protégé par une paupière circulaire ; son diamètre est compris trois fois à trois fois et trois quarts dans la longueur de la tête; il est plus grand que l'espace préorbitaire, il mesure presque le double de l'espace interorbitaire. - La ligne latérale est droite. Ec., l. long. 30 à 52 ; l. transv. 10̈. La dorsale est très reculée, opposée à l'anale; ces nageoires ont la base écailleuse et les rayons terminés en soies.

$$
\text { Br. 6. - D. } 14 \text { à } 16 \text {; A. } 18 \text {; C. } 19 \text {; P. } 11 ; \mathrm{V}, 7 \text { ou } 8 \text {. }
$$

Le corps est d'un brun violacé; la tête d'un bleu très foncé, presque noir. Les nageoires sont noiràtres. - Le péritoine est noiràtre. - D'après Valenciennes, le rectum est muni d'une valvule en spirale.

Habitat. Méditerranée, rare, Nice.

\section{Famille des Ésocidés, Esocidæ.}

Corps allongé, couvert de petites écailles lisses.

Tête; bouche très fendue; màchoire supérieure plus courte que l'inférieure, à bord formé par les intermaxillaires et les maxillaires; maxillaires non dentés; intermaxillaires garnis de dents pointues, ainsi que les palatins, le vomer et la langue; mandibule armée de dents inégales.

Appareil branchial ; ouverture des ouïes très grande; rayons branchiostèges nombreux; pseudobranchies ganglionnaires.

Nageoires; dorsale unique, reculée vers la partie postérieure du corps, opposée à l'anale; caudale fourchue ou plutòt fortement échancrée.

Vessie natatoire développée, pourvue d'un canal s'ouvrant dans l'œsophage. - Appendices pyloriques manquant.

$$
\text { GENRE ÉSOCE. - ESOX, Cuv }
$$

Caractères de la famille.

LE BROCHET COMMUN. - ESOX LUCIUS, Linn.

Poiss. France, t. III, p. 466.

N. vulg. : Buché, Brouché, Gard ; Pognan, Poitou.

Long. : 0,40 à 0,80 , quelquefois 1,00 et plus. 
La hauteur du tronc est contenue six fois et demie à sept fois dans la longueur totale. - En dessus la tête est nue, large, aplatie; sa longueur mesure le quart environ de la longueur totale; le romer forme en quelque sorte le milieu du museau; lo vomer, les palatins, et souvent les ptérygoïdiens, sont munis de dents acérées plus ou moins fortes; la mandibule est arméc de dents inégales, les unes assez petites, les autres très longues, fort pointues. Le diamètre de l'œil est compris de sept à onze fois dans la longueur de la tète, il ne fait gùere que le tiers de l'espace préorbitaire, les deux tiers de l'espace interorbitaire. Les pharyngiens sont garnis de dents en cardes fines. - La ligne latérale est plus rapprochée du dos que du ventre. Ec., l. long. 120 à $130 ; 1$. transv. 30. La dorsale est opposée à l'anale, et rapprochée de la caudale; les ventrales sont insérées à peu près vers le milieu de la longueur totale.

D. 1 1. - D. 20 a 23 ; A. 1 ส̇ 19 ; C. 19 ; P. 13 ou 14; V. 9 à 11.

La coloration est très variable; le plus souvent le dos est vert foncé ou vert jaunâtre, arec des taches d'un gris jaunàtre; les côtés sont verdâtres; le ventre est argenté. Les nag̣eoires impaires sont rougeâtres, tachetées de vert; les nageoires paires sont rosées.

Habitat. La plupart de nos cours d'eau, de nos étangs.

\section{Famille des Exocétidés, Exoccetidir.}

Gorps allonı́é, couvert d'écailles lisses; de chaque còté du ventre, une carène constituée par une série d'écailles plus relevées, plus adlérentes que les autres, traversées par un canal.

Narines ayant chacune leurs orifices dans une petite fossette triangulaire rapprochée de l'orbite.

Appareil branchial; ouies largement fendues; os pharyngiens inférieurs soudés.

Ligne latérale saillante, suivant le profil du ventre depuis la ceinture scapulaire jusque sur le tronçon de la queue.

Nageoires; dorsale unique, très reculée, opposée à l’anale, suivies parfois, l'une et l'autre, de pinnules. 
Vessie natatoire généralement présente, sans conduit pneumatophore. - Appendices pyloriques manquant; estomac sans cul-de-sac.

Deux sous-familles.

Museau en forme de bec allongé................ 1. BéLoniniens.

- court.............................. 2. ExocÉTINIENS.

\section{Sous-fanille des Béloniniens, Belonini.}

Corps très allongé, couvert d'écailles plus ou moins caduques.

Tête se prolongeant en un bec excessivement grèle; màchoire supérieure plus courte et plus étroite que l'inférieure; en arrière, son bord est, dans une très petite étendue, formé de chaque còté par le maxillaire supérieur qui est soudé à l'intermaxillaire; mandibule terminée par une espèce d'appendice élastique.

Cette sous-famille comprend deux genres.

Pinnules après la dorsale et l'anale manquant........ 1. Orphif.

- $\quad$ - $\quad$ - plusieurs......... 2. SCOnbrésoce.

Nota. - Les très jeunes spécimens n'ont pas les mâchoires allongées; quand ils grandissent, la mandibule prend un accroissement beaucoup plus rapide que la màchoire supérieure; cette différence, dans le mode d'évolution de chacune des moitiés du rostre, explique l'erreur de certains naturalistes qui ont considéré de petites Orphies comme étant des Hémiramphes.

\section{GENRE ORPHIL. - BELONE, CUV.}

Tête aplatie en dessus; màchoires très allongées, garnies de nombreuses dents coniques.

Nageoires; dorsale et anale fort reculées, non suivies de pinnules.

Le genre Orphie est composé de trois espèces.

a. Tronçon de la queue sans crête latérale............ b.

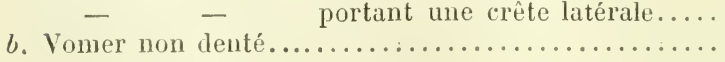
3. IMPÉRIALE.

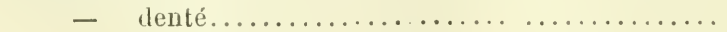
2. AIGULLLE.
1. VUlGaire.

\section{LORPHIE VULGAIRE. - BELONE VULGARIS.}

Poiss: France, t. III, p: 470. 
N. vulg. : Aiguille de mer, Aiguillette, Bécasse ou Bécassine de mer; Agüya, Cette.

Long. : 0,30 it 0,80 , quelquefois plus.

Le corps est ì peu près anguilliforme, légèrement déprimé sur le dos, arrondi sur les còtés, aplati sous le ventre qui est séparé des flanes par une carène très marquée, qui est une réritable ligne latérale; sa hauteur est contenue quatorze à dix-neuf fois dans la longueur totale. - Chez l'adulte, la longueur de la tête est comprise trois fois et demie à quatre fois dans la longueur totale; la mâchoire supérieure est beaucoup moins longue que la mandibule; elle porte une bande étroite de dents coniques fort pointues; la mandibule est munie de dents aiguës plus fortes que celles de la mâchoire supérieure. Le romer a, sur le derant, une plaque garnie de dents coniques. Le diamètre de l'œil est à peu près égal à l'espace interorbitaire. - La dorsale et l'anale sont très reculées; elles ont les rayons antérieurs un peu plus allongés que les autres; l'anale parait un peu plus haute que la dorsale et un peu plus reculée.

Br. 12. - D. 17 à 19 ; A. 21 ou 22 ; C. 15 a 1 ; P. 12 ou 13 ; V. 6.

Le dos est verdàtre; le ventre d'un blanc nacré. La dorsale et la caudale sont d'un gris plus ou moins foncé; les autres nagreoires sont d'un blanc sale.

Habitat. Còtes de l’Ouest, commune. Médilerranée, assez commune.

\section{LORPHIE AIGUHLLE. - BELONE ACUS.}

Poiss. France, t. IIl. p. 4i2.

N. vulg. : Aguglia, Nice; Agüya, Cette.

Long. : 0,40 à 0,70 .

Valenciennes a distingué de l'Orphie rulgaire, l'Orphie aiguille, qui a pour caractère spécifique " de manquer de dents au vomer ". Chez certains individus, cependant il y a parfois quelques petites dents sur le romer, mais elles sont peu visibles. Les màchoires sont munies de dents un peu plus fortes

Moreau. - Ichthyologie. 
que dans l'Orphie vulgaire. - L'anale est de mème hauteur que la dorsale et généralement un peu plus a vancée et plus longue.

Br. 12. - D. 16 à 18 ; A. 20 ou 21; C. 18 ou I9; P. 12 à 15 ; V. 6.

Les proportions et le système de coloration sont à peu près les mêmes que dans l'Orphie vulgaire.

Habitat. Celte espèce est commune dans la Médilerranée, mais n'y est pas confinée; elle n'est pas rare dans le golfe de Gascogne, à Arcachon; je ne l'ai pas vue au nord de la Gironde.

3. L'ORPHIE IMPÉRIALE OU DE CANTRAINE. - BELONE IMPERIALIS.

Poiss. France, t. III, p. 473.

Long. : 0,60 id 1,00 .

La hauteur du tronc est contenue de dix-sept fois à vingtdeux dans la longueur totale. - La longueur de la tête mesure le quart environ de la longueur totale; le bec est relativement assez gros; les mâchoires ont une rangée de dents très aiguës, assez longues, et en dehors une bande de dents courtes et fines. Le diamètre de l'œil fait le dixième de la longueur de la tète; il est d'un quart, à peu près, moins grand que l'espace interorbitaire; il fait le huitjème de l'espace préorbitaire, mesuré de l'orbite à l'extrémité des intermaxillaires. - La dorsale et l'anale sont assez hautes en avant, puis entamées d'une profonde échancrure, après laquelle la dorsale se relève beaucoup plus que l'anale, et vient finir plus en arrière, près de la caudale; le lobe inférieur de la caudale est d'un tiers au moins plus grand que le lobe supérieur; de chaque côté du tronçon de la queue est une crète ou plutôt une carène bien prononcée.

$$
\text { Br. } 14 .- \text { D. } 23 \text {; A. } 24 \text {; C. } 16 \text {; P. } 12 \text {. }
$$

Le dos est bleu foncé à reflets verdâtres, le ventre argenté. La dorsale est noirâtre.

Habitat. Méditerranée, excessivement rare, Nice, Celte. - Le 28 juillet 188\%, deux beaux spécimens ont été pèchés à Cette; le 
plus grand des deux pesilil 1,000 et mesurait près d'un mètre (1),98 environ); l'autre arait quelques centimètres de moins.

\section{GEYRE SCOMBRÉSOCE. - SCOMHRESOX, Lacép.}

Tête fort allongée; michoire supérieure très grèle, plus étroite et plus courte que l'inférieure, portant l'une et l'autre de très petites dents.

Nageoires ; dorsale el anale très reculées, suivies de pinnules.

Deux espèces.

Vessie natatoire développèe $\ldots \ldots \ldots \ldots \ldots \ldots \ldots \ldots$ 1. saunus.

- -

1. LE SCOMBRÉSOCE SAURUS OU CAMPERIEN. - SCOMBRESOX S.IURTS AIT CAMPERI.

Poiss. France, t. III, p. 475, fig, 199.

Long. : 0,20 à $0,3 \ddot{\text { s̆ }}$

La hauteur du tronc est contenue dix à treize fois dans la longueur totale; la carène latérale du ventre finit à l’aplomb de la quatrième ou de la cinquième pinnule anale. -- La longueur de la tète est comprise trois fois et un tiers à trois fois et demie dans la longueur tolale; le bec est extrêmement grêle; dents excessivement petiles. Le diamètre de l'weil est moins grand que l'espace interorbitaire. - Généralement la dorsale commence un peu plus en arrière que l'anale.

Br. 13. - D. 10 à $12+\mathrm{V}$ ou VI; A. 12 ou 13 + VI ou VII C C. 14 à 16 ; P. 12 ou1 $13 ; \mathrm{V} .6$.

Le dos est bleu; les côtés sont argentés. La dorsale, l'anale, les pirnules inférieures et les nageoires paires sont d'un bleu assez clair; la caudale et les pinnules supérieures sont d'un gris bleuâtre. Liaisselle de la pectorale est marquée d'une tache bleu foncé. - La vessie natatoire est allongée, fort développée.

Habitat. Còtes de l’Ouest, excessivement rare, baie de la Somme, Boucau près de Bayonne. Méditerranée? 
2. LE SCOMBRÉSOCE DE RONDELET. - SCOMBRESOX RONDELETII.

Poiss. France, t. III, p. 477.

N. vulg. : Gastodello, Gastaudela, Nice.

Long. : 0,20 à 0,3 ว̈.

Ainsi que j'en ai fait l'observation, il n'existe pas de caractères extérieurs qui permetlent de distinguer le Scombrésoce de Rondelet du Sc. saurus. - Le Scombrésoce de Rondelet manque de vessie natatoire; Valenciennes n'en a pas vu trace dans cinq individus qu'il a ouverts; je n'en ai pas trouvé non plus. - Lütken, d'un autre côté, prétend que les Scombresox de la Méditerranée qu’il a examinés possèdent une vessie natatoire de mème que ceux de l'océan. - Les deux espèces ne peuvent-elles pas se rencontrer dans la Méditerranée? - Il est intéressant de rechercher si la présence ou l'absence de la vessie natatoire dans nos Scombrésoces doit ètre rapportée à une différence spécifique ou à une condition physiologique.

Habitat. Méditerranée, rare, Cette; assez rare, Nice.

\section{Sous-famille des Exocétiniens, Exocœtini.}

Corps allongé.

Tête aplatie en dessus; museau court; bouche petite ; màchoire supérieure moins avancée que la mandibule, à bord formé par les intermaxillaires; dents fort petites sur les màchoires, paraissant quelquefois manquer.

Nageoire; dorsale reculée, opposée à l'anale; pectorales excessivement développées.

Vessie natatoire grande, sans conduit pneumatophore.

GLNRE EXOCET. - ETOCOETUS, Linn.

Caractères de la sous-famille. - Cinq espèces. a. Mandibule avec deux barbillons......

$b$. Ventrales n'atteignant pas à l'anale.. atteignant à l'anale........ $c$.

$c$. Ventrales avec tache noiràtre.........

- sans tache noirâtre....... d.

$d$. Pectorale à 2 rayon bifide........... 2. volant.
-
- simple..........
1. DE RONDELET. 


\section{I.'EXOCET DE RONDELET. - EYOCOETUS RONDELETII.}

Poiss. France, 1. III, p. 479.

Long. : 0,20 à 0,35 .

La hauteur du trone est contenue sept fois à neuf fois et demie dans la longueur totale, et la longueur de la tête six fois à six fois et demie; les mâchoires ont des dents excessivement fines, mais très visibles à la loupe. Le diamètre de l'reil est compris trois fois à trois fois et demic dans la longueur de la tête; il est au moins égal à l'espace préorbitaire; il est d'un quart environ plus petit que l'espace interorbitaire. - La dorsale commence après la perpendiculaire élevée sur le bord postérieur de l'orifice anal, parfois même un peu en arrière de l'origine de l'anale; les pectorales, excessivement développées, atteignent, ou peu s'en manque, à la base de la caudale; leurs premiers rayons ou leurs deux rayons supérieurs sont simples; les ventrales sont longues, elles finissent généralement un peu moins en arrière que les pectorales; la caudale a le lobe inférieur très allongé mesurant le quart ou le cinquième de la longueur totale.

Br. 11 . - D. 10 à $12 ;$ A. 10 à 12 ; C. 16 à 18 ; P. $2 / 15$ ou 16 ; V. 6.

Le dos est brun blanchàtre; le rentre argenté. La dorsale est brunâtre: la caudale est d'un gris brunâtre; l'anale est blanche; les pectorales sont d'un roux assez clair, teintées de bleu ou de brun, souvent elles ont un petit liséré blanc à la pointe de leurs rayons; les ventrales sont brunatres ou noirâtres, excepté vers le bord interne qui est blanchâtre.

Habitat. Méditerranée, assez rare, Cette, Nice.

\section{L'EAOCET VOLANT. - EXOCOETUS VOLITANS.}

Poiss. France, t. III, p. 481.

N. vulg. : Ilirondelle de mer, Ilareng volant; Peix volant, Pyrénées-Orientales; Pëy boulan, Cette; Arendoula, Nice.

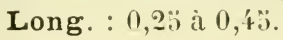


La hauteur du tronc est contenue sept fois à sept fois et demie dans la longueur totale, et la longueur de la tête cinq fois et un quart à cinq fois et trois quarts; le maxillaire supérieur est complètement caché par le sous-orbitaire, quand la bouche est lermée; les dents des màchoires sont excessivement petites, à pointe souvent mousse. Le diamètre de l'œil est compris trois fois à trois fois et quart dans la longueur de la tête, il est plus grand que l'espace préorbitaire, plus petit que l'espace interorbitaire. -- La dorsale commence en avant du plan qui est perpendiculaire à l'anus; la caudale a le lobe inférieur très allongé; les pectorales sont extrêmement développées, elles atteignent, ou peu s'en manque, à la racine de la caudale, elles ont le deuxième rayon supérieur bifide; les rentrales, insérées un peu en arrière du milieu de la longueur totale, sans la caudale, arrivent à l'anale.

Br. 10 ou 11. - D. 1 í à 13 ; A. 9; C. 18 à 20 ; P. $1 / 1$ á à 17 ; V. 6 .

Le dos est d'un gris bleuàtre; le ventre argenté. La dorsale est d'un gris blanchàtre; l'anale blanchâtre ou bleuâtre; la caudale brune; la pectorale est d'un gris plombé avec une bordure blanche à la pointe de ses rayons; la ventrale est d'une teinte bleuâtre très pâle.

Habitat. Manche, excessivement rare. Océan, très rare, CharenteInférieure, la Roche!le. Méditerranée, assez rare, Cetle, Marseille, Nice.

\section{L'EXOCET AUX VENTRALES TACHETÉES. - EYOCOETUS SPILOPUS.}

Poiss. France, t. III, p. 483.

Long. : 0,20 à 0,30 .

La hauteur du corps est contenue six fois et demie à sept fois et demie dans la longueur totale, et la longueur de la tête cinq fois à cinq fois et trois quarts; le maxillaire supérieur n'arrive pas à l'aplomb du bord antérieur de l'orbite; les màchoires sont garnies de dents très fines. Le diamètre de l'œil mesure, ou peu s'en manque, le tiers de la longueur de la tête, 
il est un peu plus grand que l'espace préorbitaire, un peu moins que l'espace interorbitaire. - La dorsale commence bien plus en avant que l'anale qui est assez courte ; la caudale a le lobe inférieur beaucoup plus allongé que le supérieur; les pectorales sont excessivement développées, leur pointe arrive près de la base de la caudale, leur deuxième rayon supérieur est généralement divisé.

$$
\text { D. } 15 \text {; A. } 9 \text { a } 11 \text {; C. } 17 \text {; P. } 1 / 14 \text {; V. } 6 .
$$

En avant la dorsale est blanche, elle est noirâtre en arrière; l'anale est blanchâtre; la caudale a le lobe supérieur grisâtre, l'inférieur brunâtre ; la pectorale est brunâtre, traversée obliquement de dedans en dehors et d'arant en arrière par une large bande d'un gris blanchàtre ou verdàtre; la ventrale est blanchâtre arec une grande tache noirâtre, qui s'étend vers l'extrémité libre de ses rayons internes principalement. Le dos est brunàtre ou bleu foncé; les côtés et le rentre sont d'un blanc argenté.

Habitat. Océan, excessivementrare, Charente-Inférieure, Gironde.

\section{L'EXOCET FUYARI. - EXOCOETUS EVOLANS.}

Poiss. France, t. III, p. 48 '.

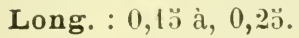

La hauteur du tronc est contenue six à sept fois dans la longueur totale, et la longueur de la tête cinq fois à cinq fois et demie; les dents sont très difficiles à distinguer. Le diamètre de l'œil est compris trois à quatre fois dans la longueur de la tète, il est plus grand que l'espace préorbitaire, plus petit que l'espace interorbitaire. - La dorsale est opposée à l'anale, commençant directement au-dessus de l'origine de l'anale, ou tantôt un peu plus en avant, tantôt un peu plus en arrière; la caudale a son lobe inférieur bien déreloppé; les pectorales sont très longues, leur extrémité atteignant à la base de la caudale; les ventrales sont insérées vers le tiers antérieur de la longueur totale ; elles sont courtes, n'arrivant pas à l'anale. Br. 9 à 11 . - D. 12 à 14 ; A. 13 à 15 ; C. 19 ou 20 ; P. $1 / 14$ ou 15 ; V. 6. 
Le dos est bleuâtre, le rentre blanc argenté. Les nageoires sont d'un bleu assez foncé.

Habitat. Océan, très rare, Morbihan, Vendee, Charente-Iıférieure. Méditerranée, très rare, Toulon, Nice.

\section{I'EXOCET PROGNÉ. - EXOCOETUS PROCNE.}

Poiss. France, t. III, p. 486, fig. 200, anim.

Long. : 0,08 à 0,12 .

La hauteur du tronc est comprise sept fois à sept fois et demie dans la longueur totale, et la longueur de la tète six à sept fois; les mâchoires sont munies de petites dents; à la symphyse de la mandibule sont attachés deux barbillons, ou deux lobes membraneux, plus ou moins noirâtres, frangés sur le bord, assez larges, mais généralement assez courts. Le diamètre de l'œil est contenu deux fois et demie à trois fois dans la longueur de la tête, il est plus grand que l'espace préorbitaire, il est égal, ou peu s'en manque, à l'espace interorbitaire. - La dorsale commence plus en avant que lanale; la caudale est fourchue, son lobe supérieur est plus court que l'inférieur; les pectorales sont bien développées, elles atteignent à la base de la caudale; les ventrales sont longues, elles arrivent parfois, en arrière, un peu plus loin que les pectorales.

$$
\text { D. } 12 \text { à } 14 ; \text { A. } 9 \text { ou } 10 ; \text { C. } 17 \text {; P. } 1 / 13 \text { a } 15 ; \text { V. } 6 \text {. }
$$

Le dos est grisâtre; les côtés et le ventre sont argentés. La dorsale est grisâtre, marquée de noir; l'anale est grisâtre avec du noir à l'extrémité de ses derniers rayons; la caudale est grisâtre, son lobe inférieur est traversé par deux bandes noirâtres; les pectorales sont noirâtres, avec une bande.ou de larges taches d'un gris blanchâtre; les ventrales sont noirâtres, avec une large bande transversale d'un gris blanchâtre; parfois les nageoires paires ont des bandes noires et blanches.

Habitat. Méditerranée, très rare, Nice, Cette.

\section{Famille des Stomiatidess, Stomiatida'.}

Corps allongé, couvert d'écailles minces, non imbriquées, plus ou 
moins caduques; points brillants, en séries, le long de la ligne du ventre.

Téte comprimée ; museau court; bouche larłe, fendue obliquement; bord de la màchoire supérieure formé par les intermaxillaires et les maxillaires; dents inégales, espacées, crochues, très longues, sur les intermaxillaires et la machoire inférieure ; langue, vomer, palatins dentés.

Appareil branchial ; fente des ouïes très grande; sous la gorge un barbillon plus ou moins allongé.

Nageoires; dorsale unique, rapprochée de la caudale, opposée à l'anale ; pectorales étroites; ventrales très reculées.

GENRE STOMIS. - STOHIS, Guv.

Caractères de la famille.

LE STOMIAS BOA. - STOMLAS BOA, Riss.

Poiss. France, t. III, p. 488.

N.vulg. : Anchova ou Anxova, Banyuls-sur-Mer, Pyrénées-Orientales; Vipera de Mar, Nice.

Long. : 0,13 à $0,20 \%$.

La hauteur du tronc est contenue onze à quatorze fois dans la longueur totale, et la longueur de la tète sept fois et demie à huit fois; la mandibule est très développée. relevée en avant de la michoire supérieure; les intermaxillaires ef la mandibule sont armés de longues dents crochues, inégales; les maxillaires supérieurs sont garnis de fines dentelures; sur le derant du vomer existent des dents crochues. Le diamètre de l'œil est compris cing à six fois dans la longueur de la tète; il est généralement un peu moins grand que lespace préorbitaire et que l'espace interorbitaire. La muqueuse de la chambre branchiale est d'un bleu noiràtre; sous la gorge, à l'extrémité de l'os hyoüde est atlaché un barbillon cylindrique, terminé par quelques lilaments, il est fort développé, ayant tantoit plus, tantôt moins de longueur que la lète. - La dorsale et l'anale sont fort reculées, elles finissent à une courte distance de la base de la caudale, qui est fourchue; les ventrales sont insérées vers le commencement du tiers postérieur 
de la longueur totale, elles sont étroites, plus longues que les pectorales, très fragiles.

$$
\text { Br. } 17 \text { - D. } 18 \text {; A. } 18 \text { ou } 19 \text {; C. } 20 \text {; P. } 6 \text {; V. } 5 .
$$

La teinte générale est d'un bleu noirâtre; de la gorge à la caudale, il y a de chaque côté de la ligne du ventre deux séries de points brillants; le barbillon est rosé, à filaments noirâtres. Les nageoires sont blanchâtres; les rayons de la dorsale, de l'anale sont grisâtres.

Habitat. Méditerranée, très rare, Nice, Banyuls-sur-Mer. Océan, solfe de Gascogne, Campagne du Travailleur.

\section{Famille des Scopélidés, Scopelidix.}

Corps de forme variable; peau nue ou couverte d'écailles ordinairement lisses, rarement ciliées.

Appareil branchial; fente des ouïes très grande.

Nageoires; deux dorsales; la seconde fort peu développée.

Vessie natatoire manquant souvent. - Ovaire avec oviducte. Cette famille se divise en quatre sous-familles :

a. $1^{\text {re }}$ dorsale commençant sur la $1^{\text {re }}$ moitié de la longueur totale, ou opposée a l'anale... $b$.

$1^{\text {re }}$ dorsale commençant sur la 2 e moitié de la longueur totale....................

b. Mandibule à dents inégales, quelques-unes fort longues.......................

Nandibule à dents à peu près égales...... c. $c$. Carène du ventre garnie de boucliers....... - salls boucliers...........

4. Paralépidiniens.

1. Chauliodontiniens.

2. Sternoptyginiens.

3. SCOPÉllNiens.

\section{Sous-famille des Chauliodontiniens, Chauliodontini.}

Corps allongé, comprimé ; peau couverte d'écailles minces, caduques, ou paraissant complètement nue.

Tête; bouche largement fendue; màchoires et palatins dentés; mandibule armée de dents espacées, inégales, quelques-unes très longues.

Vessie natatoire nulle.

Cette sous-famille se compose de trois genres.

$a .1^{\text {re }}$ dorsale non opposée à l'anale............ b. 
b. Ventrules au-dessous de la $1^{\text {re }}$ dorsale...........

- très en arrière de la $1^{\text {re }}$ dorsale....... $\therefore$ Omstostons.

1. Chincliode.

1. GENRE CHAULONE. - CHAULIODLS, Schneid.

Corps allongé, comprimé ; couvert d'écailles très ninces, caduques; plusieur's rangées de points brillants le long de la partie infírieure du corps.

Tête courte, haute, comprimée; museau très court; bouche à fente oblique, fort grande: bord de la màchoire supérieure formé par les intermaxillaires et les maxillaires; dents très longues sur les intermaxillaires et la mandibule; maxillaires supérieurs et palatins dentés; langue lisse.

Appareil branchial; rayons branchiostèges nombreux.

Nageoires; première dorsale placée sur la partic antérieure du tronc, en avant des rentrales; seconde dorsale opposée à l'anale; anale reculée, finissant près de la caudale; caudale fourchue.

\section{LE CHAULIODE DE SLOANE. - CHAULIOUUS SLOANI.}

Poiss. France, t. III, p. 492.

N. vulg. : Nasca, Nice.

Long. : $0,1 \ddot{\text { à }} 0,30$.

La hauteur du corps est contenue sept fois et demie à onze fois dans la longueur totale, et la longueur de la tête sept à neuf fois; la bouche est très grande, armée d'une facon redoutable; il y a généralement quatre longues dents sur chacun des intermaxillaires; sur le devant, la mandibule a des dents excessivement développées, et d'autres plus petites en arrière. Le diamètre de l'ieil est compris trois fois et demie à quatre fois dans la longueur de la tête; il est plus grand que l'espace préorbitaire, (qui est égal à l'espace interorbitaire. - La ligne latérale est peu distincte. Ec., I. long. „̋ environ. - La dorsale est insérée sur le quart antérieur de la longueur totale, le premier rayon est sétiforme, très allongé; la seconde dorsale est au-dessus de l'anale, qui finit près de la caudale; la caudale est fourchue, à lobe inférieur plus allongé; les ventrales sont longues, tres fragiles.

Br. 17. -D. 6-?; A. 11 ou 12 ; C. 23 ; P. 14 ; V. 7. 
La teinte générale est noirâtre; il y a de chaque côté, sous le ventre, deux séries de points argentés.

Habitat. Méditerranée, très rare, Nice.

\section{GENRE ODONTOSTOME. - ODONTOSTOMUS, Gocco.}

Corps allongé, comprimé, paraissant complètement nu.

Tête de mème hauteur que le tronc; bord de la màchoire supérieure formé par les intermaxillaires, qui sont garnis de dents courtes, égales ; mandibule, vomer, palatins armés de longues dents mobiles.

Nageoires; première dorsale au-dessus des ventrales; anale très longue; caudale fourchue.

\section{L'ODONTOSTOME BALBO. - ODONTOSTOMUS BALBO.}

Poiss. France, t. III, p. 493̈, fig. 201, anim.

N. vulg. : Maire d'Amplova, Nice.

Long. : $0,13 ̈$ à 0,20 .

La hauteur du trone est contenue six fois à six fois et demie dans la longueur totale, la longueur de la tête, quatre fois et trois quarts a cinq fois; le museau est court; la bouche est très fendue; les intermaxillaires ont les dents fines, courtes, égales ; le vomer a deux longues dents mobiles; les dents palatines sont placées sur une seule rangée; la mandibule porte généralement, de chaque côté, six dents, espacées, inégales; la deuxième est la plus développée. Le diamètre de l'œil mesure le quart environ de la longueur de la tête, il fait le triple de l'espace interorbitaire, il est à peine moins grand que l'espace préorbitaire. - La première dorsale commence sur la première moitié de la longueur totale, elle est placée en avant et au-dessus de l'insertion des ventrales; l'anale est très longue; la base de la caudale est garnie, en dessus comme en dessous, de nombreux petits rayons.

Br. 7 ou 8. - D. 12 à $14-2$ à 5 ; A. 32 à 35 ; C. 19 ; P. 11 ou 12 ; V. 9.

La teinte générale est un gris jaunâtre pointillé de noir. Les nageoires impaires sont grisâtres; les pectorales sont d'un 
gris assez pàle; les ventrales sont pâles. - Le péritoine est d'un noir très foncé.

Habitat. Méditerranée, excessivement rare, Nice.

\section{GENRE GONOSTOME. - Govostoud, Rafin.}

Corps allongé, comprimé, couvert de grandes écailles caduques; points brillants, sur plusieurs rangées, le long de la région inférieure du corps.

Tête comprimée, non écailleuse; bouche très fendue; bord de la màchoire supérieure formé par les intermaxillaires et les maxilliares; màchoires munies d'une série de dents fort inéঞales, de longues, espacées, entre lesquelles s'en trouvent de fort petites; palatins garnis de dents en velours.

Nageoires; première dorsale reculée, au-dessus de l'anale qui est très longue; pectorales insérées vers le bas de la ceinture scapulaire.

\section{LE GONOSTOME NU. - GONOSTOHA DENUDATA.}

Poiss. France, Suppl., p. 79.

Long. : 0,10 à 0,16 et plus. 0,19 .

La hauteur du tronc est comprise de six ì huit fois dans la longueur totale. - La tête est haute; sa Iongueur mesure, ou peu s'en faut, le quart de la longueur totale; la fente de la bouche s'étend jusqu'au préopercule; la màchoire supérieure est fort longue, elle est constituée en grande partie par les maxillaires; les intermaxillaires sont peu développés; les màchoires portent une rangée de longues dents, entre lesquelles il y en a de très petites. Le diamètre de l'ceil ne fait guère que le sixième de la longueur de la tète, il est à peu près égal à l'espace préorbitaire, à peine moins grand que l'espace interorbitaire. - La première dorsale, très reculée, commence dans le mème plan que l'anale, mais finit beaucoup moins loin en arrière; la caudale est fourchue; en dessus, comme en dessous, elle est armée, à la base, de six à sept crochets très aigus.

Br. 13 ou $14 .-$ D. 14 ou $15-;$ A. $30 ;$ C. $92 ;$ P. 10 à $12 ;$ V. 6 ì 8. 
Le dos et le ventre sont d'un blanc teinté de brunâtre, les côtés argentés. Les naģeoires sont pàles. Des points brillants, disposés en séries, se montrent vers le profil inférieur, depuis le bord inférieur de l'interopercule jusqu'à la racine des rayons inférieurs de la caudale.

Habitat. Méditerranée, excessivement rare, Nice.

II. Bellotti, à propos du Gonostoma denulata, écrit (Appunti, p. 131): Anche qui la stessa osservazione come per lo Smaris insidiator C. V. (loc. cit. p. 125): I due esemplari che $i$ fratelli Gal spedirono al Museo di Parigi e al dotl. Moreau, lasciando o facendo credere che fossero provenienti da Nizza, erano invece di Palermo e da me ceduti come tali... ai dettiGal. - M. Bellotti ajoute que divers autres Poissons : Fierasfer dentatus, Scopelus Risso, Maurolicus attenuatus, 11. powerix, I.hthyococcus ovatus... furono da me ceduti ai medesimi (fratel. Gal). Aux explications que je leur ai demandées, MI. Gal m’ont répondu : M. Bellotti nous a vendu, et non dati ne ceduti, les espèces de Poissons dont vous nous parlez; nous avons trouvé sur notre marché le Smaris insidiator très frais; ceux que M. Bellotti nous a vendus étaient en très mauvais état et nous n'avons pu les utiliser. - Par conséquent les spécimens, qui ont été envoyés ả Paris, par MI. Gal, en fort bon état de conservation, ne viennent nullement de Palerme, ainsi que l'affirme M. Bellotti. - MM. Gal ont trouvé à Nice quelques spécimens de Fierasfer dentatus, plusieurs exemplaires de Poro branchus linearis, Kaup ; M. Bellotti a trouvé lui-mème à Nice, en 1888, un très beau $P$. linearis ayant $0^{\mathrm{m}}, 17$ de longueur totale, et, suivant lui, ce $P$. linearis, a cause de sa taille, lui semble plutòt la forme larvaire du $F$. dentatus que le jeune du $F$. acus. - Quant aux autres petits Poissons, Scopelus Risso, etc., ils sont fournis à MM. Gal par les gamins qui vont les chercher dans les corbeilles de Poutina qu'on pèche en abondance à Nice, à l'époque du printemps. - Dans leur lettre du 22 novembre 1891, ММ. Gal me disent : Il y a environ deux mois, en présence de M. l'abbé Vérany, directeur de notre Musée, nos pècheurs nous ont apporté, dans une puisette en bois, avec de l'eau de mer, un très joli Gonostoma denudata vivant, long de $0^{\mathrm{m}}, 19$; i! ne lui manquait pas une écaille. - Ce fait est concluant; je m'abstiens de toute réllexion.

\section{Sous-famille des Stemoptyginiens, Stemoptygini.}

Corps très comprimé, très haut, brusquement rétréci après les ventrales; carène du ventre constituée par des boucliers osseux; 
peau entièrement nue; points brillants sur lat région inférieure du corps.

Tète haule, comprimće; bouche presque verticale; bord de la màchoire supérieure formé par les intermaxillaires et les maxillaires; màchoire inférieure plus avancée que la supérieure, portant l'une et l'autre des dents placées sur une seule rangée; palatins lentés.

Nageoires; première dorsale ayant de sept à neuf rayons ; seconde dorsale à rayons peu distincts: caudale fourchue; pectorales longues; extrémité de la ceinture scapulaire saillante en arant et en bas; ventrales très petites; os pelviens terminés, l'un et l'autre, en pointe libre, dirigée en arrière.

GENRE ARGYROPEIECUS. - ARGTROPELECUS, Cocco.

Caractères de la famille.

\section{L'ARGYROPELEGUS DENI-NU. -- ARGYROPELECLS HEWIGYMNUS.}

Poiss. France, t. III, p. 498.

Long. : 0,03 à $0,0 \ddot{\text { s. }}$

Le tronc proprement dit et la tête forment une espèce de disque mesurant la moitié de la longueur totale, caudale non comprise; le ventre a le bord presque droit, garni d'une carène osseuse composée d'une dizaine d'écussons; le profil inférieur se relève brusquement après l'anus. - La longueur de la tête fait environ le quart de la longueur totale; le museau est très court; la mandibule est presque verticale, elle porte, ainsi que la màchoire supérieure, une série de dents crochues. Le diamètre de l'oil mesure au moins le tiers de la longueur de tète, il est beaucoup plus grand que l'espace préorbitaire, et surtout que l'espace interorbitaire. La muqueuse de la chambre branchiale paraît noirâtre. - Avant la première dorsale existe une série de petites pièces osseuses, qui sont les interépineux, faisant saillie au-dessus de la peau, au nombre de sept ou huit; le dernier est large, finissant par une petite épine; sur le troncon de la queue est la seconde dorsale, très réduite, c'est une espèce de repli de la peau, sans rayons visibles; l'anale 
est bien développée; les pectorales sont longues, dépassant la base des ventrales, qui sont placées au-dessus de l'épine pelvienne.

Br. 9. -D. 7 ou $5-$ ?; A. 11 ou 12 ; C. 20 ou 21 ; P. 9 ou 10 ; V. 5.

Le dos est bleuâtre; les flancs et le ventre sont argentés; sous la partie inféricure du tronçon de la queue se voient des taches ou de petites plaques arg'entées. - Il y a, d'après Valencienne, une vessie natatoire.

Habitat. Méditerranée, Nice, excessivement rare.

\section{Sous-famille des Ścopélimiens, Scopelini.}

Corps plus ou moinsallongé, tantòt nu, tantòt couvert d'écailles. Tête de forme variable; màchoires dentées.

Nageoires ; premier dorsale au-dessus ou en arrière des ventrales.

Cette sous-famille se compose de cinq genres.

a. Points brillants sur le ventre plus ou moins nombreux........................ $b$.

Pas de points brillants sur le ventre.......... $d$.

৮. Bord de la mâchoire supérieure formé par les intermaxillaires seulement................

Bord de la màchoire supérieure formé par les intermaxillaires et les maxillaires........... $c$. Michoire supérieure plus courte que l'inférieure.

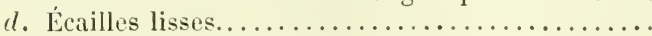

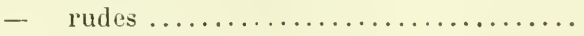

1. SCOPÈLE. $c$.

2. Maurolicus.

3. Ichтно一oceus.

4. SaUhus.

5. Aulope.

1. GEYRE SCOPELE. - SCOPLLUS, Cuv.

Corps plus ou moins allongé, couvert d'écailles lisses; points brillants épars sur les còtés, et rangés en séries vers le profil du ventre.

Tête comprimée; museau court; bouche largement fendue; intermaxillaires très allongés, formant tout le bord de la màchoire supérieure; maxillaires supérieurs longs et grêles ; màchoires garnies de petites dents en velours; palatins, ptérygödiens et langue dentés; vomer lisse ou denté.

Appareil branchial ; fente des ouies très grande; rayons branchiostèges au nombre de lıuit à dix. 
Ligne latérale formée généralement de grandes écailles.

Nageoires ; première dorsale commencant alu-dessus ou en arrière de l'inserlion des ventrales; caudale échancrée ou fourchue.

Le genre Scopèle se compose de dix espèces.

a. Sourcil non épineux.

épineux .............................

b. Diamètre de l'œil faisant au plus le quart de li longueur de la tête......................

Diametre de l'oril faisant plus du quart de la longueur de la tête....................

c. Pectorale atteignant aux premiers rayons de

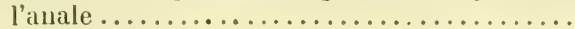

Pectorale n'atteignant pas à l'anus.......... d. $1^{\text {re }}$ dorsale ayant plus de 16 rayons..........

e. Diamètre de l'œil égal, ou peu s'en faut, à l'espace interorbitaire...................

Dianètre de l'œil d'un tiers au moins plus grand que l'espace interorbitaire..........

f. Pectorales plus longues que les ventrales.... - courtes que les ventrales....

g. Pectorales ayant moins de 10 rayous......... - plus de 10 rayons..........

h. Fente de la bouche oblique................

- _ - à peu près horizontale...

i. Hauteur du tronc faisant le $5^{\text {e }}$ de la longueur totale............................

Hauteur du tronc faisant le quart de la longueur totale ........................ $b$.

10. de Bonaparte.

d.

1. CROCODILE.

2. PSEUDOCROCOUILE.

3. DE Cocco.

$g$.

7. De Rafinesque.

6. de Canino.

$h$.

5. de Vérany.

4. de Humboldt.

8. DE BeNolT.

9. DE Risso.

\section{SCOPELE GROCODILE. - SCOPELUS CROCODILŨS.}

Poiss. France, t. III, p. :02, fig. 202, anim.

N. vulg. : Maire d'Amplova, Nice.

Long. : 0,1 ä à 0,2 ว̆.

Le corps est couvert de grandes écailles, très minces, caduques; sa hauteur est contenue cinq fois et quart à six fois dans la longueur totale, el la longueur de la tête quatre fois à quatre fois et un tiers; la màchoire supérieure est un peu inoins avancée que l'inférieure; elles sont munies, l'une et l'autre, de plusieurs rangées de dents très fines; le vomer est denté; la muqueuse de la bouche est d'un violet très foncé, ainsi que celle de la chambre respiratoire. Le diamètre de l'œil est compris quatre fois et trois quarts à cinq fois et demie dans la 
longueur de la tète; il est un peu plus grand que l'espace préorbitaire, qui mesure environ la moitié de l'espace interorbitaire.- - La ligne latérale est presque droite et formée d'écailles beaucoup plus grandes que les autres. Ec., l. long. 32 à 36 ; 1. transv. 8 ou 9. - La première dorsale commence sur la première moitié de la longueur totale, caudale non comprise: l'anale prend naissance à peu près sous le onzième rayon de la première dorsale; la caudale est fourchue, elle est précédée, en dessus comme en dessous, de trois à cinq épines crochues. Les pectorales sont effilées, très longues, leur pointe atteignant aux premiers rayons de l'anale; les rentrales sont longues, elles se portent en arrière à peu près aussi loin que les pectorales.

Br. 9. - D. 13 à $15-4$ ou 5 ; A. 15 ì 18; C. 20 ou $21 ;$ P. $14 ;$ V. 8 ou 9.

La teinte générale est d'un marron assez foncé, glacé d'argent. Une sérje de points brillants se montre de chaque côté du profil du ventre; il y a quelques points brillants épars sur les côtés et sur les joues. La caudale est brune à la base, grisâtre dans le reste de son étendue; les autres nageoires sont grises, marquées d'un pointillé noirâtre.

Habitat. Méditerranée, Nice, assez rare.

\section{SCOPELE PSEUDOCROCODILE: - SCOPELUS PSEUDO. CROCODILUS.}

Poiss. France, Suppl., p. 84.

Long. : 0,10 à $0,13 ̈$.

Le corps est couvert de grandes écailles molles, papyracées; plus ou moins caduques; sa hauteur est comprise cinq fois et demie à six fois et deux tiers dans la longueur totale, et la longueur de la tête quatre l'ois à quatre fois et demie; la màchoire supérieure est aussi avancée, ou à peine moins, que la mandibule; elles sont, l'une et l'autre, munies de petites dents en velours fort nombreuses; ii existe des dents très visibles sur le chevron du vomer; la muqueuse de la bouche, comme celle de la chambre branchiale, est noirâtre. Le diamètre de 
l'reil ne mesure pas tout à fait le quart de la longueur de la tète, il est le double de l'espace préorbitaire, il est moins grand que l'espace interorbitaire. - La ligne latérale est légèrement courbe jusqu'au-dessus de la fin de l'anale, puis se continue directement sur le tronçon de la queue; elle est formée de grandes écailles cordiformes, anguleuses à leur racine, échancrées à leur bord postérieur. Ec., l. long. environ 亿ö. - La première dorsale nait au commencement du second tiers de la longueur totale, au-dessus, ou peu s'en faut, de la base des ventrales, elle est généralement moins haute que longue; sa hauteur est plus grande que celle du tronc; la longueur de sa base est à peu près égale à la longueur de la tête; l'anale commence à peu près vers le milieu de la longueur totale; la caudale est fourchue; elle est précédée en dessus, comme en dessous, d'une série d'épines très acérées au nombre de six à neuf; la pectorale est peu léveloppée, n’atteignant pas à la base de la rentrale, qui est d'un tiers environ plus longue.

D. 19 à 21 -; A. 18 à 21 ; G. 19 ou 20 ; P. 10 à 12 ; Vे. 10 (8, Val.).

Le ton général est marron plus ou moins foncé, teinté de roux: le bord de la caudale est presque noirâtre. Des points brillants sont disposés en séries à la partic inférieure du corps; il en existe encore sur la base de la pectorale, la ceinture scapulaire, l’insertion de la ventrale, les flancs.

Habitat. Méditerranée, Nice, assez rare.

Le 28 octobre 1891, j'ai eu l'honneur de recevoir de M. Cr. Bellotti un Mémoire ayant pour titre: Appunti all' opera del Dott. E. Moreau : Histoire naturelle des Poissons de la France e al relativo supplemento. Hemoria presentata alla Societa Ituliana di Scienze Naturali del Socio Cr. Bellotti, 31 Maggio 1891, Milano. C'est, dit le Dr Bellotti, un travail de révision ayant pour but de rectifier ce qu'il considère comme entaché d'erreur. - Je reconnais à II. Bellotti, comme à tout autre, le droit de criliquer mon travail, d'y relever ce qu'il juge inexact; j'accepte l'entière responsabilité de ce que j’ai écrit, pas autre chose. Mais quand M. Bellotti vient, mal i propos, substituer un nom d'auteur à celui qui est dans mon texte, j'entends ne pas encourir le reproche d'une faute que je n'ai pas commise. Ainsi au lieu de Carcharodon lamia, Bp., M. Bellotli met (Aip. p. 111) Car- 
charodon lamia Risso, ce qui est tout à fait extraordinaire; Risso ne pouvait employer, dans son Histoire naturelle des Poissons de la Méditerranée, etc., le nom de genre Carcharodon, qui n'a été introduit dans la science que longtemps après la publication de son ouvrage. Je suis assez au courant de la littérature ichthyologique pour ne pas faire des confusions aussi étranges.

M. Bellotti (App. p. 130) écrit: Microchirus variegatus Gthr.; faire suivre cette double désignation du nom de Günther est par trop surprenant. Évidemment M. Bellotti n'a jamais vu le travail de l'auteur qu'il cite; le nom de genre Microchirus est de C. Bonaparte, je l'ai rappelé (t. III, p. 313̈), il n'est pas mème indiqué dans la synonymie de Solea variegata, Günth., t. IV, p. 469. -- Puis M. Bellotti reprend: Il capo non e soltunte un terzo, ma da un quinto fino ad un sesto della lunghezza totale; c'est vrai, il y a dans le texte une erreur matérielle, mais cette erreur se trouve corrigée dans le relevé des proportions : long. totale 0,214 ; tète, long. 0,036 . C'est précisément pour qu'il soit facile de contròler, et de réparer les fautes qui peuvent se glisser dans le texte, que je me suis donné la peine de faire ce travail ingrat, le tableau des proportions, sans lequel fort probablement M. Bellotti ne se serait pas apercu de l'erreur. - M. Bellotti a-t-il le droit d'ètre bien sévère, lui qui, à propos de l'anale d'un Paralepis, compte A. 13 (App., 137)?

Carcharias Milberli (App., p. 112-132). La première dorsale nait à l'aplomb de la fin de l'insertion des pectorales. - Questo è il carattere del Carcharias lamia M. H. - Si M. Bellotti avait pris la peine de lire la description du C. Milberti par A. Duméril (Hist. nat. Poiss., t. I, p. 360), faite d'après le spécimen, désigné par Valenciennes sous le nom de $C$. Milberti, il aurait vu dans le texte: Première dorsale commencant immédiatement derrière la base des pectorales. C'est ce mème individu que j'ai étudié et dont j'ai relevé les proportions (V. Suppl., p. 2-7). Est-ce ma faute si le type du Muséum n'est pas conformé suivant les idées de M. Bellotti? D'ailleurs Canestrini n'a-t-il pas écrit : La dorsale anteriore nasce immediatamente dietro la base delle pettorali? - Avant de formuler ses critiques, M. Bellotti aurait dù consulter les travaux des auteurs qui connaissent le sujet.

Genre Pastenague ou Trygon, Suppl., p. 10. A deux reprises différentes, M. Bellotti cite il Trygon partinaca colla coda lunga piu di una volta emezzala lunghezza del disco (App., p. 132); et (App.,p. 114): Nella tavola sinottica delle specie, il carattere dellu coda: faisant plus d'une fois et demie la longueur du disque deve riferirsi al T. Brucoe nonal T. pastinaca. - Cette erreur n'existait pas dans le manuscrit, si je l'affirme ce n'est en aucune façon pour dégager ma responsabilité, il 
y a eu transposition de mots plus à la place de moins et réciproquement, j'aurais dù mieux corriger les épreuves d'imprimerie; d'ailleurs la faute n’existe pas dans le Munuel, p. 79, feuill. 5, imprimée le 18 février 189 !, bien avant l'époque à laquelle M. Bellotti a présenté son Mémoire ulla Società Italiana di Scienze Naturali.

3. IE SCOPELE DE COCCO. - SCOPELUS COCCOI, Cocco.

Poiss. France, Suppl., p. 90.

Long. : 0,0 ' ì 0,06 .

Le profil du dos est légèrement arqué jusqu'à la fin de la première dorsale; la hauteur du tronc mesure à peu près le cinquième de la longueur totale. - La longueur de la tête est contenue quatre fois à quatre fois et demie dans la longueur totale; la bouche est tapissée d'une muqueuse noirâtre; la mâchoire supérieure est un peu plus avancée que l’inférieure; elles ont l'une et l'autre des dents excessivement fines. Le diamètre de l'ail ne fait que le quart ou le cinquième de la longueur de la tête ; il est égal à l'espace préorbitaire ou à peine plus grand; il semble un peu moins grand que l'espace interorbitaire. - La ligne latérale est droite. Ec., l. long. 33 à 41. - La première dorsale commence sur la première partie de la longueur totale, caudale non comprise, elle est placée au-dessus de l'espace qui s'étend de la base des ventrales aux premiers rayons de l'anale; la caudale est très fourchue, assez grêle; les pectorales sont un peu plus développées que les ventrales; leur pointe dépasse l'insertion des ventrales.

$$
\text { D. } 10 \text { à } 12-; 19 \text { à } 21 \text {; C. } 18 \text { à } 20 \text {; P. } 11 \text { ou } 12 \text {; V. } 6 \text { à } 8 \text {. }
$$

La région dorsale est noirâtre; les flancs sont argentés; vers le profil inférieur du corps, il y a de chaque côté une série de points brillants: il en existe d'autres épars sur les flanes.

Habitat. Océan, accidentellement. 
4. LE SGOPELE DE HUMBOLDT. - SCOPELUS HUMBOLDTI.

Poiss. France, t. III, p. :08̈.

N. vulg. : Maire d'Amplova, Nice.

Long. : 0,07 à 0,10 .

Le corps est à peu près cunéiforme; sa hauteur est contenue quatre fois et trois quarts à cinq fois et demie dans la longueur totale, et la longueur de la tête quatre fois et quart environ; le profil antérieur et supérieur de la face est fortement arqué; la fente de la bouche est à peu près horizontale. elle arrive au moins jusqu'à la perpendiculaire tangente au bord antérieur de l'orbite; la mâchoire supérieure est un peu moins arancée que la mandibule: elles sont garnies, l'une et l'autre, de dents très fines. Le diamètre de l'oil mesure au moins le tiers de la longueur de la tête, il fait le double, et plus, de l'espace préorbitaire; il est égal à l'espace interorbitaire. - La ligne latérale va directement de la tête à la base de la caudale; ses écailles sont beaucoup plus hautes que longues. Ec., l. long. 39 à 41 ; l. transv. 7 . - La première dorsale commence au-dessus, ou plus souvent un peu en arrière de l'insertion des ventrales, sur le second tiers de la longueur totale; l'anale prend naissance vers le milieu de la longueur totale; la caudale est précédée de quelques épines; les pectorales sont assez longues.

Br. 9. - D. 12 i 14 -?; A. 17 a 20 ; C. 19 ou 20 ; P. 13 ou 14; V. 8.

La teinte est d'un jaune brunàtre ou gris bleuâtre sur le dos, glacé d'argent sur les flancs et le ventre; une rangée de points brillants, dorés le plus souvent, s'étend, de chaque côté de la ligne du ventre, de la tête à la caudale; d'autres points sont disséminés sur le corps, les opercules. Les nageoires impaires sont brunes, les autres sont pâles.

Habitat. Méditerranée assez rare, Nice, IIyères.

3. LE SCOPÈLE DE VÉRANY. - SCOPELUS VER.INYT.

Poiss. France., Suppl., p. 92.

Long. : 0,10 à 0,12 . 
Le corps a le protil supérieur rectiligne, légèrement incliné de la tète à la caudale; sa hauteur est contenue cinq fois et un tiers à cinq fois et demie dans la longueur totale el la longueur dela tète quatre fois et deux tiers, ou, plus exactement, quatre fois, caudale non comprise; le museau est court, son extrémité se trouve presque sur la ligne prolongée du diamètre horizontal de l'ceil; la mandibule est très ascendante; la fente de la bouche, qui est très oblique, se prolonge en arrière jusque sous le bord postérieur de l'orbite; les mâchoires sont munies de dents très fines, très courtes, placées sur plusieurs rangées; dents sur le vomer el les arcades ptérygo-palatines. Le diamètre de l'ceil mesure presque le tiers de la longueur de la tète; il fait ledouble de l'espace préorbitaire; il est égal à l'espace interorbitaire. Il y a, d'après M. Sarato, dix rayons branchiostèges. - La ligne latérale est formée de grandes écailles dont la hauteur est à peine moindre que la longueur du diamètre de l'œil. Ec., l. long. 40 à 43. - La première dorsale commence au-dessus de la base des ventrales; après ses derniers rayons se trouvent trois ou quatre écailles impaires recouvrant la crête du dos, puis existe un sillon très prononcé, qui se continue jusqu'à l'adipeuse; les bords du sillon sont garnis de chaque còté d'une rangée d'écailles au nombre de cinq ou six ; lanale est longue et basse; les pectorales sont longues, leur extrémité arrive à peu près au milieu de la longueur des rentrales; les ventrales sont, en grande partie, recouvertes par un large bouclier écailleux quand elles sont dans l'adduction ; ce bouclier fait les trois quarts de la longueur de la nageoire.

$$
\text { Br. 10. - D. } 11 \text { ou } 12 \text { - ; A. } 21 \text { ou } 2: \text {; C. } 20 \text { à } 22 ; \text { P. } 11 \text { ou } 12 ; \text { V. } 8 .
$$

La teinte est d'un gris brunâtre ou chocolat sur le dos, glacé d'argent sur les flancs et le ventre; il y a des points brillants, de chaque côté, vers le profil inférieur du corps; d'autres points lumineux se remarquent vers la ceinture scapulaire, la ligne latérale; sous le bord inférieur du tronçon de la queue, un peu avant la base de la. caudale, sont trois écailles dorées, placées entre les points lumineux.

Habitat. Méditerranée, Nice, accidentellement. 
6. LE SCOPÈLE DE CANINO. - SCOPELUS CANINIANUS.

Priss. France, Suppl., p. 96.

Long. : 0,7 à 0,10 .

La hauteur du corps est comprise cinq fois et demie à six fois dans la longueur totale, et la longueur de la tête quatre fois à quatre fois et demie; la fente de la bouche, qui est légèrement oblique, dépasse le bord postérieur de l'orbite; les mâchoires sont garnies de petites dents aiguës, fort courtes. Le diamètre de l'œil est contenu deux fois et quart environ dans la longueur de la tête ; il fait le double de l'espace préorbitaire ; il est au moins aussi grand, el plus même, que l'espace interorbitaire. - La ligne latérale est droite, bien marquée. La première dorsale commence au-dessus, ou à peine en arrière de la base des ventrales; elle est d'un tiers environ plus haute que longue; l'anale a son origne sous le tiers postérieur de la première dorsale; la caudale est fourchue; la pectorale est allongée, sa pointe dépasse généralement la base de la ventrale; la ventrale est large, assez courte.

$$
\text { D. } 13 \text { ou } 1 \text { 't - ; A. } 20 \text {; C. } 20 \text {; P. } 8 \text { ou } 9 \text {; V. } 8 \text { on } 9 .
$$

La tête et le dos sont d'un vert foncé, noiràtre; les côtés paraissent argentés, ou d'un blanc légèrement rougeâtre. De la ceinture scapulaire à la base de la caudale existe, de chaque côté, une série de points brillants ; au-devant de l'anus est une demi-ceinture, allant d'une ligne latérale à l'autre, en passant sous le ventre, et formée, à droite et à gauche, de quatre points lumineux, en comptant ceux de la série longitudinale.

Habitat. Méditerranée, Nice, accidentellement.

7. LE SCOPELE DE RAFINESQUE. - SCOPELUS RAFINESQUII, Cocco.

Poiss. France, Suppl., p. 98.

Long. : 0,7 à 0,10 .

De la ceinture scapulaire à la caudale, le corps ra diminuant d'une façon régulière; sa hauteur est contenue quatre fois à qua- 
tre fois et quart dans la longueur totale. - La tête est très développée; elle fait le tiers antérieur de l’animal, caudale non comprise; son profil antérieur dessine une courbe très prononcée; le museau estcourt; la fente de la bouche se prolonge en arrière jusque vers l'angle du préopercule; quand la bouche est fermée, les màchoires paraissent de même longueur, mais la mâchoire supérieure déborde la mandibule sur les côtés; les màchoires sont garnies de petites dents en velours; il y a des dents jusqu'à l'extrémité postérieure du maxillaire supérieur, qui ne présente pas d'élargissement; la muqueuse de la bouche est noirâtre ainsi que celle de la chambre branchiale. Le diamètre de l'cil est compris deux fois et demie dans la longueur de la tète; il est égal àl'espace interorbitaire; il fait un peu moins du triple de l'espace préorbitaire. - La ligne latérale est droite, formée de grandes écailles, un peu réniformes. Ec., l. long. 32 à 3 ł; l. transv. 引̆ ou 6 ? - La première dorsale commence au-dessus de la base des ventrales ou à peine en arrière, elle est plus haute que longue; l'anale nait sous les derniers rayons de la première dorsale; la caudale est échancrée, sa longueur ne fait pas le sixième de la longueur totale; les pectorales sont assez courtes, leur pointe n'arrivant pas à la base des ventrales qui sont près d'un tiers plus longues que les autres nageoires paires.

$$
\text { D. } 12 \text {-; A. } 11 \text { a } 13 \text {; C. } 20 \text {; P. } 9 \text {; V. } 8 \text {. }
$$

La teinte est d'un brun marron sur le dos; les côtés sont argentés; il y a des points brillants vers le profil inférieur du corps; un point brillant se remarque sous le bord antérieur des sourcils.

Habitat. Méditerranée, Nice, excessivement rare.

\section{LE SCOPĖLE DE BENOIT. - SCOPELUS BENOITI.}

Poiss. France, Suppl., p. 101.

Long. : 0,0 à à 0,06 .

La hauteur du corps mesure le cinquième de la longueur totale, et la longueur de la tête en fait le quart; la fente de la 
bouche est très oblique; les mâchoires sont garnies de dents en velours, légèrement crochues; il y a des dents jusqu'à l'extrémité postérieure du maxillaire supérieur, qui est triangulaire, sensiblement élargie, arrivant à peine à l'aplomb du bord postérieur de l'orbite. Le diamètre de l'œil est compris deux fois et un tiers environ dans la longueur de la tête; il fait le double de l'espace préorbitaire, qui est à peu près égal à l'espace interorbitaire. - Les écailles de la ligne latérale sont cordiformes. - La première dorsale commence sur la moitié antérieure de la longueur totale, à peu près au-dessus de la base des ventrales; la caudale est légèrement fourchue; les pectorales sont longues, leur pointe arrive à l'aplomb de l'anus : les ventrales sont moitié moins longues.

D. 12 ou $13-;$ A. 17 ou $18 ;$ C. $19 ;$ P. 17 ou $18 ;$ V. i ou 8.

La teinte est brunàtre à reflets argentés; la caudale est d'un gris clair avec un pointillé plus foncé; les autres nageoires sont pâles. Les points lumineux sont cerclés de noir; il y en a vers le profil du ventre en rangée plus ou moins régulière, et d’autres épars sur le corps.

Habitat. Méditerranée, Nice, excessivement rare; M. Bellotti prétend le contraire; n'a-t-il pas confondu cette espèce avec une autre?

\section{LE SCOPÈLE DE RISSO. - SCOPELUS RISSOI, Cocco.}

Poiss. France, Suppl., p. 103.

Long. : 0,40 à 0,50 .

Le corps est trapu; sa hauteur est comprise environ trois fois et quart dans la longueur totale; la longueur de la tète y est contenue trois fois et un quart à trois fois et demie; le profil antérieur dessine une courbe régulière à peu près d'un quart de cercle; le museau est excessivement court; l'extrémité postérieure du maxillaire supérieur, qui est un peu élargie, arrive à peine à l'aplomb du bord postérieur de l'orbite; la mandibule est légèrement proéminente, relevée en avant; les mâchoires sont garnies de fort petiles dents en relours. Lœil est très 
développé; son diamètre mesure la moitié de la longueur de la tête, il fait le triple de l'espace préorbitaire et presque le double de l'espace interorbitaire. - La ligne latérale est formée d'écailles très développées, deux fois plus hautes que longues. Ec., l. long. 32 ou 333; l. transs. 6 ou 7. -- La première dorsale commence vers le milieu de la longueur totale; les pectorales sont très longues, arrivant à l'aplomb de l'origine de l'anale; elles font ì peu près le double de la longueur des ventrales.

D. 13 i $17-$; A. 17 a 20 ; C. 18 ; P. 17 ; V. 7 ou 8 .

La teinte est d'un brun foncé sur le dos, argentée sur les cotés. Il y a deux points brillants sur chacun des dentaires; d'autres sont dispersés sur les flancs, près de la ceinture scapulaire; il y en a une rangée de chaque côté rers le profil inférieur du corps.

Habitat. Méditerranée, Nice, excessivement rare.

10. IE SCOPELLE DE BONAPARTE. - SCOPELUS BONAPARTI, C. $\mathrm{V}$.

Poiss. France, t. III, p. כ07, fig. 203, anim.

Long. : 0,06 à 0,10 .

La hauteur du tronc mesure, ou peus'en manque, le sixième de la longueur totale. - La longueur de la tête est contenuc. trois fois et deux liers à quatre fois dans la longueur totale; le museau est court; la muqueuse de la bouche, comme celle de la chambre branchiale, est d'un brun très foncé, la mâchoire supérieure est développée, elle borde la mandibule, en quelque. sorte; les màchoires ont des dents en velours, très pointues, excessirement fines. Une épine triangulaire, dirigée en avant, prolonge la crète du sourcil; le diamètre de l'œil est compris trois fois à trois fois et demie dans la longueur de la tète, il est un peu plus grand que l'espace préorbitaire, un peu moins que l'espace interorbitaire. - Ec., l. long. 33 à 33̈. - La première dorsale commence au milieu de la longueur totale, caudale non comprise, au-dessus de la finde l'insertion des ventra- 
les; les pectorales sont très longues, leur extrémité arrivant au moins jusqu'à l'aplomb de l'anus; les ventrales sont de moitié plus courtes.

$$
\text { 1). } 12 \text { à } 14-\text { ? } 4 \text { ou } 5 \text {; A. } 11 \text { à } 13 \text {; C. } 15 \text {; P. } 12 \text { à } 14 \text {; V. } 8 \text {. }
$$

La teinte générale est un brun rougeâtre, glacé d’argent. Sous le ventre, se montrent, à droite comme à gauche, deux rangées principales de points dorés; après l'anus, il y a de chaque côté de la nageoire, et du tronçon de la queue, une série de points dorés; il existe encore des points brillants sur les flancs et le battant operculaire. Excepté les ventrales, qui semblent presque noires, les nageoires sont d'un brun marron, plus clair sur les pectorales.

Habitat. Méditerranée, Nice, rare.

\section{GINRE MAUROLICUS. - MAUROLICUS,}

Corps plus ou moins allongé, comprimé ; peau gẻnéralement nue, ayant parfois quelques écailles sous l'épiderme, couverte d'un pigment argenté, parfois un peu foncé; plusieurs rangées de points brillants le long de la partie inférieure du corps.

Tête; bouche plus ou moins grande; bord de la màchoire supérieure formé par les intermaxillaires et les maxillaires ; mandibule un peu plus avancée que la màchoire supérieure; les deux munies de petites dents.

Nageoires; première dorsale commencant à peu près au-dessus de l'insertion des ventrales; caudale échancrée ou fourchue.

Ce genre se compose de trois espèces.

$a$. Longueur de la tête faisant le quart de la longueur

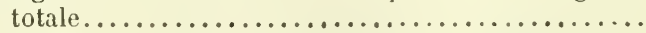

Longueur de la tête faisant le tiers de la longueur

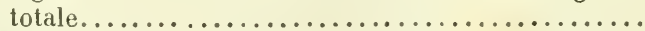

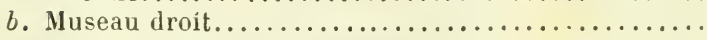

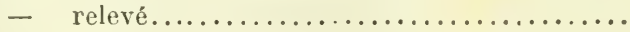

3. De Power.

2. ATTÉNUÉ.

1. AMÉTHYSTE.

1. LE MAUROLICUS AMÉTHYSTE. - MAUROLICUS AMETHYSTINO-PUNCTATUS, Cocco.

Poiss. France, t. III, p. 509 .

Long. : 0,04 à 0,06 . 
La hauteur du tronc est contenue einc fois it eing fois et demie dans la longueur totale, et la longueur de la tête quatre fois environ ; le museau assez court, est légèrement relevé; l'extrémité du maxillaire supérieur arrive en arrière sous le milieu de l'orbite; les mâchoires sont faiblement dentées. Le diamètre de l'œil mesure le tiers de la longueur de la tête, le double de l'espace interorbitaire; il est un peu plus grand que l'espace préorbitaire. - La première dorsale commence audessus, ou peut-être, un peu en avant de la base des ventrales; les pectorales sont beaucoup plus longues que les ventrales, elles ont quinze à dix-sept rayons chez un spécimen; d'après Cocco et $\mathrm{C}$. Bonaparte, elles ont seulement neuf rayons; cette différence dans le nombre des rayons est-elle suffisante pour constituer une espèce nouvelle? L'insertion des rentrales est vers le milieu de la longueur totale.

D. 10 ou 11 -?; A. 14 à 17 ; C. 17 ; P. 15 à 17 ; V. 6 .

Le dos est d'un bleu foncé, pointillé de noir; les côtés, le rentre, les pièces operculaires, les joues sont d'un blanc argenté fortéclatant; de chaque côté du ventre sont despoints brillants, légèrement rosés, disposés en séries. Les nageoires sont pâles.

Habitat. Méditerranée, Nice, excessivement rare.

2. MaUrolicus a'tTÉNUÉ. - Ma UROLICUS attenUatus, Cocco.

Poiss. France, Suppl., p. 106.

Long. : 0,04 à 0,06 .

La hauteur du corps mesure le sixième de la longueur totale, et la tète le quart; le museau est régulier, légèrement incliné d'arrière en avant; l'extrémité de la mâchoire supérieure dépasse, en arrière, l'aplomb du bord postérieur de l'orbite; l'intermaxillaire est armé de plusicurs longues dents crochues, entre lesquelles s'en trourent de plus petites; le maxillaire supérieur porte une rangée de dents inégales; la mandibule est munie de dents crochues, dans l'intervalle desquelles il y en a d'excessivement peu déreloppées. Le diamètre de l'œil fait presque le tier's de longueur de la lête, il est égal à l'espace pré- 
orbitaire. - La première dorsale commence un peu en arrière de la base des ventrales; la pointe de la pectorale arrive à la base de la ventrale, qui est un peu moins longue que la nageoire thoracique.

$$
\text { D. } 10 \text { à } 12-\text {; A. } 15 \text {; C. } 19 \text {; P. } 9 \text { ou } 10 \text {; V. } 6 \text { à } 8 .
$$

Le dos et le dessus de la tête sont brunâtres; les flancs sont argentés, ainsi que les pièces operculaires. Les nageoires sont pâles. Les points lumineux sont cerclés de noir; il y a de chaque côté du profil inférieur une série de points allant de la mandibule à la caudale, et en dehors une autre série, plus courte, s'étendant de la ceinture scapulaire à l'anale.

Habitat. Méditerranée, Nice, Irès rare.

3. LE MAUROLICUS DE POWER. - MAUROLICUS POWERIE, Cocco.

Poiss. France, Suppl., p. 108.

Long. : 0,030 à 0,030 .

Le corps est comprimé; sa hauteur est contenue environ cinq fois dans la longueur totale. La longueur de la tête mesure, ou peu s'en faut, le tier's de la longueur totale; le museau est relevé en avant; la fente de la bouche dépasse l'aplomb du bord postérieur de l'orbite; la màchoire supérieure porte une rangée de dents fort inégales, les unes, très longues, pointues, entre lesquelles s'en trouvent d'autres courtes et crochues; la mandibule présente à peu près la mème dentition, toutefois les dents paraissent moins inégales. Le diamètre de l'œil fait presque le tiers de la longueur de la tête, il est plus grand d'un cinquième environ que l'espace préorbitaire, et d'un tiers que l'espace interorbitaire. - - La première dorsale naît à peine plus en arrière que la base des rentrales.

D. 12 à 1 í-?; A. 13 à 15 ; C. 16 à 18 ; P. 11 ou 12 ; V. 6 à 8 .

Le dos et le dessus de la tête sont d'un brun plus ou moins foncé; les flancs sont argentés. De la tète à l'anus existe une double série de points brillants, beaucoup moins développés 
que ceux formant la rangée externe, qui s'étend de la ceinture scapulaire à la racine de la caudale.

Habitat. Méditerranée, excessirement rare.

\section{GENRE ICHTHYococcus. - ICHTHYococcus, GBp.}

Corps haut, comprimé, couvert d'écailles minces, lisses; points brillants sur les parties latérales et inférieures du corps.

Tête haute, comprimée, nue; màchoire supérieure recouvrant la mandibule, garnie d'une rangée de pelites dents égales, régulières, aiguës, triangulaires, se touchant par la base, représentant en quelque sorte, sur la màchoire, a leur point d'attache, le bord d'une lame de scie; mandibule peu ou pas dentée, portant plusieursséries de points brillants.

Nageoires; première dorsale opposée aux ventrales; pectorales insérées vers le bas de la ceinture scapulaire.

\section{LICHTHYOCOCCUS OVALE. - ICHTHYOCOCCUS OVATUS, GBP.}

Poiss. France, Suppl., 1. 111.

Long. : 0,40 .

La hauteur du corps est contenue trois fois à trois fois et quart dans la longueur totale. - La tête est à peu près aussi haute que longue, sa longueur est comprise environ trois fois et trois quarts dans la longueur totale; le museau est obtus, arancé, recouvrant l'extrémité de la mandibule; le maxillaire supérieur cache la partie latérale de la mandibule; la mâchoire supérieure paraît avoir le bord dentelé, comme une lame de scie, jusqu'à son extrémité postérieure; la mandibule ne porte souvent que des scabrosités, parfois elle est munie de quelques dents. Le diamètre de l'wil fait le tiers, et plus, de la longueur dé la tête; il est égal à l'espalee préorbitaire; l'espace interorbitaire est très étroit. - La première dorsale commence sur la moitié antérieure de la longueur totale, elle est à peu près aussi haute que longue; la caudale est légèrement fourchue; l’insertion des ventrales est vers le milieu de la longueur totale.

D. 12 à $14-;$ A. 16 ou 17 ; C. 19 ì $21 ;$ P. 8 ou $9 ;$ V. 6 ou 7. 
Le dos est noirâtre ou d'un bleu très foncé; la partie inférieure du corps est d'un noir très brillant; les flancs sont d'une teinte argentée, lavée de brun. Dans l'intervalle qui sépare les branches de la mandibule, il y a deux séries de points brillants; sur chaque côté de la mandibule se voit une courte série de six à huit points lumineux. De chaque côté de la région inférieure du corps sont des points brillants, rangés en séries. Sur la tète, il y a plusieurs points lumineux.

Habitat. Méditerranée, Nice, très rare.

\section{Gevre saurcs. - SAURUS, Cuv.}

Corps allongé, plus ou moins arrondi, couvert d'écailles lisses, adhérentes.

Tête oblongue; bouche largement fendue; bord de la màchoire supérieure formé par les intermaxillaires, qui sont fort allongés, arrondis, terminés en pointe; maxillaire supérieur grêle; màchoires garnies de dents pointues, disposées sur plusieurs rangées ; langue et palatins dentés.

Nageoires; première dorsale commençant en arrière des pectorales, sur la première inoitié de la longueur totale; caudale fourchue ; anale et pectorales courles.

Vessie natatoire nulle. - Appendices pyloriques peu nombreux.

\section{LE SAURUS A BANDES. - SAURUS FASCIATUS, Riss.}

Poiss. France, t. III, p. 512, fig. 204, anim.

N. vulg. : Lambert, Nice.

Long. : 0,15 à 0,30 .

La hauteur du tronc est contenue sept à neuf fois dans la longueur totale, et la longueur de la tète quatre fois et źrois quarts à cinq fois; la fente de la bouche est oblique et très grande; les mâchoires, à peu près égales, sont armées de dents aiguës, plus ou moins mobiles, disposées sur plusieurs rangées; les palatins et la langue sont dentés; parfois le cherron du vomer porte quelques petites dents. Le diamètre de l'œil est compris six à sept fois dans la longueur de la tète, il est moins 
grand que l'espace préorbitaire, égal à l'espace interorbitaire. - La ligne latérale est nettement marquéc. Ec., l. long. "̈8 à 6ï: l. transr. 10 ou 11. - La première dorsale commence en arrière de la verticale élevée sur la base des ventrales; la seconde dorsale est à peu près au-dessus du milieu de l'anale; le tronçon de la queue est en forme de pyramide quadrangulaire; la caudale porte, rers le côté interne de chacun de ses lobes, un appendice écailleux; les pectorales sont courtes; les ventrales sont beaucoup plus longues.

Br. 15 à 17. - D. 11 a $13-$ ?; A. 10 ì 13 ; C. 16 ; P. 13 ; V. 8.

La teinte générale est un gris cendré, plus ou moins verdìtre, sur le dos et les còtés qui sont traversés par des bandes courtes et irrégulières formant parfois des espèces de zigzags; la région abdominale est d'un gris argenté. La première dorsale et la caudale sont grisâtres; l'anale et les nageoires paires sont pâles.

Habitat. Méditerranée, très rare, Nice, Toulon, Marseille.

\section{GENRE AUlope. - a UlopUs, Cuv.}

Corps allongé, couveri d'écailles pectinées; anus loin de l'anale.

Tête plus ou moins écailleuse; bouche largement ouverte; bord de la màchoire supérieure formé par les intermaxillaires seuls; maxillaire supérieur bien développé, élargi en arrière; dents plus ou moins crochues, en velours ou en cardes fines sur les màchoires; palatius, romer et langue dentés.

Appareil branchial; fente des ouies très grande.

Nageoires; première dorsale commençant au-dessus et en avant de l'insertion des ventrales; caudale fourchue, anale assez courte.

Vessie natatoire nulle. - Appendices pyloriques peu nombreux.

Deux espèces.

Diamètre de l'œil plus petit que l'espace préorbitaire... 1. rilanenteux. grand que l'espace préorbitaire.. 2. D'Agassiz.

1. L'ALLOPE FILAMENTELX. -- AULOPUS FILAMENTOSUS.

Poiss. France, t. III, p. ว̈lŏ.

Moreau. - Ichthyologie. 
N. vulg. : Lambert, Nice; Maïdé das Loups, Cette.

Long. : 0,20 à 0,33 ou 0,40 .

La hauteur du trone est contenue six fois et demie à sept fois dans la longueur totale. - La longueur de la tète fait le quart de la longueur totale; la màchoire supérieure est moins avancée que l'inférieure; elles ont l'une et l'autre plusieurs rangées de dents fines, crochues, mobiles; des dents à peu près semblables se trouvent sur les ptérygopalatins, le chevron du romer, la langue. Le diamètre de l'cil est compris quatre fois et demie à cinq fois dans la longueur de la tête, il est plus petit que l'espace préorbitaire, aussi grand ou plus grand que l'espace interorbitaire. - La ligne latérale est droite. Ec., 1. long. 54 à 56 ; l. transv. 12. - La première dorsale commence au-dessus de l’insertion des ventrales; chez le male, elle a le deuxième rayon, le troisième et le quatrième beaucoup plus développés que les autres, prolongés en filaments; le deuxième rayon, qui est le plus grand, peut arriver, étant abaissé, à la seconde dorsale, qui est couverte de petites écailles; les ventrales sont assez rapprochées des pectorales.

Br. 15 à 17. - D. 15 - ?; A. 11 ou 12; C. 19 ou $20 ;$ P. 13 ; V. 9.

Le dos et les côtés sont d'un gris rougeâtre arec des taches brunes; le ventre est d'un gris rosé; parfois le corps est d'un marron clair teinté de jaune et de noirâtre; il y a souvent une tache noirâtre sur les opercules. La première dorsale et la caudale sont grisâtres arec des taches jaunes ou brunes; l'anale est pâle; les pectorales sont grisîtres; les ventrales d'un gris jaunâtre. Chez la femelle, la première dorsale est marquée, vers l'extrémité de ses rayons antérieurs, d'une large tache noiritre.

Habitat. Méditerranée, rare, Nice, Cetle.

2. L'AULOPE D'AGASSIZ. - AULOPUS AGASSIZII.

Poiss. France, Suppl., p. 114.

Long. : 0,10 à 0,1 f, el mème 0,209 , Vaill.

La hauteur du tronc est contenue sept fois et un quart à 
sept fois et demie dans la longueur totale; l'anus est entre les rentrales, il est mème recouvert par leur's rayons internes, chez. les jeunes animaux. - La longueur de la tète est comprise trois fois et demie à quatre fois dans la longueur totale; la mâchoire supérieure, beaucoup moins avancée que la mandibule, est échancréc dans sa partie médiane; clle est très arquée, présentant la figure d'un fer à cheval allongé, ses branches contournant les coités de la mandibule, et se rapprochant l'une de l'autre sous la grorge; les màchoires sont garnies de petites dents égales, légèrement crochues; le vomer, les palatins, la langue sont dentés. - L'ceil est excessivement développé; le diamètre longitudinal, qui est beaucoup plus grand que le vertical, est compris deux fois et quart à deux fois et demie dans la longueur de la tête, il est presque d'un tiers plus grand que l'espace préorbitaire; il est quatre fois, au moins, plus grand que l'espace interorbitaire. - La ligne latérale est légèrement déclive, allant à peu près directement de l’épaule à la base de la caudale. Ec., l. long. 50 à 33 ; l. transv. 10 ou 11. - La première dorsale commence à l'origine du second tiers de la longueur totale; les pectorales sont longues; les ventrales sont à peu près égales aux pectorales.

Br. 10. -D. 11 ou $12-;$ A. 9 ou $10 ;$ C. 18 a $20 ;$ P. 15 ou $16 ;$ V. 9.

Sur le vivant, la teinte est d'un vert bleuâtre ou olivâtre; chez les sujets conservés, elle est d'un jaune rougeâtre sur le dos et les flancs; le ventre est argenté.

Habitat. Méditerranée, Nice, excessivement rare.

\section{Sous-famille des Paralépidiniens, P'aralepidini.}

Corps allongé, nu ou couvert d'écailles caduques.

Tête comprimée ; musea u allongé ; bouche grande ; màchoire superieure un peu moins arancée que la mandilule, à bord formé par les intermaxillaires seuls; dentition des màchoires très variable; dents probablement caduques.

Appareil branchial ; ouïes très fendues; sept rayons branchiostèges.

Nageoires; première dorsale sur la seconde moitié de la lon- 
gueur totale; anale longue, finissant près de la caudale qui est échancrée ou fourchue; ventrales peu développées, placées sous la seconde moitié de la longueur totale.

Vessie natatoire nulle. - Appendices pyloriques manquant.

GeYRE PARALEPS. - PARALEPIS, Cuv.

Caractères de la famille.

a. Première dorsale opposée aux ventrales... b.

- _ placée en arrière des ven-

trales............... 4. SPHYRÉxö̈de.

$b$. Rayons de la $1^{\text {re }}$ dorsale au nombre de

vingt-cinq au plus.................. $c$.

Rayons de la $1^{\text {re }}$ dorsale au nombre d'une trentaine .........................

c. Taches sur le trone nulles................

- $\quad$ - bien marquées.......

3. PSEUDOCORÉtioxOÏDE.

$\therefore$. CORÉGONOÏDE.

1. ÉLÉGANT.

\section{LE PARALÉPIS ÉLÉGANT. - PARALEPIS SPECIOSUS.}

Poiss. France, Suppl., p. 118.

Long. : 0,070 à 0,10 .

Le corps est nu; sa hauteur est contenue une dizaine de fois dans la longueur totale, et la longueur de la tête quatre fois environ; les mâchoires sont munies d'une série de petites dents pointues, il y en a quelques-unes en fins crochets sur le devant de la mâchoire supérieure. Le diamètre de l'œil est compris quatre fois à cinq fois et demie dans la longueur de la tête et deux fois à deux fois et demie dans la longueur de l'espace préorbitaire; il est d'un tiers au moins plus grand que l'espace interorbitaire. - La première dorsale est opposée aux ventrales; la caudale est échancrée.

$$
\text { D. } 10-; \text { A. } 22 \text { a } 24 \text {; C. } 20 \text { P. } 13 \text {; V. } 8 \text { ou } 9 .
$$

La partie supérieure du corps est d'un blanc pâle à fỉn pointillé noirâtre; les pièces operculaires et la région abdominale sont d'un blanc argenté; un peu en arrière de la ceinture scapulaire est une série de taches semi-lunaires, d'un noir foncé, s'étendant jusqu à la région anale; généralement les taches sont au nombre de sept sur chaque côté.

Habitat. Méditerranée, Nice, excessivement rare. 
2. LE PARALEPIS CORÉgONOIDE. - PARALEPIS COREGONOIDES, Riss.

Poiss. France, t. III, p. ä19, fig. 20\%̈, anim., et Suppl., p. 120. N. vulg. : Lussion, Nice.

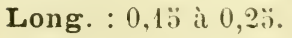

La hauteur du tronc est contenue de neuf à seize fois dans la longueur totale, et la longueur de la tête quatre fois et quart à quatre fois et demie; la màchoire supérieure est munie de dents plus ou moins fines, à pointe tournée en arrière; les palatins ont de petites dents crochues; je n'en vois pas sur le vomer, ni la langue; la mandibule porte des dents coniques, pointues, un peu plus fortes que celles de la màchoire supérieure; parfois chez les individus de grande taille, il ne reste plus trace de dents; il est probable que les dents sont caduques. Le diamètre de l'œil est compris cinq fois à cinq fois et demie dans la longueur de la tête, et deux fois et demie dans la longueur de l'espace préorbitaire; il est un peu plus grand que l'espace interorbitaire. - La ligne latérale est neltement dessinée de l'épaule à la base de la caudale; ses écailles, au nombre de 64 environ, sont presque triangulaires, avec le bord postérieur festonné et presque trilobé. - La première dorsale est opposée aux ventrales; la seconde dorsale parait avoir deux ou trois rayons; la caudale est fourchue; l'insertion des ventrales est tantôt sous le premier, tantôt sous le sixième et mème le septième rayon de la première dor'sale.

Br. 7. -D. 9 ou $10-2$ ou 3 ; A. 22 à 25 ; C. 19 a 22 ; P. 13 à 15 ; V. 8 ou ?.

Le corps est argenté et couleur lilas, nuancé de noir sous le ventre, daprès Risso. Les nageoires impaires sont grisâtres, les autres pàles.

Habitat. Méditerranée, très rare, Nice.

\section{LE PARALEPIS PSEUDOCOREGONOIDE. - PARALEPIS PSEUDOCOREG(J)OIIES, Sarato.}

Poiss. France, Suppl., p. 121.

Long. : 0,13 a i $0,2,2 \cdot$. 
La hauteur du tronc est contenue douze à treize fois dans la longueur totale, et la longueur de la tête quatre fois et demie à cinq fois; la mâchoire inférieure est à peine plus avancée que la supérieure; les derts des intermaxillaires sont tout à fait rudimentaires; les dents de la mandibule sont petites en avant, en arrière elles sont disposées sur deux rangées et fort inégales, les internes droites alternativement courtes et longues, les externes basses et recourbées; les dents palatines sont aussi très inégales; la langue a sur les côtés cinq à sept petits crochets. Le diamètre de l'œil mesure à peine le sixième de la longueur de la tête. - La ligne latérale est droite. - La seconde dorsale a six rayons, d'après Cuvier ; l'anale se continue jusqu'à la caudale; les ventrales sont petites, placées sous la première dorsale.

Voici la formule des nageoires indiquée dans l'Histoire naturelle des Poissons C.V. t. VII, p. \$10:

$$
\text { D. } 10-6 ; \text { A. } 3 / 27 \text { C. } 17 \text { P. } 13 ; \text { V. } 1 / 8 \text {. }
$$

Habitat. Méditerranée, Nice, excessivement rare.

\section{LE PARALÉPIS SPYRÉNOIDE. - PARALEPIS SPIIYR ENOIDES, Riss.}

Poiss. France, t. III, p. 521.

N. vulg. : Lussion, Nice.

Long. : 0,13 à 0,30 .

La hauteur du corps est contenue douze à quatorze fois dans la longueur totale, et la longueur de la tête cinq fois et quart à cinq fois et trois quarts; la mâchoire supérieure est garnie de dents excessivement fines, crochues, à pointe tournée en arrière; la mandibule a près de la symphyse quatre dents mobiles; les deux antérieures sont extrêmement petites, les deux autres sont plus développéos, très aiguës, à pointe dirigée en arrière; après un espace vide, il y a, sur chaque branche de la mandibule, une rangée de huit à dix dents écartées fort pointues, mobiles, entre lesquelles s'en trourent sourent de très petites. Le diamètre de l'œil est compris quatre fois et demie à cinq fois dans la longueur de la tête; il fait la moitié 
de l'espace préorbitaire; il est plus grand que l'espace interorbitaire. - La ligne latérale, bien marquée, est composée d'environ 72 écailles très minces. - La première dorsale commence tout à fait en arrière des ventrales; la caudale est fourchue.

D. $10-3$ ì $6 ;$ A. 28 à $30 ;$ C. 16 à $18 ;$ P. 12 ou $13 ;$ V. 8 ou 9.

Le corps est d'un blanc transparent sur le dos, argenté sur les flanes. Les nageoires sont pàles.

Habitat. Méditerranée, rare, Nice.

I.e nom de genre Paralepis n'est pas de Risso, comme l'indique I. Bellotti (A pp., p. 136), mais bien de Guvier, ainsi que je l'ai rappelé (t. III, p. 3̈18); un critique devrait au moins faire des citalions exactes. Quando nel 1877, écrit M. Bellotti, publicai la Memoria sui Paralepidini del Mediterraneo la specie P. Cuvieri, Bp. (Mem., p. 3, D. 10, A. 23), mi era nota soltante pel cenno datone dailo stesso autore (F.it.) e per la figura inserita nel Cuvier Règne anim. illust. (pl. 18, fig. 2). - Si M. Bellotli avait été au courant de la science, il n'aurait pas commis, dans son étude sui Paralepidini, une confusion aussi étrange. Plus de trente années auparavant, en 1846, dans son Cat. Pesei Europ., C. Bonaparte avait nettement exposé son opinion, je l'ai rappelé dans Suppl., p. 120 ; il ne parle ni de $P$. Cuvieri, ni de $P$. Risso, il cite seulement le $P$. eoregonoides, Riss., Hist. nal. fig. $10 ̈$ (Cat., p. 33̈, no 292). - Pour augmenter l'embarras, M. Bellotti dans ses Appunti, p. 138, veut que la désignation de P. Risso, Bp., devienne synonyme de celle de $P$. coregonoides, Risso, de ses Paralepidini, avec A. 30. - C'est un vrai chaos. - Yous royons $P$. eoregonoides, Riss. (dans Puralep. p. 2, $\mathrm{n}^{\circ} 4$ ) avec D. 10, A. 30 et P. coregonoides, Riss. (dans App., p. 1't0, $n^{0} \ddot{3}$ ) avec D. 10-2; A. 23. - Le P. Risso, Bp., ex Bellotti, App., p. 138, ne peut, d'après ce qui précède, ètre conservé dans la science sans faire naìtre de nouvelles confusións, il doit ètre remplacé par le $P$. pseudocoregonoides, Sarato; c'est le seul moyen de s'y reconnaìtre.

Avant que j'eusse fait remarquer, dans Suppl., p. 120, que le Paralepis de l'atlas du Règ. Anim. a l'anale composée de trente rayons, $M$. Bellotti trouvait la figure bonne, et la domnait, dans $P a$ ralepidini del Hediterraneo, p. 3, comme représentant son $P$. Curieri, D. 10, A. 23, avec linsertion des ventrales sous le troisième rayon de la première dorsale; depuis mon observation, M. Bellotli prétend que la figure est inexacte, qu'il y a trop de rayons à l'anale, et il 
l'indique dans Apmunti, p. 140, comme étant l'image du P. coregonoides, Risso, in Cuv Règ. Anim. illustr., pl. 18, fig. 2 (colla viduzione della pinna anale a soli 23 raggi in luogo di 30 erroneamente figurati). - M. Bellotti use de singuliers procédés pour essayer de justifier sa manière de voir; il aurait beaucoup mieux fait de reconnaitre qu'il s'était trompé; non, il affirme, contre toute évidence, qu'il y a 30 raggi anali figurati per errore d'incizione invece de 23 . - Le nombre de 30 rayons à l'anale est le nombre normal, et c'est, on ne peut en douter, d'après les indications de Valenciennes que le dessinateur a tracé les trente rayons. - Valenciennes regardait, avec raison, comme étant identiques, le $P$. coregonoides, Règ. Anim. ill., pl. 18, fig. 2, et le P. coregonoides, décrit Hist. nat. Poiss, t. III, p. 33̈ , et fig. pl. 66-67. - La figgure de l'atlas du Règ. Anim. est très exacte telle qu'elle est, le retranchement de sept rayons à l'anale la rendrait méconnaissable. Mi. Bellotti a peut-ètre examiné cette figure, mais assurément il ne l'a pas comprise. - Pour démontrer que cette figure (Règ. Anim.) est l'image fidèle du P. coregonoides, G. V. t. III, p. 337 , je vais, laissant de còté la question du nornbre des rayons de l'anale, emprunter à M. Bellotti lui-mème, la formule qu'il a donnée du nombre des rayons des dorsales, ou plutôt de la seconde dorsale, qui seule présente de l'importance pour la détermination de chacun de ces deux Paralepis :

P. coregonoides, Risso (Bellotti, App., p. 140, 141), D. 10-2 ; A. 23. P. Risso, Bp. (Bellotti, App., p. 138-139), D. 10-6; A. 30.

Un simple coup d'œil jeté sur la figure 2, pl. 18, atlas Règn. Anim., ou mème sur la reproduction assez mauraise qu'en a donnée M. Bellotti (App., fig. 7), suffit, d'après le nombre des rayons de la seconde dorsale, pour juger à quelle espèce doit ètre rapportée la figure en question; il y a concordance entre le nombre des rayons de l'anale et celui des rayons de la seconde dorsale. - M. Bellotti aurait pu se dispenser de faire ces nouvelles confusions; ses travaux sur les $P a$ ralepis sont incompréhensibles.

Quant aux singulières erreurs, commises par M. Vinciguerra relativementà la position de l'anale chez les Paralepis, et que j'ai relevées dans Suppl., p. 12', M. Bellotti écrit: (A pp., p. 137) Riguardo alla confusione apparente dalla descrizione data lal dott. Vinciguerra del Paralepis Cuvieri, è evidente che deva attribuirsi unicamente a errore di stampa. Quoi, une faute d'impressiou! C'est inexact. M. Bellotti le sait aussi bien que moi; pour le prouver, je n'ai rien de mieux à faire que de reproduire la citation du texte de $\mathbf{M}$. Vinciguerra, qui se trouve dans suppl.p. 12t. La Puralepis Cuvieri... è bene distinta per la posizione della pinna unale, inseritu sotto il terzo raggio ilella dorsale 
e fornita di soli 23 raggi, mentre la veru coregonoides ha l'anale inseritu sotto il settimo raggio dorsale e fornitu di 30 raggji. Oì est-elle cette faute d'impression?

A propos du genre Gobius, Appenti, p. lí6, j’ai cité le travail de I. C. Sarato, sur la ressie natatoire des Gobies, dans Manuel, p. 166, feuil. 11, impriméele 27 mai 1891 , avant que M. Bellotti eùt présenté son Mémoire à la Société italienne des Sciences naturelles de Milan.

\section{Famille des Salmonides. Salmonidir.}

Gorps allongé, couvert d'écailles lisses.

Tête nue; de forme variable; bord de la màchoire supérieure formé par les intermaxillaires et les maxillaires.

Yeux latéraux, entourés généralement d'une paupière adipeuse. A ppareil branchial; ouies largement fendues; pseudobranchies.

Nageoires; première dorsale soutenue par des rayons simples et par des rayons branchus; seconde dorsale adipeuse.

Vessie natatoire grande, à un seul lobe, généralement pourvue dun conduit pneumatophore. - Canal intestinal; estomac en cul-de-sac; appendices pyloriques manquant rarement. - Ovaires sans oviducte; œufs tombant dans la cavité abdominale avant leur passage au dehors.

La famille des Salmonidés est composée de six genres.

a. Màchoire supérieure allant en arrière plus loin que le diamìtre vertical de l'œil............. b.

Màchoire supérieure allant en arrière moins loin que le diamitre vertical de l'œil............. $c$.

b. Mandibule pas plus avancée que la màchoire supé-

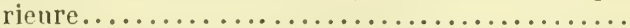

Mandibule plus a vancée que la màchoire supérieure.

$c$. Diamètre de l'œil moins grand ou pas plus grand que l'espace préorbitaire...................

Diamètre de l'œil d'un tiers au moins plus grand que l'espace préorhitaire..................

d. $1^{\text {re }}$ lorsale anssi longue que la tête............. moins longue que la tête...........

e. Écailles de la ligne longitudinale au nombre de

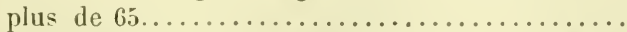

Écailles de la ligne longitudinale au nombre de

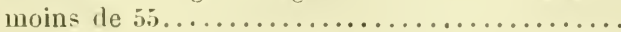

1. SAUnOx.

2. ÉPERLAx. $l$.

li. Micirostone.

3. THYMaLle. e.

4. Corégone.

5. Argentine.

1. GEYRE SAUMON. - SALMO, Linn.

Corps allongé, comprimé, couvert de petites écailles adhérentes. Tète; bouche largement ouverte, bien armée; dents sur les 
màchoires, les palatins, la langue, et sur le vomer, au moins chez les jeunes; extrémité du maxillaire supérieur dépassant le prolongement du diamètre vertical de l'œil; au moment de la reproduction, la màchoire inférieure est généralement crochue chez les màles, très rarement chez les femelles.

Appareil branchial; rayons branchiostèges au nombre de neuf à douze.

Nageoires; première dorsale commencant avant l'insertion des ventrales, ayant douze à quinze rayons; caudale carrée ou échancrée, quelquefois un peu fourchue.

Appendices pyloriques nombreux.

Ce genre se divise en trois sous-genres; chez les adultes:

a. Maxillaire supérieur pas plus long que l'espace préor-

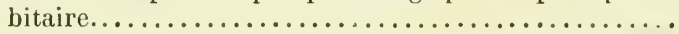

Maxillaire supérieur d'un septième au moins plus long que l'espace préorbitaire.................... b.

$b$. Dents sur le chevron et le corps du vomer............

1. SAlMoN.

2. Truite.

3. OMBLE.

\section{SOUS-GENRE SAUMON. - SALMO.}

Tête; vomer à chevron pentagonal, plus long que large, portant chez les jeunes une rangée de dents transversale, à corps sans carène bien saillante, denté chez les jeunes; les dents sont caduques, manquent parfois complètement, chez les adultes.

\section{LE SAUHON COMNUN. - SALMO SALAR.}

Poiss. France, t. III, p. ว̈23, fig. 206 jeune Saumon, et Suppl., p. 12'.

N. vulg. : Soumon, Haute-Loire; le jeune Saumon est appelé : Renay en Lorraine; Taconnet dans le Morvan; Tocan ou Tacon en Auvergne, etc.; le màle à mandibule crochue est le Bécard.

Long. : 0,50 à 1,00 et plus.

La hauteur du tronc est contenue quatre fois et trois quarts à six fois dans la longueur totale. - La tête est conique; chez les adultes, sa longueur présente à peu près les mêmes proportions que la hauteur du corps; la bouche est largement ouverte : la mâchoire supérieure est ordinairement un peu plus avancée que la mandibule, armées l'une et l'autre de fortes 
denls coniques; les palatins ont une rangée de dents pointues; la langue est munie de chaque côté de trois ou quatre dents aiguës; le romer est parfois complètement édenté, et sur le milieu du corps, il ne reste plus trace de carène; ordinairement il existe quelques dents sur le corps du vomer et sur le chevron, qui est pentagonal, ou plutôt sur la ligne qui l'unit au corps de l'os; chez les jeunes, il y a une rangée transversale de plusieurs dents sur le chevron et une ou deux rangées sur le corps. Le maxillaire supérieur, chez les Tacons, est plus long que l'espèce préorbitaire, mais chez les adultes les proportions changent, la longueur du maxillaire devient égale à celle de l'espace préorbitaire, puis elle arrive à être moins grande. Le diamètre de l'œil, suivant la taille des animaux, est compris de quatre à neuf fois dans la longueur de la tête; il est, excepté chez les très jeunes, plus petit que l'espace préorbitaire, qui est, en général, un peu moins grand que l'espace interorbitaire. - L'opercule est marqué de stries, dirigées les unes vers son bord postérieur, les autres vers son bord inférieur; il forme avec le sous-opercule une plaque à bord postérieur sensiblement demi-circulaire; l'angle postérieur et inférieur de l'opercule est généralement un peu plus rapproché de la commissure supérieure de la fente branchiale que de l'angle antérieur et inférieur du sous-opercule. La distance du bord postérieur de l'orbite au bold postérieur du préopercule est moindre que l'espace préorbitaire. - La ligne latérale est un peu plus rapprochée du dos que du ventre. Ec., l. long. 120 à 130; 1. transv. 40 à 49 . - La $1^{\text {re }}$ dorsale est trapézoïde; la caudale est fort échancrée chez les jeunes.

Br. 11.-D. 14 à $17-0 ;$ A. 10 à 12 ; C. $20 ;$ P. 13 ou 14; V. i à 9.

Le dos est bleu ardoisé, les llanes sont d'un gris argenté; le ventre est argenté; des taches noirâtres, plus ou moins arrondies, se montrent sur les pièces operculaires, d'autres en $\mathrm{X}$, plus ou moins nombreuses, existent sur le corps, principalement au-dessus de la ligne latérale. La dorsale et la caudale sont d'un gris plus ou moins foncé; les nageoires paires ont les rayons externes noirâtres, les autres gris ou blanchàtres. Au moment du frai, des taches rougeâtres marquent le dos, les 
flancs, les pièces operculaires. Chez les jeunes, la coloration est très variable; il y a sur les côtés des bandes verticales obscures, des taches noiràtres, rougeâtres.

Habitat. Le Saumon se trouve dans la plupart de nos rivières qui se jettent dans la Manche el dans l'Océan. En 1882, j’ai reçu trois Saumoneaux, pèchés dans la Méditerranée, entre Cette el Agde, du 14 au 18 mai.

L'histoire du Saumon ne nous est pas complètement connue; il serait donc prudent de ne pas y mèler le paradoxe pour la rendre encore plus obscure qu'elle l'est déjà. - Certains auteurs prétendent que les Saumons n'entrent pas dans les fleuves pour y frayer. Dans quel but alors? Les sujets frappés de stérilité restent à la mer (cette stérilité est peut-ètre la cause du séjour très prolongé que font certains Smolts dans les eaux saumàtres), mais ils sont anadromes dès qu'ils deviennent aptes à se reproduire; chez la plupart d'entre eux la stérilité paraît temporaire. - 1 moins d'obstacles qu'ils ne peurent franchir, les Poissons, pour frayer, remontent très haut dans les rivières. L'eau douce n'exerce sur eux aucune action débilitante, ainsi qu'on l'affirme; si quelque temps après leur entrée dans les fleuves, ils subissent de notables changements dans leur système de coloration, s'ils éprouvent un amaigrissement sensible, ces modifications dans leur état général ne sont pas causées par l'influence de l'eau douce, mais proviennent des conditions physiologiques dans lesquelles ils se trouvent; plus approche l'époque du frai, plus sont marqués les symptòmes de dépérissement; après avoir accompli l'acte de la reproduction, les màles ont perdu jusqu'à moitié de leur poids et les femelles plus d'un tiers, suivant M. l'ingénieur Caméré (Dépouillement des renseignements fournis par les différents services des Ponts et Chaussẻes dressé par M. l'ingénieur R. Denys, Épinal, 1889, p. ว̋́x). - Ces individus épuisés peuvent, on l'a nettement constaté, réparer en partie leurs forces, avant de regagner la mer.

L'eau de source encore est si loin d'avoir une action toxique sur les adultes et d'ètre nuisible au développement des jeunes que les reproducteurs choisissent souvent pour établir leurs frayères; les endroits du lit des fleuves où viennent sourdre les eaux fraîches; ainsi dans l'arrondissement de Blois au pont de Muides, les Saumons fraient sur des hancs de gravier où l'eau est courante; il y a des sources d'eau calcaire fraiche venant des coteaux. C'est la seule frayère signalée entre l'embouchure (de la Loire) et Digoin (loc. cit., p. 23). - M. l'ingénieur en chef Caméré (loc. cit., p. 52) nous 
apprend que dans le lépartement de l'Eure et de la Seine-Inférieure, les points où fraient les Saumons, sont situés dans les parties du lit où émergent des eaux artésiennes qu'accompagnent toujours des dépòts calcaires, assez friables, connus sous le nom de falaises.

Les Saumons, l'expérience en a été faite, peuvent à la rigueur, sans aller à la mer, vivre en eau douce et mème s'y reproduire. En arril 1857, écrit le $D^{\mathrm{r}}$ Jules Cloquet, plusieurs milliers de Saumons furent mis, par M. Coste, dans l'étang de Saint-Cucufa. Ces Poissons, pèchés en 18̈̈9, àgés de vingt-deux mois, pèsent en moyenne 120 grammes et ont une longueur de 23 à 30 centimètres. Ce n'est pas sans surprise que M. Coste a constaté que tous ces Poissons sont en pleine reproduction. Les femelles avaient leurs œul's à maturité, et des fécondations artificielles ont élé faites arec succès. La reproduction du Saumon dans les eaux privées et closes est donc un fait acquis à la science ( $D^{\mathrm{r}}$ J. Cloquet : Note sur la reproduction du Saumon dans un étang, dans Bull. Soc. Acclimat., Paris, 1839, t. VI, p. 23̈3). - Dans le lac Pavin, plusieurs Saumons, provenant de fécondations artificielles, ont été pèchés au bout de trois ans, ayant un poids de 500 à 700 grammes; un autre, capturé au bout de quatre ans au plus, pesait 1100 grammes, était long de ä6 centimètres (Gillet de Grandmont, loc. cit., 1863, t. X, p. 260). En Norvège, on a cherché à élever et à acclimater le Saumon dans des lacs d'eau douce, d'où il lui est impossible de gagner la mer; dans plusieurs lacs, et en peu d'années, on a pêché des Poissons de 6 el mème de 8 kilogrammes. Ces Saumons ont une chair un peu moins rose que celle de ceux qui ront à la mer, malgré cela, elle est d'aussi bonne qualité. Il manque la sanction du temps, fait observer II. Hetting, le superintendant de la pisciculture en Norvège, pour savoir si le Saumon des lacs conservera ou perdra, après plusieurs générations, ses qualités primitives. Ces expériences réfutent les erreurs des Anglais qui nient que les Saumons puissent virre plus de deux ans et quelques mois exclusivement en eau douce (L. Soubeiran, Exposition, Produits et Engins de Pêche de Bergen, 1863, loc. cit., 1866, t. II, p. 189).

A l'époque du frai, les màles presque toujours, très rarement les femelles, éprouvent une hypertrophie de l'extrémité antérieure de la mandibule, qui se recourbe en un crochet plus ou moins saillant; après le temps de la reproduclion, le crochet diminue et peut disparaitre, mais parfois il persiste surtout che\% les màles d'une certaine taille qui sont appelés bécards, et mème, en général, le nom de bécard s'applique exclusirement au màle. - Le principe posé par M. Künstler: les bécards sont aussi bien femelle que 
màle, prèts à pondre ou ayant pondu (Notice sur le Saumon de la Dordogne, Imprimerie Nationale, Paris 1890, p. 6), est absolument faux; la preuve s'en trouve dans le tableau dressé, par M. l'ingénieur Caméré, d'après les documents qui lui ont été fournis par M. Geneste, fermier de la pècherie de Bergerac, ou précisément M. Künstler a fait ses études; voici, chez les reproducteurs, les proportions des bécards : mâles, 92, 8 p. 100 ; femelles 12 p. 100.

Arrivés à l'endroit où ils doivent frayer, et le fait avait été déjà signalé par Gesner, il y a plus de trois siècles, les Sammons, les femelles surtout, creusent des sillons, des fosses, des nids, où les œufs sont pondus et aussitòt fécondés. - M. Künstler n'a pas grande confiance dans l'exactitude des observations des naluralistes qui ont parlé de la ponte des Saumons sur les frayères; pour ce qui est de la Dordogne, jamais, écrit-il (loc. cit., p.!8), à notre connaissance, un pècheur n'a vu de Saumon autre part que dans ses filets. - Aux vagues renseignements, recueillis par M. Künstler, il m'est facile d'en opposer d'autres plus précis, venant de témoins oculaires que je connais; l'année dernière, à propos des barrages de Bergerac et de Mauzac, qui empèchent le Saumon et d'autres Poissons migrateurs de remonter le cours de la Dordogne, M. Vachal, conseiller général de la Corrèze, in'écrivait: Lorsque les eaux sont devenues limpides et demi-basses, on voit (ou plutòt on voyait), et j'ai moimème vu du haut du pont d'Argentat, à une quinzaine de mètres au-dessus du niveau de la rivière, les femelles écarter, avec leurs queues, les pierres des graviers léchés par un courant d'environ 50 centimètres de hauteur, et $y$ creuser une fosse ovale à grand axe parallèle au courant. - Cette description de frayère est fort nette, absolument concordante avec celle des naturalistes qui ont vu pondre les Saumons dans les conditions naturelles, et nullement "dans des circonstances remarquables", ainsi que M. Künstler se plaît à le dire avec ironie (C. rend. S. Congr. intern. Zool., Paris, 1889, p. 87); de plus, les ingénieurs citent un très grand nombre de frayères dans la Dordogne, on les rencontre dans toute la longueur de la rivière (Dépouil. Ponts., p. 13). - Dans la Canche enfin, et c'est un témoignage que personne ne récusera, le 23 décembre 1890, M. le Dr Sauvage et M. l'ingénieur Pierret ont vu des Saumons pondre sur Ia frayère de Brimeux, à quelques kilomètres à l'aınont de Montreuil (Pas-de-Calais).

La durée de l'incubation est plus ou moins longue, elle varie, suivant F. Day, de trente-cinq à cent quarante-huit jours. - Le jeune Saumon est le Parr des Anglais; il peut rester une, deux et mème trois années avant de se transformer en Smolt et de faire son 
premier voyage à la mer, où il prend un développement extraordinaire, acquiert un poids de trois à six livres, et, en général, au bout de peu de temps, de quelques mois le plus souvent, sous le nom de Grilse, revient à l'endroit où il est né. - Après avoir frayé et aroir séjourné en eau douce quelques mois, il fait, étant GrilseKelt, une seconde descente à la mer. Il reste en eau saumàtre de trente-huit jours à plusieurs mois, et, devenu Saumon parfait, il opère sa seconde montée pour frayer de nouveau. - Quelle singulière manie! Emprunter des noms anglais pour indiquer les diverses phases de l'érolution des Saumons, quand il existe déjà des termes qui expriment les mèmes idées, et qui se trouvent dans l'ouvrage de Duhamel : $1^{\circ}$ Digitules, ce sont les Parrs; 20 Salares, les Smolts; les Digitales et les Salares sont confondus généralement sous les noms de Tacons ou Tocans; $3^{\circ}$ Suriones ou Grilses; $4^{\circ}$ enfin les désignations Suumons ou Sulmones sont de mène origine. - En Angleterre, le nom de Kelt s'applique uniquement au sujet venant de frayer et nullement au Saumon après le stade Grilse, comme l'écrit M. Künstler (Notice, p. 11); car dans ce pays la pèche du Kelt est absolument interdite. - Lne multitude de Kelts meurent chaque année, épuisés par l'acte de la reproduction (Seeley, Fresh-Water Fish. Europe, London, 1886, p. 278). - Le temps de frai n'est pas limité aux mois d'octobre et de novembre, il peut se prolonger jusqu'en janvier et février.

Pendant longtemps on a douté que le Tacon fùt réellement le jeune du Saumon, cependant Gesner avait donné la figure, très reconnaissable, d'un petit Saumon, qu'en France on appelle Tucon. Plus tard Duhamel en fournit une preuve bien nette; il fait observer que sur la Nive, les nasses du moulin de Saint-Jean-Pied-de-Port sont assez élevées pour empècher les Saumons, qui viennent frayer, de les franchir, aussi ne voit-on pas de Tocans au-dessus de ces nasses, tandis qu'il y en a beaucoup en dessous jusqu'à Cambo.

Les expériences de John Shaw sur la précocité sexuelle des jeunes màles ont confirmé des faits connus depuis nombre d'années, signalés par Gesner écrivant: Les jeunes màles fécondent les œufs de grandes femelles, les jeunes femelles n'ont pas d'wufs. - Les pècheurs de la Sémoi, rapporte Duhamel, avaient observé que les jeunes Tacons màles ont de la laite, les femelles n'ont pas d'wufs.

On attribue aussi aux Anglais l'idée d'avoir, les premiers, vers 1830, altaché des marques aux Saumons, pour les reconnaître à leur retour en eau douce. Nais au milieu dn siècle dernier, Deslandes, commissaire de la marine, dit : J'arais chargé des pècheurs de Chàteaulin de retenir une douzaine de Saumons parmi ceux qui 
descendent la rivière, et après leur avoir attaché à chacun un petit cercle de cuivre vers la queue, de les remettre dans l'eau, ce qu'ils ont exécuté avec beaucoup d’adresse, et en trois années différentes. J'ai ensuite su d'eux-mêmes qu'ils avaient repris quelques-uns de ces Saumons, une année cinq, une autre année trois, une autre enfin deux (Valmont de Bomare, Saumon, p. 127).

Après avoir frayé, les Saumons descendent à la mer et y séjournent pendant tout l'hiver et tout l'été suivant, et ne remontent au plus tòt qu'en automne, d'après M. Kü̈nstler, qui ajoute (loc. cit., p. 8) : La reproduction du Saumon parait donc ètre au minimum biennale. Cette opinion appuyée sur des observations précises se trouve corroborée par des études postérieures de Giard sur les parasites du Saumon, travail qui établit pleinement que le séjour de ces poissons dans la mer est relativement long. - La note, que M. Giard a publiée dans les Comptes rendus de l'Académie des Sciences (Paris, $\ddot{~ a o u ̀ t ~ 1 \& 89), ~ a y a n t ~ p o u r ~ t i t r e ~: ~ S u r ~ q u e l q u e s ~ p a r t i c u l a r i t e ́ s ~ e ́ t h o l o g i-~}$ ques de la Truite de mer, ne corrobore en rien l'opinion de M. Künstler, elle explique simplement la cause du lonǵ séjour en mer des Truites parasitées, qui, devenues stériles, ont perdu, avec la faculté de se reproduire, leur instinct migrateur (Giard). De mème, d’après Benecke, les Saunons stériles ne remontent pas les rivières et se prennent en grand nombre sur les còtes de la Baltique (Seeley, loc. cit., p. 275). - La stérilité n'est pas rare chez les Saumons, généralement elle ne semble pas être permanente, elle est plutòt temporaire; que tant qu'elle persiste, les Poissons restent à la mer, on le concoit facilement; mais que dans les conditions normales, ils y séjournent toute une année, comme l'affirme I. Künstler, rien ne le fait supposer.

Quelles sont donc les observations précises sur lesquelles M. Künstler appuie son opinion? Il en parle, mais ne les cite pas. Sont-elles aussi précises que celles qui lui ont servi à établir son principe du bécurdisme: Les bécards sont aussi bien femelle que màle, prèts à pondre, etc.? - Aux observations inédites de M. Künstler, j'en opposerai d'autres qui ont un caractère d'authencité indiscutable, relatées par divers auteurs, relevées sur des Saumons marqués à leur descente à la mer, sur des Saumons témoins, comme on pourrait les appeler. Mieux que la théorie, l'expérimentation fournit des données exactes sur le temps qui s'écoule entre le moment de la descente des Saumons à la mer et celui de leur reprise en eau douce :

$1^{\circ}$ Grilse-kielt de 2 livres, marqué à sa descente à la mer, repris à son retour, quatre mois plus tard, pesant 8 livres (Seeley, p. 270). - Marqué le 31 mars 1838, repris le 2 aoủt de la mème année, Day, 
British Fishes, t. II, p, 79). - Suivant M. Blanchard, les Grilses, après la ponte, demeurent encore quelque temps dans les eaux douces, puis se rendent i la mer, où ils ne séjournent souvent pas plus de deux mois, ils reviennenl, ayant atteint un poids de 3 à 6 kilogrammes. Pour le Saumon qui en est à son second ou à son troisième voyage, l'accroissement n'est pas moins prodigieux pendant un très court séjour à la mer (Blanchard, Poiss. Eaux douces de France, 1866, p. 4377$)$.

$2^{\circ}$ Saumon. - a. Pennant rapporte qu'un sujet marqué $\tau$ livres $3 / \mathfrak{f}$, le 7 férrier, pesait 17 livres $1 / 2$, quand il fut repris le 17 mars suivant (Seeley, p. 270). - b. Un Saumon de la Tay, pris après la ponte et marqué d'une étiquette par le duc d'Atholl au mois de mars 18łă, pesant 10 livres, repèché, muni de son étiquette, cinq semaines et trois jours plus tard, par conséquent après une bien courte excursion à la mer pesait 21 livres 1/4 (Blanch., p. 43̈8). c. En 1839 , le duc d'Atholl a capturé, au moment de leur descente à la mer, trois Saumons, pesant, chacun d'eux, 10 livres, 11 livres 1/2, 12 livres $1 / 2$, six mois après, à leur retour en eau douce, ils furent repèchés, ayant acquis un poids respectif de 17, 18 et 19 livres.

Ces diverses citations, et j'aurais pu en indiquer de plus nombreuses, démontrent deux faits importants : que le séjour en mer des Saumons, à moins d'anomalie, de stérilité, n'est pas de si longue durée que l'affirme M. Künstler; que leur reproduction est annuelle, au moins pendant une certaine période de leur existence.

Duhamel rapporte une observation que lui a communiquée le régisseur de la pècherie du Pont-du-Chàteau : quand les Saumons arrivent à la digue qui barre l'Allier, les œufs sont si petits que tous ensemble ne font pas un volume plus gros qu'un pouce; au lieu que quand ils sont restés quelques mois en rivière, cette masse d'œufs augmente tellement qu'elle pèse quelquefois plus de 2 livres. - Il y a une concordance très grande entre celte observation et le résultat des recherches auxquelles s'est livré M. Jousset de Bellesme sur l'évolution des œufs de divers Salmonidés, le développement des œufs serait excessivement rapide vers les derniers temps qui précèdent la ponte. - A propos de la pècherie du Pont-du-Chàteau, Duhamel ajoute : les Saumons sont gras en arrivant de la mer; mais ils maigrissent dans la rivière, de sorte qu'un Saumon, qui en décembre pesait 20 livres, n'en pèse plus que 12 quand il est resté dans la rivière jusqu'en mai..., les Saumons se déchargent de leurs œufs dans la rivière, et je crois que c'est la maladie du frai qui est la cause de leur maigreur.

M. Küunstler prétend que la chair du Saumon reproducteur n'étani Moreav. - Ichthyologie. 
pas comestible, la reproduction naturelle se protège par elle-même en delıors de toute action législative (V. Compt. rend. Séances, Congrès Zoolog., Paris, 1889, p. 90). - Il faut bien mal connaître les habitudes des braconniers pour exprimer une semblable opinion. - En tout cas, il ne s'agit pas de savoir si la chair du Saumon, à l'époque du frai, est de telle ou telle qualité, mais de voir si l'ardeur que mettent les braconniers à ravager les frayères n'est pas abominable et ne doit pas ètre réprimée avec la plus extrême sévérité. - Que d'artifices mis en usage pour cette œuvre de destruction! Ainsi Gesner indique ce procédé employé de son temps : une femelle est prise, attachée à une corde et amenée petit à petit vers la rive, où un pècheur, caché derrière des feuillages, frappe de son trident le màle qui s'approche pour frayer. - La persistance avec laquelle les reproducteurs reviennent à leurs frayères augmente encore la facilité de leur capture. On en trouve un exemple curieux rapporté par Seeley (lüc. cit., p. 277) : Une paire deSaumons, màle et femelle, étant vus en train de préparer leur frayère, le mâle est harponné et tiré de l’eau. La femelle immédiatement gagne le fond de la rivière, et après un certain temps revient avec un autre mâle. Celui-ci ayant subi le sort du premier, la femelle se jette encore dans le fond et ramène un troisième màle. Un autre coup de harpon frappait le nouvel arrivant, jusqu'à ce que la veuve, ne trouvant plus de màle de son espèce, revint accompagnée d'une grande Truite de rivière qui l'aida à préparer sa fosse à frayer. - Suivant Duhamel (l. c., p. 265), les pêcheurs basques, vers les sources des petites rivières, tendent sur le fond des trappes en fer, dans les endroits où ils jugent que les Saumons vont déposer leurs œufs et où ils aperçoivent les sillons préparés pour les recevoir : ils prennent souvent sous ces trappes deux Saumons, un màle et une femelle. Il parait que les habitudes de braconnage se continuent dans le bassin de l'Adour; afin d'y mettre obstacle, MM. les Ingénieurs proposent une excellente mesure, c'est de protéger les frayères au moyen de pieux armés de clous qui rendent impossible l'emploi du filet (Rapport, dépouil., etc., p. 7). Ce mode de protection devrait bien être appliqué dans la Canche; d'après M. Giard, vers le mois d'octobre et de novembre, c'est par centaines qu'on voit, dans cette rivière, des bécards sur le gravier de Marenla, où tous deviennent la proie des braconniers. Pendant les époques où la pêche est fermée, le poisson, transporté clandestinement, est consommé dans le pays. - D’après ce qui précède, on peut juger combien la reproduction naturelle se protège par elle-même en dehors de toute action législative. 


\section{SOUS-GENRE TRUITE. - TRUTTA, Duham.}

Tête; maxillaire supérieur plus long que l'espace préorbitaire; vomer plus ou moins denté.

Ce sous-genre est formé de trois espèces.

a. Rayons branchiostèges au nombre de neuf........ de dix à douze. $b$.

3. de Baillon.

b. Espace postorbitaire faisant à peine la moitié de la longueur de la tête....................... Espace postorbitaire faisant plus de la moitié de la longueur de la tète......................

2. CoMmune.

1. DE MER.

\section{LA TRUITE DE MER. - TRUTTA MARINA, Duham.}

Poiss, France, t. III, p. 537.

N. vulg. : Truite de mer, Truite de Dieppe, marché de Paris.

Long. : 0,40 à 0,80 .

La hauteur du tronc est contenue cinq fois et demie à six fois et deux tiers dans la longueur totale, et la longueur de la tête cinq fois à cinq fois et demie; le museau est arrondi, la bouche largement ouverte; la màchoire supérieure légèrement plus avancée que l’inférieure, ayant, l'une et l'autre, des dents assez fortes, un peu crochues, ainsi que les palatins; la langue est munie de deux séries longitudinales de trois à cinq dents crochues; le vomer a le chevron triangulaire ou un peu trapézoïde, avec une rangée transversale de trois à cinq dents, le corps à carène plus ou moins saillante, souvent garnie de dents en série plus ou moins irrégulière, ordinairement en deux rangées chez les jeunes ; le maxillaire supérieur, sensiblement plus long que l’espace préorbitaire, dépasse en geénéral le bord postérieur de l'orbite. Chez les sujets de grande taille, le diamètre de l'œil ne fait que le septième ou le huitième de la longueur de la tête; il ne mesure pas la moitié de l'espace préorbitaire. - Lopercule est gravé de stries bien marquées, dirigées les unes vers le bord postérieur, les autres vers le bord inférieur; il forme, avec le sous-opercule, une plaque dessinant en arrière une courbe allongée; son angle inférieur et postérieur est plus éloigné de la commissure supérieure de la fente branchiale que 
de l'angle inférieur et antérieur du sous-opercule. La distance du bord postérieur de l'orbite au bord postérieur du préoper-. cule est à peu près égale à l'espace préorbitaire, parfois même un peu moindre. - La ligne latérale est un peu plus rapprochée du profil supérieur. Ec., l. long. 120 à 130 ; l. transv. 46 à 56 . Chez les adultes, la première dorsale est trapézoïde, à peu près aussi haute que longue; la caudale est carrée ou peu échancrée. Br. 10 à 12. - D. 12 à $15-0$; A. 11 à 13 ; C. 18 à 20 ; P. 13 ou 14 ; V. 9 ou 10.

Le dos est gris verdâtre; les côtés sont blanchàtres; le ventre est argenté; des taches noirâtres, irrégulières en $\mathrm{X}$ le plus généralement sont plus ou moins nombreuses au-dessus de la ligne latérale, plus rares au-dessous ; souvent les pièces operculaires sont marquées de taches noires arrondies. La dorsale et la caudale sont d'un gris brunâtre; l'anale et les ventrales sont blanches ou d'un gris pâle.

Habitat. De la mer du Nord aux còtes de l'Océan; elle est assez. fréquente dans le Pas-de-Calais, dans la Seine-Inférieure aux environs de Dieppe; elle est rare au sud de la Loire.

Les spécimens adultes du Saumon et de la Truite de mer présentent les caractères différentiels suivants :

$1^{\circ}$ Le maxillaire supérieur n'est pas plus grand que l'espace préorbitaire, il est toujours moins grand que l'espace interorbitaire che\% le Saumon; c'est le contraire chez la Truite de mer:

$2^{\circ}$ L'espace préorbitaire est d'un septième plus long que l'espace compris entre le bord postérieur de l'orbite et le bord postérieur du préopercule, chez le Saumon; il n'est pas plus long chez la Truite de mer;

$3^{\circ}$ L'angle postérieur et inférieur de l'opercule est généralement plus près de la commissure branchiale supérieure que de l'angle antérieur et inférieur du sous-opercule chez le Saumon; c'est le contraire chez la Truite de mer;

$4^{\circ} \mathrm{La}$ distance qui sépare le hord postérieur de l’occipital basilaire du trou carotidien ne fait pas le tiers de la longueur de la base du cràne, chez le Saumon; elle en mesure plus du tiers chez la Truite de mer;

$5^{\circ}$ Le vomer est souvent édenté, il a le cherron pentagonal ou légèrement hexagonal, et le corps à carène médiane peu prononcée et même nulle après la chute des dents, chez le Saumon; le vomer 
semble plus ou moins denté, avec le chevron triangulaire, chez la Truite de mer: et le corps à carène médiane plus ou moins prononcée.

$6^{\circ}$ Suirant Günther et Day, il y a onze écailles dans une ligne oblique allant de la nageoire adipeuse à la ligne latérale, chez le Saumon; il y en a quatorze et plus chez les Truites. - Fünther rapporte le Salmo aryenteus (Gïnth., t. VI, p. 86), ayant 12 ou 13 écailles dans la ligne oblique, à Furio argenteus, Valenc., tandis que Fis Day le considère comme étant un Salmo salar; les autres caractères, mentionnés par Günther, conviennent au Fario argenteus, Valenc., par conséquent le nombre des écailles dans la ligne indiquée est insulfisant pour établir une détermination spécifique.

Le nom de Truite saumonée est donné d'une facon abusive au Tacon, qui devenu Grilse, fait sa première montée en eau douce, à la Truite de mer et encore à la Truite commune dont la chair est rougeàtre.

\section{LA TRUITE COMMUNE. - TRUTTA FARIO.}

Poiss. France, t. III, p. ə333.

N. vuig. : Truite de rivière; Truite ordinaire; Truite des lacs; Truite saumonée, quand la chair est rouge ; Troucia, Nice ; Truito ou Trucho, Gard; Troucha, Cette.

Long. : 0,20 à 0,60 et 1,00 .

Le corps est généralement un peu ovale, comprimé; sa hauteur est comprise quatre fois et un tiers à cinq fois et quari dans la longueur totale. - La tête est forte; sa longueur est contenue trois fois et deux tiers à quatre fois et trois quarts dans la longueur totale; le museau est gros; la bouche est largement fendue; la mâchoire supérieure est ordinairement plus avancée que l’inférieure, portant l'une et l'au tre une rangée de deuts crochues, ainsi que les palatins; le vomer a le chevron i peu près triangulaire, garni d'une rangée transversale de plusieurs dents, il a le corps, en général, assez étroit, avec une carène saillante, munie d'une ou de deux séries de dents moins caduques ordinairement que chez la Truite de mer; de chaque côté la langue a une rangée de trois ou quatre dents; le maxillaire supérieur est plus long que l'espace préorbitaire. suivant la taille des sujets, le diamètre de l'ieil est compris 
quatre fois et demie à sept fois dans la longueur de la tête; l'espace postorbitaire, ou la distance du bord postérieur de l'orbite au bord postérieur du battant operculaire fait à peine, chez les sujets de taille moyenne, la moitié de la longueur de la tête. Le bord postérieur du battant operculaire n'est pas courbe, il est oblique de haut en bas et d'avant en arrière; l'opercule est lisse ou peu strié; son angle postérieur et inférieur est à la même distance de l'angle antérieur et inférieur du sous-opercule que de la commissure supérieure de la fente branchiale. - La ligne latérale est à peu près droite. Ec., 1. long. 108 à 128 ; l. transv. 49 à 39 . - La caudale est fourchue chez les jeunes, échancrée ou carrée chez les adultes.

Br. 11. - D. 12 à $15-0$; A. 10 ì 12 ; C. 18 à 21 ; P. 13 ou 14 ; V. 9.

Le système de coloration est excessivement variable. Le dos est souvent d'un vert plus ou moins foncé; la gorge et le ventre sont jaunâtres. Sur la tête, le dos, les flancs, il y a des taches noires plus ou moins arrondies; des taches rougeâtres, parfois ocellées se montrent sur le corps, sur la dorsale. Quelquefois on trouve des sujets d'une teinte noirâtre, d'autre d'une teinte pâle et presque sans taches.

Habitat. La Truite est très commune dans la plupart de nos rivières.

3. LA TRUITE DE BAILLON. - TRUTTA BAILLON1.

Poiss. France, I. III, p. 3338.

Long. : 0,30 à 0,40 .

La Truite de Baillon, écrit Valenciennes, ressemble beaucoup à un jeune Saumon; la hauteur ${ }^{\bullet} d u$ tronc mesure le cinquième environ de la longueur totale. - La longueur de la tête est comprise quatre fois et un liers à quatre fois et demie dans la longueur totale; les mâchoires sont égales, ou la mâchoire supérieure est à peine plus avancée ; elles sont garnies de dents fines, très aiguës; le corps du vomer porte deux rangées de dents serrées, beaucoup plus petites que celles de la Truite commune; les dents des palatins, de la langue sont assez peu 
développées : le maxillaire supérieur ne dépasse pas le bord postérieur de l'orbite; le surmaxillaire est étroit, allongé; sa longueur fait plus de quatre fois sa hauteur. Le diamètre de l'œil fait à peine le sixième de la longueur de la tête ; il est d'un tiers moins grand que l'espace préorbitaire, qui est un peu plus petit que l'espace interorbitaire. - La ligne latérale est droite. Ec., l. long. 11 à ì 120, environ; 1 . transv. 38 à 42 . La première dorsale est un peu plus haute que longue; la caudale est fort échancrée ou même un peu fourchue.

$$
\text { Br. 9. - D. 13-0;A. 11; C. 23; P. } 12 \text { à } 14 ; \text { V. } 9 \text { ou } 10 .
$$

Le dos est plombé à reflets violacés, et couvert de taches assez grosses, empourprées (Valenc.) ; sur l'animal conservé, les taches sont devenues noirâtres. Les côtés et le ventre sont argentés. La première dorsale est marquée de petites taches brunes; la caudale est grisâtre, sans taches; l'anale et les pectorales sont jaunâtres; les ventrales blanches.

Habitat. Excessivement rare, Somme.

La Truite de Baillon n'est en aucune façon une variété de Salmo ou Trutta fario, comme le suppose V. Fatio, t. V, p. 346. - Le nombre des rayons branchiostèges qui est de neuf seulement, a été retrouvé par Valenciennes chez deux spécimens rapportés de Norwège par Noël de la Morinière.

\section{SOUS-GENRE OMBLE. - UWBLA.}

Téte; vomer denté sur le chevron seulement.

Ligne longitudinale composée de deux cents écailles au moins.

L'OMBLE-CHEVALIER. - UMBLA SALVELINUS.

Poiss. France, t. III, p. s30, fig. 207, anim.

N. vulg. : Ombre, Doubs, Jura.

Long. : 0,30 à 0,40 , quelquefois 0,80 .

La hauteur du tronc est contenue cinq fois et quart ì six fois dans la longueur totale, et la longueur de la tête quatre fois et demie à cinq fois et quart; les mâchoires sont égales, ou la mâchoire supérieure est à peine plus avancée; elles sont armées 
l'une et l'autre d'une rangée de dents assez fortes, aiguës, crochues; les palatins ont une rangée de dents crochues; il y a quelques dents sur le chevron du vomer seulement; la langue a de chaque côté une rangée de quatre à six dents fortes, parfois sur le bout elle en porte une petite. Le diamètre de l'œil est compris cinq fois et demie à six fois et deux tiers dans la longueur de la tête; il fait à peu près la moitié de l'espace préorbitaire qui est sensiblement égal à l'espace interorbitaire, chez les sujets déreloppés. - La ligne latérale est droite. Ec.. l. long. 208 à 213 : 1. transr. $\dddot{31 ~ đ ̀ ~ 68 . ~-~ L a ~ c a u d a l e ~ e s t ~}$ échancrée.

Br. 10 ou 11. - D. 1: à $15-0$; A. 10 à 13 ; C. 19 ou 20 ; P. 13 à 15; V. 9 à 11 .

Le dos est gris verdâtre, lè ventre d'un jaune orangé assez clair teinté de blanc ou de rose; des taches blanchâtres ou jaunâtres, parfois ocellées, ayant au centre un point rougeâtre, se montrent sur le dos et les côtés, principalement chez les jeunes individus; les taches, chez les sujets de grande taille, tendent à s'effacer et même disparaissent complètement. La première dorsale est pâle, rembrunie en avant; la caudale est pâle, à reflets d'un gris jaunâtre; l'anale et les nageoires paires sont d'un orangé pâle, elles ont le premier rayon, parfois le deuxième et le troisième d'un blanc laiteux.

Habitat. L'Omble-chevalier se trouve daus la Meurthe, dans les lacs des Vosges, dans le lac de Genève, le lac du Bourget, où il est assez commun; assez rare dans l'Ain, le Doubs, le Rhòne.

Depuis longtemps déjà on a tenté d'acclimater dans notre pays un certain nombre de Salmonidés étrangers, surtont des espèces américaines, Sulmo irideus, S. fontinalis, Oncorhynchus quinnat; jusqu'à présent les succès ne sont pas brillants. - En 1878, Carbonier làcha des alevins de Quinnat dans plusieurs cours d'eau, la Sarthe, la Vienne, l'Yonne, le Gave de Pau; depuis on a multiplié les expériences, on a mis du Quinnat un peu partout; on a même installé un établissement pour l'élevage de ce Poisson, dans l'Aude, à Quillan; on se flattait de peupler la Méditerranée d'une espèce nouvelle; un individu a été pris à Banyuls en 1890; on a fondé sur cette capture les plus grandes espérances, 5 pendant plusieurs mois ce fut un enthousiasme délirant, puis le silence s'est fait. - M. P. Vincent, ancien fermier de l'étang des Settons (Nièvre), avait, en 1878, reç 
2000 œufs de Quinnat qui lui donnèrent environ 1500 alevins, mesurant en novembre 1879 une quinzaine de centimètres; je ne sais ce qu'ils sont devenus. Assurément l'endroit était bien choisi pour obtenir d'excellents résultats; la Féra y avait pullulé d’une facon merveilleuse. - C'est dans ce remarquable bassin que le pr. Coste avait en l'idée de créer une Sammonerie artificielle; la station est la meilleure qu'il soit possible d'imaginer; encore aujourd'hui on devrait l'utiliser pour $y$ faire naitre ou pour y conserver une masse de Saumoneaux, destinés au rempoissonnement de nos rivières, ce qui raudrait beaucoup mieux que de les laisser détruire sans profit a Gouloux, et dans tout le cours de la Cure, de Montsauche à Cravant. - Contrairement à des assertions erronées, à des idées préconcues, jai démontré que le Saumon peut vivre dans la Méditerranée, qu'il y vit; j’ai rappelé (Suppl., p. 12'-126) qu'en 1882, les 1'́ 17 et 18 mai, trois Saumoneaux ont été capturés par des pècheurs de Cette; a-t-on jamais pris autant de Quinnats dans ces eaux si fatales, affirme-t-on, à notre espèce indigène? Quant aux premiers essais tentés pour la propagation du Saumon commun dans la Néditerranée, il est évident qu'ils n'ont pas réussi, mais ponvait-on espérer un succès en se plaçant pour expérimenter dans les conditions les plus déplorables: Je l'ai dit, ce n'est pas dans les rivières du Midi qu'il faut mettre les alevins, mais dans les affluents supérieurs du Rhòne, au-dessous de Bellegarde, bien entendu; l'Ain paraît tout indiqué; il en est beaucoup d'autres que je [n'ai pas à désigner. On pourrait avoir une énorme provision d'œufs fécondés ou d'alevins dans l'étang des Settons; près de sa digue, le Saumon, malgré les barrages, remonte encore en grand nombre; en 1882, un propriétaire de Cravant a pris d'un seul coup de filet 42 Saumons; en 1886 on constatait, dans l'Yonne, à Sens, la montée d'une grande quantité de Saumons.

\section{GENRE ÉPERLAX. - OSMERUS, Arted.}

Corps allongé, plus ou moins fusiforme; écailles très minces, caduques.

Tête large en dessus; bouche très grande; màchoire supérieure plus courte que la mandibule; dents sur les màchoires, les ptéryłopalatins, le vomer, la lanģue; maxillaire supérieur dépassant en arrière le prolongement du diamètre vertical de l'œil.

Nageoires; première dorsale commençant au-dessus ou en arrière de l'insertion des rentrales; caudale fourchue.

Vessie natatoire grande. - Appendices pyloriques courts, peu nombreux. 
L'ÉPERLAN COMHUN. - OSMERUS EPERLANUS, Lacép.

Poiss. France, t. III, p. 541 .

Long. : 0,15 à 0,2 b̆

La hauteur du corps est contenue six à sept fois dans la longueur totale, et la longueur de la tête quatre fois et demie à cinq fois et un quart; le museau est court; la mâchoire supérieure est moins avancée que l'inférieure; l'intermaxillaire a des dents assez fortes, le maxillaire, de très fines; la mandibule porte, en général, deux rangées de dents; le vomer est armé de grosses dents. Le diamètre de l'cil est compris quatre fois et demie à cinq fois et demie dans la longueur de la tête; il est plus petit que l'espace préorbitaire; il est à peu près égal à l'espace interorbitaire. - La première dorsale commence ordinairement au-dessus de l'insertion des ventrales.

Br. 7 ou $8 .-$ D. 9 à 11 - 0 ; A. 15 ou 16 ; C. 18 à 20 ; P. 8 ou 9 .

Le dos est gris verdâtre, transparent, pointillé de noir; les flancs et le ventre sont argentés; une bande verdâtre, sépare la teinte des côtés de celle du dos; cette bande manque chez les jeunes animaux. La première dorsale est d'un blanc teinté de noir; l'anale et les ventrales sont blanches: la caudale est grisâtre, noirâtre chez les jeunes; les pectorales sont blanches, avec le premier rayon noirâtre en dehors. - Les appendices pyloriques sont courts, peu nombreux, de quatre à six.

Habitat. Nos còtes de l'Ouest; l'Éperlan entre dans les rivières pour frayer; il remonte la Seine jusqu'à Rouen et mème plus haut; on le pèche dans le port de Dunkerque.

3. GENRE OMBRE OU THYMALLE. - THYMALLUS, CUV.

Corps allongé, légèrement comprimé, couvert d'écailles assez grandes.

Tête petite; bouche peu fendue; màchoires garnies de dents fines, courtes, pointues; le maxillaire supérieur est aplati, court, son extrémité arrivant à peine sous le bord antéricur de l'orbite; langue lisse. 
Nageoires; première dorsale aussi longue que la tête, avancée, commençant vers le milieu de l'espace séparant le bout du museau de la seconde dorsale; caudale fourchue.

Vessie natatoire développée. - Appendices pyloriques nombreux.

\section{L'OMBRE COMINUNE. - THYMALLUS VULGARIS.}

Poiss. France, t. III, p. 343.

N. vulg.: Oumbré, Gard ; Umbra, Pyrénées-Orientales (Companyo).

Long. : 0,20 à 0,30 , quelquefois 0,40 .

La hauteur du tronc est contenue cinq fois à cinq fois et demie dans la longueur totale, et la longueur de la tête cinq à six fois; le museau est convexe; la bouche terminale, un peu en-dessous; la mâchoire supérieure est un peu plus avancée que l'inférieure, elles ont l'une et l'autre une rangée de petites dents crochues; il y a en général des dents sur le chevron du vomer et sur le devant des palatins. Le diamètre de l'œil mesure le quart environ de la longueur de la tête, il est au moins aussi grand que l'espace interorbitaire, un peu moins que l'espace préorbitaire. - La ligne latérale est composée d'écailles plus petites que celles des rangées contiguës. Ec., l., long. 77 à 87 ; l. transv. 17 à 19. - La première dorsale est moins haute que longue, elle est aussi longue et parfois même plus longue que la tête, elle prend naissance sur la fin du premier tiers ou le commencement du second tiers de la longueur totale; l'adipeuse est assez grande; la caudale est fourchue; les ventrales sont insérées à peu près sous le milieu de la base de la première dorsale.

Br. 10. -D. 20 à $24-0$; A. 11 à 14. - C. 19 à 21 ; P. 15 ou 16 ; V. 10 ou 11 .

Le dos est blanc teinté de gris; les flancs et le ventre sont d'un blanc argenté, légèrement grisâtre sur le bord des écailles; souvent le corps est marqué de bandes longitudinales grisâtres. La première dorsale est d'un blanc rosé jaunâtre avec quelques séries de taches brunes formant des espèces de bandes dans les espaces intraradiaires; l'anale est couleur chair, teintée de brun; la caudale est d'un gris clail’ ; les pec- 
torales sont d'un ruse jaunàtre; les ventrales, d'un rose lavé de gris.

Habitat. LOmbre se Lrouve dans la Meurthe, la Moselle, la Meuse, le Chiers, le looubs, l'Ain (elle est assez commune aux environs de Pont-d'Ain), dans le lac d'Annecy, le lac du Bourget, dans le Rhòne, le Gardon, l'Hérault, dans la Loire, et la plupart des cours d'eau du département de la Haute-Loire; je l'ai vue en assez grande quanlité sur le marché du Puy.

\section{GENRE CORÉgone. - coregonUs, Arted.}

Corps allongé, plus ou moins comprimé, couvert, d'écailles asse» petites.

Tête de forme variable; bouche médiocre; màchoires non dentéos, ou n'ayant que des dents fort petites et caduques; langue non dentée; maxillaire supérieur aplati, court, n'arrivant pas, en arrière, au prolongement du diamètre vertical de l'œil.

Appareil branchial; huit à dix rayons branchiostèges.

Nageoires; première dorsale commençant plus en avant que les rentrales, après le milieu de l'espace séparant le bout du museau de la seconde dorsale; elle est généralement plus haute que longue, elle est beaucoup moins longue que la tète, ayant 13 i 17 rayons.

Vessie natatoire très grande. - Appendices pyloriques fort nombreux.

Ce genre se compose de qualre espèces.

a. Museau obtus........................... b.

- conique, très allongé................. q. hourno.

l. Màchoire supérieure égale à la mandibule........ 1. Lavaret.

- $\quad$ - plus avancée que la mandibule. $c$.

c. Pectorale d'un quart moins longue que la tête..... 2. FÉRA.

- à peine moins longue que la tête....... 3. gravenche.

1. IE COREGONE LAVARET. - COREGOVUS LAVARETUS.

Poiss. France, t. III, p. 546 .

$\mathbf{L o n}_{0}$ : : 0,20 à 0,40 .

La hauteur du tronc est contenue cing fois à cing fois el demie dans la longueur totale. - En dessus la tête est presque transparente; sa longueur mesure le sixième environ de la longueur totale; le museau est assez épais, non proémi- 
nent; la bouche est terminale; la mìchoire supérieure borde l'inférieure, quand la bouche est fermée; elles manquent de dents l'une et l'autre, ainsi que le vomer; l'extrémité du maxillaire supérieur arrive à peine sous le bord antérieur de l'orbite. Le diamètre de l'œil fait, ou peu s'en manque, le quart de la longueur de la tête, il est à peine moins grand que l'espace préorbitaire, qui lui-mème est plus pelit que l'espace interorbitaire. - La ligne latérale est bien dessinée. Ec., 1. long. $8 \ddot{3}$ à 92; 1. transr. 18 à 20. -- La première dorsale est trapézoïde, d'un cinquième ou d'un sixième plus haute que longue; l'anale est généralement un peu moins haute que longue; les peclorales sont un peu plus longues que les ventrales.

Br. 9 ou 10. - D. 14 à I6-0; A. 1 is ou 16 ; C. 19 ou 20 ; P. 15 ou 16 ; V. 12 ou 13 .

Le dos est gris bleuâtre à reflets, argentés; les côtés et le ventre sont argentés. Les nageoires sont grisàtres.

Habitat. Le Lavaret est très commun dans le lac du Bourget; il est quelquefois pèclıé dans le Rhòne et accidentellement dans l'Ain: suivant M. Charvet, il se trouve dans le Drac et dans l'Isère, mais, il r est très rare, tandis qu'il est assez abondant dans le Guier. - Il a été rapporté par M. le comte de Chambost, dans le lac d'Aiguebelette, où il se trouvait du temps de Rondelet (V. Rond., Poiss. des lacs, p. 118).

\section{LE COREGONE lÉR.I. - COREGONES FERA.}

Poiss. France, t. III, p. $̈ 49$.

Lony. : $0,2 \%$, à $0, \% 30$.

La hauteur du corps est contenue quatre fois et demie à cinq fois dans la longueur totale, et la longueur de la tête, cinq fois et demie à six fois; le museau est plus haut, plus saillant que chez le Lavaret; il est coupé un peu obliquement de haut en bas, d’arant en arıière; la mâchoire supérieure est plus avancée que l'inférieure. tantìt elle a, comme il en existe sur les palatins, de petites dents, tantòt elle en manque complètement. Le diamètre de l'œil est compris quatre 
fois et demie à cinq fois dans la longueur de la tête; il est égal, ou peu s'en manque, à l'espace préorbitaire, qui lui-même est à peine moins grand que l'espace interorbitaire. - La ligne latérale est bien marquée. Ec., l. long. 74 à $80 ; 1$. transv. 17 à 20. - La première dorsale est trapézoïde, très haute en avant; la pectorale est, en général, d'un quart moins longue que la tête.

Br. 8. - D. 1' ou 15 - 0; A. 13 à 16; C. 19 à 21; P. 14 ou 15 ; V. 11 à 13.

Le dos est d'un brun assez clair à reflets verdâtres; le ventre est blanchâtre. La dorsale et la caudale sont grisâtres.

Habitat. La Féra est très commune dans le lac Léman; elle s'est fort bien acclimatée dans l'étang des Settons, près Montsauche (Nièvre); parfois quelques-uns de ces Poissons s'échappent de l'étang et sont pêechés dans la Cure ou dans l'Yonne. Elle a réussi dans le lac Chauvet (Puy-de-Dòme).

Le Coregonus besola, Fatio, Faune des Vertébrés de la Suisse, t. V, p. 268, n'est pas, nous pensons l'avoir démontré d'une façon très nette, dans Suppl., p. 126, un Corégone d'espèce nouvelle, mais doit ètre rapporté au type Corégone féra, dont il n'est au plus qu'une variété, vivant dans le lac du Bourget, et désigné, par les pêcheurs savoisiens, sous le nom de Bezoule. Ce Poisson n'est ni en tout, ni en partie celui que j'ai décrit comme étant un Lavaret, ainsi que l'indique Fatio dans la synonymie.

\section{LE CORÉGONE GRAVENCHE. - COREGONUS HIEMALIS, Jur.}

Poiss, France, t. III, p. 551.

N. vulg. : Gravenche, Féra blanche, lac Léman.

Long. : 0,20 à 0,30 .

La hauteur du tronc est contenue quatre fois et un quart à cinq fois et un quart dans la longueur totale, et la longueur de la tête quatre fois et demie à cinq fois et trois quarts; le museau est assez avancé, coupé obliquement; la bouche est petite, presque transversale, non dentée; la mâchoire supérieure est un peu plus longue que la mandibule; le maxillaire supérieur, assez large en arrière, finit, ou peu s'en manque, sous le bord antérieur de l'orbite. Le diamètro 
de l'œil mesure le quart environ de la longueur de la tête; il est à peu près égal à l'espace préorbitaire, qui est un peu moins grand que l'espace interorbitaire. - La ligne latérale est bien marquée, à peu près droite. Ec. l. long. 70 à $8 \%$; 1. transv. 18 à 21. - La première dorsale est trapézoïde; elle commence un peu en avant de l'insertion des ventrales; la pectorale est à peine moins longue que la tête, le plus ordinairement.

Br. $8 .-$ D. 14 a $17-0 ; A .13$ à 17 ; C. 19 ou 20 ; P. 15 ou 16 ; V. 12 ou 13.

Le dos est d'un gris violet clair; les côtés et le ventre sont argentés. Les nageoires sont plus pâles que chez le Féra.

Habitat. Lac Léman; ne se pêche guère que dans le mois de décembre.

4. LE GORÉGONE HOUTING. - COREGONUS OXYRHYNCHUS.

Poiss. France, t. III, p. อ๊ŏ2.

Long. : 0,20 à 0,4 ว̆.

La hauteur du corps est comprise quatre fois et deux tiers à cinq fois et trois quarts dans la longueur totale; la longueur de la tête est contenue quatre fois et deux tiers à six fois dans la longueur totale; le museau forme une saillie conique dépassant de beaucoup la fente de la bouche, qui est petite, non dentée en général; il y a quelques points durs sur la langue. Le diamètre de l'œil est compris quatre fois et demie à cinq fois, dans la longueur de la tête; il est d'un tiers ou de moitié plus petit que l'espace préorbitaire, qui est plus grand que l'espace interorbitaire. - La ligne latérale est à peu près droite. Ec., l. long. 76 à 80 ; l. transv. 19 à 21 . La première dorsale commence en avant de l'insertion des ventrales, vers le milieu de la longueur totale.

Br. 9. - D. 13 ou $14-0$; A. 13 à 16 ; C. 19 ou 20 ; P. 15 ou 16 ; V. 12 ou 13.

La teinte est d'un gris verdatre sur le dos, gris plombé sur les flancs; le museau est noirâtre.

Habitat, Ce Poisson vit dans les eaux saumàtres et les eaux 
douces qu'il parait remonter pour frayer; il est excessivement rare en France, parfois pèché dans le Doubs; il est de temps en temps apporté sur le marché de Paris, arec des Poissons venant de la Hollande.

B. GENRE ARGENTINE. - ARGENTINA, Arted.

Corps allongé, couvert d'écailles caduques, grandes et minces.

Tête légèrement aplatie en dessus; houche peu fendue; maxillaire supérieur ne dépassant pas, en arrière, la perpendiculaire tangente au bord antérieur de l'orbite; mâchoire inférieure non dentée ; une bandelette arquée de petites dents sur le chevron du vomer et le devant des palatins.

Appareil branchial; six rayons branchiostèges.

Nageoires ; première dorsale commençant en avant de l'insertion des ventrales; caudale fourchue

\section{L'ARGENTINE SPHYRĖNE. - ARGENTINA SPHYRENA.}

Poiss. France, t. III, p. 5̋̉x, fig. 208, anim.

N. vulg. : Argentin, Nice; Péi d'Argen, Pëy d'archen, Cette.

Long. : 0,14 à 0,20 , quelquefois un peu plus.

La hauteur du tronc est contenue sept fois et demie à huil fois dans la longueur totale, et la longueur de la tête quatre fois à quatre fois et demie; les mâchoires sont à peu près égales, elles ne sont pas dentées, ou bien il n’existe que des dents excessivement fines à la màchoire supérieure; la langue est armée de dents crochues; le cherron du vomer et les palatins ont une bandelette de petites dents qui semblent caduques. Le diamètre de l'oil mesure environ le tiers de la longueur de la tête, il est égal à l'espace préorbitaire. - La ligne latérale est sur le tiers supérieur du corps. Ec., l. long. 40̈ à 50; l. transv. 6 ou 7. - La première dorsale est trapézoïde, beaucoup plus haute que longue; l'anale est base et reculée; l'insertion des rentrales est sous les derniers rayons de la première dorsale.

$$
\text { Br. 6. - D. } 9 \text { ou } 10-0 \text {; A. } 11 \text { ou } 12 \text {; C. } 16 \text {; P. } 12 \text { a } 14 \text {; V. } 10 \text { ou } 11 .
$$

Le corps est d'un blanc nacré fort brillant. La première dorsale est d'un gris pâle; la caudale, d'un gris assez foncé ; 
l'anale est blanchàtre; les nageoires paires sont pâles et légèrement rosées. Le péritoine est noiràtre. - Les appendices pyloriques sont au nombre de dix à douze. La vessie natatoire semble manquer de conduit pneumatophore; elle est enduite d'un pigment argenté, recherché pour la fabrication des fausses perles.

Habitat. Méditerranée; l'Argentine est assez comnune à Nice, à Narseille; très commune à Cette, au moins l'été.

\section{GeNRE MiCROSTONE. - MCROSTOMA, Cuv.}

Gorps très allongé, couvert d'écailles lisses et minces, enduites d'un pigment argenté.

Tête large en dessus; bouche peu fendue; màchoire supérieure non dentée; mandibule et chevron du vomer garnis de dents.

Appareil branchial : rayons branchiostèges peu nombreux.

Nageoires; première dorsale plus ou moins reculée, finissant arant l'origine de l'anale; seconde dorsale très réduite ou manquant; caudale fourchue.

Ce genre comprend deux espèces.

fre dorsale commençant au-dessus ou en arrière de l'inser-

tion des ventrales............................... 1. ArRoxpt. $1^{\text {re }}$ dorsale commençant en avant de l'insertion des ventrales. 2. oubuḱ.

\section{LE MICROSTOME ARRONDI. - MICROSTOMA ROTUNDATA.}

Poiss. France, t. III, p. 5้วั7.

N. vulg. : Yassou, Nice.

Long. : 0,12 à 0,21 .

Lahauteur du tronc, qui est à peu près cylindrique jusqu'aux ventrales, est contenue dix à quinze fois dans la longueur totale, et la longueur de la tête cinq fois à six fois et un quart; le museau est court; la mâchoire supérieure, à peine moins avancée que l'inférieure, n'est pas dentée; la mandibule est garnie de petites dents coniques; le chevron du vomer en porte de courtes, légèrement crochues. Lé diamètre de l'œil est compris deux fois et demie à trois fois dans la longueur de la lête; il mesure presque le double de l'espace préorbitaire qui est à peu près égal à l'espace interorbitaire. La muqueuse de 
la chambre branchiale est généralement brunâtre, au moins chez l'adulte. - La ligne latérale est droite. Ec., l. long. 44 à §2. - Chez les jeunes animaux, il y a deux dorsales; seule la première persiste chez les adultes; elle est reculée, commencant un peu en arrière de l'insertion des ventrales, rarement dans le même plan vertical, of toujours sur la seconde moitié de la longueur totale.

Br. 4. - D. 9 à $11-0 ;$ A. 8 ou 9 ; C. 19 à $22 ;$ P. 8 ; V. 10 ou 11.

Le corps est d'un blanc argenté fort brillant. Les nageoires sont pâles ou légè̀rement teintées de jaune. - Le péritoine est noirâtre.

Habitat. Méditerranée, excessivement rare, Nice.

2. LE MICROSTONE OLBLIE. - MICROSTOMA OBLITUY. Facc.

Poiss. France, Suppl., p. 128.

Long. : 0,12 à 0,20 .

La hauteur du corps, qui est comprimé, cunéiforme, est contenue de sept fois et demie à dix fois dans la longueur totale, et la longueur de la tête quatre fois ct demie à cinq fois et un quart; la mâchoire supérieure,un peu moins longue quc la mandibule,n est pas dentée; en arrière sur le vomer, et probablement sur l'appareil ptérygopalatin, est une arcade régulière de dents rapprochées, serrées les unes contre les autres, égales, étroites; les dents de la mandibule présentent les mêmes dispositions, elles paraissent toutefois un peu plus longues; chez les adultes, la muqueuse de la bouche, ainsi que celle de la chambre branchiale, est noirâtre, elle est rosée chez les jeunes. Le diamètre de l'oeil fait le tiers au moins de la longueur de la tête, le double de l'espace préorbitaire; il est à peu près égal à l'espace interorbitaire. - La première dorsale commence sur la première moitié de la longueur totale, plus en avant que la base des ventrales; la seconde dorsale est relativement développée, à peu près opposée au milieu de la base de l'anale qui est fort reculée; la caudale est échancrée ou plutôt fourchue.

Br. 4. - D. 10 a $12-0$; A. 10 à 12; C. 20 ou 21 ; P. 10 a 12; V. 1201113.

La teinte est d'un blanc argenté fort brillant. 
Habitat. Médilerranée, Nice, excessivement rare; un grand spécimen a été trouvé sur la plage de Nice, le 2 novembre 1887.

\section{Ordre des Apodes, Apodes.}

Corps très allongé, couvert d'une peau épaisse généralement nue ou n’ayant que de petites écailles sous-épidermiques, non imbriquées. - Vertèbres nombreuses.

Tête de forme variahle; bouche dentée; intermaxillaires soudés, et unis à l'ethmoïde et au vomer.

Appareil branchial; fente des oües étroite; pièces opercu. laires et rayous branchiostèges enveloppés dans la peau.

Nageoires; pas de ventrales; pectorales manquant assez sourent: nageoires impaires peu déreloppées; caudale tantòt manquant. tantòt unie aux autres nageoires impaires; ceinture scapulaire non altachée au cràne; parfois réduite à une petite tige osseuse.

Vessie natatoire pourvue d'un conduit pneumatophore.

Appendices pyloriques paraissant toujours manquer.

Ovaire sans oviducte.

L'ordre des Apodes est composé de cinı familles.

$a$. Caudale nulle.................... $b$. - existante.......................

b. Pectorales nulles ou fort peu distinctes..... - bien formées, ayant plus de sept rayons....................

c. Pectorales nulles.

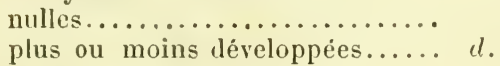

$d$. Orifice postérieur de la narine vers le bord de la lévre supérieure................. Orifice postérieur de la narine au-devant de

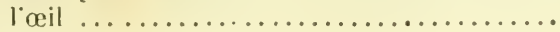

j. Simagebraxchides.

4. OPHSUHDÉS.

3. MURÉxidés.

2. MYRIDÉs.

1. Avguthidis.

\section{Famille des Anguillides, Anguillida.}

Corps allongé, serpentiforme, arrondi en avant, comprimé vers la queue, nu ou à très petites écailles cachées dans la peau; anus placé loin de la tète; pas de còtes.

Tête longue; màchoires dentées; langue libre.

Narines à deux orifices éloignés l'un de l'autre; orifice postérieur au-devant de l'oil.

Appareil branchial: ouverture des ouies à liı hase de la pectorale. 
Nageoires impaires réunies; pertorales plus ou moins développées.

Cette famille comprend deux genres.

Màchoire supérieure plus courte que l'inférieure........ 1. Anguille.

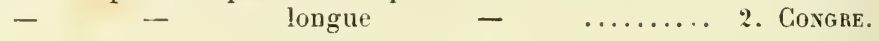

\section{GENRE ANGUILLE. - ANGUILLA.}

Corps garni de fort petites écailles cachées dans la peau.

Tête; màchoire supérieure plus courte que l'inférieure; portant, l'une et l'autre, des dents en cardes fines, ainsi que le vomer.

Nageoires; dorsale commençant très en arrière des pectorales.

\section{L'ANGUILLE VULGAIRE. - ANGUILLA VULGARIS.}

Poiss. France, t. III, p. 360.

N. vulg. : Verniaux. Jeunes : Civelles, Bouirons.

Long. : 0,40 à 1,00 et plus.

Le corps est couvert d'une peau très épaisse dans laquelle sont cachées de fort petites écailles. Les mâchoires et le vomer sont garnis de dents en cardes fines. Le diamètre de l'œil est contenu de huit à douze fois dans la longueur de la tête. Le système de coloration est très variable; le dos est souvent brun olivâtre ou brun jaunâtre; le ventre est blanchàtre.

Habitat. L'Anguille est très commune dans nos eaux.

VAR. A. - L'Anguille à museau large. - Anguilla latirostris.

Poiss. France, t. III, p. 562.

N. vulg. : Pimperneaux.

Le museau est large, aplati, ayant plus de largeur que de hauteur; les mâchoires sont très développées, surtout la mandibule qui est plus large que la màchoire supérieure; les yeux paraissent grands.

Habitat. Cette Anguille est commune à l'embouchure des égouts, dans la retenue des ports, dans les pares à huîtres.

VAr. B. - Anguille plat-bec. - Anguilla platycephala.

Poiss. France, t. III, p. 363.

La tète est aplatie; le museau est plat, à bord assez arrondi, asséz 
semblable à un bec de Canard. Lioil est petit, l'iris d'un blanc jaunàtre teinté de rougge. La coloration est gris jaunàtre.

\section{Moxstr. - L'Anguille de Kiéner. -- Anguilla Kieneri.}

Poiss. Franer, t. III, p. כ̈63.

C'est un sujet monstrueux, ayant des yeux énormes.

Il est inutile de citer les noms des espèces imaginées par Kaup.

Suivant Ercolani, les Anguilles sont hermaphrodites, c'est une erreur; j'ai démontré ( d'ovules femelles, provenant de sujets de sexe différent. - Les prétendus ovules, figurés par Ercolani, sont de simples cellules adipeuses contenant des cristaux de margitrine (Ercolani, Perfetto ermaphrodismo delle Anguille, Bologna, 1872).

\section{GENRE CONGRE. - CUNGER, CUv.}

Corps; peau entièrement nue, sans aucun vestige d'écailles.

Tète: màchoire supérieure plus longue que l'inférieure, armées, l'une et l'autre, de dents placées sur plusieurs rangées.

Nageoires; dorsale commençant au-dessus des pectorales, ou très près de leur extrémité.

Ce genre comprend trois espèces.

$a$. Lèvre supérieure ordinaire............. b. - _ soutenue de chaque còté par deux tiges osseuses..

b. Dorsale commencant au-dessus de la base des

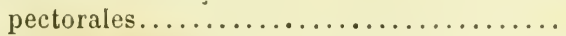
Dorsale commeneant au-dessus de la fin des pectorales........................

3. A LARGES lè̀VRes.

2. DES İLES BALÉARES.

1. CoMmex.

1. IE CONGRE COMNIN. - CONGER VULGARIS.

Poiss. France, t. III, p. 563.

N. vulg. : Grouch, Felat, Nice; Coungré, Cette; Cungre, Mussole, Pyrénées-Orientales; Anguille de mer.

Long. : 0,50 à 2,00 et plus.

La måchoire supérieure est plus arancée que l̈inférieure; en avant, elle est garnie de dents en cardes assez fortes; sur les cotés, le maxillaire porte une rangée de dents égales, serrées les unes contre les autres, il présente. sur le bord interne, une 
autre série de dents assez courtes, se prolongeant plus ou moins en arrière; le vomer a des dents en cardes; ì la mandibule, les dents présentent à peu près la même disposition qu à la màchoire supérieure. Le diamètre de l'œil mesure environ la moitié de l'espace préorbitaire. L'orifice antérieur de la narine est tubuleux. - Ordinairement la dorsale commence audessus de la fin des pectorales; la pectorale est soutenue par quinze à dix-neuf rayons. - Le dos est, en général, d'un gris jaunâtre ou brunàtre; le ventre est blanchàtre. Les nageoires impaires sont d'un blanc grisâtre, à bordure noire; les pectorales sont grisâtres. La ligne latérale est souvent marquée de points blanchàtres.

Habitat. l.e Congre est commun sur loutes nos còtes.

$$
\text { Vак. - Le Congre noir. - Conger Niger. }
$$

Poiss. Frunce, t. III, 1. 3̈66.

N. vulg. : Grouch negre, Nice; Coungré négré, Cette ; Congre de roches, côtes de Bretagne.

Le museau est assez aigu. Le dos est noiràtre, le ventre grisàtre.

Habitat. Il est pèché sur toutes nos còtes.

Jecne. - Le Leptocéphale de Morris. - Leptocephulus Morrisii.

Poiss. France, t. III, p. :36 6 .

J'ai démontré que le Leptocéphale de Morris est le jeune du Congre commun. - Malgré l'assertion de quelques naturalistes, qui semblent n'avoir pas suffisamment étudié l'anatomie de celte larve, les organes de la reproduction sont faciles à reconnaitre.

2. LE CONGRE DES ILES BALÉARES. - CONGER BALEARICUS.

Poiss. France, t. III, p. 369.

N. vulg. : Ugliassou, Nice.

Long. : 0,20 à 0,30 .

La bouche est l'endue à peu près jusque sous le bord antérieur de l'orbite; les mâchoires et le vomer ont de fort petites dents en cardes, à pointe tournée en arrière. Le diamètre de l'aul est compris cinq à six fois dans la longueur de la tête. 
Loritice antérieur de la narine esl tubuleus. - La dorsale nait ordinairement au-dessus de l'ouverture des ouĩes; les pectorales, courtes et étroites, ont seulement huit ou neuf rayons. - La teinte générale est jaune verdâtre. Les nageoires impaires sont blanches, bordées de noir; les pectorales semblent d'un gris jaunatre. La ligne latérale parait brunàtro.

Habitat. Méditerranie. Nice, très rare: commun dans les Pyrénées-Orientales, d'après le I)r Companyo.

3. LE CONGRE A LARGES LEVRES. - CONGER MYSTAX.

Poiss. France, t. III, p. "̈ill.

N. vulg. : Nourua, Nice.

Long. : 0,2 :̈ à 0,300 .

Le museau est saillant, pointu; la fente de la bouche s'étend plus loin que le bord antérieur de l'orbite; la lève supérieure est une large expansion membraneuse, soutenue par deux tiges osseuses, jouissant d'une certaine mobilité; la mâchoire supérieure est beaucoup plus allongée que l'inférieure; elles sont garnies, l'une et l'autre, de plusieurs rangées de dents coniques, plus longues et plus fortes à la rangée externe; le romer a les dents mousses. Le diamètre de l'œil est contenu de cinq à sept fois dans la longueur de la tête, il mesure la moitié, et parfois plus, de l'espace préorbitaire, il est plus grand que l'espace interorbitaire. L'orifice antérieur de la narine est tubuleux. - La dorsale prend naissance à peu près au-dessus du milieu de la longueur des pectorales, qui ont une douzaine de rayons. - La coloration est d'un gris assez pàle. Les nageoires impaires ont un liséré brun peu marqué.

Habitat. Méditerranée, Nice, rare; suivant M. Doumet, il est commun à Cette; d'après le I) Companyo, il est commun sur la còte des Pyrénées-Orientales.

2. Firmille des Myridrs, Myridie.

Corps allongé, plıs on moins arrondi; peau nue; còtes nombreuses. 
Tête assez étroite, à museau pointu; bouche bien fendlie; màchoires garnies de dents courtes, pointues, en cardes.

Narines ayant l'orifice antérieur tubuleux, l'orifice postérieur non tubuleux, vers le bord de la lèvre supérieure.

Nageoires; dorsale commençant au-dessus ou un peu en arrière de la fin des pectorales, unie à la caudale, ainsi que l'anale.

\section{GENRE MYRE. - MYRUS, KaUp.}

Caractères de la famille.

LE MYRE COMMUN. - MYRUS VULGARIS, Kaup.

Poiss. France, t. III, p. 472.

N. vulg. : Moruo, Morua, Nice; Demouieïzèla, Celte.

Long. : 0,30 à 0,80 .

Les flancs sont soutenus par des côtes nombreuses bien développées. - La tête est assez pointue; le museau est très avancé; la bouche est fendue jusque sous le bord postérieur de l'orbite : la màchoire supérieure, plus avancée que la mandibule, montre en avant un disque garni de dents assez petites, très aiguës, sur les côtés une bande assez large de dents courtes, un peu crochues; le vomer porte une plaque ovale ou plutôt losangique couverte de dents, les unes mousses, les autres pointues; il y a sur la mandibule une bande large de dents courtes, à pointe tournée en arrière. Le diamètre de l'œil est compris huit à neuf fois dans la longueur de la tête; il fait la moitié environ de l'espace préorbitaire; il est à peu près égal à l'espace interorbitaire. L'orifice postérieur de la narine est une fente oblique sur le bord externe de la lèvre supérieure. - La ligne latérale est indiquée par une suite de petites saillies, et généralement par une série de points blanchâtres ou grisâtres. - La pectorale compte une douzaine de rayons. - Le dos est gris verdàtre, parfois rougeâtre; le ventre est d'un gris jaunâtre ou couleur chair; la tête est violacée, traversée de raies blanchâtres; de chaque côté du museau est une rangée de points blanchâtres. Les nageoires impaires sont blanchàtres, bordées de noir; les pectorales sont rosées. 
Habitat. Méditerranée, assez rare, Nice, Cette. Océan, excessivement rare, golfe de Gascogne, Bayonne, Arcachon.

\section{Famille des Murénidés, Murarnider.}

Corps allongé ; peau nue, enduite d'une mucosité épaisse. Nageoires; nageoires impaires unies; pas de pectorales. Cette famille comprend deux genres.

Dents de la màchoire supérieure sur une ou deux rangées. 1. Munèse.

- - - - encardes, trèsnombreuses. 2. Neтtastone.

\section{GENRE MURENE. - MUREN $A$.}

Tête comprimée; bouche fendue plus loin que le bord postérieur de l'orbite; dents sur les màchoires et le vomer.

Narines ayant leurs orifices tubuleux.

Nageoires; dorsale très longue, peu distincte en avant.

Le genre Murène est formé de deux espèces.

Dents à la màchoire supérieure sur une rangée......... 1. HÉLĖxE.

- $\quad-\quad$ deux rangées ....... 2. cxicolone.

\section{LA MURENE HELENE. - MURENA HELENA, Linn.}

Poiss. France, t. III, p. כ̈7̈, fig. 209, anim.

N. vulg. : Mourena, Nice; Murena, Hérault, Pyrénées-Orientales. Long. : 0,60 à 1,30 ,

La tète est en forme de pyramide à quatre faces très inégales; les faces latérales sont beaucoup plus larges que les autres; le museau est pointu; la bouche largement fendue; la màchoire supérieure, légèrement plus avancée que l'inférieure, est armée de dents fortes, crochues, un peu tranchantes, disposées sur une seule rangée, ainsi que celles de la mandibule; le vomer est denté; l'arcade palatine, incomplète, semble réduite à sa partie ptérygoïdienne. Le diamètre de l'œil fait environ le tiers de l'espace préorbitaire, les deux tiers de l'espace interorbitaire, chez les animaux très déreloppés. - La dorsale commence un peu en arrière de l'ouverture branchiale. - Le système de coloration est variable; ordinairement la teinte est 
d'un brun noiratre avec des plaques jaunes semées de petites taches noires: souvent le fond est jaunatre avec des raies noires isolées ou circonscrivant de larges taches jaunes marquées de points noirâtres; quelquefois la teinte est noirâtre tachetée de blanc et de jaune, ou bien encore fauve avec des bandes obscures; en raison de ces différences de coloration, Risso avait admis les trois espèces suivantes : M. hélène, II. fauee, M. tachetée.

Habitat. Méditerranée, la Murène hélène est assez commune à Nice, Toulon; assez rare à Celte, Port-Vendres. Océan, assez rare. Bayoune; très rare, Arcachon; excessivement rare au nord de la Gironde, la Rochelle.

?. LA MURENE UNICOLORE. - IURAEA UNICOLOR, Delar.

Poiss. France, t. III, p. $37 \%$.

N. vulg. : Mourena sensa spina, Nice.

Long. : 0,00 à 1,00 .

La tète est comprimée; le museau un peu arrondi; les màchoires sont étroites, à peu près égales; la mâchoire supérieure porte deux rangées de dents; la mandibude a généralement une double rangée de dents sur la moitié antérieure, et une rangée simple sur la moitié postérieure; le vomer est, en avant, muni de quelques dents crochues, et, sur le chevron, est garni de deux rangées de dents assez petites. Le diamètre de l'œil mesure environ les deux cinquièmes de l'espace préorbitaire, la moitié de l'espace interorbitaire. - La dorsale commence sur la nuque, en avant de l'ouverture branchiale. - La teinte est uniforme, d'un marron plus ou moins foncé. Les nageoires ont une bordure jaunâtre.

Habitat. Méditerranée, rare, Nice, Celte.

2. GENRE NETTASTOME. - NETTASTOMA, Ratin.

Corps arrondi en avant, terminé par une queue fort grèle.

Tête; museau très allongé; bouche largement fendue; mâchoires garnies de dents en cardes fines, excessivement nombreuses. 
Narines; oritices très éloignés l’un de l'autre. l'antérienr lubuleux, le postérieur ovale, en avant de l'wil.

\section{LE NETTASTOME QUELE NOIRE, - NETTASTOM.I IEL.I NURA, Rafin.}

Poiss. France, t. III, p. :3ig, fig. 210, tìte.

N. vulg. : Masca, Nice.

Long. : 0,30 à 0,80 .

Le museau, fort allongé, est aplati, terminé par un petit tubercule charnu, assez élastique; la fente de la bouche s'étend jusque sous le bord postérieur de l'orbite; la màchoire supérieure est plus longue et plus large que linférieure; elles sont garnies, l'une et l'autre, de dents en cardes fines sur une large bande; les dents des rangées internes sont beaucoup plus fortes et plus longues que celles des rangées externes; le vomer porte une bande longitudinale de dents étroite en avant, beaucoup plus large en arrière. Le diamètre de l'œil est contenu quatre fois à quatre fois et demie dans la longueur de l'espace préorbitaire; il est plus grand que l'espace interorbitaire. - La dorsale commence au-dessus de l'ouverture branchiale. - Le dos est d'une teinte marron; le ventre est d'un gris plombé. Les nageoires sont bordées de noir sur une certaine partie de leur étendue.

Habitat. Méditerranée, Nice, assez rare.

Chez ce Nettastome, l'occipital basilaire est terminé par un simple condyle hémisphérique, qui se loge dans une espèce de cotyle creusée dans la face antérieure de la première vertèbre. - Dans la Murène hélène, au contraire, la première vertèbre a le centrum fortement convexe en avant.

\section{Famille des Ophisuridés. Ophisuridar.}

Corps très allongé, plus ou moins cylindrique, tout à fait nu.

Téte; museau avancé; dents sur les màchoires, le vomer.

Narines ayant l'orifice postérieur vers le bord de la lèvre supérieure.

Nageoires; dorsale et anale tinissant avant la pointe de la queue; caudale nulle; pectorales bien formies. 


\section{GENRE OPHISURE. - OPHISURUS, Lacép.}

Caractères de la famille.

Ce genre comprend deux espèces.

Espace préorbitaire faisant plus de trois fois le diamètre

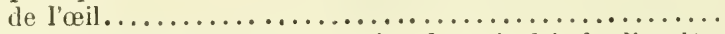

Espace préorbitaire faisaut moins de truis fois le diamètre de l'œil...................................

1. SERPENT

2. D'Espagie.

\section{L'OPHISURE SERPENT. - OPHISURUS SERPENS.}

Poiss. France, t. III, p. ว81, fig. 211, anim.

N. vulg. : Bissa de mar, Nice; Ser de mer, Cette; Colubro de mer, Pyrénées-Orientales.

Long. : 1,00 à 2,20 .

La tête est étroite, longue, pointue; le museau est effilé, conique; la fente de la bouche se prolonge très en arrière des yeux; les mâchoires sont fort étroites en avant; la màchoire supérieure est plus avancée que la mandibule; à son extrémité, elle porte, de chaque côté, une rangée de dents pointues, crochues, beaucoup plus fortes que les suivantes; à partir de l'aplomb de l'orifice postérieur de la narine, elle est munie de dents placées sur deux séries; le vomer est armé de dents crochues; la mandibule a les dents sur une seule rangée, les dents antérieures sont crochues, beaucoup plus développées que les autres. Le diamètre de l'œil est compris dix à treize fois dans la longueur de la tète; il mesure le quart ou le cinquième de l'espace préorbitaire; il est à peine moins grand que l'espace interorbitaire. L'orifice postérieur de la narine est une fente placée sur le côté externe de la lèrre supérieure. La dorsale commence en arrière de l'extrémité de la pectorale, et finit à une assez courte distance de la pointe de la queue; la pectorale est peu développée; elle a quatorze à seize rayons. - Le dos est jaune doré, teinté de brun; le ventre est grisâtre ou blanc argenté. La dorsale et l'anale sont lisérées de noir; les pectorales sont jaunâtres.

Habitat. Méditerranée, assez commun, Nice, Cette. 


\section{L'OPIIISURE D'ESPAGNE. - OPHISURUS MISPANUS.}

Poiss. France, t. III, p. 384, fig. 212, anim.

Long. : 0,30 à 0,60 .

En dessus la tête est laiblement déprimée; le museau est mousse, un peu conique, faisant une petite saillie en avant de la bouche, entre les tubes des orifices antérieurs des narines; la fente de la bouche dépasse à peine la perpendiculaire tangente au bord postérieur de l'orbite; la mâchoire supérieure est plus avancée que l'inférieure; en avant, sous le museau, elle porte un petit groupe isolé de dents aiguës, crochues; sur les còtés des mâchoires, sur le vomer, les dents sont en rangée simple. Le diamètre de l'œil mesure environ le dixième de la longueur de la tête, la moitié de l'espace préorbitaire, il est à peine moins grand que l'espace interorbitaire. Le tube de l'orifice antérieur de la narine est large, développé, placé vers le bout du museau; l'orifice postérieur est sur la lèvre supérieure, à l'aplomb du bord antérieur de l'orbite. - La dorsale, qui est fort basse, commence vers la fin du quart antérieur de la longueur totale; la pectorale est courte, soutenue par dix à douze rayons. - La teinte est d'un jaune rougeâtre assez clair, arec un fin pointillé noirâtre. La dorsale et l'anale sont d'un blanc ou d'un gris jaunâtre.

Habitat. Méditerranée, excessivement rare, Cannes, Nice.

\section{Fumille des Sphagebranchidés, Sphagebranchida'.}

Corps très allongé, plus ou moins cylindrique; peau complètement nue.

Tête longue; màchoire supérieure plus avancée que l'inférieure, pourvues, l'une et l'autre, de petites dents.

Narines ayant l'orifice antérieur tubuleux.

Appareil branchial; ouvertures des ouies sous la gorge, rapprochées l'une de l'autre.

Nageoires; caudale nulle; dorsale el anale très basses, parfois mè̀me peu distinctes; pectorales nulles ou rudimentaires. 
GENRE SPHAGEBRANCHE. - SPIAGERRANCHUS, Bloch.

Caractères de la famille.

Le genre Sphagebranche est composé de deux espèces.

Extrémité de la mandibule plus rapprochée du bout du mu-

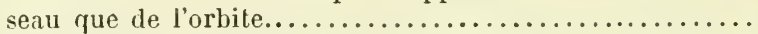
Extremité de la mandibule plus rapprochée de l'orbite que

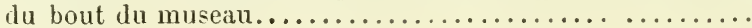

1. IMBERBE.

2. MVUGLE.

\section{LE SPHAGEBRANGHE IMBERBE. - SPILAGEBRA NCHUS} IIIBERBIS, Delar.

Poiss. France, t. III, p. ̈̈s6.

N. vulg. : Mourua, Nice.

Long. : 0,2 ว̆ à 0,30 .

La tète est conique, renflée en arrière, distincte du corps; le museau est proéminent, pointu; la fente de la bouche finit un peu en arrière de l'orbite; les dents des maxillaires et de la mandibule sont disposées sur une seule rangée. L'œil est plus rapproché de la commissure de la bouche que du bout du museau; il est petit, son diamètre ne faisant guère que le sixième de l'espace préorbitaire. L'orifice antérieur de la narine est vers le bord de la lèvre supérieure. Loouverture des ouïes est étroite; elle est séparée de celle du côté opposé par une distance à peu près égale à la longueur de son grand diamètre. - La dorsale et lanale sont excessivement basses, cachées dans un sillon; les pectorales sont extrêmement réduites, souvent même elles manquent chez les sujets de grande taille, à leur place. il ne reste parfois qu'une saillie peu sensible. - Le dos est gris violet, tacheté de points noiràtres; le ventre est d'un blanc pâle ou jaunàtre à reflets argentés; parfois la teinte grénérale est jaunâtre, variée de rouge ou de violet. La dorsale et l'anale sont blanches.

Habitat. Médilerranée, très rare, Nice, Cette. 
2. I.E SPHAGEBRANCHE AVEUGLE. - SPHAGERRA NCHUS reCTS.

Poiss. France, t. III, p. ̈̈8s.

N. vulg. : Bissa, Nice.

Long. : $0,2 \ddot{3}$ ì 0,30 .

Le corps est fort allongé, beaucoup plus grèle que chez le sphagebranche imberbe; en général, la tète se continue avec le tronc sans ligne de démarcation bien apparente, elle est longue, conique; le museau est aigu, très proéminent: la fente de la bouche sétend heaucoup plus loin que le bord postérieur de lorbite; les maxillaires supérieurs et la mandibule ont une rangée de petites dents acérées. Chez les animaux développés. on distingue assez facilement les yeux. L'orifice antérieur de la narine est sous le bord du museau; il semble plus rapproché de la pointe du rostre que de l'extrémité de la mandibule. Les fentes branchiales sont très étroites, fort près l'une de l'autre. - La dorsale et l'anale sont extrêmement basses, et même elles paraissent manquer chez les ánimaux conservés; il n’existe aucun vestige de pectorale. - Le dos est rougeâtre, semé de points noirs; les côtés sont d'un rouge jaunàtre; le ventre est blanc grisatre; quelquefois la teinte générale est d'un brun peu foncé.

Habitat. Méditerranée, très rare, Nice, Cette.

2. SOUS-CLASSE DES MARSIPOBRANCHES. - UARSIPOBRA NCHIT, Bp.

Corps allongé, courert d'une peau nue. Squelette cartilagineux ou fibro-cartilagineux.

Tête non mobile sur la colonne verlébrale; bouche en forme de rentouse; pas de véritables màchoires.

Appareil branchial; branchies renfermées dans des poches.

Nageoires; pas de nageoires paires; nageoires impaires soulenues par des pièces squeleltiques.

Vessie natatoire nulle. 


\section{Ordre des Gyclostomes, Cyclostomi.}

L'ordre des Cyclostomes est réduit au sous-ordre des Pétromyzones, ou Cyclostomes à palais non perforé. - La Myxine, Myxine glutinosa (Cyclostome à palais perforé) n'a pas encore été signalée sur nos còtes.

\section{Sous-ordre des Pétromyzones, Petromyzones.}

Corps allongé, plus ou moins cylindrique; squelette cartilagineux ou fibro-cartilagineux; corde dorsale persistante, sans aucune trace de segmentation.

Tête; son squelette est formé de pièces cartilagineuses (V. t. III, fig. 213); bouche de forme variable; cràne très peu développé (cerveau, V. t. III, fig. 214).

Yeux latéraux, sans procès ciliaires, sans ligament falciforme; cachés sous la peau chez les très jeunes animaux.

Narines placées dans des capsules en communication avec le canal de l'évent qui débouche sur le milieu de la tète (V. t. III, p. 215$)$.

Oreille logée dans une capsule cartilagineuse; composée d'un vestibule membraneux et de deux canaux semi-circulaires.

Appareil respiratoire; l'appareil hyoïdien est à peu près réduit à une seule pièce, le cartilage lingual; chez l'animal adulte, les lames respiratoires sont renfermées dans des poches au nombre de sept de chaque côté, s'ouvrant chacune au dehors par un orifice particulier.

Appareil circulatoire; le cœur présente dans sa conformation beaucoup de rapport avec celui des Poissons osseux.

Appareil digestif; le canal intestinal va directentent de la bouche à l'anus, sans dilatation stomacale; pas d'appendices pyloriques.

Glande sous-orbitaire formée de tubes renflés à leur extrémité avengle (V. t. III, fig. 216).

Conservation de l'espèce; l'ovaire et le testicule n'ont pas de canal vecteur; les produits de ces glandes tombent, quand ils sont mûrs, dans la cavité abdominale, d'où ils sortent par les conduits péritonéaux. - Animaux subissant des métamorphoses: 
Framille dess Pétromyzonidés, Polromyzomidie, Bp.

Corps allongé, cylindrique en avant, comprimé à partir de la première dorsale, couvert d'une peau nue, visqueuse.

Tête se terminant chez les adultes par une large bouche circulaire formant ventouse, armée d'un appareil dentaire présentant une disposition variable suivant les espèces.

Appareil branchial; ouvertures branchiales au nombre de sept de chaque còté.

Nageoires soutenues par des rayons cartilagineux; deux dorsales plus ou moins séparées l'une de l'autre; anale courte, unie à la caudale, ainsi que la seconde dorsale.

GENRE LAMPROIE. - PETROMYZON, Arted.

Caraclères de la famille.

a. Pièce maxillaire supérieure à deux pointes rapprochées...............................

Pièce maxillaire supérieure à deux pointes écartées. $b$.

b. Dorsales éloignées.......................... 2. fluviatile.

- rapprochées.................... 3. de Plader.

\section{LA LAMPROIE MARINE. - I'ETROMYZON MARINUS, Linn.}

Poiss. France, t. III, 1. 602, fig. 21\%, anim.

N. vulg. : Lamprua, Nice ; Haoutböy, Lampruzza, Cette; Lampré, Lamprézo, Gard ; Set-ulls, Pyrénées-Orientales; Anguille lampresse, Charente-Inférieure; Grande Lamproie, Lamproie marbrée.

Long. : 0,60 à 1,00 .

Aucune ligne de démarcation ne sépare le tronc de la tête; la bouche est circulaire, entourée d'une lèrre charnue, garnie sur le côté interne de cirres ou de petits tentacules fort nombreux; elle est munie de dents coniques, placées en séries régulières; les dents, qui sont en avant et sur les côtés du fond de la bouche, sont généralement à deux pointes; la plus forte est celle qui se trouve sur la ligne médiane en arant du pharynx, et qui a été comparée à une mâchoire supérieure; elle est opposée à une pic̀ce dentaire munie de sept ou huit pointes, qui est en arrière des dents linguales, et qui parfois a été regardée comme une màchoire inférieure. Le cartilage lingual a son 
extrémilé antérieure armée de trois pièces dentelées. Les yeux sont petits, arrondis. - Les dorsales sont plus ou moins séparées l'une de l'autre suivant la taille des sujets; l'anale est courte. - Le dos et les côtés sont d'un blanc grisâtre ou jaunâtre, marqués de taches irrégulières d'un noir plus ou moins foncé; le ventre est blanchâtre.

Habitat. La Lamproie marine est commune en France; áu printemps elle s'engage dans les fleuves qu'elle remonte parfois à une grande distance.

\section{LA LAMPROIE FLUVIATILE. - PETROMYZON FLUVIATILIS, Linn.}

Poiss. France, t. III, p. 60t.

N. vulg. : Lamprillon, Lamproie d'Alose, Jura; lou Fifre, Haute-Loire; Lamprézo, Lampré, Gard ; Set-ulls, Pyrénées-Orientales; Petite Lampresse, Pibale, Charente-Inférieure; Bète à sept trous, Somme; Lamprillon, Lamproyon, Petite Lamproie, Sept-œil, dans beaucoup de départements.

Long. : 0,09 à 0,30 , quelquefois 0,50 .

La Lamproie de rivière ressemble beaucoup à la Lamproie marine, sauf la taille qui est moindre. - La bouche est un sucoir arrondi ayant une rangée circulaire de dents pointues; il y a souvent, de chaque côté de l'entrée du pharynx, deux ou trois dents bicuspides; la pièce maxillaire supérieure est courbe, lisse dans sa partie médiane, armée à chaque extrémité d'une grosse dentelure plus ou moins pointue; la pièce mandibulaire ou maxillaire inférieure, est en croissant, à sept ou huit dentelures aiguës, la dentelure externe est souvent bicuspidée. Le cartilage lingual porte une espèce de pièce transversale semi-circulaire, ayant une dent médiane grosse et large et cinq ou six petites dents latérales à droite comme à gauche; chez les jeunes animaux, le disque buccal est garni de plusieurs séries de dents. Les yeux sont plus ou moins éloignés du museau. - Les dorsales sont séparées l'une de l'autre par un intervalle assez large chez les sujets de grande taille, étroit chez les individus peu développés. - Le dos est plombé, noirâtre, le côté est grisâtre, le ventre est blanc argenté ou jaunâtre; chez certains sujets, le corps est marqué de bandes 
noiratres transversales ; parfois la teinte générale est argentée, parfois elle est rougeatre.

Habitat. Elle se trouve lans la plupart de nos rivières.

3. LA LAMPROIE DE PIANER. - PETROMYZON PLANERI, Bloch.

Poiss. France, t. III, p. 606.

Long. : 0,09 à 0,2 əे.

Suivant les ichthyologistes, chez lit Lamproie de Planer, les nareoires dorsales sont plus rapprochées et les dents sont plus obtuses que chez la Lamproie fluviatile; ces caractères n'ont aucune valeur pour la détermination spécifique; quant au système de coloration, il est le mème dans la Lamproie de Planer que dans la Lamproie fluviatile. A. Müller dit bien que les Ammocètes de la Lamproie fluviatile et celles de la Lamproie de Planer ont une vésicule biliaire et des otolithes, qui ne persistent que chez la Lamproie de Planer et nullement chez la Lamproie fluviatile: mais le développement était-il bien le mème chez les sujets considérés comme appartenant à deux espèces distinctes ?

\section{LARve. - Ammocète branchiale. - Ammocetes branchialis.}

Puiss. France, t. III, p. 607.

N. vulg. : Chatouille, Satoille, Lamprillon, Lamproyon, Sucet, suce-pierre, Sept-œil rouge, Sept-œil aveugle.

La bouche présente à peu près la figure d'un fer à cheval; elle est entourée d'une bordure de papilles divisées en rameaux secondaires; elle n'est pas dentée; la lèrre supérieure est très grande, ses prolongements latéraux entourent une partie de la lèrre inférieure, qui est arquée. A l'entrée du pharynx est un voile qui descend en avant de la chambre branchiale, qui diminue peu à peu et disparait chez l'animal adulte. Chez les très jeunes sujets, les yeux sont complètement cachés, et l'ouverture de l'évent n'existe pas. La région branchiale est renflée; les ouvertures des ouies sont dans une espèce de rainure; l'orifice de l'wsophage est à l'extrémité postérieure de la chambre branchiale. - Les nageoires dorsales sont très basses et unies chez les très jeunes animaux. - La teinte est le plus souvent d'un gris verdàtre sur le dos, argentée sous le ventre; parfois elle est rougeàtre.

Habitat. Les Ammocètes se trouvent dans les rivières, mais surtout dans les petits cours d'eau que paraissent rechercher les Lamproies au moment du frai. 


\section{SOUS-CLASSE DES PHARYNGOBRANGHES. PHARYNGOBRA NCHII.}

Corps très peu développé; peau nue. Squelette fibreux ou fibrocartilagineux.

Tête non distincte du tronc; bouche placée en dessous, longitudi-nale, non dentée, entourée de tentacules.

Appareil branchial; branchies pharyngiennes, couvertes de cils vibratiles; eau passant de l'appareil branchial dans la cavité péritonéale et sortant par le pore abdominal.

Nageoires; pas de nageoires paires: nageoires impaires unies. Sang incolore.

\section{Ordre des Amphioxiens, Amphioxi.}

Corps mince, terminé en pointe; squelette formé d'un tissu scléreux de faible consistance; corde dorsale fusiforme s'étendant d'une extrémité à l'autre de l'animal.

Tête non distincte du tronc, dépassée en avant par la puinte de la corde dorsale; cràne très peu développé (V. t. III, fig. 218, coupe verticale du cràne; fig. 219, compe verticale du rachis); bouche longitudinale, sans màchoires, entourée de cartilages soutenant des tentacules.

Organe de la vue très réduit; un ou deux yeux.

Organe de l'odorat; près des yeux est une grande cupule, garnie de cils vibratiles, considérée comme étant l'organe olfactif.

Appareil respiratoire; il est placé dans la partie antérieure de la cavité viscérale commune; les parois de la chambre branchiale sont soutenues par des pièces, figurant les barreaux d'une espèce de cage, séparées par des fentes à travers lesquelles s'écoule l'eau qui, après avoir servi à la respiration, passe dans la cavité péritonéale, et s'échappe au dehors par le pore abdominal, situé en avant de l'anus.

Appareil circulatoire; le cœur est remplacé par un vaisseau longitudinal d'un calibre uniforme.

Appareil digestif; l'œsophage, court, étroit, s'ouvre dans une espèce de poche stomacale; l'intestin ne fait aucun repli; sa muqueuse est couverte de cils vibratiles.

Conservation de l'espèce; chez les màles et les femelles, les organes de la reproduction consistent en poches fermées, au nombre de vingt-deux à vingt-six paires: quand les produits de la géné- 
ration sont mirs, ils tombent dans la cavité abdominale el en sortent par la bouche suivant howalewski, par le pore abdominal suivant d'autres naturalistes.

\section{Famille des Branchiostomides, Branchiostomidit.}

Corps allongé, comprimé, terminé en pointe.

Tête; bouche fendue en long, plicée en dessous, bordée d'une rangée de tentacules.

GENIE BRANCHOSTOML: - IR INCHIOSTOMA, Costa.

Caractères de la famille.

\section{LE BR.INCHIOSTOME LANGEOLE. - BRANCHIOSTOMA LAXCEOLATLU.}

Puiss. France, t. 11I, p. 618, fig. 2.20, anim.

Long. : 0,040 à 0,030 , quelquefois $0,0 \tau 0$.

De forme lancéolée, ce Branchiostome est plus ou moins effilé à ses deux extrémités; le dos est anguleux; le ventre est bordé par un repli très bas, allant, de chaque côté, de la bouche à l'anus. La tête n'est pas distincte du corps; la bouche, ouverte en long, est placée en dessous, en arrière de l'extrémité de la corde dorsale; elle est entourée d'une rangée do tentacules nobiles, au nombre de dix à quinze paires. - La dorsale est excessivement longue; elle commencesur ]a tête, et s'unit, ainsi que l'anale, à une très petite caudale pointue. - La teinte est d'un gris excessivement clair ; le corps est transparent.

Habitat. Le Branchiostone se troure sur nos différentes còtes.

Noт1. - Suivant l'observation du professeur Sp. Brusina d'Agram, Scorpana ustulata, Lowe, est Sc. Licolorata, Mardo; celte Scorpène décrite Suppl., p. 20, et Hanuel. p. 213̈, doit par conséquent porter le nom spécifique bicoloratu, que lui a donné l'ichllyologiste vénitien, V. Elenchi Pesci Dalmatia, Botteri. - S. Brusina, Zagreb, 1891 , p. 11. P. 124, au lieu de ruditus, lire radialus qui est dans le manuscri!. 


\section{MEROU BRUN. - EPINEPHELUS GIGAS.}

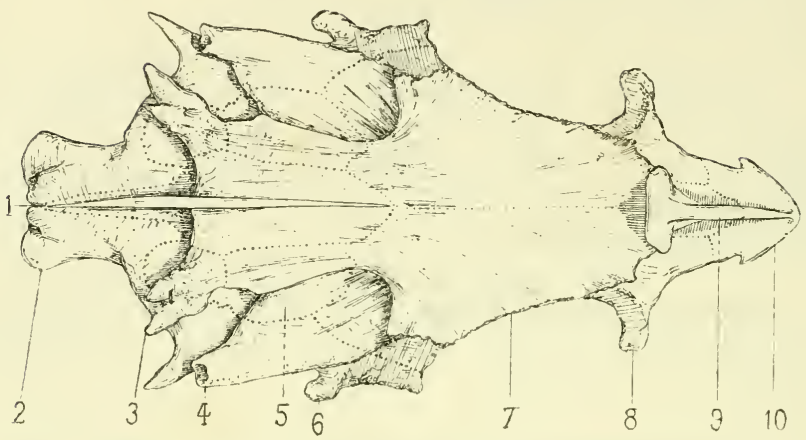

Fig. 1. - Cràne vu en dessus.

1. Occipital supérieur.

2. Occipital latéral.

3. Occipital externe.

4. Mastoïdien.

ว. Parićtal.
6. Frontal postérieur,

7. Frontal principal.

8. Frontal antérieur.

9. Nasal (Elhmoïde, Cur.).

10. Vomer.

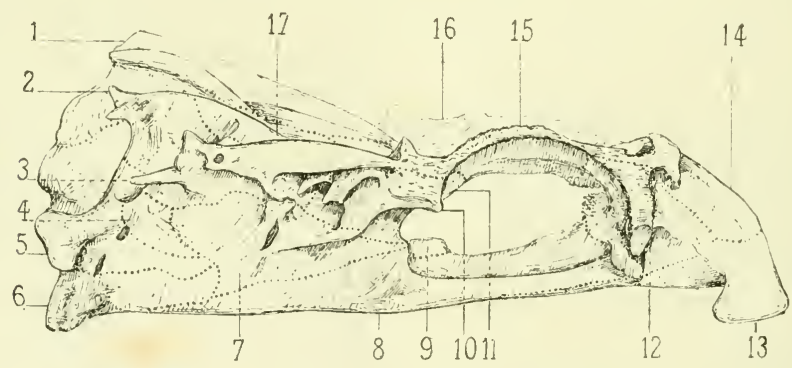

Fig. ?. - Cràne vu de profil.

1. Occipital supericur.

2. Occipital externe.

3. Mastoïdien.

4. Occipital latéral.

ว. Roclıer.

6. Occipital inférieur.

7. Aile du sphénoïde.

8. Sphénoïde.

?. Sploćnoïre antérieur
10. Frontal postérieur.

11. Aile orbilaire.

12. Frontal antérieur.

13. Vomer.

14. Nasal.

15. Frontal principal droit.

16. Frontal principal gauclır.

17. Pariétal. 
PERCHE DE RIVIERE. - PERCA FLUVIATILIS.

in

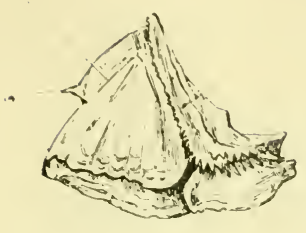

3

b

\section{$\xi$}

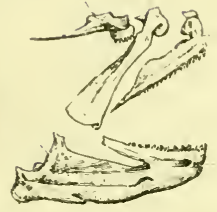

Fig. 1. - Pièces operculaires.

1. Opercule.

2. Préopercule.

3. Interopercule.

4. Sous-opercule.

э. Saillic de l'opercule.

Fig. :. - Appareil maxillaire et vomer.

3 1. Vomer.

2. Maxillaire supérieur.

3. Intermaxillaire.

4. Dentaire.

4 5. Articulaire.

Fig. 3. - Arcade ptérygopalatine et jugal.

2 1. Ptérygoídien interne.

2. Palatin.

3. Jugal ou hypotympanique.

$s$

4. Ptérygoïdien externe.

IETTASTOME QUEUE NOIRE. - NETTASTOMA MELANURA.

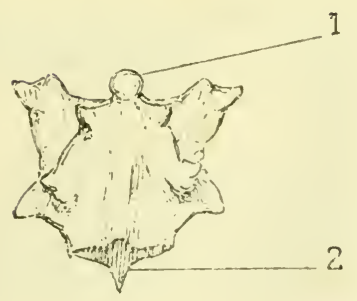

\section{Cràne; region posterieure} et inférieure.

1. Condyle de l'occipital basilaire. V. p. Бڤ03.

2. Sphénoïle roupé. 
NETTASTONE QLEUE NOIRE.

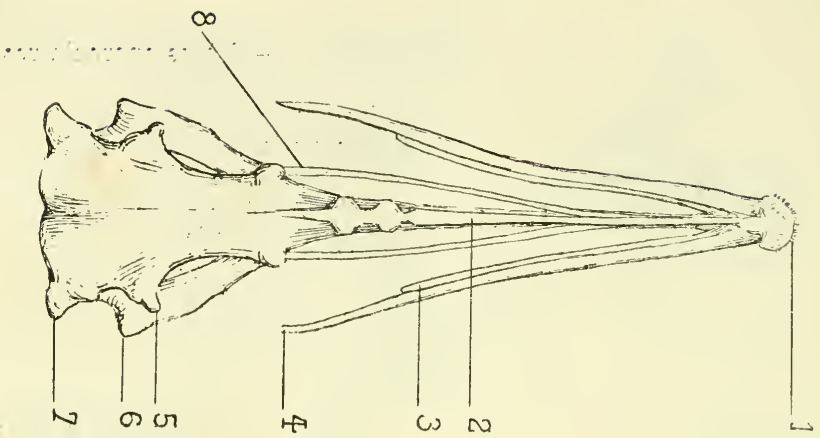

Tète vue par la partie supérieure.
1. Vomer.
2. Ethmonasal.
3. Bandelette palatine.
4. Maxillaire supérieur.

3. Frontal postérieur.

6. Suspenseur commun.

7. Nastoïdien,

| $x$. Arcaule plérygoïdienue.

17

1

16

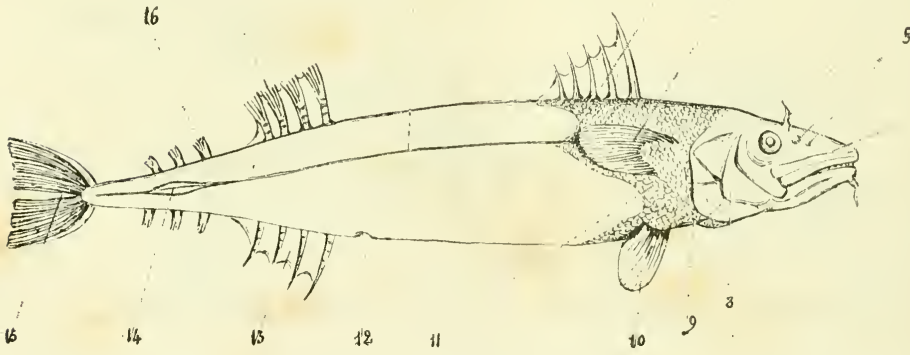

Figure destinée à montrer les organes extérieurs chez les Poissuns osseux.

1. Ligne latérale.

2. Première dorsale épinense.

3. Pectorale.

4. Tentacule.

ร. Orifices de la narine.

6. Mâchoire supérieure.

7. Màchoire inférieure avec barl,illon.

8. Pièces operculaires.

s. Fente des brauchies.
10. Ventrale.

11. Corselet.

12. Anus.

13. Anale à rayons articulís.

14. Carène de la queue.

15. Caudale avec rayons simples et ramifićs.

16. Fausses nageoires ou pinnules.

17. Seconde dorsale a rayons branchus. 


\section{IABLE DES NOMS SGIENTIFIQUES}

A

AbLette............... $\$ 95$

Ablette commune.. ........ $\$ 96$

- hachette.. ......... 497

- spirlin............. 497

ABRAMIS............. 492

tbramis abramo-rutilus...... 495

- brama............ 492

- bjarkna..........

- Buggenhagii........

Abanchiocères.

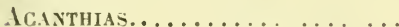

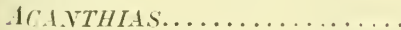

Acanthias Blainvilie..........

Icanthias commun..........

Icanthias vulgaris.......... .

uyatus......... 35, 37

Acaxtholabre............. 368

Acantholabre de Palloni...... 368

ICANTHOLABRUS.......... 368

.1cantholabrus Palloni........ 368

Acanthopterygiens....... 118

ACANTHOPTÉRYGIENS ABDOMNALX . $3{ }^{6} 6$

$$
\text { - Jugulahes.. } 118
$$

Acanthopterygi

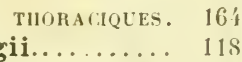

ICANTHOPTERYGII ABDOMINALES......... $3 i 6$ JUGLLARES ........ 118

THORACICI.

\section{Acératobranches}

ACERINA. .

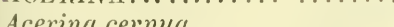

1

ACÉRINE...................

ACIPENSER.......... 86
Acipenser sturio........... 87

- Valencicnnii....... 88

Acipenseridx.............. 85

Acipenséridés..............

Aigle................ 244

Aiguillat................. 31

Aiguillat commun.......... 31

33

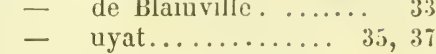

ALBURNUS.............. 495

Ilburnus bipunctatus........ 497

- dolobratus....... 497

- lucidus............. 496

Alépocéphale............. 525

Alépocéphale à bec......... 525

Alepocephalidx............. 595

Alépocéphalidés............. 525

ALEPOCEPHALUS.......... 525

Alepocephatus rostratus....... 525

Alopecidx................. 9

1lopécidés................. 9

ALOPIAS.............. 9

Hopias vutpes............. 9

ALOSA............... 521

Ilosa finta............... 522

- sardina............ 523

- vulgaris............. 521

ILOSE................. 521

Nose commune........... 521

- finte............... 522

- sardine............. 523

Ammorite branchiale....... 611

Ammocretes branchialis....... 611

Aнмопте................ 401

Ammodyte cicerelle......... 402

$227 \quad-\quad$ équille................... 402

$86 \quad-\quad$ lancon......... 401 
AMMODYTES. .

Ammodytes cicerellus.

- $\quad$ tanceolalus........

Ammodytidx. tubianus.

Ammodytidés.

Ammopleurops lacteus.

Amphioxi..

Amphioxiens

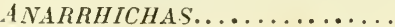

Anarrhichas lupus...........

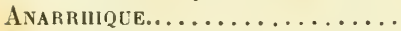

Anarrhique loup............

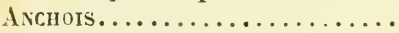

Anchois vulgaire............

Ange...

ANGLILLA.

Anguilla Kieneri.

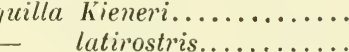

- platycephala.........

- vulgaris ............

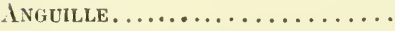

Inguille à museau large.....

- de Kiéner...........

- plat-bec...........

Anguillidæx.

vulgaire ...........

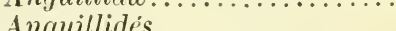

Axturas.................

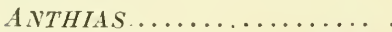

Anthias sacer..............

Anthias sacré.............

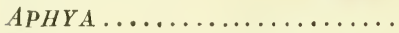

Aphya pellucidu...........

Арние....................

Aphye pellucide.............

Apodes.................

Apodes.

Apogon ..................

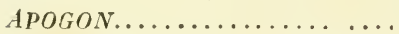

Apogon commun...........

Apogon imberbis............

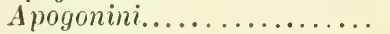

Apogoniniens.

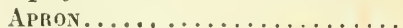

Apron commull...........

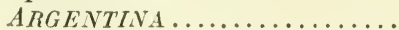

Argentina sphyrizena.........

Argentine.................

Argentine sphyrène..........

Argyropelacus.............

ARGYROPELECLS ........
401 Argyropelecus demi-nu ......

402

101

402

101

401

470

612

612

151

151

151

151

524

524

49

596

597

596

596

596

596

596

597

596

596

595

595

236

$236^{\circ}$

236

236

189

189

189

189

595

595

239

239

239

239

238

238

226

226

592

592

592

592

543

$5+3$

Argyropelecus hemigymnus....

Aspidophore armé .......... 212

ASPIDOPHORUS............ 212

Aspidophorus cataphractus.... 212

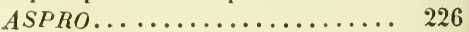

Aspro vulgaris ............. 226

Astrodermus elegans......... $\quad \mathbf{9 6 6}$

ATHERINA............... 394

Atherina Boyeri.......... 396

- hepsetus.......... 395

- mochon........... 396

- presbyter........... 397

- Rissoi............. 398

Athérine.................. 39't

Athérine de Boyer......... 396

— de Risso........... 398

- hepset............ 395

- mochon .......... 396

- prêtre........... 397

Atherinilæ.............. 39 t

Athérinidés............... 394

AulopE.................. 561

Aulope d'Agassiz.......... 562

- filamenteux......... 561

AULOPLS.............. 50.

Aulopus Agassizii........... 562

- filamentosus........ 561

Aulostomidx .............. 384

Aulostomidés.............. 384

Aurata bilunulata........... 317

Ausonia Cuvieri............ 287

Auxide. ................. 250

Auxide bise............. 251

A UxIS.................. 250

Auxis tisus............. 251

\section{B}

Batiste................ 114

Baliste caprisque.......... 114

BALISTES ................ 114

Balistes capriscus............ 114

Balisti lx................ 114

Balistidés.................. 114

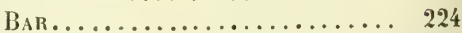

Bar commun............. 224

- noiràtre.............. 225

- ponctué.............. 225

- tacheté.............. 225 
Barbeau

Barbeau commun. méridional.

B arbier.

Barbier

Barbue commume.

BARBLS.

Barbus fluvintilis.

- meridion'

Batides.

Butides.

Batrachidix

Batrachidés.

B.ITRACHOIDE.

Batrachoïde didactyle........

BATRACHUS..............

Batrachus didactylus.........

BAudroIE.

Baudroie budegassa.

$$
\text { - commune }
$$

BELONE.

Belone acu

\section{- imperialis.}

Belonini.

$$
\text { vulgaris }
$$

Béloniniens.

Berycidix.

Bérycides.

Béryx.

BERYX

Béryx didactyle.

Beryx didactylus.

Buexivie.

Blennie aux dorsales inégales.

- basilic..............

- cagnette............

- chevelu..............

de Moutagu.

de Roux.

gattorugine ...........

graphique..........

palmicorne..........

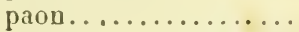

papillon.............

pholis ..............

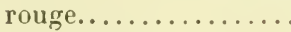

- sphiux.

tentaculaire..........

- tête rouge.

Blenniidx

trigloïle.

Blenniides
48.5

485

486

236

236

466

485

is5

486

53

53

163

163

163

163

163

163

160

162

160

528

529

530

525

$5: 8$

528

219

219

221

$2: 1$

221

221

128

141

143

132

142

142

133

13 i

137

131

130

138

145

135

140

136

139

14 '

$12 i$

127
BLENVIUS ............ 128

Blennius basiliscus .......... 143

- cagnola........... 132

142

139

134

137

141

142

138

131

130

145

133

135

140

136

144

312

312

313

25?

467

$46 \pi$

i68

468

467

$46 \pi$

47

489

490

312

313

312

277

จ

277

Braminiens................. 277
Branchiociores..........

BRA.VCHIOSTOMA.......... 613

Branchiostoma lanceolatum.... 613

Braxcinosto.e........... 613

Branchiostome lancéoli...... 613

Branchiostomidx........... 613

Brenchiostomides........... 613

BиĔe............... 492

Brême bordelière.......... 493

492

$49 i$

526

$\therefore 26$ 
Callionymidx.

Gallanthias....
CALLa NTHIAS

Callanthias péloritain .........

Callanthias peloritanus.......

Caclionyme.

Callionyme belène.

dragonne....................

- dragonneau.......

- élégant.

$-$

$-$

lacert.

lyre. ...

phaëton.

tacheté .

Callionymides

CALLIONYMUS

Callionymus belenus...........

- $\quad$ dracunculus......

- elegans..........

- $\quad \operatorname{lyra} . . . . . . . . .$.

- maculatus........

- Morissonii.......

Cantharini. phaeton..........

Canthariniens.

CANTHARLS.

Cantharus brama.............

- griseus...........

- orbicularis........

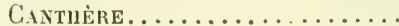

Canthère brème.............

- gris................

- orbiculaire.........

Cuprini....................

Capriniens................

Capros......................

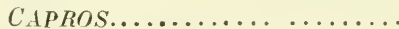

Capros aper..................

Capros sanglier..............

Carangini................

Caranginiens ...

Ciranx.

CARANX.

Caranx fuseau ............

Caranx fusus ..... ..........

- luna................

Caranx lune..............

- suaréou.............

Caranx suareus.............
159

327

327

327

329

327

329

327

329

327

329

273

273

273

273

274

274

260

260

263

203

264

264

263

26:3

265

265
Ciarassin.

Carassin commun........... 483

doré............. 484

CARASSIUS.............. 483

Carassius auratus.. ......... 484

vulgaris ........ 483

CARCHARIAS............. 25

Carchurias glaucus.......... 25

27

26

Carcharidx............... 25

Carcharidés............... 25

CARCHARODON............ 15

Carcharodon lamia.......... 15

Carcharodonte.............. 51

Carcharodonte lamie........ 15

Cardine................... 462

Garpe.................... 481

Carpe à cuir............. 482

_ à miroir............. 482

- a tête de Dauphin...... 482

- commune ............ 481

- de Kollar............ $\$ 82$

- nue................ 482

Carrelet................. 44?

Cistagnole................ 277

Castagnole............... 277

CEVTRINA................ 42

Centrina vulpecula......... 43

Centrine................. 42

Centrine humantin......... 43

CENTRISCUS............. 38't

Centriscus scolopax......... 384

Centrisoue................. 384

Centrisque bécasse........ . 384

Cevtrolophe.............. 278

Centrolophe de Valenciennes.. 280

- épais........... 281

- liparis........... 282

- nègre.......... 279

- ovale.......... 281

- pompile........ 279

Centrolophini............... 278

Centrolophiniens........... 278

CENTROLOPHUS............ 278

Centrolophus crassus.......... 281

\begin{tabular}{|c|c|c|}
\hline & liparis.... & 28 ? \\
\hline & niger $\ldots \ldots \ldots \ldots$ & 279 \\
\hline & ovalis............ & 281 \\
\hline & pompilus......... & 279 \\
\hline & Valenciennesii.... & \\
\hline
\end{tabular}


Centronotiniens

Cextrophore.

Centrophore calcéiforme granuleux.

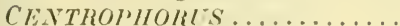

Centrophorus calceus granulosus. lusilanicus

Centroscrune

Centroscymne célolépis CENTROSCYMNIS.

Centroscymmus calolepis.

Cephakcconthus spiner

CEPHALOPTERA...............

Cephaloptera

Giorna..........

Massena.......

Céphaloptère.

Céphaloptère de Giorna.

de Masséna.....

CEPHALOPTERI..............

CÉpialoptériens

Cephalopteridre.

Céphaloptèridés.

CEPOLA.

Cepola rubescens.

CÉPole.

Cépole rougeàtre...........

Cepolini.

Cépoliniens.

\section{Ceratobranches.}

Cersier.

Cernier brun

Cernua Costir...

Chabot de rivière.

Charax..........................

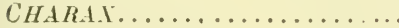

Charax puntazzo.

Charax puntazzo............

Chaulisdontini..............

Chauliodontiniens.

Giralliode..................

Chauliode de Sloane.........

CHALLIODIS................

Chauliodus Sloani.............

Chevatye...................

Chevaine commun...........

- soufie..............

- vandoise...........

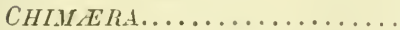

Chimæra monstrosa...........

Ghimæræ

Chimæridx...

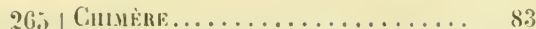

36 Chimere monstrueuse....... 84

40 Chimères............... 82

36 Chiméridés................ 83

36 CHO.VDROSTOMA.......... 507

i0 Chondrostomı Fienci........ . 508

$36 \quad$ - nesus........ 507

38 Choxniostome............. 507

i1 Chondrostome de Genć....... 50s

il $\quad$ - nase......... 507

4! Chondrostomini.. ........... 506

41 Chondrostominiens.......... 506

Chorignathes .......... 117

Ghorignathi........... 11 i

Chronis.................. 375

CHROMIS............... 375

Chromis castagneau......... $3 \pi$.

Chromis castanea............ 3ii

CHRYSOPHRYS............ 325

Chrysophrys aurata....... . 325

if - crassirostris..... 326

75 Cuives................... 146

75 CLINTS............... 146

298 Clinus argentatus........... 146

298 Clinus argenté............. 146

298 CLLPEA................ 515

298 Clupea harengus ............ 515

298 - Pontica........... 516

298 Clupeirl................ 514

2 Chupéidés................. 514

2:29 Cobitida ................. 508

229 Cobitidés................ 508

2:36 Cobitis................. 509

208 Cobitis barbatula........... 509

310 - fossilis.............. 511

$310-\operatorname{trnia.............~} 510$

311 Colfre................... 116

311 Coffre a bec............... 116

$538 \quad$ - trigone............. 117

538 Colin.................. 415

529 CONGER.............. 597

539 Conger Balearicus..... ...... 598

$539-\operatorname{mystax.\ldots \ldots \ldots \ldots \ldots ..\ldots 99}$

$539-$ niger............... 598

503 - vulgaris........... 597

504 Covgre................. 597

503 Congre à larges lévres ....... 599

50 - commun .......... 597

83 - des iles Baléares..... 598

$8 \mathrm{t}-$ noir............... 508

82 Сокв.................... 245

\$3 Corb noir................ 245 
Coréguxe

Corégone féra............ - gravenche..........

- houting...........

- iavaret...........

COREGONUS...............

Corejonus besola...........

fera........... 58

- hyemalis...........

- lavaretus........

- oxyringnchus......

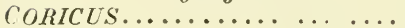

Coricus rostratus.............

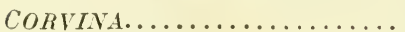

Corvina nigra.............

CORYPH E.

Coryphæna equiselis..........

- hippurus ........

Coryphanini.............

Coryphène...............

Coryphène équiset..........

hippurus.........

Curyphéniniens............

Cotre...................

Cotte à longues épines.......

- chabot..............

- scorpion..............

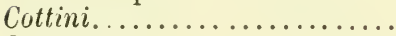

Cotliniens................

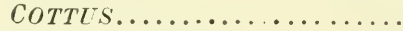

Cottus bubalis..............

- gobio...............

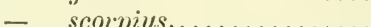

CRÉNILABHE.

Crénilabre à cing taches... . .

\begin{tabular}{|c|c|}
\hline & arque............. \\
\hline - & bleu.............. \\
\hline & de Baillon........ \\
\hline & de Bory ........... \\
\hline & de Brünnich....... \\
\hline - & littoral........... \\
\hline & 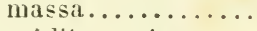 \\
\hline & méditerranéen ..... \\
\hline & mélope $\ldots \ldots \ldots \ldots$ \\
\hline & ocellé.......... \\
\hline & onvatre............. \\
\hline & 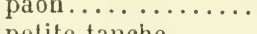 \\
\hline & pente tancne....... \\
\hline & quede noire...... \\
\hline & 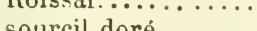 \\
\hline 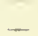 & tioré \\
\hline & 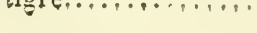 \\
\hline
\end{tabular}

588 Crénilabre vert tendre...... 362

589 CRE VILABRUS........... 350

590 Crenilabrus arcuatus......... 362

$591 \quad$ - Bailloni........ 359

$5 \mathrm{ss} \quad$ - Boryanus....... 360

58s $\quad$ Brunnichii...... 361

$590 \quad-\quad$ chlorosochrus.... 362

589 - chrysophrys..... 356

$590 \quad$ - corulcus........ 358

58s $\quad$ L littoralis....... 352

$591 \quad$ - massa......... 364

365 - mediterraneus.... 360

365 - $\quad$ melanocercus..... 357

$245 \quad-\quad$ melops.......... 355

$245 \quad$ - ocellatus........ 351

$287 \quad$ - olivaceus....... 352

$288 \quad-\quad$ pavo........... 363

\$88 quinquemaculatus.. 353

287 - Roissali........ 353

287 - $\quad$ tigrinus........ 354

gss _ $\quad$ tinca.......... 361

¿88 Citévolabre................ 366

287 Cténolabre bordé........... 367

?08 - des roches....... 366

$211-$ iris............ 367

208 CTE.VLABRUS ......... 366

210 Ctenolabrus iris............ 367

$208 \quad$ - limbatus........ 367

$\because 08 \quad$ - rupesiris........ 366

208 Cubicepini.............. 274

211 Cubicepiniens............. 274

208 Cubiceps.................. 275

210 CUBICEPS.............. 275

350 Cubiceps gracilis.......... 275

353 Cubiceps grèle............ 275

362 C'vcloptène.............. 471

358 Cyclopteridx............. 471

359 Cycloptéridés.............. 471

360 CYCLOPTERINI......... \$1

361 Cyclopténiniens............. \$71

352 Cyclopterus............... 471

36 ' Cyclopterus lumpu.......... 472

360 Cyclostomes.............. 608

355 Cyclostomi.............. 608

$3 ; 1$ Crprin.................. 481

352 Crpbinonon.............. 512

363 CYPRINODON............ 512

361 Cyprinodon colaritanus....... 512

357 Cyprinodon de Cagliari....... 512

353 Cyprinodontidæ........... 512

356 Cyprinodiontidés.......... 512

354 CYPRINUS,............. 481 
Cyprimus carpio.

451

Kollarii.

D

DAC'TYloptère

Dactyloptère volant

D)ACTYLOPTERUS

Dactylopterus volitans.........

Dantade...................

Daurade à museau renflí...... - vulgaire...........

UENTÉ

Denté aux gros yeux........ - ordinaire.............

DENTEX...............

Dentex macrophthalmus .. ....

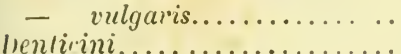

Dentiniciens................

Diana semilunata...........

\section{$\mathbf{E}$}

Echeneini.

Echénéiniens.

ÉCHÉNÉIS

ECHEYEIS.

Échéuéis naucrate.

rémora.

Echeneis naucrates.

remora.

ÉCHINORHINR.

ECHINORHINUS.

Echinorlinus spinosus.

Eurssole.

Émissole

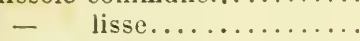

- pointillée...........

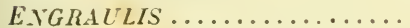

Engraulis encrasicholus.

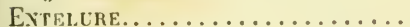

Entelure de mer.............

EvTELURU

Entelurus aquoress... .......

anguineus..........

Éperlan commun.... .......

EPLAÉPHÉLE......

195

195

195

195

325

326

325

330

332

331

330

332

331

330

330

$28 i$
Épinéphèle géant.

234

234

Epinephelus acutirostiis...... $\quad 235$

Coste.......... 235

Épixoche................. 381

Érythriu. . . . . . . . . . . .

ÉSOCE.................... 526

Esocidx............... 520

Esocidés................ 526

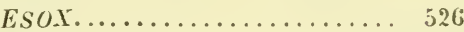

Esox lucius............... 520

293 Espadon................. 290

293 Espadon épée........... . 290

293 Esprot................. 518

294 Estldaeon............... 86

2!9:3 Esturgeon commun......... 87

2) $\mathbf{t}$ - de Valenciennes.... 88

293 - ordinaire....... 87

47 Exocer................ 532

47 Exocet aux ventrales tachetées. 53t

47 - de Rondelet......... 533

$17 \quad$ - fuvard............ 533

$17 \quad$ - procné............. 536

19 - volant ........... 533

$\rightarrow 0$ Exocétidés... . . . . . . . . . 527

52 Exocetiniens............. 53?

i2t Exocutida.............. 527

10.5 Exocatini............. 5...

105 E.XOCQETLS............... 532

106 Eirocatus evalans........... 533

$105 \quad$ - procne........... 530

105 - Rondelelii........ 533

106 - spilopus......... 534

$585 \quad-$ volilans........ 533 
F

Fario argenteus........... $\quad$ \$81

Fiéraster............... 405

FIERASFER........... 405

Fierasfer dentatus........... 406

Fiérasfer denté............ 406

imberbe.. ...... 405

Fierasfer imberbis.......... 405

FLET .................. 415

Flet commun............ 415

- moineau............... 440

Flétan................. 439

FLESTS................ 445

Flesus passer.............. 446

- vulgaris........... 445

\section{G}

GADE.

Gade capelan...............

- églefin.

- morue.

- tacaud.

Gadidx.

Gadidés.

Galini.

Gadiniens

GADUS.

Gadus ærglefinus.............

- luscus..............

- minutus.............

- morhua.............

Galeidæ.

Galéidés....................

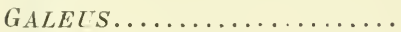

Galeus canis...............

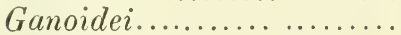

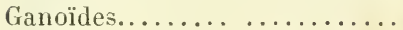

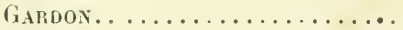

Gardon commun............

- de Selys............

- pâle..............

- rutiloïde...........

GASTEROSTEA.............

Gasterostea pungitia..........

Gusterosteirl...............

Gustérostéidés ..............

GASTEROSTEUS.............

Gasterosteus aculeatus........

109

409

412

411

410

408

408

409

409

40)

412

410

409

411
Gaslerosteus biaculeatus....... 38?

breviceps........ 38:3

Burgundianus.... 38:3

lavis.......... 38:;

leiurus......... $38:$

Lotharingus..... 383

pungitius ....... 383

seminrmatus .... 382

semiloricatus. ... 382

tetracanthus..... 38:

trachurus....... $38:$

Gastré................. 38:3

Gastré.................. 38:3

Germon................. 256

Girelle.................. 369

Girelle commune............ 369

371

370

$3 \% 0$

372

Goвı.................... 165

- à filament........... 169

à gouttelettes........ 170

- à haute dorsale....... 178

_ à joue poreuse......... 180

- á large tète.......... 173

_. á longs rayons........ 179

.. i quatre bandes...... 172

_. d quatre taches....... 1 i⿱

- bordé............... 188

- buhotte............ 177

- céphalote........... 16?

- colonien............. 174

- de Lesueur.......... 179

- de Ruthensparre....... 187

- doré............... 182

- ensanglanté.......... 171

- lote............... 16i

- jozo.............. 178

- noir.............. 183

- paganel............ 185

- réticulé............. 176

- trompeur........... 181

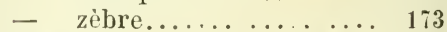

Gobiidx ................. 165

Gobiidés................. 165

Goвro.................. $48 s$

Gobio fluviatilis............. 488

GoBIUS .................. 165

Gobius ater................ 184

$381-$ auratus............ 182 
Gobius bicolor.............. 186

- cruito.................. 100

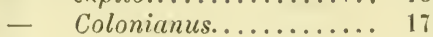

- cruentatus................ 171

- fallax.............. 181

- filamentosus.......... 169

- geniporus.............

- guttatus..............

$-$

$-$

-

$-$

$-$

-

-

-

$-$

-

-

三

-

-

-

Jeffresii.

jozo.......................

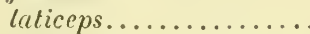

Lesueurii.

limbatus.

longiradiatus

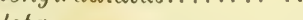

minutus.

nebulosus

n.......

paganellus.

pictus.

quadrimaculatus.........

quadrivittatus.........

reticulatus...........

Ruthensparri.........

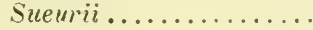

zebrus.

GoNNELLE ................

Gonnelle vulgaire............

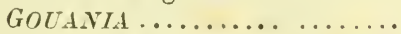

Gouania Wildenowii..........

Goüs.ıı..................

Goüanie de Wildenow..

Goujon.

Goujon de rivière.

GONOSTOMA.

Gonostoma denudutu. .......

Govostone.

Gonostome nu.

Grande Roussette.

Grenille..................

Gremille commune.........

Grilse.

Griset

Groxpl.

Grondin gris

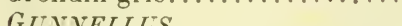

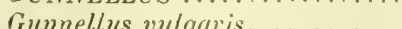

Gymnodontes

Gymnodontes
69

74

180

170

176

178

173

179

188

179

$16 \%$

177

176

183

185

17 '

175

172

176

187

179

173

149

149

478

478

478

478

488

488

541

5 i 1

$5+1$

$5 ' 1$

6

227

227

575

29

198

202

149

149

110

110

\section{H}

Hareng ................ 515

Hareng commun.......... 515

516

519

519

519

519

29

29

30

28

29

28

29

92

93

92

92

93

92

91

91

4.39

439

439

219

220

219

$\because 20$

436

137

436

Hymenocephalus Italicus...... 437

HYOBRANCHES .......... ?

HYOBRANCHH .........

Існтнтососсus............. јј)

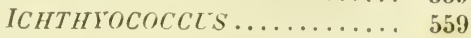

Ichthyococeus ovale........ 559

- ovatus......... 559

Ichthyostei.............. 89

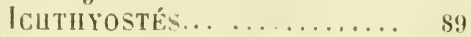

IDE .................

Ide jesse............. 502

$I D I, \ldots \ldots \ldots \ldots \ldots \ldots \ldots \ldots$

More.l: - Ichthyologie. 
Idus jeses................ - melanotus.

\section{$\boldsymbol{J}$}

Joël.....................

JULIS ..................

Julis festiva................

- Giofredi................

- pavo...................

- speciosa...............

- vulgaris.............

K

kelt......

L

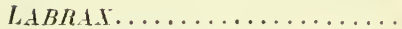

Labrax lupus................

- nigrescens............

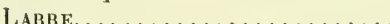

Labre bordé ................

- des roches............

- linéolé.................

- livide.

- louche..

- mêlé.

- merle.

- nérée.

- paré..

- pesquit

- tourd...

- varié..

- vert

Labridx

Labridés..

Labrini

Labriniens.

LABRLS ...

Labrus bergylta

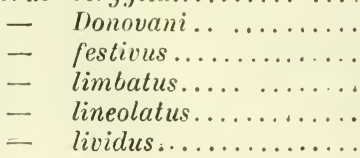

502

502

Labrus luscus

merula.

mixtus...

nereus...

saxorum...

turdus.

viridis.

369

371

370

372

370

369

LAYIE.

Lamie loug-nez

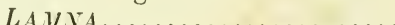

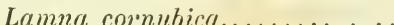
575

Lamnidre...

Lamnidés.

Lamprini. .

Lampriniens.

LA

Lampris luna............ . 276

Lampris lune............. 276

Lamprome................. 609

Lamproie de Planer.......... 611

- fluviatile.......... $\boldsymbol{6 1 0}$

LEPADOGASTER ......... 474

Lepadogaster timaculatus...... 477

- Brownii........ 466

- Candolii........ 476

- dentatus........ 478

- Gouanii........ 475

- gracilis......... 478

Lépabogastère............ 474

Lépadogastère à deux taches... 477

- de Brown..... 476

- de Candolle.... 476

._ de Goüan...... 475 - grêle ........... 4is

Lépadogastériniens........... 4í

Lepidoleprus Gioma......... 43.

LÉPIDOPE.................. 295

Lépidope argenté........... 295

LEPIDOPIS ................ 295

Lepidopus argentalus.........

Leptocéphale de Morris ..... 598

Leptocephalus Morrisii........ 598

Leuciscini................. 489

marine.......... $609 x$ 
Leucisciniens

LEUCISCUS.

Leuciscus pallens.............

- prasinus... ........

- rutiloides...........

- $\quad$ rutilus..............

Liche....................

Liche amie...............

- glaycos...............

- vadigo................

LICHLA...................

Lichia amia................

- glaucus................

- vadigo.................

Lieu ......................

LIMAYDA ................

Limanda vulgaris...........

LIMANDE..................

Limande commune..........

Lingue.

LiPARIS . .

LIPARIS ...

Liparis commun.............

Liparis vulgaris.............

LoCHE..................

Loche d'étang.............

- de rivière .............

- franche............. 509

Lompe................ 472

Lophiidæ.................. 160

Lophiidés................ 160

LOPHIUS................. 160

Lophius budegassa........... 162

- piscatorius.......... 160

Lophobranches......... 90

Lophobranchii.

LOPHOTE.....................

Lophote de Lacépède........

LOPHOTES ................

Lophotes Cepedianus...........

Luphotini.

Lophotiniens

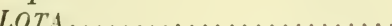

Lola elongata.............

- lepidion.................

- molva

- vulgaris.

LOTE OU LOTTE.

Lote allongée .

- commune.

- lépidion.

424

425

$4 ? 3$

422

422

$42+1$

$4: 2$

425
489 Lote molve .............. \$23

499 Lotini................. 421

501 Lotinicns................ 421

501 Lolvareou................ 285

501 Louvareou astroderme....... 286

$500 \quad$ - impérial......... 285

501 Louvariniens.............. 28́

267 Luvarini................. 281

$\because 68$ LUVARLS .............. 285

:67 Luvarus astrodermus......... 286

269 - imperialis......... 285

\section{M}

M. Асrolre................. 433

Macroure célorhynque....... 434

- sclérorhynque ..... 435 - trachyrhynque.... 436

Marrouridés............... 433

Macruridæ ................ 433

MACRURUS............. 433

Macrurus Italicus........... 437

- coelorhynchres..... $\mathbf{4 3 \mathbf { 4 }}$

... sclerorhynchus ..... $\$ 35$

- Trachyrhynchus..... 436

MLENA .............. 333

Mrna jusculum............. 335

- Osbekii............... 334

- vomerina............. 336

- vulgaris............. 333

Irnidx............... 332

Vatare................... 244

Maigre commun........... 244

Makaira,............... 291

MAKAIRA.............. 291

Makaira nigricans........... 291

.97 - veliferca.......... 291

297 Makaira noiritre........... 291

$297-$ voilier........... 291

297 Malacocéphale Iisse......... 437

297 Malacocephalus lavis........ 437

297 Malacoptèrygiens........ 400

422 MaLaCOPtÉRYGIENS ABDOMiNaUX 479 pseudapodes. 400

subrachiens.. 407

Malacopterygii......... 400

IILACOPTER IGII A BDOMINA-

LES ..... 479

pseudapodes. 400

subrachii... 407

Malarmat................. 197 
MARSIPOBRANCHES.

MARSIPOBRANCIII

Marteau.

Marteau ....

Marteau commun.

$$
\text { - maillet. }
$$

Maurolice

$M A L R O L I C L S$

Yaurolicus améthyste ........

$$
\text { - atténué........... }
$$

Maurolicus amethystino-punctatus.............

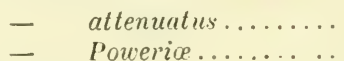

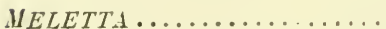

Meletla phalerica...........

- sprattus.

- vu'garis..............

Melette . .

. Yelette commune............

- esprot...............

- phalérique............

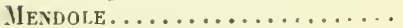

Mendole commune.

— juscle..............

Ménidés...................

Merlax...................

Ierlan argenté.............

- commun............

- jaune...............

- noir................

- poutassou..........

MERLAVGLS............. \$13

Merlangus argentatus........ 417

- carbonarius........

- pollachius...........

- poutassou...........

Merlucie..................

Merlncini..................

Merluciniens.............. .

MERLUCIUS................

Mertucius vulgaris...........

Merlus .....................

Merlus ordinaire............

Mérou

Mẻrou à museau aigu.........

- brun.................

Meunier.
607

607

23

24

23

24

556

556

556

557

558

556

$55 i$

558

517

517

วิ1S

518

517

ว18

518

517

333

$3: 33$

$33 \dot{4}$

$3: 35$

336

332

$+13$

417

413

414

415

$+16$

415

414

416

413

419

419

419

419

420

419

420

$23 \dot{i}$

235

234

50 '
Microchire.

Microchire jaune.

453

453

454

MICROCHIRLS........... 453

Microchirus luteus.......... \$53

MLROSTOy

. Ficrostoma oblitum ......... 594

rotundaiu........ 593

Microstone............... 593

Microstome arrondi......... 593

- oublié.......... 594

Milandre............... 20

Milandre ............... 20

Misgurne............... 511

Mojochire ............... 455

Mcnochire velu........... 455

MOYOCHIRES ............ 455

Monochirus hispidus........ 455

Mora ................. 418

MORA.................. 418

Mora de la Méditerranée..... \$18

Mora Mediterranea.......... 418

Morini................. 418

Woriniens................ 418

MOTELLA.............. 427

Motella fusca............. 430

- glauca........... 431

- maculata... ... ..... 429

- mustela.......... 430

- tricirrata.......... $\mathbf{4 2 8}$

Motelle............... $42 i$

Motelle à trois barbillons..... $\quad \mathbf{4 2 8}$

- brune............. 430

- mustèle ........... $\$ 30$

- tachetée........... 429

Mourine ................. 6

Mourine vachette.......... is

MUGE................... 3Si

.luge à grosses lèvres....... 392

- blanc.............. 390

- capiton.............. 389

- céphale.............. 388

- doré............... 388

- Iabéon .............. 392

- raccourci.. .......... 393

- sauteur ............ 391

MLGIL................ 387

Mugil albus............... 390

- auratus............... 388

- capito............... 389

- cephalus............. 388 
Mugil chelo.

- curtus.

- laben.

Mugilidx.

Muyilidés.

MCLLE

Ilulle brun.

- rouget...

Mullidæ

Iullidés.

MLLLL'S

Mullus barbatus.

- fuscatus.

- summuletus

MIRAEIA.

Muræna helena.

Muranidæ.

$$
\text { unicolor. }
$$

IL B.̇.̇e.

Ilurène hẻlène.

- faure.

- tachetée.

- unicolore.

Iurénictés.

WUSTÈLE

Mustẻle à cinq barbillons....

Iustelidx

Mustélites.

MLSTELTS

Mustelus lavis.

- punctulaim........

MYlobate.

$$
\text { vulgaris }
$$

Iyliobate aigle

Myliobatilæ

Myliobaticles

MYLIOBATIS

Myliobalis aquila.

Mra...........
Myre commun.
Myridx.......

Myridés.

MYRIS.

Nyrus vulgaris

Myxine glutimosin

\section{$\mathbf{N}$}

$392 \mid$ Naucrate pilote............ 266

393 . NAC CRATES............. 265

39? Naucrates ductor........... 266

391 Nerophimi.............. 105

386 Vernpliniens............. 105

386 Néropha................ 107

190 . NEROPHIS............... 107

193 Nérophis annelé........... 108

$192 \quad-\quad$ lombriciforme.... 107

191 - lombricoïde...... 107

$190 \quad-\quad$ ophidion.......... 109

190 Ner.phis anmulatus.......... 109

$190 \quad$ - lumbriciformis...... 107

19: - ophidion........... 109

193 NETTASTOMA.......... 603

191 Nettastoma melanura ........ $\quad$ :03

601 Nettastone............... 603

601 Nettastome queue noir....... (i03

602 Notachitue............. 377

601 Notacanthe de Bonaparte..... 378

(j01 - dela Méditerranée. 37

$601 \quad-\quad$ de Risso........ 379

$602 \quad$ - ne\%.......... $3: 9$

602 Notacanthidx........... 377

60: Notucanthidés.............. 377

601 NoTACANTHLS........... $37 i$

427 Notacanthus Bonnpartii...... 378

t30 - lacerta........ 380

$17 \quad-\quad$ Mediterraneus... $37 i$

$17 \quad$ - Rissoanus....... 379

17 VotID.NI.............

19 Notidamidx.............. 28

20 Votidunidés................. 28

17 Notinaviexs.............. ?8

$i(j$

ii

76

i6

76

$\because$

is

600

600

ј99

599

60.1

600

608

OBLAD..................... $3 \mathrm{it}$

Ublada melanura.......... 314

ObL.AdE ................... 314

Oblade ordinaire........... 314

Obladini................. 311

Obladini................. 311

Odontaspidx ............. 10

Odontaspide ............. 10

Olontaspide féroce......... 11

taureau......... 11

Odontespides............ 10

ODONTASPIS............. 10

Odonlaspis ferox........... 11

265 oxтosrou:

taurus............

\section{1}

NaCCRate. 
Odontostome Balbo......... 540

ODONTOSTOWUS........... 540

Odontostomus Balbo......... 540

Omble.................. 583

Omble-chevalier........... 583

Омвне................. 586

Ombre commune.......... 587

Onbrixe ................ 241

Ombrine commune......... 241

de Lafont......... 242

Oncorhynchus quinnat........ 58

Onus biscayensis........... 430

Ophidie................ 403

Ophidie barbu............ 404

- de Vassali.

Ophidiidx

Ophidiidés.

OPHIDIIM.

Ophidium barbatum

Vassali.

Ophisure.

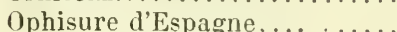

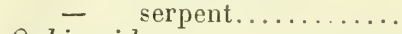

Ophisuridx

Ophisuridés

OPHISURUS

Ophisurus Hispanıs

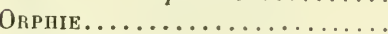

Orphie aiguille

- de Cantraine

- impériale.

- vulgaire.

Orthagoriscila

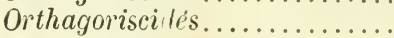

ORTHAGORISCLS...........

Orthagoriscus mola..........

obiongus ........

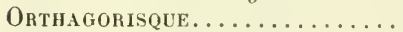

Orthagorisque mole..........

- oblong........

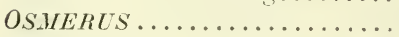

Osmerus"eperlanus...........

OSTRACION

Ostracion nasus..............

Ostracionitigonus.

trigonus ..........

Ostracionidés.

ONYRHINA.

Oxyrhina:Spallanzanii.........

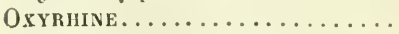

Oxyrhine de.spallanzani......

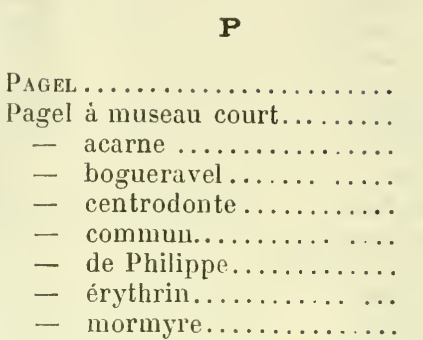

315

317

320

318

319

316

321

316 318

315

320

318

317

316

316

318

321

322

322

324

322

324

324

322

563

563

564

564

565

564

565

566

565

567

565

567

564

566

Parr ................... 575

Pastenagee.............. 78

Pastenague bouclée........ 81

- bruccon ........ 80

- commune....... 79

- violette........ 80

PASTINACA............. 78

Pastinaca aspera........... 81

Pélanýde............... 256

Pélamyde commune...... . . 257

14 - de Bonaparte...... 258 
Pilamyde sarde.......... 257

PELAMYS.............. . 256

l'elamys Bonapartii......... 258

— sarda ............. 257

Pèlerix................. 16

Pèlerin............... $\quad 16$

PERCA.............. . 223

Perca fluviatilis............ 223

Perche................ 22:3

Perche de rivière.......... 223

Percidx.............. .222

Percidés................ $2: 2$

Percini............... $2: 2$

Perriniens.............. 222

Péristéblox............... 196

PERISTEDI(M............. 196

l'eristedion cataphractum......

Perlon (Heptanche) ..........

Perlon (Trigle).............

Petit Perlon a pectorales tachetées.....................

Petite Roussette ............

Petite Vive................

PETROMYZOY.

l'etromyzon fluviatilis..... .

Pétromyzones.

marinus...

Planeri...

Retromyzones

Petromyzonidx.

Pétromyzonides.

PHARY YGUBRANCHES .....

PIIRTVGOBRANCHII......

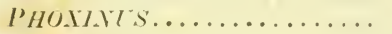

Phoxinus lavis.............

- montanus.........

Pilycis.

PIIYCIS

Phycis blennoide............

- mediterranéen.......

Phycis blennoides

- Mediterraneus.........

Physicule.

Physicule de Dalwigk........

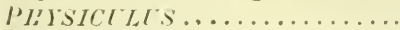

Pliysiculus Dalwigliii.........

PICAKEL.

Picarel chrysẻle

de Vauri.

insidiateur...........

Martin-pêcheur.......

ordinaire...........

30

205

609

611

608

608

C09

609

612

612

491

491

492

426

426

426

427

$4: 6$

427

4.31

431

431

4:31

336

339

340

$3: 0$

338

337
Pilote.

266

Plagiostomes............. 3

Plagiostomi............ 3

PLAGUSIA............. 469

I'lagusia anceps.......... 469

469

Plagusie.................. 469
Plagusie douteuse. . . . . . . 469

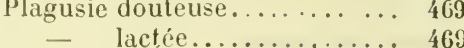

PLATESSA............. 441

Platessa cynoglossus.......... 44 t

- microcephalus........ 443

vulgaris.......... $\mathbf{4 4 2}$

Plectognathes........... 109

Plectognathi............ 109

Plectropomus fasciatus...... . 235

197 Plechonecte............... 456

Pleuronecte arnoglosse....... 460

- de Bosc........ 461

de Grohmanu..... 459

élégant....... 464

guitare........ 463

mégastome..... 462

mouchelé....... 460

targeur........ 457

unimaculé...... 458
PLEIRONECTES.......... 456

Pleuronectes arnoglossus... . . 460

461

464

463

460

459

457

462

458

438

438

441

444

442

413

89

229

229

229

375

375

240

240

240

240 
Porobranchus linearis.........

Pristida

Pristides

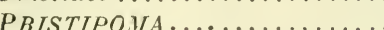

Pristipoma Bennelli..........

Pristipone................

Pristipome de Bennett.......

PRISTIS..................

Pristis antiquorum...........

- pectinatus.

Pristiure

Pristiure à bouche noire.....

PRISTIURUS .................

Pristiurus melanostomus.......

Proctostegini................

Promécocéphale..............

Promécocéphale lagocéphale...

PROMECOCEPHALUS.........

Promecocephalus lagocephalus. .

Pteridiidx.

Pteridizilés.

Ptéribion....................

Ptéridion noir ..............

PTERIDIUM.................

Pteridium atrum............

PTEROPLATEA..............

Pleroplatea altavela..........

Préroplatée.................

Ptéroplatée altavelle.........

\section{Q}

Quinnat

$\mathbf{R}$

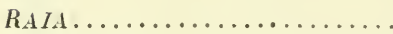

Raia alba................

- aspera..............

- asterics................

- batis.................

- brachyura ............

- Uramante...

- chagrinea..............

- circularis.

- clavata....

- fullonica.............

- macrorhynchus.........

- marginata............ maroccana...
$406 \mid$ Raia microcellata........... 67

50 - miraletus............ 69

$50 \quad-$ mosaica............... 73

246 - oxyrhynchus......... 62

246 - punctuta............. 70

246 - quadrimaculata....... 69

246 - radiuta............... 59

51 - radula............... 68

51 - speculum............ 71

51 - undulata.........66, 66, 73

8 RaIE................... 56

8 Raie à petits yeux......... 67

8 - à quatre taches........ 69

$8 \quad-$ i queue courte ........6 67

$284 \quad-\quad$ au bec pointu......... 62

111 - au long bec......... 63

$111 \quad$ - batis .............. $6 \mathbf{6}^{\prime}$

111 - blanche............ 6 í $^{\prime}$

111 - bordée........... 65

407 - bouclée........... 58

407 - chagrinée...........6 61

407 - chardon........... 72

408 - circulaire............ 60

407 - estellée............. 71

408 - étoilée.............. 71

81 - macrorhynque........ 63

$82 \quad-$ miraillet............ 69

81 - miroir.............. 71

82 - mosaïque............ 73

— ondulée................

- oxhyrhynque......... 62

- ponctuée............ $\mathbf{7 0}$

- radiée................ 59

$584 \quad$ - ràpe................ 68

Raies................ 50

Raiidx................. 56

Raiidés................... 56

Raiinæ................ 50

56 Ranicepini.............. 432

64 Ranicépiniens ............ 432

i3 Ranicers................. 432

71 RANICEPS............... 432

64 Raniceps trifurcatus.......... 432

67 Raniceps trifurqué......... 432

66 Rasox.................. 373

61 Rason ordinaire........... 373

(i0 Régaleg.................. 299

58 Régalec iris............... 300

i2 $\quad-\quad$ trait................ 300

63 REGALECUS.............. 299

65 Regalecus iris............. 300

$66-$ tehr........... 300 
RevarL..............

Renard.

Requix.

Requin a museau obtus.......

- bleu..............

-. de Milbert.

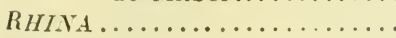

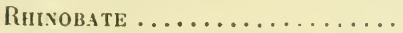

Rhinobate de Colonnat........

Rhinobatidx.

Rhinobatidés

RHI.VOBATLS.

Rhinotiatus Columnæ.

RHODELS.

Rliodens ammis.

RHонив................

RHO.HBLS.

Rhombus lipvis.

Rogenia alba................

Rotexgle.

Roteugle.

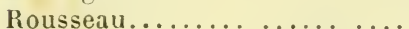

RoussetTe

Roussette à grandes taches... . i petites taches....

ROLVET

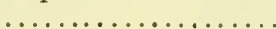

Rouvel précieux

$R U_{V E T T U S} \ldots \ldots \ldots \ldots \ldots \ldots . . . \ldots$

Ruceltus metiosus..........

\section{$\mathbf{S}$}

SAGRE

Sagre.

Salares.

SAL.VO

salmo argenteus.

- fontinalis.

- ivideus.

- salar.

salmonidx

Sulmonides..................

Sar proprement dit.........

SARDINELLA..............

Sardinella aurita. ..... ....

Sardinelle................

Sarulinelle auriculée..........

Surgini.

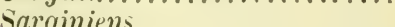

Sarginiens................

Sirgue
Sargue annulaire

309

- de Rondelet......... 307

- ordinaire.......... 306

- vieille ............. 308

S.RRTS ............... 306

Sargus annularis.... ...... 309

- Rondeletii........... 307

- vetula ............. 308

- vulgaris.......... 306

Sauclet................ 395

SaLmon ............... 570

Saumon commun.......... 5i

SAUREL................. 260

Saurel commun.......... 261

262

262

560

$5 f(0$

560

560

499

499

374

$3 i 4$

374

$37 \dot{4}$

SCARUS............... 374

Scarus Crelensis ........... 374

SCHÉdorhue.............. 28?

Schédophile médusophag .... 282

SCHEDOPHILUS ........... 282

Schedophilus medusophagus.... 282

SCIA.VA................. 244

Sciæna aquila.............. 244

Sciænıdæ................ 241

SCIE................... 51

Scie des Anciens........... 51

— pectinée.............. 51

ScIÈve .................. 244

Sciénidés................. 241

Sclérodermes .......... 113

Sclerodermi............ 113

SCOMBER............... 248

Scomber scomber............ 249

250

Scombre................ 248

scombre colias............. $2 \vdots 0$

maquereau........ 249

SCOMBRÉSOCE ............. 531

Scombrésoce campérien..... 531

de Rondelet..... 532

saurus ....... 531 
SCOMBRESOX.

Scombresox Camperi Rondeletii..

sombrida saurus.

Scombridés.

Scombrini.

Scombriniens

Scopéle

Scopèle crocodile

de Benoit............

de Bonaparte... .....

de Canino

de Cocco

de Humboldt

de Rafinesque.

de Risso.

de Vérany.

Scupelida

pseudocrocodile......

Scopélidés.

Scopelini

Scopéliniens.

SCOPELUS

Scopelus Benoiti.

\begin{tabular}{|c|c|}
\hline 一 & Bonapartii......... \\
\hline - & Caninianus.......... \\
\hline & Coccoi.............. \\
\hline & $\begin{array}{l}\text { crocodilus............ } \\
\text { Humboldti ......... }\end{array}$ \\
\hline & pseudocrocodilus.... \\
\hline & $\begin{array}{l}\text { Rafinesquii ......... } \\
\text { Rissoi }\end{array}$ \\
\hline & Veranyi \\
\hline
\end{tabular}

SCORP ENA ...............................

Scorpana bicolorata..........

\begin{tabular}{|c|c|}
\hline- & lutea............... \\
\hline & porcus ............ \\
\hline & 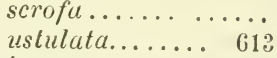 \\
\hline
\end{tabular}

Scorpanini ustulata...... 613,

ScorpéNe.

Scorpène brune.

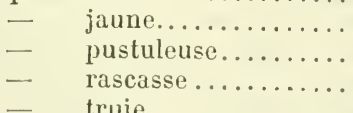

Scorpeniniens.

Scylliidx

Scylliidés.

Scyllium canicula.
5) 31

531

532

531

247

247

248

248

544

545

553

555

552

549

550

552

554

550

$\therefore 46$

538

538

5 'ti

544

544

553

555

552

549

545

550

546

552

554

550

213

613

215

216

214

215

213

213

216

21.5

215

216

214

213

5
5
6
6
Scyllium catulus.

ScYune .................. 44

Scymne commune......... 44

Scymnidx ............... 43

Scymnidés............... 43

SCIMNUS .............. 4t

Scymnus lichia........... 44

Sébaste................. 217

Sébaste dactyloptère ........ 217

- de Bibron........... 218

SEBASTES .............. 217

Sebastes Bibroni........... 218

Selacha.................

SELACHE............... 16

Selache maximus.... ...... 16

Sélaciens............... 4

SERIOLA................ 269

Seriola Dumerilii........... 269

SÉriole.................. 269

Sériole de Duméril. ....... . 269

Serran .................. 230

Serran cabrille........... 231

— écriture... . ...... . 230

- hépate........... 233

Serranini............... 228

Serraniniens.............. 228

SERRA.VTS ............. 230

Serranus acutirostris....... 236

$2: 36$

236

231

233

230

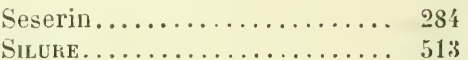

Silure glanis............. 513

Siluridx............... 513

Siluridés............... \$13

SILURUS ............... 513

Silurus glanis............. . 513

SHHONOSTO.1HA........... 101

Siphonostoma argentatum.... 103

pyrois........ 104

Rondeletii...... 104

typhle....... 102

Siphonostome............. 101

Siphonostome argenté....... 103

de Rondelet.... 104

pyroïs........ 104

typhle........ 102

336 
smaris alcerto.

338 chryselis..... 33i, 338, 33!) gagarella........... 337 grarilis.......... 338, 340 insidiator............ 3 it) Maurii......... 33s, 340 vulgaris ........... 337

Smolt

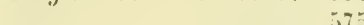

SOLE

Sole à pectorale noire......

- commune.............

- de Klein.

- Lascaris

- ocellée.

- séteau.

SIILEA

Solea cuneata.

- Kleinii...

- Lascaris. .

- melanochira.

- oculata.

Sparaillon vulgaris

sparidx.

sparidés.

Sparini.

Spariniens.

Sparus berda.

Spet

Sphagebranche.

sphagebranche

sphagebranchida

aveugle.......

imberbe......

Sphagebranchilles.

SPHAGEBRANCHIS... ......

Sphngebranchus cacus........

Sphyranidx

imberbis......

Sphyisna spet.............

SpIIYRène ..................

Sphyrène spet............

Sphyrénidés ..............

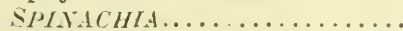

Spinachia vulgaris...........

Spinacidx................

Spinucidés.

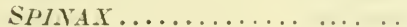

Spinax niger...............

Sprattus.

Squale dienfer

Squales.

447

449

448

451

450

452

451

447

451

451

450

449

4.32

is

309

305

305

315

315

317

399

606

607

606

605

605

606

607

606

399

399

399

399)

399

399

353

383

30

30

33

34

.)18

$: 35$
SQrales a dorsale unique......

28

- ANHYPOPTÉRIENS.......

30

- IYPOPTÉRIENS .......

- MaNQUANT H'ANALE, ... 30

Squali................. 4

S()I LI AXIPYPOPTERII ..... 30

5

SQLII IEX

HYMTERII........

$S() L A L I 1 \ldots \ldots \ldots \ldots \ldots \ldots \ldots$

SuUALIUS.............. 03

Squalius Burdigalensiv. ..... 506

cephalus.......... 504

- leuciscus........... 505

- souffia............ 503

- rostralus ......... . 506

Squalus infermus............ 35

uyatus .......... 35

SOUATINA.............. 48

squatina angelus ........... 49

Squatine................. 48

Squatine ocellée ........... 49

Squatinida............... 48

Squatinides ............... 48

Squatinoraiz......... 50

Squatinoraies.......... 50

Sternoptygini........... 542

Sternoptyginiens .... . .... 542

Stomas................ 537

STOMIAS............. $53 \pi$

Stomias boa.............. $53 \pi$

Stomias boa............ 537

Stomiatidx............... 536

Stomiatidés ............. 536

STROMATEE ............ 283

Stromatée fiatole.......... 283

- microchire....... 284

- $\operatorname{seserin} \ldots \ldots \ldots \ldots .284$

STRO.UTELS ............ 283

Stromateus fiatola.......... 283

Sturiones. ............................. 85

Sturioniens........... 85

Sublet.................. 365

sublet groin............. 365

Sirgiatue............. 95.

Syugnathe abaster........ 100

- aiguille.......... 95

- le Duméril. ..... 99

- ithon........... 98

- phlégon......... 101

- rougeàtre........ 96

4 - ténuirostre....... 97 
Syngmathida

Syngnathilés.

syngnathini.

Synynuthiniens

SYNGVATHLS.

Syngnuthus abaster

acus..............

Dumerilii .........

ethon............

pelagie'us..........

phlegon..........

rubescens.........

tenuivostri.......

\section{$\mathbf{T}$}

Tærioila

Trnioüdés

Taxche.

Tanche vulgaire

TEunodon.

TEMNODON

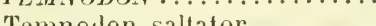

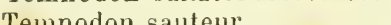

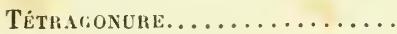

Tétragonure de Cuvier.......

Tetrugonurila

Tétragonuridés.............

TETRAGONURLS...........

Tetrayonurus Cuvieri.........

Tetruodontidx...

Télraodontidés..............

Tétrapture................

Tétrapture aiguille..........

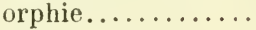

TETRAPTURUS............

Telrapturus belone..........

Thalassine................

Thalassine de Rondelet......

THALASSINTS ..............

Thalassinus Rondeletii........

Trox .....................

Thon à pectorales courtes....

- commun.............

Thonine.

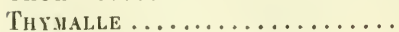

THYMLLUS...............

Thymaltus vulgaris...........

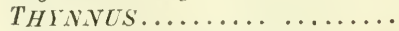

Thynnus alalonga.......... brachypterus......
91

91

$9 \dot{1}$

94

95

100

95

99

98

104

101

96

97

To

To \\ Tor}

Torpille.................. 53

Torpille à taches........... 54

- de Nobili........... 55

- marbrée........... 54

$29 \%$

297

487

$48 \%$

270

270

270

270

38.5

386

385

385

385

386

110

110

292

$2 ! 2$

292

292

292

21

21

21

21

251

255

25'

253

586

586

587

251

256

255

Thynnus pelamys.......... $\$ 252$

Thyrsitini............... 258

Thyrsitiniens............. 258

I.VCA................ 487

Tinca vulgaris............ 487

Torpedidæ............... . 53

Torpédidés................ 53

TORPEDO............... 53

Torpedo marmorata......... 54

- Nobiliana........... 55

- cculata............ 54

Touille................. 13

Trachinidx............... 119

Trachinidés.............. 119

TRACHINTS.............. 121

Trachinus araneus....... 126, 1:5

- draco............ 123

- radiatus...... 126, 12 '

- vipera. .......... 121

TRACHIRUS ............ 260

Trachumus Cuvieri......... 262

- fallax.......... 262

- Nediterraneus..... 262

- trachurus........ 261

Trachypténe............. 301

Trachyptère à crête........ 30x

à rayous lisses.... 33

de Spinola...... 303

faux......... 301

iris.................. 302

Trachypterini............ 299

Trachyptériniens........... 299

TRACHYPTERLS........... 301

Trachypterus cristatus ....... 304

- falx............ 301

- leiopterus......... 303

- iris.......... 302

- Spinolæ...... 303

Trichune................ 296

Trichiure lepture......... 296

Trichiuridx............. 29'

Trichiurides.............. 294

TRICHILRLS............. 296

Trichiurus ............... 296

TRIGLA................. 198

Trigla aspera............ 207 
Trigla cavillone........... 207

- $\operatorname{cor} a x \ldots . . \ldots \ldots \ldots \ldots .205$

- cuculus.............. 201

- gurnardus.............

- lyra................

- milvus................

$$
\text { pini. }
$$

paciloptera.

Trugle.

Trigle cavillone............

- corbeau...........

- gornaud..............

- imbriago ...........

- lyre.................

-.. milan.

- morrude.

- pin.

- rude.

Triglirlx

Triglides.

Triglini

Triyliniens.

TRIPTÉRYGIOX.

TRIPTERIGION.

Triptérygion à bec

Tripterygion nasus

Truite

Truite commune.

- de Baillon...

- de mer.

- saumonée

THLTTA.

Trutta Bailloni

- fario.

- marina.

TRYGON.

TRYGON

Trygon aspera

- brucco.

- violaced.

- vulgaris.

Trygonidx.

Trygonidés

Turbot

Turbot

205

202

200

204

$20: 3$

201

199

207

193

193

$19 \dot{4}$

19 '

147

147

177

147

579

581

582

579

581

579

582

581

5ั9

is

78

81

80

80

9

78

78

461

16.)
- lineat $\ldots . . . \ldots \ldots \ldots . . .$.

U.MBRINA ............ 241

Limbrina cirrosa ........... 241

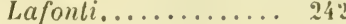

202 UnALEPTE............... 420

200 Uralepte de liaraldi ........ $4: 21$

204 URALEPTUS............. $\$ 20$

:0:3 Uraleptus Maraldi........... 421

199 URANoscope............... 119

206 Uranoscope rat........... 1:20

198 URANOSCOPLS............ 119

207 Uranoscopus scaber.......... 120

\section{U}

UWBLA . . . . . . . . . .

Umbla salvelinus............
VAIRON .................

Vairon commun ........... 491

492

506

506

501

491

406

313

344

121

124

125

123

\section{$\mathbf{X}$}

Xipheini.............. 289

Xiphéiniens............. 289

XIPHIAS ................ 290

Xiphias gladius............ 290

XYRICHTHYS............. 373

Xyrichthys novacula........ 373

\section{$\mathbf{Z}$}

ZÉE............................ 271

Zée ì épaule armée........ 272

- forgeron............ 272

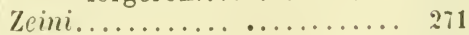

Zeiniens................ 271

ZEUS................. 271

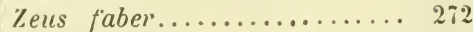

- pungio.............. 272

Zoarcès............... 150 
ZOARCES .............. $150 \mid$ Zygrena malleus........... 23

Zoarcès vivipare........... $150 \quad$ - tudes............. 24

Zoarces viviparus........... 150 Zygænidæ.............. 22

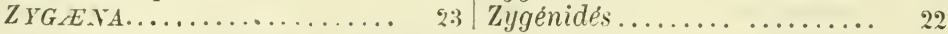

FIN DE LA TABLE DES MOMS SCIENTIFIQLES. 


\section{TABLE DES NOWS VULGAIRES}

Able bordé ............ 497

- grise ............. 497

- rayé $\ldots \ldots \ldots \ldots \ldots \ldots . . .497$

Ablet.................. 496

Abusseau............... 397

Accourci............... 505

Aguglia................ 529

Agugliat.............. 31

Aguiat............. 33,31

Agüуа............... 529

Aigle................ 244

ligle de mer......... . 244 77

Aiguille de mer............ 529

Aiguillette............... 529

Alaousa.................. 521

Alalonga............... 256

Alàouso ................ 521

Alène............... 63, 62

Allacha................. 5 520

Allancon............... 40.

\lléchart ............. 520

\loge................ 507

Alot .................... 256

Alouse.................. 521

Alouse de Chatellerault...... 52:

Ame noire............... 507

Amendoula................ 333

Amplova ................ 52t

Anadélo................. 226

Anchou.

Anchova.

Inchoya

Ancon.

Anfoussou ...........................

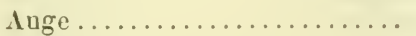

Ange de mer..............

Angel.
Ingelot................. 49

Anguille de mer.......... 597

- lampresse.......... 609

— vésarde............ 102

Antchoia................. 24

Anxova............ 537, 524

Aourade................ 325

Aourneau bias.... ........ 250

Appêchart.......... 476, 475

Aragna................. 123

Arbano................. 29

Arenc ................. 520

Arendoula............... 533

Arestou ................ 504

Argentin...... 59:2, 300, 297, 295

Arite................. 381

Arlequin............... 491

Aronde................ 195

Arondelle............... 195

Arounce-bras............. 5 t

Arvasscii ................. 319

Aublet................... 496

Aubour................. 505

Iubour mugé............. 393

Anbourne ............... 505

Aubusseau .............. 397

Au.lëyat............... 256

Augustine ........... 64, 63

Aulendra de mar........... 195

49 Aurada.................. 325

537 Aurin................... 405

524 Luriol.................. 249

507 Auriou .................. 249

$2: 3$ Asé .............. 209

160 Avive ............... 12:3

49 Azé................ 42:2

49 Bagre ................ 322 


\begin{tabular}{|c|c|c|c|}
\hline & & & \\
\hline aoudroie ................. & 160 & 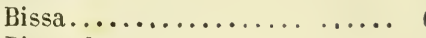 & \\
\hline aque-Sarranc . ........... & 230 & Bissa de mar............. & 04 \\
\hline 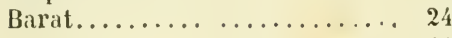 & 249 & Bisson $\ldots \ldots \ldots \ldots \ldots \ldots \ldots$ & \\
\hline arbache...$\ldots \ldots \ldots \ldots \ldots$. 46 & 466 & Bizet............ 261, & \\
\hline rbarin.......... 485,19 & 191 & Blada............. 314 & \\
\hline arbeau................ 19 & 191 & Blade...$\ldots \ldots \ldots \ldots \ldots \ldots$ & \\
\hline arbéou................. & 486 & 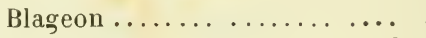 & \\
\hline rberin $\ldots \ldots \ldots \ldots \ldots$ & 191 & Blanc ............. 503 & \\
\hline 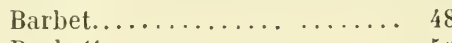 & & Blanchaille.. ............. & \\
\hline pette.............. & 549 & $\ldots \ldots \ldots \ldots \ldots$ & \\
\hline arbier... ............ & 236 & ta.......... 73 & \\
\hline arbillon ................ & 485 & te $\ldots \ldots \ldots \ldots \ldots \ldots$ & \\
\hline 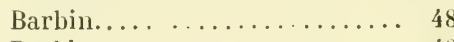 & & $\ldots \ldots \ldots \ldots \ldots \ldots \ldots \ldots$ & \\
\hline $0 \ldots \ldots \ldots \ldots \ldots \ldots \ldots$ is & & $u \ldots \ldots \ldots \ldots \ldots$ & \\
\hline bot $\ldots \ldots \ldots \ldots \ldots \ldots, 509,42$ & & $\ldots \ldots \ldots \ldots \ldots \ldots \ldots \ldots$ & \\
\hline botin............. 50 & 509 & $\ldots \ldots \ldots \ldots \ldots \ldots \ldots$ & \\
\hline te............ 509, 42 & & $\ldots \ldots \ldots \ldots \ldots \ldots \ldots$ & \\
\hline he............ 40 & 466 & $\ldots \ldots \ldots \ldots \ldots \ldots \ldots$ & \\
\hline $\operatorname{lin} \ldots \ldots \ldots \ldots \ldots \ldots$ 34 & 4, 8 & $\ldots \ldots \ldots \ldots \ldots \ldots \ldots \ldots$ & \\
\hline$\ldots \ldots \ldots \ldots \ldots \ldots \ldots$ & 210 & $\ldots \ldots \ldots \ldots \ldots \ldots$ & \\
\hline$\ldots \ldots \ldots \ldots \ldots \ldots \ldots \ldots$ & & $\ldots \ldots \ldots \ldots \ldots \ldots$ & \\
\hline -Godde............. & 410 & $\ldots \ldots \ldots \ldots \ldots \ldots$ & \\
\hline ret...$\ldots \ldots \ldots \ldots$. & 365 & $\ldots \ldots \ldots \ldots \ldots$ & \\
\hline$\ldots \ldots \ldots \ldots \ldots \ldots \ldots$ & & $\ldots \ldots \ldots \ldots \ldots \ldots$ & \\
\hline il................... & 160 & & \\
\hline uille................ & 160 & $\ldots \ldots \ldots \ldots \ldots \ldots \ldots$ & \\
\hline$\ldots \ldots \ldots \ldots \ldots \ldots \ldots 2$ & 209 & $\ldots \ldots \ldots \ldots \ldots \ldots$ & \\
\hline a, etc.... 139. 13? 13i, 1 & 130 & oura a sept traous.... & \\
\hline ca d'Arga............ & 147 & $\ldots \ldots \ldots \ldots \ldots \ldots$ & \\
\hline$\ldots \ldots \ldots \ldots \ldots \ldots 145,1$ & 138 & & \\
\hline$\ldots \ldots \ldots \ldots \ldots \ldots \ldots$ & 136 & $\ldots \ldots \ldots \ldots \ldots \ldots$ & \\
\hline letta............. 3 & 391 & $\ldots \ldots \ldots \ldots \ldots \ldots$ & \\
\hline$\ldots \ldots \ldots \ldots \ldots \ldots 5$ & 570 & $\ldots \ldots \ldots \ldots \ldots \ldots$ & \\
\hline$\ldots \ldots \ldots \ldots \ldots \ldots, 3$ & & $\ldots \ldots \ldots \ldots \ldots \ldots$ & \\
\hline mer........ $5: !), 3$ & 384 & $\ldots \ldots \ldots \ldots \ldots \ldots$ & \\
\hline de mer......... 5 & 529 & $\ldots \ldots \ldots \ldots \ldots$ & \\
\hline$\ldots \ldots \ldots \ldots \ldots 2$ & 249 & & \\
\hline $1 \ldots \ldots \ldots \ldots$ ?(1)3, 202, 2 & 200 & $\ldots \ldots \ldots \ldots \ldots$ & \\
\hline$r \ldots \ldots \ldots \ldots \ldots \ldots, 20$ & 203 & $\ldots \ldots \ldots \ldots \ldots \ldots$ & \\
\hline$\ldots \ldots \ldots \ldots \ldots \ldots \ldots$ & 203 & $u \ldots \ldots \ldots \ldots \ldots \ldots$ & 31 \\
\hline$n \ldots \ldots \ldots \ldots \ldots \ldots$ & 348 & $\ldots \ldots \ldots \ldots \ldots$ & \\
\hline$\ldots \ldots \ldots \ldots \ldots \ldots$ & 509 & $\ldots \ldots \ldots \ldots \ldots \ldots$ & \\
\hline yda $\ldots \ldots \ldots \ldots \ldots \ldots$ & 337 & tte . . . . . . . & \\
\hline$\ldots \ldots \ldots \ldots \ldots \ldots \ldots$ & 450 & $\ldots \ldots \ldots$ & \\
\hline $1 \ldots \ldots \ldots \ldots \ldots$ & 465 & $\ldots \ldots \ldots \ldots$ & \\
\hline$\ldots \ldots \ldots \ldots \ldots \ldots \ldots$ & & at $\ldots \ldots \ldots \ldots \ldots \ldots$ & \\
\hline pt trous ........... & 610 & 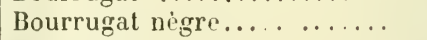 & \\
\hline & 590 & $\ldots \ldots \ldots \ldots$ & \\
\hline 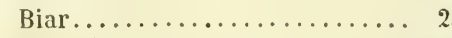 & & icou $\ldots \ldots \ldots \ldots \ldots \ldots$ & \\
\hline goula........... 138,1 & 130 & 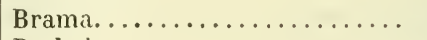 & \\
\hline 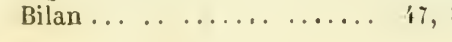 & & Brehel. . ............. & \\
\hline
\end{tabular}


Brêtue

319) Capoun tjaouné

Brême blanche.

49:3 Capoutehin

- communc....... 492, 327

Caraman

199

- des rochers.

$3: 7$

- gardonuée.

49:3

Brimette

493

Citrangue.

261

Ciarasche ............... 48?

Brèmo.

493 Cardinal .

384

Brène

319

Brigne.

224

Cardine. .

204

Brill .

219

Brouché

52

Broueu.

Broutchet de uner...........

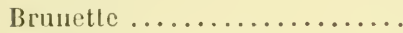

Buché

Buga.

Bugoravella

Buhotte .

ii

399

73

526

312

318

177

Cabassoun

395

396

Cabasuc

177

504

Cabẻda.

Cabeliau.

Cabès.

Cabillaud

Cabiouna

Cabos. 203, 202

Cabot. $50 f, 396,38 s, 208,14 j, 13 i, 131$

Cabot-vorage............ 160

Cabote

205

Cabotin.

Cabouta boulante .......... 205

Cabre

231

Cafaril.

209

Cagnot $25,21,20$

Cagnot-blaı

Caine.

Calagis.

Calegnairis

Caligueiris

Camard..

Canadelle.

Canicule.

Cantarèla.

Cantha négra.

Canthàro

Canthéna

Canthèno.

Cauurla.

Carreau.......... 48:482

Carrelet............ 166, 442

Castagnolit............. 277

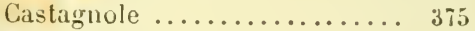

Castagnolla.......... 375, 27 .

Castaudela............... 5:3:

Castodello.............. 532

Cat .................... 8 1

Cata rouquiëyda........... 7

- roussa ............. 6

Catonyé............. 6

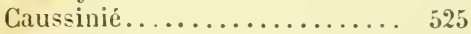

Cavail mari.............. 92

Cavaluca................ 250

Cavau........... 108, 98, 92

Cavergne.............. 504

Cavillon................. 207

Célan ................. 5283

Cẻlerin ................. 523

Cernier................. 299

Chabaou............... 209

Chaboisseau.......... 50', 209

Chabot............... 504

Chabot de riviele......... 208

Chabroua ............. 488

Chacil................. 203

Chagrin ................ 227

Chamsot................ 209

Chandarma.............. 23

Chapsut................ 209

Chaquedit .............. 123

Charbounier ............. 415

Charrin ............... 49?

Chasseur.............. 132

Chatonille ............. (511

Chitvanue.............. 50t

Moreau. - Ichthyologie. 
Cherenne..................

Chérin ................ 499

Cheval marin .............. 92

Chevanne................ 50'

Chevassou................ 59'

Chevauneau................ 504

Chevesne............... 50't

Chibaou de ma............ 92

Chichard $\ldots \ldots \ldots \ldots \ldots \ldots \ldots .261$

Chicharou.............. 261

Chidella................. 369

Chien broquu.............. 31

- de mer.......... 31, 21, 18

- de mer épineux........ 31

Chieucla.................. 317

Chiffe ................ 507

Chinchard............... 261

Chique-tabac............. 307

Chiqueur............... 153

Chiqueux................ $1 ; 3$

Chol..................... 396

Choucha................. 77

Choucha bastarda........... 82

Chrau ................... 2:1

Cieucla .................... 317

Cippa, Cippe............. 491

Civelles................... 596

Clabélada..................

Clabëyda bastarda .......... 368

rouquieyda .......... 355

Claviera .................. 363

Clonée ................... 58

Cochon de mer............. 43

Code .................... 410

Coffre.............. 117, 43

Coliart................... fít $^{\prime}$

Colin.............. . 420, 414

Colubro de mer............ 604

Congre de roches.......... 598

Concie ................. 497

Coquette................. 349

Coracin de mer............ 24;

Corb negré.............. 245

Corbeau................. 245

Cordonnier............... 381

Cornard.................. 153

Coucou....................

Coulaqua..................

Coungré...................

Coungré négré..............

Counict...................
Courpata................ 386

Coustout ................ 261

Coustut ................. 261

Crabe................... 231

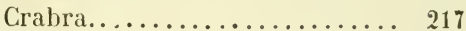

Grahotte.................. 343

Crak ................... 231

Crapaud..................... 160

Crapaud de mer........ 216, 161

Créac................... 87

Crébro-varlé ............. 381

Culobre de mar............ 604

Cunaote................... 95

Cuorp................... 245

Cungre................. 597

Daïnẻ.............. 244, 241

Dama ................. 404

Daourada d'aou rosé......... 492

Dard.............. 505, 290

Dauphin ............... 226

Daurade .............. 32i, 325

Daurat ................ 484

Demoiselle ............... 70

Demouzièla............... 600

Dente, Denté .............. 331

Dentaou, Dentou ........... 331

Diable................... 160

Diablé................... 138

Diable de mer............. 161

Digitales................ 575

Digne ................. 224

Donzéla ................. 40,

Donzella.................. 369

Donzelle................ 404

Dorade..................... 325

Dorée............... 325, 272

Dorette................... 325

Dormille............. 510, 509

Dormille fine ............. 509

Doucet................ 155, 153

Doucette.................. 18

Doumaïzella............ 404, 298

Dragon.................. 155

Dragonnet................ 155

Durgan.................. 486;

Échabot.................... 209

Ecrivain................. 507

242 Édingle ................ 491

521 Ėgrefin ............. 414, 412

597 Empedur................ 290

598 Emperatour.............. 290

349 Empereur............... 290 
Endormille .

Endourmidoüyda

Épée.

Éperlan.

Eperlan de Seine.

Epervier.

Epiuarde

Epinette.

Epinglotte.

Épinoche à trois épines .......

Erlung. . .

Escarpa

Escarpot

Escorpit...

Esperlin.

Espet.

Espignaube ................

Esprot. . .

Estidioum

Estijoùn.

Estorjeon

Estrangla-cat

Estrauglo-cat.

Esturjhoûn. .

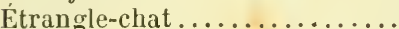

Éturbo

Faisan d'eau.

Faitou.

Fanfré

Fanfrẻ d'Amérique

- négré.

\section{rascas}

Faux

Faux-Eperlan

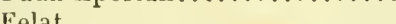

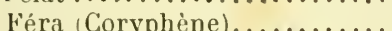

Féra blanche..................

Ferrassa.

Ferraza.

Figou

Flamba

Flavetin

Fléau.

Flétan.

Fléton.

Flondre d'eau douce.......... 4is,

Flossade............... 62, 61

Floteau.................. 41'2

Flùte.

Fouet

Fougère

Fournie.

86,397

497

77

381

31

381

481

481

87

381

303,301

391
509 | Frincais 501,500

5 frumi ..................6. 62

290 Fumat............... 65,63

381

491

214

309

399

381

518

87

87

381

87

383

465

465

439

260, 114

279

408

229

397

597

$2 \times 8$

590

442

43:)

439

45

Furet

Gal.................. 27

Galafat................ 266

Galina.................. 54

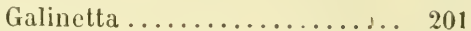

Gallet................. 327

Gallina.......... 20j, 20i, $19 j$

Galline .................... 205

Gallinetta........... 205, 199

Gandoise ................. 505

Gaouta-roussa.......... 389, 388

Gardon blanc.............. 500

— de fond............. 499

- rouge.............. 499

Garlizen................ 448

Gascon..................261

Gascoun ................. 261

Gation .................. 522

Gatta causieriera........... $4 \dot{4}$

Gatta d'arga............... 7

Gatte................... 44

Gau ................... 209

Gerlé.................... 340

Gerle-blavié .............. 338

Germon ................ 250

Gerret ................ 337

Gianelli................ 162

Giarret.................. 337

Giréla................... 369

Girella ................. 369

Girella turca .............. 372

Girelle .................. 369

Gobi di ribiëyda .......... 488

Gobi négra.............. 178

Gobie roujé................ 1 i1

Gohou giaune............. 182

- raiat ............ 1i9, 173

- rougé................ 171

- variat.............. 178

Godde .................... 410

Godet................. 209

Goeffon................. 488

Gofi ................... 488

Goifon................. 488

Gora.................. 334

Gornito ................ 216

Goujon perchat........... 227

Goulard .................. 52 '

Grados................ 397 
iranadié 436,434

Grand Turbot ............. 465

Hotant

Granda Missola............. 2

Grande Kerliche ........... 511

- Lamproie.............

- Morue-barbue .........

- Vieille...

- Vive.....................

Grano .... 609

423

$34: 3$

$1: 3$

Gravelet.............. 505,

Gravenche.................

203

Gravier.....................

Grélin.

$590 \quad$ Jolivet....................... 402

Hotu....

507

1 Hurlin

$2: 23$

Ibrougna................ 200

Ilagna ................. 123

Imbriaco ................ 200

Imbriago................ 200

Jacquard ................. 209

Jacquine................... 522

Gremenilje .............. 22

Gremille................. 22

Gremillet.................. 22

Grenouille pêcheuse .........

Grimon

\section{1}

Gronau. .

22

Grondin.

Grondin barbarin

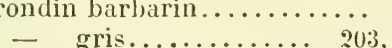

201

- $\quad$ rouge.............. 203, 199

Gros-Argentin............ $3: 1$

- Mollet............. 472

- Poutassou

- Seigneur

- yeux

- yol

Grosse Plie

Grouch.........................

Grouch nègre ..............

Grougnant.

Grugnao

Guillaume.

Gurnard

Gurnaud

Gutte. ...

Hachet te

Haoutböy

Hareng de Bergues...........

- volant...

IIarenguet. .

Harriot.

IIas

Haut .

Haut-Bar

Hazelin.

Hirondelle de mer

Kiankiarquia ............. 410

Labru................... 392

Lacia.................... 521

Ladatte.................. 224

Ladrot................... 524

Laiche-à-tout............ 504

Lambert.... 562, 560, 158, 157, 156

Lamea ................. 15

Lamia .................. 14

Lamie ............ 15, 14, 11

Lampré.............. 610,609

Lampresse.............. 610

Lamprézo............ 610, 609

Lamprillon............ 611, 610

Lamproie d'Alose........... 610

marbrée........ 609

Lamproyon ............ 611,610

Lamprua................ 609

Lampruzza .............. 609

Lampuge................. 283

Lanceron................ 509

Lancette ................ 77

Landoise................. 505

Landole ................. 195

Langaneu.......... 364, 362, 353

Langue d'avocat ........... 452

Languette.............. 452

Laousa.................. 521

Lapouricha............... 121

Lapouriche $\ldots \ldots \ldots \ldots \ldots \ldots . .121$

Lavandière............... 153

Léaud.................. 413

Lebette................. 491

Lébra ................... 138

Lecca.................... 267

Leccia .............. 269, 268

Lente................... 331

Lentèque................ 145 
Lentillat

63,81 299

Lernia. . .

Liame.

Liche.

Lictre.

Lievre.

lievre de mer.

Lignotte.

Limaude-Sole.

Limandier.

Lime.

Linota.

Lioumbrigna

Lippa.

Lissa nigra

Litcha

Lizeu. .

Llampuga

Llobarro

Lloumbrigna

Loca

Loche

Loche de mer

- franche...

Locho ...

Lochon

Loco

Loco-vernière ..............

Long-nez .................

Longue-oreille

Loque-tencho.

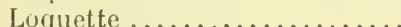

Loquo-trenquo ..............

Lotte.

Lotza ....

Lotl-Fifre

Loubas

Loubas nègre

Loubassoll

Loubine

Loubineau.

Loubiou

Loup. . . .

Loup ticassat.

Loupassou.

Loursoua.

Loutchia

Louvine

Louvotte.

Lubin

Lune .

Lune d'argent.
$46 \%$

$\therefore$

123

132

(1):

$4 ! 9$

4 : 3

462

140

201

$\because 03$

283

392

$268,: 67$

442

269

$2: 24$

203

131

428

430

¿09)

509

509

491

491

13

256

510

150

509

150

510

610

224

225

225

224

224

363

224

225

224

509

509

224

497

$22 \%$

11 ?

11:
- de mer............. 112

Lurette................. 497

Lussi............... 402, 39

Lussion.............. 566, 565

Micreuse................ 261

Madame................ 77

Madeleine .............. 160

Mädé das Loups ........... 562

Maigre................ 244

Maire d'Amplova..... 55"1, 545, 540

Makerelle ............... 261

Malarmat ............... 197

Mange-goëmon............ 327

Maugin.................. 33

Maouarmat.............. 197

Maquerean-bàtard .......... 261

Marache................ 160

Marbrada................ 73

Marchand d'esca............ 475

Marmotte............... $4 i 3$

Marteau................. 23

Marteu................... 23

Martrame............... 49

Masca..............6 603, 539

Mata-Souldat.......... 337, 333

Méchant Requin ........... 27

- Souras............. 27

Mègre................. 244

Mégro.................. 244

Meissolo.................. 18

Mélantoun................ 13

VIelet................. 518

Meleta, Meletta........... 517

Vellet .................. 39

Menise, Menuise........... 519

Mère des Soles.............. 462

Merlau (Merlus)............ 420

Verlan Poutassou .......... 416

Merlan vert.............. $4 \$ 5$

Merluche............... 420

Méro................ $2: 9$

Méron..................

Nirou.............. 234 299

Meuil, Metille........... 387

Meunier............ 504, 2013

Mézaigne............... 497

Milaudré ............... 21

Miragliet............ 69,65

Miraiet, Mirayet ....... $70,68,65$

Mirandelle.............. 496

Mirli ................. 497

Missoila ................. 19 
Missola.

Missola lenteida.

Mola

Nollet

Molve

Mora

Mordacle.

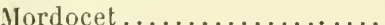

Morme

Mloro.

Morou

Morua

Morue borgne

- de Saint-Pierre.

- franche

- Iongue.

- noire.

- petite.

Moruo.

Motelle

Mouchon

Mougnou.

Moula .

Moulet.

Moulette.

Moulue.

Mouna.

Mouna négra

Mlouné

Mounge clavélat

- gris . rous.

Moure-plat

Ilourena.

Mourena semza spina

Mourina.

Mourine.

Mourmena.

Mourre-agut

Mourua

Moustache.

Moustella blanca

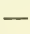

\section{bruna.}

- de fount

- de rocca.

Moustelle. negra.

Moutaille.

Moutelle.

Voutelle de rivière.

Mouteulle

Muge.
18 Nuge noir.

410

423

418

49

145

318

418

$3 \mathrm{i}$

600

410

412

411

423

412

410

600

422

307

177

426

410

506,156

411

426

430

:09

47

29

30

46

601

602

77

iT

318

311

606,599

510,509

426

427

425

426

421

422

509

, 18

510

509

$35 \%$

Ilugon labru.

392

Mlugou daurin .............. 388

— flavetoun............ 391

Mulet................... 507

Mulets .................. 387

Muola ..................... 112

Muou................... 120

Nurena.................. 601

Mussole ................. 597

Mustela de mar............. 18

Nablo.................... 496

Nas-Harg................ 13

Néblada................... 314

Nègre.................. 24'

Nez.................507, 13

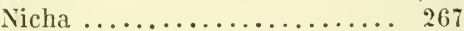

Nissola .................. 20

Nonnat................. 189

Nounat................. 189

Oblado................... 31 t'

OEillet ............ 518,516

Officier................ 410

Omblais ............... 494

Ombre ................. 583

Oreille ................... 120

Orohe................. 201

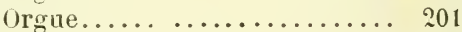

Oumbré................ 587

Oumbrina ................. 241

Ovelle.................. 496

Pachel .................. 316

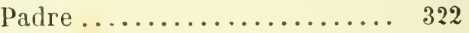

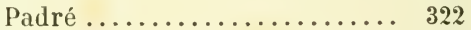

Pageau.................. 316

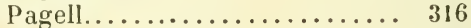

Pageo de plana............ 320

324

Pageu .............. 324, 316

Pagré ................. 322

Palaïga ................. 448

Palamida .................. 257

Palloun............... 20, 19

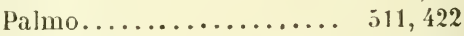

Pampaloti ............... 461

Pampoliti ............... 463

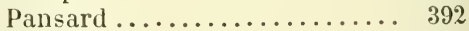

Papillon de mer............ 149

Parayou.................. 309

Passar................... 466

Pasténagra...............

Pastenaigra.............. 
Pataclet

309 | Petit Barbarin ... . . . . . . . 192

ratjel .

310

Peau bleue ...............

Pégouse.

Peï ange.

- barbaresque.

- boulant

- can .

- d'Africa.

- l'America

- d'Archén

- d'Argen

- d'Artjen

- empereur

- escoumé.

- espaza.

- fouran

- fuorca.

- luna.

- porc.

- puorc

- raton.

- Saint-Christophe

-_ San-Pierre.

- Sant-Pierre.

- Suvareou.

- troumpetta

Peïpuorc

Peis rei..

Peix escomer.

- volant.

Peiz espasa

Pélamida.

Pelletet. .

Pelouzéla.

Perca.

Perchaude.

Perche à goujon

- gardonnée.

- goujonnée.

Perdrix de mer..

Pergo

de rivière

Perlan.

Perlon

Perpeïra $\ldots \ldots \ldots \ldots \ldots$

Perroquet de mer...........

Pescarlide.

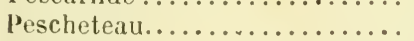

Pesquit. . .

Pétaijdé

Pétense.

$\begin{array}{r}25 \\ \hline\end{array}$

452

285

195

25,21

276

286

29

592

301

290

399

9

288

197

23

i3

475,274

?)

272

272

476

263

384

274

244

399

533

290

267

490

69

223

¿2:1

227

227

$\because 27$

448

$\because 23$

223

205

205

459

343

17

161

355

233

490
- Barbot.......... 510, 509

Petite Brème............. 493

- Lamproie............ 610

- Morue............... 410

- Vive................ 121

Peultet................. 490

Pëy boulan.............. 533

- d'Argen ............. 592

- escoumé.............. 399

Piaise ............... 442

Pialuda................ 455

Piastro ................ 490

Pibale .................. 610

Picaud ................ 445

Picot.................. 381

Pignou................ 178

Pilchard ................. 523

Pilonneau............ 327, 317

Pimperneaux........... 596

Pinaou.............. 204, 156

Pintou roussou $\ldots \ldots \ldots \ldots \ldots \ldots .6$

Pique................... 224

Pirlon.................. 205

Pisova .................. 63

Plana .................. 446

Plate................... 499

Platelle................. 499

Plie-Sole ................ 443

Ploumarenc de nid.......... 363

Pognan................ 520

Poisson cheville........... 399

- de mai............. 521

- ėpée .............. 9

- lune.............. 112

rouge............ 484

Saint-Christophe..... 272

Saint-Pierre....... 272

462

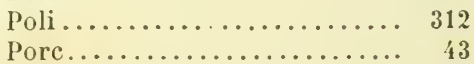

Porquet ............. 114, 43

Poule de mer........ 410, 272

Prêtre................. 397

Prétrẻ................. 463

Puorc marin ............ 43

Purcell................. 114

Querelle................. 261

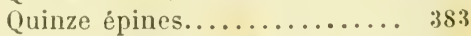

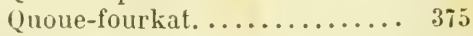

liaie bàtarde.............. 67

- blanche........... 67, 64 
Raie cendrée

- commune...................

- douce.

64 4 Rousse .

$6:$

Rousseau

$500,499,6$

- grise...

71,70

- lisse ..................

- mêlée

Ramada

Roussignou.

499,319

Rascassa.

Routget. 346

Rascasse

Ruarde....

Rascasse blanche........... 120

Rascassou............... 207

Rascoun................ 207

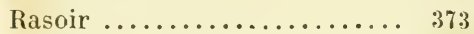

Rason................... 373

Rat........... 120, 73, 67, 65

Rat de mer............ 3i3, 84

Ratapenada............... 195

Ratepenade............... 195

Ravanënco.............. 496

Razza.................. $i 3$

Renard ............... 428, 9

Renay................ 570

Requin................. 13

Responsadoux............ 120

Rhombou ............. 451

Riéland.................. 497

Rippe ................. 381

Roche.................. 499

Roi des Harengs........... $8^{\prime}$

Roi-poisson .............. 226

Rombou .... 468, 467, 466, 460, 458

Rombou clavelat .......... 465

Rondolle................. 195

Rose.............. 272, 120

Rosière................. 490

Rossat ................ 49!

Rosse ................. 499

Rossette............ 500, 499

Rotengle................ 499

Rotisson................ 504

Roncairou............... 361

Roucaou.......... :3(:3, 349,345

Rouchet................. 191

Rouchié.................. 348

Roudgeole............... 298

Rouge d'Yport............ 191

Rouget.......... 205, 199, 191

Rouget barbet............. 191

Roujhë................. 491

Roun clavelat............ 465

Round................. 466

Rouquie... 360,357,356, 355, 354

Rujet-gros............... 191

Rum .................. 466

Rum clavelat............. 465

Russa.................... 391

Sabatiè................... 381

Sabounié ................ 392

Sabourolle ................ 214

Sabre.................. 521

Saccarailla ............... 21't

Saccoille................. 214

Sacillet................. 448

Salougne ................. 499

Salpe..................... 313

Sama.................... 392

Sangar................. 499

Sans-Nom ................ 493

Saopi.................... 313

Saouclet................ 395

Saoupa.................. 313

Saouquèna ................ 325

Sarda.................... $5 ? 3$

Sarde..................... 327

Sardina ................ 523

Sardine........... 523, 496, 491

Sardinyola ................ 523

Sarguet .................. 307

Sarguet negré ............. 306

Sargou................... 307

Sirrgou-rascas.............. 306

Sariola................. 269

Sarpa .................... 313

Sarpananza ........... 239, 236

Sarran.................. 230

Sarre ................... 499

Sars.................... 50:

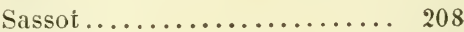

Satouille............. 611,510

Saurel.................... 261

Sautereau.................... 388

Savary .................. 153

Savetier................. 381

Scorpène................ 214

Scorpion.................. 214

Scotofic................... 424

Scrosena................ 24 
Siche.

Séchot.

Sept-ail.

Sept-ail aveugle............

$$
\text { rouge. }
$$

Ser dé mar.

$$
\text { - de mer }
$$

Séra.

Seréne.

Sergent.

Seriola

Serpent de mer.

Serran

Set-ulls...

Séteau.

Séton

Seulfe.

Seuffle-grise

Séveran

Siège

Siejo

Sieurel.

Singe de mer

Siouclet

Sirène.

Six-Denier's

Sæeffe

Soffi

Sofio.

Sofio plitto.

Soiffe.

Sola

Sola chaouna

- d'arga.

- de fount

Sole brusque

- de rochers..

- franche.

- pole.

Somneur.

Sopi

Sorcier.

Souflet.

Soufia...

Soumon .

Souras

Souris de mer.

Souvareau.

Sparaillon...

Sparlin

Spirlin

Streglia de fanga
155 Streglia de rocea

Sublaire........... 365, 360

Sublairé............... 365

Suce-pierre.............. 611

Sucet.................. 611

Suck-Cagnenk ............ 261

Suitfe.................. 505

Sussapaga............... 293

Syrène.................. 145

Tacaud................. 410

Tacen............. 575,570

Taconnet .......... 575,570

Tanche de mer............ 343

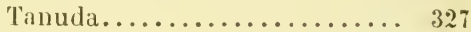

Tanudo................. 327

Tardineau............... 442

Tare.................... 77

Targeur............... 457

Targie................ 457

Taupe ................... 13

Tchival de mar ........... 92

Tenca.......... 487, 368, 349

Tëncho ................ 510

Tenco ............... 487

Tenillé ................... 318

Tère....................

Terre ............. 99,77

Terrefrauche ............ 77

Testard .................. 50 t

Tête d'Aze................ 209

Thou aux longues ailes ...... 256

- blane ........... 285, 256

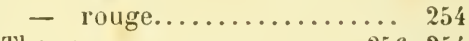

Thoun ................. 256, 254

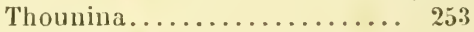

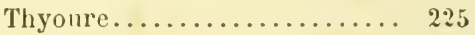

Tihoure............... 244

Tinche................. 487

Tinié.................... 318

Tire ................ 6 i, 63

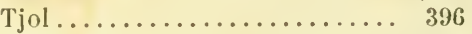

Tocall ................. 570

Tonare................ 79

Toquet................ 121

Touare............... is

Touille.............. 21, 13

Touille à l'épée ........... 9

193,192 Tourpija............. 54 
Tout-nu

177 Vachetta .............. 351, 75

Tragan

488

Traouque-sable

....... 505, 501, 491

Tréboulet................... 465

Tremblant................ 5

Tremblard................

Tremble..................

Tremblenx.................

Tremoulina................ 54

Triocha.............. 114,43

Trombetta............... 384

Trompette................ 95

Troque................. 397

Troucha................. 58

Troucia................... 581

Troyne................. 397

Trucho ................. 581

Truite de Dieppe........... 579

- de mer............. 579

- de rivière............. 581

- des lacs............. 581

- ordinaire............. 581

saumonée ............ 581

Truito.................. 581

Turbot.............. 465, 464

Turbot sans piquants ....... 466

Turgan................. 505

Ugliassou................ 598

Umbra .................. 58i

Vaca, Vacca........... 21$\rceil, 75$

Vache

Vairon de Saône........... 497

Varlet de Ville ............. 338

Vaudreuil ................ 161

Verdelet................. 491

Verdon................. 491

Verdoun........... $349,348,11$

Verniaux ............... 596

Vernieira............ 393, 337

Véron ............ 505, 501, 491

Verrat............. 274, 249

Verrue................. 241

Verruga................ 450

Vieille................... 343

Vieille jaune............... 343

- rayée............ 349,343

- tachetée.............. 343

- verte............... 343

Vilain $\ldots \ldots \ldots \ldots \ldots \ldots \ldots, 504,209$

Vilna................... 504

Violon .............. 349, 231

Vipera de mar............. $53 i$

Vive................... 123

Vive de Mousse............ 210

Voiron.................. 504

Vrac ................... 343

Vras.................. 343

Yassou ................. 593

Yol nègre ................ 389

Zyeux de verre............ 496

FIN DE LA TABLE DES NOMS VULGAIRES. 





\section{A LA VEME LIBRAIRIE}

Histoire naturelle des poissons de la France, par M. le Dr Émile

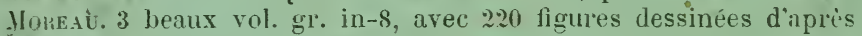
unture, et un supplément..................... fr. Le supplément seul......................... 8 lir.

Traité de pisciculture pratique, ou des procédés de inultiplication et d'incubation naturelle ou artificielle des poissons d'eau douce, par M. Koltz. 4 édit. $1 \mathrm{vol}$. in-18, avec de nombreuses figures. $2 \mathrm{fr} .50$

L'Ami du Pêcheur. Traité pratique de la pêche ḋ toutes lignes, par II. B. Poitevix. Ourrage comprenant la jurisprudence en matière de pêche. $5^{\text {e }}$ édition. 1 vol. gr. in-18, arec 98 figures dans le texte et 4 planches.............................. 50

La Carpe. Nouveaux procédés d'élevage et d'aménagement des étangs, par le systime de Dubisci, par le Dr Albert LE PLAY, agriculteur à Libourne, membre de la Société nationale d'agriculture.

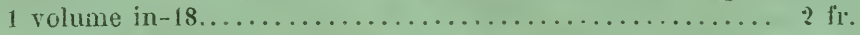

Éléments de Zoologie, par M. Paul BErt, membre rle l'Institut, et R. Blanciarn, professeur agrégó a la Faculté de médecine. 1 vol. petit ill-8, avec 613 figures.................... $₹$ โ 1 .

Le Livre de la ferme et des maisons de campagne, public sous la direction de M. P. Jolgiviux, par une réunion. d'agronomes. éédition entièrement refondue. 2 vol. grt. in- 8 , arec 2,690 figures dans

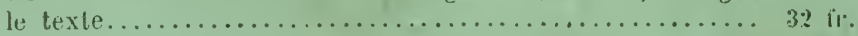

Journal de l'Agriculture, de la ferme et des misons de campagne, de l'économie rurale et de l'horticulture, fondé par II. J.-A. Barral. Rédacteur en chef : Henry śsisier. Le Journal de l'Agriculture paraît le mercredi et le samedi. Il forme, chaque année, deux volumes gr. in-8, avec nombreuses figures. Prix de l'abonnement annuel : Paris et départemenls, $20 \mathrm{fr}$.; Union postale, $22 \mathrm{fr}$.

La Nature, revue illustrée des sciences et de leur's applications anx arts et à l'industrie, publiée par 11. Gaston Tissandier, avec le concours de nombreux collaborateurs. Elle parait tous les samedis depuis le 1 er juin 1873, par livraisons de 16 pages grand in-8 jésus, richement illustrées. Chaque année de la publication forme 2 beaux volumes grand in-8. Prix de l'abonnement annuel: Paris, 20 fr.; Départemeuts, $25 \mathrm{fr}$. ; Union postale, $26 \mathrm{fr}$. 




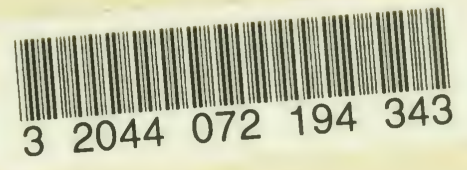


ait 18 